\title{
A TEXTUAL STUDY OF FAMILY 1 IN THE GOSPEL
}

$$
\text { OF JOHN }
$$

by

\author{
ALISON SARAH WELSBY
}

A thesis submitted to The University of Birmingham

for the degree of

DOCTOR OF PHILOSOPHY

Institute for Textual Scholarship and Electronic Editing

College of Arts and Law

The University of Birmingham 


\section{UNIVERSITYOF BIRMINGHAM}

\section{University of Birmingham Research Archive \\ e-theses repository}

This unpublished thesis/dissertation is copyright of the author and/or third parties. The intellectual property rights of the author or third parties in respect of this work are as defined by The Copyright Designs and Patents Act 1988 or as modified by any successor legislation.

Any use made of information contained in this thesis/dissertation must be in accordance with that legislation and must be properly acknowledged. Further distribution or reproduction in any format is prohibited without the permission of the copyright holder. 


\begin{abstract}
This is a textual study of seventeen Family 1 manuscripts in the Gospel of John: Gregory-Aland 1, 22, 118, 131, 205abs, 205, 209, 565, 872, 884, 1192, 1210, $1278,1582,2193,2372$, and 2713. Part 1 contains an analysis of a full collation of these manuscripts in John and concludes with a family stemma that expresses the relationships between the manuscripts and how they connect to the non-extant Family 1 archetype. Part 2 contains a reconstructed Family 1 text with critical apparatus for John. The results of this thesis confirm that 1 and 1582 are leading Family 1 manuscripts in John, but demonstrate that a new subgroup exists, represented by 565, 884 and 2193, that rivals the textual witness of 1 and 1582 . This subgroup descends from the Family 1 archetype through a different intermediate ancestor to that shared by 1 and 1582. The discovery of this subgroup has broadened the textual contours of Family 1, leading to many new readings, both text and marginal, that should be considered Family 1 readings. The reconstructed text is based on the witness of this wider textual group and is offered as a replacement to Kirsopp Lake's 1902 text of John.
\end{abstract}




\section{Contents}

Part One: Analysis of Seventeen Manuscripts in the Gospel of John ......................... 1

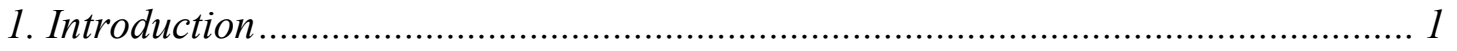

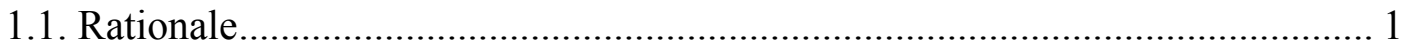

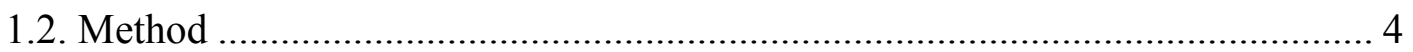

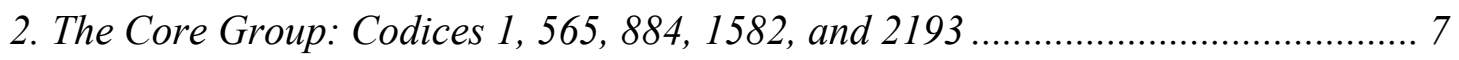

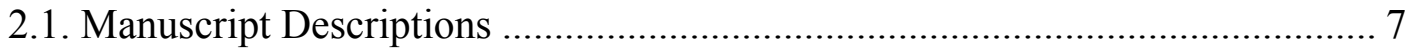

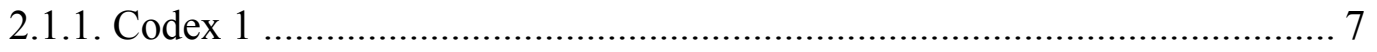

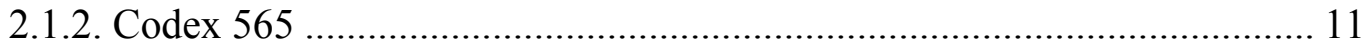

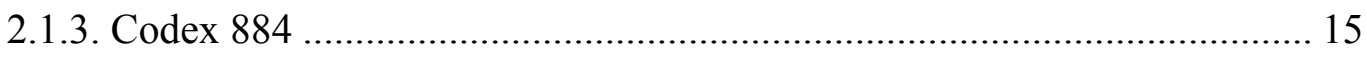

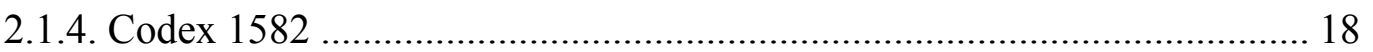

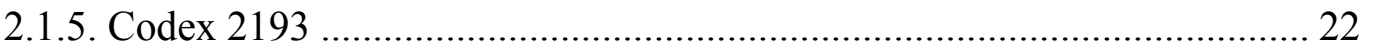

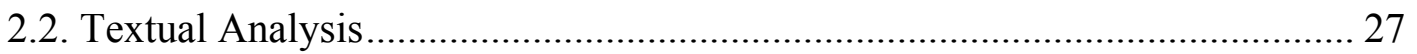

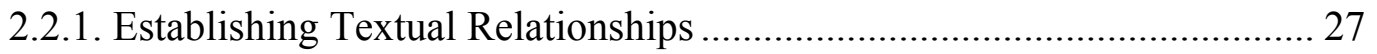

2.2.2. Non-Majority Text Agreements …......................................................... 28

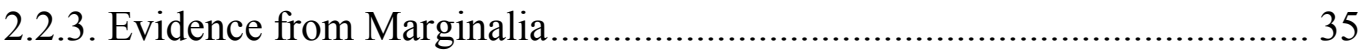

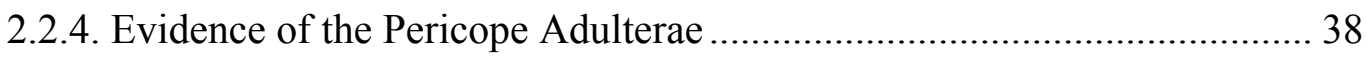

2.2.5. Non-Majority Text Correction and Disagreements................................. 40

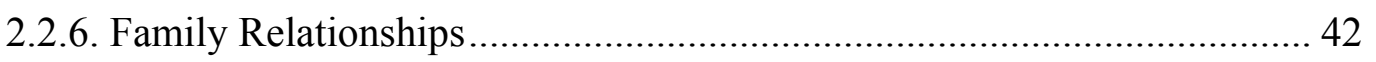

2.2.7. Codices 565, 884 and 2193 have a Shared Ancestor, B......................... 44

2.2.8. Codices 565, 884 and 2193 are Independent Witnesses of B ................. 45

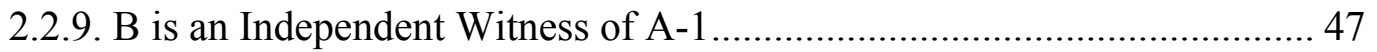

2.2.10. B is Independent of All Other Extant Family Manuscripts.................... 51

2.2.11. Codices 1 and 1582 are Independent of One Another ........................... 53

2.2.12. Codices 1 and 1582 Share an Intermediate Exemplar, C ....................... 57

2.2.13. New Readings for Family 1 in the Gospel of John .............................. 59 


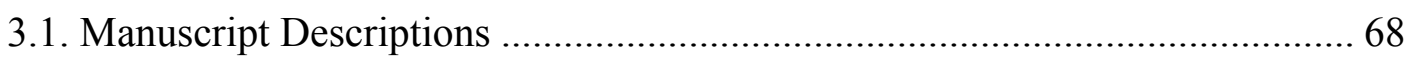

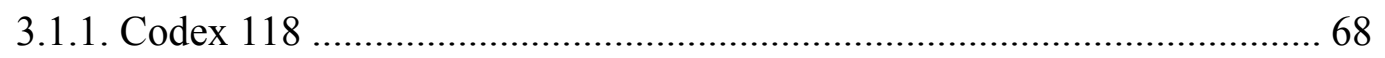

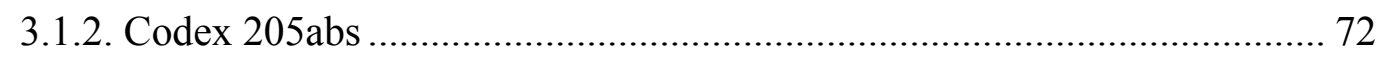

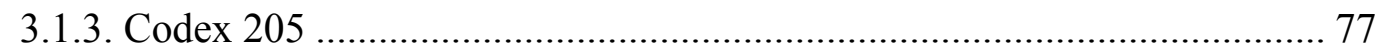

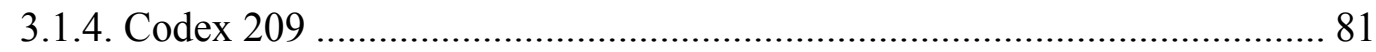

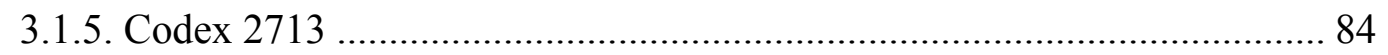

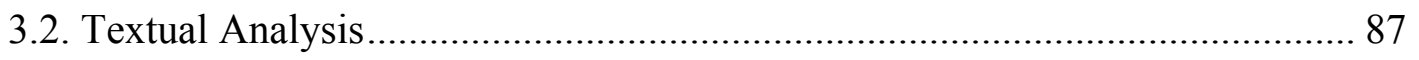

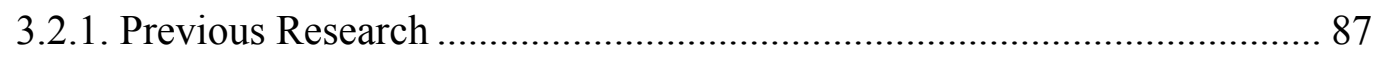

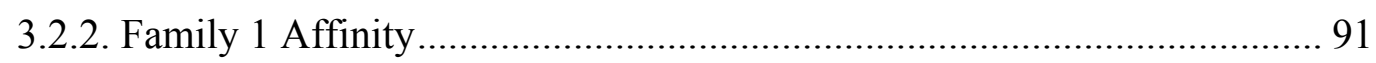

3.2.3. Codices 118, 205abs, 205, 209 and 2713 Form a Distinct Subgroup ....... 94

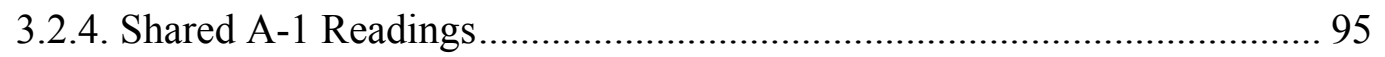

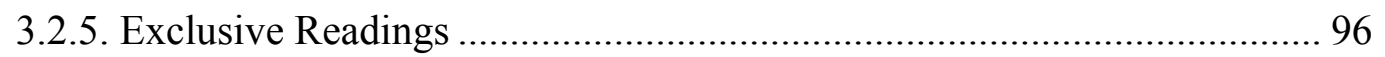

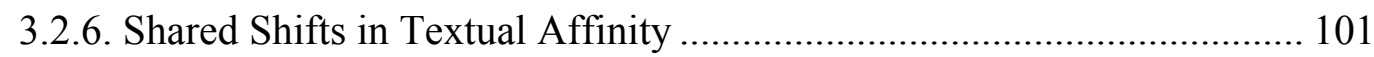

3.2.7. Explanation of the Textual Shifts in Manuscript E ................................ 106

3.2.8. Manuscript E Shares an Intermediate Exemplar with Codex 1 ............. 110

3.2.9. Manuscript $\mathrm{E}$ is Independent of Codex 1 ........................................... 114

3.2.10. Codex 1 and Manuscript E Descend from Manuscript D .................... 116

3.2.11. Codices 118, 205abs, 209, and 2713 are Independent Witnesses of E 117

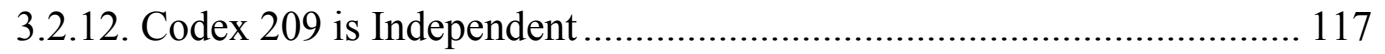

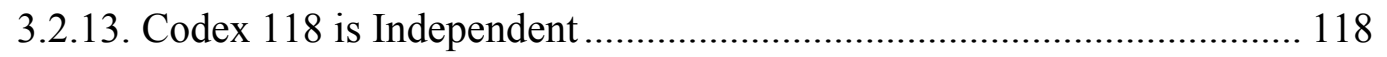

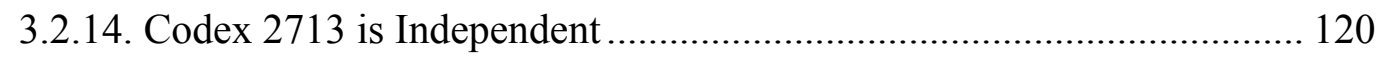

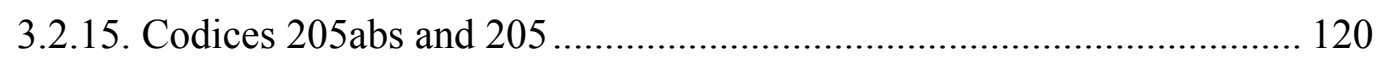

3.2.16. Codex 205 is a Copy of Codex 205abs ............................................. 122

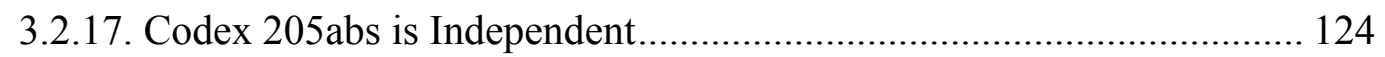

3.2.18. Summary of the Venice Group ............................................................ 126

4. A Manuscript Subgroup: Codices 22, 1192, 1210, 1278 and 2372 ................... 128

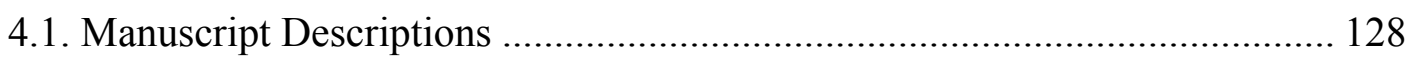

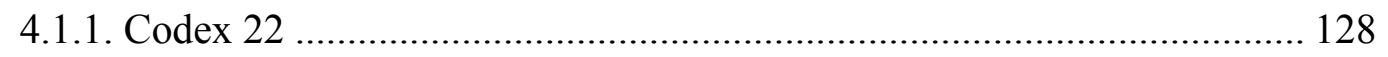




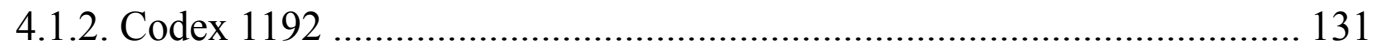

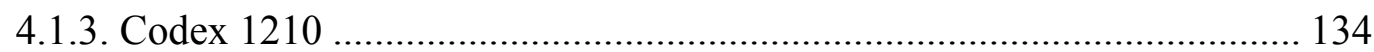

4.1.4. Two Decorative Style Manuscripts: Codices 1278 and 2372 ................ 136

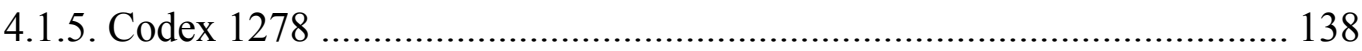

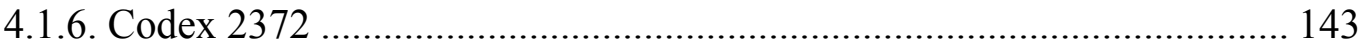

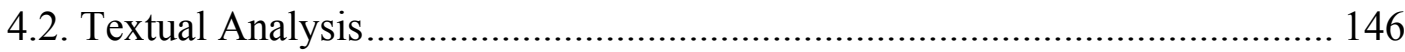

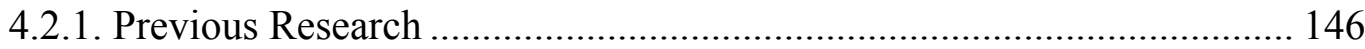

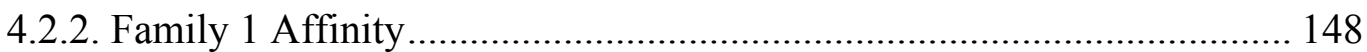

4.2.3. Codices 22, 1192, 1210, 1278, 2372 Share an Intermediate Ancestor ... 152

4.2.4. Shared A-1 Readings........................................................................ 152

4.2.5. Exclusive Readings ........................................................................... 154

4.2.6. $\mathrm{G}$ is the Intermediate Ancestor of 22, 1192, 1210, 1278 and $2372 \ldots \ldots . .157$

4.2.7. $\mathrm{G}$ is an Independent Witness of A-1 ................................................ 158

4.2.8. Does Manuscript G Descend from Manuscript C or Manuscript B? ...... 158

4.2.9. Codex 22 is an Independent Witness of Manuscript G......................... 159

4.2.10. Codex 1192 is an Independent Witness of Manuscript G.................... 160

4.2.11. Codex 1210 is a Copy of Codex 22 …............................................... 161

4.2.12. Codices 1278 and 2372 Descend from an Intermediate Ancestor ........ 167

4.2.13. Codices 1278 and 2372 are Sibling Manuscripts .............................. 171

4.2.14. Manuscript $H$ is Independent of 22 and 1192 ................................... 173

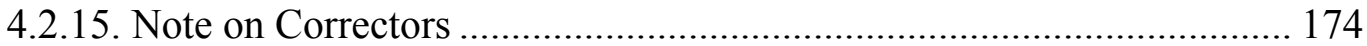

4.2.16. Summary of a Manuscript Subgroup ................................................... 177

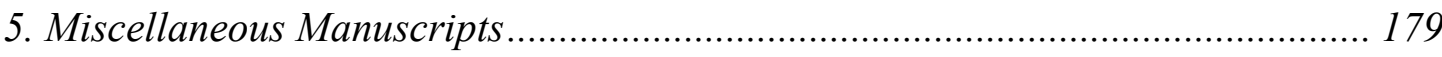

5.1. Manuscript Description of Codex 131 ....................................................... 179

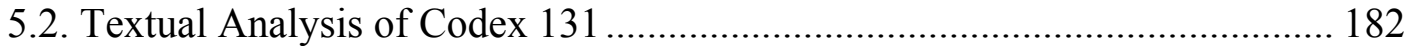

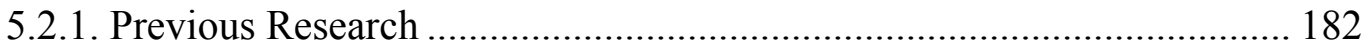

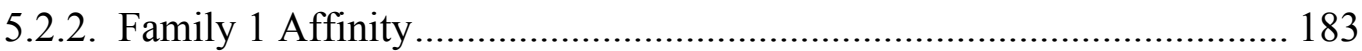

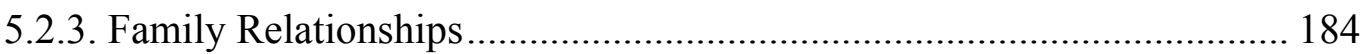

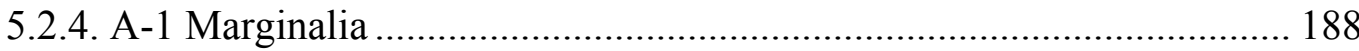


5.2.5. 121 Singular Readings

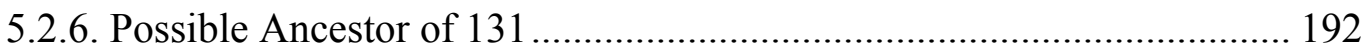

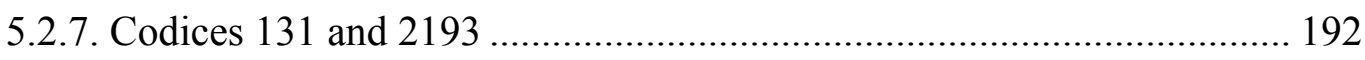

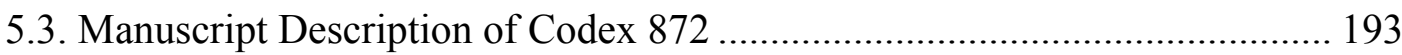

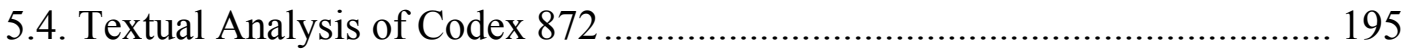

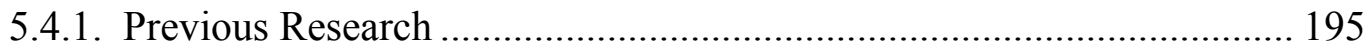

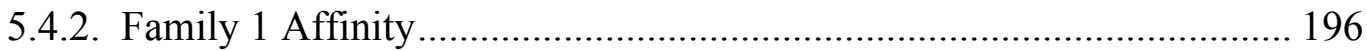

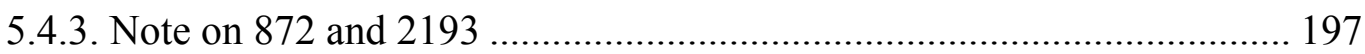

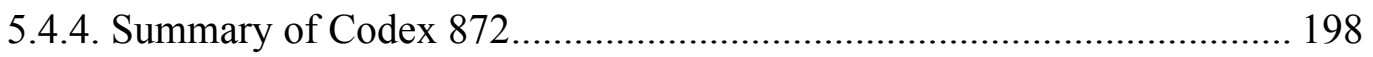

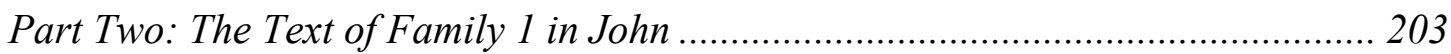

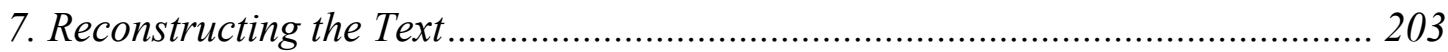

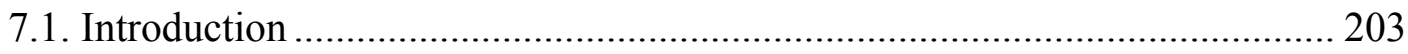

7.2. Majority Text Readings in the Reconstructed Text ................................... 203

7.3. Theory For the Reconstructed Text and Apparatus ..................................... 204

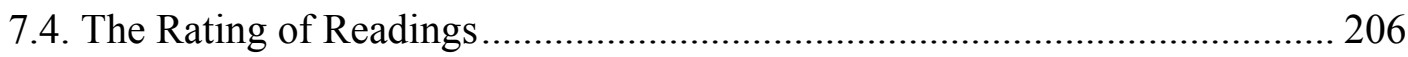

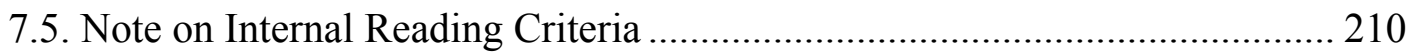

7.6. D! Rated readings in Core Group Manuscripts ............................................ 211

7.7. Note on the Treatment of Marginal Readings ............................................ 217

7.8. Note on Dealing with $\mathrm{M}^{\mathrm{pt}}$ Readings in the Main Gospel Text...................... 218

7.9. The Text of the Pericope Adulterae in A-1 .............................................. 218

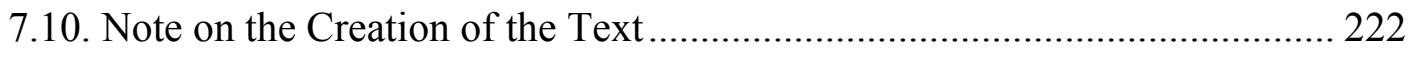

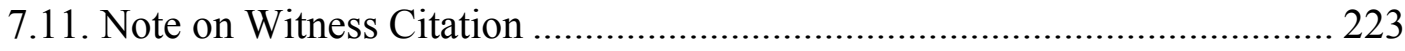

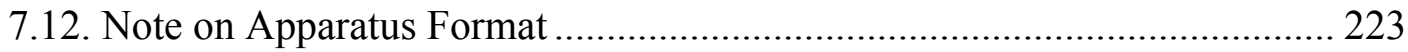

7.13. List of Symbols and Abbreviations Used in the Reconstructed Text .......... 224

7.14. Miscellaneous Notes on the Apparatus ..................................................... 227 


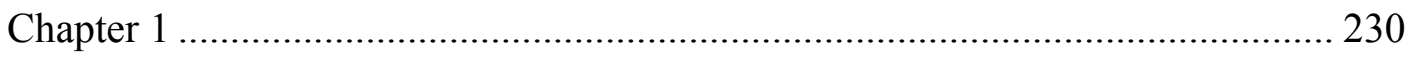

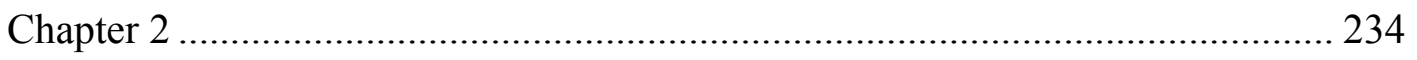

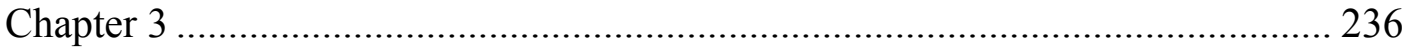

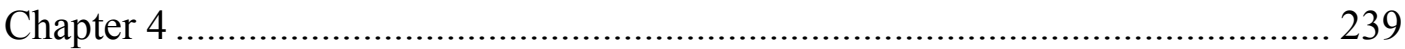

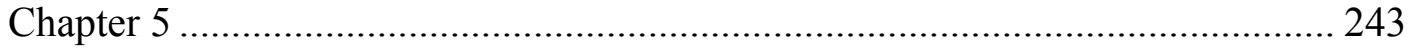

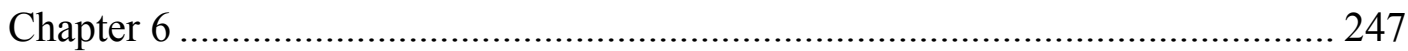

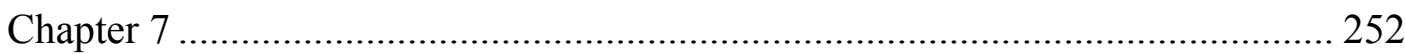

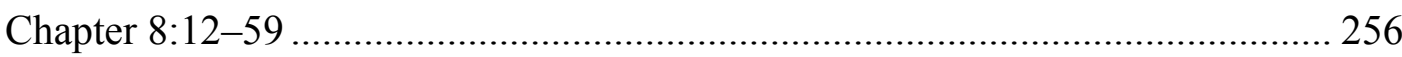

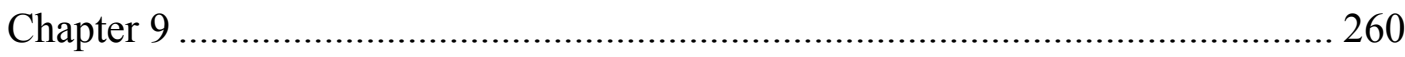

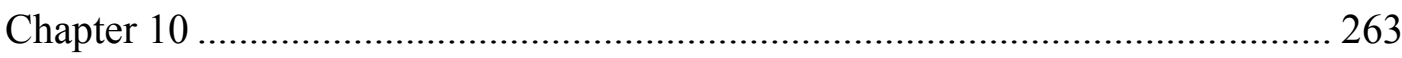

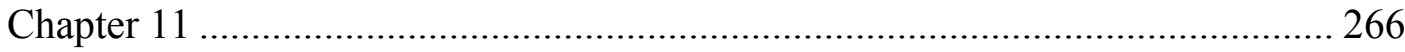

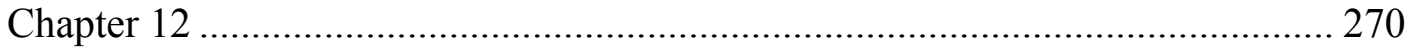

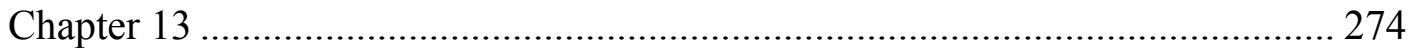

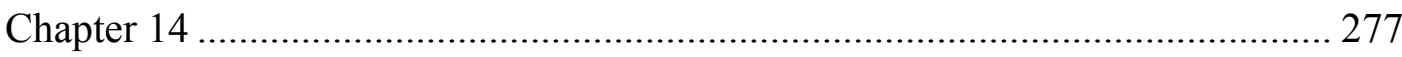

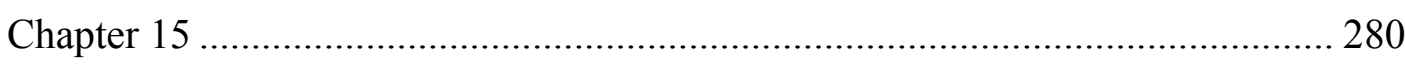

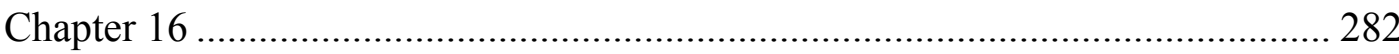

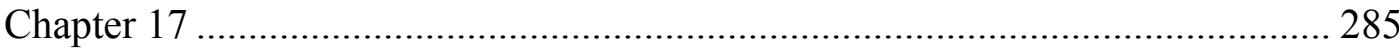

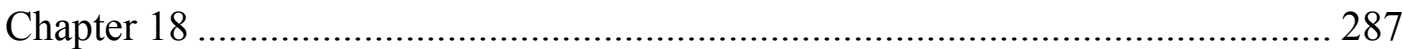

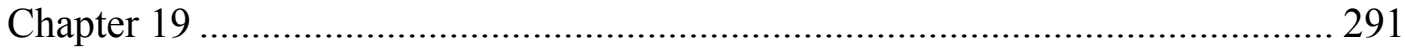

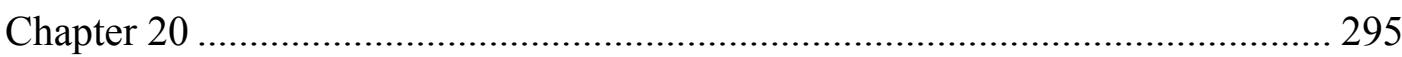

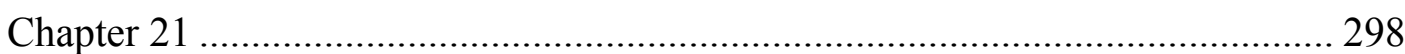

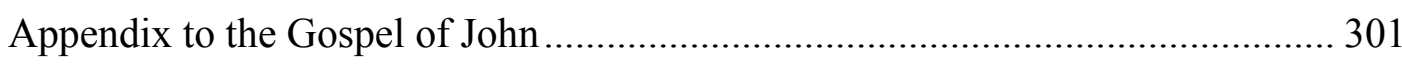

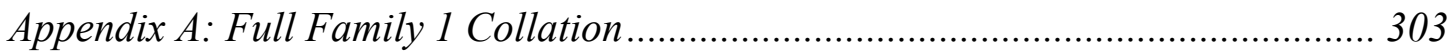

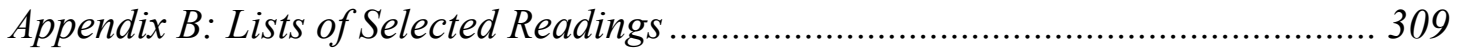

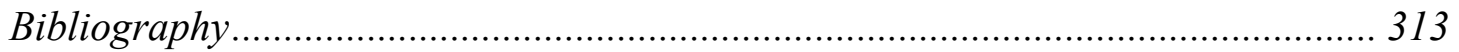




\section{Figures and Tables}

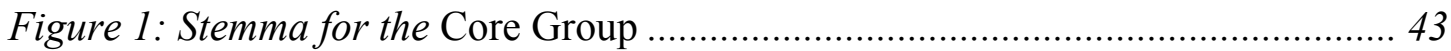

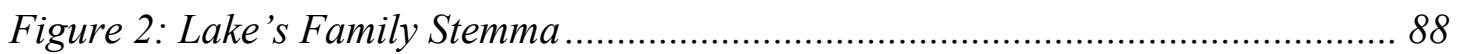

Figure 3: Schmid's Stemma for Revelation (205abs, 205, 209) .............................. 91

Figure 4: Stemma for the Venice Group .......................................................... 127

Figure 5: Stemma for Manuscript G.......................................................... 178

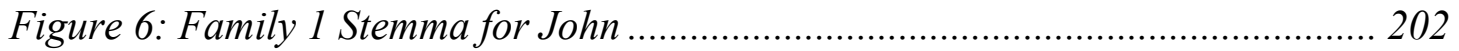

Table 1: 565, 884 and 2193 Non-Majority Text Agreements with 1 and 1582.......... 34

Table 2: Demonstrating the Independence of 565, 884 and $2193 \ldots \ldots \ldots \ldots \ldots \ldots \ldots \ldots . . . . . . . . . . . . . .66$

Table 3: A-1 Readings in the Venice Manuscripts .................................................... 93

Table 4: A-1 Readings in 22, 1192, 1210, 1278 and 2372................................ 149

Table 5: 22, 1192, 1210, 1278 and 2372 Share a Pool of A-1 Readings................. 154

Table 6: 131 's Non-Majority Text Agreements.................................................... 185 


\section{Plates}

Plates appear at the end of Part 1:

Plate 1: Codex 22: A Section of Text from John (f. 184r)

Plate 2: Codex 205abs: Text from the Opening of John (f. 377r)

Plate 3: Codex 565: Evangelist Portrait for Mark \& Opening Text (ff. 129v-130r)

Plate 4: Codex 565: A Section of Text from John (f. 404r)

Plate 5: Codex 1192: Text from the Opening of John (f. 196r)

Plate 6: Codex 1582: Text from the Opening of John (f. 223r)

Plate 7: Codex 2193: Evangelist Portrait for Luke (f. 128v)

Plate 8: Codex 2713: A Section of Text from John (f. 359r) 


\section{Part One: Analysis of Seventeen Manuscripts in the Gospel of John}

\section{Introduction}

\subsection{Rationale}

Kirsopp Lake published the seminal work on Family 1 in 1902: Codex 1 of the Gospels and its Allies. ${ }^{1}$ His study firmly established the existence of a closely-knit textual family of the Gospels that shared a unique profile of Non-Majority Text readings. Lake's Family 1 included the manuscripts: Gregory-Aland 1, 118, 131, 205abs, 205 and $209 .^{2}$ Lake demonstrated that these six manuscripts descended from the same non-extant archetype, and that 1, 131, 209, and possibly 118, are independent witnesses to that archetype. ${ }^{3}$ Lake found that Codex 1 was the leading family manuscript; that is to say, it was the manuscript that retained the highest number of Non-Majority Text readings from the archetype.

A more recent study of Family 1 in the Gospel of Matthew by Amy Anderson has widened the membership of the family group and, by the introduction of new members, has altered the profile of Non-Majority Text readings that the family supports. ${ }^{4}$ Anderson examined the text of thirteen manuscripts in Matthew:

\footnotetext{
${ }^{1}$ Kirsopp Lake, Codex 1 of the Gospels and Its Allies (Cambridge: Cambridge University Press, 1902).

${ }^{2}$ Family manuscripts will be referred to by their Gregory-Aland numbers throughout.

${ }^{3}$ He expressed some doubt over whether 118 was independent and not a copy of 209. Lake, Codex 1, xxv.

${ }^{4}$ Amy S. Anderson, The Textual Tradition of the Gospels: Family 1 in Matthew (Leiden: E. J. Brill, 2004).
} 
Codices 1, 22, 118, 131, 205, 209, 872, 1192, 1210, 1278, 1582, 2193 and 2542.

She collated 1 and 1582 in full and the other manuscripts in two test chapters and 436 test passages. Anderson was able to draw up a new and more complex stemma for the family, and after her full collation of 1 and 1582, nominated 1582 as the leading Family 1 manuscript. Anderson also drew attention to a number of inaccuracies in Lake's edition, highlighting the need for a new text of Family 1 in all four gospels. ${ }^{5}$

This thesis examines the text of Family 1 in the Gospel of John by analysis of a full collation of seventeen manuscripts in John: Codices 1, 22, 118, 131, 205abs, 205, 209, 565, 872, 884, 1192, 1210, 1278, 1582, 2193, 2372, and 2713. Anderson collated twelve of these manuscripts in Matthew: eight she found to be Family 1 manuscripts: 1, 22, 118, 205, 209, 1192 1210, and 1582; while four manuscripts: $131,872,1278$, and 2193 were found to have only very weak family affinity and so were categorised by Anderson as 'miscellaneous manuscripts'.6 The first eight manuscripts were collated for this study to test whether Anderson's basic stemma could be applied to the Gospel of John, and to discover whether a full collation of the gospel could provide sufficient data to answer questions left open by Anderson, including whether 205 was a copy of 209, and whether the 'tentative' conclusion that 22, 1192 and 1210 share an intermediate ancestor was correct. $^{7}$ The last four manuscripts were collated to test whether their family

\footnotetext{
${ }^{5}$ Anderson, Matthew, 98-100.

${ }^{6}$ For summary see Anderson, Matthew, 145.

${ }^{7}$ Anderson, Matthew, 116 and 121.
} 
affinity became stronger in John. Particularly in the case of 2193, the Text und Textwert volumes indicate that such a shift towards the family text was likely in John. ${ }^{8}$ Codices 565, 884 and 2372 were not collated by Anderson, ${ }^{9}$ but were included for this study because the Text und Textwert volumes indicated that they may be Family 1 members in John. Codex 205abs was not collated by Anderson (or Lake), as it was presumed to be a copy of $205 .^{10}$ It was collated for this study as no evidence has yet been provided to support this assumption; and, on the contrary, Josef Schmid, in his study of the text of the Apocalypse, has suggested that 205 and $205 \mathrm{abs}$ are sibling manuscripts. ${ }^{11} 2542$ has not been examined; Anderson found that it was predominately Majority Text in Matthew, and it is not extant in John. ${ }^{12}$

\footnotetext{
${ }^{8}$ K. Aland, B. Aland, and K. Wachtel, ed., Text und Textwert der griechischen Handschriften des Neuen Testaments V. Das Johannesevangelium. Volume 1.1 and 1.2. (Berlin: Walter de Gruyter, 2005). Vol. 1.1, 85; vol. 1.2, 648.

${ }^{9}$ Anderson did make note of 884 but it is not extant in Matthew.

${ }^{10}$ Anderson, Matthew, 115.

11 Josef Schmid, Studien zur Geschichte des griechischen Apokalypse-textes, 1. Teil. Der Apokalypse-Kommentar des Andreas von Kaisareia: Einleitung (München: Karl Zink, 1956), 285293.

${ }^{12}$ Anderson, Matthew, 144-145.
} 


\subsection{Method}

\section{Transcriptions}

For this study, electronic transcriptions were made of each of the seventeen manuscripts from the microfilm. ${ }^{13}$ Transcriptions record the text, layout and any corrections or marginal readings in the manuscripts. ${ }^{14}$ Transcription guidelines and conventions used by the International Greek New Testament Project (IGNTP) were adapted to suit the needs of the study. ${ }^{15}$ To ensure a high level of accuracy, two initial transcriptions were made of each manuscript and then collated against one another to check for transcriptional errors. All discrepancies between the two transcriptions were checked against the microfilm, and any transcriptional errors corrected to make a final transcription. ${ }^{16}$ Codices $118,205 \mathrm{abs}, 205,209,565$ and 1278 were also physically examined, so that any text unclear on the microfilm could be checked on the manuscript itself. Transcribed text is based only on the physical and visible evidence of a microfilm or manuscript; that is to say, no readings in the transcriptions have been conjectured on the basis of textual

\footnotetext{
13 Transcriptions were made by altering an electronic base text. The International Greek New Testament Project's (IGNTP) Textus Receptus base was employed for all transcriptions (privately circulated).

${ }^{14}$ Accents, breathings and punctuation were not recorded in the transcriptions and final sigmas were not used.

${ }^{15}$ Unpublished guidelines privately circulated.

${ }^{16}$ With the exception of 2713 .
} 
analysis or predictions of the textual relationships between manuscripts. ${ }^{17}$ The full transcriptions are available at:

http://arts-itsee.bham.ac.uk/AnaServer?family1+0+start.anv.

\section{Collation}

Electronic methods for collation made it feasible for each manuscript to be collated in full for the gospel. The transcriptions were collated using the Project Edition of Peter Robinson's Collate 2.1. ${ }^{18}$ Codex 1582 was used as a base text for the collation. ${ }^{19}$ Before the final collation was produced, a number of regularisations were made to remove very minor variants considered to be genetically insignificant. The final collation contains over 1,000 variant units; it can be found in Appendix A. ${ }^{20}$

\section{Rating of Readings}

To provide further information for the analysis of the final collation, each reading in each variation unit was either marked as a Majority Text reading or categorised

\footnotetext{
${ }^{17}$ See Appendix A for further details of the transcriptions and collation.

18 Peter Robinson, Collate 2.1 (Scholarly Digital Editions: March 1992-September 2003) www.sd-editions.com.

${ }^{19} 1582$ was considered suitable as it was expected to be one of the stronger Family manuscripts; it contains few omissions or lacunas and has a relatively standard orthography.

${ }^{20}$ Such minor variants included: the presence of absence of movable nu, itacisms, most nonsense readings, abbreviations, very minor spelling differences, and variations in the use of nomina sacra.
} 
according to how well attested the reading is in the wider Greek textual tradition of the gospel. Zane Hodges and Arthur Farstad's The Greek New Testament According to the Majority Text was used to label the Majority Text readings. ${ }^{21}$ The three sigla used in Hodges and Farstad: $\mathfrak{M}, \mathrm{M}$, and $\mathrm{M}^{\mathrm{pt}}$, were retained to distinguish between straightforward Majority Text readings (MR), Majority Text readings with reduced support $(\mathrm{M})$, and readings where the Majority Text is divided $\left(\mathrm{M}^{\mathrm{pt}}\right) .^{22}$ For the Non-Majority Text readings the IGNTP Papyri, Majuscule, and Byzantine editions of John were used to calculate the level of support each reading had in the wider Greek manuscript tradition of John. ${ }^{23}$ Readings not attested by any manuscript in the wider tradition were labelled distinctive (D); readings supported by no more than 9 manuscripts were labelled rare $(\mathbf{R})$; and readings supported by 10 or more manuscripts were labelled widely attested $(\mathbf{W})$.

Part 1 of this study consists of the analysis of the collation of John and Part 2 provides a new text of Family 1 in John, reconstructed from the extant witnesses confirmed to be family members in the gospel.

\footnotetext{
${ }^{21}$ Zane C. Hodges and Arthur L. Farstad, The Greek New Testament According to the Majority Text (New York: Thomas Nelson Publishers, 1982).

${ }^{22}$ See Hodges and Farstad, Majority Text, xiv-xxi, for more detailed explanation.

${ }^{23}$ W. J. Elliott and D. C. Parker, ed., The New Testament in Greek IV. The Gospel According to St. John, vol. 1: The Papyri (Leiden: E. J. Brill, 1995).

U.B. Schmid with W.J. Elliott and D.C. Parker, ed., The New Testament in Greek IV. The Gospel According to St. John, vol. 2: The Majuscules (Leiden: E. J. Brill, 2007).

Roderic L. Mullen with Simon Crisp and D.C. Parker, ed., The Gospel According to St. John in the Byzantine Tradition (Stuttgart: Deutsche Bibelgesellschaft, 2007).
} 


\subsection{Manuscript Descriptions}

\subsubsection{Codex 1}

\section{Contents and Layout}

Codex 1 is a Greek New Testament Codex containing Acts (ff. 5r-42v), the Catholic Epistles (ff. 42r-62r), the Pauline Epistles (ff. 70v-160v) and the Four Gospels (ff. 161r-303r). It is kept at the University of Basel library where it has the library catalogue reference A. N. IV.2. ${ }^{24}$ It contains 297 folios; the text is written in brown ink on vellum in 1 column per page with 38 lines per column; the pages measure 18.3 by $18.5 \mathrm{~cm}$ and the text 10.6 by $11.9 \mathrm{~cm}$; initial letters are used throughout in gilded red. ${ }^{25}$ Each gospel begins on a fresh recto page

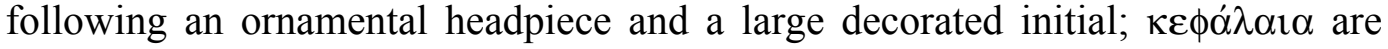
present for Mark and John; Ammonian sections are given but without Eusebian canon tables. F. $265 \mathrm{v}$ contains a portrait of John dictating to Prochoros. The manuscript contains a critical note on the Pericope Adulterae and on the ending of the Gospel of Mark.

\footnotetext{
${ }^{24}$ Formerly: B. VI. 27; von Soden: $\delta 254$ (formerly: $\delta 50$ ).

${ }^{25}$ Details not evident from the microfilm have been taken from W. H. P. Hatch, Facsimiles and Descriptions of Minuscule Manuscripts of the New Testament (Cambridge, MA: Harvard University Press, 1951).
} 


\section{Script and Dating}

The hand of Codex 1 is not neat but is easily legible. There are some ligatures and abbreviations in the main body of text, but most occur at line endings. Certain letters are regularly enlarged, especially kappa, upsilon, chi and lambda. Mute iota is adscript, usually resting slightly below the line; breathings are mostly round with only very rare occurrences of square breathings; nomina sacra have accents and breathings; circumflex accents are raised above breathing marks; and accents, breathings and abbreviation marks are all distinct from one another and from letters. Burgon, Lake, and Omont have dated Codex 1 to the twelfth century ${ }^{26}$ while Scrivener, Gregory and Wettstein have ascribed it to the tenth. ${ }^{27}$ The round breathings, enlarged letters and regularity of abbreviations would support a twelfth century dating. ${ }^{28}$

\section{Illuminations}

F. 265v contains a portrait depicting a standing John, dictating his gospel to the scribe Prochoros; John's head is turned towards the hand of God, which extends from a cloud in the top right hand corner of the image. A mountainous landscape, symbolizing the island of Patmos, is painted as the backdrop, and helps to date the

\footnotetext{
${ }^{26}$ Lake, Codex 1, ix; H. Omont, Catalogue des manuscripts grecs des bibliothèques de Suisse (Paris: E. Leroux, 1903), 7.

${ }^{27}$ C. R. Gregory, Textkritik des Neuen Testamentes, Erster Band (Leipzig: J.C. Hinrichs, 1900), 127; Lake, Codex 1, ix.

${ }^{28}$ Ruth Barbour, Greek Literary Hands-AD. 400-1600 (Oxford: Clarendon, 1981), xx, xxviii and xxix.
} 
miniature to the twelfth century, when this particular setting for John and Prochoros became popular. ${ }^{29}$ Analysis of the miniature, therefore, supports the palaeographical dating of the manuscript. Above the evangelist portrait, inside a medallion, is a vignette of the Anastasis, another image common to the latter part of the twelfth century. ${ }^{30}$ Interestingly, this evangelist portrait in Codex 1 suggests a possible artistic link with another manuscript collated for this study, Codex 1278 , which contains the same motif and combination of images in its miniature for the Gospel of John: the same seated Prochoros; a standing position for the evangelist; John's head turned for inspiration to the hand of God in the top right corner; and the same rocky backdrop.

\section{Correctors and Later Hands}

Codex 1 has not been systematically corrected; only about 20 corrections were recorded in the transcription of John and the majority of these were very minor spelling alterations. Some corrections are discernable on the microfilm as being made by the first hand; these have been labelled $\mathrm{C}^{*}$. All remaining corrections have not been distinguished and are labelled simply as C. A number of later hands have added notes and supplementary material to the codex. Lake, who examined it in person, discusses these later hands in more detail. ${ }^{31}$

\footnotetext{
${ }^{29}$ Hugo Buchthal, "A Byzantine Miniature of the Fourth Evangelist and Its Relatives," Dumbarton Oaks Papers 15 (1961): 132.

${ }^{30}$ Buchthal, "Byzantine Miniature," 133.

${ }^{31}$ Lake, Codex 1, x.
} 
Codex 1 was previously owned by John of Ragusa (ca. 1380-1443), the cleric who officially opened the Council of Basel in 1431. Ragusa bequeathed the manuscript to the Dominican convent in Basel, and in 1559 it passed from the convent to Basel University library. ${ }^{32}$ Ragusa served as a legate of the Council of Basel to Constantinople between 1435 and 1437, commissioned to convince a Greek delegation of the Council's conciliarist cause. ${ }^{33}$ A leading member of the Greek delegation was Cardinal Bessarion, the owner of three other manuscripts collated for this study, 205abs, 205 and 209. This provides a remarkable historical link between Codex 1 and Bessarion's three manuscripts. While in Constantinople, Ragusa had also been commissioned to collect biblical and patristic Greek manuscripts to be used by the Council. ${ }^{34}$ It is very probable that Ragusa acquired Codex 1 during this visit to the Greek delegation; he may even have acquired the manuscript through Bessarion himself, who owned one of the largest Greek libraries of the time. Codex 209 was almost certainly present with Bessarion at this point; as a note in the manuscript, added by Bessarion, records that the Latin chapter numbers were added for help in disputations with the Latins. As Lake suggests, these disputations were almost certainly those of the Council of Florence (1438-39), to which Bessarion would travel after meeting

\footnotetext{
${ }^{32}$ Gregory, Textkritik, Erster Band, 127.

${ }^{33}$ Deno J. Geanakoplos, "The Council of Florence (1438-1439) and the Problem of Union Between the Greek and the Latin Churches," Church History 24, 4 (Dec., 1955): 328.

${ }^{34}$ Robert S. Nelson, "The Italian Appreciation of Illuminated Byzantine Manuscripts, ca. 12001450 ," Dumbarton Oaks Papers 49, Symposium on Byzantium and the Italians, $13^{\text {th }}-15^{\text {th }}$ Centuries (1995): 222.
} 
with Ragusa's delegation in Constantinople. ${ }^{35}$ It is remarkable that Bessarion also owned a number of classical manuscripts copied by the scribe Ephraim, also the scribe of Codex $1582 .^{36}$

\section{Transcription of the Gospel of John}

The Gospel of John begins on f. 266r and ends on f. 303v. The Pericope Adulterae is located at the end of the gospel following a critical note. The folio containing John 19:5-31a has been dislocated and is bound at the end of the manuscript. Codex 1 was transcribed from the microfilm; the folio numbers in the transcription follow those of the manuscript's original foliation, which jumps from f. 290 to f. 298.

\subsubsection{Codex 565}

\section{Contents and Layout}

Codex 565 is a ninth-century codex containing the Four Gospels. It is kept at St. Petersburg National Library where it has the library catalogue number Gr. $53 .{ }^{37}$ The codex is an extremely opulent production, written on purple vellum in gold ink, with large text and generous margins. The manuscript contains 405 folios; the

\footnotetext{
${ }^{35}$ Lake, Codex 1, xxi.

${ }^{36}$ For a discussion of these manuscripts see Anderson, Matthew, 33-34; 39-41.

${ }^{37}$ Other numbers: Scrivener 473; von Soden $\varepsilon$ 93; Tischendorf $2^{\text {pe }}$.
} 
text is written in 1 column per page ${ }^{38}$ with $17-19$ lines per column; and the average dimensions are 20.7 by $13 \mathrm{~cm}$. Each gospel begins on a fresh recto page, opposite a portrait of the seated evangelist. The portraits were probably added to the codex at a later date. Each gospel is preceded by a list of $\kappa \varepsilon \phi \alpha \dot{\lambda} \alpha \alpha_{\alpha}$; the Ammonian sections are present throughout; the Eusebian canon tables were added later. There are a number of lacunas in the manuscript: Matthew 20:18-26, 21:4522:9; Luke 10:36-11:2, 18:25-37, 20:24-36; and John 11:26-48, 13:2-23, and 17:1-12. The missing text, except for John 11:26-48, 13:2-23, has been supplemented by a later hand on inserted parchment leaves, dyed in a lighter purple. The manuscript contains a critical note on the text of the Pericope Adulterae, though the text of the pericope itself is no longer extant. The manuscript is stored with a single paper page containing a late fragment of the beginning of John.

\section{Script and Dating}

The text of 565 is large, neat and rounded with very few majuscule letter forms and little variation in letter size. There are very few ligatures and very few abbreviations: only nu-superlines, koí compendiums, and abbreviations for omicron-sigma. These abbreviations only occur at line endings. ${ }^{39}$ Breathing marks are all square; nomina sacra do not have breathings or accents; and there is

\footnotetext{
${ }^{38}$ Except for the genealogy in Luke which is written in 2 columns ff. $227 \mathrm{v}-228 \mathrm{v}$.

${ }^{39}$ With the only exception in John being f. 381r, line 9, where a $\alpha \alpha$ i compendium occurs in the middle of a line.
} 
no mute iota. These palaeographical details support a ninth century date for the codex. $^{40}$

\section{Illuminations}

Codex 565 contains a seated evangelist portrait for each gospel. The portraits for Matthew, Luke and John appear to form an artistic set, with similar style, palette and dimensions; however, the image for Luke stands out as distinctive, and is painted directly onto a paper leaf, which was then inserted into the codex. The pages containing the set of three miniatures are not integral to the codex and were bound in separately, and it is likely that they also were not part of the original production. They do not match the quality and finish of the manuscript itself, and the dimensions of each picture do not fit comfortably onto the page. The three portraits, however, depict the evangelists writing on purple parchment, which may be an indication that even though the pictures were not part of the original production, they were specifically painted to be added to the manuscript. There are a number of smaller illuminations, painted onto paper and added to the margins of the manuscript. In f. 124r, for example, an image of two men carrying the body of Christ has been pasted into the margin.

\footnotetext{
${ }^{40}$ Most scholars agree on this date. Hort, Gregory and von Soden suggest either a ninth or tenth century date. (Hatch, Facsimiles, 80). See Barbour, Literary Hands, xvi, xix and xxviii.
} 


\section{Correctors and Later Hands}

Codex 565 has not been systematically corrected in John; fewer than 10 corrections were made in the whole gospel and none of textual significance. Corrections by the first hand have been labelled $\mathrm{C}^{*}$, and corrections made by the hand that added the supplementary page in John have been labelled C2. Corrections, usually small erasures, where it is difficult to distinguish between $\mathrm{C}^{*}$ and $\mathrm{C} 2$ have been labelled C. Most of the missing leaves in 565 have been supplemented on parchment leaves of a lighter purple. The hand which copied these pages is significantly later than the first hand, the script containing a high number of ligatures, abbreviations, enlarged letters and rounded breathings.

Provenance

Gregory records that the manuscript was previously owned by St. John's Convent in Gumush-Khaneh, Asia Minor; and that in 1829 it was given by the convent to Tsar Nicholas I of Russia. ${ }^{41}$

\section{Transcription of the Gospel of John}

The text of John begins on f. 330r and John 21:25 ends on f. 405v. The gospel is followed by a shorter version of the critical note found in Codices 1 and 1582 , introducing the problem of the Pericope Adulterae. The note was written in different ink to the rest of the manuscript and has faded considerably. The

\footnotetext{
${ }^{41}$ Gregory, Textkritik, Erster Band, 203.
} 
Pericope Adulterae is not present in the manuscript, but the existence of the note indicates that it was originally present and was located at the end of the gospel. The transcription of 565 was made from the microfilm and colour photographs of the last folios (ff. 398-405). Transcriptions of sections of text unclear on the microfilm were checked against the transcription for the IGNTP Byzantine Text electronic edition, ${ }^{42}$ and later by an examination, in St. Petersburg, of the manuscript itself.

\subsubsection{Codex 884}

\section{Contents and Layout}

Codex 884 is an eleventh-century manuscript containing the gospels of Luke and John with commentary. It is kept at the Vatican library in Rome and is designated Reg. Gr. 3. ${ }^{43}$ The manuscript contains 256 parchment folios measuring 35.3 by $26.5 \mathrm{~cm} .{ }^{44}$ The text is written in 1 column per page with $30-33$ lines per column. The biblical text is written in semi-majuscule while the commentary is written in a minuscule hand; a diple before a line is used to indicate the presence of biblical text. Von Soden has identified the commentary text in Luke as that of Titus of

\footnotetext{
${ }^{42}$ R. L. Mullen with Simon Crisp and D. C. Parker and in association with W. J. Elliott, U. B. Schmid, R. Kevern, M. B. Morrill and C. J. Smith, ed., An Electronic Edition of the Gospel According to John in the Byzantine Tradition. (Birmingham: ITSEE, 2007).

http://arts-itsee.bham.ac.uk/AnaServer?byzantine+0+start.anv. Accessed Jan-March 2008.

${ }^{43}$ Other reference numbers: Scrivener 696; von Soden $\mathrm{A}^{126} \mathrm{C}^{21}$.

${ }^{44}$ It was not possible to examine 884 in person. Details not apparent from the microfilm are taken from Gregory, Textkritik, Erster Band, 229.
} 
Bostra. $^{45}$ Luke 1:1-3:1 and John 1:24-2:19 are missing and have not been supplemented.

\section{Script and Dating}

On the evidence of formatting factors, such as the number of lines per page and the use of decorative initial letters, McReynolds has demonstrated that at least three different scribes worked on the manuscript. ${ }^{46}$ All three hands are busy but neat, with a relatively high number of ligatures and abbreviations occurring in the main body of text. Abbreviations include one letter raised above words to substitute for missing letters. Some letters are enlarged; breathings are round, and breathings and accents are distinct from letters and other marks. Most scholars agree on an eleventh-century date, except for Scrivener who dates the manuscript to the thirteenth century. ${ }^{47}$

\section{Illuminations}

There are no extant illuminations in 884 .

\footnotetext{
${ }^{45}$ These details are taken from P. R. McReynolds, "Two New Members of Family One of the New Testament Text: 884 and 2542," in J. Dummer et al., ed., Texte und Textkritik: eine Aufsatzsammlung (Berlin: Wiley VCH, 1987), 398.

${ }^{46}$ McReynolds, “Two New Members,” 398.

${ }^{47}$ F. H. A. Scrivener, A Plain Introduction to the Criticism of the New Testament for the Use of Biblical Students (Cambridge: Deighton, Bell and Co., 1883), 403; McReynolds, "Two New Members," 397-8.
} 


\section{Correctors and Later Hands}

Codex 884 contains a number of corrections; the script of the corrector's text is very similar to that of the main text; however, because it was not possible to examine the manuscript itself and because the microfilm was often of a poor quality, no attempt was made to label corrections.

\section{Provenance}

Very little is known of Codex 884 before it entered into the Vatican collection. While collating the manuscript and checking text against the IGNTP Byzantine Text edition, a closeness with a number of other commentary manuscripts, including K0141, K194 and K994, became very apparent. It would be an interesting avenue of study to discover the relationship between this branch of commentary manuscripts and the text of Family 1.

\section{Transcription of the Gospel of John}

Text and commentary for the Gospel of John begins on f. $119 \mathrm{v}$ and ends on f. 255v. The Pericope Adulterae text is present and located after John 7:52. The manuscript was transcribed from the microfilm. Folio numbers are not visible on the microfilm so page numbers, referring to the pages of the microfilm scans, were used to navigate the transcription. 


\subsubsection{Codex 1582}

\section{Contents and Layout}

Codex $1582^{48}$ is a tenth-century Four Gospel codex kept at the Vatopedi Monastery, Mount Athos, where it has the library catalogue number $949 .{ }^{49}$ It contains 290 folios, ${ }^{50}$ with text written in 1 column per page with 20 lines to a column. Pages measure 21 by $15 \mathrm{~cm}$ and the text 14.2 by $8 \mathrm{~cm}^{51}$ Each gospel begins on a fresh recto page, preceded by a list of $\kappa \varepsilon \phi \alpha ́ \lambda \alpha \iota \alpha$ and an evangelist portrait. The gospel text begins part-way down the page, beneath a decorative headpiece measuring approximately 7.5 by $8.2 \mathrm{~cm} .{ }^{52}$ Most of the manuscript's original text is still extant except for Matthew 5:3-5:19, Matthew 22:29b-23:3a and John 8:7b-11. The text of Matthew 5:3-5:19 and John 8:7b-11 has been supplied by a later hand on f. 13 and f. 287 r. The manuscript contains a number of variant readings in each gospel; these readings are usually supplied in the margins and marked by a wavy line or the gamma-rho symbol. Most of the marginal readings occur earlier in the codex. The manuscript also contains a critical note

\footnotetext{
${ }^{48}$ For a comprehensive description of 1582 and its scribe see Anderson, Matthew, 1-58.

${ }^{49}$ Earlier Vatopedi 747; von Soden $\varepsilon 183$.

${ }^{50}$ Most reference works record 287 folios; however, the first 4 folios have not been numbered by the foliator, nor has the folio following f. 190.

51 Aubrey Diller, "Notes on Greek Codices of the Tenth Century," Transactions and Proceedings of the American Philological Association 78 (1947): 186.

52 I. Spatharakis, Corpus of Dated Illuminated Greek Manuscripts. Vols.1-2 (Leiden: E. J. Brill, 1981), 11.
} 
about the authenticity of the ending of Mark and a note about the text of the Pericope Adulterae; both notes are written in semi-majuscule letters.

\section{Script and Dating}

The script of 1582 is neat and even, with very few—and only slightly — enlarged letters, but a number of majuscule forms. Breathings are square; mute iota is adscript; breathings and accents are always clearly distinct; and the circumflex accent is small and raised quite high above other marks. There are very few abbreviations, most often кoí compendium and nu-superline, and these usually occur only at line endings. Some nomina sacra have breathings and accents but not all; Anderson suggests that these were added by a later hand. ${ }^{53}$ A number of palaeographers have studied the scribe of 1582 in detail, including Aubrey Diller who has suggested that his script is an example of an early and innovative minuscule. ${ }^{54}$ A later transcription of a colophon on $\mathrm{f}$. $287 \mathrm{r}$ allows a precise dating of the manuscript; the colophon states that the manuscript was copied in the year 948 by the monk Ephraim. Most scholars have accepted this colophon as authentic and the dating is supported by the manuscript's palaeographical features. $^{55}$

\footnotetext{
${ }^{53}$ Anderson, Matthew, 17.

${ }^{54}$ Aubrey Diller, Studies in Greek Manuscript Tradition (Amsterdam: Adolf M. Hakkert, 1983), 309-320.

${ }^{55}$ For a fuller discussion of the colophon see Anderson, Matthew, 5-6; Kirsopp Lake and Silva Lake, “The Scribe Ephraim,” Journal of Biblical Literature 62, 4 (1943): 265.
} 
Each gospel is preceded by a portrait of a seated evangelist, painted against a plain gold background inside a decorative border. ${ }^{56}$ Anderson suggests that these miniatures were not originally intended for the codex, but were added later, though they are of a similar age to the manuscript. ${ }^{57}$ Each gospel begins beneath a decorative headpiece; these headpieces are original, and Anderson suggests are typical of tenth-century Constantinopolitan production. ${ }^{58}$

\section{Correctors and Later Hands}

The first hand, the scribe Ephraim, has made a very small number of corrections in the manuscript; these have been labelled $\mathrm{C}^{*}$ in the transcription. A later hand, which Anderson, on the basis of a thorough palaeographical analysis, dates between 1100 and $1150,{ }^{59}$ has added two supplementary pages, f. 13 and f. 287, supplying the text of Matthew 5:3-5:19 and John 8:7b-11. This same hand has systematically corrected the manuscript, almost always with the reading of the Majority Text. ${ }^{60}$ This corrector has been labelled $\mathrm{C} 1$ in the transcription. When it

\footnotetext{
${ }^{56}$ F. 4v, f. $83 v$, f. $138 v$, f. $222 v$.

${ }^{57}$ Anderson, Matthew, 11-14.

${ }^{58}$ Anderson, Matthew, 14.

59 Anderson, Matthew, 51-52.

${ }^{60}$ Anderson has also made a palaeographical analysis of the corrections in 1582 , comparing the letter forms of corrected text with the letter forms of the supplementary pages (f. 13 and f. 287). Anderson has demonstrated that the $\mathrm{C} 1$ corrector is identical with the supplementor. See Anderson, Matthew, 45-51.
} 
has been difficult to distinguish between $\mathrm{C} 1$ and $\mathrm{C}^{*}$, the correction has been labelled C. The hand that transcribed the date colophon is much later and clearly distinct from $\mathrm{C} 1$; Spatharakis dates this hand to the fifteenth century. ${ }^{61}$

\section{Provenance}

Most scholars agree, based on 1582's quality and fine script, that it was a product of Constantinople. It was copied by a scribe who also copied a number of other manuscripts — biblical and classical—considered extremely valuable for both their contents and the type of text they contain. ${ }^{62}$ It is likely, therefore, that Ephraim worked in a large and important scriptorium, where he would have had access to high quality exemplars. Little is known of 1582 's previous owners before it came to the Vatopedi monastery; it is interesting, however, that a number of other manuscripts copied by Ephraim are found in the collection of Cardinal Bessarion, owner of 205abs, 205 and 209. It is possible that some of the biblical exemplars used by Bessarion's scribes were acquired from this same scriptorium where Ephraim had once worked.

\footnotetext{
${ }^{61}$ Spatharakis, Corpus, 11.

${ }^{62}$ For discussion of Ephraim's other work see: Anderson, Matthew, 30-46; Lake, "The Scribe Ephraim"; Diller, "Notes"; and Aubrey Diller, "Codex T of Plato," Classical Philology 75, 4 (1980): 322-324.
} 
Transcription of the Gospel of John

The Gospel of John begins on f. 223r and John 21:25 ends on f. 285v. F. 286r contains a critical note on the text of the Pericope Adulterae and the pericope text is given as an appendix, beginning part way down the page. The original pericope text is missing from $8: 7 \mathrm{~b}$ and the remaining text has been added by the supplementary hand and corrector $\mathrm{C} 1$ on $\mathrm{f}$. $287 \mathrm{r}$. The transcription of 1582 was made from the microfilm as access to its location on Mount Athos is prohibited to women.

\subsubsection{Codex 2193}

\section{Contents and Layout}

Codex 2193 is a tenth-century Four Gospel codex kept at the Iviron monastery on Mount Athos. It has the library catalogue number $1387 .{ }^{63}$ The manuscript contains 259 parchment folios measuring 23.5 by $18.5 \mathrm{~cm}$. The text is given in 2 columns per page with 22 lines per column, written in tempera ink. ${ }^{64}$ In addition to the gospel text, the manuscript contains Eusebius's letter to Carpianus; decorated canon tables with Ammonian sections given throughout; and a list of $\kappa \varepsilon \phi \alpha ́ \lambda \alpha 1 \alpha$ and an evangelist portrait for each gospel. Each gospel begins on a recto page, opposite the evangelist portrait. The gospel title is written in thick majuscule

\footnotetext{
${ }^{63}$ Formerly 247; von Soden $\varepsilon 1131$.

${ }^{64}$ It was not possible to examine 2193. Details not evident from the microfilm are taken from Helen C. Evans and William D. Wixon, ed., The Glory of Byzantium: Art and Culture of the Middle Byzantine Era A.D. 843-1261 (New York: The Metropolitan Museum of Art, 1997), 91.
} 
letters inside a decorative rectangular box that sits at the top of the first column of text. The first letter in each gospel is enlarged and decorated. Smaller initial letters are used throughout the codex; when appropriate they have accents and breathings. Abbreviated gospel titles appear at the top of verso folios throughout the manuscript. A later hand has added lectionary material and a hypothesis for each gospel. The text is also marked with musical notations, though it is unclear whether these were added at the time of production or by a later hand.

\section{Script and Dating}

The script of 2193 is neat and rounded; Maria Agati describes it as a typical example of tenth-century minuscule bouletée. ${ }^{65}$ Some majuscule letter forms are used, including lambda, gamma, sigma and pi; and the scribe has a particular preference for majuscule nu. Letter size varies very little; breathing marks are all square; nomina sacra have accents and breathings; the circumflex accent is compact; and accents and breathings are not linked to each other or to letters. Some simple ligatures are used, such as epsilon-sigma, epsilon-gamma or omicron-upsilon but most letters, except for linking cross bars, are quite distinct. With the exception of $\alpha \alpha i$ compendium, extremely few abbreviations are used; they are almost only found at line endings and are only used for the letters and letter combinations alpha-iota, epsilon-nu, nu, and once in John alpha-iota-

\footnotetext{
${ }^{65}$ See Maria Luisa Agati, La Minuscola "Bouletée" (Vatican City: Scuola Vaticana di Paleografia, Diplomatica e Archivistica, 1992), 85-86.
} 
sigma. ${ }^{66}$ Punctuation is regular; diaeresis is used over iota and upsilon; and mute iota is not employed. ${ }^{67} 2193$ contains a number of variant readings. These are usually given in the margins of the manuscript and are marked with the gammarho symbol.

\section{Illuminations}

Codex 2193 contains a set of four evangelist portraits. ${ }^{68}$ The evangelists are all painted dressed in a similar draped robe, in a standing pose, against a plain background, each evangelist holding a codex. Each picture has a rubricated majuscule title 'O АГІО $\Sigma$ ' followed by the evangelist's name. The portraits are detailed and of extremely high quality. John is portrayed, as is traditional, as an old man. He holds his codex open to the viewer, displaying the opening text of his gospel. Standing portraits were common in the tenth century, but rare beyond then; the portraits, therefore, support a tenth-century date for the codex, making 2193 one of the oldest manuscripts collated for the study. ${ }^{69}$ The standing portraits show striking similarity to those found in a number of other Greek Gospel manuscripts, including Gregory-Aland 14 (Paris, Bibliothèque Nationale, gr. 70) and Gregory-Aland 123 (Vienna, Theol. Gr. 240). Both manuscripts are dated to

\footnotetext{
${ }^{66}$ Aside from the אai compendium fewer than twenty abbreviations were found in the main text of John.

${ }^{67}$ The first $\alpha \rho \chi \eta$ in John is given an iota adscript; however, no other adscripts (or subscripts) have been noted in the manuscript. This initial iota adscript may have been added by a later hand.

${ }^{68}$ F. 10v, f. 79v, f. $128 v$, f. $205 \mathrm{v}$.

${ }^{69}$ A. M. Friend, "The Portraits of the Evangelists in Greek and Latin Manuscripts," Art Studies 5 (1927): 124-133; Evans, Glory, 91.
} 
the tenth century, and Gregory-Aland 14 can be dated precisely by a colophon to $964^{70}$

\section{Correctors and Later Hands}

Codex 2193 has been heavily corrected by at least two different hands. One corrector is very distinct: using a neat, rounded semi-majuscule script, with most corrections given in the margin, and a diagonal with dots either side to mark the corrected point in the text. The same hand also employs deletion dots and transposition marks. This hand has been labelled $\mathrm{C} 1$ in the transcription. $\mathrm{C} 1$ is either the original scribe or a $\delta \operatorname{co} \theta \omega \tau \eta$ s working in the same scriptorium. Because the semi-majuscule letters are difficult to compare with the minuscule script of the main text, and because (as with 1582) it was not possible to examine the manuscript in person, it is difficult to draw a definitive conclusion. $\mathrm{C} 1$ has also added a number of variant readings to the manuscript, marking these with the gamma-rho symbol. The collation of $\mathrm{Cl}$ 's corrections and marginal readings, against the readings of other Family 1 manuscripts, supports this palaeographical analysis - $\mathrm{C} 1$ having a number of very rare agreements with other important family manuscripts when $2193 *$ has only the reading of the Majority Text. ${ }^{71}$

Another corrector in 2193 has a less rounded, sloping and pointy hand with a number of features which distinguish it from $\mathrm{C} 1$ and the original scribe, most

\footnotetext{
70 For plates see J. Ebersolt, La Miniature Byzantine (Paris: Librairie Nationale d'Art et d'Histoire, 1926) plate XXX (Paris); Friend, "Portraits (1927)," plate I (Paris and Vienna).

${ }^{71}$ See Appendix B for relevant lists of readings.
} 


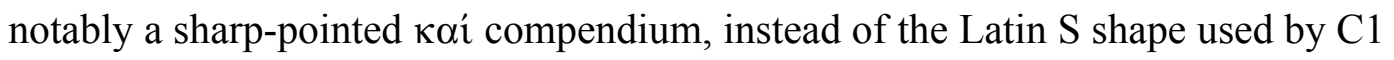
and the first hand. Corrections in this hand have been labelled C. Although the script of $\mathrm{C}$ is clearly distinct from the hand of the original scribe, the collation of the $\mathrm{C}$ corrections indicates that the $\mathrm{C}$ corrector may also have been a $\delta 10 \rho \theta \omega \tau \eta \dot{n}$ at the scriptorium where 2193 was copied, also making corrections against the exemplar used by the original scribe.

A significant number of the marginal variants and corrections have been erased in 2193, leaving only smudges or faint traces of the gamma-rho symbol or diagonal with dots used by $\mathrm{C} 1$. It is impossible to ascertain when these erasures were made.

\section{Provenance}

The fine quality and decoration of 2193 suggests it was a product of Constantinople. A note at the end of the codex, dated 1529, records that the manuscript was owned by the Archbishop of Thessaly. Little else is known of the manuscript before it passed to the Iviron monastery on Mount Athos.

Transcription for the Gospel of John

The Gospel of John begins on f. 206r and ends f. 257v. The Pericope Adulterae is not present at John 7:53, but it has been added by a supplementary hand at the end of the codex. A semi-majuscule note reading 'EI $\Sigma$ TE $\Lambda \mathrm{O} \Sigma$ TOY BIB $\Lambda \mathrm{IO} \Upsilon$ ' is written at the top of the column containing John 7:52. Between 7:52 and 8:12 
there is a small smudge, which might represent the erasure of some kind of diacritical mark or the beginning of erased text. The transcription of 2193 was made from the microfilm.

\subsection{Textual Analysis}

\subsubsection{Establishing Textual Relationships}

Anderson, in her work on Family 1 in the Gospel of Matthew, demonstrated through a shared pool of Non-Majority Text readings that Codex 1 and Codex 1582 are independent textual witnesses to a no longer extant ancestor, which she called A-1. Anderson showed that seven other manuscripts, linked by this same pool of Non-Majority Text readings, Codices 22, 118, 205abs, 205, 209, 1192 and 1210, also descend from A-1; but that 1 and 1582 are the best representatives, because they have retained the highest number of its Non-Majority Text readings, while the other manuscripts have received greater amounts of corrections towards the Majority Text. ${ }^{72}$

In a full collation of 1 and 1582 in Matthew, after minor regularisations, Anderson found only 34 units of variation between the two manuscripts, 5 of these being occasions when a variant reading given in 1582 agrees with the text of 1. ${ }^{73}$ This study has found that a similar closeness exists between 1 and 1582 in

\footnotetext{
${ }^{72}$ Anderson, Matthew, 101.

${ }^{73}$ Anderson, Matthew, 84-102.
} 
the Gospel of John. After minor regularisations only 44 first hand disagreements were found and in 2 of these cases, a marginal reading in 1582 supports the text of Codex 1, and in at least 2 cases a first hand correction in 1582 agrees with the text of $1 .^{74}$ This chapter argues that in John, 1 and 1582 are still closely linked and remain leading Family 1 manuscripts; however, a new group of three manuscripts has emerged - Codex 565, Codex 884 and Codex 2193 - that together equal 1 and 1582 in their closeness to the archetype A-1, but are related to A-1 through a different intermediate ancestor. These five manuscripts constitute what will be called the core group.

\subsubsection{Non-Majority Text Agreements}

The textual link between Codices 1 and 1582 and Codices 565, 884 and 2193 is based on a high percentage of Non-Majority Text agreements between the two sets of manuscripts. In a full collation of seventeen possible Family 1 manuscripts in John, 1 and 1582 share 513 Non-Majority Text readings. Of these 513 readings only 52 are not supported by either 565,884 , or 2193 , and many of these readings are supported by two or all three of the manuscripts. Moreover, 15 of these Non-Majority Text readings are distinctive and 261 are rare. In many

\footnotetext{
${ }^{74} 3$ differences are listed in the full family collation but have not been counted here as the differences are of the variety that would have been regularised out, had it not been for the decision to retain all differences at points of wider family variation. A further two differences have been ignored as spelling 'errors' by Codex 1 of the name $\pi \imath \lambda \iota \pi \pi \circ \sigma$. These readings were retained in the full collation for the sake of consistency in recording all spelling variations on proper names. This count does not include readings in the text of the Pericope Adulterae.
} 
cases the agreements are lengthy and differ quite significantly from the Majority Text.

A number of these agreements constitute the omission of relatively lengthy strings of text as in the 2 examples below: ${ }^{75}$

14:14 DEF！1 22118 205abs 2052095658841210 1278*1582 2372 R

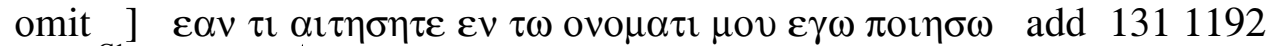
$\left.1278^{\mathrm{Cl}} 2193 \mathbf{M}^{\mathrm{pt}}\right]$ o $\varepsilon \alpha \nu \alpha i \tau \eta \sigma \eta \tau \varepsilon \varepsilon \nu \tau \omega$ ovo $\mu \alpha \tau 1 \mu \nu v \varepsilon \gamma \omega \pi \mathrm{oi \eta} \sigma \omega$ add 2713 R

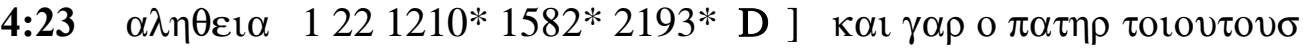 $\zeta \eta \tau \varepsilon 1 \tau o v \sigma \pi \rho о \sigma \kappa v \nu o v v \tau \alpha \sigma \alpha v \tau o v$ add 118131 205abs 205209565872 $88411921210^{\mathrm{C}^{*}} 12781582^{\mathrm{C} 1} 2193^{\mathrm{C}} 23722713 \mathfrak{M}$}

Other agreements involve unusual place names or the spellings of characters. In 19:13, for example, the Majority Text reading $\gamma \alpha \beta \alpha \theta \alpha$ or $\gamma \alpha \beta \beta \alpha \theta \alpha$ is replaced with the distinctive reading $\kappa \alpha \pi \phi \alpha \theta \alpha$ :

19:13 $\left.\kappa \alpha \pi \phi \alpha \theta \alpha \quad 1^{\text {note }} 225658841192^{\text {mgl[dub] }} 1582 \mathrm{D}\right] \quad \gamma \alpha \beta \beta \alpha \theta \alpha \quad 118$ sup 131 205abs $\left.205^{\mathrm{C}^{*}} 2091192^{\mathrm{txt}} 1210^{\mathrm{C*}} 2193 \mathbf{M}^{\mathrm{pt}}\right] \quad \gamma \alpha \beta \alpha \theta \alpha 205^{*} 1210^{*} 1278$ $\left.2713 \mathbf{M}^{\mathrm{pt}}\right] \kappa \alpha \pi \pi \alpha \theta \alpha 1192^{\mathrm{mg} 2} \quad \mathbf{D}$

Note 1: letters $\kappa \alpha \pi$ smudged.

Note $1192^{\mathrm{mg} 1}$ : letter $\pi$ uncertain.

In 8 units some or all of the five manuscripts agree on the rare spelling of Mary with a final mu:

11:20 $\mu \alpha \rho i \alpha \mu 884565^{\text {note }} 1582$ 2193* R ] $\mu \alpha \rho i \alpha 122118131$ 205abs 205209 $8721192121012782193^{\mathrm{C}} 23722713 \mathfrak{M}$

Note 565: final $\mu$ untypical.

\footnotetext{
${ }^{75}$ For details of the layout of variation units, and a summary of symbols and abbreviations used, see Appendix A.
} 
12:3 $\mu \alpha \rho \imath \alpha \mu 15658841582$ 2193* R ] $\mu \alpha \rho{ }^{*} 22118131$ 205abs 205209 $8721192121012782193^{\mathrm{C}} 23722713 \mathfrak{M}$

19:25 $\mu \alpha \rho \imath \alpha \mu(1 \mathrm{st}) 15658841582$ R ] $\mu \alpha \rho \imath \alpha 22$ 118sup 131 205abs 205209 $11921210127821932713 \mathfrak{M}$

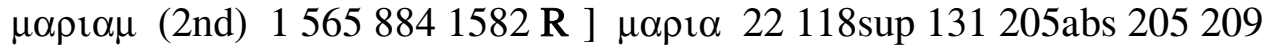
11921210127821932713 M

20:1 $\mu \alpha \rho \imath \alpha \mu 15651582$ R ] $\mu \alpha \rho \imath \alpha 22$ 118sup 131 205abs 2052098841192 1210127821932713 sup $\mathfrak{R}$

Note 2713: missing text.

20:11 $\mu \alpha \rho \imath \alpha \mu 1205 a b s 2052095658841582$ R ] $\mu \alpha \rho \imath \alpha 22$ 118sup 1311192 1210127821932713 sup $\mathfrak{M}$

Note 2713: missing text.

20:16 $\mu \alpha \rho i \alpha \mu \quad 15651582$ 2193* R ] $\mu \alpha \rho i \alpha \quad 22$ 118sup 131 205abs 205209 $8841192121012782193^{\mathrm{C}} 2713$ sup $\mathfrak{M}$

Note 2713: missing text.

20:18 $\mu \alpha \rho \imath \alpha \mu \quad 15651582$ R ] $\mu \alpha \rho \imath \alpha \quad 22$ 118sup 131 205abs 205209884 $11921210127821932713 \mathfrak{M}$

Many agreements involve rare variant synonyms as in the three examples below:

19:5 $\varepsilon \chi \omega v 12256588412101582 *$ R ] $\phi о \rho \omega v$ 118sup 131 205abs 205209 $119212781582^{\mathrm{C} 1} 21932713 \mathfrak{M}$

19:28 $\eta \gamma \rho \alpha \phi \eta \pi \lambda \eta \rho \omega \theta \eta \quad 1$ 205abs $2052095658841278 \quad 15822713 \quad$ R ] $\tau \varepsilon \lambda \varepsilon \iota \omega \theta \eta \eta \gamma \rho \alpha \phi \eta 22$ 118sup 131119212102193 M

19:37 $\gamma \rho \alpha \phi \eta 12256588412101582 \mathrm{R}$ ] $\lambda \varepsilon \gamma \varepsilon \varepsilon$ add 118sup 131 205abs 205 $2091192127821932713 \mathfrak{M}$ 
These synonyms include a number of variant prepositions. In two of the examples below the readings are distinctive:

6:46 $\quad \varepsilon \kappa 122118$ 205abs $20520956512101278^{* d u b} 1582219323722713$ D ] $\pi \alpha \rho \alpha 13187288411921278^{\mathrm{C}} \mathfrak{M}$

12:49 $\alpha \pi \quad 122118$ 205abs 2052095651192121012781582219323722713 D ] $\varepsilon \xi 131872884 \mathfrak{M}$

16:13 $\varepsilon v \tau \eta \alpha \lambda \eta \theta \varepsilon 1 \alpha \pi \alpha \sigma \eta \quad 15658841582$ R ] $\varepsilon 1 \sigma \pi \alpha \sigma \alpha \nu \tau \eta \nu \alpha \lambda \eta \theta \varepsilon \iota \alpha \nu 118$ 131 205abs $205209119212101278219323722713 \mathfrak{M}$

Agreements also include a number of 'additions' to the Majority Text. Six rare examples are given below:

4:3 $\quad \gamma \eta \nu 1118$ 205abs 2052095658841582 2193*2713 R ] omit 22131 $8721192121012782193^{\mathrm{C}} 2372$ M

8:33 Kol $\varepsilon 1 \pi$ ov 156588415822193 R ] omit 22118131 205abs 205209 $872119212102713 \mathbf{M}]$ ol tovdotor 12782372 R

9:3 $\quad$ Kol $\varepsilon ı \pi \varepsilon v ~ \alpha v \tau o 1 \sigma \quad 1118$ 205abs 205209565884158221932713 R ] omit $221318721192121012782372 \mathfrak{M}$

14:11 $\varepsilon \sigma \tau \mathrm{\tau} v \quad 156588415822193^{\mathrm{C}} \quad \mathrm{R}$ ] omit 22118131 205abs 205209 $1192121012782193 * 23722713 \mathfrak{M}$

17:20 $\pi \varepsilon \rho \imath \pi \alpha v \tau \omega \nu 156588415822193$ R ] omit 118sup D ] $\pi \varepsilon \rho \imath 22131$ 205abs $20520911921210127823722713 \mathfrak{M}$

20:1 $\quad \alpha \pi$ o $\tau \eta \sigma \theta v \rho \alpha \sigma \quad 122$ 205abs 20520956588412101582 R ] $\varepsilon \kappa$ 118sup $13111921278^{\mathrm{C} 1} 21932713 \mathfrak{M}$ ] [13] $1278^{*}$ 
Other readings involve significant changes in tense or form:

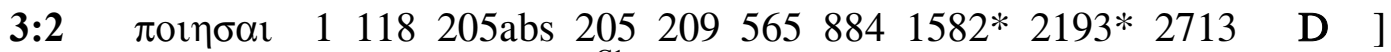

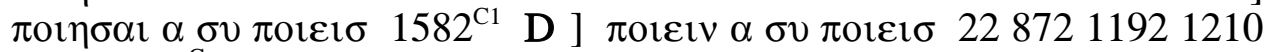

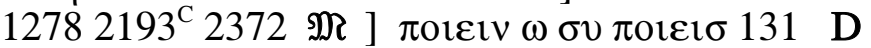

5:19 $\lambda \varepsilon \gamma \varepsilon 11118$ 205abs 20520915822193 D ] $\varepsilon 1 \pi \varepsilon v 221318728841192$ $12101278^{\mathrm{C}} 2713$ M ] $\varepsilon \lambda \varepsilon \gamma \varepsilon v 5652372 \mathrm{R}$ ] [5-6] 1278*

6:59 $\varepsilon \lambda \alpha \lambda \eta \sigma \varepsilon \nu 1205 a b s 2052095651582$ 2193*2713 D ] $\varepsilon 1 \pi \varepsilon \nu 22118$ $1318728841192121012782372 \mathfrak{M}$ ] [dub] $2193^{\mathrm{C} 1}$

Note 2193: a C1 reading has been erased.

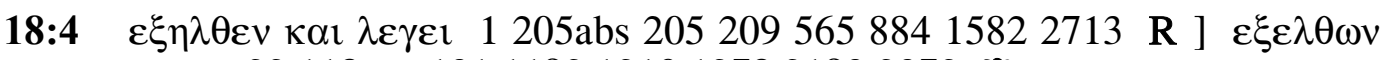

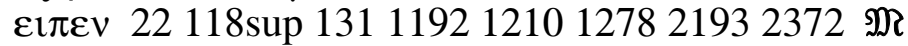

Only a selection of the Non-Majority Text agreements shared by these manuscripts has been given; the remaining can be found in the full collation in Appendix A. The sample, however, gives some sense of the nature and type of the Non-Majority Text agreements existing between 1, 565, 884, 1582 and 2193. These readings and the quantity in which they appear could not have arisen independently in the five manuscripts; instead, they are the result of a close genetic relationship.

Table 1 below gives an individual count for Codices 565, 884 and 2193, of the number of their Non-Majority Text agreements on readings shared by both 1 and 1582. ${ }^{76}$ The first column indicates the chapter number, and the second column

\footnotetext{
${ }^{76}$ Note that lacunas in 565 and 884 affect the count, explaining for example why 884 has only 2 Non-Majority Text agreements with 1 and 1582 in chapters 1 and 2. 884 is missing text in 1:212:19. ( 1 and 1582 share 26 Non-Majority Text agreements in this section). 565 is missing text in 11:26-11:48; 13:2-13:23; and 17:1-17:12. (In these 3 sections 1 and 1582 share a total of 25 Non-
} 
gives the total number of Non-Majority Text agreements between 1 and $1582 .^{77}$ The third, fourth and fifth columns give the figures of agreements for each of the three manuscripts. Agreements were counted a chapter at a time to test for possible shifts in textual affinity in each manuscript.

Majority Text readings.) The readings of $565^{\text {sup }}(17: 1-17: 12)$ have not been counted. Note also that readings in Pericope Adulterae have not been counted.

${ }^{77}$ Non-Majority Text agreements between first hand corrections and marginal readings in 1582 with the text of 1 have been counted here. 
Table 1: 565, 884 and 2193 Non-Majority Text Agreements with 1 and 1582

\begin{tabular}{|c|c|c|c|c|}
\hline Chapter & $\begin{array}{c}\text { Total } 11582 \\
\text { NMT } \\
\text { agreement* }\end{array}$ & $\begin{array}{c}\text { 565: } 11582 \\
\text { NMT } \\
\text { agreements }\end{array}$ & $\begin{array}{c}\text { 884: } 11582 \\
\text { NMT } \\
\text { agreements }\end{array}$ & $\begin{array}{c}\text { 2193: } 11582 \\
\text { NMT } \\
\text { agreements }\end{array}$ \\
\hline 1 & 22 & 1 & 2 & 17 \\
\hline 2 & 10 & 10 & 1 & 9 \\
\hline 3 & 15 & 14 & 10 & 9 \\
\hline 4 & 29 & 22 & 19 & 23 \\
\hline 5 & 18 & 14 & 8 & 15 \\
\hline 6 & 48 & 40 & 28 & 40 \\
\hline 7 & 36 & 32 & 11 & 30 \\
\hline $8: 12-8: 59$ & 27 & 20 & 7 & 23 \\
\hline 9 & 31 & 23 & 9 & 25 \\
\hline 10 & 27 & 23 & 19 & 23 \\
\hline 11 & 29 & 17 & 23 & 24 \\
\hline 12 & 24 & 22 & 19 & 21 \\
\hline 13 & 19 & 11 & 11 & 6 \\
\hline 14 & 19 & 15 & 16 & 3 \\
\hline 15 & 11 & 8 & 7 & 2 \\
\hline 16 & 17 & 8 & 8 & 1 \\
\hline 17 & 17 & 6 & 9 & 2 \\
\hline 18 & 33 & 25 & 22 & 7 \\
\hline 19 & 40 & 34 & 32 & 7 \\
\hline 20 & 20 & 15 & 9 & 2 \\
\hline 21 & 21 & 16 & 10 & 2 \\
\hline Total: & 513 & 376 & 280 & 291 \\
\hline
\end{tabular}


Table 1 demonstrates that support for 1 and 1582 in 565 and 884 is spread relatively consistently throughout the gospel, except in chapter 1 in 565 , where there is only 1 Non-Majority Text agreement with 1 and 1582 (and this a widely attested reading) ${ }^{78}$ In the case of 2193 , the manuscript shows consistent support for the Non-Majority Text readings of 1 and 1582 until chapter 13 where the number of agreements significantly decreases.

\subsubsection{Evidence from Marginalia}

Variant readings given in the margins of 1582 and 2193, and also readings which may have originally existed as variant readings in A-1, but have slipped into the texts of these five manuscripts, provide further evidence of their textual consanguinity. ${ }^{79}$ One rare variant reading is shared by 1582 and 2193 in 12:28:

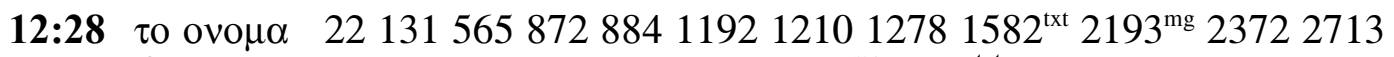

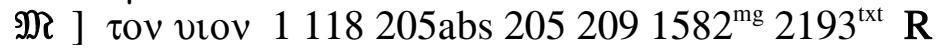

1582 records $\tau$ ov viov as the variant while 2193 has $\tau$ o ovo $\mu \alpha$; however, both record the existence of the same two juxtaposed readings. The rarity of the NonMajority Text reading combined with its existence at a marked point of variation in both manuscripts provides strong evidence of a close textual link between 1582

\footnotetext{
${ }^{78}$ For further discussion of Codex 565 in 1-2:5 see section 7.6.

${ }^{79}$ Variant readings are clearly distinguished from corrections in both manuscripts. The scribe of 1582 used a wavy line and the scribe of 2193 the gamma-rho symbol.
} 
and 2193: both manuscripts must have been copied from an exemplar that contained the two readings. Codex 1 does not record the existence of any textual variation at this point but it does support the Non-Majority Text reading, $\tau$ ov viov, evidence that Codex 1 also shares this close genetic link with 2193.

In John $6: 23,1582^{\mathrm{C}^{*}}$ and $2193^{\mathrm{C}}$ share a distinctive reading which Codex 1 supports in its text:

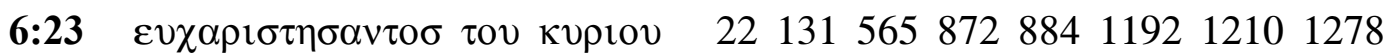

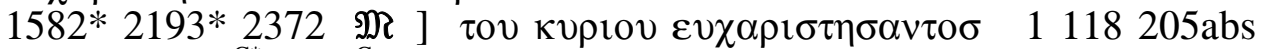
$2052091582^{\mathrm{C}^{*}} 2193^{\mathrm{C}} 2713 \mathrm{D}$

It is unclear whether the alternative reading given in 1582 and 2193 is a correction or a variant reading; both manuscripts contain the same transposition marks to indicate the alteration, but in neither manuscript is the usual symbol for the presence of a variant used. What is important, however, is that because the second reading is distinctive, and therefore extremely unlikely to have arisen independently in both manuscripts, the scribes of 1582 and 2193 are very likely to be reproducing the formatting of their exemplars, and this strengthens the evidence for a genetic connection between the two manuscripts through a shared ancestor. ${ }^{80}$ The existence of the distinctive reading in the text of Codex 1 indicates that it also shares this ancestor, though it has only retained one reading.

In a further unit, 565 and 2193 are the only supporters within the family of a rare variant present in the margin of 1582 :

${ }^{80}$ Anderson has argued that the reading is a variant: Anderson, Matthew, 61. 


\section{8:38 $\quad$ o $\varepsilon \gamma \omega \quad 1 \quad 1582^{\text {txt }} \quad$ D ] $\quad \alpha \varepsilon \gamma \omega \quad 5651582^{\text {mg }} 2193 \quad$ R ] $\varepsilon \gamma \omega$ o 22118 205abs $205209872119212101278^{\mathrm{C}} 2713$ MR ] $\varepsilon \gamma \omega \alpha 1318841278^{*}$ 2372 R}

While 565 and 2193 do not contain the reading in the format of a marginal variation, the existence of the reading in their texts indicates that it may have been present as a marginal reading in a shared ancestor. This same marginal reading may also have been present in an ancestor of 884,884 's reading being a possible conflation of the marginal reading and the Majority Text reading.

A final reading where only 2193 contains the full variant further strengthens the evidence of a genetic link:

\section{2:6 $\varepsilon \chi \omega \nu \quad 56515822193^{\text {txt }}$ R ] $\varepsilon \chi \omega \nu \kappa \alpha \imath \quad 1 \quad$ D ] $\varepsilon \iota \chi \varepsilon v \kappa \alpha \iota 22118131$ 205abs 20520987288411921210127823722713 M ] $\varepsilon \chi \omega v$ [3] $2193^{\mathrm{mg}}$}

The marginal reading of 2193 is uncertain, as it has been erased by a later hand, leaving only a faint trace of the gamma-rho symbol and the beginning of the erased reading ' $\varepsilon \chi \omega v . .$. '; however, the scraping of the parchment after $\varepsilon \chi \omega \mathrm{v}$ is still visible on the microfilm and the space left would fit $\kappa \alpha$ perfectly, making the reading ' $\varepsilon \chi \omega \nu \kappa \alpha$ ' a reasonable conjecture for $2193^{\mathrm{mg}} \cdot{ }^{81}$ If this is the reading of $2193^{\mathrm{mg}}$ it adds further evidence for the existence of an ancestor shared with 1 and 1582. In this case, the ancestor must have contained both readings as given in 2193. The reading is particularly interesting as the witness of 2193 can explain the unusual Non-Majority split between 1 and 1582. The reading also provides

\footnotetext{
${ }^{81}$ F. 236v column 2.
} 
evidence of 2193's independence from 1582 and 1 and demonstrates its potential importance as a witness to the family text.

\subsubsection{Evidence of the Pericope Adulterae}

Further evidence that links Codices $1,565,1582$, and possibly 2193 , is a note commenting on the Pericope Adulterae. This note, as it appears in 1582 and 1, without any significant variation, states that the pericope does not appear in many manuscripts and was not commented on by the Church Fathers John Chrysostom, Cyril of Alexandria and Theodore of Mopsuestia. ${ }^{82}$ Codex 1 and Codex 1582 add the Pericope Adulterae at the end of John following this note. Below is the text of the note as it appears in $1582 .{ }^{83}$

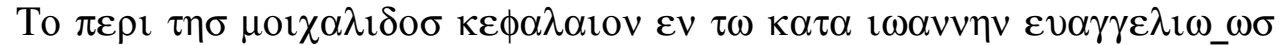

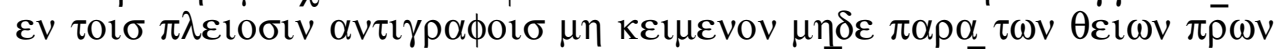

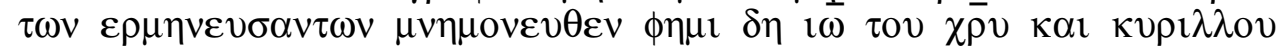

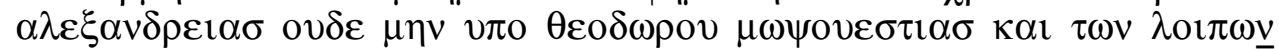

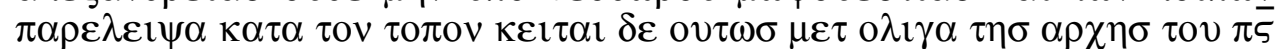

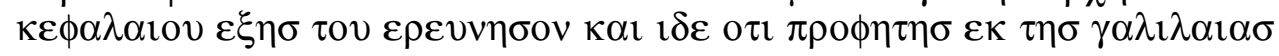
о৩к $\varepsilon \gamma \varepsilon ı \varepsilon \tau \alpha$.

Codex 565 contains an abridged version of this note, omitting the section of text from and including $\mu \eta \delta \varepsilon$ to $\lambda o \imath \pi \omega v$. 565's version of the note differs only in one other place: reading $v U v$ where 1 and 1582 have $\pi \lambda \varepsilon$ coorv. ${ }^{84}$ The formatting of

\footnotetext{
${ }^{82} 1582$ and 1 only differ in their use of abbreviations.

${ }^{83}$ With certain abbreviations in 1582 retained.

${ }^{84}$ There are two very brief sections of illegible text in the note in 565 . The number of illegible letters matches the number of letters in 1 and 1582, and in the first example the first part of a word is readable and agrees with 1 and 1582. It is likely that at these point 565 agrees with 1 and 1582 .
} 
565 and 1582 is also linked, as in both manuscripts the note is copied in semimajuscule letters to distinguish it from the running gospel text. ${ }^{85}$ As in 1 and 1582,565 's note appears as a postscript to the Gospel of John, only the pericope is now missing. ${ }^{86}$ As this note is not known to exist in any other manuscripts it provides compelling evidence of an extremely close link between 1, 565 and 1582.

Codex 2193 does not contain the Pericope Adulterae after John 7:52, but a later hand has added it to the end of the codex, either because the pericope was never included or because it was included (and at this location) but was damaged or lost. What is interesting is that the supplementary hand which added the pericope introduces it with the same string of text from John 7:52 used in the critical note found in 1,565 and $1582 .{ }^{87}$ It is possible that the supplementary hand was copying from a damaged or detached portion of 2193, which also contained a version of the critical note. 1 and 1582 share 3 Non-Majority Text agreements in the first part of the pericope (before the original text of 1582 is missing) and 2193 shares 1 of these readings:

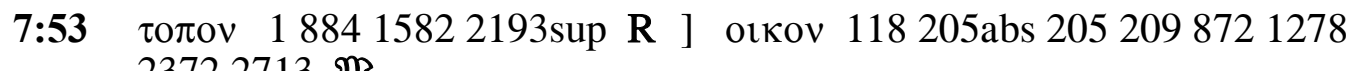
$23722713 \mathfrak{M}$

\footnotetext{
${ }^{85}$ In Codex 1 the note is formatted in the same way as the gospel text.

${ }^{86}$ A number of editions, including B. Aland et al., ed., Novum Testamentum Graece, 27th Edition (Stuttgart: Deutsche Bibelgesellschaft, 2002), record 565 as omitting the Pericope Adulterae. The existence of a note introducing the pericope makes an omission unlikely; instead it must be assumed that 565 originally contained the pericope, following the note, but that it is no longer extant.

${ }^{87} 2193$ reads $\varepsilon \gamma \eta \gamma \varepsilon \rho \tau \alpha \iota$ where 1,565 and 1582 have $\varepsilon \gamma \varepsilon \iota \rho \varepsilon \tau \alpha \mathrm{t}$.
} 
The existence of this rare agreement supports the possibility that 2193's supplementary text might have been copied from a damaged original folio, the supplementor making some Majority Text corrections but missing this reading in 7:53. Codex 884 includes the pericope at John 7:52 without comment, and it contains no clue to the existence of the critical note in an ancestor. However, as 884 also supports the rare reading in $7: 52$, it is possible that the scribe of 884 also inherited the pericope text from the same ancestor, but that the scribe relocated it to John 7:52 and discarded the note. 884 is a commentary text and such alterations would have been determined by the need to synchronise the location of biblical text with the relevant commentary text. It would also be expected that any extrabiblical text, such as the note on the Pericope Adulterae, that did not form part of the main commentary text would have been discarded.

\subsubsection{Non-Majority Text Correction and Disagreements}

The large numbers of Non-Majority Text agreements shared by Codices 1, 565, 884,1582 and 2193 in the Gospel of John demonstrate that these five manuscripts are closely linked. This link is confirmed by an analysis of the quantities and types of their disagreements; and taken together analysis of the agreements and disagreements provides compelling evidence that these five manuscripts are extremely close.

Codex 1 and Codex 1582 have the highest number of Non-Majority Text agreements (513); they also have the lowest number of disagreements: only 44 in 
the whole of John. They are the closest of the five manuscripts. ${ }^{88} 565,884$ and 2193 have a greater textual distance from one another and from 1 and 1582:

- 565 and 884 share 284 first hand Non-Majority Text agreements and have 280 disagreements.

- 565 and 2193 share 255 first hand Non-Majority Text agreements and have 330 disagreements.

- 884 and 2193 share 170 first hand Non-Majority Text agreements and have 445 disagreements. ${ }^{89}$

This greater distance, however, can be explained by separate processes of Majority Text correction that occurred during the copying of 565, 884 and 2193, and/or the copying of intermediate exemplars. By far the most common type of disagreement that occurs between 565, 884 and 2193, and between any one of these manuscripts and 1 and 1582, is a Non-Majority Text-Majority Text split. Out of a total of 769 disagreements that occur between the five manuscripts, in only 69 units does any Non-Majority Text division exist between the manuscripts. In 10 of these units the division is caused by lengthy omissions in one manuscript, very likely immediate errors caused by the scribe of that manuscript (most often 884); and in 4 units the division is the result of a first hand reading in only one

\footnotetext{
${ }^{88}$ All these figures are calculated after minor regularisations have been made.

${ }^{89}$ In 10 of the cases of first hand disagreement between 565 and 2193 there is Non-Majority Text agreement between the text of one manuscript and a correction or marginal reading in the other. This is also so for 11 cases of disagreement between 884 and 2193.
} 
manuscript that has been corrected back to the Non-Majority Text reading of the other manuscripts. $^{90}$ This leaves only 55 readings, a relatively small number, where there is significant Non-Majority Text division. These readings will be discussed shortly, but in the meantime what is significant is that the five manuscripts share a pool of Non-Majority Text readings and no individual manuscript contains significant numbers of Non-Majority Text readings that might have originated outside of this pool. The manuscripts have a dual textual makeup: they contain a selection of Non-Majority Text readings, which originate from a shared source, mixed in with differing amounts of Majority Text readings, the result of standardised correction procedure.

\subsubsection{Family Relationships}

It has been shown that Codices 1, 565, 884, 1582 and 2193 descend from a shared ancestor, from which they inherited almost all of their Non-Majority Text readings. Following Anderson in her study of Matthew, this ancestor is referred to as A-1 ${ }^{91}$ It is now necessary to describe more exactly how these five manuscripts descend from A-1 and how they relate to one another. It will be argued that 565, 884 and 2193 are descended, independently of one another, from a shared intermediate ancestor, designated here Manuscript B. B is a descendant of A-1 and is independent of 1 and 1582. It will also be argued that 1 and 1582 are

\footnotetext{
903 very minor disagreements have not been counted but appear in the full family collation $(12: 21$, $12: 22,14: 9)$.

${ }^{91}$ Anderson, Matthew, 102.
} 
independent witnesses to a different intermediate ancestor, designated here Manuscript C. B and C will be shown to be independent of one another. ${ }^{92}$

Figure 1: Stemma for the Core Group

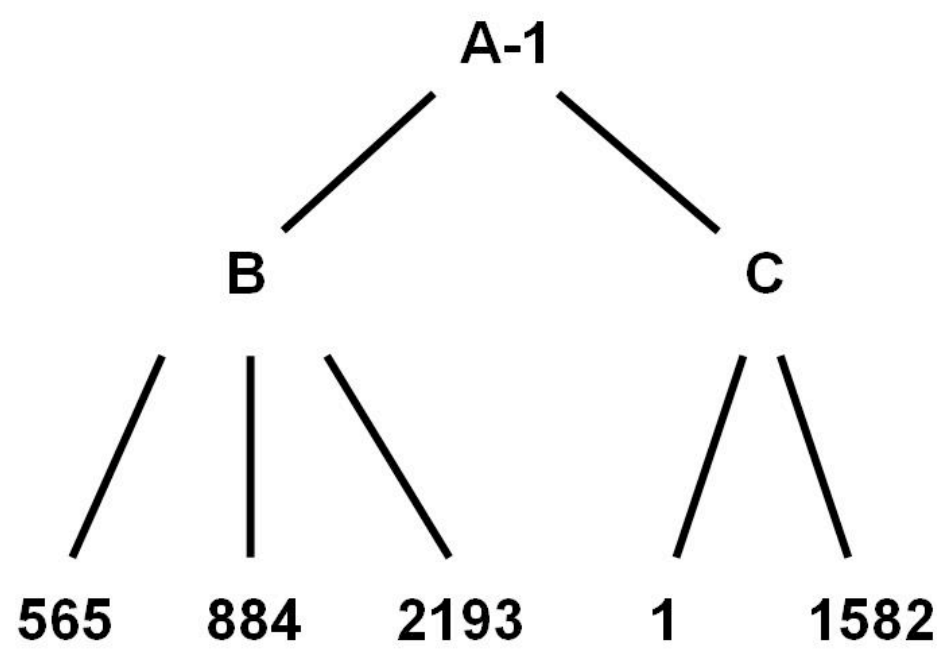

The above stemma expresses the simplest possible relationships between the five extant manuscripts; there may be intermediate exemplars between A-1 and B and $\mathrm{C}$, and between $\mathrm{B}$ and $\mathrm{C}$ and their extant descendants, but these possible manuscripts do not have any bearing on the existing relationships. ${ }^{92}$ Note that A-1, Manuscript $\mathrm{B}$ and Manuscript $\mathrm{C}$ are conjectured manuscripts which help to
explain the relationships between the extant manuscripts. 


\subsubsection{Codices 565, 884 and 2193 have a Shared Ancestor, B}

Two omissions of relatively lengthy strings of text shared by 565, 884 and 2193 provide good evidence that the three manuscripts descend from a more immediate shared ancestor, not shared with 1 and 1582. In both cases, the omissions constitute rare readings and no other known Family 1 manuscripts shares them:

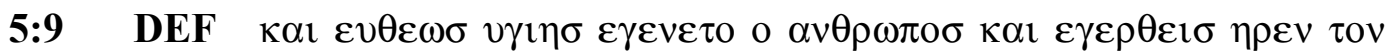
$\kappa \rho \alpha \beta \alpha \tau \tau o v \alpha v \tau o v \kappa \alpha \iota \pi \varepsilon \rho 1 \varepsilon \pi \alpha \tau \varepsilon \imath$ ] omit $5658842193^{*} \mathbf{R}$

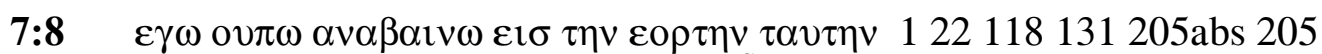
$20987211921210127815822193^{\mathrm{C}} 23722713$ M ] omit 565884 2193* R

It is unlikely that on two occasions in one gospel, all three manuscripts would omit these two strings of text independently. It is much more probable that the three manuscripts, which we already know are close, share an intermediate ancestor, itself descended from A-1, in which the omissions first occurred. Both omissions, homeoteleutons, cause fracture to the text: in the case of 5:9, the lame man is not healed, and in 7:8, the sense of Jesus's words is lost. These types of omissions do not tend to last long in a textual tradition but are corrected by scribes as copying events occur. These two omissions, therefore, are also indications that not many copying events, if any, exist between this intermediate ancestor, B, and its descendants 565, 884 and 2193.

A third omission offers further evidence regarding the link between 884 and 2193: 


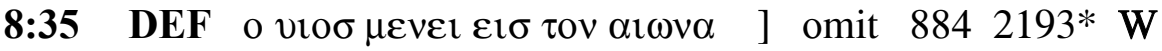

Again it is most probable that this omission occurred in a shared intermediate ancestor of 884 and 2193 and not independently in each. 565 does not omit this text, but could still share this ancestor, the scribe of 565 filling in the omissionin this case with the reading of the Majority Text.

\subsubsection{Codices 565, 884 and 2193 are Independent Witnesses of B}

Codices 565, 884 and 2193 inherit their A-1 readings from Manuscript B. Whether each individual manuscript is important as a textual witness to $\mathrm{B}$, and therefore $\mathrm{A}-1$, is determined by whether or not the manuscript is an independent witness of $\mathrm{B}$, or whether it is related to $\mathrm{B}$ only through another extant manuscript. In the cases of 565,884 and 2193 , each manuscript contains a number of NonMajority Text readings which are supported by Codices 1 and 1582 but not by the

other descendants of $\mathrm{B}$. These readings demonstrate that each manuscript inherited its B readings independently of B's other extant descendants. Table 2 records the number of Non-Majority Text agreements each manuscript $— 565,884$, 2193-has with 1 and 1582 when the other two manuscripts agree with the Majority Text. 
Table 2: Demonstrating the Independence of 565, 884 and 2193

\begin{tabular}{|c|c|c|c|c|c|c|c|c|c|}
\hline 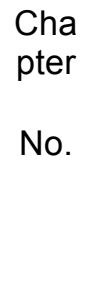 & $\begin{array}{c}565,1 \\
\& 1582 \\
\text { NMT } \\
\text { read. } \\
\text { without } \\
884 \& \\
2193\end{array}$ & $\begin{array}{c}565,1 \\
\& 1582 \\
\text { NMT } \\
\text { read. } \\
\text { without } \\
884\end{array}$ & $\begin{array}{c}565,1 \\
\& 1582 \\
\text { NMT } \\
\text { read. } \\
\text { without } \\
2193\end{array}$ & $\begin{array}{c}884,1 \\
\& 1582 \\
\text { NMT } \\
\text { read. } \\
\text { without } \\
565 \& \\
2193\end{array}$ & $\begin{array}{c}884,1 \\
\& 1582 \\
\text { NMT } \\
\text { read. } \\
\text { without } \\
565\end{array}$ & $\begin{array}{c}884,1 \\
\& 1582 \\
\text { NMT } \\
\text { read. } \\
\text { without } \\
2193\end{array}$ & $\begin{array}{c}2193,1 \\
\& 1582 \\
\text { NMT } \\
\text { read. } \\
\text { without } \\
565 \& \\
884\end{array}$ & $\begin{array}{c}2193,1 \\
\& 1582 \\
\text { NMT } \\
\text { read. } \\
\text { without } \\
565\end{array}$ & $\begin{array}{c}2193,1 \\
\& 1582 \\
\text { NMT } \\
\text { read. } \\
\text { without } \\
884\end{array}$ \\
\hline 1 & 0 & 0 & 0 & 0 & 2 & 0 & 3 & 16 & 3 \\
\hline 2 & 0 & 0 & 2 & 0 & 0 & 0 & 0 & 0 & 0 \\
\hline 3 & 3 & 4 & 5 & 0 & 0 & 1 & 0 & 0 & 1 \\
\hline 4 & 1 & 3 & 3 & 0 & 0 & 2 & 4 & 4 & 6 \\
\hline 5 & 0 & 6 & 1 & 0 & 0 & 1 & 2 & 2 & 8 \\
\hline 6 & 1 & 14 & 3 & 1 & 1 & 3 & 2 & 3 & 15 \\
\hline 7 & 2 & 24 & 2 & 2 & 3 & 2 & 0 & 1 & 22 \\
\hline 8 & 0 & 13 & 0 & 1 & 1 & 1 & 3 & 3 & 16 \\
\hline 9 & 1 & 15 & 1 & 1 & 1 & 1 & 3 & 3 & 17 \\
\hline 10 & 1 & 5 & 4 & 0 & 1 & 3 & 2 & 3 & 6 \\
\hline 11 & 0 & 1 & 3 & 0 & 0 & 4 & 2 & 2 & 4 \\
\hline 12 & 0 & 3 & 2 & 0 & 0 & 2 & 1 & 1 & 4 \\
\hline 13 & 2 & 2 & 8 & 0 & 0 & 8 & 1 & 1 & 3 \\
\hline 14 & 1 & 1 & 12 & 1 & 1 & 12 & 0 & 0 & 0 \\
\hline 15 & 2 & 2 & 7 & 1 & 1 & 6 & 1 & 1 & 1 \\
\hline 16 & 0 & 1 & 5 & 1 & 1 & 7 & 0 & 0 & 1 \\
\hline 17 & 0 & 0 & 4 & 0 & 0 & 7 & 0 & 0 & 0 \\
\hline 18 & 5 & 5 & 18 & 2 & 2 & 15 & 0 & 0 & 0 \\
\hline 19 & 2 & 3 & 28 & 0 & 1 & 27 & 0 & 1 & 1 \\
\hline 20 & 5 & 6 & 13 & 0 & 0 & 8 & 0 & 0 & 1 \\
\hline 21 & 8 & 8 & 17 & 0 & 0 & 9 & 1 & 1 & 1 \\
\hline Total & 34 & 116 & 138 & 10 & 15 & 119 & 25 & 42 & 110 \\
\hline
\end{tabular}


Table 2 shows that each manuscript contains sufficient Non-Majority agreements with 1 and 1582 to demonstrate its independence as a descendant of Manuscript B; these readings can all be found in the full family collation in Appendix A. 884 has the fewest of these readings, which is in keeping with it being the weakest member of the group, while 565 and 2193 contain significantly more. 2193's independence from 884 and 565 is also supported by the existence of its marginalia, not present in either 565 or 884; and the independence of 565 and 884 from 2193 is supported by the fact that neither manuscript shares 2193 's shift in textual affinity towards the Majority Text from chapter 13 onwards. ${ }^{93}$ The three manuscripts differ in how well they represent the text of Manuscript B, but they can all be shown to be independent witnesses and are, therefore, all of value in reconstructing the text of $\mathrm{B}$.

\subsection{9. $B$ is an Independent Witness of A-1}

A number of the Non-Majority Text readings found in Manuscript B's descendants can be used to demonstrate that B descends from A-1 independently of both 1 and 1582. Firstly, B's independence from Codex 1 can be demonstrated by a number of occasions when one or more of the descendants of B share a NonMajority Text reading with 1582 without the support of 1 . Below are four such occasions when the readings are rare:

\footnotetext{
${ }^{93}$ This shift is very evident from the figures in table 1.
} 
11:20 $\mu \alpha \rho \imath \alpha \mu 565^{\text {note }} 8841582$ 2193* R ] $\mu \alpha \rho i \alpha 122118131$ 205abs 205209 $8721192121012782193^{\mathrm{C}} 23722713 \mathfrak{M}$

Note 565: final $\mu$ untypical.

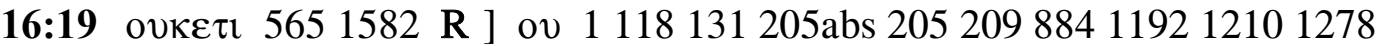
$219323722713 \mathfrak{M}$

21:16 $\pi \rho \circ \beta \alpha \tau 1 \alpha 22565$ 1582* R ] $\pi \rho \circ \beta \alpha \tau \alpha$ 118sup 131884119212101278 $1582^{\mathrm{C}} 21932713^{\text {[lac] }} \mathfrak{M}$

Note 2713: letters $\pi \rho \circ \beta \alpha$ supplied.

21:17 $\pi \rho \circ \beta \alpha \tau \imath \alpha 22565$ 1582* R ] $\pi \rho \circ \beta \alpha \tau \alpha$ 1 118sup 131 205abs 205209884 $1192121012781582^{\mathrm{C}} 21932713 \mathfrak{M}$

In 11:20, 16:19 and 21:17, Codex 1 agrees with the Majority Text; and in the case

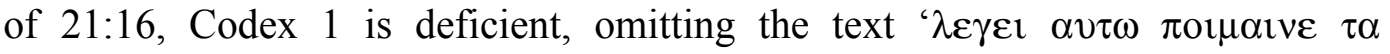
$\pi \rho \circ \beta \alpha \tau \imath \alpha \mu \mathrm{ov}$ '. The descendants of $\mathrm{B}$, therefore, cannot have inherited these 4 Non-Majority Text readings from Codex 1, but the readings must have been transmitted by another ancestor. ${ }^{94}$ Codex 1 also contains three other relatively long omissions in 5:26, 14:2, and 19:38. None of these omissions appear in any of the descendants of $\mathrm{B}$, which would be expected if B were an ancestor of Codex 1 .

In addition to these readings the existence of marginalia in 2193, which finds support with the marginalia of 1582, consolidates the evidence for B's independence from Codex 1, as 1 contains no marginalia, and has incorporated

\footnotetext{
${ }^{94}$ Codex 1 contains 3 other similar omissions in 5:26, 14:2, and 19:38. None of these omissions appear in any of the descendants of B.
} 
only certain marginal readings into its text. ${ }^{95}$ The most notable readings are found in $6: 23,8: 38$ and 12:28:

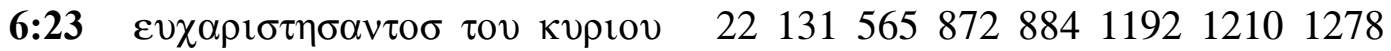

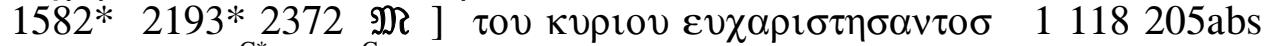
$2052091582^{\mathrm{C}^{*}} 2193^{\mathrm{C}} 2713 \mathrm{D}$

8:38 o $\varepsilon \gamma \omega \quad 11582^{\text {txt }} \quad$ D ] $\left.\alpha \varepsilon \gamma \omega 5651582^{\mathrm{mg}} 2193 \quad \mathrm{R}\right] \quad \varepsilon \gamma \omega$ o 22118 205abs $205209872119212101278^{C} 2713 \mathfrak{M}$ ] $\varepsilon \gamma \omega \alpha 1318841278^{*}$ 2372 R

12:28 то оvона $221315658728841192121012781582^{\text {txt }} 2193^{\text {mg }} 23722713$ M ] $\tau$ ov viov 1118 205abs $2052091582^{\mathrm{mg}} 2193^{\text {txt }} \mathbf{R}$

While in the case of $6: 23$, the reading could be either a correction or marginal reading, the presence of the two alternatives at this point in both 2193 and 1582, while Codex 1 has only a single reading, supports the evidence for 2193's independence from 1. In 8:38, 1582 contains two Non-Majority Text variants, one distinctive and the other rare. Codex 1 supports the distinctive reading, while 2193 and 565 support the rare.

Again, 2193 and 565 could not have inherited their rare reading from Codex 1, but the reading must have come from an ancestor which contained either the two readings or only the single rare reading. One of the most significant pieces of evidence for B's independence is the marginal reading already discussed, in 12:6:

\footnotetext{
${ }^{95}$ See, for example, 12:28 or the possible marginal reading in 6:23. Both readings in 2193 have support from 1582.
} 


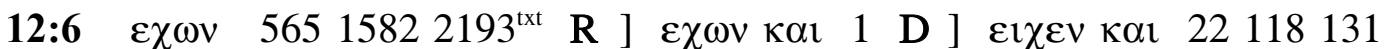 205abs 20520987288411921210127823722713 M ] $\varepsilon \chi \omega v$ [3] $2193^{\mathrm{mg}}$}

It is significant because the two readings in 2193 explain the Non-Majority Text split between 1 and 1582. 2193 has retained the most complete information from the shared ancestor, providing strong evidence of its independence from both 1 and 1582. This evidence for B's independence from 1582 is further supported by 3 variation units where Codex 1 and a descendant of B agree or partially agree on a Non-Majority Text reading while 1582 either agrees with the Majority Text or has a different Non-Majority Text reading:

7:52 $\quad \varepsilon \gamma \varepsilon 1 \rho \varepsilon \tau \alpha \iota 15822193$ W ] $\quad \varepsilon \gamma \varepsilon 1 \gamma \varepsilon \rho \tau \alpha \iota 1118131565$ R ] $\varepsilon \gamma \eta \gamma \varepsilon \rho \tau \alpha l$ 22 205abs 205209872884119212101278 2193supp $23722713 \mathfrak{M}$

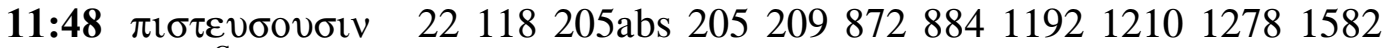
$\left.2193^{\mathrm{C}} 2372 \mathfrak{M}\right] \pi \mathrm{l} \sigma \varepsilon v \sigma \omega \sigma \mathrm{lv} \quad 11312193 * 2713 \mathrm{~W}$

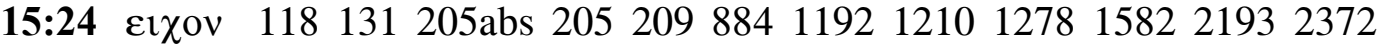
$2713 \mathfrak{M}$ ] $\varepsilon \imath \chi \omega \sigma \alpha \nu 1 \mathrm{D}] \varepsilon \imath \chi 0 \sigma \alpha \nu 565 \mathrm{R}$

In one further variation unit, a first hand correction in Codex 1 agrees with the rare reading of a $\delta \mathrm{top} \theta \omega \tau \eta \dot{s}$ of 2193 , while 1582 has only the reading of the Majority Text:

12:28 $\pi \alpha \tau \varepsilon \rho ~ 1 * 22118$ 205abs $205209565872884119212101278^{\mathrm{C}} 1582$ $2193 * 2713$ M ] $\alpha \gamma 1 \varepsilon$ add $1^{\mathrm{C}^{*}} 1312193^{\mathrm{C}} 2372 \mathrm{R}$ ] [4] add $1278^{*}$ 
The additional support of 2372 , and possibly $1278^{*}$, for this reading provides evidence that the rare reading originated with the family ancestor and not independently with the scribe of 1 and $\delta 10 \rho \theta \omega \tau \eta \dot{\varsigma}$ of $2193 .{ }^{96}$

Only a small number of readings, and some readings constituting only very slight differences, have been used to demonstrate Manuscript B's independence from 1 and 1582. This is because only readings where either 1 or 1582 , but not both, support the Non-Majority Text reading in the descendant/s of B have been used. Only for these readings can it be confirmed that the Non-Majority Text reading in the descendant/s of B was inherited from A-1, and did not originate in the extant witnesses $(565,884$ or 2193$)$ or in Manuscript B. Individual readings that cannot be shown with a good level of certainty to have been inherited from A-1 cannot offer conclusive evidence for B's independence. ${ }^{97}$

\subsubsection{B is Independent of All Other Extant Family Manuscripts}

The descendants of $\mathrm{B}$ have retained relatively high numbers of A-1 readings compared with other family manuscripts (except for 1 and 1582). This means that it is relatively easy to demonstrate the independence of 565, 884 and 2193 from these manuscripts. There are almost a hundred Non-Majority Text readings found in both 1 and 1582 that are only supported by one, two or all three of the descendants of $\mathrm{B}$, and these readings are spread consistently throughout the

\footnotetext{
${ }^{96}$ In chapter 4, 1278 and 2372 will be shown to form part of a family subgroup that is independent of both 1 and 2193 .

${ }^{97}$ Note that 1 and 1582 disagree on only 44 occasions.
} 
gospel. Those readings where all three manuscripts support the Non-Majority Text reading in 1 and 1582 are reproduced below. They clearly demonstrate that B and its three descendants are independent of all other extant manuscripts collated:

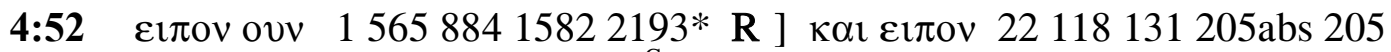
$2098721192121012782193^{\mathrm{C}} 23722713 \mathfrak{M}$

7:15 $\varepsilon \theta \alpha u \mu \alpha \zeta o v$ ovv 15658841582 2193* W ] $\varepsilon \theta \alpha v \mu \alpha \zeta o v \delta \varepsilon 118$ 205abs 2052092713 D ] $\quad \kappa \alpha \varepsilon \varepsilon \theta \alpha \mu \alpha \zeta o v 221318721192121012782193^{\mathrm{C}}$ $2372 \mathfrak{M}$

8:33 Kal عıлov 156588415822193 R ] omit 22118131 205abs 205209 $872119212102713 \mathbf{M}]$ or tovdator 12782372 R

8:42 $\varepsilon 1 \pi \varepsilon v 15658841582$ 2193* W ] ovv add 22118131 205abs 205209 $8721192121012782193^{\mathrm{C}} 23722713 \mathrm{M}$

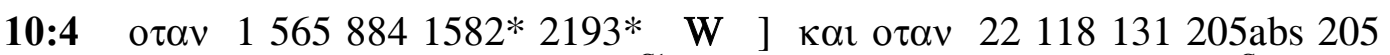
$2098721192121012781582^{\mathrm{Cl}} 23722713 \mathfrak{M}$ ] $\mathrm{o} \tau \alpha \nu \delta \varepsilon 2193^{\mathrm{C}} \mathbf{R}$

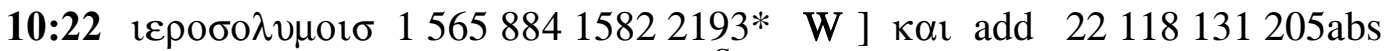
$2052098721192121012782193^{\mathrm{C}} 23722713 \mathfrak{M}$

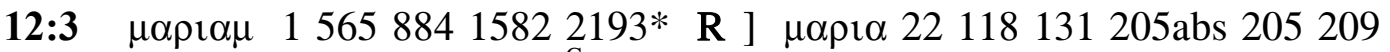
$8721192121012782193^{\mathrm{C}} 23722713 \mathfrak{M}$

12:35 $\omega \sigma \quad 156588415822193 * W$ W $\varepsilon \omega \sigma 22118131$ 205abs 205209872 $1192121012782193^{\mathrm{C}} 23722713 \mathfrak{M}$

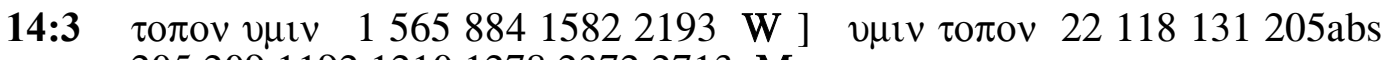
$20520911921210127823722713 \mathbf{M}$

14:11 $\varepsilon \sigma \tau \iota v \quad 156588415822193^{\mathrm{C}} \quad$ R ] omit 22118131 205abs 205209 $1192121012782193 * 23722713 \mathfrak{M}$ 
14:28 o $\tau$ ( (2nd) 15658841582 2193* W ] $\varepsilon \imath \pi \mathrm{ov}$ add 118131 205abs 205 $2091192121012782193^{\mathrm{C}} 23722713 \mathfrak{M}$

15:11 $\eta \quad$ (3rd) $156588415822193^{\text {txt }}$ R ] $\mu \varepsilon \imath v \eta 118131$ 205abs 205209 $1192121012782193^{\mathrm{mg}} 23722713 \mathfrak{M}$

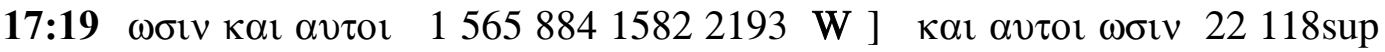
131 205abs $20520911921210127823722713 \mathbf{M}$

17:20 $\pi \varepsilon \rho \imath \pi \alpha \nu \tau \omega \nu 156588415822193$ R ] omit 118sup D ] $\pi \varepsilon \rho \imath 22131$ 205abs $20520911921210127823722713 \mathfrak{M}$

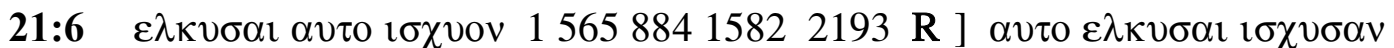
22 118sup 131 205abs $205209119212101278 \quad \mathfrak{M}$ ] $\varepsilon \lambda \kappa v \sigma \alpha l \alpha v \tau o$

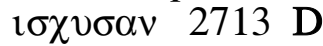

The establishment of the independence of Manuscript B and its extant descendants will prove significant for the reconstruction of the text of A-1. The descendants' high numbers of Non-Majority Text agreements shared with 1 and 1582 demonstrate that they have carefully retained a high number of readings from A-1, and are, therefore, reliable witnesses of A-1; and the manuscripts' independence and separate descent from A-1 means that it would be reasonable to presume that they have retained readings from A-1 that other manuscripts, including 1 and 1582, have not. Such readings will be given consideration as possible A-1 readings and will serve to widen the textual contours of the family.

\subsubsection{Codices 1 and 1582 are Independent of One Another}

Anderson analysed in detail the relationship between 1 and 1582 by a full collation of the text of both manuscripts in Matthew. From this collation, 
Anderson concluded that 1 and 1582 are both independent witnesses of a Family 1 ancestor. ${ }^{98}$ Anderson's conclusion is supported by the collation of the Gospel of John. Among the 44 disagreements between 1 and 1582 in the Gospel of John there are a small number of readings that indicate that each manuscript is independent of the other. There are 2 units where 1 and 1582 both contain a different Non-Majority Text reading:

7:52 $\quad$ ع 22 205abs 205209872884119212101278 2193supp 23722713 M

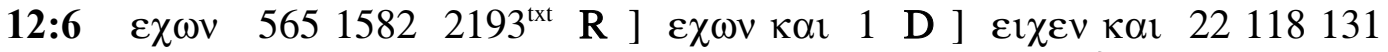 205abs 20520987288411921210127823722713 M ] $\varepsilon \chi \omega \mathrm{V}$ [3] $2193^{\mathrm{mg}}$}

In both cases, the reading of 1 and the reading of 1582 is supported by a descendant of B, suggesting that 1 and 1582 were copied from an intermediate manuscript that contained two readings at each point, rather than 1 being copied from 1582, or vice versa. This is almost certainly the case for the reading in 12:6, where the witness of 2193 provides very strong evidence that A-1 contained both a text reading and a marginal reading at this point.

In addition to these Non-Majority Text splits, Codex 1 contains 1 Non-Majority Text reading which has the support of $2193 *$ while 1582 has the Majority Text reading:

${ }^{98}$ Anderson, Matthew, 84-96. 


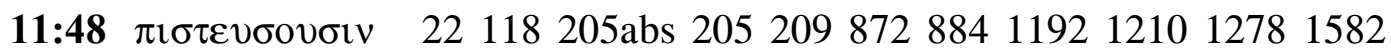
$2193^{\mathrm{C}} 2372 \mathfrak{M}$ ] $\pi \mathrm{i \sigma \tau \varepsilon v \sigma \omega \sigma \textrm {lv }} 11312193 * 2713 \mathrm{~W}$

1 distinctive reading that has partial support from 565 while 1582 is Majority:

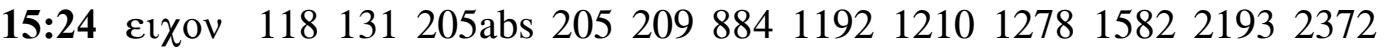
$2713 \mathfrak{M}$ ] $\varepsilon \imath \chi \omega \sigma \alpha \nu 1 \mathrm{D}$ ] $\varepsilon \iota \chi 0 \sigma \alpha \nu 565 \mathrm{R}$

And there is 1 rare agreement between $1^{\mathrm{C}^{*}}$ and $2193^{\mathrm{C}}$.

12:28 $\pi \alpha \tau \varepsilon \rho \quad 1^{*} 22118$ 205abs $205209565872884119212101278^{\mathrm{C}} 1582$ 2193*2713 $\mathfrak{M}$ ] $\alpha \gamma 1 \varepsilon$ add $1^{\mathrm{C} *} 1312193^{\mathrm{C}} 2372 \mathrm{R}$ ] [4] add 1278*

Finally, there is a distinctive reading in Codex 1 supported by $1278^{*}$ and 2372 , two manuscripts which will be discussed later and shown to descend from A-1 by a different route to Codex 1:

\section{3:26 tov $22131205565872884119212101278^{\mathrm{C}} 15822193 \mathfrak{M}$ ] omit 1 118 205abs 209 1278*2372 2713 D}

There are 4 variation units where 1582 has a Non-Majority Text reading, either rare or distinctive, supported by an independent descendant of A-1, while 1 agrees with the Majority Text, indicating that 1582 is independent of $1 .{ }^{99}$

\footnotetext{
${ }^{99}$ Codex 22 will be discussed in a later chapter and shown to be a independent witness of A-1.
} 
11:20 $\mu \alpha \rho \imath \alpha \mu 565^{\text {note }} 8841582$ 2193* R ] $\mu \alpha \rho \imath \alpha 122118131$ 205abs 205209 $8721192121012782193^{\mathrm{C}} 23722713 \mathfrak{M}$

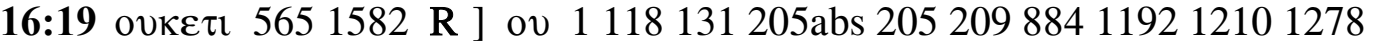
$219323722713 \mathfrak{M}$

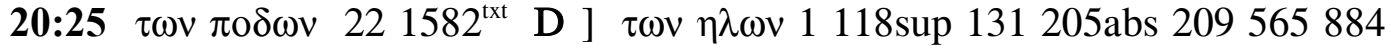
$1192121012781582^{\mathrm{mg}} 21932713 \mathfrak{M}$ ] $\tau$ ov $v \lambda \omega \nu 205 \mathrm{D}$

21:17 $\pi \rho \circ \beta \alpha \tau 1 \alpha 22565$ 1582* $\quad$ R ] $\pi \rho \circ \beta \alpha \tau \alpha \quad 1$ 118sup 131 205abs 205209 $8841192121012781582^{\mathrm{C}} 21932713 \mathfrak{M}$

In a further reading, Codex 1 (and the Venice group) omits a string of text where 1582, with the agreement of 22 and 565 , contains a rare reading: $\pi \rho \circ \beta \alpha \tau 1 \alpha$.

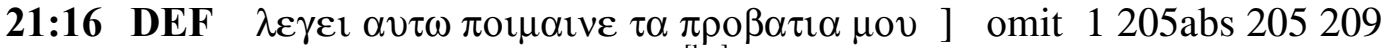
D ] $\lambda \varepsilon \gamma \varepsilon i \alpha v \tau \omega \pi \mathrm{or}[12] \tau \alpha 2713^{\text {[lac] }}$

$\pi \rho \circ \beta \alpha \tau \iota \alpha 225651582 *$ R ] $\pi \rho \circ \beta \alpha \tau \alpha$ 118sup 131884119212101278 $1582^{\mathrm{C}} 21932713^{[\mathrm{lac}]} \mathfrak{M}$

Note 2713: letters $\pi \rho \circ \beta \alpha$ supplied.

The agreement of 22,565 and 1582 , indicates that $\pi \rho o \beta \alpha \tau 1 \alpha$ was the reading of A-1 and that the omission must have occurred in a shared ancestor of Codex 1 and the Venice group.

Finally, as already discussed, the marginal readings in 1582 at 8:38 and 12:28 are substantiated by support from 2193 and offer further evidence that 1582 is independent of 1 . 


\subsubsection{Codices 1 and 1582 Share an Intermediate Exemplar, $C$}

If 1 and 1582 are independent of one another, their textual closeness must be explained by both manuscripts being very accurate copies of their shared ancestor. The text of this shared ancestor can be reconstructed from the agreements of 1 and 1582, and because both manuscripts are such accurate copies and have received very little correction towards the Majority Text, very little text which existed in the ancestor has been lost. The text of Manuscript B can also be reconstructed from readings found in its descendants, 565, 884 and 2193; however, because of the high levels of Majority Text correction in each individual descendant, only the Non-Majority Text readings are useful for reconstructing B's text. When two or more of B's descendants agree on a Non-Majority Text reading it is very likely that that reading existed in $\mathrm{B}$.

If we reconstruct the text of B from these Non-Majority Text agreements, do the same with the ancestor of 1 and 1582, then compare the two reconstructed texts, we find that B contains 48 Non-Majority Text text readings, spread evenly through the gospel, that are not present in the ancestor of 1 and $1582 .^{100}$ In addition, 2193 contains 6 extant Non-Majority Text variant readings that are very likely to have been inherited from Manuscript B, but are not present in the reconstructed ancestor of 1 and 1582, in either the text or the margin. ${ }^{101}$ There are

\footnotetext{
${ }^{100}$ The long omission in 5:9 has been counted as 2 variation units because within the string of text omitted by 565,884 and $2193^{*}$, there are two variant units where the rest of the family is split. See Appendix A for the full units and for further details of the treatment of deficient (DEF) manuscripts. Another reading (5:36) supported by 565 and $2193^{\text {txt }}$ has not been counted, because it is included among the 6 Non-Majority variant readings in 2193.

${ }^{101}$ In one of these readings (10:39) the marginal reading has been supplied on the evidence of a Non-Majority Text reading in the text of 565.
} 
also over 200 further Non-Majority Text readings that are found in only one descendant of B, but are not found in the reconstructed ancestor of 1 and $1582 .{ }^{102}$ Although these latter readings cannot be judged, individually, to have certainly been inherited from Manuscript B, clearly a number of them will have been, given the high levels of Majority Text correction among B's descendants (such correction makes it extremely probable that on some occasions only one descendant will have retained the A-1 reading). Some of these Non-Majority Text readings may have originated in Manuscript B and not be inherited from A-1; for example, the three long omissions already mentioned $(5: 9,7: 8$ and $8: 35)$, or other readings that might have resulted from scribal error or 'correction' by the scribe of B. ${ }^{103}$ It is, however, clear that a number of these readings must have existed in A-1.

As 1 and 1582 are so close, with only 44 disagreements, it is extremely unlikely that both manuscripts would omit these more certain Non-Majority Text B readings, the marginalia witnessed to by 2193 , and the other possible NonMajority Text B readings, independently of one another. This is especially so with the marginal readings, as 1 and 1582 tend to treat them differently: Codex 1 incorporating the marginal readings into its text, and 1582 retaining them. These differences between the reconstructed text of $\mathrm{B}$ and the reconstructed text of the nearest ancestor of 1 and 1582 indicate that 1 and 1582 share an intermediate ancestor that stands between them and A-1, that is not B and is not shared with B.

\footnotetext{
${ }^{102}$ Long omissions, readings with a first hand correction, and other readings which may be judged to have originated in the descendant itself have not been included in this count.

${ }^{103}$ See earlier note. These 3 omissions are counted as 4 units.
} 
This intermediate manuscript will be called Manuscript $\mathrm{C}$. Manuscript $\mathrm{C}$ received some correction towards the Majority Text and filtered out these Non-Majority Text A-1 readings discussed above, along with a significant proportion of the marginalia that was preserved in B and retained in 2193.

\subsubsection{New Readings for Family 1 in the Gospel of John}

The discovery of a new subgroup descended from Manuscript B is significant for reconstructing the text of A-1 in the Gospel of John. Anderson suggested in her work on Matthew that because the number of marginal readings in 1582 reduces towards the end of the codex, particularly by Luke and John, that the scribe of 1582's exemplar must have 'gradually left off copying the apparatus' of its exemplar. ${ }^{104}$ The discovery of the additional marginalia for John in 2193 confirms Anderson's suspicion. The scribe of Manuscript C must have copied only a small number of the marginal readings he found in A-1; however, the scribes of Manuscript B, and its descendant 2193, copied more of these marginal readings. Consequently, a much fuller version of the marginalia that existed in A-1 can now be reconstructed. Below is a list of the 10 extant marginal readings, both Majority Text and Non-Majority Text, that exist in 2193 but not 1582 .

\footnotetext{
${ }^{104}$ Anderson, Matthew, 61.
} 
1:28 $\beta \eta \theta \alpha \beta \alpha \rho \alpha \quad 122^{\text {txt }} 1192^{\text {txt }} 1278^{\text {mg }} 15822193^{\text {txt }} 2713$ [W] ] $\beta \eta \theta \alpha v i \alpha 22^{\text {mg }}$ 118131 205abs $20520987212101278^{\text {txt }} 2193^{\text {mg }} 2372 \quad$ M ] $\beta i \theta \alpha v i \alpha 565$ $1192^{\mathrm{mg}}[\mathbf{M}]$

Note: 2193 and 1278 have $\varepsilon v$ re-written in the margin as part of the variant reading; 22 and 1192 do not.

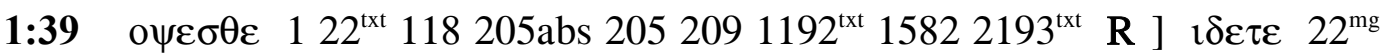
$1315658721192^{\mathrm{mg}} 121012782193^{\mathrm{mg}} 23722713 \mathfrak{M}$

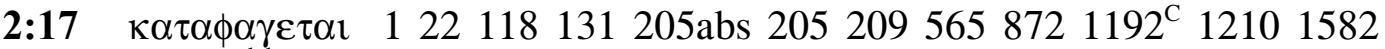
$2193^{\text {mgdub }} 2713$ M ] $\left.\kappa \alpha \tau \alpha \phi \alpha \gamma \varepsilon \tau \varepsilon 1192^{*} \mathbf{R}\right]$ ] $\alpha \tau \varepsilon \phi \alpha \gamma \varepsilon v 2193^{\text {txt }} 2372$ W ] $\kappa \alpha \tau \varepsilon \phi \alpha \gamma \varepsilon \tau \alpha i \quad 1278 \quad \mathbf{R}$

5:36 $\alpha \pi \varepsilon \sigma \tau \alpha \lambda \kappa \varepsilon v \quad 122118$ 205abs 2052098728841192121012781582 $2193^{\mathrm{mg}} 23722713$ MN ] $\alpha \pi \varepsilon \sigma \tau \varepsilon 1 \lambda \varepsilon v 1315652193^{\mathrm{txt}} \mathbf{R}$

7:41 or $\delta \varepsilon \quad 1118205$ abs $20520956515822193^{\text {txt }} 2713$ W ] $\alpha \lambda \lambda$ or 22131 $8728841192121012782193^{\mathrm{mg}} 2372$ M

Note 2193: the marginal reading has been erased.

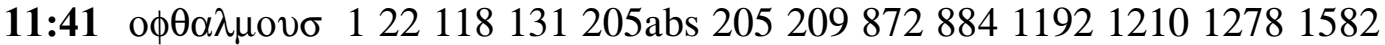

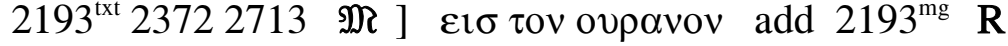

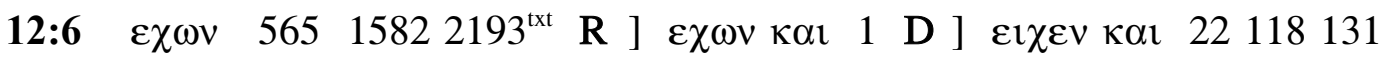
205abs 20520987288411921210127823722713 M ] $\varepsilon \chi \omega v$ [3] $2193^{\mathrm{mg}}$

Note 2193: a marginal reading has been erased.

14:30 о৩к $\varepsilon \chi \varepsilon 1 \quad 1118$ 205abs $20520956588411921210127815822193^{\text {txt }}$ $23722713 \mathfrak{M}$ ] ع

Note 2193: the marginal reading has been erased.

15:11 $\eta \quad$ (3rd) $156588415822193^{\text {txt }}$ R ] $\mu \varepsilon \imath v \eta 118$ 131 205abs 205209 $1192121012782193^{\mathrm{mg}} 23722713 \mathfrak{M}$

21:11 $\varepsilon \pi \imath \tau \eta \nu ~ \gamma \eta \nu ~ 1205 a b s 2052095658841582$ R ] $\varepsilon \pi \imath \tau \eta \sigma \gamma \eta \sigma 22$ 118sup $1311192121012782193^{\text {txt }} 2713$ M ] $\varepsilon 1 \sigma \tau \eta v \gamma \eta v 2193^{\mathrm{mg}} \mathrm{W}$ 
Further to these readings there are 6 units where a marginal reading definitely existed in 2193 but has been erased and is no longer legible. In some cases the readings of other manuscripts may provide clues to the text of the erased marginal readings.

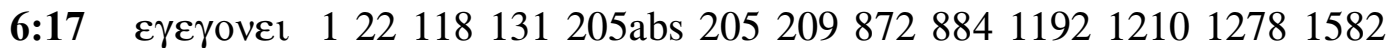

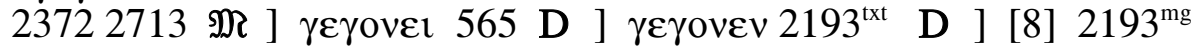

Note 2193: a marginal reading has been erased.

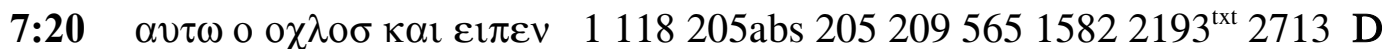

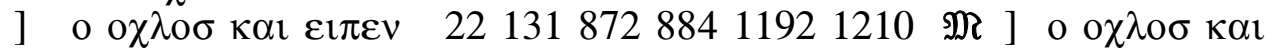
$\varepsilon \imath \pi \varepsilon v \alpha v \tau \omega 12782372$ D ] [dub] $2193^{\mathrm{mg}}$

Note 2193: a marginal reading has been erased.

9:6 $\quad \alpha v \tau o v \tau o v \sigma o \phi \theta \alpha \lambda \mu \circ v \sigma 1118$ 205abs $20520956515822193^{\text {txt }}$ D ] $\tau$ ov

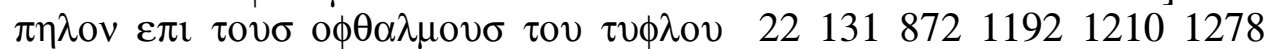

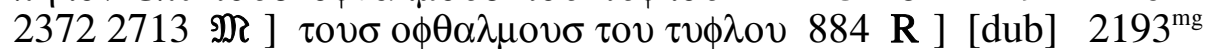

Note 2193: a marginal reading has been erased.

11:31 $\delta$ o $\alpha \nu \tau \varepsilon \sigma 122118$ 205abs $205209884119212101278^{*} 1582^{*} 2193^{\text {txt }}$ $23722713 \mathrm{~W}$ ] $\lambda \varepsilon \gamma \circ \nu \tau \varepsilon \sigma \quad 1318721278^{\mathrm{C}} 1582^{\mathrm{C} 1} \mathfrak{M}$ ] [8] $2193^{\mathrm{mg}}$

Note 2193: a marginal reading has been erased.

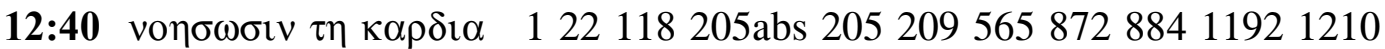
$127815822193^{\text {note }} 23722713 \mathfrak{M}$ ] $\tau \eta \kappa \alpha \rho \delta 1 \alpha \sigma v v \omega \sigma r 131$ R

Note 2193: a marginal reading or $\mathrm{C} 1$ reading has been erased.

12:47 $\phi \cup \lambda \alpha \xi \eta \quad 122118$ 205abs $205209565884121015822193^{\text {txt }} 23722713$ W ] $\pi i \sigma \tau \varepsilon v \sigma \eta 13187211921278^{\mathrm{C}} \mathbf{M}$ ] [6] 1278* ] [8] $2193^{\mathrm{mgdub}}$

Note 2193: a marginal reading has been erased. 
Finally there are a further 5 units, given below, where it is possible that a marginal reading existed in 2193 , but is has been erased so effectively that it is difficult to be certain. On these occasions there are very faint traces on the microfilm of scraping on the parchment and occasionally traces of letters or the gamma-rho symbol; in most of these cases there is definitely a reading in the margin, but it is unclear whether the reading is a correction or marginal reading. In 10:39, the existence of a singular distinctive reading in the text of 565 may support the existence of a marginal reading in 2193, as on other occasions 565 has incorporated marginal readings into its text.

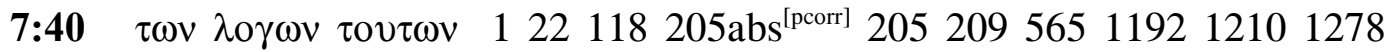

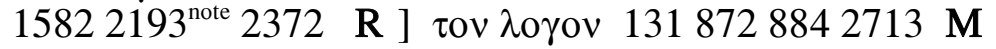

Note 205abs: all omegas are possibly corrections.

Note 2193: a marginal reading may have been erased.

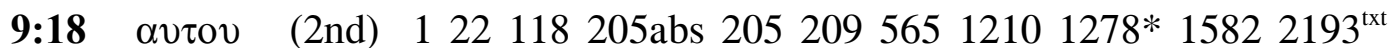

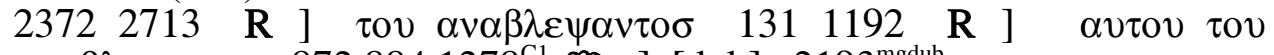
$\alpha v \alpha \beta \lambda \varepsilon \psi \alpha \nu \tau 0 \sigma 8728841278^{\mathrm{Cl}} \mathfrak{M}$ ] [dub] $2193^{\text {mgdub }}$

Note 2193: a marginal reading may have been erased.

10:39 $\varepsilon \kappa \quad 122118131205 a b s 20520987288411921210127815822193^{\text {txt }}$ $23722713 \mathfrak{M}$ ] $\alpha \pi \mathrm{o} 565 \mathrm{D}$ ] [dub] $2193^{\mathrm{mgdub}}$

Note 2193: a marginal reading may have been erased.

11:16 $\alpha \pi \circ \theta \alpha \nu \omega \mu \varepsilon v \mu \varepsilon \tau 122118131$ 205abs 20520956587288411921278 $\left.15822193^{\text {note }} 23722713 \mathfrak{M}\right] \alpha \pi \circ \theta \alpha v o \mu \varepsilon v \mu \varepsilon \tau 1210 \mathbf{R}$

Note 2193: a marginal reading or $\mathrm{C} 1$ reading may have been erased. 


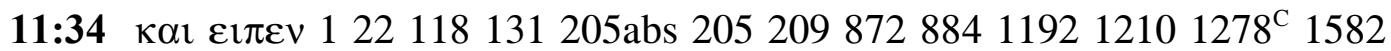
$2193^{\text {note }} 2713 \mathfrak{M}$ ] $\varepsilon 1 \pi \varepsilon v 2372 \mathrm{D}$ ] [5] 1278*

Note 2193: a correction or marginal reading may have been erased.

An examination of 2193 itself may be able to confirm whether or not these readings are marginal variants or corrections, and it may even be possible to decipher the text of some of the readings, as well as perhaps uncover further erased readings that have betrayed no marking on the microfilm.

Of the 48 almost certain B text readings, the 3 longer omissions (counted as 4 readings) can be dismissed as originating in $\mathrm{B}$ itself, and 4 other readings are suspect because they may have resulted from partial Majority Text correction, and may have originated in $\mathrm{B}$ itself. ${ }^{105}$ There still remain, however, a significant number of almost certain $\mathrm{B}$ readings, and numerous less certain, but possible, readings that were probably inherited from A-1, but have not been preserved in Manuscript $\mathrm{C}$. These readings, along with the marginal readings, serve to alter the reconstruction of the text of A-1. A selection of these readings are given below, and the remaining can be found in Appendix B; these readings should be considered very probable A-1 readings.

The first 4 readings involve points of Non-Majority Text division between the core group, and may reflect the existence of further marginalia in A-1. In the first 2 units $\mathrm{B}$ has perhaps retained both readings and $\mathrm{C}$ only one. In 14:31 A-1 probably read $\varepsilon \delta \omega \kappa \varepsilon v$ for the Majority $\varepsilon v \varepsilon \tau \varepsilon 1 \lambda \alpha \tau o$, but may have had $\varepsilon v \tau o \lambda \eta \nu$ as a marginal variation or correction. B and the ancestor of 1 and 1582 copied $10510: 7,16: 13,16: 26,19: 35$. 
$\varepsilon \delta \omega \kappa \varepsilon v$, but because $\varepsilon v \tau 0 \lambda \eta v$ was placed in the margin, added the word at different points in the text.

3:28 Euor 122118 205abs $2052095651192127815822193 *$ *uppl 23722713

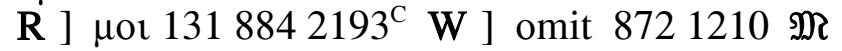

7:12 o $\tau$ ( (2nd) $15651582 \quad$ D ] ov $\alpha \lambda \lambda \alpha \quad 22118131$ 205abs 205209872

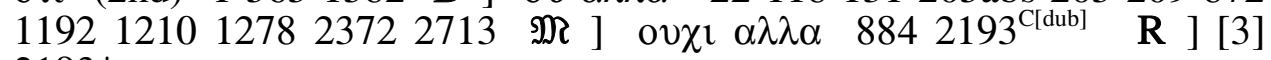
2193*

Note $2193^{\mathrm{C}}$ : letters $\chi \imath$ uncertain.

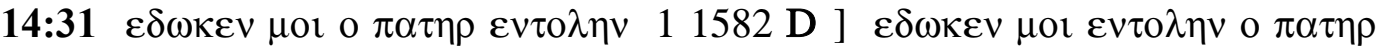
$5658841210 \quad \mathbf{R}] \quad \varepsilon v \varepsilon \tau \varepsilon i \lambda \alpha \tau o \mu$ o $\quad \pi \alpha \tau \eta \rho \quad 118131$ 205abs 205209 11921278219323722713 M

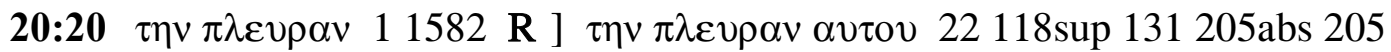

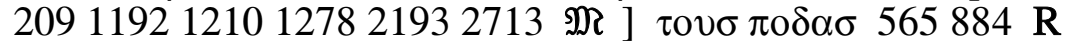

In 12:3 there is Non-Majority Text division, which may again be the result of marginalia in A-1, but it might also have been caused by the ancestor of 1 and 1582 being 'partially' corrected to the Majority Text.

12:3 $\tau \alpha \imath \sigma \theta \rho \imath \xi_{\imath v} \alpha v \tau \eta \sigma \varepsilon \xi \varepsilon \mu \alpha \xi \varepsilon v 1118$ 205abs 20520915822713 D ] $\tau \alpha \imath \sigma$ $\theta \rho \imath \xi \mathrm{lv} \alpha v \tau \eta \sigma \alpha \pi \varepsilon \mu \alpha \xi \varepsilon v 5658842193$ R ] $\varepsilon \xi_{\varepsilon} \mu \alpha \xi \varepsilon v \tau \alpha 1 \sigma \theta \rho \imath \xi \mathrm{lv} \alpha v \tau \eta \sigma$

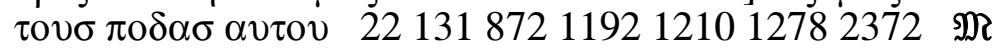

A-1 perhaps read $\tau \alpha \imath \sigma \theta \rho \imath \xi ı v \alpha \nu \tau \eta \sigma \alpha \pi \varepsilon \mu \alpha \xi \varepsilon v$, B preserved this reading while the ancestor of 1 and 1582 changed $\alpha \pi \varepsilon \mu \alpha \xi \varepsilon v$ to $\varepsilon \xi \varepsilon \mu \alpha \xi \varepsilon v$ to agree with the Majority Text. Either way, the ancestor of 1 and 1582 has not preserved the full Non-Majority Text reading as it existed in A-1. 
The following readings are simple text readings preserved by two or more of the descendants of B. Despite not being supported by 1 and 1582, they are still likely to have been inherited from A-1.

6:22 o (1st) 122118131 205abs 20520987211921210127815822193 $23722713 \mathfrak{M}$ ] omit $565884 \mathrm{R}$

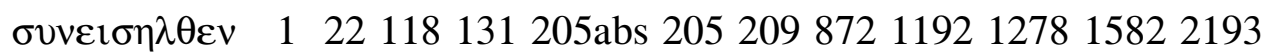

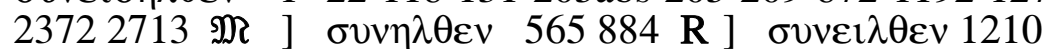

6:52 ovv 122118131 205abs 205209872119212101278158221932372 $2713 \mathfrak{M}] \delta \varepsilon 565884 \mathrm{R}$

6:55 $\quad \gamma \alpha \rho \quad 122118131$ 205abs 205209872119212101278158221932372 $2713 \mathfrak{M}$ ] omit $565884 \mathrm{R}$

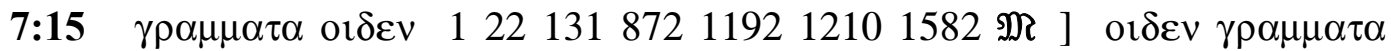
118 205abs 2052095658841278219323722713 R

7:33 $\mu \varepsilon \quad 122118131$ 205abs 205209872119212101278158221932372 $2713 \mathfrak{M}] \pi \alpha \tau \varepsilon \rho \alpha$ add $565884 \mathrm{R}$

7:42 $\alpha \pi \mathrm{o} \quad 122118131$ 205abs 20520987288411921210127815822372 M ] $\varepsilon \kappa 5652193$ D

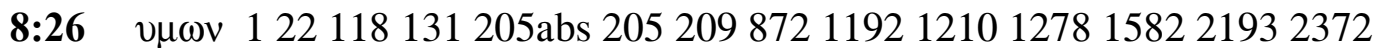
$2713 \mathfrak{M}]$ v $\mu \alpha \sigma 565884 \mathbf{R}$

9:31 $\alpha \mu \alpha \rho \tau \omega \lambda \omega v \quad 122118$ 205abs 2052098728841192121012781582 $2193^{\mathrm{C}} 2372^{*} \mathfrak{M}$ ] $\alpha \mu \alpha \rho \tau \omega \lambda$ ov $1315652193 * 27132372^{\mathrm{C}} \quad \mathrm{W}$

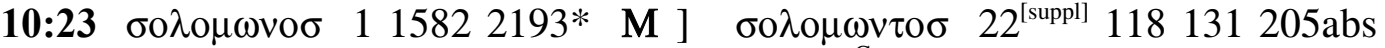
$2052095658728841192121012782193^{\mathrm{C}} 23722713$ W

Note 22: letter o (2nd) supplied. 
11:4 $\alpha \nu \tau \eta \eta \alpha \sigma \theta \varepsilon v \varepsilon 1 \alpha \quad 122118131205$ abs 205209872119212101278

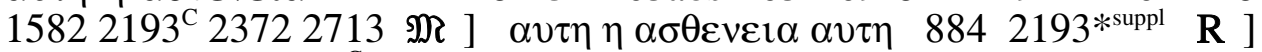
$\left.\alpha \sigma \theta \varepsilon v \varepsilon 1 \alpha \alpha v \tau \eta 565^{\mathrm{C}} \mathrm{D}\right] \alpha[3-4] \alpha \sigma \theta \varepsilon v \varepsilon 1 \alpha \alpha v \tau \eta 565^{*}$

12:12 o 122118131 205abs $20520987211921210127815822193^{\mathrm{C}} 2372$ $2713 \mathfrak{M}$ ] omit $5658842193 * \mathbf{R}$

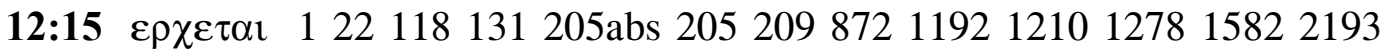
$23722713 \mathfrak{M}]$ oor add $565884 \mathrm{R}$

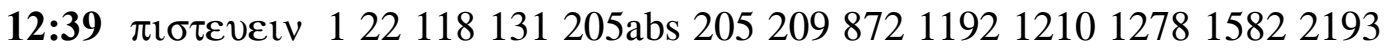
$23722713 \mathfrak{M}] \pi 1 \sigma \tau \varepsilon v \sigma \alpha \iota 565884 \mathrm{R}$

12:49 $\varepsilon \lambda \alpha \lambda \eta \sigma \alpha 122118131$ 205abs 20520987211921210127815822193 $23722713 \mathfrak{M}] \varepsilon \lambda \eta \lambda v \theta \alpha 565884 \mathrm{R}$

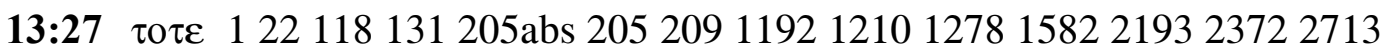
M ] omit $565884 \mathrm{R}$

15:27 $\delta \varepsilon 1118131$ 205abs $2052091192121012781582219323722713 \mathfrak{M}$ ] omit $565884 \mathrm{R}$

16:17 $\varepsilon \gamma \omega 113188411921210127815822372$ M ] omit 118 205abs 205 20956521932713 W

16:29 aviov 122 118sup 131 205abs 205209119212101278158221932372 $2713 \mathfrak{M}$ ] omit $565884 \mathrm{R}$

17:2 $\delta \varepsilon \delta \omega \kappa \alpha \sigma 122$ 118sup 131 205abs 205209 565sup 1192121012781582 $23722713 \mathfrak{M}$ ] $\varepsilon \delta \omega \kappa \alpha \sigma 8842193$ W

17:23 $\varepsilon \gamma \omega 122$ 118sup 131 205abs 205209119212101278158221932372

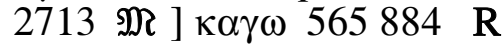

18:18 or (2nd) 122 118sup 131 205abs 20520911921210127815822193 $23722713 \mathfrak{M}$ ] omit $565884 \mathrm{R}$ 


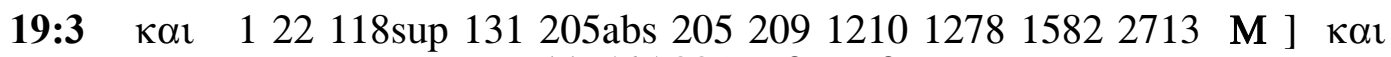

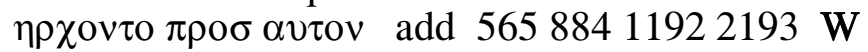

19:11 $\varepsilon \iota \chi \varepsilon \sigma 122$ 118sup 131 205abs $205209884119212101278^{\mathrm{C}} 15822193^{\mathrm{C}}$ $2713 \mathfrak{M}$ ] $\varepsilon \chi \varepsilon\left\llcorner\sigma 5651278^{* d u b} \mathrm{~W}\right.$ ] [5] 2193*

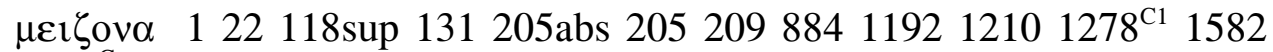
$2193^{\mathrm{C}} 2713$ M ] $\mu \varepsilon i \zeta o v 5651278 * 2193 * \mathbf{R}$

19:13 $\delta \varepsilon \quad 122$ 118sup 131 205abs $205209119212101278158221932713 \mathfrak{M}$ ] omit $565884 \mathrm{R}$ 


\subsection{Manuscript Descriptions}

\subsubsection{Codex 118}

\section{Content and Layout}

Codex 118 is a thirteenth-century ${ }^{106}$ Four Gospel codex kept at the Bodleian library, Oxford; it has the library number Auct. D. inf. 2. 17. ${ }^{107}$ It contains 262 folios though only 168 of these are original leaves. ${ }^{108}$ Two sections of Luke are missing and have been replaced by a later hand on parchment leaves; and parts of Matthew and John are missing and have been replaced by a still later hand on paper leaves. ${ }^{109}$ At least two of the replacement leaves for Luke are palimpsests. ${ }^{110}$ The original leaves are written in black ink on parchment that has yellowed considerably. The text is written in 1 column with 23-27 lines per page. The dimensions of the original pages are 20 by $13.5 \mathrm{~cm}$ and the text 16 by $10 \mathrm{~cm}$.

\footnotetext{
${ }^{106} \mathrm{~K}$. Aland, Kurzgefasste Liste der griechischen Handschriften des Neuen Testaments (ANTF 1), (Berlin: Walter de Gruyter, 1963), 53.

${ }^{107}$ Bodleian Quarto Catalogue number: Misc. 13; Summary Catalogue number: 8991. Other identification numbers: von Soden $\varepsilon$ 346; Marsh 24. 'MARSH 24' appears on the spine of the leather binding.

${ }^{108}$ The original leaves begin on f. 27 and end on f. 194; f. 139, f. 146 and f. 147 are also supplementary pages. The last folio is numbered 261 but as two folios are numbered 230 there are actually 262 folios.

${ }^{109}$ Lacunas: Matthew 1:1-6:2; Luke 13:35-14:20 and 18:7-19:9; John 16:25-21:25.

${ }^{110}$ F. 139 and f. 146. F. C. Burkitt identified the majuscule text as Psalm 18 and dated the script to the eleventh century. His comments are hand written in the Bodleian Quarto catalogue. The note is dated 1896
} 
Each gospel begins on a new quire; the first page of each gospel is decorated with a modest border in the top margin painted in red, followed by a rubricated minuscule gospel title and an enlarged first letter. ${ }^{111}$ Smaller initial letters are used throughout the codex and are painted in the same red ink. ${ }^{112}$ The first quire number in the manuscript is $\gamma$, indicating that there are two missing quires at the beginning of the codex. Lake calculated that Matthew 1:1-6:2 would fit onto quire $\beta$ so reasonably concluded that the manuscript must have included various prefatory material. ${ }^{113}$ A number of later hands have added to the codex:

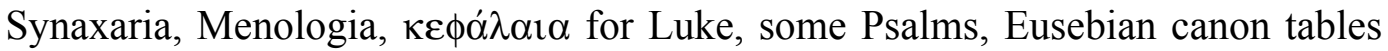
and $\sigma \tau i \chi o r$ for Luke and John.

There is some damage to the codex: the top half of $\mathrm{f} .120 \mathrm{r}$ has been torn off and is missing and the first 10 lines of text on $\mathrm{f}$. $104 \mathrm{v}$ have been made illegible, probably the result of a spillage as a large yellow mark remains. Other damage, such as nibbling marks from mice, has not affected the text.

\footnotetext{
${ }^{111}$ The beginning of Matthew is missing text. Lake, however, calculated that the missing text would fit exactly onto one quire and so the gospel would have begun on the first page of that quire. Lake, Codex 1, xv.

${ }^{112}$ It is common in 118 for rubricated initial letters to be missing. Often on such occasions, a tiny black letter can be detected at the very edge of the left margin, indicating that the scribe had intended one to be added. Such letters were normally trimmed off in the binding process but in 118 many are still visible. This method for adding initial letters was not uncommon. For discussion and other examples of this phenomenon see Annemarie Weyl Carr, "Two Manuscripts of Joasaph in the United States," The Art Bulletin 63, 2 (1981): 179; and Jeffrey C. Anderson, "The Illustration of Cod. Sinai. Gr. 339," The Art Bulletin 61, 2 (1979): 173.

${ }^{113}$ Lake, Codex 1, xv.
} 
Script and Dating

Codex 118 has a busy but legible script. The main body of text is filled with ligatures and abbreviations, and wavy super-lines over nomina sacra and other names add to the text's hectic appearance. There are lots of majuscule letter forms and various letters are often enlarged, most commonly zeta, kappa, lambda, phi, psi, and xi. Breathing marks are round; nomina sacra have accents and breathings; accents, breathings and abbreviations are always distinct from letters and from one another; and mute iota is subscript. ${ }^{114}$ Uncontracted proper names are often given a super-line. The palaeographical features of 118 are extremely typical of a thirteenth-century minuscule hand.

\section{Illuminations}

There are no illuminations in 118 .

\section{Correctors and Later Hands}

Codex 118 has not been systematically corrected. The only corrections made at the time of production were by the original scribe himself or by the rubricator (possibly identical with the original scribe). The rubricator made very infrequent corrections in red ink. The 'errors' he noted were almost certainly spotted by chance as he worked his way through the manuscript to add the initial letters, for

\footnotetext{
${ }^{114}$ F. $181 \mathrm{r}$ has a very peculiar appearance: the text is written in the hand of the original scribe but the majority of the accents have been added by the scribe who supplemented Matthew and Luke on paper pages centuries later.
} 
he made his corrections in the same ink he was using to rubricate the manuscript. First hand corrections in black ink are only sporadic and were probably made during the process of coping, rather than while checking the work afterwards. ${ }^{115}$ All other corrections were made centuries later, by the scribe who added the supplementary pages for Matthew and John. These corrections were all made in brown ink. In the transcription these three correctors have been distinguished: ' $\mathrm{C}^{*}$ ', the original hand; ' $\mathrm{C} 2$ ', the rubricator; and ' $\mathrm{C} 3$ ', the scribe who supplemented Matthew and John. Some corrections, usually simple erasures, where it is difficult to distinguish between hands, have been labelled C.

\section{Provenance}

Three previous owners of 118 can be identified: firstly, a man known as

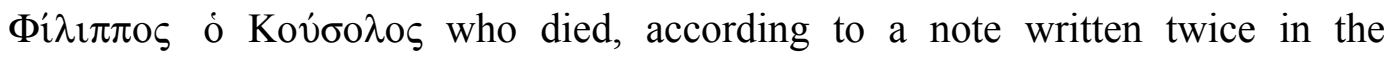
manuscript, in 1554; second, a Dr Halifax who was chaplain of Aleppo between 1687 and 1695; and third, the Archbishop of Armagh, Narcissus March, who died in 1714 and bequeathed the manuscript to the Bodleian library. ${ }^{116}$

\footnotetext{
${ }^{115}$ The codex is not a very high quality production and corrections were not always made with care. One characteristic of the original hand of 118 is his tendency to only half finish corrections. Most often this is when he makes an erasure by wiping or scraping clean the parchment, but does not return to add the corrected text. The first example of this in John is 1:2 where instead of writing epsilon-nu for $\varepsilon v$ the scribe made an error, writing epsilon followed by another letter, not a $\mathrm{nu}$, but that is no longer legible; he notices this mistake and erases the second letter, but never comes back to add the nu (f. 163r).

116 Irmgard Hutter, Corpus der byzantinischen Miniaturenhandschriften: Oxford, Bodleian Library, vol. 3, (Stuttgart: Hiersemann, 1982), 120.
} 
John begins on $\mathrm{f} .163 \mathrm{r}$ in the hand of the original scribe. His text ends on f. 194v at John 16:25b and the remaining text of the gospel was added by a fifteenthcentury hand. The Pericope Adulterae stands at 7:53 and there is no indication of any text critical difficulties with the passage. 118 was transcribed from the microfilm, and the manuscript itself was consulted, in Oxford, to check unclear text and to examine closely the various hands that have added to the codex. Unless otherwise stated codicological details come from my own examination.

\subsubsection{Codex 205abs}

\section{Contents and Layout}

Codex 205abs is a fifteenth-century Greek Bible, kept at the Biblioteca Nazionale Marciana in Venice. ${ }^{117}$ It has the library catalogue reference Gr. Z. 6 (336). The manuscript has recently been given a new Gregory-Aland number, 2886. For this thesis, however, it will be referred to by the older Gregory-Aland number, 205abs. ${ }^{118}$ The codex is large and heavy, bound in thick leather; it contains 438 folios with pages measuring 38 by $26 \mathrm{~cm} .{ }^{119}$ The text is written in tiny minuscule letters in 1 column per page with 45 lines per column. The text measures 27 by

\footnotetext{
117 New Testament contents: Gospels (ff. 347r-384v), Acts (ff. 385r-395v), Catholic Epistles (ff. 396r-400r), Revelation (ff. 401v-406v), Pauline Epistles (ff. 411r-432r).

${ }^{118}$ Other references: Tischendorf / Scrivener $206^{\mathrm{e}}, 94^{\mathrm{a}}, 107^{\mathrm{p}}, 101^{\mathrm{I}}$.

119 Two additional, unnumbered paper folios have been added to the beginning and end of the codex.
} 
$16.3 \mathrm{~cm}$. The last page of each quire is marked with the first words that follow on the next quire, presumably intended as an aid for sewing together the manuscript. $^{120}$ Ff. 1-190 (Genesis to the first half of Ezekiel) and ff. 347-438 (the whole New Testament) were written on parchment leaves and ff. 191-346 (the second half of Ezekiel to the blank pages following the uncompleted Maccabees) were written on paper leaves. Each gospel begins with a list of $\kappa \varepsilon \phi \alpha ́ \lambda \alpha \iota \alpha$ and the $\kappa \varepsilon \phi \alpha ́ \lambda \alpha \iota \alpha$ rubricated titles are given in the margins. Except for $\kappa \varepsilon \phi \alpha \dot{\lambda} \alpha \iota \alpha$ and book titles included by the first scribe, written across recto and verso pages, there are no other reading aids in the manuscript. Like other manuscripts in the Family 1 group, 205abs contains a note regarding the authenticity of the ending of the Gospel of Mark on f. 364v. ${ }^{121}$

Many of the finishing touches to 205abs were never made, giving it a somewhat incomplete appearance: hardly any rubricated letters were added, though space was left for them; many pages do not have titles; and the book of Maccabees has only 21 lines of text followed by blank pages. ${ }^{122}$

\footnotetext{
${ }^{120}$ Note that 205, a manuscript of very similar physical format and proportions, also copied for Cardinal Bessarion, has quires marked with Greek numerals. This could be an indication that both manuscripts were produced at the same time and that the scribes wished to ensure that the leaves of each manuscript were not confused.

${ }^{121}$ F. $364 \mathrm{v}$. This note is very faded on the manuscript and is barely visible on the microfilm.

${ }^{122}$ F. 341r. Only 21 lines of the book have been copied, blank pages, presumably for the rest of the book, follow.
} 


\section{Script and Dating}

205abs was copied by two scribes, each using a slightly different shade of brown ink. Mioni's library catalogue names these scribes Cosmas Trapezuntius (copied ff. $1-160$ and ff. 347-431) and Demetrius Xanthopulos (copied ff. 161-341). ${ }^{123}$ Both were professional copyists who produced high numbers of manuscripts during their lifetimes. ${ }^{124}$ The hands are similar: both wrote in a tiny and economical minuscule; around 50 percent of letters are abbreviated or written high above the line; and most other letters are formed in tight and minute ligatures. Both scribes managed to squeeze over a hundred non-abbreviated letters onto a line. Breathing marks are smooth; nomina sacra are accented; breathings and accents are distinct from letters and abbreviations; and there is no mute iota. There are numerous majuscule forms, for many letters, in a higher proportion to the minuscule alternative, and letters vary significantly in their relative size. Both scribes use a number of distinctive late letter forms such as the modern beta and the lunate sigma. In Bessarion's personal inscription on $\mathrm{f} .2 \mathrm{v}$ he gives himself one of his earlier titles: 'Cardinalis Episcopus Tusculanus'. This indicates that the manuscript was complete by 1468, after which Bessarion held higher official titles

\footnotetext{
${ }^{123}$ Elpidius Mioni, Bibliothecae Divi Marci Venetiarum: Codices Graeci Manuscripti. Vol. I (Rome: Istituto poligrafico dello Stato, 1967), 10.

124 See E. Gamillscheg et al., Repertorium der griechischen Kopisten 800-1600 (Vienna: österreichische Akademie der Wissenschaften, 1981), 68, for entry on Demetrius Xanthopulos.
} 
and used these to inscribe his later acquisitions. ${ }^{125}$ Such a dating would suggest that Codex 205abs was completed before Codex $205 .^{126}$

\section{Illuminations}

205abs does not contain any illuminations; there is space, however, at various points in the codex, where large decorated letters and headpieces were intended.

\section{Correctors and Later Hands}

Minimal corrections have been made to 205abs and almost all of these are very tiny interlinear corrections, presumably made by the scribe as he copied and noticed errors. In John all the corrections are first hand with the exception of the addition of $\tau \alpha$ in $3: 2$, which is written in a darker ink than the rest of the text. All corrections, except for the one in 3.2 , have been labelled $\mathrm{C}^{*}$ in the transcription. The correction in 3:2 has been labelled C.

\section{Provenance}

205abs was owned by and copied for Cardinal Bessarion (ca. 1400-72). Bessarion's commitment to the collection, preservation and copying of ancient Greek books is widely documented. The apparent rush with which 205abs was

\footnotetext{
${ }^{125}$ Labowsky suggests this method of dating when a manuscript came into Bessarion's possession: Lotte Labowsky, Bessarion's Library and the Biblioteca Marciana, Six Early Inventories (Rome: Edizioni di Storia e Letteratura, 1979), 19.

${ }^{126}$ This is of note as most scholars have presumed that 205abs is a copy of 205. See the textual analysis of these two manuscripts beginning in section 3.2.15.
} 
completed fits in with what we know of Bessarion and his sense of urgency in preserving valuable and rare texts. ${ }^{127}$ Bessarion bequeath $205 \mathrm{abs}$, along with the rest of his library, to the city of Venice and it has been held at the Biblioteca Nazionale Marciana ever since. The manuscript is listed in a number of library inventories from 1468 onwards. ${ }^{128}$

\section{Transcription of the Gospel of John}

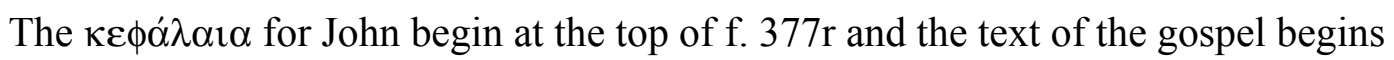
at the bottom of the same page. There is quite a large space between the $\kappa \varepsilon \phi \alpha ́ \lambda \alpha \iota \alpha$ and the gospel text, perhaps a space intended for a decorative headpiece. John ends on f. 384v. The whole gospel is extant and the Pericope Adulterae stands at John 7:52 with no indications of textual difficulty with the passage. The transcription for 205abs was made from the microfilm, and the manuscript itself was examined, in Venice, to check points of unclear text, to examine the corrections, and to record palaeographic and codicological information. Unless otherwise stated codicological details come from my own examination of the codex.

\footnotetext{
${ }^{127}$ For more on Bessarion see: John Monfasani, Byzantine Scholars in Renaissance Italy: Cardinal Bessarion and Other Émigrés (London: Variorum, 1995); Nelson, "Italian"; Labowsky, Inventories.

128 Labowsky, Inventories: inventory A of 1468, p. 157; inventory B of 1474 followed consecutively by 205 and 209, p. 216; inventory C of 1524 listed beside 205, p. 262; inventory D of 1543 , close to 209 and 205, p. 318.
} 


\subsubsection{Codex 205}

\section{Contents and Layout}

Codex 205 is a fifteenth-century Greek Bible kept at the Biblioteca Nazionale Marciana in Venice. ${ }^{129}$ It is designated Gr. Z. 5 (420). ${ }^{130}$ The codex contains 444 large parchment folios measuring 39.1 by $27.4 \mathrm{~cm} .{ }^{131}$ The text is written in 1 column per page with 55 lines per column; the text measures 29.1 by $18.2 \mathrm{~cm}$. The codex is bound in thick leather and the page edges are gilt; quires are marked with a Greek numeral in the bottom right margin. Each book begins with a rubricated title written in majuscule letters. Book titles are repeated regularly in the top margins of the manuscript, written across from a verso to a recto page. The

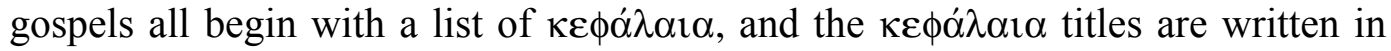
the margins in red ink; the first letter of each modern chapter number in the gospels is also rubricated. There is no Eusebian equipment or lectionary data for the gospels. Like other Family 1 manuscripts, 205 contains a critical note on the ending of the Gospel of Mark. ${ }^{132}$

\footnotetext{
${ }^{129}$ New Testament contents: Gospels (ff. 361r-396r), Acts (ff. 396v-406b), Catholic Epistles (ff. 407r-412r), Revelation (ff. 412r-417r), Pauline Epistles (ff. 417v-441v).

${ }^{130}$ Other references: von Soden $\delta 500$; Tischendorf / Scrivener $205^{\mathrm{e}}, 93^{\mathrm{a}}, 106^{\mathrm{p}}, 99^{\mathrm{r}}$.

131 There are an additional 4 unnumbered paper folios, 2 at the beginning and 2 at the end of the codex. Aland, Kurzgefasste Liste, 59, gives the number of folios as 80, which is incorrect.

${ }^{132}$ F. 377 r. This note, written in red ink, is very faded and barely visible on the microfilm.
} 


\section{Script and Dating}

Codex 205 was copied by 2 scribes: one completed the New Testament and the other the Old Testament. The former wrote in black ink and the latter in brown. At a cursory examination, both hands appear very similar: the script is tiny and filled with minute ligatures and abbreviations; letter size differs a little, but there are no dramatically inflated letters; numerous majuscule forms occur; breathings are smooth; accents and breathings are distinct from letters and other marks; nomina sacra are accented, diaeresis is used but no mute iota; superlines are regularly placed over un-contracted names of people; many late letter forms are employed; and a hyphen is used whenever a word is broken at a line ending.

There are a number of subtle differences, however, that help to distinguish the two scribes. The scribe who copied the Old Testament has longer accents; his chi and xi hang lower below the line; his gammas have a wider loop; and his flatbacked epsilons lie on their sides so that they often resemble an alpha. The scribe of the New Testament has distinctive taus that descend much lower and are often taller than those of the first scribe; his majuscule alphas have a flatter back; and he uses a distinctive rho-phi ligature. Gregory and other catalogues identify Johannes Rhosus as the scribe of 205, a professional copyist who produced Greek manuscripts in Italy for over 50 years, ${ }^{133}$ but none mention the second scribe. ${ }^{134}$ In Bessarion's inscription in the manuscript he gives his title as: 'Cardinalis

\footnotetext{
${ }^{133}$ Monfasani, Byzantine Scholars, 230.

${ }^{134}$ Monfasani, Byzantine Scholars, 167.
} 
Nicenus Episcopus Sabinensis'. This was a title he held from 1468, which indicates that the manuscript was completed sometime after $1468 .^{135}$

\section{Illuminations}

Codex 205 contains a number of brightly coloured initial letters painted in a mixture of blues, gold, purples, reds, greens and pinks. These illuminated letters are normally used for the very first letter of a book. The majority of colourful letters occur earlier on in the codex and in the Psalms. Letters beginning new sections in books are rubricated, using the same ink as used for decorative borders, book titles, and $\kappa \varepsilon \phi \alpha ́ \lambda \alpha \iota \alpha$. In the left margin on the opening page of Genesis there are seven small miniatures, painted inside medallions, depicting the seven days of creation.

\section{Correctors and Later Hands}

There is very little in the margins of 205 . The few corrections in the manuscript are usually interlinear. The only corrections made in John are by the first hand; they have all been labelled $C^{*}$ in the transcription.

\section{Provenance}

Codex 205 was copied for Cardinal Bessarion; Bessarion was particularly interested in copying majuscule manuscripts or manuscripts considered valuable

${ }^{135}$ See Labowsky, Inventories, 19-20, for this method of dating Bessarion's manuscripts. 
for the age or quality of their text. ${ }^{136}$ It is probable that in commissioning 205, Bessarion was intentionally concerned with preserving its non-standard biblical text. The cardinal had access to many valuable exemplars of various Greek texts and we know that he managed to acquire at least two manuscripts copied by the scribe of Codex 1582. ${ }^{137}$ One of these manuscripts, containing various texts of Plato, known as Codex T, was added to by the scribe Johannes Rhosus himself. ${ }^{138}$ It is of course possible that an exemplar used to copy some of Bessarion's biblical manuscripts was acquired from the same scriptorium or library as Codex T.

\section{Transcription of the Gospel of John}

John begins on f. 388v and ends on f. 396r. The whole gospel is extant and the Pericope Adulterae stands after 7:52 with no indication of textual difficulties with the passage. 205 was transcribed from the microfilm, and the manuscript itself was examined, in Venice, to check unclear text, examine corrections, and record palaeographical and codicological data. ${ }^{139}$ Unless otherwise stated codicological details come from my personal examination of the codex.

\footnotetext{
${ }^{136}$ Nelson, "Italian," 233.

${ }^{137}$ A manuscript of Aristotle's Organon: Venetus S. Marci 780 (formally 201); and a Plato: Codex Venetus Marc. Gr. IV 1 (colloc. 542). For discussion of these manuscripts see Anderson, Matthew, 33-34 and 39-41.

${ }^{138}$ See Diller, “Codex,” 322-324.

${ }^{139}$ Some rubricated text is only visible on the manuscript itself.
} 


\subsubsection{Codex 209}

\section{Content and Layout}

Codex 209 is a fourteenth-century codex containing Acts (ff. 2r-56v), the Catholic Epistles (ff. 59v-84r), the Pauline Epistles (ff. 87r-200v), the Four Gospels (ff. 206r-281v), and Revelation (ff. 282r-409r), which was added in the fifteenth century. The manuscript is kept at the Biblioteca Nazionale Marciana in Venice where it has the library reference: Gr. Z. $10 .^{140}$ There are 281 original parchment folios and 30 supplementary folios, also parchment leaves, containing Revelation. ${ }^{141}$ The original fourteenth-century pages were all written by the same scribe in black ink. These pages measure 19.3 by $12 \mathrm{~cm}$; the text is written in 1 column containing 27 lines; and the text measures 13.7 by $7 \mathrm{~cm}$. Each gospel begins on a fresh recto page, followed by a modest decorative border filling the top quarter of the page, with the gospel title below written in large majuscule letters; rubricated initial letters are used throughout and each gospel is preceded by a list of $\kappa \varepsilon \phi \alpha ́ \lambda \alpha \iota \alpha$; the Ammonian sections are given throughout.

\section{Script and Dating}

The hand of 209 is busy but legible. There are a high number of majuscule forms and letters differ quite dramatically in size, giving the hand an overall appearance

\footnotetext{
${ }^{140}$ Von Soden $\delta 457$.

${ }^{141}$ Much later two paper folios were added to the end of the codex. One contains a short note in Italian.
} 
of unevenness. Abbreviations are used regularly at line endings but, except for

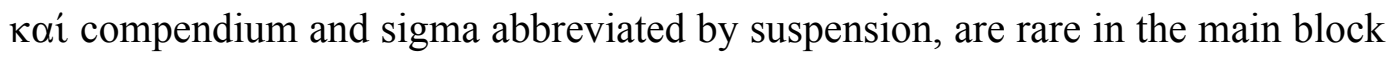
of text. The scribe does, however, frequently raise unabbreviated letters above the line to save space. Nomina sacra have accents and breathings; diaeresis is used consistently over omicron and upsilon; breathings are round; accents and breathings are always distinct; there is no mute iota; and the scribe often places a

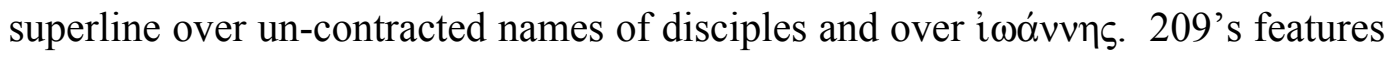
are typical of a fourteenth-century minuscule hand. ${ }^{142}$

\section{Illuminations}

Codex 209 does not contain any illuminations; however, a blank leaf was left before each gospel—perhaps leaves originally intended for evangelist portraits. ${ }^{143}$

\section{Correctors and Later Hands}

A number of hands have added to, or corrected, sections of text in 209 , though this correction is not systematic. The transcription of John distinguishes between two hands: $\mathrm{C}^{*}$, the original scribe who made his corrections in the same black ink as the text, and $\mathrm{C} 1$ who made corrections in a lighter ink with a golden tint. $\mathrm{C} 1$ is the scribe who added the Apocalypse.

\footnotetext{
${ }^{142}$ Lake disputed the fourteenth century date of 209 because he thought that 118 , a thirteenthcentury manuscript was a copy of 209 and hence 209 must also be thirteenth-century. Lake, however, acknowledged that on palaeographical grounds, 209 should be dated to the fourteenth century. Lake, Codex 1, xx-xxi.

${ }^{143}$ Ff. 204v-205v (Matthew); f. 257 (Mark); f. 290 (Luke); ff. 242v-243v (John).
} 


\section{Provenance}

Codex 209 was also owned by Cardinal Bessarion, who inscribed his name and title on f. 1v of the manuscript: 'Bessarionis Cardinalis Episcopus Tusculanus'. A note in the codex written in the same hand explains that the Latin chapter numbers were added for help in disputations with the Latins. Lake suggests that these disputations were those of the Council of Florence (1438-39), which Bessarion attended as a member of the Greek delegation. ${ }^{144}$ If Lake's theory is correct this would mean that Bessarion had the manuscript in his possession by 1438 when the Council began. As Bessarion travelled to the Council directly from Constantinople it is possible that the manuscript was acquired there. It is remarkable that the owner of Codex 1, at this time, was John of Ragusa, a legate of the Council of Basel who was sent to meet with Bessarion's Greek delegation in Constantinople. Both Bessarion and Ragusa spent time during their stay in Constantinople searching for manuscripts; and it is very possible that both men acquired their manuscripts from the same scriptorium or library. ${ }^{145}$

\section{Transcription of the Gospel of John}

The text of John begins on f. $344 \mathrm{r}$ and ends on $\mathrm{f}$. 381v. There is no lacuna in the gospel and the Pericope Adulterae stands at 7:52 with no indications of textual

\footnotetext{
${ }^{144}$ Lake, Codex 1, xxi.

145 For an engaging narrative account see Joseph Gill, The Council of Florence (Cambridge: Cambridge University Press, 1959).
} 
difficulties with the passage. 209 was transcribed from the microfilm and the manuscript itself was examined, in Venice, for codicological data, to check points of text unclear on the microfilm, and to label the correctors. Unless otherwise stated, codicological details come from my own examination of the codex.

\subsubsection{Codex 2713}

\section{Contents and Layout}

Codex 2713 is a thirteenth-century Four Gospel codex kept at the Holy Monastery of St. Stephen in Meteora, Greece. It has the library reference Meteora Stephanu 11. ${ }^{146}$ The codex contains 365 folios. It was written on paper with pages measuring 18 by $14 \mathrm{~cm}$. The text is written in 1 column measuring 14 by $9.5 \mathrm{~cm}$ with 18 lines per column. ${ }^{147}$ Ff. $3 r-11$ r contains lectionary material and the gospels begin on f. 14r. Each gospel opens with a list of $\kappa \varepsilon \phi \alpha ́ \lambda \alpha \iota \alpha$ written in semi-majuscule letters; the кєфó $\lambda \alpha \iota \alpha$ titles are repeated in the upper and lower margins in the same semi-majuscule. Matthew and Luke begin on recto pages and John and Mark on verso pages. Each gospel begins with a modest decorative border in the top margin followed by the gospel title written in large majuscule letters. The very first letter of each gospel is decorated and enlarged. Smaller initial letters are used throughout the codex. The paper used by the scribe was not

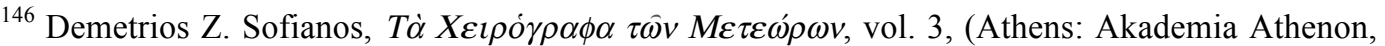
1986) was consulted for codicological information, including folio numbering which is not visible on the microfilm.

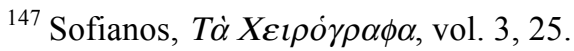


of very good quality; there are numerous points where the scribe has left large spaces, often in the middle of words, because the paper at that point was not good enough to write on. Some folios towards the end of the codex have been damaged so that an owner has cut triangular sections of paper from a number of pages and has added supplementary text on new strips. The supplementary text was written in a sprawling, untrained hand. The damage covers about 4 lines of text on each affected page. $^{148}$

\section{Script and Dating}

The text of 2713 is written in large round, neat letters. There are very few abbreviations and, with the exception of $\kappa \alpha i$ compendium, which the scribe invariably uses, ${ }^{149}$ abbreviations only occur at the ends of lines. There are many majuscule letter forms but not much variation in the size of letters. The circumflex accent stretches over 2-3 letters, a common characteristic of a thirteenth-century hand. ${ }^{150}$ Breathing marks are all round; there is no mute iota; punctuation is regular; nomina sacra have accents and breathings; breathings and accents are always distinct from letters; and superlines are used over all un-contracted names.

\footnotetext{
${ }^{148}$ F. 356r to f. 362r of John have been affected.

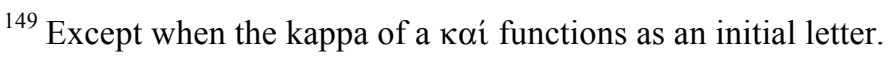

${ }^{150}$ Barbour, Literary Hands, xxviii.
} 
Illuminations

There are no illuminations in 2713 .

\section{Correctors and Later Hands}

There are only a small number of corrections in 2713 . Two correctors have been distinguished in the transcription: $\mathrm{C}^{*}$, the hand of the original scribe, who made about 8 corrections in John; and C1, a fifteenth-century untrained hand, the same person who supplemented the triangular lacunas at the end of the codex. A few small corrections, mostly erasures, are undistinguished and have been labelled C.

\section{Provenance}

Very little is known of 2713's origins or previous owners.

\section{Transcription of the Gospel of John}

John begins on f. $288 \mathrm{v}$ and ends on f. 362 r. Verses throughout chapters 20 and 21 have been affected by the small lacunas mentioned above. The Pericope Adulterae comes after John 7:52 without comment. 2713 was transcribed from the negative microfilm kept at the Institut für neutestamentliche Textforschung in Münster. Because of time limitations in accessing the microfilm, 2713 is the only 
manuscript that has been transcribed only once. However, a hardcopy of the transcription was checked by eye and corrected against the microfilm. ${ }^{151}$

\subsection{Textual Analysis}

\subsubsection{Previous Research}

Codex 118 and Codex 209 have been considered members of Family 1 since Kirsopp Lake's seminal work on the group. Lake collated both manuscripts for his Family 1 edition and both manuscripts were included in his family stemma. On the basis of his collation of the Four Gospels, Lake concluded that 118 and 209 either share an exemplar, X, or that 118 is a copy of 209 . On the basis of palaeographical evidence - that the script of 118 is dated a century earlier than that of 209-Lake accepted the former conclusion. He then argued that manuscript $\mathrm{X}$ descends from two manuscripts: $\mathrm{Y}$ and $\mathrm{Z}, \mathrm{Z}$ being a Majority Text manuscript, used to fill in mutilated sections of $\mathrm{Y}$, and $\mathrm{Y}$, a copy of manuscript $\mathrm{W}$, the exemplar of Codex 1. ${ }^{152}$ Lake's stemma is reproduced below.

\footnotetext{
${ }^{151}$ It is much quicker to check the accuracy of a transcription in this way than to make two electronic transcriptions and collate them to find discrepancies. However, the latter produces a higher standard of accuracy.

${ }^{152}$ Lake, Codex 1, xxiii-xxxiv.
} 
Cent. XII

Cent. xIII

Cent. IIV

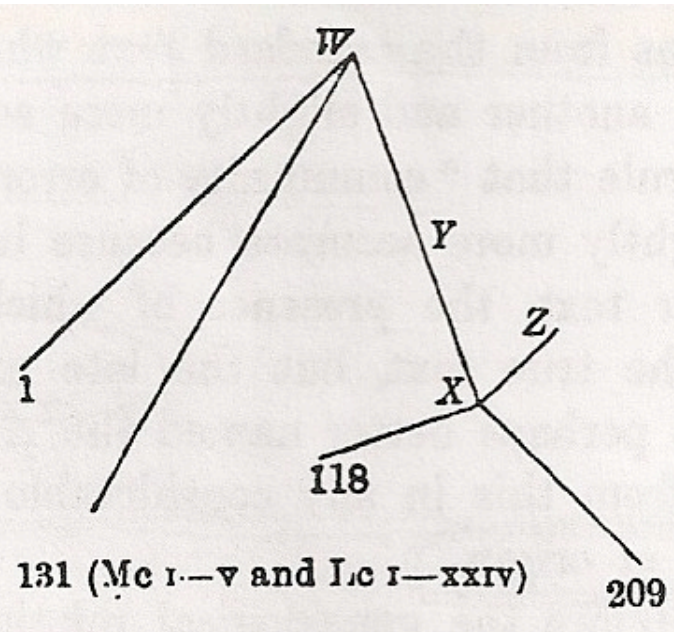

Lake was aware of the existence of 205 but after only brief consideration discarded the manuscript as a direct copy of 209 , and so did not collate it for his edition or investigate its text. ${ }^{153}$ Lake does not mention 205abs.

Amy Anderson in her study of the text of Matthew examined 118, 205 and 209. ${ }^{154}$ Her results confirmed Lake's basic conclusions: that the three manuscripts form a family subgroup that descends from a mutilated manuscript (Anderson calls X-1), which in turn descends from an ancestor shared with Codex 1 (Anderson calls X). ${ }^{155}$ Anderson's chapter collations and family readings collation, however, did not provide sufficient textual evidence to determine whether 205 and 118 are independent descendants of X-1 or whether they are

\footnotetext{
${ }^{153}$ Lake writes of 205: 'I was convinced when I studied the question at Venice that 205 was a copy of 209. An hour's work only revealed two or three differences between the manuscripts, and those clearly accidental. It is for this reason that no further notice has been taken of 205'. Lake, Codex 1, xxi-xxii.

${ }^{154}$ Anderson, Matthew, 110-119.

${ }^{155}$ See Anderson's Family 1 stemma: Anderson, Matthew, 101.
} 
copies of 209. ${ }^{156}$ Anderson did not collate 205abs, discarding the manuscript as 'evidently a copy of 205 '. 157

Frederick Wisse examined Codices 118, 205, and 209 for his profiling in Luke, grouping them together in his 'Group 1', and noting that 118 was a 'core member' ${ }^{\text {,58 }}$ and that 205 and 209 are 'a pair'. Wisse disagreed with Lake, asserting that 205 was not a copy of 209 , though he did not offer evidence for this conclusion. ${ }^{159}$ Wisse did not collate 205abs, again discarding it as a copy of $205 .^{160}$

The Text und Textwert volumes for John confirm the closeness between 118, 205 and 209 (205abs was not collated). In the Gruppierung list for each manuscript, the remaining two manuscripts are listed as the closest manuscripts with overall agreements ranging between $93 \%$ and $97 \%$, and Non-Majority Text agreement between $90 \%$ and $94 \% .{ }^{161}$ Text und Textwert also brought to attention a further manuscript, not examined by Lake or Anderson, as a possible relation of 118, 205 and 209 in John: Codex 2713. 2713 is listed after 209 and 205 in 118's Gruppierung list with an overall agreement of $90 \%$ and a Non-Majority Text

\footnotetext{
${ }^{156}$ Anderson does suggest that in light of the earlier dating of 118, 'the better solution' is that 118 and 209 share an exemplar. Anderson, Matthew, 117.

157 Anderson, Matthew, 115.

${ }^{158}$ Wisse, Frederick, The Profile Methods for the Classification and Evaluation of Manuscript Evidence, as applied to the Continuous Greek Text of the Gospel of Luke, (Grand Rapids: Eerdmans, 1982), 55.

${ }^{159}$ Wisse, Profile Methods, 57 and 106.

${ }^{160}$ Wisse, Profile Methods, 106.

${ }^{161}$ Aland, Text und Textwert Johannesevangelium, vol. 1.1, 57 and 59.
} 
agreement of $93 \%,{ }^{162}$ and is listed after 205 and 118 in 209's Gruppierung list with an overall agreement of $90 \%$ and a Non-Majority Text agreement of $96 \%$. Codex 118 is listed (the only manuscript) in the Gruppierung list of 2713, with an overall agreement of $90 \%$ and a Non-Majority Text agreement of $93 \%{ }^{163}$ In view of this information, 2713 was collated in full for this study along with the already established members of the group: 118, 205 and $209 .{ }^{164}$

Josef Schmid has studied 205abs, 205 and 209 in their texts of Revelation. ${ }^{165}$ On the basis of a number of significant readings in 205 that do not occur in 205abs, he concluded that 205abs was not a copy of 205 but a sibling manuscript. In light of Schmid's results and the fact that no definitive evidence has been published to support the claim that 205abs is a copy of $205,205 \mathrm{abs}$ was also collated in full for this study. Schmid also concluded that in Revelation (though the text in 209 was added a century after the rest of the manuscript was copied) neither 205 or $205 \mathrm{abs}$ are copies of 209 but descend from a shared ancestor, 205 and 205 sharing a further intermediate ancestor. Schmid's stemma for Revelation, which includes 205abs, 205 and 209, is reproduced below. ${ }^{166}$

\footnotetext{
${ }^{162}$ Aland, Text und Textwert Johannesevangelium, vol. 1.1, 57.

${ }^{163}$ Aland, Text und Textwert Johannesevangelium, vol. 1.1, 89.

${ }^{164}$ Note that in Luke, Wisse did not find any relationship between 2713 and the three manuscripts 118,205 and 209. In chapter 1, Wisse classified 2713 in his $\mathrm{K}^{\mathrm{X}}$ group and in chapters 10 and 20 in Group CI 2148. Wisse, Profile Methods, 90.

165 Josef Schmid, Studien zur Geschichte des griechischen Apokalypse-textes, 1. Teil. Der Apokalypse-Kommentar des Andreas von Kaisareia: Einleitung (München: Karl Zink, 1956), 285293.

${ }^{166}$ Schmid, Studien, 293. Note that 205abs is referred to as $205^{\mathrm{A}}$.
} 
Figure 3: Schmid's Stemma for Revelation (205abs, 205, 209)

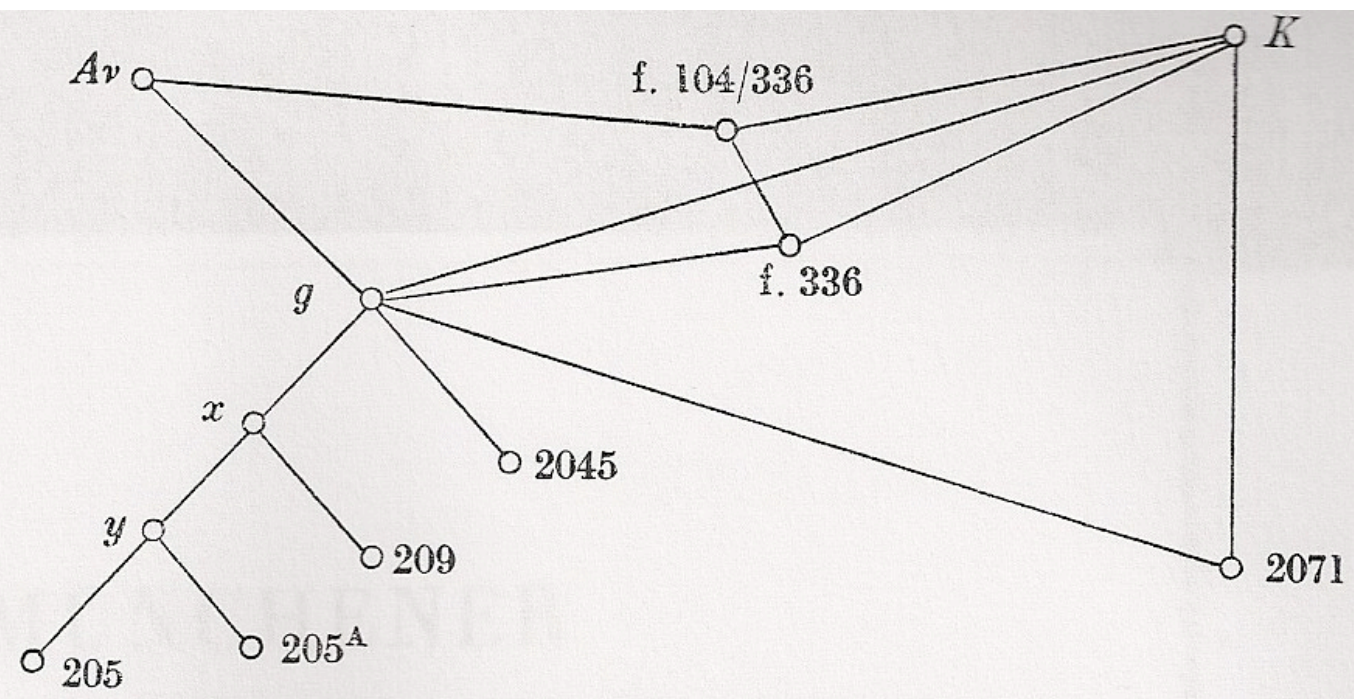

\subsubsection{Family 1 Affinity}

The results of the collation of 118, 205abs, 205, 209 and 2713, together with the core group manuscripts and other potential Family 1 manuscripts, show that in John these five manuscripts share a significant number of Non-Majority Text readings with the core group manuscripts. It was demonstrated in the previous chapter that most of the Non-Majority Text readings supported by the core group were inherited from the no-longer extant archetype A-1. The Non-Majority Text agreements between 118, 205abs, 205, 209 and 2713 and the core group, therefore, indicate that these five manuscripts also descend from A-1.

The strongest evidence for a Non-Majority Text reading having existed in A-1 is agreement on that reading between at least one descendant of Manuscript B $(565,884,2193)$ and at least one descendant of Manuscript C (1, 1582). Using 
this criterion for an A-1 reading, table 3 records the number of A-1 readings retained by $118,205 \mathrm{abs}, 205,209$ and 2713 in John. ${ }^{167}$ The readings have been counted chapter by chapter so that textual shifts and block mixture can be detected. The first number given in each cell is the total number of A-1 readings in a chapter in that manuscript; and the second number is the total number of NonMajority Text readings, whether A-1 or not. For example, in chapter 1, Codex 118 has 10 A-1 readings and an overall 13 Non-Majority Text readings.

Note that 118 is missing text from 16:25 on, and the remaining gospel text has been supplied by a supplementary hand. Codex 118 and $118^{\text {sup }}$ have been treated separately. A very late hand added supplementary text to 2713 , but the text of $2713^{\text {sup }}$ does not contain any Non-Majority Text agreements with core group members and has, therefore, been ignored.

\footnotetext{
${ }^{167}$ All corrections in 2193 and first hand corrections in the other core group manuscripts have been counted.
} 
Table 3: A-1 Readings in the Venice Manuscripts

\begin{tabular}{|c|c|c|c|c|c|c|}
\hline Chapter & 118 & 118sup & 205abs & 205 & 209 & 2713 \\
\hline 1 & $10 / 13$ & & $15 / 18$ & $15 / 19$ & $15 / 19$ & $5 / 7$ \\
\hline 2 & $8 / 8$ & & $8 / 10$ & $8 / 9$ & $8 / 9$ & $6 / 9$ \\
\hline 3 & $10 / 15$ & & $13 / 17$ & $12 / 17$ & $13 / 17$ & $11 / 14$ \\
\hline 4 & $18 / 20$ & & $23 / 29$ & $23 / 28$ & $23 / 28$ & $18 / 23$ \\
\hline 5 & $11 / 14$ & & $13 / 19$ & $12 / 19$ & $13 / 15$ & $10 / 16$ \\
\hline 6 & $38 / 46$ & & $43 / 54$ & $42 / 54$ & $42 / 50$ & $39 / 56$ \\
\hline 7 & $26 / 33$ & & $27 / 37$ & $26 / 37$ & $25 / 33$ & $19 / 27$ \\
\hline 8 & $10 / 28$ & & $9 / 22$ & $7 / 23$ & $10 / 23$ & $9 / 21$ \\
\hline 9 & $23 / 28$ & & $23 / 28$ & $23 / 28$ & $23 / 28$ & $19 / 31$ \\
\hline 10 & $14 / 22$ & & $15 / 24$ & $15 / 27$ & $15 / 23$ & $14 / 25$ \\
\hline 11 & $20 / 28$ & & $21 / 31$ & $21 / 31$ & $21 / 29$ & $20 / 29$ \\
\hline 12 & $20 / 25$ & & $21 / 28$ & $21 / 29$ & $21 / 26$ & $18 / 24$ \\
\hline 13 & $10 / 17$ & & $10 / 18$ & $10 / 20$ & $10 / 18$ & $9 / 20$ \\
\hline 14 & $1 / 9$ & & $1 / 11$ & $1 / 12$ & $1 / 9$ & $0 / 12$ \\
\hline 15 & $0 / 4$ & & $0 / 5$ & $0 / 6$ & $0 / 6$ & $0 / 4$ \\
\hline 16 & $0 / 9$ & & $0 / 11$ & $0 / 13$ & $0 / 11$ & $0 / 11$ \\
\hline 17 & & $1 / 10$ & $1 / 13$ & $1 / 12$ & $1 / 8$ & $1 / 6$ \\
\hline 18 & & $2 / 10$ & $24 / 31$ & $23 / 31$ & $24 / 30$ & $19 / 28$ \\
\hline 19 & & $2 / 8$ & $20 / 30$ & $20 / 28$ & $20 / 30$ & $18 / 26$ \\
\hline 20 & & $0 / 1$ & $7 / 15$ & $6 / 17$ & $17 / 16$ & $1 / 3$ \\
\hline 21 & & $0 / 3$ & $6 / 17$ & $5 / 20$ & $5 / 16$ & $0 / 4$ \\
\hline Total & 219/319 & $5 / 32$ & $300 / 468$ & $291 / 480$ & $307 / 444$ & $236 / 396$ \\
\hline
\end{tabular}


Table 3 shows that for chapters 1-7, 9-12 and 18-19 all manuscripts (where extant) contain a high number of A-1 readings, and that a high proportion of their overall Non-Majority Text readings are A-1 readings. For chapters 8, 13 and 2021 each manuscript has fewer A-1 readings and a lower ratio of A-1 readings to overall Non-Majority Text readings, but still a significant number of readings to indicate a genetic relationship with the core group and A-1 in these sections. After the drop in A-1 readings in chapter 13, there are virtually no A-1 readings in any of the five manuscripts for chapters 14-17. Table 3 , therefore, reveals that 118, 205abs, 205, 209 and 2713 have a strong textual link with members of the core group, and therefore A-1, but that they also contain large sections where they lose this affinity.

In addition to the readings counted in table 3, each manuscript also contains a number of other Non-Majority Text readings that are likely to have originated in A-1, but not as certainly as those counted as A-1 readings in the table. These are readings that have the support of either a descendant/s of Manuscript B or a descendant/s of Manuscript C, but not a descendant of both. Codex 118 has 32 of these readings; $118^{\text {sup }}$ has 4; Codex 205abs has 47, Codex 205 has 46; Codex 209 has 51; and Codex 2713 has 34.

\subsubsection{Codices 118, 205abs, 205, 209 and 2713 Form a Distinct Subgroup}

Lake and Anderson agree that 118 and 209 form a distinct Family 1 subgroup. The collation of John supports their conclusions and adds Codex 2713 to this subgroup. There are three main pieces of evidence to support this: firstly, all five 
manuscripts share the same pool of Non-Majority Text readings inherited from A1; secondly, they are bound by a selection of distinctive and rare readings that are exclusive to the group; and, thirdly, as Lake and Anderson showed for 118, 205 and 209, they share the same shifts in textual affinity, clearly visible in table 3 . It is reasonable to conclude from this evidence that these five manuscripts descend from a shared intermediate ancestor, not shared by any other manuscripts so-far collated, from which they inherited their A-1 reading, their exclusive readings and their shared shifts in textual affinity.

\subsubsection{Shared A-1 Readings}

The vast majority of A-1 readings found in any one of the five manuscripts are supported by most other manuscripts in the group; that is to say, the manuscripts share a very clearly defined pool of A-1 readings, and this reduced pool is unique to the subgroup. Before the lacuna in Codex $118(16: 25)$, there are a total of 250 A-1 readings supported by one or more of the five manuscripts. Of these readings 178 are supported by all five manuscripts; 53 readings are supported by four; 12 readings are supported by three; 2 readings are supported by two; and 5 readings are supported by only one manuscript. Where a manuscript does not support an A1 reading found in the other manuscripts, it almost always has a Majority Text reading; that is to say, the disagreement is probably the result of Majority Text correction. 
After $16: 25$, ignoring $118^{\text {sup }}$, there are a total of 59 A-1 readings supported by one or more of the four extant manuscripts. 34 of these readings are supported by all four manuscripts; 21 are supported by three; 2 are supported by only two manuscripts; and 2 readings are supported by only one manuscript. ${ }^{168}$

\subsubsection{Exclusive Readings}

The group is further defined by the existence of a significant number of NonMajority Text readings exclusive to the group or to most of the manuscripts in the group. Many of these readings differ quite significantly from the readings of the core group, the Majority Text and also from readings found in the wider textual tradition of the gospel. These exclusive readings could not have all arisen independently in the five manuscripts, but offer further evidence of a shared intermediate ancestor, where these readings originated, ${ }^{169}$ or were passed onto from a different source. Before the lacuna in 118, all five manuscripts share 26 exclusive Non-Majority Text readings. 15 of these are distinctive, 10 rare, and 1 widely attested. The 26 readings are listed below.

\section{4:49 $\quad \pi \rho i v \quad 122131565872884119212101278158221932372 \quad \mathfrak{M}] \quad \eta$ add 118 205abs $2052092713 \mathrm{R}$}

\footnotetext{
${ }^{168}$ Note that the small sections of missing text in chapters 20 and 21 in Codex 2713 may have impacted the count slightly, so that there are more readings supported by only three manuscripts, instead of by four in these chapters.

${ }^{169}$ See for example 7:32, 10:9, 14:9 and 15:7.
} 


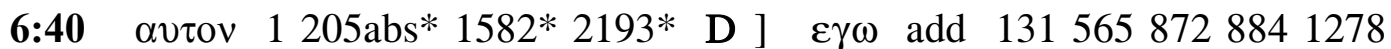
$\left.1582^{\mathrm{C} 1} 2372 \mathbf{M}^{\mathrm{pt}}\right] \varepsilon \gamma \omega \varepsilon v$ add $\left.22119212102193^{\mathrm{C}} \mathbf{M}^{\mathrm{pt}}\right] \varepsilon v$ add 118 $205 \mathrm{abs}^{\mathrm{C*}} 2052092713 \mathrm{D}$

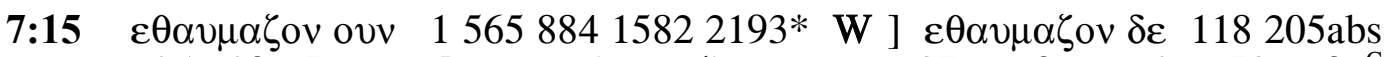
2052092713 D ] $\quad \kappa \alpha \varepsilon \varepsilon \theta \alpha \mu \alpha \zeta o v 221318721192121012782193^{\mathrm{C}}$ $2372 \mathfrak{M}$

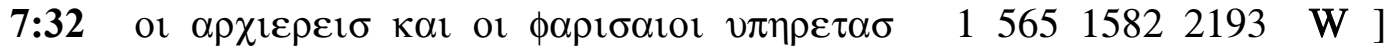

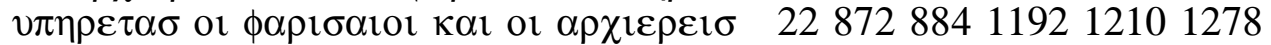

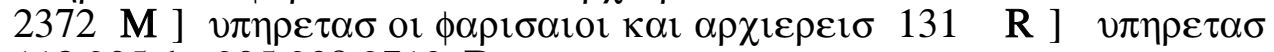
118 205abs 2052092713

8:27 [ante] ovא 122131565872884119212101278158221932372 న ] Kol add 118 205abs 2052092713 R

8:35 o $\left.12213156587211921210127815822193^{\mathrm{C}} 2372 \mathfrak{M}\right] \quad \delta \varepsilon$ add 118 205abs 2052092713 R

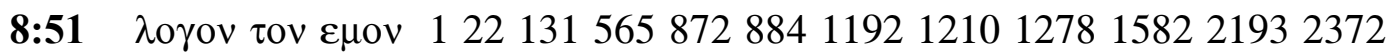

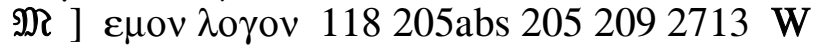

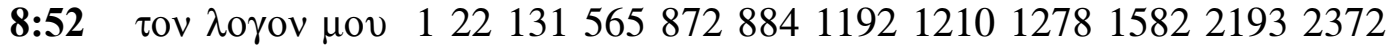

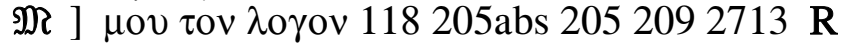

8:59 $\delta 1 \alpha \quad 122131565872884119212101278158221932372 \mathfrak{M}] \quad \varepsilon \kappa$ 118 205abs 2052092713 D

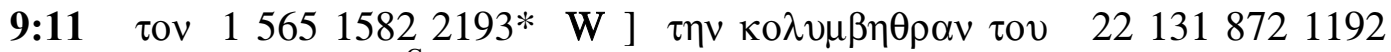
$121012782193^{\mathrm{C}} 2372 \mathfrak{M}$ ] ov 118 205abs 2052092713 D ] omit $884 \mathrm{R}$

10:9 $\theta v \rho \alpha 122131565872884119212101278158221932372$ M ] $\tau \omega v$ $\pi \rho o \beta \alpha \tau \omega \nu$ add 118 205abs 2052092713 D

Note: one lectionary adds $\tau \omega \pi \rho \circ \beta \alpha \tau \omega v$.

11:33 $\varepsilon \tau \alpha \rho \alpha \chi \theta \eta \tau \omega \pi v \varepsilon v \mu \alpha \tau \imath \omega \sigma \varepsilon \mu \beta \rho \mu \omega \mu \varepsilon v o \sigma \quad 12212101582^{\text {txt }} 2193$ R ]

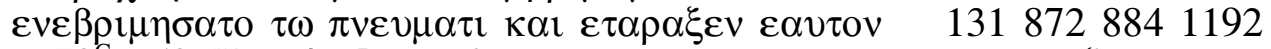

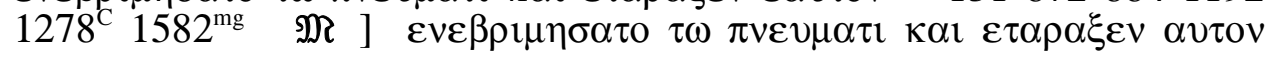


$\begin{array}{lllllllllll}118 & 205 a b s & 205 & 209 & 2713 & \text { R }] \quad \varepsilon \tau \alpha \rho \alpha \chi \theta \eta & \tau \omega & \pi v \varepsilon v \mu \alpha \tau \imath & \kappa \alpha \iota\end{array}$ $\varepsilon \mu \beta \rho \mu \omega \mu \varepsilon v о \sigma 2372$ D ] $\varepsilon[31] 1278^{*}$

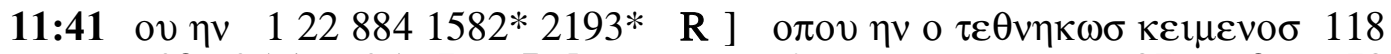

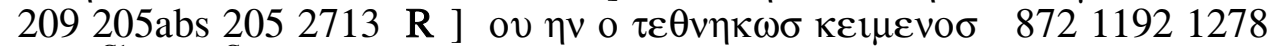
$1582^{\mathrm{Cl}} 2193^{\mathrm{C}} 2372 \mathfrak{M}$ ] ov $\eta$ o $\tau \varepsilon \theta v \eta \kappa \omega \sigma \kappa \alpha l \kappa \varepsilon \mu \varepsilon v o \sigma \quad 131$ D ] ov

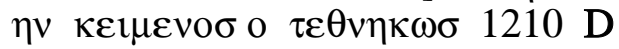

11:45 אal 122131872884119212101278158221932372 M ] omit 118 205abs 2052092713

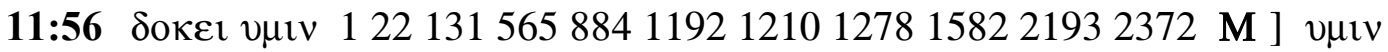

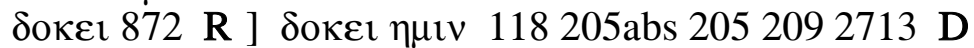

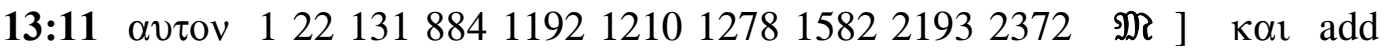
118 205abs 2052092713 D

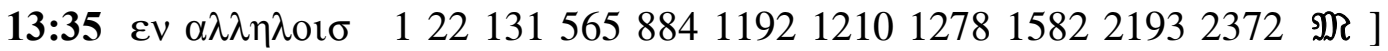
$\mu \varepsilon \tau \alpha \lambda \lambda \eta \lambda \omega \nu 118$ 205abs $2052092713 \mathbf{R}$

13:38 $\alpha v \tau \omega$ o 12213156588411921210127815822372 M ] o 118 205abs 2052092713 R ] omit 2193 W

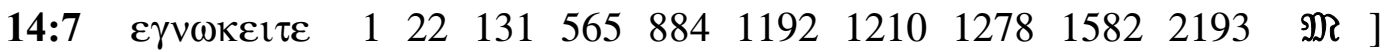
$\varepsilon \gamma \nu \omega \kappa[\alpha] \tau \varepsilon 2372^{\text {pcorr }} \quad R$ ] $\varepsilon \gamma \nu \omega \kappa \eta \tau \varepsilon 118$ 205abs 2052092713 D

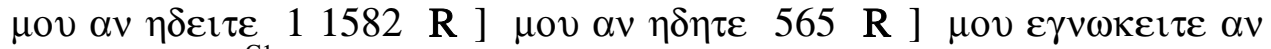
$1318841278^{\mathrm{C} 1} 2193$ M ] $\mu \mathrm{ov} \eta \delta \varepsilon 1 \tau \varepsilon \alpha \nu 22119212102372$ R ] $\mu \mathrm{ov}$ $\varepsilon \gamma \nu \omega \kappa \eta \tau \varepsilon \alpha \nu 118$ 205abs 2052092713 D ] $\mu[6] \tau \varepsilon \alpha \nu 1278 *$

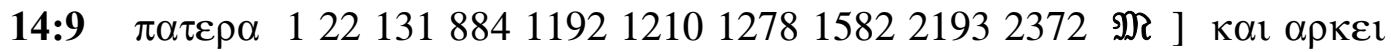
$\eta \mu \mathrm{\nu} v$ add 118205 205abs $2092713 \mathrm{D}$

Note 205abs: omits $\pi \alpha \tau \varepsilon \rho \alpha$.

14:29 $\pi \rho i v \quad 1131565884119212101278158221932372$ M ] $\eta$ add 118 205abs 2052092713 D

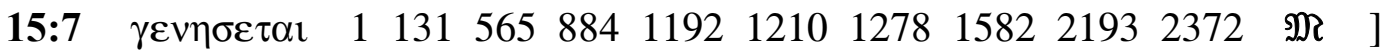

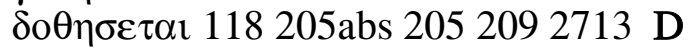




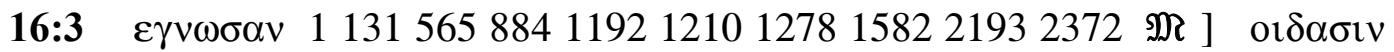
118 205abs 2052092713 R

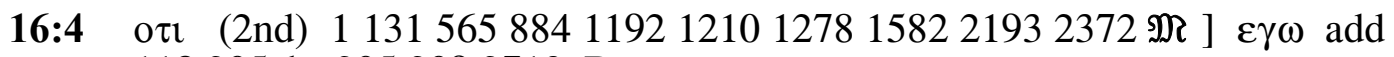
118 205abs 2052092713

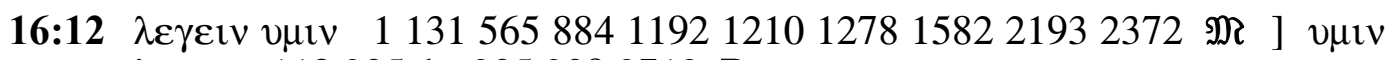
$\lambda \varepsilon \gamma \varepsilon i v 118$ 205abs $2052092713 \mathbf{R}$

In addition to these readings, there are a number of further exclusive readings supported by only some of the five manuscripts, usually while the other manuscript or manuscripts have a Majority Text reading. Before 16:25, Codices 118, 205abs, 205 and 209 share 14 exclusive readings, 2 of which are distinctive, 11 rare and 1 widely attested ${ }^{170}$ 205abs, 205, 209 and 2713 share 9 exclusive readings, 2 of which are distinctive, 6 rare and 1 widely attested; ${ }^{171}$ 205abs, 205 and 209 share 14 exclusive readings, 9 of which are distinctive and 5 rare. ${ }^{172}$

In two further sets of readings, a number of the five manuscripts either contain a long omission or show evidence of descending from an ancestor which contained the same omission. In 7:42 Codex 2713 omits a string of text from $\kappa \alpha \iota$ to $\delta \alpha v i \delta$ :

\footnotetext{
${ }^{170} 1: 27,7: 30,7: 31,9: 22,10: 17,10: 22,10: 42,11: 15,14: 10,14: 13,14: 26,15: 6,15: 20,16: 23$.

${ }^{171} 4: 21,6: 58,8: 19,13: 10,17: 4,17: 7,17: 11,19: 1,19: 28$.

${ }^{172} 6: 32,6: 57,11: 22,15: 6,15: 7,16: 29,17: 12,20: 1,20: 2,20: 5,20: 15,20: 27,21: 21,21: 25$.
} 


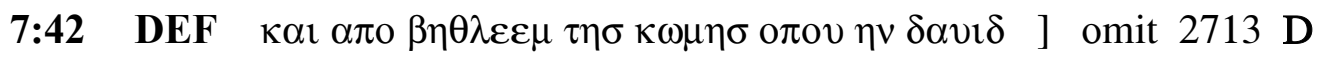

Kal 122131205 abs 20520956587288411921210127815822193 $2372 \mathfrak{M}$ ] omit $118^{\mathrm{C}} \mathrm{D}$ ] [2] $118^{*}$

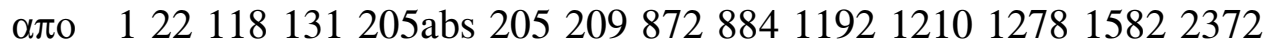
M ] $\varepsilon \kappa 5652193$ D

$\beta \eta \theta \lambda \varepsilon \varepsilon \mu \quad 122118131$ 205abs 2052098728841192121012781582 $21932372 \mathfrak{M}] \beta 1 \theta \lambda \varepsilon \varepsilon \mu 565 \mathrm{R}$

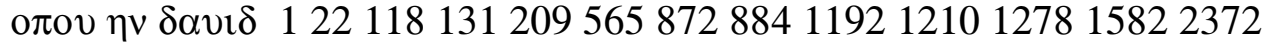

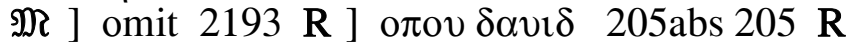

At the same point in the text the first hand of 118 did not begin writing $\kappa \alpha$, but something else, which has been erased and is now unreadable. This is evidence that the exemplar of 118 also omitted the text from $\kappa \alpha$ to $\delta \alpha v i \delta$, and that the scribe of 118 had begun to duplicate this omission, beginning to write the text immediately following $\delta \alpha v i \delta$, but then noticed the omission as an error, and filled in the missing text. That 205abs and 205 have a rare variation for part of the

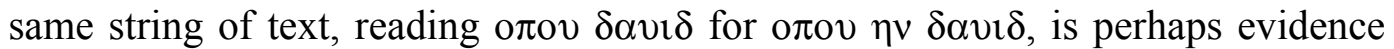
that they also descend from a manuscript that omitted the same string but which was corrected, creating the new reading. Codex 209 includes the string of text. It is possible that 209 also descended from an exemplar with the omission, but the scribe noticed the omission immediately and filled in the missing text. Alternatively, another scribe (perhaps the scribe of 118?) could have corrected the exemplar; a correction which 209, the later of the two manuscripts, then followed. In 8:24 the first hand of 209 omits the text from and including $\varepsilon \alpha v$ to $v \mu \omega v$ : 


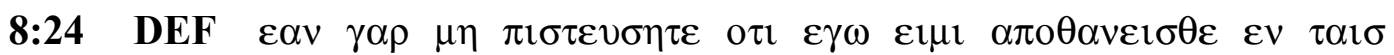
$\alpha \mu \alpha \rho \tau \iota \alpha \iota \sigma v \mu \omega v$ ] omit $872209 * \mathbf{R}$

$\varepsilon \alpha v \gamma \alpha \rho \mu \eta \quad 122118^{\mathrm{C}^{*}} 131$ 205abs $205209^{\mathrm{C}^{*}} 565884119212101278$ $1582219323722713^{\text {note }} \mathfrak{M}$ ] $\varepsilon \lambda \varepsilon \gamma o v$ ovv $\alpha v \tau \omega 118^{*} \mathrm{D}$

Note 2713: letters $\varepsilon \alpha \nu \gamma$ smudged.

Note 118: 8:25 begins $\varepsilon \lambda \varepsilon \gamma o v$ ovv $\alpha v \tau \omega$.

The exemplar of 118 also clearly contained this omission as the scribe first begins to duplicate the omission, copying the text $\varepsilon \lambda \varepsilon \gamma o v$ ovv $\alpha v \tau \omega$ which immediately follows $v \mu \omega v$; but then, noticing the omission, erases $\varepsilon \lambda \varepsilon \gamma o v$ ovv $\alpha v \tau \omega$ to first fill in the missing text. The first four letters of this same string of text are smudged in 2713. This smudging is possibly the result of erased text and provides evidence that 2713's exemplar also contained the omission, and like the scribe of 118 , at first began to duplicate the omission but then corrected it. These two omissions, or the signs of omission in a manuscript's exemplar, provide further evidence of an intermediate exemplar shared by 118, 205abs, 205, 209 and 2713.

\subsubsection{Shared Shifts in Textual Affinity}

As Lake demonstrated for 118 and 209, Codices 118, 205abs, 205, 209 and 2713 are further defined as a group by shared swings in textual affinity, the manuscripts alternating between closeness to the core group and closeness to the Majority Text. ${ }^{173}$ Lake showed that these swings occur in sections of Matthew, Luke and

\footnotetext{
${ }^{173}$ Note that for Lake the core group was represented only by Codex 1.
} 
John. In John, Lake identified four sections where 209 and 118 lose their textual affinity and follow the Majority Text: 8:28-8:43, 10:4-10:18, 11:33-11:48 and 13:34-18:3. ${ }^{174}$ Lake also noted that after chapter 20, although 118 and 209 have a number of Non-Majority Text agreements with Codex 1, they have a higher percentage of Majority Text readings than in the other places where they are close to $1 .{ }^{175}$ The collation of John for this thesis supports Lake's findings and confirms that 205abs, 205 and 2713 share these same textual swings.

The decline in the number of A-1 readings found in 118, 205abs, 205, 209 and 2713 is clearly visible in the figures in table 3, especially for the longest section John 13:34-18:3. In chapter 14, Codices 118, 205abs, 205 and 209 contain only 1 out of a possible 19 A-1 readings, and Codex 2713 contains 0 (zero); in chapters 15 and 16, where there is a total of 22 possible A-1 readings, 118, 205abs, 205, 209 and 2713 contain 0 (zero); and in chapter 17 (where 118 is missing text) there are 11 possible A-1 readings, and 205abs, 205, 209 and 2713 support only 1 of them. The numbers of A-1 readings for chapters 8, 11, 20 and 21 are also significantly below average in all five manuscripts, though as the sections do not equate to exact chapters, the drops in Non-Majority Text agreements with the core group manuscripts are not as evident in the table as in chapters 14, 15, 16 and 17 where the section incorporates whole chapters. The precise contours of Lake's sections can be more fully explored in the full family collation.

\footnotetext{
${ }^{174}$ Lake, Codex 1, xxviii.

${ }^{175}$ Lake, Codex 1, xxix.
} 
In chapter 8, although each manuscript in the group contains between 7 and 10 A-1 readings, none of these A-1 readings are found in the section 8:28-8:43. ${ }^{176}$ The last A-1 reading supported by the group before this section is found in 8:26:

\section{8:26 $\lambda \alpha \lambda \omega \quad 122118$ 205abs $205209565119212101278 * 158221932372$ $2713 \mathrm{~W}] \lambda \varepsilon \gamma \omega 1318728841278^{\mathrm{Cl}} \mathbf{M}$}

The first A-1 reading after the section is found in 8:46:

8:46 $\quad \varepsilon l \quad 1118$ 205abs $2052095658841582 * 2193 * 2713 \quad \mathrm{~W}] \delta \varepsilon$ add 22 $\left.1311192121012782193^{\mathrm{C}} 2372 \mathbf{M}\right] \delta \varepsilon \tau \eta \nu$ add $8721582^{\mathrm{C} 1} \mathrm{D}$

It is very likely that a rare agreement exists between 118, 2713 and the core group manuscript 884 in 8:44:

\section{8:44 $\pi \alpha \tau \rho o \sigma \quad(1 \mathrm{st}) \quad 122 \quad 131$ 205abs $205209565872884^{\mathrm{C}} 119212101278$ $158221932372 \mathfrak{M}$ ] $v \mu \omega v$ add 1182713 R ] [4] add 884*}

The first hand reading of 884 has been erased and is now illegible; however, there is space for four letters where $v \mu \omega v$ would fit and make clear sense, following after $\pi \alpha \tau \rho o \sigma$, but more significantly, another commentary manuscript, which 884 has a clear and close textual relationship with in John, K994, does read $\pi \alpha \tau \rho \circ \sigma$ $v \mu \omega v$, providing strong evidence that $884^{*}$ also did. 8:44 may, therefore, be the point where the intermediate ancestor of the group rejoins the family text. ${ }^{177}$

\footnotetext{
${ }^{176}$ In 8:28-8:43 the core group contain 9 A-1 readings. This would be the total possible number of A-1 readings that any of the five manuscripts could contain.

177 The relationship between Codex 884 and K994 has not been examined in detail for this thesis; however, when consulting the IGNTP Byzantine edition (to label Non-Majority Text readings), it became obvious that 884 and K994 were very closely related in John. They share an extremely
} 
In chapter 10, the five manuscripts contain between 14 and 15 A-1 readings and only 2 of these readings occur in the section 10:4-10:18. ${ }^{178}$ The final A-1 reading before the section begins is found in 10:3:

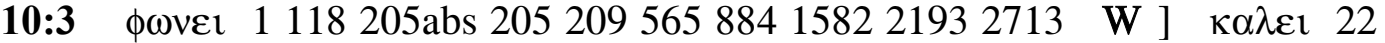
$1318721192121012782372 \mathfrak{M}$

The first A-1 reading following the section is in 10:19:

10:19 $\varepsilon \gamma \varepsilon v \varepsilon \tau o \pi \alpha \lambda \iota v \quad 1118$ 205abs $205209565884158221932713 \quad$ R ] $\pi \alpha \lambda \iota v \varepsilon \gamma \varepsilon v \varepsilon \tau 0 \quad 221318721192121012782372 \mathfrak{M}$

In chapter 11, the five manuscripts support between 20 and 21 A-1 readings and only 1 of these A-1 readings is found in the section 11:33-11:48. ${ }^{179}$ The final A-1 reading supported by the group before the section is found in 11:32:

11:32 $\pi \rho \circ \sigma \quad 1118$ 205abs 205209884158221932713 R ] $\varepsilon 1 \sigma \quad 22131872$ 1192121012782372 MR

The first A-1 reading supported by a member of the group after this section is at the end of verse 48:

\footnotetext{
high number of Non-Majority Text readings, often very unusual, and a significant number of exclusive readings. See Mullen, Electronic Edition.

${ }^{178}$ In 10:4-10:18 there are a total of 9 A-1 readings among the core group manuscripts.

${ }^{179}$ In 11:33-11:48 there are a total of 8 A-1 readings among the core group manuscripts.
} 


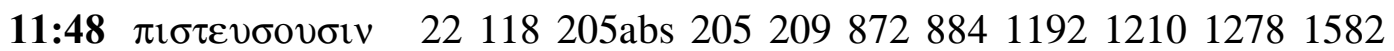
$2193^{\mathrm{C}} 2372 \mathfrak{M}$ ] $\pi \mathrm{i \sigma \tau \varepsilon v \sigma \omega \sigma \textrm {lv }} 11312193 * 2713 \mathrm{~W}$

The reading in 11:48, however, is widely attested, amounts to but a slight variation from the Majority Text and is supported by only 2713. The reading could have arisen in 2713 independently and may not represent the point where the group's intermediate ancestor rejoins the family text; instead, the family text may begin again at 11:49 where all members of the group support a rare A-1 reading:

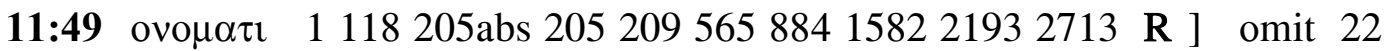
$1318721192121012782372 \mathfrak{M R}$

In chapter 13, each of the five manuscripts contains between 9 and 10 A-1 readings, and all but one of these readings occur before 13:34. The final A-1 reading supported by the group before the section begins is in 13:33:

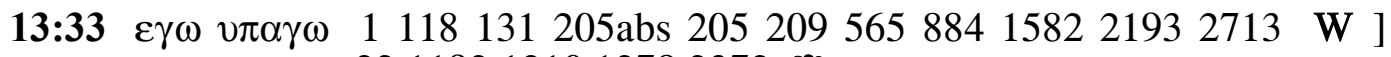

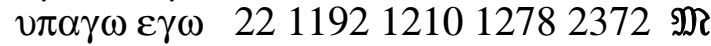

Between 13:34 and 18:3 there are only 3 A-1 readings. ${ }^{180}$ The first A-1 reading following the section is in 18:4:

18:4 $\delta \varepsilon \quad 1$ 205abs 20520956515822713 R ] ovv 22 118sup 1318841192 $1210127821932372 \mathfrak{M}$

\footnotetext{
${ }^{180}$ In section 13:34-18:3 there are a total of 53 A-1 readings found among the core group manuscripts.
} 
For the rest of chapter 18 each of the five manuscripts contains between 19 and 24 A-1 readings.

These very clearly definable textual shifts, shared by all five manuscripts, could not have arisen independently in each; rather, they offer conclusive evidence to support the existence of an intermediate ancestor, shared by all five manuscripts, in which these textual shifts originated. This intermediate ancestor will be called Manuscript E. ${ }^{181}$

\subsubsection{Explanation of the Textual Shifts in Manuscript $E$}

Lake argued that the four sections in John where Manuscript E loses its textual affinity with the family are the result of mutilation in E's usual exemplar. Lake theorised that each page in E's exemplar contained 18-19 lines, those lines containing the same amount of text as the lines in 'Lloyd's Greek Testament'. From this, Lake argued that E's exemplar was missing 'two conjugate leaves, a single inserted leaf, and a complete quaternion' that contained the text of 8:28$8: 43,10: 4-10: 18,11: 33-11: 48$ and $13: 34-18: 3 .^{182}$ Lake further argued that for these missing sections a Majority Text manuscript was used to supplement the gospel text.

\footnotetext{
${ }^{181}$ Lake did not call this shared intermediate ancestor, E; however, for clarity, from here onwards, it will be referred to as E.

${ }^{182}$ Lake, Codex 1, xxviii.
} 
Lake's conclusions are coherent; however, it should be noted that within three of the sections, where Lake suggested that a different exemplar was used, there still exists a handful of Non-Majority Text agreements between the descendants of Manuscript E and the core group manuscripts. These readings may be evidence of a continued link between $\mathrm{E}$ and its A-1-Type exemplar in these sections.

In section 10:4-10:18, E's descendants contain 2 A-1 readings and 2 NonMajority Text readings shared with single branches of the core group:

\section{A-1 Readings}

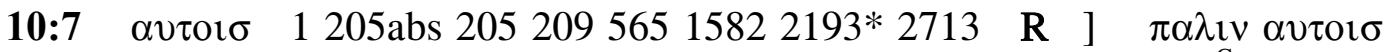
$2211813187211921210 \quad \mathbf{M}] \quad \alpha v \tau 01 \sigma \pi \alpha \lambda \imath v 88412782193^{\mathrm{C}} 2372$ R

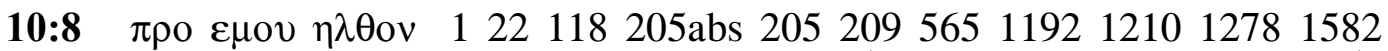
21932372 R ] $\eta \lambda \theta$ ov $\pi \rho \circ \varepsilon \mu o v 2713 \mathbf{M}^{\mathrm{pt}}$ ] $\eta \lambda \theta$ ov $131872884 \mathbf{M}^{\mathrm{pt}}$

2 Non-Majority Text Readings Supported by Single Branches of the Core Group

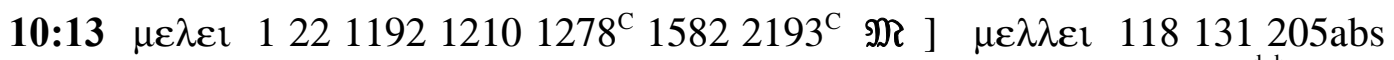
$2052095658841278 * 2193 * 23722713 \mathrm{~W}$ ] $\mu \varepsilon \lambda[\varepsilon 1]$ [3] $872 *$ dub

Note 872: the letters $\varepsilon 1$ may have been altered.

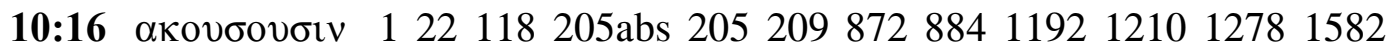

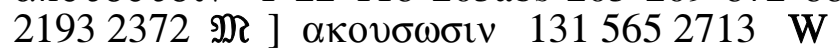

The readings in 10:13 and 10:16 amount to only very slight variations from the Majority Text readings; and both are widely attested variants, so there is a reasonable chance that they may have arisen independently in E. The readings in 10:7 and 10:8, however, constitute more significant differences from the Majority 
Text and are both rare, so there is a much smaller possibility that they could have arisen independently in Manuscript E.

In 11:33-11:48 (not including the reading of 2713 in 11:48, already discussed) the descendants of E contain 1 A-1 reading and 1 Non-Majority reading shared with 884:

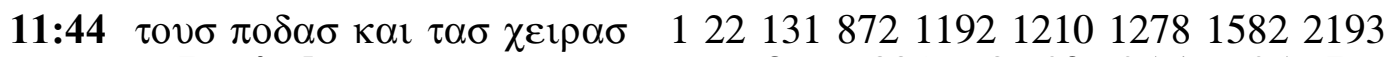

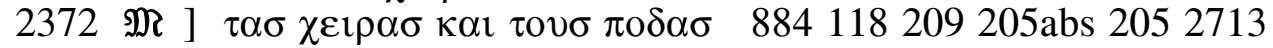
R

11:45 ovv 1118 205abs 205209884158221932713 R ] $\varepsilon \kappa$ add 22131872 $1192121012782372 \mathfrak{M}$

In the longest section, 13:34-18:3, the descendants of E support 3 A-1 readings; and 7 Non-Majority Text readings supported by one branch of the core group. ${ }^{183}$ These readings are reproduced below, beginning with the A-1 readings:

3 A-1 Readings

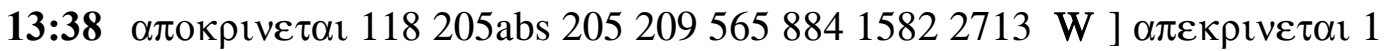
D ] $\alpha \pi \varepsilon \kappa \rho i \theta \eta \quad 2213111921210127821932372 \mathfrak{M}$

14:14 DEF！ 122118 205abs 2052095658841210 1278*1582 2372 R

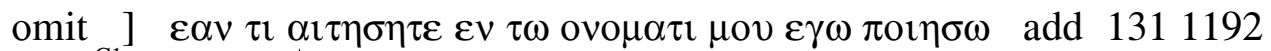

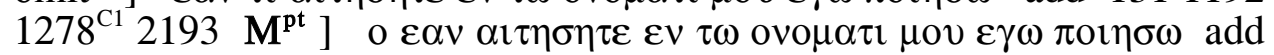
2713 R

\footnotetext{
${ }^{183}$ There are also 2 Non-Majority Text readings shared with the Decorative Style Group, which will be discussed in the next chapter. See 16:17 and 16:26, both are rare readings.
} 


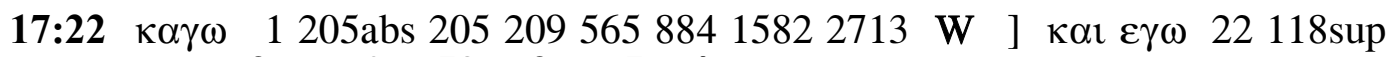
$13111921210127821932372 \mathfrak{M}$

7 Possible A-1 Readings

14:15 $\tau \alpha \sigma \varepsilon \mu \alpha \sigma 122131565884119212101278158223722713$ M ] $\mu$ ov 118 205abs 2052092193 R

16:4 $\mu \nu \eta \mu о v \varepsilon v \eta \tau \varepsilon \alpha v \tau \omega \nu 13111921210127815822372$ M ] $\mu \nu \eta \mu о v \varepsilon v \varepsilon 1 \tau \varepsilon$

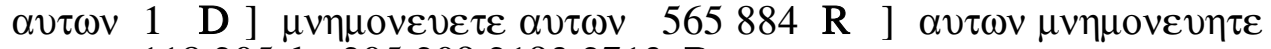
$\alpha \nu \tau \omega v 118$ 205abs $20520921932713 \mathbf{R}$

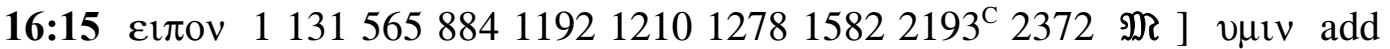
118 205abs $2052092193 * 2713$ R

16:17 $\varepsilon \gamma \omega 113188411921210127815822372$ M ] omit 118 205abs 205 20956521932713 W

17:21 $\mathrm{\kappa} \alpha \mathrm{l}$ (2nd) 1131 205abs 2052091582 R ] omit 22 118sup 565884 $119212101278219323722713 \mathfrak{M}$

17:22 $\delta \varepsilon \delta \omega \kappa \alpha \sigma 122$ 118sup 131 205abs 2052095658841192121012781582 $2372 \mathfrak{M}] \varepsilon \delta \omega \kappa \alpha \sigma 21932713$ W

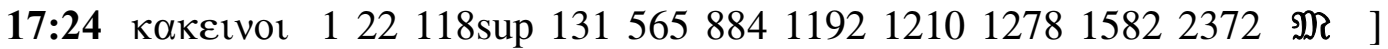

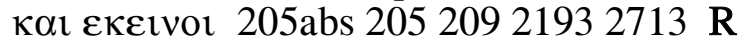

6 of these readings are rare and may indicate the continuation of the textual link between Manuscript E and its A-1-type exemplar in this section. The omission of the whole of 14:14 in E is clearly the most significant reading and very unlikely to have occurred independently in E. 
In conclusion, Lake's four sections are clearly distinct; however, the existence of a small number of A-1 readings and other Non-Majority Text readings shared with single branches or single manuscripts in the core group suggests that when the scribe of E copied these sections, his A-1-type exemplar was not discarded completely. It is likely that the mutilated and/or detached pages were still employed where text remained visible as a base for copying Manuscript E, even if much of the text was taken from another primarily Majority Text manuscript. Alternatively, Lake's sections may be the result of a change of scribe during the copying of Manuscript E, from a relatively close-copying scribe to a scribe with a greater tendency to Majority Text correction. This would certainly be a better explanation for chapters 20 and 21, where the higher percentage of Majority Text readings could be the result of the similar but slightly less thorough correction.

\subsubsection{Manuscript E Shares an Intermediate Exemplar with Codex 1}

Lake concluded that the intermediate exemplar shared by 118 and 209 descends from the same exemplar as Codex 1. This exemplar was called $\mathrm{W}$ by Lake. $\mathrm{W}$ is the archetype of the whole of Family 1 known to Lake, including Codex $131 .^{184}$ Anderson, in her study of Matthew, collated an additional nine manuscripts, examining the relationship between the intermediate ancestor of the Venice group and Codex 1, within the context of a more complex family group. ${ }^{185}$ She

\footnotetext{
${ }^{184}$ Lake, Codex 1, xxiv-xxv.

${ }^{185}$ Anderson examined thirteen manuscripts: Codices 1, 22, 118, 131, 205, 209, 872, 1192, 1210, 1278, 1582, 2193 and 2542.
} 
concluded that Manuscript $\mathrm{E}^{186}$ and Codex 1 still share an intermediate ancestor that is not shared by any other manuscripts in the larger family. The collation of John supports Anderson's conclusion, demonstrating that these relationships are the same in the Gospel of John.

The descendants of Manuscript E have a higher number of Non-Majority Text agreements with the descendants of $\mathrm{C}$ (1 and 1582) than with the descendants of B $(884,565,2193)$. However, it is difficult to draw any conclusions regarding the relationship between manuscripts $\mathrm{E}, \mathrm{C}$ and $\mathrm{B}$ from this information; this is because it is not possible to determine how much Majority Text correction in the descendants of $\mathrm{E}, \mathrm{B}$ and $\mathrm{C}$ (particularly in $\mathrm{B}$ ) has distorted the profile of NonMajority Text agreements among those descendants. Instead, indications of E's relationship to the rest of the family stemma can be found in a number of unique Non-Majority Text agreements between the descendants of E and Codex 1 . These exclusive agreements are particularly significant because of 1's normal closeness to 1582 , and the fact that 1582 and the descendants of $\mathrm{E}$ have no Non-Majority Text readings without Codex 1 . Such exclusive agreements, therefore, provide strong evidence that Manuscript $\mathrm{E}$ descends from Manuscript $\mathrm{C}$ through an intermediate manuscript shared with Codex 1.

Codex 1 and the descendants of E share a total of 7 exclusive Non-Majority Text readings, all of which are either rare or distinctive. The two most significant readings are omissions of a long string of text:

\footnotetext{
${ }^{186}$ Though Anderson does not, of course, use the label 'Manuscript E'.
} 


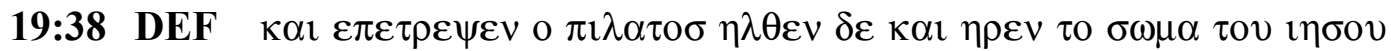
] omit $1^{\text {note }} 205$ abs $205209 R$

Note 1: omission marked by a later hand.

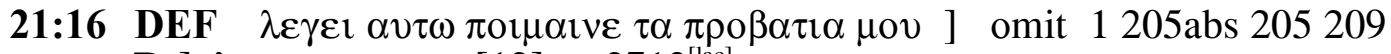
D ] $\lambda \varepsilon \gamma \varepsilon i \alpha v \tau \omega \pi \mathrm{or}[12] \tau \alpha 2713^{[\mathrm{lac}]}$

$\pi \rho \circ \beta \alpha \tau \iota \alpha 225651582 *$ R ] $\pi \rho \circ \beta \alpha \tau \alpha$ 118sup 131884119212101278 $1582^{\mathrm{C}} 21932713^{\text {[lac] }} \mathfrak{M}$

Note 2713: letters $\pi \rho \circ \beta \alpha$ supplied.

It is highly improbable that these two omissions would have occurred independently in Codex 1 and Manuscript E, so they provide evidence of the existence of a shared intermediate ancestor in which the two omissions first occurred. ${ }^{187}$ It is notable that where E and 1 have omitted text in 21:16, 1582 and 565 (and 22) share a rare Non-Majority Text reading: $\pi \rho \circ \beta \alpha \tau \iota \alpha$. This crossbranch agreement on $\pi \rho \circ \beta \alpha \tau \iota \alpha$ gives a high level of certainty that $\pi \rho \circ \beta \alpha \tau \iota \alpha$ was the reading of $\mathrm{A}-1$, and not the omission. Its presence strengthens the evidence that the omission occurred in an intermediate exemplar shared by Codex 1 and Manuscript E. Of the other 5 exclusive agreements between 1 and the descendants of $\mathrm{E}$, all but one are agreements on distinctive readings. They supply further evidence for the existence of an intermediate ancestor shared by 1 and $E:^{188}$

\footnotetext{
${ }^{187}$ The alternative solution that $\mathrm{E}$ (having the highest number of Majority Text readings) is descended from 1 itself will be discussed presently.

${ }^{188}$ Note that in $6: 33$, the scribe of 118 has probably made a correction towards the Majority Text and likewise with 2713 in 12:39.
} 
4:12 $\eta \mu \omega v \quad 221181315658728841192121012781582219323722713$ M ] $\tau$ ov add 1205 abs 205209 D

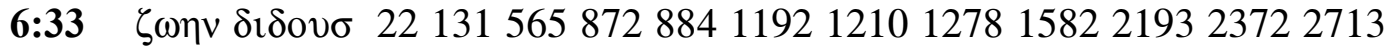

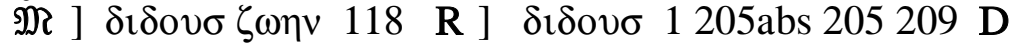

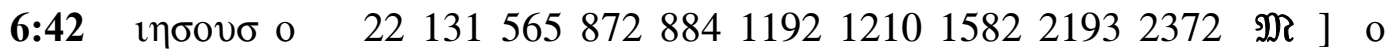
ıпбоvб o 1118 205abs 2052092713 D ] o 1278 R

12:39 $\varepsilon 1 \pi \varepsilon v ~ \eta \sigma \alpha \iota \alpha \sigma 22118131565872884119212101278158221932372$ $\mathfrak{M}] \eta \sigma \alpha \iota \alpha \sigma \quad 1205 \mathrm{abs} 205209$ D ] $\eta \sigma \alpha \iota \alpha \sigma \varepsilon \imath \pi \varepsilon v 2713$ D

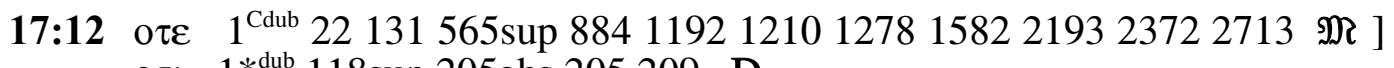
o $\tau 11^{* \text { dub }} 118$ sup 205abs 205209 D

The conclusion that $\mathrm{E}$ descends from Manuscript $\mathrm{C}$ rather than Manuscript $\mathrm{B}$ is further supported by the fact that the descendants of E do not share any of the long omissions that are found among B's descendants. ${ }^{189}$ In the case of B's long omission in 5:9, the descendants of $\mathrm{E}$ agree on 2 rare Non-Majority Text readings with the descendants of $\mathrm{C}$ :

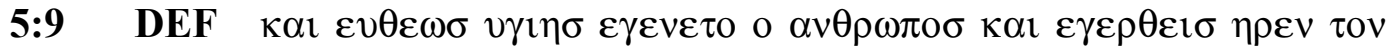

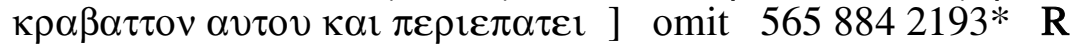

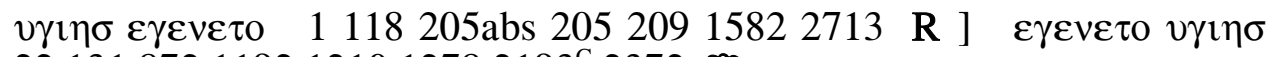
$221318721192121012782193^{\mathrm{C}} 2372 \mathfrak{M}$

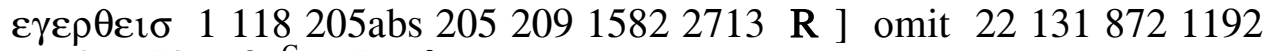
$121012782193^{\mathrm{C}} 2372 \mathfrak{M}$

${ }^{189} 5: 9,7: 8$ and $8: 35$. 
Manuscript E could not have descended from B and also share these rare readings with 1 and 1582 .

\subsubsection{Manuscript $E$ is Independent of Codex 1}

The alternative explanation to account for the exclusive readings shared by 1 and E's descendants is that Manuscript E (having the highest number of Majority Text readings) descends from Codex 1 itself. Lake and Anderson both rejected this possibility. Anderson does not give clear reasons, but Lake suggested two: firstly, that 1 is not damaged and so cannot account for E's shifts in textual affinity, and secondly because in the sections where E is following its Family 1-type exemplar, the descendants of E contain a number of Non-Majority Text readings in places where Codex 1 is Majority. Lake argued that these reading must have come from the family archetype. ${ }^{190}$

Lake's first argument is insufficient, as E could have descended from Codex 1 via an intermediate copy, so that a copy of 1 , and not 1 itself, would be the mutilated manuscript. Lake's second argument-that E's descendants contain a number of Non-Majority Text readings in places where Codex 1 is Majority-is more informative; however, in Lake's smaller family group, there was no way to verify whether these Non-Majority Text readings were inherited from the Family 1-type exemplar or from another source. The extension of the family group for the Gospel of John, by the inclusion of the descendants of Manuscript B, however,

${ }^{190}$ Lake, Codex 1, xxxiv. 
provides a way of assessing these Non-Majority Text readings found in E's descendants where Codex 1 (and 1582) is Majority.

In the sections where $\mathrm{E}$ is following the Family 1-type exemplar, E's descendants have 8 rare agreements with B's descendants while Codex 1 (and 1582) follow the Majority Text. ${ }^{191}$ The agreement with B's descendants provides evidence that these readings were inherited from A-1, rather than being inherited from a different source. As Codex 1 (and 1582) follows the Majority Text at these points, the readings provide evidence that $\mathrm{E}$ is descended from A-1 independently of Codex 1 (and 1582). These 8 rare agreements are reproduced below:

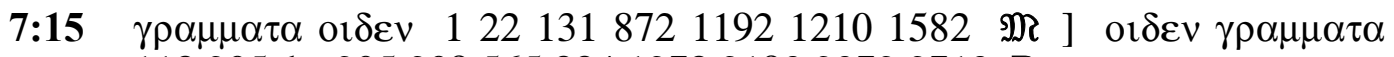
118 205abs 2052095658841278219323722713 R

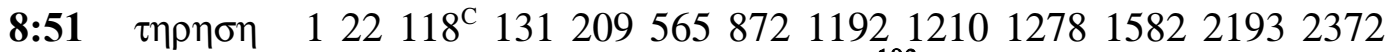
$2713 \mathfrak{M}] \pi$ oin $\sigma$ 118*205abs $205884 \mathbf{R}^{192}$

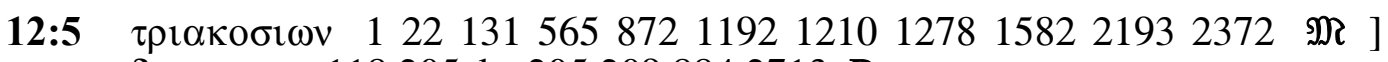

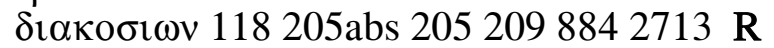

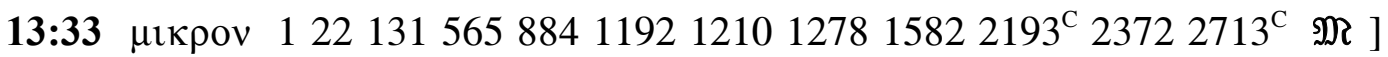

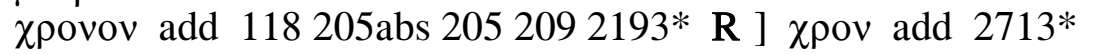

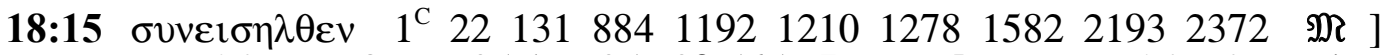

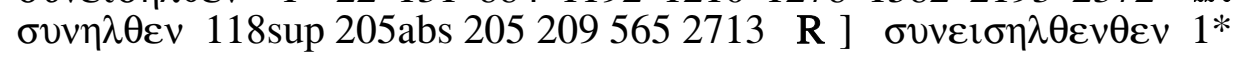

\footnotetext{
${ }^{191}$ There is 1 further very likely rare agreement between 118,2713 and 884 in 8:44; however, the first hand reading of 884 is not legible. See section 3.2.6. for a discussion of this reading.

${ }^{192}$ Note that this reading, though labelled rare, has only the agreement of one other manuscriptK994, a commentary manuscript that very probably related to 884 . If it were not for this agreement the reading would have been labelled distinctive.
} 
18:39 ovv 122 118sup $131565884119212101278 \quad 1582$ M ] $\mathrm{iv \alpha}$ add 205abs 20520921932713 R

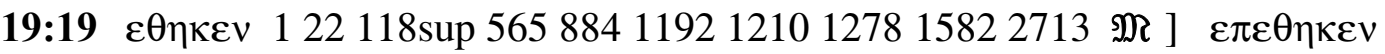
131 205abs 2052092193 R

21:4 $\eta \delta \eta 122$ 118sup 131884119212101278158221932713 M ] omit 205abs $205209565 \mathrm{R}$

There are 5 further Non-Majority Text agreements between E's descendants and B's descendants while 1 and 1582 are Majority. These readings, although they are all widely attested, and some constitute only very slight variations from the Majority Text reading, still add some weight to the evidence of E's independence. The readings have not been reproduced here but can be found in the full family collation. $^{193}$

\subsubsection{Codex 1 and Manuscript E Descend from Manuscript D}

In conclusion, the best explanation for the exclusive agreements and omissions shared by Codex 1 and the descendants of E is that Codex 1 and Manuscript E share an intermediate exemplar, which stands between them and Manuscript C. This intermediate exemplar will be called Manuscript D. Codex 1 and Manuscript E are both independent witnesses of Manuscript D.

${ }^{193} 10: 23,12: 4,12: 6,16: 17$, and 18:10. 


\subsubsection{Codices 118, 205abs, 209, and 2713 are Independent Witnesses of $\mathbf{E}$}

Of the Venice subgroup, Codex 209 has the highest number of Non-Majority Text agreements with the core group; and so its independence from the other manuscripts in the subgroup was not questioned by Lake or Anderson. Lake and Anderson both tentatively concluded that 118 was independent of 209 , though neither found sufficient textual evidence to support a final conclusion. ${ }^{194}$ Lake, though he provided no evidence, claimed that 205 was a copy of 209 and he did not examine 205abs. Anderson examined 205 and found insufficient evidence to determine whether or not it was a copy of 209: and regarding 205abs, she stated, though did not provide evidence, that it is a copy of $205 .{ }^{195}$ Neither Lake nor Anderson examined 2713. The results of the collation of John indicate that four of the manuscripts, 118, 205abs, 209 and 2713, are independent of one another, though they differ in the amount of Majority Text correction each has received.

\subsubsection{Codex 209 is Independent}

Codex 209 has 5 Non-Majority agreements with members of the core group while the four other descendants of $\mathrm{E}$ have either a Majority Text reading or (in one case) a Non-Majority Text reading not supported by any core group manuscript. 209 has 26 Non-Majority Text agreements with two or more core group manuscripts against Codex 118; 8 against Codex 205abs; 17 against Codex 205;

\footnotetext{
${ }^{194}$ Lake, Codex 1, xxv; Anderson, Matthew, 110-116.

195 Anderson, Matthew, 116.
} 
and over 70 against Codex 2713. 209 is clearly independent of the other four descendants of Manuscript E.

\subsubsection{Codex 118 is Independent}

Codex 118 has 42 Non-Majority Text agreements with two or more core group manuscripts against Codex 2713; 8 against Codex 205; and 4 against Codex 205abs. ${ }^{196}$ It also has 2 exclusive Non-Majority Text readings with 209 without the other three manuscripts and 2 exclusive Non-Majority Text readings with 2713. We can conclude, therefore, that 118 is independent of 205abs, 205, and 2713. It is more difficult to determine whether 118 is independent of 209 . Of the 61 first hand disagreements between 118 and 209, the vast majority of units are cases where 209 follows the core group while 118 is Majority. 118 has only 2 agreements with 2 or more members of the core group while 209 is Majority, and neither reading offers very solid evidence:

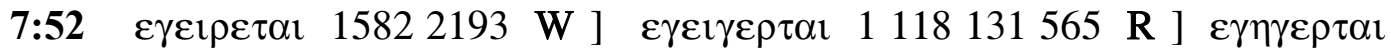
22 205abs 205209872884119212101278 2193supp $23722713 \mathfrak{M}$

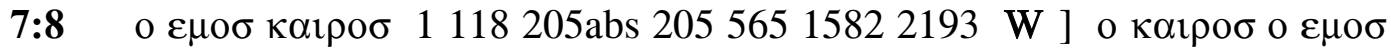
221318728841192121012782372 M ] $\varepsilon \mu о \sigma$ ка1роб 209 R ] o $\varepsilon \mu о \sigma$ о каıроб 2713 D

In the first reading, the variation between the two manuscripts is very slight. It is also a reading where the core group manuscripts are split. In the second unit, it

${ }^{196}$ Note this is before 16:25 where 118's lacuna begins. 
could be argued that the reading of 209 may have caused the reading in 118, by the scribe of 118 making an incomplete correction towards the Majority Text. Neither reading, therefore, provides sufficient evidence that 118 is independent of 209. There are, however, two other readings that supply evidence to suggest that 118 is independent. One reading is a rare Non-Majority Text agreement between 118 and the core group manuscript 884 , and the other reading a possible, but very likely, rare Non-Majority Text agreement, also with 884 :

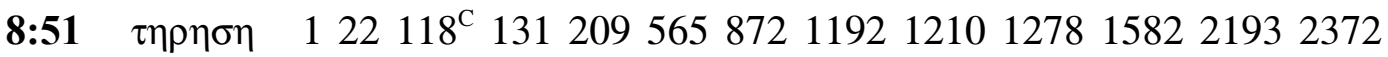 $2713 \mathfrak{M}] \pi$ oinon 118*205abs $205884 \mathrm{R}$}

8:44 $\pi \alpha \tau \rho o \sigma \quad(1 \mathrm{st}) \quad 122131$ 205abs $205209565872884^{\mathrm{C}} 119212101278$ $158221932372 \mathfrak{M}$ ] $v \mu \omega v$ add $1182713 \mathbf{R}$ ] [4] add $884 *$

The reading in 8:51 is particularly unusual. The IGNTP editions for John cite only one other manuscript that supports the reading, a commentary text manuscript, K994, which is closely related to, and therefore potentially not independent of, 884. ${ }^{197}$ The agreement between 118 and 884 on this reading is, therefore, significant. In the second unit, although the first hand reading of 884 has been erased and is now illegible; it has already been shown that the reading is very likely to be $v \mu \omega v .{ }^{198}$ As 209 supports neither of these two rare readings, they provide evidence that 118 is not a copy of 209, but is an independent

\footnotetext{
${ }^{197}$ See section 3.2.6. for discussion of K994 and its relationship with 884 .

${ }^{198}$ See section 3.2.6. for a more detailed discussion of this reading.
} 
representative of Manuscript E. ${ }^{199}$ This conclusion is supported by the palaeographical dating of both manuscripts.

\subsubsection{Codex 2713 is Independent}

Codex 2713 has 16 Non-Majority Text agreements with two or more core group manuscripts against Codex 118; 11 against Codex 205abs; 9 against Codex 205; and 5 against Codex $209 .{ }^{200}$ Although it is one of the weaker family manuscripts in the subgroup, it can still be shown to be an independent witness to Manuscript E.

\subsubsection{Codices 205abs and 205}

The collation of John has demonstrated that the assumption that 205abs is a copy of 205 is incorrect, and that on the contrary, 205 is likely to be a copy of $205 \mathrm{abs}$. Codex 205abs contains 5 A-1 readings while 205 is either Majority, or in 2 cases, has a Non-Majority Text singular reading:

3:17 viov 122118 205abs 20956511921582 R ] ovtov add 131205872 $88412101278219323722713 \mathfrak{M}$

\footnotetext{
${ }^{199}$ Note that the actual manuscript was examined in great detail at these two points to check whether there was any possibility that 209 originally supported either reading but had been corrected. There were no signs of any markings or erasures at either point.

${ }^{200}$ In 1 further reading 2713 has a slightly altered version of an A-1 reading (probably the result of partial Majority Text correction) while the four other manuscripts follow the Majority Text (21:16).
} 


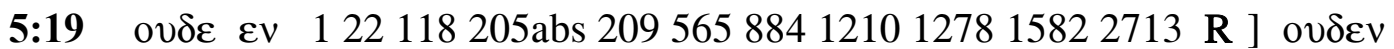
$13120587211922193^{\text {pcorr }} 2372 \mathfrak{M}$

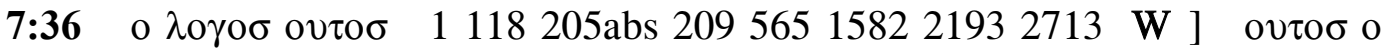

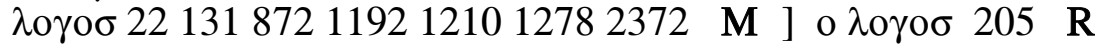

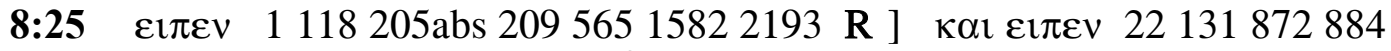
$11921210127823722713 \mathfrak{M}$ ] $\varepsilon 1 \pi \varepsilon v$ ovv 205 R

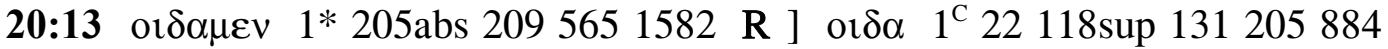
$11921210127821932713 \mathfrak{M}$

In addition, 205abs contains 2 Non-Majority Text readings supported by one core group manuscript and the rest of the subgroup, while 205 is Majority:

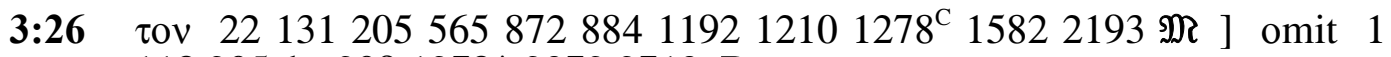
118 205abs $2091278 * 23722713$ D

4:12 or $\left.122131^{\mathrm{C}} 20556588411921210127815822193^{\mathrm{C}} 2372 \quad \mathfrak{M}\right]$ omit $118131 * 205 a b s 2098722193 * 2713 \mathbf{R}$

Finally, 205abs contains a further 2 readings supported by 209 and 2713 while 205 is Majority. These 2 readings were probably inherited from Manuscript E, as no family manuscript outside of the subgroup supports them:

19:20 $\varepsilon \lambda \lambda \eta v \imath \sigma \tau \imath \rho \omega \mu \alpha \imath \sigma \tau \imath \quad 122$ 118sup $131565884119212101278^{\mathrm{C}} 1582$

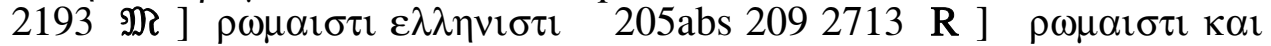

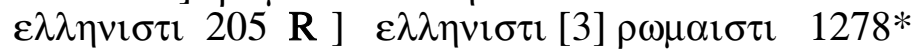

19:31 $\eta \quad 122$ 118sup 13120556588411921210127815822193 M ] omit 205abs 2092713 W 
The existence of these Non-Majority Text readings in 205abs, inherited from A-1 or Manuscript E, while 205 is Majority or has a singular reading, provides sufficient evidence to demonstrate that 205abs is not a copy of 205 . This evidence is strengthened by the fact that 205 contains a high number of singular readings - 26. If 205abs were a copy of 205, it would be expected that 205 would contain very few singular readings, because any reading that originated in 205 would have a high chance of being passed on to 205abs and hence would no longer be a singular reading.

\subsubsection{Codex 205 is a Copy of Codex 205abs}

Codex 205 contains no A-1 readings that are not also supported by 205abs. 205 has only 1 agreement with a core group manuscript against 205abs, and in this reading the variation is only very slight:

\section{2:4 $\pi \alpha \rho \alpha \delta 1 \delta o v \alpha \imath \quad 122118131$ 205abs 2095658721192121012781582 $219323722713 \mathfrak{M}] \pi \alpha \rho \alpha \delta$ ovvaı 205884 R}

Furthermore, 205 has only 1 agreement with another member of the E subgroup without 205abs:

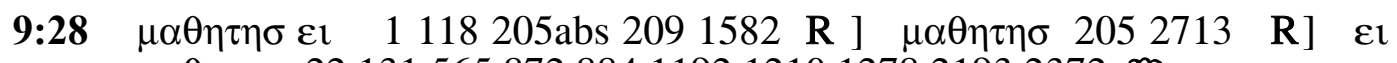
$\mu \alpha \theta \eta \tau \eta \sigma 2213156587288411921210127821932372 \mathfrak{M}$

In this reading, 205abs supports a family reading along with 209, indicating that Manuscript E contained the family reading and that 205 and 2713 agree only by 
chance, either because of the accidental omission of $\varepsilon$, or an uncompleted correction of the family reading towards the Majority Text. Beside these 2 readings, 205 has no other agreements with any family manuscript collated in John without 205abs. As these 2 readings are very insignificant it is possible to argue that 205 is in fact a copy of 205 abs.

This hypothesis is supported by the fact that 205abs has very few singular readings, only 3 , which are reproduced below:

2:2 Kol (1st) 122118131205209565872119212101278158221932372 $2713 \mathfrak{M}$ ] omit 205abs R

Note 205abs: there is a smudge or marking at this point.

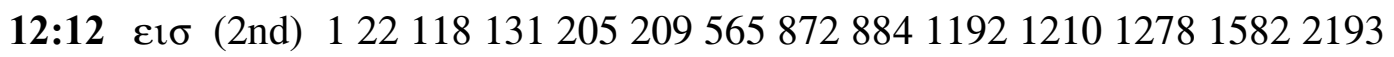
23722713 M ] omit 205abs D

19:35 кal (2nd) 122 118sup 13120520956588411921210127815822193 $2713 \mathfrak{M}] \eta$ add 205abs D

Such a small number of singular readings would be expected from a manuscript collated against its copy, as any readings originating in the parent manuscript would be passed on to the copy and thus would no longer be classified as singular readings. It is reasonable to suggest that these 3 singular readings in 205abs were spotted by the scribe of 205 and corrected, as in each case 205 contains a Majority Text reading-Majority Text readings being the readings with which a scribe would most likely correct. 
205abs and 205 share a high number of exclusive Non-Majority Text readings, 26 altogether. 13 of these readings are distinctive and 11 are rare. They include 2 omissions of strings of text; these agreements are unlikely to have occurred independently in both manuscripts:

11:9 о $1192121012781582219323722713 \mathfrak{M}$ ] omit 205abs 205 D

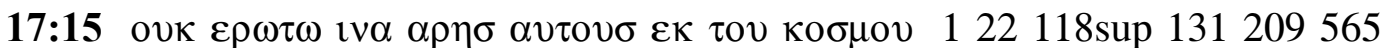
$8841192121012781582219323722713 \mathfrak{M}$ ] omit 205abs 205 R

These 26 exclusive readings provide further evidence that 205abs and 205 are very closely linked, that either one manuscript is a copy of the other, or that they are sibling manuscripts. If the latter were the case, we would expect that both manuscripts would show independent links to Manuscript E, but this is not the case. While 205abs contains links to E without 205, Codex 205, with the exception of the 2 very slight and insignificant readings already discussed, does not show links to $\mathrm{E}$ without 205abs. On the basis of this evidence it will be concluded that in John 205 is a copy of 205 abs.

\subsubsection{Codex 205abs is Independent}

Codex 205abs has 22 Non-Majority Text agreements with two or more core group manuscripts while 118 is either Majority or has a Non-Majority Text reading unsupported by any core group manuscript; 205abs has approximately 70 such readings against Codex 2713. 205abs is, therefore, clearly independent of 
both 118 and 2713. Codex 209 is a stronger Family 1 manuscript than 205abs, but of the 66 first hand disagreements between the two manuscripts, there are 5 readings that offer evidence that 205abs descends from E independently of 209. ${ }^{201}$ These readings are given below:

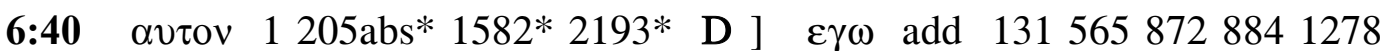
$\left.1582^{\mathrm{Cl}} 2372 \mathbf{M}^{\mathrm{pt}}\right] \varepsilon \gamma \omega \varepsilon v$ add $\left.22119212102193^{\mathrm{C}} \mathbf{M}^{\mathrm{pt}}\right] \varepsilon v$ add 118 $205 \mathrm{abs}^{\mathrm{C} *} 2052092713 \mathrm{D}$

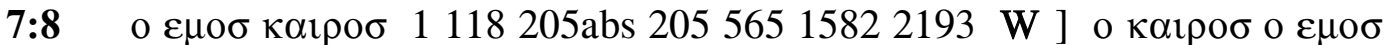
221318728841192121012782372 M ] $\varepsilon \mu о \sigma \kappa \alpha i \rho o \sigma \quad 209$ R ] o $\varepsilon \mu о \sigma$ о каıроб 2713 D

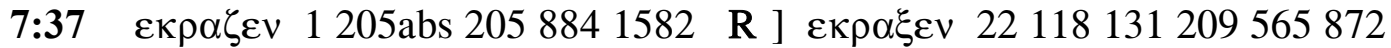
$119212101278219323722713 \mathfrak{M}$

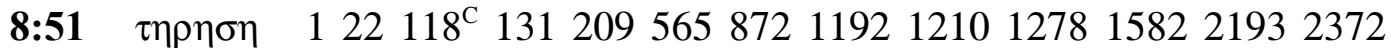

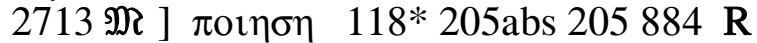

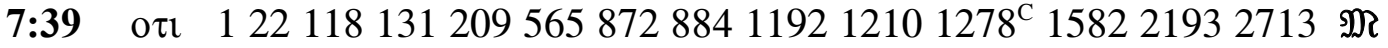
] o add 205abs $2051278 * 2372 \mathbf{R}$

The first three of these readings are cases where 205abs supports an A-1 reading against 209. The rare reading in 8:51 may also be inherited from $\mathrm{A}-1$, as it has the support of the core group manuscript 884 , but it is certainly likely to be an E reading with the agreement of 118 . The final reading is a rare agreement between

\footnotetext{
${ }^{201}$ A possible sixth reading in 5:28 has been ignored as it amounts to only a very slight variation, and is an agreement with a correction, rather than a first hand, in a core group manuscript.
} 
205abs, 1278* and 2372, the latter being two descendants of A-1, which descend from A-1 via a different route. ${ }^{202}$

These readings are small in number; however, considering that 205abs and 209 are very close - separated by no more than a few copying events - it is possible that there would be only these few readings where 205abs has links to E without 209. The scarcity of these readings does not undermine the argument that $205 \mathrm{abs}$ is independent; rather, it reveals that the scribe of 209 was a very accurate copyist and made very few corrections towards the Majority Text, while the scribe of 205abs or the scribe of an intermediate exemplar was less accurate and/or made more corrections towards the Majority Text.

\subsubsection{Summary of the Venice Group}

In conclusion, a Family 1 subgroup of four manuscripts exists-118, 205abs, 209 and 2713 - all of which are independent copies of a no-longer extant manuscript, Manuscript E. Manuscript E descends from A-1 through Manuscript D, an intermediate ancestor shared with Codex 1. Manuscript D in turn descends from Manuscript $\mathrm{C}$, an ancestor also shared with 1582. Figure 4 below expresses these relationships as a stemma diagram. While each of these four subgroup manuscripts can provide evidence of readings that existed in E, Codex 209 is the most accurate copy and best representative of Manuscript E. Codex 205 is also a descendant of $\mathrm{E}$, but via 205abs so it is not an independent witness.

${ }^{202}$ See chapter 4. 
Figure 4: Stemma for the Venice Group

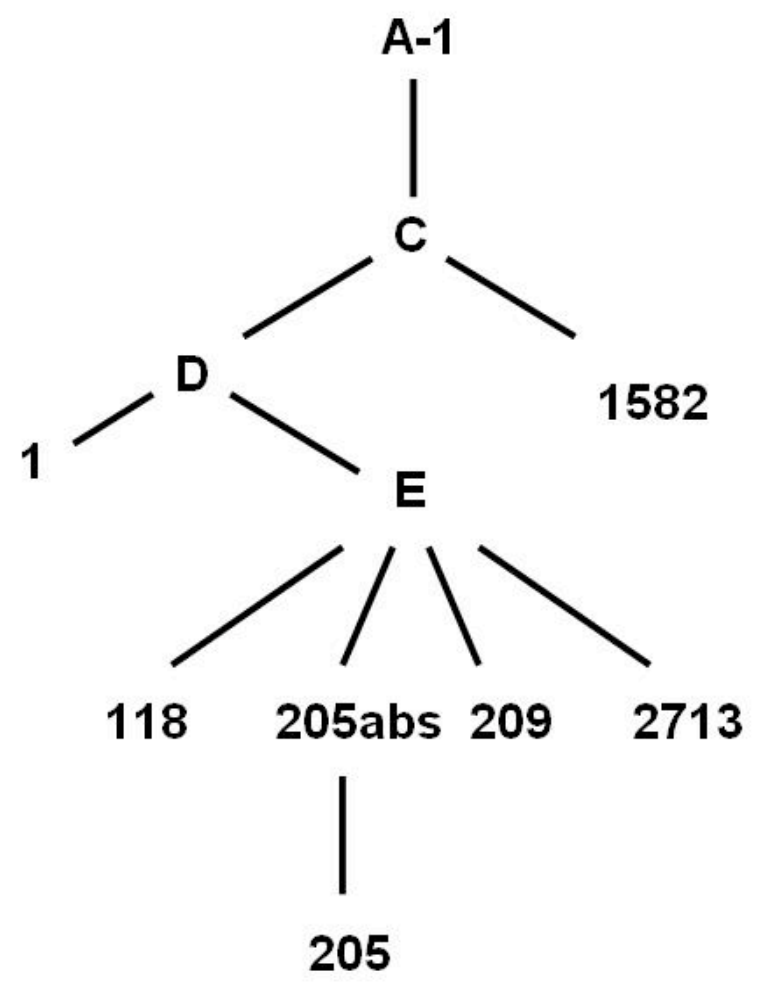




\section{A Manuscript Subgroup: Codices 22, 1192, 1210, 1278 and 2372}

\subsection{Manuscript Descriptions}

\subsubsection{Codex 22}

\section{Contents and Layout}

Codex 22 is a Four Gospel codex, dated to the eleventh or twelfth century. It is kept at the Bibliothèque Nationale, Paris, where it is designated gr. $72 .^{203}$ The manuscript contains 232 goatskin leaves, which Sanders describes as 'of excellent quality, thin and pliable'. ${ }^{204}$ Pages measure 18.8 by $26 \mathrm{~cm}$ and the text is written in 1 column per page with 22 lines per column. ${ }^{205}$ The manuscript contains partial Eusebian apparatus, and $\kappa \varepsilon \phi \alpha ́ \lambda \alpha \iota \alpha$ for each gospel. Each gospel begins on a recto page followed by a decorative headpiece and majuscule gospel title, filling twothirds of the page. Matthew 1:1-2:2, 4:20-5:25 and John 14:22-16:27 are missing. Ff. 7-10 have been dislocated and should come before ff. 1-6. The codex contains a number of variant readings, which are given in the margins beside a gamma-rho symbol. It also contains a critical note on the ending of the Gospel of Mark, the same version as 1192 and 1210, but shorter than the version found in

\footnotetext{
${ }^{203}$ Earlier: Colbert 2467; von Soden ع 288.

${ }^{204}$ Henry A. Sanders, “A New Collation of Codex 22," Journal of Biblical Literature 33 (1914): 94.

${ }^{205}$ Codicological details taken from Sanders, "Codex 22". Sanders was able to examine the physical manuscript in detail.
} 
Codices 1 and 1582. Some sections of the microfilm are unclear and some of the inner margins have been cut off on the images.

\section{Script and Dating}

The script of 22 is neat and spacious, though letters are often squeezed in at the end of lines. There are very few enlarged letters, only occasional taus, lambdas, and kappas. There are some ligatures and majuscule forms but very few abbreviations. Mute iota is adscript; nomina sacra have accents and breathings; breathings are a combination of square and round. These palaeographical features fit with an eleventh or twelfth century dating of the manuscript; the textual analysis of the manuscript supports the earlier date. ${ }^{206}$

\section{Illuminations}

There are no evangelist portraits in 22 but the headpieces for the gospels are illuminated.

\section{Correctors and Later Hands}

The corrections in Codex 22 have been given special attention by Sanders who noted the changes back and forth from the Family 1 text to the Majority Text and from the Majority Text to the Family 1 text. $^{207}$ On the basis of a change in ink

\footnotetext{
${ }^{206}$ See discussion of Codices 22 and 1210 in section 4.2.11.

${ }^{207}$ Sanders, “Codex 22," 95.
} 
Sanders suggested that a second hand, but a contemporary, made most of these corrections. $^{208}$ The corrections towards the Family 1 text would support the suggestion that this corrector was a $\delta\llcorner 0 \rho \theta \omega \tau \eta \dot{s}$ employed at the scriptorium where 22 was produced, and that he used the manuscript's unusual exemplar to make at least some of the corrections. As it was not possible to examine the manuscript in person, and as the microfilm is not of high quality, all corrections have been labelled $\mathrm{C}$ in the transcription.

\section{Provenance}

Codex 22 belonged to the vast manuscript collection of Jean-Baptiste Colbert (1619-83). After Colbert's death his library passed to hs son, who later sold the library to the French King Louis XV.

\section{Transcription of the Gospel of John}

John begins on $\mathrm{f}$. $182 \mathrm{r}$ and ends on f. $232 \mathrm{r}$. John 14:22-16:27 is missing and the Pericope Adulterae is omitted without comment. The transcription was made from the microfilm and sections of unclear text were checked against Sanders's collation. $^{209}$

\footnotetext{
${ }^{208}$ Sanders, “Codex 22,” 94.

${ }^{209}$ Sanders, “Codex 22,” 114-117.
} 


\subsubsection{Codex 1192}

\section{Contents and Layout}

Codex 1192 is an eleventh-century Tetraevangelion located at the monastery of St. Catherine, Mount Sinai, where it has the catalogue number Gr. $155 .^{210}$ The manuscript contains 243 folios of 'fine and smooth' parchment measuring 21.5 by $16.6 \mathrm{~cm}$; the main text is written in black ink; gospel titles and initial letters are red

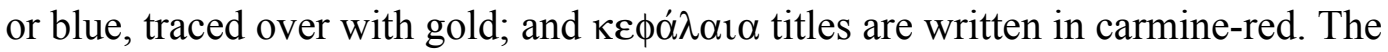
manuscript is bound in wooden boards covered with green silk. ${ }^{211}$ The text is written in 1 column per page with 25 lines to a column. ${ }^{212}$ The manuscript contains Eusebius's letter to Carpianus, decorated canon tables, a lectionary

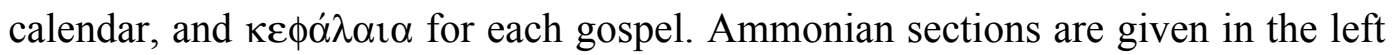
and right margins throughout and $\kappa \varepsilon \phi \alpha ́ \lambda \alpha \iota \alpha$ titles written in semi-majuscule in the top and bottom margins. Each gospel begins on a fresh recto page with the gospel title written in large majuscule letters, surrounded by a decorative border filling one-third of the page. The very first letter of each gospel is large and decorated; the bar of the first epsilon in John is a hand pointing to the rest of the text. There is no major lacuna in the manuscript; however, there are short sections of text on a

\footnotetext{
${ }^{210}$ Von Soden $\varepsilon 1115$.

${ }^{211}$ It was not possible to examine 1192 in person. Published plates and the black and white microfilm have been consulted. Details of colour and the binding are taken from Kurt Weitzmann and George Galavaris, The Monastery of Saint Catherine at Mount Sinai: the Illuminated Greek Manuscripts. Vol. 1: from the Ninth to the Twelfth Century (Princeton: Princeton University Press, 1990), 51.

${ }^{212}$ Occasionally one word is right-justified on a twenty-sixth line. (E.g. f. 198r, f. 200v, f. 201v, f. $207 \mathrm{v}$, f. 209r.)
} 
number of folios that appear smudged on the microfilm and may represent water damage on the manuscript. ${ }^{213}$ There is a small hole in f. 215 affecting a few letters on either side. Weitzmann and Galavaris record that the parchment is 'torn in places, showing evidence of extensive use'. ${ }^{214}$ The manuscript contains a shorter version of the note on the ending of the Gospel of Mark, and a number of textual variants are recorded, written in semi-majuscule letters in the margins, using the gamma-rho symbol to distinguish variant readings from corrections.

\section{Script and Dating}

Codex 1192 was copied by one scribe. The hand is even and regular. There are a fair number of majuscule forms but not much variation in letter size. Breathings are all square; mute iota is adscript; nomina sacra and initial letters have accents and breathings. The circumflex accent is small and is placed above the other accents and breathings; punctuation is regular. The scribe uses a limited number of abbreviations, mainly kaí compendium, nu-superline, sigma by suspension, and tachygraphic abbreviations for omega-nu, alpha-iota and alpha-sigma. These abbreviations, including kai compendium, are only used at line endings. ${ }^{215}$ On the basis of the flamboyance of the ornament, Weitzmann and Galavaris argue for an

\footnotetext{
${ }^{213}$ In John f. 231 and f. 232.

${ }^{214}$ Weitzmann and Galavaris, Saint Catherine, 51. This is not clearly visible on the black and white microfilm.

${ }^{215}$ Only one exception to this was found in John, a kai compendium on f. 236v.
} 
eleventh-century dating for 1192 . The palaeographical features of the manuscript also support such a dating. ${ }^{216}$

\section{Illuminations}

1192 contains decorated canon tables (starting on f. 2 r) and the first letter of each gospel is illuminated. Weitzmann and Galavaris describe the laced patterns and decorative palmettes and tendrils that wind around the arches and frames of the canon tables as 'crude'. ${ }^{217}$ There are no evangelist portraits.

\section{Correctors and Later Hands}

There are a small number of corrections in 1192, though they are not the result of a systematic correction. The Gospel of John contains just over 20 corrections. $^{218}$ These are all small and interlinear, usually the addition or omission of one or two letters. All corrections in the transcription for this manuscript are labelled $\mathrm{C}^{219} \mathrm{~A}$ later hand has added some brief notes written in Arabic in the margins of a few folios. $^{220}$

\footnotetext{
${ }^{216}$ Weitzmann and Galavaris, Saint Catherine, 51

${ }^{217}$ Weitzmann and Galavaris, Saint Catherine, 51.

${ }^{218}$ Not including additions or deletions of mute iota.

${ }^{219}$ Because all of the corrections are either very short additions or erasures and because it was not possible to examine the manuscript in person, no attempt has been made to distinguish correctors. However, preliminary conclusions drawn from an examination of the microfilm are that the main scribe made all of the corrections in John.

${ }^{220}$ E.g. In John f. 224v, f. 229v, f. 230r.
} 
Provenance

Little is known of the origins or previous owners of 1192 before it passed to Saint Catherine's monastery.

\section{Transcription of the Gospel of John}

The Gospel of John begins on f. 196r and ends on f. 243r. The Pericope Adulterae is omitted without comment. The manuscript was transcribed from the microfilm.

\subsubsection{Codex 1210}

\section{Contents and Layout}

Codex 1210 is a Four Gospel codex dated to the eleventh or twelfth century. It is kept at St. Catherine's monastery, Mount Sinai, where it is designated Gr. $173 .^{221}$ The codex contains 246 parchment folios measuring 19.2 by $15.5 \mathrm{~cm}$. The text is written in 1 column per page with 22 lines per column. The text is written in black ink with red initials. The manuscript contains Eusebian canon tables with Ammonian section numbers given throughout, lection notes, and $\kappa \varepsilon \phi \alpha \dot{\lambda} \alpha \iota \alpha$ for each gospel. ${ }^{222}$ Each gospel begins on a fresh recto page beneath a very modest decorative border and a majuscule gospel title. The manuscript contains a critical

\footnotetext{
${ }^{221}$ Other references: von Soden $\varepsilon 1198$.

${ }^{222}$ W. H. P. Hatch, The Greek Manuscripts of the New Testament at Mount Sinai: Facsimiles and Descriptions (Paris: Librairie orientaliste Paul Geuthner, 1932), plate VII.
} 
note on the ending of the Gospel of Mark, a shorter version of the note found in Codices 1 and 1582.

\section{Script and Dating}

1210 was copied by one scribe; the hand is neat with letters all of a similar size. The text has an appearance of flatness, with letters compressed to fit into the line. There are not many abbreviations but more ligatures; nomina sacra have accents and breathings; mute iota is adscript; and the circumflex accent is stretched out, sometimes over 2 letters. The scribe uses a number of distinctive letter forms, including a distinctive flat-backed alpha. Gardthausen and Gregory date 1210 to the eleventh or twelfth century. The textual analysis of 1210 would support the later date. $^{223}$

\section{Illuminations}

1210 does not contain any illuminations.

\section{Correctors and Later Hands}

1210 contains a small number of first hand corrections. These have been labelled $\mathrm{C}^{*}$ in the transcription. A later hand has also added a small number of corrections; these have been labelled $\mathrm{C}$. Corrections that cannot be distinguished, especially erasures, have been labelled C.

${ }^{223}$ See discussion of the relationship between 1210 and Codex 22 in section 4.2.11. 
Provenance

Little is known of 1210's origins or previous owners before it passed to St. Catherine's.

\section{Transcription of the Gospel of John}

John begins on f. $182 \mathrm{r}$ and ends on f. 236v. The Pericope Adulterae is omitted without comment. 1210 was transcribed from the microfilm.

\subsubsection{Two Decorative Style Manuscripts: Codices 1278 and 2372}

The final two manuscripts investigated in this chapter, Codices 1278 and 2372, have been examined in a number of Byzantine art history studies on the Decorative Style Tradition - a provincial manuscript tradition that developed as a result of the gradual decentralisation and disintegration of the Byzantine Empire. The Tradition is thought to contain over 100 extant manuscripts, mostly gospels, copied and illuminated between 1150 and $1250 .^{224}$ On artistic grounds, Buchthal and Weyl Carr both locate 1278 and 2372 in 'the Interregnum Subgroup', a late stage of the Tradition's development that began in the decades following the sack

\footnotetext{
${ }^{224}$ See especially: Annemarie Weyl Carr, Byzantine Illumination 1150-1250: The Study of a Provincial Tradition (Chicago: University of Chicago Press, 1987); Hugo Buchthal, "Studies in Byzantine Illumination of the Thirteenth Century," Jahrbuch der Berliner Museen, 25, (1983): 27 102.
} 
of Constantinople in 1204, and the establishment of the Latin Kingdoms. ${ }^{225}$ The provinces during this period of political turmoil witnessed an enormous influx of resources, patronage, and artistic models from Constantinople, and as result, the 'Interregnum Subgroup' includes some of the most opulent and high quality manuscripts of the whole Decorative Style Tradition. ${ }^{226}$

1278 and 2327, along with five other gospel codices, form a close-knit core of manuscripts within the wider 'Interregnum Subgroup'. These manuscripts include: Athos, Dionysiou 4; Berlin, Staatsbibliothek, graecus quarto 66; Cracow, Biblioteka Czartoryskich no. 1870; Athos, Iviron, no. 55; and Moscow, Lenin Library, gr. 9. ${ }^{227}$ They are so closely related in terms of artistic motifs and features that Buchthal suggests they were copied in the same scriptorium. He also argues that the artistic features of the later manuscripts in the group were based directly on the earlier productions. ${ }^{228}$ One of these earlier manuscripts, Berlin 66 , can be dated by an Arabic note in the manuscript to before $1219 .{ }^{229} 1278$ and 2372 are judged by Buchthal to be slightly later productions, but must not have been copied much later than $1219 .^{230}$ No definitive location for a scriptorium has been

\footnotetext{
${ }^{225}$ Buchthal, "Byzantine Illumination,” 27-32; Weyl Carr, Illumination, 80-85.

${ }^{226}$ Weyl Carr, Illumination, 105-25.

${ }^{227}$ Weyl Carr, Illumination, 81.

${ }^{228}$ Buchthal, "Byzantine Illumination,” 101.

${ }^{229}$ Buchthal, "Byzantine Illumination,” 86.

${ }^{230}$ Buchthal, "Byzantine Illumination,” 68 and 101.
} 
established; however, Buchthal has tentatively suggested Nicaea and the imperial Monastery of Sosandra. ${ }^{231}$

A further collation of other manuscripts in the 'Interregnum Subgroup' could harvest interesting results, not only helping to locate the point where the Family 1 text, found first in manuscripts of a Constantinopolitan origin, was introduced into the Decorative Style Tradition, but also to shed light on how scribes and illuminators worked together, and to discover how often textual links mirror the artistic relationships between manuscripts.

\subsubsection{Codex 1278}

\section{Contents and Layout}

Codex 1278 is an early thirteenth-century ${ }^{232}$ Tetraevangelion located at John Rylands Library, Manchester, where it has the catalogue reference Gr. Ms. $17{ }^{233}$ It contains 352 folios of high quality, thick parchment, bound in red leather. The text is written in 1 column per page with 20 lines to a column; ${ }^{234}$ the average page dimensions are 23.3 by $17 \mathrm{~cm}$ and the text dimensions 16 by $11 \mathrm{~cm}$. The ink of the main text is black; ${ }^{235}$ initial letters are painted in gold with a red-orange colour underneath that changes shade throughout the codex; and there are a number of

\footnotetext{
${ }^{231}$ Buchthal, "Byzantine Illumination," 101.

${ }^{232}$ Aland, Kurzgefasste Liste, 121, dates the manuscript to the twelfth century.

${ }^{233}$ Earlier library catalogue number: R. 4592; von Soden $\varepsilon 277$.

${ }^{234}$ Except for the genealogy in Luke which is written in 2 columns.

${ }^{235}$ Except for ff. $68 \mathrm{r}-69 \mathrm{r}$ where the colour changes to brown.
} 
illuminated zoomorphic initials dispersed throughout the codex, but with the majority appearing earlier on. The first quire signature is labelled $\beta$, indicating that one quire, which must have contained some kind of prefatory material, is now

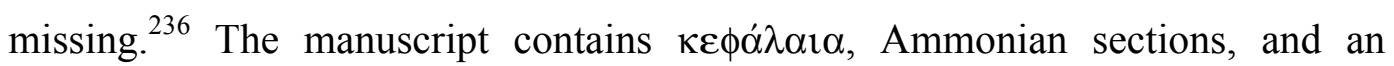
evangelist portrait for each gospel, along with a miniature of Moses receiving the law. Each gospel begins on a fresh recto page with an ornate and colourful rectangular headpiece followed by a majuscule gospel title. The text on the opening page of each gospel is written in the same red-orange, with gold ink over the top.

\section{Script and Dating}

1278 was copied by a single scribe. The text is large, clear, spacious and angular. There are a number of ligatures, and abbreviations are common at the ends of lines but, except for koí compendiums, rare elsewhere. There are some majuscule forms and certain letters are regularly enlarged, especially zeta, xi, theta, phi, psi, tau and lambda and less often epsilon, omicron and omega. Breathings are round; nomina sacra have accents and breathings; and accents and breathings are always distinct from letters. Punctuation is regular; diaeresis is used over omicron and upsilon; and there is no mute iota. Old Testament quotations are marked with diples and the gamma-rho symbol is used to indicate variant readings. ${ }^{237}$

\footnotetext{
${ }^{236}$ Most other manuscripts in the core group of the Interregnum Subgroup contain canon tables, so it is probable that these are missing from the first quire.

${ }^{237}$ Only 1 variant reading is given in John.
} 
Buchthal and Carr agree that 1278 is one of the most stylistically advanced manuscripts in the Interregnum Subgroup, ${ }^{238}$ the artist having borrowed, developed and improved upon motifs from most other manuscripts in the group. ${ }^{239}$ Codex 1278 is, therefore, on artistic grounds, considered to have been produced after Codex 2372.

\section{Illuminations}

1278 contains an evangelist portrait for each gospel, painted on the verso folios before each incipit page. ${ }^{240}$ Buchthal describes the colour scheme of these portraits (and the other illuminations in the manuscript) as 'sombre and subdued' compared to the other manuscripts in the artistic subgroup, but suggests that many of the features of each portrait are based on one of the earlier manuscripts, Dionysiou 4. ${ }^{241}$ The miniature for the Gospel of John depicts the aged evangelist, stooping to dictate his gospel to the seated scribe Prochoros, against a rocky backdrop, the evangelist turning to face the hand of God, which descends from the top right hand corner. This iconography may provide an interesting artistic link to Codex 1, which contains the same motif with many identical features. It is possible that a shared ancestor of 1 and 1278, which can explain the textual link between the two manuscripts, also contained a similar portrait; and that this

\footnotetext{
${ }^{238}$ See Weyl Carr, Illumination, 254; Buchthal, "Byzantine Illumination,” 82-86.

${ }^{239}$ Buchthal, "Byzantine Illumination,” 101.

${ }^{240}$ F. 5v, f. $107 v$, f. $170 v$, f. $271 v$.

${ }^{241}$ Buchthal, "Byzantine Illumination,” 84.
} 
ancestor was responsible for introducing the artistic motif into the Decorative Style Tradition. F. 2v contains a fifth portrait - an image of Moses receiving the law; Buchthal suggests that this too is based on a miniature in Dionysiou $4 .^{242}$

The opening page of each gospel begins with an illuminated rectangular headpiece, decorated in leafy patterns and foliage, surrounded by exotic birds or monkeys. ${ }^{243}$ A zoomorphic initial is used as the first letter for each gospel, and smaller, less elaborate zoomorphic initials occur throughout: colourful birds and winged beasts, with feathers outstretched to form the bar or arm of a letter; monkeys and other exotic mammals, splayed or curled around themselves to form letters; and serpents or smaller animals hanging from plant foliage, dangling into the shape of letters. Most of these illuminated initials are purely decorative and do not seem to hold any iconographic significance.

1278 is a beautifully produced and illuminated manuscript; however, it is notable that although the quality of materials remains constant, the lavishness of the decoration reduces further on in the codex. Matthew and Mark, for example, contain most of the illuminated letters while Luke and John each contain only one, and the final headpiece for John is unfinished. This perhaps suggests a increased pressure on either time or expense towards the end of production.

\footnotetext{
${ }^{242}$ Buchthal, "Byzantine Illumination," 82. For in-depth discussion of this motif and the other manuscripts that contain it see Hugo Buchthal, "A Byzantine Miniature of the Fourth Evangelist and Its Relatives," Dumbarton Oaks Papers 15 (1961): 127-139.

${ }^{243}$ F. 6r, f. 108 r, f. 171 r, f. 272 r.
} 
1278 has been systematically corrected by a professional $\delta 10 \rho \theta \omega \tau \eta \dot{\zeta}$, probably at the same scriptorium where the manuscript was produced: movable-nus have been consistently added or removed; accents, breathings and punctuation on most pages have been altered or added; and in John alone, over ninety textual corrections have been made. The $\delta 10 \rho \theta \omega \tau \eta \dot{s}$ took great care to blend his corrections neatly with the original letters and page layout, without disturbing the beautiful presentation of the manuscript. As a result, however, letters and words by the first hand are often completely erased, leaving only fine traces of scraping on the parchment beneath the corrector's text. Many corrections are only detectable on the manuscript itself and even then, it is often impossible to discover the reading of the first hand. The $\delta$ iop $\theta \omega \tau$ ń $\varsigma$ used brown ink and some of his letter forms and abbreviations are distinct from those of the original hand, such as his flat-backed alpha or his кoi compendium, shaped like a Latin S. Corrections by the $\delta$ เop$\theta \omega \tau \eta \dot{s}$ have been labelled $\mathrm{C} 1$ in the transcription. The scribe who added the initial letters (in red-orange with gold) also made a few minor corrections, these have been labelled C2. Corrections by the first hand have been labelled $\mathrm{C}^{*}$ and those left undistinguished C.

\section{The Transcription of the Gospel of John}

John begins on f. $272 \mathrm{r}$ and ends on f. 351v. There is no lacuna in the gospel and the Pericope Adulterae stands at 7:52 without comment. 1278 was transcribed 
from the microfilm and unclear text was checked, in Manchester, on the manuscript itself. Corrections were labelled only after thorough examination of the manuscript. Unless otherwise stated codicological details come from my own examination of the codex.

\subsubsection{Codex 2372}

\section{Contents and Layout}

Codex 2372 is a thirteenth-century Four Gospel codex kept at the Walters Art Gallery in Baltimore where it is designated Ms. 528. The manuscript contains $234^{244}$ extant parchment folios and is bound in wooden boards and decorated leather covers. ${ }^{245}$ The text is written in 1 column per page with 23 lines to a column. The pages measure 22.3 by $15.4 \mathrm{~cm}$ and the text 14.8 by $10.3 \mathrm{~cm} .^{246}$ The manuscript contains Ammonian sections but without canon tables or other material. Each gospel begins beneath a large decorative headpiece and a majuscule gospel title. There is an evangelist portrait for the Gospel of Luke. The text is written in black ink with titles, smaller initials, Ammonian sections and the first page of each gospel in gilt magenta. Initial letters are used throughout and a number of these are illuminated zoomorphic letters. Matthew 9:2-33; Mark $16: 17 \mathrm{~b}$ to the end; Luke 24:29 to the end; and John 18:31 to the end are missing.

\footnotetext{
${ }^{244}$ The first folio is not original.

${ }^{245}$ According to Horowitz, these date to the thirteenth century: Deborah Horowitz, A Catalogue of Greek Manuscripts at the Walters Art Museum and Essays in Honour of Gary Vikan, vol. 62, (Houten: HES \& DE GRAAF Publishers, 2004), 104-6.

${ }^{246}$ Weyl Carr, Illumination, 210.
} 


\section{Script and Dating}

2372 was copied by a single scribe in a wide, fluent and very regular hand. There are few abbreviations, and these mostly occur at line endings; lambda, chi, theta, delta, epsilon and gamma are often enlarged; and there are a number of majuscule letter forms. Breathings are round; nomina sacra have breathings and accents; the circumflex accent is compact; and there is no mute iota. The hand is very similar to that of 1278 . Buchthal suggests, on artistic grounds, that 2372 was copied at a later date than the Berlin, Cracow and Dionysiou manuscripts, but before Codex $1278 .^{247}$

\section{Illuminations}

F. $115 \mathrm{v}$ contains one extant evangelist portrait for the Gospel of Luke. This portrait has been painted over by a very recent hand, which Horowitz dates to the early twentieth century; little of the original portrait can be detected. ${ }^{248}$ It is likely that 2372 originally contained a complete set of evangelist portraits. ${ }^{249}$ There remain four beautifully painted carpet headpieces ${ }^{250}$ which are original-the palette and style matching perfectly the illuminated zoomorphic letters which the

\footnotetext{
${ }^{247}$ Buchthal, "Byzantine Illumination," 68.

${ }^{248}$ Horowitz, Catalogue, 105.

${ }^{249}$ This would be fitting with the expense and care taken over other illuminations, and, moreover, all other related manuscripts in the Interregnum Subgroup contain complete portrait sets.

${ }^{250}$ F. 2v, f. 70v, f. 116r, f. 188 r.
} 
original scribe left space for. ${ }^{251}$ Each headpiece measures around 10 by $10 \mathrm{~cm}$ and they are decorated with intricate symmetrical patterns and flanked by birds and leafy palmettes. ${ }^{252}$ Buchthal suggests that the original illuminations in 2372 are superior to those in all but one of the other Interregnum manuscripts. $\mathrm{He}$ considers the headpieces 'the most original work in the whole group', after the illuminations of the pre-eminent Dionysiou $4 .^{253} 2372$ also contains a number of illuminated zoomorphic initials, many based on designs and combinations in earlier manuscripts in the Interregnum subgroup. ${ }^{254}$

\section{Correctors and Later Hands}

2372 contains a high number of corrections, but most of these are minor orthographic alterations, most commonly corrections of movables nus. All corrections in the transcription of 2372 have been labelled C.

\footnotetext{
${ }^{251}$ Buchthal, "Byzantine Illumination,"p. 68.

${ }^{252}$ Horowitz, Catalogue, 104.

${ }^{253}$ Buchthal, "Byzantine Illumination," 68.

${ }^{254}$ Buchthal draws particular attention to the cat forming the initial E which begins the Gospel of Luke and matches the same letter in Moscow gr.9. Buchthal, "Byzantine Illumination," 68.
} 
A late colophon on an added leaf records that 2372 was owned in the nineteenth century by a certain Nikolaos Pakoulis or Nikolaos Rakoulis. ${ }^{255}$ It was purchased by the Walters collection from Paris in the early part of the twentieth century. ${ }^{256}$

\section{Transcription of the Gospel of John}

John begins on f. $188 \mathrm{r}$ and John 18:31 breaks off on f. $234 \mathrm{v}$; the rest of the gospel is missing. The Pericope Adulterae is present and stands after John 7:52. The transcription was made from the microfilm.

\subsection{Textual Analysis}

\subsubsection{Previous Research}

Codices 22, 1192 and 1210 were not examined by Lake in his monograph on Family 1 but were later associated with the group by von Soden and Sanders. ${ }^{257}$ Wisse examined the three manuscripts for his profiling in Luke and placed them in his '22b Group'. 258 Anderson collated the three manuscripts for her study of

\footnotetext{
${ }^{255}$ Weyl Carr and Horowitz give different spellings of this name. Weyl Carr, Illumination, 210; Horowitz, Catalogue, 105.

${ }^{256}$ See Horowitz, Catalogue, for manuscripts purchased in this period.

${ }^{257}$ Sanders, “Codex 22,” 91-117.

${ }^{258}$ Wisse, Profile Methods, 53, 72 and 107-8.
} 
Matthew and incorporated them into her family stemma, tentatively concluding that they formed a subgroup descended from A-1 through a shared intermediate ancestor, which Anderson called Y. ${ }^{259}$ The Text und Textwert volumes for John confirm that the three manuscripts are close. In the Gruppierung list for 22, Codices 1210 and 1192 are the closest manuscripts; in Codex 1192's list, 1210 and 22 are the second and third closest manuscripts; and in the list for 1210, 22 and 1192 are the closest manuscripts. ${ }^{260}$

Lake did not examine 1278 and 2372 in his monograph on Family 1; Hoskier first drew attention to 1278 's text in a published collation of 1890 , but did not associate it with Family 1. ${ }^{261}$ Wisse examined both manuscripts in his profiling for Luke, classifying them as '22a' manuscripts. ${ }^{262}$ Anderson examined 1278 in her study of Matthew, but not 2372. She grouped 1278 under 'miscellaneous manuscripts' and concluded that there was not enough textual evidence to incorporate it into her family stemma. ${ }^{263}$ In the Text und Textwert volumes for John, 1278 appears fourth in the Gruppierung list for $2372 .^{264}$

For this study, Codices 22, 1192, 1210, 1278 and 2372 were transcribed and collated in full in the Gospel of John, along with the manuscripts already

\footnotetext{
${ }^{259}$ Anderson, Matthew, 120-132.

${ }^{260}$ Aland, Text und Textwert, vol. 1.1, 55 and 73.

${ }^{261}$ C. Herman Hoskier, A Full Account and Collation of the Greek Cursive Codex Evangelium 604 (London: D. Nutt, 1890), Appendix A, 2-25.

${ }^{262}$ Wisse, Profile Methods, 74, 86 and 107-108.

${ }^{263}$ Anderson, Matthew, 139.

${ }^{264}$ Aland, Text und Textwert, vol. 1.1, 86.
} 
discussed. The results of the collation confirm that the five manuscripts are closely related and form a Family 1 subgroup with two branches: the 22 group, comprising Codices 22, 1192 and 1210, and the Decorative Style group, comprising Codices 1278 and 2372. All five manuscripts have been incorporated into the family stemma for John.

\subsubsection{Family 1 Affinity}

In the Gospel of John, Codices 22, 1192, 1210, 1278 and 2373 show significant textual affinity with the core group manuscripts. Using the criterion that a NonMajority Text reading supported by one or more of the descendants of Manuscript B $(565,884$, and 2193), and one or more of the descendants of Manuscript C (1 and 1582), constitutes an A-1 reading, table 4 tallies the number of A-1 readings in each of the five manuscripts, chapter by chapter. ${ }^{265}$ The first figure given in each cell is the number of A-1 readings that a manuscript contains in that chapter and the second figure is the total number of Non-Majority Text readings in that chapter. Note that 22 is missing text in $14: 22-16: 27$, and 2372 is missing text from 18:31 to the end of the gospel. ${ }^{266}$

\footnotetext{
${ }^{265}$ Corrections in 2193 and first hand corrections in the other core group manuscripts have been counted as agreements. The Pericope Adulterae is not included.

${ }^{266}$ For 22, 1192, 1210, 1278 and 2372, only first hand text readings have been counted, marginal readings and corrections have been ignored.
} 
Table 4: A-1 Readings in 22, 1192, 1210, 1278 and $2372^{267}$

\begin{tabular}{|c|c|c|c|c|c|}
\hline Chapter & 22 & 1192 & 1210 & 1278 & 2372 \\
\hline 1 & $7 / 11$ & $7 / 10$ & $3 / 4$ & $2 / 10$ & $2 / 8$ \\
\hline 2 & $4 / 4$ & $5 / 6$ & $4 / 4$ & $2 / 5$ & $2 / 4$ \\
\hline 3 & $6 / 8$ & $4 / 5$ & $3 / 6$ & $4 / 10$ & $3 / 11$ \\
\hline 4 & $5 / 7$ & $2 / 6$ & $4 / 8$ & $1 / 8$ & $1 / 8$ \\
\hline 5 & $9 / 14$ & $7 / 10$ & $5 / 11$ & $2 / 11$ & $4 / 18$ \\
\hline 6 & $13 / 15$ & $13 / 19$ & $13 / 16$ & $9 / 16$ & $8 / 17$ \\
\hline 7 & $8 / 8$ & $5 / 5$ & $7 / 7$ & $7 / 18$ & $7 / 18$ \\
\hline 8 & $5 / 8$ & $3 / 5$ & $5 / 10$ & $2 / 15$ & $3 / 17$ \\
\hline 9 & $5 / 10$ & $2 / 3$ & $5 / 9$ & $4 / 11$ & $6 / 14$ \\
\hline 10 & $5 / 9$ & $5 / 10$ & $3 / 5$ & $7 / 15$ & $7 / 16$ \\
\hline 11 & $7 / 8$ & $4 / 7$ & $5 / 9$ & $3 / 10$ & $4 / 15$ \\
\hline 12 & $7 / 11$ & $6 / 11$ & $8 / 12$ & $9 / 14$ & $8 / 16$ \\
\hline 13 & $2 / 5$ & $0 / 5$ & $2 / 6$ & $0 / 10$ & $1 / 9$ \\
\hline 14 & 3/7 (lac.) & $2 / 5$ & $4 / 8$ & $2 / 10$ & $2 / 10$ \\
\hline 15 & & $0 / 3$ & $2 / 3$ & $0 / 3$ & $0 / 2$ \\
\hline 16 & & $1 / 3$ & $1 / 6$ & $1 / 6$ & $1 / 7$ \\
\hline 17 & 0/1 (lac.) & $0 / 1$ & $0 / 2$ & $0 / 7$ & $0 / 5$ \\
\hline 18 & $4 / 6$ & $4 / 5$ & $4 / 9$ & $4 / 13$ & 5/14 (lac.) \\
\hline 19 & $9 / 12$ & $3 / 7$ & $8 / 9$ & $7 / 10$ & \\
\hline 20 & $3 / 7$ & $0 / 0$ & $1 / 1$ & $3 / 5$ & \\
\hline 21 & $8 / 10$ & $2 / 5$ & $3 / 3$ & $4 / 5$ & \\
\hline Total & 110/161 & $75 / 131$ & $90 / 148$ & $73 / 212$ & $64 / 209$ \\
\hline
\end{tabular}

267 Note that the group shows signs of block mixture in chapters 13-18. The Venice group manuscripts also contain block mixture, or move away from the family at this point; however, there are no significant agreements between the non-family readings of the Venice group and the 5 manuscripts under discussion here, nor is there any special agreement on the pattern of block mixture. 
In addition to the readings counted in table 4, each manuscript contains a number of other Non-Majority Text readings that are likely to have originated in A-1, but not as certainly as those counted in table 4. These are readings that have the support of either one or more of the core group descendants of B or one or more of the core group descendants of Manuscript C, but not both. Codex 22 has 16 of these readings; Codex 1192 has 12; Codex 1210 has 15; Codex 1278 has 24; and Codex 2372 has 24.

Codices 22, 1192 and 1210 are further linked to A-1 as all three manuscripts omit the text of the Pericope Adulterae, which in A-1 (and four of the core group manuscripts) was located at the end of John as an appendix. By the eleventh and twelfth centuries, when 22, 1192 and 1210 were copied, this appendix may have been lost in an intermediate copy, or a scribe may have failed to copy it, resulting in 22,1192 and 1210 omitting the pericope altogether.

Furthermore, between Codices 22, 1192 and 1278, there is support for 9 marginal readings, some of which are supported by core group manuscripts. 22 contains 5 marginal readings, 1192 contains all 9, and 1278 contains 1 . Of these marginal readings 2 are also supported by 2193 :

1:28 $\beta \eta \theta \alpha \beta \alpha \rho \alpha \quad 122^{\text {txt }} 1192^{\text {txt }} 1278^{\text {mg }} 15822193^{\text {txt }} 2713$ [W] ] $\beta \eta \theta \alpha v i \alpha 22^{\text {mg }}$ 118 131 205abs $\left.20520987212101278^{\text {txt }} 2193^{\mathrm{mg}} 2372 \quad \mathbf{M}\right]$ ] $\beta i \theta v i \alpha 565$ $1192^{\mathrm{mg}}[\mathbf{M}]$

Note: 2193 and 1278 have $\varepsilon v$ re-written in the margin as part of the variant reading; 22 and 1192 do not. 


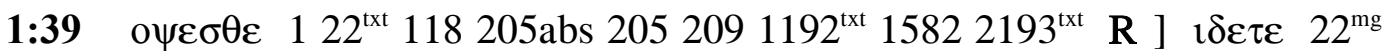
$1315658721192^{\mathrm{mg}} 121012782193^{\mathrm{mg}} 23722713 \mathfrak{M}$

In the case of the 5 remaining marginal readings given below, while no core group manuscript has a corresponding marginal reading, all of the Non-Majority Text readings that form part of the marginal units find support among the text readings of, or corrector readings of, core group manuscripts. ${ }^{268}$

1:19 $\lambda \varepsilon v i \tau \alpha \sigma \quad 122118131$ 205abs $2052095658728841192^{\text {txt }} 12101582$ 2193*2713 M ] $\pi \rho \circ \sigma \alpha v \tau$ ov add $1192^{\mathrm{mg}} 12782193^{\mathrm{Cl}} 2372 \mathrm{~W}$

5:16 lovodior 122 205abs $2052095658841192^{\mathrm{txt}} 12101582 * 2193 * 2713$

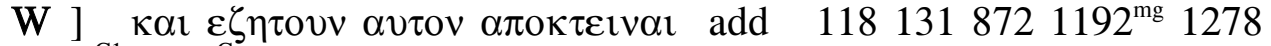
$1582^{\mathrm{C} 1} 2193^{\mathrm{C}} 2372$ M

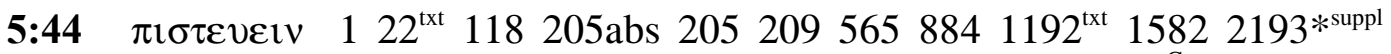
$2713 \mathrm{R}] \pi \iota \sigma \tau \varepsilon v \sigma \alpha \imath \quad 22^{\mathrm{mg}} 1318721192^{\mathrm{mg}} 121012782193^{\mathrm{C}} 2372 \mathfrak{M}$

10:4 $\pi \alpha v \tau \alpha 122^{\text {txt }} 5651192^{\text {txt }} 1582 * 2193 *$ suppl $\quad$ W $] \quad \pi \rho o \beta \alpha \tau \alpha \quad 22^{\text {mg }} 118131$ 205abs $2052098728841192^{\mathrm{mg}} 121012781582^{\mathrm{Cl}} 2193^{\mathrm{C}} 23722713 \mathfrak{M}$

19:13 $\kappa \alpha \pi \phi \alpha \theta \alpha \quad 1^{\text {note }} 225658841192^{\text {mgl[dub] }} 1582$ D ] $\quad \gamma \alpha \beta \beta \alpha \theta \alpha \quad 118$ sup 131 205abs $\left.205^{\mathrm{C}^{*}} 2091192^{\mathrm{txt}} 1210^{\mathrm{C}^{*}} 2193 \mathbf{M}^{\mathrm{pt}}\right] \quad \gamma \alpha \beta \alpha \theta \alpha 205^{*} 1210^{*} 1278$ $\left.2713 \mathbf{M}^{\mathrm{pt}}\right] \kappa \alpha \pi \pi \alpha \theta \alpha 1192^{\mathrm{mg} 2} \quad \mathrm{D}$

Note 1: letters $\kappa \alpha \pi$ smudged.

Note $1192^{\mathrm{mg} 1}$ : letter $\pi$ uncertain.

Furthermore, in the first 4 of these remaining marginal readings, a correction by a $\delta \operatorname{so\rho } \theta \omega \tau \eta \dot{s}$ of 2193 corresponds to the marginal reading. This could suggest that

\footnotetext{
${ }^{268}$ In 19:13, 1192 gives two spellings of a variant place name in the margin: $\kappa \alpha \pi \phi \alpha \theta \alpha$ and $\kappa \alpha \pi \pi \alpha \cdot \theta \alpha .1,565$, and 884 support the first spelling.
} 
the same marginal readings also existed in Manuscript B at the same points, but that the first hand of 2193 missed the readings and they were added instead by the $\delta ı \rho \theta \omega \tau \eta \dot{s}$, who corrected 2193 against its original exemplar. For the final reading in 19:13 there is no such support from a corrector in 2193; however, it should be noted that by chapter 19, Codex 2193 has weakened significantly in its shared affinity with the other core group manuscripts, and so the absence of its support is less significant than if it occurred earlier in the gospel.

\subsubsection{Codices 22, 1192, 1210, 1278, 2372 Share an Intermediate Ancestor}

The collation of the Gospel of John confirms the findings of Anderson: that Codices 22, 1192 and 1210 are members of a distinct textual group, and that 22, 1192 and 1210 share an intermediate ancestor that descends from A-1 independently of the other extant family manuscripts. The collation of 1278 and 2372 indicates that they also descend from this same intermediate ancestor, but through another intermediate copy.

\subsubsection{Shared A-1 Readings}

The five manuscripts share a similar pool of Non-Majority Text readings inherited from A-1. Using the same criterion for an A-1 reading as in table 4, the core group contains a total of 461 A-1 readings. Codices 22, 1192, 1210, 1278 and 2372 share a pool of 145 of these readings, Codex 22 supporting 110 of them; 
Codex 1192, 75; Codex 1210, 90; Codex 1278, 74 and Codex 2372, $62 .{ }^{269}$ This shared pool of readings is the result of a shared intermediate ancestor, which descended from A-1 but retained only this reduced pool of A-1 readings.

Table 5 charts the percentage of agreements on A-1 readings between each of the five manuscripts. The data for each manuscript is recorded in a vertical column, and in each horizontal row of that column is given the percentage of A-1 readings which that manuscript supports in the manuscript cited for the row. Support is first given as a percentage followed by the actual figures of agreements in round brackets. In the first column, row two, for example, we find that Codex 22 supports $89 \%$ of the A-1 readings found in 1192; and in the second column, row one, we find that 1192 supports $60 \%$ of the A-1 readings found in $22 .{ }^{270}$

\footnotetext{
${ }^{269}$ Codex 22 is missing text in 14:22-16:27 where there are 4 A-1 readings supported by other manuscripts in the group and 2372 is missing text from 18:31 to the end of the gospel where there are $26 \mathrm{~A}-1$ readings.

${ }^{270}$ In table 5 only first hand text readings have been counted, correction and marginal readings have not been included.
} 
Table 5: 22, 1192, 1210, 1278 and 2372 Share a Pool of A-1 Readings

\begin{tabular}{|l|c|c|c|c|c|}
\hline & $\begin{array}{c}\mathbf{2 2} \\
\text { Supports }\end{array}$ & $\begin{array}{c}\mathbf{1 1 9 2} \\
\text { Supports }\end{array}$ & $\begin{array}{c}\mathbf{1 2 1 0} \\
\text { Supports }\end{array}$ & $\begin{array}{c}\mathbf{1 2 7 8} \\
\text { Supports }\end{array}$ & $\begin{array}{c}\mathbf{2 3 7 2} \\
\text { Supports }\end{array}$ \\
\hline Codex 22 & & $60 \%(66 / 110)$ & $75 \%(83 / 110)$ & $48 \%(53 / 110)$ & $52 \%(47 / 90)$ \\
\hline Codex 1192 & $89 \%(66 / 74)$ & & $72 \%(54 / 75)$ & $47 \%(35 / 75)$ & $51 \%(35 / 69)$ \\
\hline Codex 1210 & $97 \%(83 / 86)$ & $60 \%(54 / 90)$ & & $51 \%(46 / 90)$ & $54 \%(42 / 78)$ \\
\hline Codex 1278 & $74 \%(51 / 69)$ & $48 \%(35 / 73)$ & $63 \%(46 / 73)$ & & $92 \%(55 / 60)$ \\
\hline Codex 2372 & $75 \%(47 / 63)$ & $55 \%(35 / 64)$ & $66 \%(42 / 64)$ & $86 \%(55 / 64)$ & \\
\hline
\end{tabular}

The figures in table 5 demonstrate the connections between individual pairs of manuscripts through their shared A-1 readings. They reveal a particular closeness between 22 and 1210: with 22, the manuscript with the highest number of A-1 readings, supporting $97 \%$ of 1210 's A-1 readings. The figures also distinguish 1278 and 2372 as a potential subgroup, agreeing relatively closely on a reduced pool of A-1 readings.

\subsubsection{Exclusive Readings}

Codices 22, 1192, 1210, 1278 and 2372 are further bound by a number of NonMajority Text readings that are exclusive to the five manuscripts. These readings provide further evidence of the existence of an intermediate ancestor shared by the group. There are 6 exclusive Non-Majority Text readings which all five 
manuscripts support and 5 of these are rare readings. ${ }^{271}$ These 6 exclusive readings, supported by all five manuscripts, are given below:

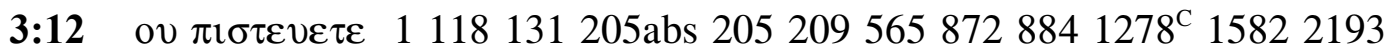

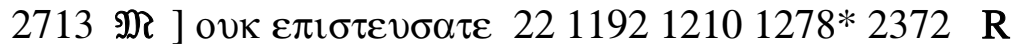

4:14 o 1118131 205abs $205209565872884^{\mathrm{C}} 1278^{\mathrm{C}} 158221932713$ M ] $\varepsilon \gamma \omega$ add $22119212101278 * 2372 \quad \mathbf{R}$

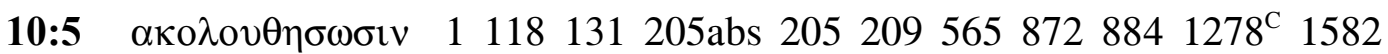

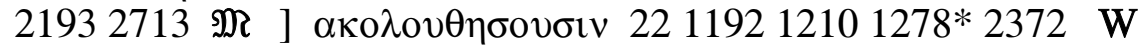

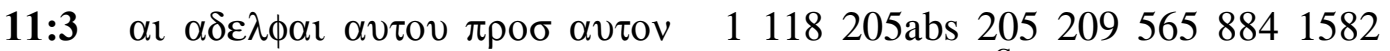

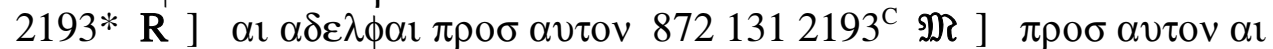
$\alpha \delta \varepsilon \lambda \phi \alpha \imath 221192121012782372$ R ] $\alpha \iota \alpha \delta \varepsilon \lambda \phi \alpha \iota \alpha v \tau o v 2713$ D

13:37 о $\pi \varepsilon \tau \rho \circ \sigma 11582$ 2193* W ] $\pi \varepsilon \tau \rho \circ \sigma 118131$ 205abs 205209565884 $1192^{\mathrm{C}} 1278^{\mathrm{C} 1} 2193^{\mathrm{C}} 2713 \mathfrak{M}$ ] omit $221192^{*} 12101278^{*} 2372 \mathrm{R}$

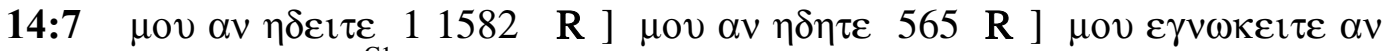
$1318841278^{\mathrm{C} 1} 2193$ M ] $\mu \mathrm{OV} \eta \delta \varepsilon 1 \tau \varepsilon$ ov 22119212102372 R ] $\mu \mathrm{ov}$ $\varepsilon \gamma \nu \omega \kappa \eta \tau \varepsilon \alpha \nu 118$ 205abs 2052092713 D ] $\mu[6] \tau \varepsilon \alpha \nu 1278 *$

There are a further 6 exclusive Non-Majority Text readings supported by four members of the group while one manuscript agrees with the Majority Text. In the case of 1:26, however, 1210, the first hand reading of which is no longer legible, may have originally agreed with the other four manuscripts before it was corrected. The distinctive reading in 18:14 is particularly notable as it constitutes

${ }^{271}$ Note that some of the first hand readings of 1278 have been supplied. 
a significant addition that would not have arisen independently all four manuscripts. These 6 exclusive readings with partial support are given below:

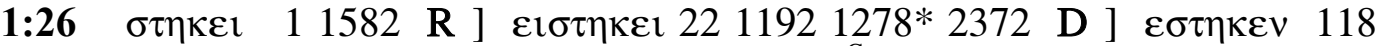
131 205abs $2052095658721210^{\text {pcorr }} 1278^{\mathrm{C}} 21932713 \mathfrak{M}$

Note 1210: first letter possibly a correction.

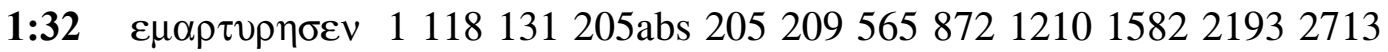
M ] o add 22119212782372 W

5:7 $\quad \varepsilon \gamma \omega \quad 1118131$ 205abs 2052095658728841278158221932713 M ] omit 22119212102372 R

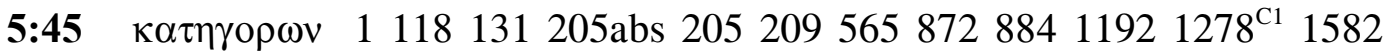

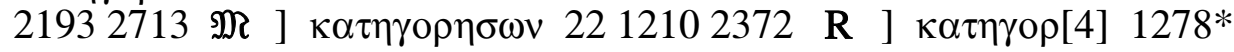

9:19 $\lambda \varepsilon \gamma \varepsilon \tau \varepsilon \quad 1118131$ 205abs $20520956587288411921278^{\mathrm{C}} 15822193$ $2713 \mathfrak{M}$ ] $\varepsilon \lambda \varepsilon \gamma \varepsilon \tau \varepsilon \quad 2212101278 * 2372^{\text {note }} \mathbf{W}$

Note 2372: smudged.

18:14 $\lambda$ oov 1118 sup 131 205abs $20520956588411921278^{\mathrm{C}} 158221932713$

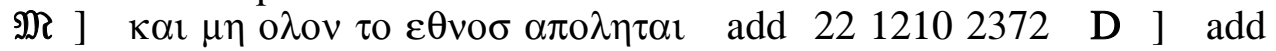
[24] $1278 *$

There is 1 further distinctive and exclusive reading, when 22 is missing text, supported by three of the manuscripts, while the fourth is Majority:

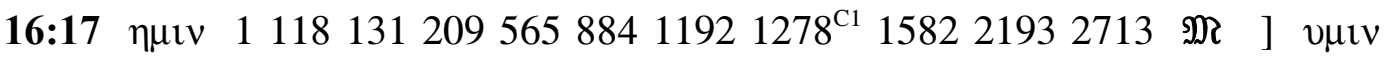
205abs 205 D ] omit $12101278 * 2372$ D 
These exclusive Non-Majority Text readings could not have all arisen independently in the five manuscripts, but must have been inherited from a shared ancestor which contained and transmitted them. It is possible that a number of the readings originated in the ancestor itself.

The marginal readings discussed above provide further evidence of genetic links between the manuscripts. Codices 22 and 1192 agree on 5 of these marginal readings, and 1278 supports one of the five, but with the text and margin reading reversed. $^{272}$

\subsection{6. $\mathrm{G}$ is the Intermediate Ancestor of 22, 1192, 1210, 1278 and 2372}

The best explanation for these five manuscripts' shared pool of A-1 readings, shared exclusive Non-Majority Text readings, and shared marginal readings is the existence of a shared intermediate ancestor. This ancestor will be called Manuscript G. Manuscript $\mathrm{G}$ is a descendant of A-1 which has been substantially corrected towards the Majority Text. ${ }^{273}$ From the evidence of its known descendants, we can presume that it contained at least 145 A-1 readings, 9 marginal readings, and a number of Non-Majority Text readings that may have originated in Manuscript G itself.

\footnotetext{
$2721: 28,1: 39,5: 44,8: 38$.

${ }^{273}$ Or, alternatively, one of its near intermediate ancestors has been corrected.
} 


\subsection{7. $\mathrm{G}$ is an Independent Witness of $\mathrm{A}-1$}

A reconstruction of the text of Manuscript $G$ through the Non-Majority Text readings of its descendants can be used to demonstrate that Manuscript $G$ is independent of the other manuscripts collated for this study. Firstly, Manuscript G contains 14 Non-Majority Text readings that have the support of 1 and/or 1582, but not the support of any descendant of B. The support of 1 and/or 1582 for these readings indicates that the readings were inherited from either A-1 or Manuscript C; and as no descendant of B supports the readings, G's independence from 565 , 884 and 2193 is demonstrated. Secondly, Manuscript G contains 23 NonMajority Text readings that have the support of at least one descendant of B but not of 1 or 1582; and furthermore, G contains 2 marginal readings supported only by 2193. The support for these Non-Majority Text readings from B's descendants indicates that the readings either come from A-1 or Manuscript B; and as neither 1 or 1582 support the readings, G's independence from 1 and 1582 is demonstrated.

\subsubsection{Does Manuscript G Descend from Manuscript C or Manuscript B?}

In chapter 2 of this thesis, it was argued that 1 and 1582 are very close representatives of their shared intermediate ancestor, Manuscript $\mathrm{C}$; that they have received very little correction towards the Majority Text; and that, therefore, the text of Manuscript $\mathrm{C}$ can be largely reconstructed from the agreements of 1 and 1582, with very few $\mathrm{C}$ readings being lost. On the other hand, it was shown that the descendants of Manuscript B have each received more significant amounts of 
Majority Text correction; and, therefore, the text of B cannot be reconstructed from its descendants to the same extent as the text of $\mathrm{C}$ : that is to say, a significant number of Non-Majority Text readings may have existed in B but have not been retained by 565,884 and 2193 . On this basis, we can conclude that the 27 NonMajority Text readings supported by Manuscript $\mathrm{G}$ and the descendants of B are unlikely to have existed in Manuscript C; and so it follows that Manuscript $G$ does not descend from $\mathrm{C}$.

A similar conclusion, however, cannot be made regarding the 14 Non-Majority Text readings supported by Manuscript $\mathrm{G}$ and 1 and/or 1582; for the text of $\mathrm{B}$ cannot be reconstructed from the texts of 565,884 and 2193 to the extent that we can be sure that it did not contain these 14 Non-Majority Text readings. The possibility, therefore, that $\mathrm{G}$ is a descendant of $\mathrm{B}$ cannot be excluded.

In conclusion, Manuscript $\mathrm{G}$ descends from A-1 either through Manuscript B or by another route, independent of both $\mathrm{C}$ and $\mathrm{B}$. The collation of John has not provided sufficient evidence to determine the exact descent of G. On the full family stemma, therefore, a dotted line linking Manuscript G to both A-1 directly and to A-1 through Manuscript B has been employed to indicate this uncertainty.

\subsubsection{Codex 22 is an Independent Witness of Manuscript $G$}

Of the subgroup, Codex 22 has the strongest textual affinity with the core group manuscripts, having retained a higher number of A-1 readings from Manuscript G than any of the other manuscripts in the subgroup. 22 is clearly independent of the 
other four manuscripts, containing 39 A-1 readings without 1192; 27 without 1210; 52 without 1278; and 43 (before 18:31) without 2372.

\subsubsection{Codex 1192 is an Independent Witness of Manuscript G}

1192 is also an independent representative of Manuscript G. It contains 6 A-1 readings where 22 is Majority (and extant); 19 where 1210 is Majority or contains a singular reading; 36 where 1278 is Majority, contains a singular, or has an exclusive agreement with 2372; and 34 (before 18:31) where 2372 is Majority, singular, or has an exclusive agreement with $1278 . .^{274} 4$ of the A-1 readings in 1192 are readings not supported by any of the other four manuscripts in the subgroup. These are reproduced below along with an exclusive Non-Majority Text agreement shared only with the descendants of B:

4 A-1 Readings

2:8 ol $\delta \varepsilon 1118$ 205abs 2052095651192158221932713 W ] $\kappa \alpha$ r 22131 $872121012782372 \mathfrak{M}$

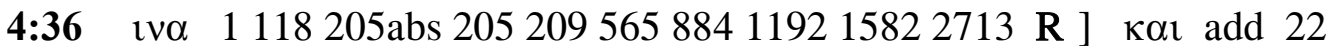
$1318721210127821932372 \mathfrak{M}$

6:40 $\quad \gamma \alpha \rho 1118$ 205abs $2052095658841192158221932713 \quad$ W ] $\delta \varepsilon 22$ $131872121012782372 \quad \mathbf{M}$

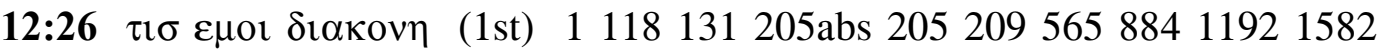

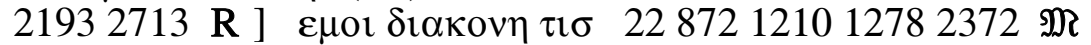

${ }^{274}$ Corrections and marginal readings have been counted as agreements. 
1 Exclusive Non-Majority Text Reading

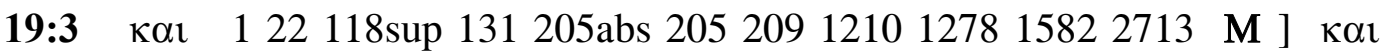

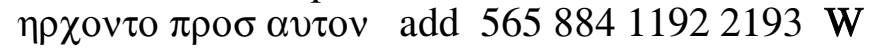

\subsubsection{Codex 1210 is a Copy of Codex 22}

1210 contains 90 A-1 readings: 86 of these occur in sections where 22 is extant, and all but 2 of these 86 readings are shared by $22 .{ }^{275}$ The first A-1 reading which 1210 contains without the support of 22 is a widely attested reading that could have arisen in 1210 independently:

12:30 $\eta \phi \omega v \eta \alpha v \tau \eta 1118205 a b s 2052095658841210158221932713$ W ] $\alpha v \tau \eta \eta \phi \omega \vee \eta 22131872119212782372 \mathfrak{M}$

Notably, all of the other descendants of Manuscript G follow the Majority Text at this point, supporting the suggestion that Manuscript $\mathrm{G}$ may not have contained this reading, but that it originated independently in 1210, through a scribal change. The existence of this reading in 1210, therefore, does not provide evidence of an link to Manuscript $G$ independent of 22. In the second unit, the reading of 22 has been labelled dubious, because of a smudge, visible on the microfilm, and slightly untypical letter forms:

\footnotetext{
${ }^{275}$ In table 5, a total of 3 readings in 1210 were counted as unsupported by 22 . As table 5 did not count corrections, a reading in $3: 24$ was not counted where $22^{\mathrm{C}}$ supports an A-1 reading in 1210 .
} 
6:37 $\mu \varepsilon \quad(1 \mathrm{st}) 1565872884119212101582 \quad \mathrm{R}] \varepsilon \mu \varepsilon \quad 22^{\mathrm{dub}} 118131$ 205abs $2052091278219323722713 \mathfrak{M}$

It is possible that in 6:37, Codex 22 has been corrected, and that the first hand originally read $\mu \varepsilon$, in agreement with 1210 , but that the reading was subsequently altered, being corrected to $\varepsilon \mu \varepsilon$. Neither of these readings, therefore, provide evidence that 1210 might be independent of 22. Aside from this 1 A-1 reading, 1210 only has 7 other Non-Majority Text agreements with collated manuscripts against Codex 22:

8:41 ov $\gamma \varepsilon \gamma \varepsilon v v \eta \mu \varepsilon \theta \alpha \quad 122118131$ 205abs $205209884^{\text {note }} 119212781582$ $21932713 \mathfrak{M}$ ] ov $\gamma \varepsilon \gamma \varepsilon v \eta \mu \varepsilon \theta \alpha \quad 56512102372 \mathrm{R}$ ] оvк $\varepsilon \gamma \varepsilon v v \eta[5]$ 872* ] оขк $\varepsilon \gamma \varepsilon v v \eta \theta \eta \mu \varepsilon \nu 872^{\mathrm{C}} \mathbf{R}$

Note 884: letter $v$ (2nd) juts into the margin.

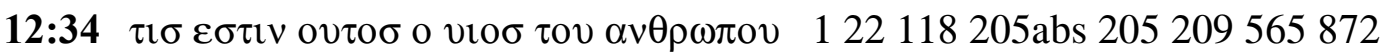
$884119212781582219323722713 \mathfrak{M}$ ] omit $1311210 \quad \mathrm{~W}$

17:7 $\quad \varepsilon \delta \omega \kappa \alpha \sigma \quad 113112101582 \quad \mathrm{R} \quad] \quad \delta \varepsilon \delta \omega \kappa \alpha \sigma \quad 22$ 118sup 205abs 205209 565sup $88411921278219323722713 \mathfrak{M}$

18:9 $\varepsilon \iota \pi \varepsilon v 122$ 118sup $131209565884119212781582219323722713 \mathfrak{M}$ ] $\varepsilon 1 \pi$ ov 205abs $2051210 \mathrm{R}$

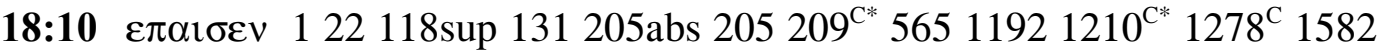
$21932713 \mathfrak{M}] \varepsilon \pi \varepsilon \sigma \varepsilon v 209 * 8841210 * 1278 * 2372 \mathrm{~W}$

18:16 $\tau \eta \theta v \rho \alpha 122$ 118sup 205abs $20520956588411921278^{\mathrm{C}} 15822193 \mathfrak{M}$ ] $\tau \eta v \theta v \rho \alpha 131 \quad 1210 \quad \mathbf{R}$ ] $\tau \eta \nu \theta v \rho \alpha \nu 23722713$ W ] $\tau \eta[1] \quad \theta v \rho \alpha$ $1278^{*}$ 
19:27 $\alpha v \tau \eta v$ o $\mu \alpha \theta \eta \tau \eta \sigma \quad 113156588412781582 \quad \mathbf{M}^{\mathrm{pt}}$ ] o $\mu \alpha \theta \eta \tau \eta \sigma \alpha v \tau \eta \nu$ 22 118sup $11922193 \mathbf{M}^{\mathrm{pt}}$ ] $\alpha v \tau \eta \nu$ o $\mu \alpha \theta \eta \tau \eta \sigma \varepsilon \kappa \varepsilon \imath v o \sigma \quad 205 \mathrm{abs} 205209$ $12102713 \mathrm{~W}$

Each of these agreements is very slight, most amounting to the change of only one or two letters; and four of the variations are widely attested and, therefore, readings which may have arisen independently in the supporting manuscripts. 2 readings are shared only with Codex 131, a manuscript which has an uncertain family affinity in John. ${ }^{276}$ These readings, therefore, do not provide evidence to indicate that 1210 is independent of 22. Codex 22, on the other hand, has $27 \mathrm{~A}-1$ readings when 1210 follows the Majority Text. In 4 of these cases 22 contains a correction towards the Majority Text and it is notable that 1210 follows the Majority correction on every occasion:

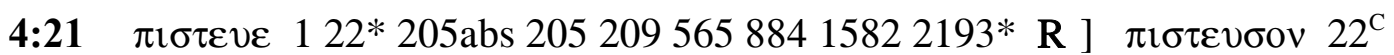
$1181318721192121012782193^{\mathrm{C}} 23722713 \mathfrak{M}$

6:10 $\alpha v \varepsilon \pi \varepsilon \sigma \alpha v \quad 122 * 118$ 205abs 205209 1192* 1582 2193*2713 W ]

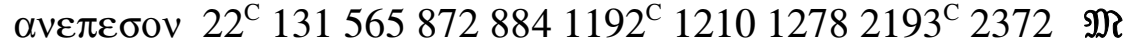

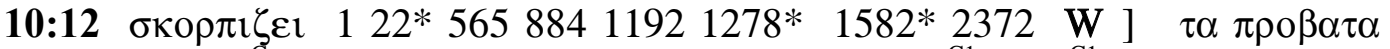
add $22^{\mathrm{C}} 118131$ 205abs $20520987212101278^{\mathrm{C} 1} 1582^{\mathrm{C} 1} 21932713 \mathfrak{M}$

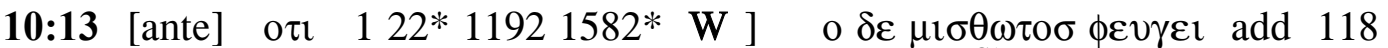
131 205abs $\left.205209565872884121012781582^{\mathrm{Cl}} 219323722713 \mathfrak{M}\right]$ o $\delta \varepsilon \mu \iota \sigma \theta$ o

${ }^{276} 131$ will be discussed in the following chapter. 
In addition, 22 contains 5 marginal readings, given below, where the text reading is Non-Majority and the margin reading Majority. In all but 1 case (8:38), 1210 takes as its text the Majority Text reading given in the margin of 22:

1:28 $\beta \eta \theta \alpha \beta \alpha \rho \alpha \quad 122^{\text {txt }} 1192^{\text {txt }} 1278^{\text {mg }} 15822193^{\text {txt }} 2713$ [W] ] $\beta \eta \theta \alpha v i \alpha 22^{\text {mg }}$

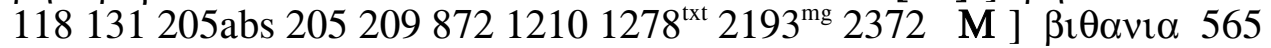
$1192^{\mathrm{mg}}[\mathbf{M}]$

Note: 2193 and 1278 have $\varepsilon v$ re-written in the margin as part of the variant reading; 22 and 1192 do not.

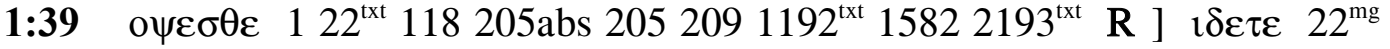
$1315658721192^{\mathrm{mg}} 121012782193^{\mathrm{mg}} 23722713 \mathfrak{M}$

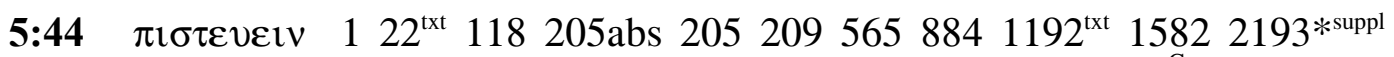
$2713 \mathrm{R}] \pi \imath \sigma \tau \varepsilon v \sigma \alpha \imath \quad 22^{\mathrm{mg}} 1318721192^{\mathrm{mg}} 121012782193^{\mathrm{C}} 2372 \mathfrak{M}$

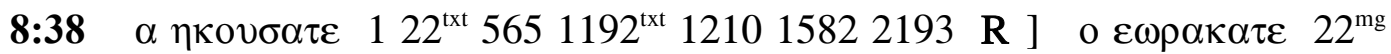
118 205abs $2052098721192^{\mathrm{mg}} 12782713$ M ] $\alpha \varepsilon \omega \rho \alpha \kappa \alpha \tau \varepsilon 8842372$

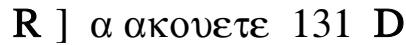

10:4 $\pi \alpha v \tau \alpha 122^{\text {txt }} 5651192^{\text {txt }} 1582^{*} 2193^{\text {suppl }} \quad$ W $] \quad \pi \rho \beta \beta \alpha \tau \alpha \quad 22^{\text {mg }} 118131$ 205abs $2052098728841192^{\mathrm{mg}} 121012781582^{\mathrm{Cl}} 2193^{\mathrm{C}} 23722713 \mathfrak{M}$

This link between the Majority Text corrections and marginal readings in 22 and the text of 1210 offers a further indication that 1210 may be a copy of 22 . Finally, 6 exclusive Non-Majority Text agreements shared only by 1210 and 22 provide further evidence of a copying relationship:

1:32 oqu 1118131 205abs 205209565872119212781582219323722713 M ] omit $221210 \mathrm{R}$ 
3:31 o (1st) 1118131 205abs 2052095658728841192127815822193 $23722713 \mathfrak{M}$ ] omit $221210 \mathrm{D}$

9:7 ovv 1118131 205abs 20520956587288411921278158221932372 $2713 \mathfrak{M}$ ] omit $221210 \mathrm{D}$

9:27 оvк 1118131 205abs 20520956587288411921278158221932372 2713 M ] omit 221210 D

11:25 $\delta \varepsilon \quad 122^{\mathrm{C}} 118$ 205abs 205209565884158221932713 R ] ovv 22* 1210 W ] omit $131872119212782372 \mathfrak{M}$

18:1 $\varepsilon 1 \sigma \eta \lambda \theta \varepsilon v \quad 1$ 118sup 131 205abs 2052095658841192127815822193 $23722713 \mathfrak{M}] \varepsilon 1 \sigma \eta \lambda \theta$ ov $221210 \mathrm{R}$

As would be expected if 1210 were a copy of 22 , the manuscript has no other exclusive Non-Majority Text agreements with single members of the subgroup; whereas 22 has 2 exclusive readings with 1192 while 1210 is Majority. There are 73 first hand disagreements between 1210 and 22. Besides the 29 A-1 readings (2 in 1210, 27 in 22) and 1210's 7 Non-Majority Text agreements with the other manuscripts discussed above, these differences consist of 6 readings where 22 agrees with members of the core group without 1210 (but on readings not counted as A-1 readings); ${ }^{277} 4$ readings where 22 agrees with other members of the subgroup on a Non-Majority Text reading while 1210 is Majority; ${ }^{278} 7$ readings where the Majority Text is split and 22 and 1210 support different Majority

\footnotetext{
${ }^{277} 10: 38,20: 15,20: 25,20: 25,20: 29,21: 4$.

$2781: 26,1: 32,13: 4,19: 32$
} 
readings, ${ }^{279} 6$ singular readings in $22 ;^{.280}$ and 12 singular readings in $1210 .^{281}$ In every case of 22's singular readings, 1210 follows the Majority Text, and in 2 cases, Codex 22 has a Majority Text correction, bringing it into agreement with 1210. 1210's singular readings are mostly omissions of strings of text which are likely to have originated in 1210 itself. $^{282}$ Overall, the evidence indicates that 1210 is a copy of 22.

This conclusion is supported by the results of Anderson's study of the Gospel of Matthew. In Anderson's collation of Matthew 23, she found that 1210 had 5 Non-Majority Text agreements with 1 and 1582, and that all of these readings were supported by 22. Of the 'interesting readings' of 1210 which Anderson lists, only 2 do not have the complete agreement of 22 :

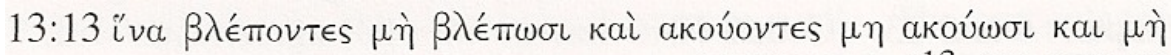

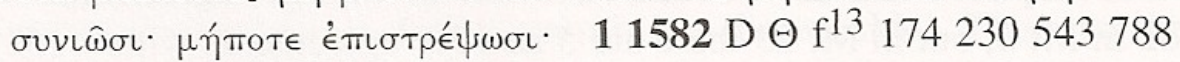

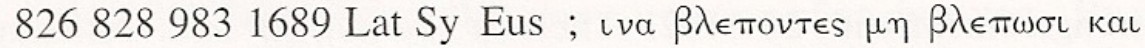

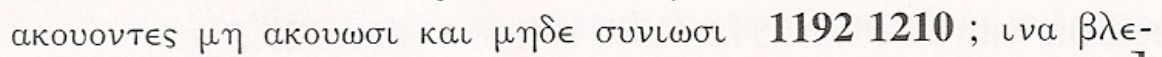

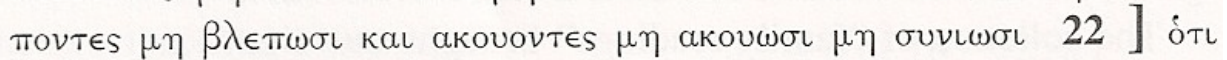

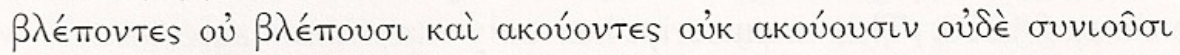

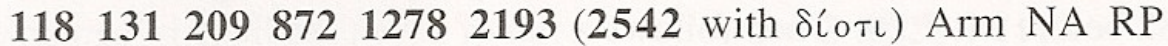

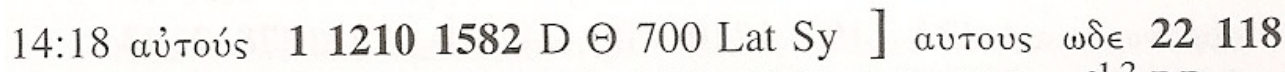
$1312098721192127821932542 \mathrm{C} \mathrm{L} \mathrm{W} \Delta+\mathrm{f}^{13} \mathrm{RP} ; \omega \delta \epsilon$ autous $\aleph \mathrm{B}+33$

${ }^{279}$ Majority Text splits: 1:32, 2:5, 4:35, 18:11, 19:14, 19:35, and 21:1.

${ }^{280} 22$ 's singular readings: $1: 38,5: 8,12: 2,14: 5,19: 24,21: 18$.

${ }^{281} 1210$ in fact has 14 singular readings; but 2 singular readings have already been counted under the category of 'Codex 22 's A-1 readings without 1210', i.e. occasions when 22 contains an A-1 reading while 1210 has a singular reading.

${ }^{282} 1210$ 's singular readings: $3: 11,4: 13,4: 14,5: 36,5: 43,6: 22,6: 51,8: 33,10: 24,11: 16,11: 41$, $13: 30,13: 31,20: 11$. 
These two readings, both widely attested, in the whole of Anderson's chapter collations and family readings collation, are not sufficient to provide evidence of 1210's independence, the widely attested omission of a $\kappa \alpha \mathrm{l}$ and a $\omega \delta \varepsilon$ being possible to occur independently. ${ }^{283}$

\subsubsection{Codices 1278 and 2372 Descend from an Intermediate Ancestor}

1278 and 2372 form a pair that is distinct from the other three manuscripts in the subgroup. They share the same reduced pool of 84 A-1 readings, 1278 supporting 73 , and 2372,$64 ;^{284}$ and they share 39 exclusive Non-Majority Text readings, ${ }^{285}$ 12 of which are distinctive and 22 are rare. The distinctive agreements are listed below:

4:5 $\quad \tau \eta \sigma \sigma \alpha \mu \alpha \rho \varepsilon \iota \alpha \sigma \quad 122118131205 \mathrm{abs} 20520956587288411921210$ $\left.1278^{\mathrm{C} 1} 158221932713 \mathfrak{N}\right]$ omit $1278^{*} 2372 \mathrm{D}$

4:15 $\varepsilon \nu \theta \alpha \delta \varepsilon \alpha \nu \tau \lambda \varepsilon i v \quad 122118131205 \mathrm{abs} 20520956587288411921210$ $\left.1278^{\mathrm{C} 1} 158221932713 \mathfrak{M}\right] \quad \alpha \nu \tau \lambda \varepsilon \iota v \varepsilon v \theta \alpha \delta \varepsilon 1278^{*} 2372 \mathrm{D}$

4:43 $\tau \alpha \sigma \quad 122118131$ 205abs $205209565872884119212101278^{\mathrm{C}} 1582$ $21932713 \mathfrak{N}$ ] omit $1278 * 2372$ D

\footnotetext{
${ }^{283}$ Anderson, Matthew, 130-131. Note: in 13:13, Anderson misses a correction in Codex 22 of $\mu \eta$ to $\mu \eta \delta \varepsilon$ in 22 , bringing it into slightly closer agreement with 1210 and 1192 . See f. $29 \mathrm{v}$ of Codex 22 , line 15 , end of line.

${ }^{284}$ Or a pool of 70 A-1 readings, not counting those after the lacuna in 2372.

285 There are a further 14 possible readings, but where the first hand reading of 1278 has been corrected and is no longer legible: 1:41, 3:21, 5:7, 11:33, 11:34, 13:26, 13:29, 13:35, 14:24, 16:25, 16:32, 17:6, 18:13, 18:22.
} 
4:46 ovv 122118131 205abs $205209565872884119212101278^{\mathrm{C} 1} 1582$ $21932713 \mathfrak{M}$ ] omit $1278 * 2372 \mathrm{D}$

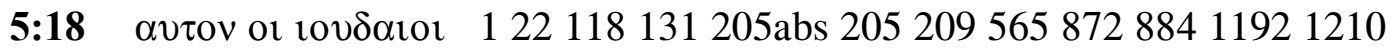

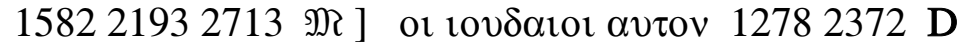

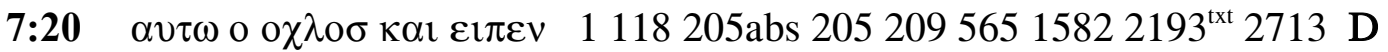

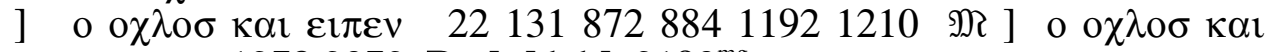
$\varepsilon \imath \pi \varepsilon v \alpha v \tau \omega 12782372$ D ] [dub] $2193^{\mathrm{mg}}$

Note 2193: a marginal reading has been erased.

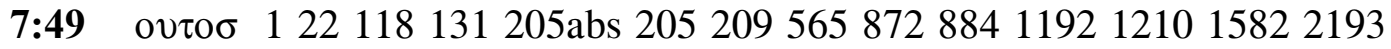
$2713 \mathfrak{N}$ ] omit 12782372 D

8:33 ovdevı 122118131 205abs $205209565872884119212101278^{\mathrm{C}} 1582$ $21932713 \mathfrak{M}$ ] ovdev 1278*2372 D

8:59 ovv 122118131 205abs 2052095658728841192121015822193 $2713 \mathfrak{N}$ ] omit $12782372 \mathrm{D}$

13:8 $\pi \varepsilon \tau \rho o \sigma \quad 122118131$ 205abs $20520987288411921210 \quad 1278^{\mathrm{C}} \quad 1582$ M ] $\sigma \iota \mu \omega v \pi \varepsilon \tau \rho \circ \sigma \quad 1278^{* \text { [suppl] }} 2372$ D ] o $\pi \varepsilon \tau \rho \circ \sigma 21932713$ R

Note 1278: letters $\sigma \mu \omega \omega$ supplied.

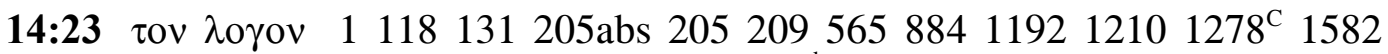

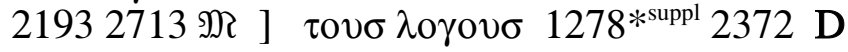

17:12 $\mu \varepsilon \tau \alpha v \tau \omega v \quad 122$ 118sup 131 205abs 205209 565sup 88411921210 $1278^{\mathrm{C} 1} 158221932713 \mathfrak{N}$ ] omit $23721278^{*} \mathrm{D}$

1278 and 2372's shared pool of A-1 readings and their high number of exclusive Non-Majority Text readings provides very strong evidence that they share an 
intermediate ancestor, separating them from the rest of the subgroup. This ancestor will be called Manuscript $\mathrm{H}$.

Codices 1278 and 2372 also both contain (while 22, 1192 and 1210 do not) a text of the Pericope Adulterae located at John 7:52. The text in both manuscripts is very close, with only 2 first hand disagreements:

8:5 $\left.\quad \eta \mu \imath \nu \mu \omega \sigma \eta \sigma \quad 11582 \mathbf{M}^{3 \mathrm{pt} 4}\right] \mu \omega v \sigma \eta \sigma \eta \mu \mathrm{v} 8842193 \sup \mathbf{M}^{1 \mathrm{pt} 5}$ ] $\eta \mu \omega v$ $\mu \omega v \sigma \eta \sigma 118$ 205abs $2052091278 \mathbf{M}^{23 \mathbf{p t} 67}$ ] $\eta \mu \omega v \mu \omega \sigma \eta \sigma 8722713$ $\mathbf{M}^{23 p t 67}$ ] $v \mu \omega v \mu \omega v \sigma \eta \sigma 2372$ D

Note: $\mu \omega v \sigma \eta \sigma$ has been regularised to $\mu \omega \sigma \eta \sigma$ in Hodges and Farstad, Majority Text. Thus in labelling the Family 1 collation for this single unit, the difference between $\mu \omega v \sigma \eta \sigma$ and $\mu \omega \sigma \eta \sigma$ has been ignored.

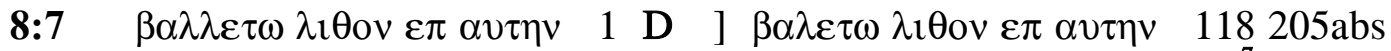
$20520912782372 \mathrm{D}$ ] $\tau$ ov $\lambda_{1} \theta$ ov $\varepsilon \pi \alpha v \tau \eta \beta \alpha \lambda \varepsilon \tau \omega 872^{*} \quad \mathbf{M}^{7}$ ] $\tau$ ov

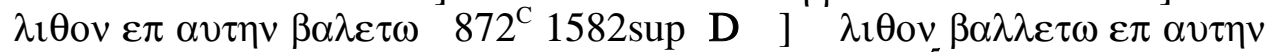
2713 R ] $\varepsilon \pi \alpha v \tau \eta v \tau$ $0 v \lambda_{1} \theta$ ov $\beta \alpha \lambda \varepsilon \tau \omega$ 2192sup $\mathbf{M}^{5}$ ] $\varepsilon \pi \alpha v \tau \eta v \lambda_{i} \theta o v$ $\beta \alpha \lambda \lambda \varepsilon \tau \omega \quad 884 \mathbf{R}$

The text is also very strongly Majority, neither manuscript supporting any of the 12 Non-Majority Text readings found among the core group manuscripts and their supplements, with the exception of a reading in 8:7 where a distinctive agreement shared with 1278, 2372 and the Venice group has the same word order as a reading in Codex 1:

8:7 $\quad \beta \alpha \lambda \lambda \varepsilon \tau \omega \lambda \iota \theta$ ov $\varepsilon \pi \alpha v \tau \eta \nu$ 1 D ] $\beta \alpha \lambda \varepsilon \tau \omega \lambda \iota \theta$ ov $\varepsilon \pi \alpha v \tau \eta \nu 118$ 205abs $20520912782372 \mathrm{D}$ ] $\tau$ ov $\lambda \mathrm{i \theta ov} \varepsilon \pi \alpha \nu \tau \eta \beta \alpha \lambda \varepsilon \tau \omega 872 * \quad \mathbf{M}^{7}$ ] $\tau$ ov $\lambda \mathrm{l} \theta$ ov $\varepsilon \pi \alpha v \tau \eta v \beta \alpha \lambda \varepsilon \tau \omega \quad 872^{\mathrm{C}}$ 1582sup D ] $\lambda \mathrm{l} \theta$ ov $\beta \alpha \lambda \lambda \varepsilon \tau \omega \varepsilon \pi \alpha v \tau \eta v$

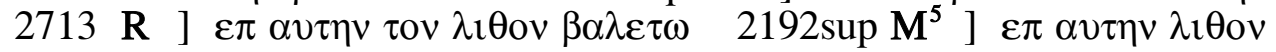
$\beta \alpha \lambda \lambda \varepsilon \tau \omega \quad 884 \mathbf{R}$ 
The pair only contains 2 other Non-Majority Text readings in the pericope. The first, only supported by 2372 , is not significant, consisting of only the change of $\eta \mu \omega v$ to $v \mu \omega v$, a characteristic slip very common to the scribe of $2372 ;^{286}$ and the second, a reading that is exclusive to the two manuscripts:

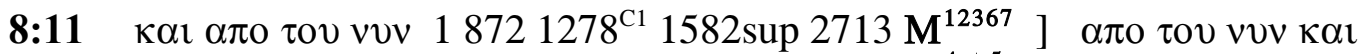

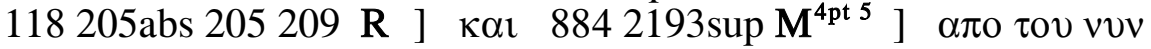 $1278 * 2372 \mathrm{D}$}

The closeness of the text of the Pericope Adulterae in 2372 and 1278 indicates that the scribes of both manuscripts copied the pericope from their shared ancestor, Manuscript $\mathrm{H}$. As both codices place the story after John 7:52, it is probable that Manuscript $\mathrm{H}$ also included it at this location. Given that the other descendants of G, Codices 22 and 1192 (and 1210) do not contain the pericope, there are two possibilities regarding whether Manuscript $G$ contained it and where. The first possibility is that Manuscript $\mathrm{H}$ copied the pericope from Manuscript $\mathrm{G}$ where it was located at the end of the gospel, but that the pericope was lost or detached before Codices 22 and 1192 were copied. (This would mean that Manuscript $\mathrm{H}$ is older than 22 and 1192.) It is unlikely if Manuscript $\mathrm{G}$ contained the pericope that it was located at 7:52, otherwise 22 and 1192 would have included it. The alternative scenario is that $\mathrm{G}$ did not contain the pericope but that Manuscript $\mathrm{H}$ copied it from another manuscript. Given that the text of

\footnotetext{
${ }^{286}$ See above, unit 8:5. Many of these 'slips' have been regularised out of the collation because they cause a nonsense reading. Variations of $\nu \mu \omega v$ and $\eta \mu \omega v$ etc. have only been left in the collation if they can make some sense.
} 
the pericope in 1278 and 2372 shows no special connection to the text found in the core group manuscripts, the latter alternative is the most probable. In any case, if the first scenario were correct, any textual link to the pericope of A-1 has been erased through Majority Text correction. For either scenario, the witness of 1278 and 2372 for the text of the Pericope Adulterae is of little use for the reconstruction of the text found in A-1.

\subsubsection{Codices 1278 and 2372 are Sibling Manuscripts}

1278 and 2372 are independent of one another. This can be demonstrated because they both contain a number of A-1 readings where the other manuscript is Majority. Before 2372's lacuna, 1278 contains 5 A-1 readings without 2372:

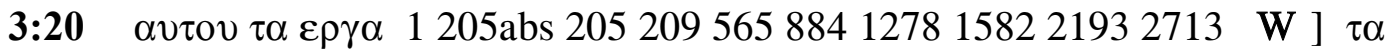

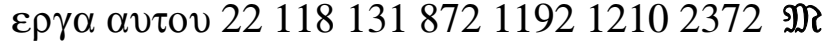

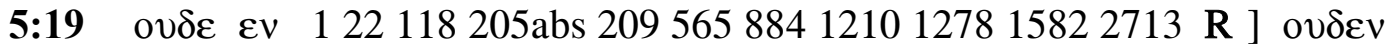
$13120587211922193^{\text {pcorr }} 2372 \mathfrak{M}$

6:12 $\varepsilon \pi \lambda \eta \sigma \theta \eta \sigma \alpha \nu \quad 122118131$ 205abs 205209565884119212101278 1582*2193*2713 R ] $\varepsilon v \varepsilon \pi \lambda \eta \sigma \theta \eta \sigma \alpha \nu 8721582^{\mathrm{C} 1} 2193^{\mathrm{C}} 2372 \mathfrak{M}$

7:9 $\quad \tau \alpha v \tau \alpha \quad 1118$ 205abs $2052095651278 * 15822193 \mathrm{R}] \quad \delta \varepsilon$ add 22131 $872884119212101278^{\mathrm{Cl}} 23722713 \mathfrak{M}$

12:13 o (2nd) 122118 205abs $2052095658841192^{\mathrm{C}} 12101278 * 1582^{*} \mathrm{~W}$ ] omit $1318721192 * 1278^{\mathrm{C}} 1582^{\mathrm{C} 1} 219323722713 \mathfrak{M}$

Note 1582: text supplied. 
Codex 1278 contains an additional 2 Non-Majority Text agreements with 1 and 1582 , without 2372 , one of which is rare:

1:42 $\sigma \mu \omega \nu$ v $1209 * 1278 * 1582 * \mathbf{R}]$ o add 22118131 205abs $205209^{\mathrm{C} *}$ $565872119212101278^{\mathrm{C}^{*}} 1582^{\mathrm{Cl}} 219323722713 \mathfrak{M}$

14:12 $\pi \alpha \tau \varepsilon \rho \alpha \quad 122119212101278 * 1582 * \mathrm{~W}] \mu$ ov add 118131 205abs 205 $2095658841278^{\mathrm{C} 1} 1582^{\mathrm{C}} 219323722713 \mathfrak{M}$

Codex 2372 contains 6 A-1 readings without the support of 1278, including one occasion (9:15) where 1278 is deficient for a long string of text:

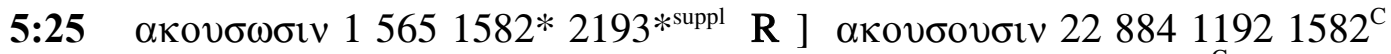

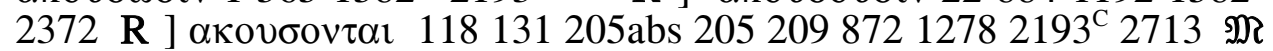
] $\alpha \kappa o[3] v \tau \varepsilon 1210$

5:47 $\pi 1 \sigma \tau \varepsilon v \sigma \eta \tau \varepsilon ~ 1118$ 205abs $2052095651582 * 2193 *$ suppl 23722713 W ] $\pi 1 \sigma \tau \varepsilon v \sigma \varepsilon \tau \varepsilon \quad 221318728841192121012781582^{\mathrm{Cl}} 2193^{\mathrm{C}} \mathfrak{M}$

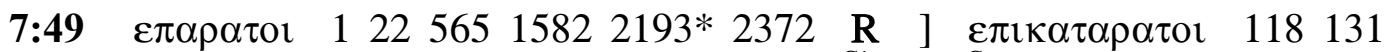

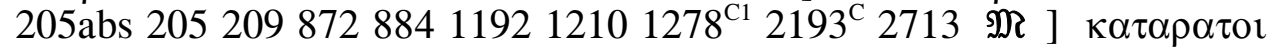
$1278 * \mathrm{D}$

8:12 $\left.\pi \varepsilon \rho \imath \pi \alpha \tau \sigma \varepsilon \imath 1565^{*} 1582 * 2193^{\text {pcorr }} 2372 \mathrm{~W}\right] \pi \varepsilon \rho \imath \pi \alpha \tau \eta \sigma \eta 22118131$ 205abs $205209565^{\mathrm{C}} 8728841192121012781582^{\mathrm{Cl}} 2713 \mathbf{M}$

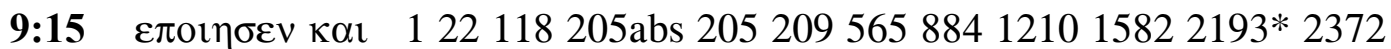
2713 R ] omit $13187211921278^{\mathrm{Cl}} 2193^{\mathrm{C}} \mathfrak{M}$

9:16 $\delta \varepsilon \quad 122 \quad 118$ 205abs $205209565119212101582219323722713 \quad$ R ] omit 1318728841278 M 
Codex 2372 also contains 1 Non-Majority Text agreement with $2193^{\text {txt }}$ (2:17), 1 with 884 (8:38), 1 with the other descendants of G (5:7), and 1 with Codex 1 and 1582 (6:43), all against 1278:

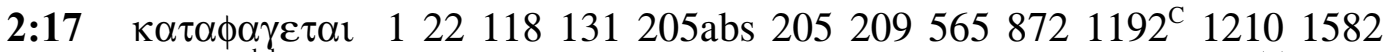
$2193^{\text {mgdub }} 2713$ M ] $\kappa \alpha \tau \alpha \phi \alpha \gamma \varepsilon \tau \varepsilon 1192 *$ R ] $\kappa \alpha \tau \varepsilon \phi \alpha \gamma \varepsilon v 2193^{\text {txt }} 2372$ W ] $\kappa \alpha \tau \varepsilon \phi \alpha \gamma \varepsilon \tau \alpha l \quad 1278 \quad \mathbf{R}$

8:38 $\left.\alpha \eta \kappa o v \sigma \alpha \tau \varepsilon 122^{\text {txt }} 5651192^{\text {txt }} 121015822193 \mathbf{R}\right]$ о $\varepsilon \omega \rho \alpha \kappa \alpha \tau \varepsilon 22^{\text {mg }}$ 118 205abs $2052098721192^{\mathrm{mg}} 12782713 \mathfrak{M}$ ] $\alpha \varepsilon \omega \rho \alpha \kappa \alpha \tau \varepsilon 8842372$ R ] $\alpha \alpha \kappa o v \varepsilon \tau \varepsilon 131 \mathrm{D}$

5:7 $\quad \varepsilon \gamma \omega \quad 1118131$ 205abs 2052095658728841278158221932713 M ] omit 22119212102372 R

6:43 ovv 1118 205abs $2052091582 * 2372 * 2713$ R ] ovv o 22131565872 $8841192121012781582^{\mathrm{Cl}} 2193^{*} 2372^{\mathrm{C}} \mathfrak{M}$ ] o $2193^{\mathrm{C}} \mathbf{R}$

\subsubsection{Manuscript $H$ is Independent of 22 and 1192}

Manuscript $\mathrm{H}$ can be shown to be an independent representative of Manuscript $\mathrm{G}$, not dependent on either 22 or 1192. Between H's two descendants, 1278 and 2372, there are 18 A-1 readings that are not supported by 22 or 1192 (or 1210). 7 of these readings are labelled rare and are reproduced below:

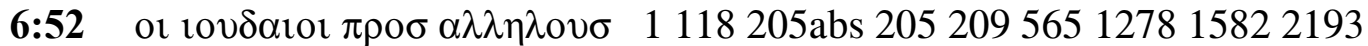

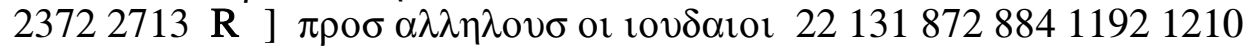
M

7:9 $\quad \tau \alpha u \tau \alpha \quad 1118$ 205abs $2052095651278 * 15822193 \quad \mathbf{R}] \quad \delta \varepsilon$ add 22131 $872884119212101278^{\mathrm{Cl}} 23722713 \mathfrak{M}$ 
12:28 $\pi \alpha \tau \varepsilon \rho ~ 1^{*} 22118$ 205abs $205209565872884119212101278^{\mathrm{C}} 1582$ $2193 * 2713 \mathfrak{M}$ ] $\alpha \gamma 1 \varepsilon$ add $1^{\mathrm{C}} 1312193^{\mathrm{C}} 2372 \mathrm{R}$ ] [4] add $1278^{*}$

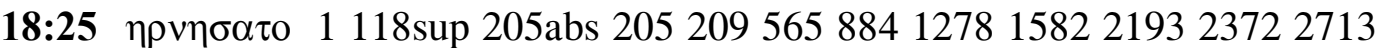
R ] ovv add 2213111921210 M

19:28 $\eta \gamma \rho \alpha \phi \eta \pi \lambda \eta \rho \omega \theta \eta \quad 1$ 205abs $2052095658841278 \quad 15822713 \quad$ R ] $\tau \varepsilon \lambda \varepsilon \iota \omega \theta \eta \eta \gamma \rho \alpha \phi \eta 22$ 118sup 131119212102193 M

20:23 $\alpha \phi \varepsilon \omega \nu \tau \alpha l 1205$ abs $2052095651582 \quad$ R ] $\alpha \phi \imath \varepsilon v \tau \alpha \imath 22$ 118sup 131884 $119212101278^{\mathrm{Cl}} 21932713 \mathfrak{M}$ ] $\alpha \phi[2] v \tau \alpha 11278^{*}$

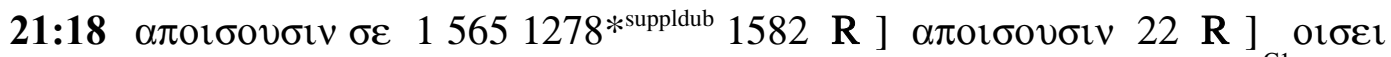

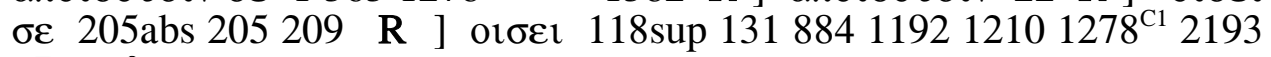
$2713 \mathfrak{M}$

Note $1278^{*}$ presence of $\sigma \varepsilon$ uncertain. ${ }^{287}$

These links to the A-1 readings in Manuscript $G$ show that Manuscript $H$ is independent of both 22 and 1192.

\subsubsection{Note on Correctors}

In John, Codex 22 contains 7 Majority Text corrections and 6 Non-Majority Text corrections. 3 of the Non-Majority corrections are A-1 readings and a further correction is an agreement with 1, 1582, 1278 and 2372 :

\footnotetext{
${ }^{287}$ Note in 20:23 the agreement of 1278 has been conjectured; in 21:18, 22 has partial support for the $\mathrm{A}-1$ reading.
} 
3 A-1 Corrections in 22:

3:24 $\left.\varepsilon 1 \sigma \quad 122^{\mathrm{C}} 565884121015822193 \quad \mathbf{R}\right] \tau \eta v$ add $22 * 118131$ 205abs $2052098721192127823722713 \mathfrak{M}$

10:21 $\alpha$ vor $\xi \alpha \mathrm{l} 122^{\mathrm{C}} 118$ 205abs 2052095658841582 2193*2372 2713 R ]

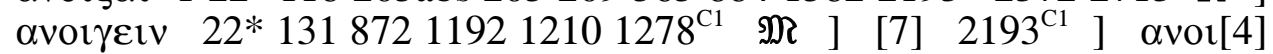
$1278^{*}$

Note 2193: a C1 reading has been erased.

11:25 $\delta \varepsilon \quad 122^{\mathrm{C}} 118$ 205abs $\left.205209565884158221932713 \quad \mathbf{R}\right]$ ovv 22* 1210 W ] omit $131872119212782372 \mathfrak{M}$

1 Non-Majority Text Correction in 22:

17:17 $\alpha \lambda \eta \theta \varepsilon 1 \alpha \quad 122^{\mathrm{C}} 1278$ 1582*2372 W ] $\quad$ Wov add $22 * 118$ sup 131 205abs $205209565884119212101582^{\mathrm{C}} 21932713 \mathfrak{M}$

Codex 1192 contains 8 Majority Text corrections and 1 Non-Majority Text correction, a widely attested A-1 reading:

12:13 o (2nd) 122118 205abs $2052095658841192^{\mathrm{C}} 12101278^{*} 1582^{*} \mathrm{~W}$ ] omit $1318721192 * 1278^{\mathrm{C}} 1582^{\mathrm{C} 1} 219323722713 \mathfrak{M}$

Note 1582: text supplied.

1210 contains 9 corrections and these are all towards the Majority Text. 1278 contains 126 Majority Text corrections and 10 Non-Majority Text corrections. 4 of the Non-Majority Text corrections are A-1 readings and 1 has the support of 884: 
4 A-1 Corrections in 1278:

1:43 $\eta \theta \varepsilon \lambda \eta \sigma \varepsilon v 122118$ 205abs $205209565872119212101278^{\mathrm{C}} 15822193$

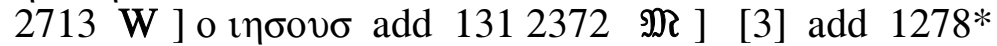

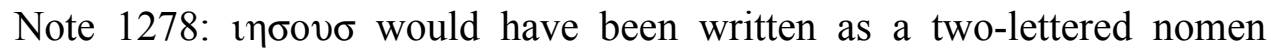
sacrum: $\imath \bar{\sigma}$.

6:35 $\delta \varepsilon \quad 122 \quad 118131 \quad 205 a b s 2052095658728841192 \quad 12101278^{\mathrm{C}} 1582$ $2193 \mathbf{R}$ ] ovv 2713 M ] omit $1278 * 2372$ R

6:58 $\tau \rho \omega \gamma \omega v \quad 122118131$ 205abs $205209565872119212101278 * 1582$ 219323722713 M ] $\mu$ ov add $8841278^{\mathrm{C} 1}$ W

9:17 ovv 1118 205abs $2052095658841278^{\mathrm{C} 1} 15822193 * 2713$ W ] omit $22131872119212101278^{*} 2193^{\mathrm{C}} 2372 \mathbf{M}$

1 Correction with the Support of 884 :

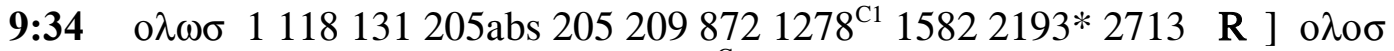
$22565884119212101278^{*} 2193^{\mathrm{C}} 2372 \mathbf{M}$

Codex 2372 contains 4 Majority Text corrections, 1 illegible but minor correction (10:38), and 2 Non-Majority Text corrections, one of which has the agreement of 2 descendants of $\mathrm{B}$ :

9:31 $\alpha \mu \alpha \rho \tau \omega \lambda \omega v \quad 122118$ 205abs 2052098728841192121012781582 $2193^{\mathrm{C}} 2372 * \mathfrak{M}$ ] $\alpha \mu \alpha \rho \tau \omega \lambda$ ov $1315652193 * 27132372^{\mathrm{C}} \quad \mathrm{W}$

These A-1 corrections found among the five manuscripts, and the corrections supported by single branches of the core group, are likely to be first hand corrections, made by the scribes of each manuscript, using the same exemplar as the manuscript was copied from, or else corrections by a $\delta 10 \rho \theta \omega \tau \eta \dot{s}$ working in 
the same scriptorium. ${ }^{288}$ The higher numbers of A-1 corrections in 22 and 1278 strengthen the evidence for the group's link with the rest of Family 1, and indicates that Manuscript $\mathrm{G}$ contained further A-1 readings to those supported by the texts of these five manuscripts.

\subsubsection{Summary of a Manuscript Subgroup}

Codices 22, 1192, 1210, 1278 and 2372 form a Family 1 subgroup with two branches. Manuscript $\mathrm{G}$ is the shared ancestor of the whole group and Manuscript $\mathrm{H}$ the shared intermediate ancestor of codices 1278 and 2372. All manuscripts but 1210 are independent representatives of Manuscript G; and Manuscript $\mathrm{G}$ is an independent representative of A-1, descending either through Manuscript B or another route. The diagram below expresses these relationships as a stemma.

${ }^{288}$ As a general rule, correctors have only been distinguished in manuscripts that have been physically examined, not in those transcribed only from the microfilm. 
Figure 5: Stemma for Manuscript G

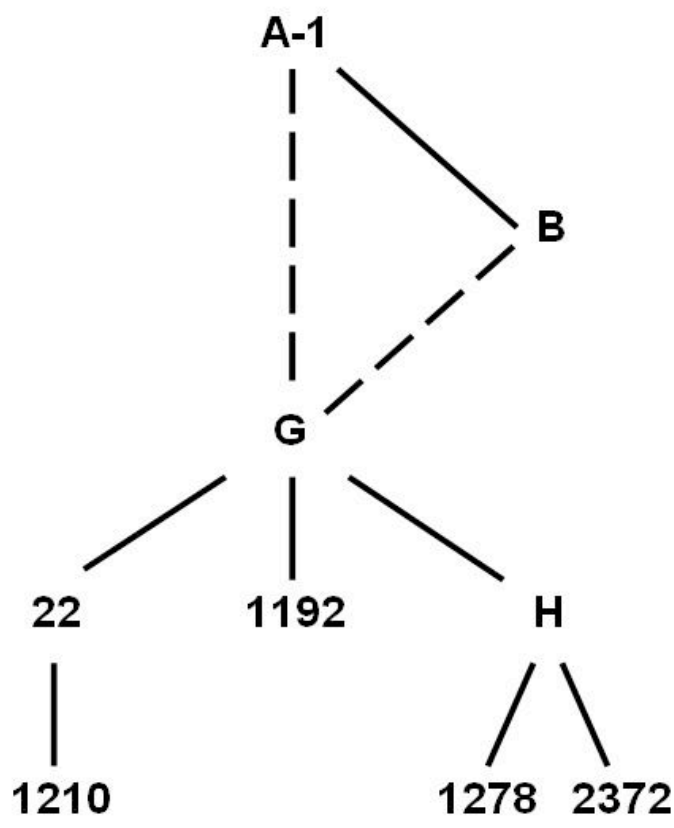




\section{Miscellaneous Manuscripts}

\subsection{Manuscript Description of Codex 131}

\section{Contents and Layout}

Codex 131 is a thirteenth-century codex containing the Gospels, Acts, the Catholic Epistles and the Pauline Epistles, including Hebrews. It is kept at the Vatican library where it is designated Gr. $360 .^{289}$ The codex contains 233 parchment folios with text written in 2 columns per page with 30-38 lines to a column. Pages measure 23.5 by $17.5 \mathrm{~cm}$ and the columns of text 15.4 by $4.8 \mathrm{~cm} .^{290}$ The manuscript contains Eusebius's letter to Carpianus, canon tables and Ammonian sections, $\kappa \varepsilon \phi \alpha ́ \lambda \alpha \imath \alpha$ and partial lectionary material. Each gospel begins on a fresh recto page, beneath a decorative headpiece and begins with a large ornamental initial. Smaller rubricated initials appear throughout the codex; the main text is written in brown ink. ${ }^{291}$

\section{Script and Dating}

The script of 131 is regular and clear, though letters do not fit neatly onto the line. There is little variation in letter size, some ligatures and abbreviations, the latter occurring mostly at line endings; nomina sacra have accents and breathings; the

\footnotetext{
${ }^{289}$ Other references: von Soden $\delta 467$.

${ }^{290}$ Codicological information not evident from the microfilm is taken from Gregory, Textkritik, Erster Band, 156; and Hatch, Facsimiles, 246.

${ }^{291}$ Hatch, Facsimiles, 246.
} 
circumflex is the length of one letter and raised above other marks; breathings are round; and there is no mute iota. On the basis of a palaeographical analysis, Turyn has identified the scribe of 131 as the priest Andreas who also copied and signed a dated manuscript containing Anastasius Sinaita's Questions and Answers: Brescia, Bibl. Civica Queriniana, MS A.VII.25. This manuscript of Anastasius contains a colophon dating it to $1286 / 87 .^{292}$ If Turyn's analysis is correct we can presume that 131 was also copied sometime in the second part of the thirteenth century. Such a dating is supported by a colophon in 131, added by a later hand, but dated to 1303 , indicating that the manuscript was in existence by then. $^{293}$

\section{Illuminations}

There are no portraits in 131. It is unclear from the microfilm whether decorated headpieces and canon tables are illuminated; Gregory only records that initials are given in red ink. ${ }^{294}$

\footnotetext{
292 A. Turyn, Dated Greek Manuscripts of the Thirteenth and Fourteenth Centuries in the Libraries of Italy (Chicago: University of Illinois Press, 1972), vol. 1, 52; vol. 2, plate 38.

${ }^{293}$ See Lake, Codex 1, xviii, for further discussion of the colophon.

${ }^{294}$ Gregory, Textkritik, Erster Band, 156.
} 
A number of later hands have added supplementary material to 131 and one hand has made various orthographic corrections throughout the manuscript. As it was not possible to examine the manuscript itself, all corrections have been labelled $\mathrm{C}$.

\section{Provenance}

131 was previously owned by Aldus Manutius the Younger (1547-97), the grandson of the Venetian humanist and printer Aldus Manutius (1449-1515). Manutius the Younger gave the manuscript to Pope Sixtus V (1585-90) and it has been kept at the Vatican ever since. ${ }^{295}$ Various names have been written on blank pages in the codex, in a hand much earlier than the fifteenth century. Lake has suggested that as these names include those of women and children, the codex was not owned by a monastery, but by a private individual, when these names were added. ${ }^{296}$

\section{Transcription of the Gospel of John}

The Gospel of John begins on f. 107r and ends on f. 132r. The Pericope Adulterae is omitted without comment. The manuscript was transcribed from the microfilm.

\footnotetext{
${ }^{295}$ Scrivener, Introduction, 199.

${ }^{296}$ Lake, Codex 1, xviii.
} 


\subsection{Textual Analysis of Codex 131}

\subsubsection{Previous Research}

Lake included Codex 131 in Family 1 for Mark 1-5 and Luke 1-24. He concluded that in these sections Codex 131 descended from the family archetype (Lake's W), but was not a copy of Codex 1 and did not descend from the intermediate ancestor of the Venice group (for Lake, Codices 118 and 209). ${ }^{297}$ Lake concluded that in the other sections of Mark and Luke, and in the whole of Matthew and John, 131 follows closely the Majority Text with only 'a certain number of variants' ${ }^{298}$ In his critical edition, Lake only cited the readings of 131 for Mark 1-5 and Luke 1-24.

For Luke 1, 10 and 20, Wisse has confirmed Lake's results, classifying 131 in these chapters as part of his 'Group 1' along with Codices 1, 118, 205, 209 and 1582, and, in chapter 20, $884 .{ }^{299}$ Anderson has also confirmed Lake's conclusion for Matthew, classifying 131 as a primarily Majority Text manuscript and grouping it along with other 'Miscellaneous Manuscripts'. The results of the collation of John show that 131 is not a clear Family 1 manuscript in the gospel, but that it contains a certain number of readings that link it to the group and indicate that it may be related to a very distant Family 1 ancestor in John.

\footnotetext{
${ }^{297}$ Lake, Codex 1, xxiv, xxxiv-xxxv.

${ }^{298}$ Lake, Codex 1, xxxiv.

${ }^{299}$ Wisse, Profile Methods, 55.
} 


\subsubsection{Family 1 Affinity}

Codex 131 contains 34 Non-Majority Text A-1 readings in John. ${ }^{300} 22$ of these are widely attested and 12 are rare. There are a further 69 readings where 131 agrees on a Non-Majority Text reading with at least one other manuscript collated. These readings may not be sufficient to confirm 131 as a definite Family 1 manuscript in John, or to incorporate the manuscript into the family stemma; however, they do provide evidence that 131 in John may descend from either a very distant Family 1 ancestor or an ancestor that was heavily corrected to the Majority Text in John. This is supported by the fact that 131 does not include the Pericope Adulterae, a characteristic of many Family 1 manuscripts. The absence of the pericope suggests that 131 may descend from a Family 1 ancestor that contained the pericope as an appendix but which was then lost before the scribe of 131 copied the manuscript. Given 131's Family 1 affinity in sections of Mark and Luke, it would be reasonable to suggest that the A-1 readings and other Non-Majority Text agreements with family members come from this same ancestor in John, but that the text of John in this ancestor was heavily corrected or else damaged in parts, so that much of the family text was substituted with readings from the Majority Text.

\footnotetext{
${ }^{300}$ Using the criterion of agreement between at least 1 descendant of $\mathrm{B}$ and at least 1 descendant of $\mathrm{C}$.
} 


\subsubsection{Family Relationships}

Table 6 records the number of Non-Majority Text agreements 131 has with each of the other manuscripts collated. The first column tallies the number of agreements on A-1 readings; the second column, the number of agreements on other Non-Majority Text readings (not those counted as definite A-1 readings); the third column gives the number of exclusive Non-Majority Text agreements which 131 has with each manuscript; and the fourth column, the overall number of Non-Majority Text agreements. The other manuscripts are listed in order, according to their total number of Non-Majority Text agreements with 131, beginning with the manuscript with the highest number of agreements. The agreements of correctors have been counted separately and are given in the row immediate below the first hand agreements of that manuscript. ${ }^{301}$

\footnotetext{
${ }^{301}$ Note some of the readings of $1278^{*}$ have been supplied.
} 
Table 6: 131's Non-Majority Text Agreements

\begin{tabular}{|c|c|c|c|c|}
\hline & $\begin{array}{c}\text { Agreements } \\
\text { on A-1 } \\
\text { Readings }\end{array}$ & $\begin{array}{c}\text { Non-A-1 } \\
\text { NMT } \\
\text { Agreements }\end{array}$ & $\begin{array}{c}\text { Exclusive } \\
\text { NMT } \\
\text { Agreements }\end{array}$ & $\begin{array}{c}\text { Total of } \\
\text { NMT } \\
\text { agreements }\end{array}$ \\
\hline 2193 & 28 & 15 & 8 & 43 \\
\hline $2193^{\mathrm{C} / \mathrm{C} 1 / \mathrm{MG}}$ & 2 & 10 & 6 & 12 \\
\hline 205abs & 28 & 14 & 0 & 41 \\
\hline 205 & 28 & 14 & 1 & 41 \\
\hline 209 & 27 & 13 & 1 & 40 \\
\hline $209^{C}$ & 1 & 0 & 0 & 1 \\
\hline 565 & 29 & 9 & 1 & 38 \\
\hline 2713 & 25 & 11 & 1 & 36 \\
\hline 118 & 23 & 12 & 2 & 35 \\
\hline $118^{C}$ & 1 & 1 & 1 & 2 \\
\hline 1 & 33 & 2 & 0 & 35 \\
\hline $1^{\mathrm{C}}$ & 1 & 0 & 0 & 1 \\
\hline 1582 & 31 & 2 & 0 & 33 \\
\hline 884 & 22 & 10 & 5 & 32 \\
\hline 1278 & 8 & 16 & 3 & 24 \\
\hline $1278^{\mathrm{C} / \mathrm{C} 1}$ & 2 & 0 & 0 & 2 \\
\hline 1192 & 10 & 10 & 3 & 20 \\
\hline 2372 & 5 & 14 & 0 & 19 \\
\hline $2372^{C}$ & 0 & 1 & 0 & 1 \\
\hline 1210 & 9 & 9 & 1 & 18 \\
\hline 22 & 9 & 6 & 0 & 15 \\
\hline 872 & 2 & 7 & 0 & 9 \\
\hline
\end{tabular}


Although 131's Family 1 affinity in John is only slight, an analysis of its NonMajority Text agreements with established family manuscripts and groups can give a hint, at least, to 131 's possible Family 1 descent. Of the 69 Non-Majority Text readings not classified as A-1 readings, only 2 have the agreement of 1 or 1582, while 34 have the agreement of at least one of the descendants of Manuscript B. As table 6 shows, 2193 has the highest number of Non-Majority Text agreements with 131: 55 including 131's agreements with 2193's corrections and marginal readings. 205abs, 205 and 209 follow 2193 in the table; however, many of the agreements which these three manuscripts have in common with 131 are very minor and probably the result of an independent orthographic tendency, in both 131 and the intermediate ancestor of 205abs, 205 and 209, to duplicate lambdas. As a result of this tendency, there are 5 probable coincidental NonMajority agreements between each manuscript and $131 .^{302}$ When these agreements are ignored, 565 becomes the manuscript with the second highest number of Non-Majority Text agreements with 131. The table also shows that 2193 and 884 have relatively high numbers of exclusive Non-Majority Text agreements with 131.9 of these readings are reproduced below along with 1 rare omission of a string of text shared exclusively with 565 :

5:37 $\quad \alpha \kappa \eta \kappa о \alpha \tau \varepsilon \pi \omega \pi о \tau \varepsilon \quad 122118$ 205abs 205209565872119212101278

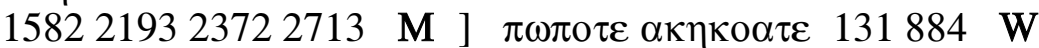

\footnotetext{
${ }^{302} 6: 37,12: 6,20: 25,21: 6$ (twice), 21:7. In all but one of these units, 205abs, 205 and/or 209 are the only manuscripts in agreement with 131 .
} 
6:16 $\varepsilon \pi \mathrm{rl} 122118$ 205abs 205209565872119212101278158221932372 $2713 \mathfrak{M}] \varepsilon 1 \sigma 131884 \mathrm{R}$

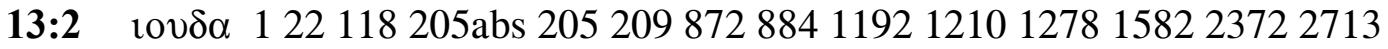
$\mathfrak{M}$ ] omit $1312193 \mathbf{R}$

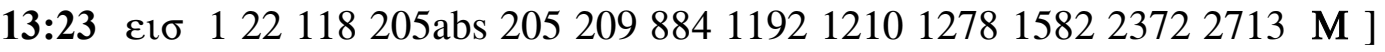
$\varepsilon \kappa$ add $1312193 \mathrm{~W}$

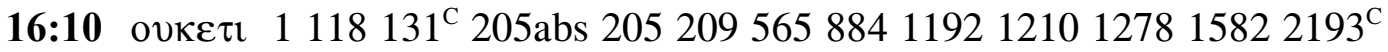
$23722713 \mathfrak{M}]$ ov $131 * 2193 * \mathbf{R}$

16:15 $\lambda \alpha \mu \beta \alpha v \varepsilon 1 \quad 1118$ 205abs 20520956588411921210127815822372 $2713 \mathfrak{M}] \lambda \eta \psi \varepsilon \tau \alpha \imath 1312193 \quad \mathrm{~W}$

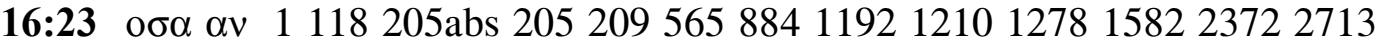
M ] o $\varepsilon \alpha v 1312193 \mathbf{R}$

18:36 $\alpha \pi \varepsilon \kappa \rho \imath \theta \eta \quad 122$ 118sup 205abs 20520956511921210127815822193 $2713 \mathfrak{M}$ ] o add $131884 \mathrm{R}$

19:4 $\varepsilon \xi \omega$ o $\pi \imath \lambda \alpha \tau o \sigma 122$ 205abs 205209565119212101278158221932713 $\mathfrak{M}$ ] $о$ o $\pi \imath \lambda \alpha \tau \sigma \sigma 131884$ R ] o $\pi \imath \lambda \alpha \tau \circ \sigma \varepsilon \xi \omega$ 118sup R

Rare omission:

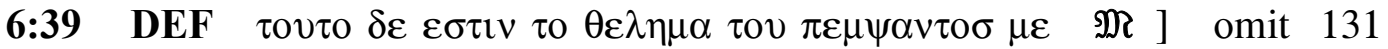
$565 \mathrm{R}$

7 of these readings are rare and the shared omission with 565 in $6: 39$ is a very notable agreement. In conclusion, 131 in John has a leaning towards NonMajority Text agreement with the descendants of Manuscript B, which could be an indication that 131 's distant family ancestor is Manuscript B. This could be 
supported by the fact that of the 35 remaining 'non-A-1' Non-Majority Text readings, not supported by a descendant of B, 20 have the support of either the 22 group or the Decorative Style group, groups that may also descend from Manuscript B.

\subsubsection{A-1 Marginalia}

Codex 131 does not contain any marginal readings; however, it does have 2 notable text agreements with variant readings in 2193 :

5:36 $\alpha \pi \varepsilon \sigma \tau \alpha \lambda \kappa \varepsilon v ~ 122118$ 205abs 2052098728841192121012781582 $2193^{\mathrm{mg}} 23722713$ M ] $\alpha \pi \varepsilon \sigma \tau \varepsilon 1 \lambda \varepsilon v 1315652193^{\mathrm{txt}} \mathbf{R}$

14:30 очк $\varepsilon \chi \varepsilon \iota 1118$ 205abs $20520956588411921210127815822193^{\text {txt }}$

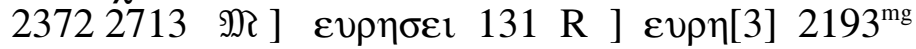

Note 2193: the marginal reading has been erased.

Both of these readings are rare and the first reading also has the support of 565 , which confirms that the reading was inherited from Manuscript $B .^{303} 131$ also supports 4 Non-Majority Text readings found in descendants of B at points of Non-Majority Text division between the core group:

3:28 Euor 122118 205abs $2052095651192127815822193 *$ *uppl 23722713 R ] Hor $1318842193^{\mathrm{C}} \mathrm{W}$ ] omit 8721210 M

\footnotetext{
${ }^{303}$ There is 1 interesting singular reading in 131 at 12:40, at a point where 2193 contains either a marginal reading or a correction that has been erased and is no longer legible.
} 
8:38 o $\varepsilon \gamma \omega \quad 11582^{\text {txt }}$ D ] $\alpha \varepsilon \gamma \omega \quad 5651582^{\text {mg }} 2193$ R ] $\varepsilon \gamma \omega$ o 22118 205abs $205209872119212101278^{\mathrm{C}} 2713$ MR ] $\varepsilon \gamma \omega \alpha 1318841278^{*}$ 2372 R

12:29 $\left.\varepsilon \sigma \tau \omega \sigma \alpha \kappa o v \omega V \quad 1205 a b s 2052095658841582^{*} 2193^{* \text { supp] }} \mathbf{R}\right] \varepsilon \sigma \tau \omega \sigma$

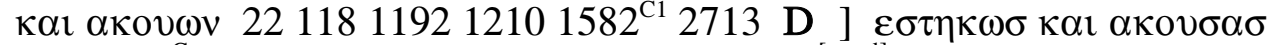
$1312193^{\mathrm{C}} \mathrm{W}$ ] $\varepsilon \sigma \tau \eta \kappa \omega \sigma \kappa \alpha l \alpha \kappa o v \omega v 1278^{*[\text { suppl] }} 2372 \mathrm{R}$ ] $\varepsilon \sigma \tau \omega \sigma \kappa \alpha l$ $\alpha \kappa o v \sigma \alpha \sigma 8721278^{\mathrm{Cl}} \mathfrak{M}$

Note 2193: letters $\varepsilon \sigma \tau$ supplied.

Note 1278: $\varepsilon \sigma \tau \eta \kappa \omega \sigma$ supplied.

16:19 $\varepsilon \gamma v \omega 15658841582 *$ R ] ovv add 118 205abs 20520911921210 $12781582^{\mathrm{C} 1} 23722713 \mathfrak{M}$ ] $\delta \varepsilon$ add $1312193 \mathbf{R}$

This kind of Non-Majority Text division may be evidence of lost marginalia that existed in A-1 in a margin-text format, but where only one of the variant readings has been retained by each manuscript, or branch of manuscripts, in the core group. It could be significant, therefore, that 131 supports the descendants of B on 4 such occasions. 131 also has 12 Non-Majority Text agreements with corrections in 2193, including 2 occasions where the reading has been classed as an A-1 reading:

7:1 $\quad \mu \varepsilon \tau \alpha \tau \alpha v \tau \alpha \pi \varepsilon \rho 1 \varepsilon \pi \alpha \tau \varepsilon$ о

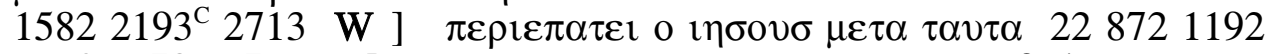

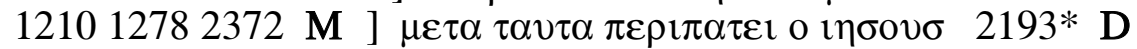

12:28 $\pi \alpha \tau \varepsilon \rho ~ 1 * 22 \quad 118$ 205abs $205209565872884119212101278^{\mathrm{C}} 1582$ $2193^{*} 2713 \mathfrak{M}$ ] $\alpha \gamma 1 \varepsilon$ add $1^{\mathrm{C}} 1312193^{\mathrm{C}} 2372 \mathrm{R}$ ] [4] add $1278^{*}$ 
The 10 other readings do not have the support of either 1 or 1582 so have not been classified as A-1 readings, but of course, they may still have existed in A-1 ${ }^{304}$ Those readings not already reproduced above are listed below:

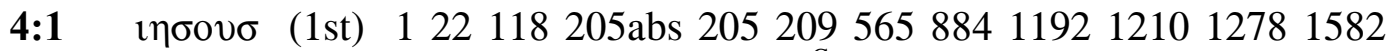
2193*2372 M ] кирเоб $1318722193^{\mathrm{C}} 2713 \mathbf{R}$

5:4 $\quad \gamma \alpha \rho 122118$ 205abs 2052095658728841192121012781582 2193* 23722713 M ] אvpiov add $1312193^{\mathrm{C}} \mathbf{R}$

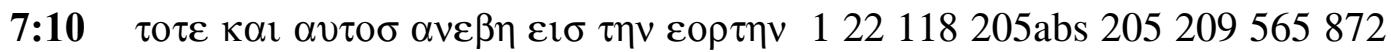

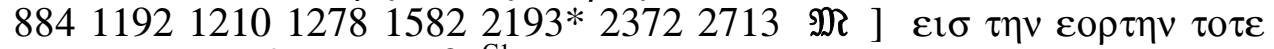

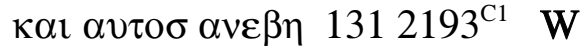

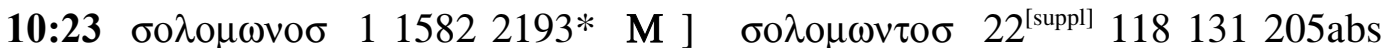
$2052095658728841192121012782193^{\mathrm{C}} 23722713 \mathrm{~W}$

Note 22: letter o (2nd) supplied.

11:46 $\alpha \quad 122118$ 205abs $20520987288411921210127815822193 * 2372$ $2713 \mathbf{M}]$ oбd $1312193^{\mathrm{C}} \mathrm{R}$

11:48 Kal (3rd) 122118 205abs 2052095658728841192121012781582 $2193 * 23722713 \mathfrak{M}$ ] omit $1312193^{\mathrm{C}} \mathbf{R}$

11:51 $\eta \mu \varepsilon \lambda \lambda \varepsilon v 122118$ 205abs 20520956588411921210 1582*2193*2713 M ] o add $13187212781582^{\mathrm{C} 1} 2193^{\mathrm{C}} 2372 \mathrm{~W}$

Note: some manuscripts read $\varepsilon \mu \varepsilon \lambda \lambda \varepsilon v$.

It has already been suggested that some of the Non-Majority Text corrections in 2193 may have originally existed as marginal readings in Manuscript B or A-1,

\footnotetext{
${ }^{304}$ Note that the reading in 10:23 does have the support of the Venice group which descends from Manuscript $\mathrm{C}$ along with 1 and 1582.
} 
but have been copied by a $\delta 10 \rho \theta \omega \tau \eta \dot{s}$ of 2193 as corrections. 131's relatively high number of agreements with the Non-Majority Text corrections in 2193, therefore, may represent further agreement in 131 with A-1's marginalia.

\subsubsection{Singular Readings}

131 contains 121 Non-Majority Text readings classed as singular because no other manuscript collated supports them. Half of these readings are distinctive and many are very unusual, almost idiosyncratic. In 5:36, for example, Jesus claims his witness is greater than that of the Father, rather than John the Baptist. On some occasions, it appears that the scribe paraphrases the reading of the Majority Text. A short selection of these singular readings is given below:

5:36 uwavvov 122118 205abs 2052095658728841192121012781582 $219323722713 \mathfrak{M}] \pi \alpha \tau \rho \circ \sigma \mu \mathrm{ov} 131 \quad \mathrm{D}$

9:2 $\quad$ $\alpha \beta \beta \imath 122118$ 205abs 20520956587288411921210127815822193 $23722713 \mathfrak{M}$ ] $\delta 1 \delta \alpha \sigma \kappa \alpha \lambda \varepsilon 131 \mathrm{D}$

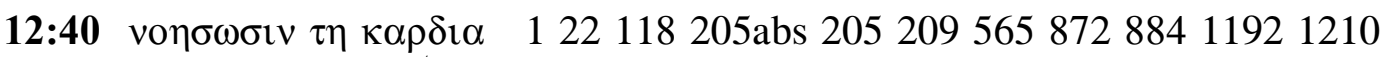
$127815822193^{\text {note }} 23722713 \mathfrak{M}$ ] $\tau \eta \kappa \alpha \rho \delta 1 \alpha \sigma v v \omega \sigma r 131$ R

Note 2193: a marginal reading or $\mathrm{C} 1$ reading has been erased.

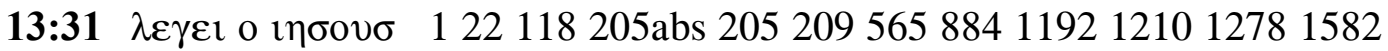

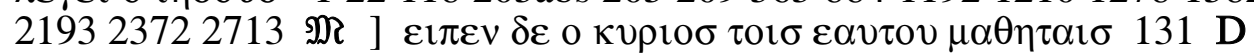

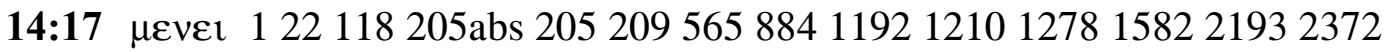
$2713 \mathfrak{M}] \varepsilon \sigma \tau \iota 131 \mathrm{D}$ 


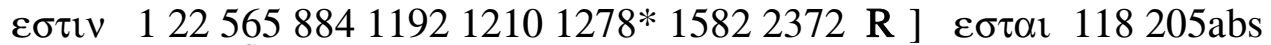
$2052091278^{\mathrm{C}} 2193^{\text {pcorr }} 2713 \mathfrak{M}$ ] $\mu \varepsilon v \varepsilon 1131 \mathrm{D}$

\subsubsection{Possible Ancestor of 131}

There is insufficient evidence to incorporate Codex 131 into the family stemma for John; furthermore, the manuscript contains a number of unusual Non-Majority Text singular readings that find no support among the family and may have originated in 131 itself, calling into question the level of accuracy in the copying of the manuscript. The collation, however, has still provided some clues to 131 's relationship with the rest of Family 1 in John. It is possible that 131 was copied from a Family 1 manuscript that was heavily corrected towards the Majority Text in John, but that also contained Family 1 marginalia. The scribe of 131 (or an intermediate manuscript), following the corrected text of his exemplar, may have interpreted the marginal variants as further corrections and so incorporated them into the new text he was copying. This would explain why 131 has only 34 A-1 readings, but 18 agreements with either marginal readings, possible marginal readings, or corrections in 2193.

\subsubsection{Codices 131 and 2193}

131 has its highest number of Non-Majority Text agreements with 2193, but as it has other Non-Majority Text agreements with other family manuscripts against 2193 (4 A-1 readings and 44 other Non-Majority Text agreements), it is unlikely to be a descendant of 2193 itself. 131's links with 2193 and its Non-Majority Text 
agreements with the other two descendants of B-including 5 exclusive agreements with 884 and an exclusive long omission with 565-support the tentative suggestion that in John, 131 may be a very distant descendant of Manuscript B.

\subsection{Manuscript Description of Codex 872}

\section{Contents and Layout}

Codex 872 is a twelfth-century Four Gospel codex kept at the Vatican library where it is designated Gr. $2160 .^{305}$ The manuscript contains 180 extant parchment folios. The text is written in 2 columns per page with 26 lines to a column. Pages measure 21 by $16 \mathrm{~cm} .{ }^{306}$ The manuscript contains Eusebius's letter to Carpianus; canon tables with Ammonian sections given throughout; and $\kappa \varepsilon \phi \alpha \dot{\lambda} \alpha \iota \alpha$ for each gospel. Each gospel begins on a recto page beneath a decorative border and a majuscule gospel title. Initial letters occur throughout. Matthew 1:4-1:22, 6:4-21 and John 13:16 to the end of the gospel are missing.

\section{Script and Dating}

The hand of 872 is neat and rounded with letters fitting carefully on the line. There is not much variation in letter size, but zeta, kappa and lambda are

\footnotetext{
${ }^{305}$ Other references: von Soden $\varepsilon$ 203; Scrivener 690.

${ }^{306}$ Paul Canart and Vittorio Peri, Sussidi Bibliografici per i Manoscritti Greci della Biblioteca Vaticana, Studi e Testi 261 (Rome: Biblioteca Apostolica Vaticana, 1970), 689.
} 
occasionally slighter larger than other letters. Breathings are a mixture of square and round; the circumflex accent sometimes stretches over 2-3 letters; there is no mute iota; some ligatures and abbreviations are used but are mostly concentrated at line endings; and initial letters and nomina sacra have accents and breathings.

\section{Illuminations}

F. 153r contains a portrait for the Gospel of John. The elderly evangelist is seated in his robe beside a writing table, painted against an architectural background which has now largely worn away. No other portraits are extant.

\section{Correctors and Later Hands}

A later hand has worked systematically through the manuscript, opening up ligatures, expanding abbreviations, and ensuring that words broken across a line do not begin on the new line with a vowel. There are also a number of textual corrections in 872 ; these have all been labelled $\mathrm{C}$ in the transcription.

\section{Provenance}

Codex 872 is part of the Vatican library's manuscript collection. 
Transcription of the Gospel of John

John begins on f. $154 \mathrm{r}$ and John 13:16b ends on f. 180v. The rest of the gospel is missing. The Pericope Adulterae is present and located after 7:52. The manuscript was transcribed from the microfilm.

\subsection{Textual Analysis of Codex 872}

\subsubsection{Previous Research}

Lake did not examine Codex 872 for his study of Family 1. It was first associated with the group by von Soden who classified the manuscript as $\mathrm{I}^{\mathrm{n} b}$. The Text und Textwert volumes for Matthew, Luke and John classify 872 as a predominantly Majority Text manuscript; but the results for the Gospel of Mark indicate that it may be a member of Family 1, the Hauptliste for Mark listing 872's closest relatives as Codices 1, 1582 and $2193 .{ }^{307}$ In Luke, Wisse did not include the manuscript in his Group 1, 22a, or 22b but with a Majority Text group, $\mathrm{K}^{\mathrm{X}} \cdot{ }^{308}$

Anderson collated 872 for her study of Matthew. ${ }^{309}$ In her test chapters she found only 4 Non-Majority Text agreements with 1 and 1582, and 1 further NonMajority Text agreement with the Venice group (Anderson's 118, 205, 209); in her family readings collation she found only 31 agreements with the family, and

\footnotetext{
${ }^{307} 1,1582$ and 2193 are among the top four manuscripts in 872 's Hauptliste for Mark. $\mathrm{P}^{45}$ is first in the list but on the basis of only 2 extant agreements: see K. Aland, B. Aland and K. Wachtel, ed., Text und Textwert der griechischen Handschriften des Neuen Testaments. IV, Die synoptischen Evangelien. Das Markusevangelium. Band 4,2 (Berlin: Walter de Gruyter, 1999).

${ }^{308}$ Wisse, Profile Methods, 67.

${ }^{309}$ Anderson, Matthew, 134-138.
} 
most agreements had very broad support from outside the family. ${ }^{310}$ In view of this low number of Non-Majority Text agreements with the family, Anderson classed the manuscript under 'Miscellaneous Manuscripts'; however, her results did lead her to suggest a possible connection with the corrected 2193, which Anderson also concluded was a predominately Majority Text manuscript in Matthew. ${ }^{311}$ Anderson did not place either 2193 or 872 onto her main Family 1 stemma, but included them separately, with 872 expressed as copy of the corrected 2193. ${ }^{312}$

\subsubsection{Family 1 Affinity}

Codex 872 is extant for John 1-13:16. In the collation of this section, 872 was found to contain only 6 A-1 readings, none of which were distinctive, 3 of which were rare and 3 widely attested. 872 contains 18 other Non-Majority Text agreements with members of the family: 1 distinctive reading, 9 rare readings and 8 widely attested readings. It contains the Pericope Adulterae at John 7:52, and with no notable Non-Majority Text agreements with the family, and no consistent pattern of agreement with any particular family manuscript or group in its Majority Text subgroup readings. It also contains 22 Non-Majority Text singular readings.

\footnotetext{
${ }^{310}$ Anderson, Matthew, 134-135.

${ }^{311}$ Anderson's results indicated that 2193 is strongly Majority Text in Matthew; it was also classed as a 'Miscellaneous Manuscript'. Anderson, Matthew, 142-143.

${ }^{312}$ Anderson, Matthew, 101.
} 


\subsubsection{Note on 872 and 2193}

If the tiny number of Non-Majority Text agreements with other family manuscripts represents a distant link to a family ancestor of 872 in John, there is no special evidence to link the manuscript to the corrected version of 2193 . There are only 2 Non-Majority Text agreements between $2193^{\mathrm{C}}$ and 872 that are of note:

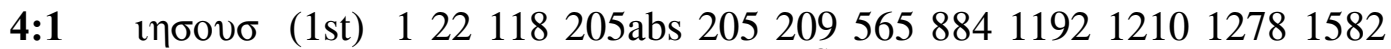
2193*2372 M ] кирเоб $1318722193^{\mathrm{C}} 2713 \mathbf{R}$

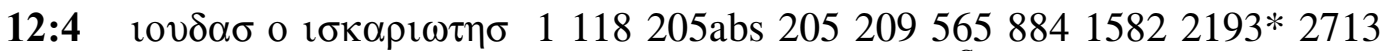
R ] $10 v \delta \alpha \sigma \sigma u \omega \omega v \sigma \sigma$ o $1 \sigma \kappa \alpha \rho \imath \omega \tau \eta \sigma \quad 8722193^{\mathrm{C}}$ R ] $10 v \delta \alpha \sigma \sigma i \mu \omega v o \sigma$

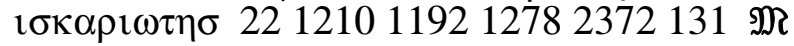

These agreements, however, are insignificant as 2193 contains a total of 48 NonMajority Text corrections in John. ${ }^{313}$ Additionally, a number of readings might be used (if 872 had a reasonable level of family affinity) to demonstrate 872 's independence from 2193. Such readings would include 1 A-1 reading (out of a total of 6) supported by 872 without 2193, and 4 Non-Majority Text agreements with other descendants of B without 2193. 2 of these latter agreements are significant omissions shared with only 565 :

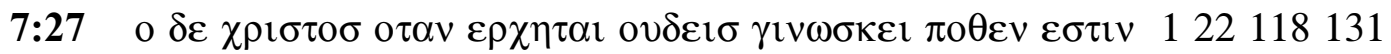
205abs $2052098841192121012781582219323722713 \quad \mathfrak{M}$ ] omit $565872 \mathrm{R}$

${ }^{313}$ There are 4 other very minor agreements. See Appendix B. 


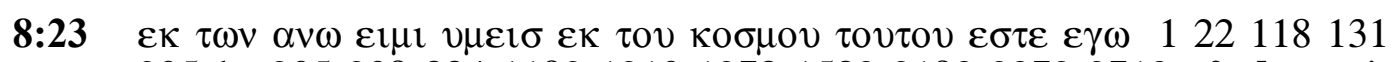
205abs 2052098841192121012781582219323722713 M ] omit 565872 R

The presence of these two readings would undermine the existence of a possible link to the corrected version of 2193 in John, at least, but instead would indicate a potential connection to B or 565 .

\subsubsection{Summary of Codex 872}

872 in John does not contain sufficient A-1 readings or other Non-Majority Text agreements with established family members to classify it as a Family 1 member in John, or even to associate it with the group. Only because 872 in the Gospel of Mark shows some Family 1 affinity might the few shared readings it has with members in John be considered as traces of a link to a very distant family ancestor. 


\section{Conclusion and Family Stemma}

The stemma developed for this study, given below as figure 6, expresses the simplest possible relationships between the seventeen manuscripts examined. Conjectured manuscripts have been incorporated into the stemma only when they explain a relationship between extant manuscripts or groups of manuscripts. Other intermediate manuscripts may have existed, but they are not of significance to the relationships between extant manuscripts. Conjectured manuscripts are always referred to by a letter.

The conclusions of this thesis are as follows:

- A-1 is the archetype of all known Family 1 manuscripts. It contained many ancient and rare Non-Majority Text readings and a substantial number of variant readings were given in the margins.

- 565, 884 and 2193 descend from A-1 through a shared intermediate ancestor called Manuscript B. Manuscript B is an independent witness of A-1. B contained a significant number of Non-Majority Text readings inherited from A-1 and retained a significant proportion of A-1's marginalia. 565, 884 and 2193 are all independent witnesses to the text of $\mathrm{B}$, but have each received significant amounts of Majority Text correction. 
- 1 and 1582 descend from A-1 through a shared intermediate ancestor called Manuscript C. Manuscript C is an independent witness of A-1. C contained a significant number of Non-Majority Text readings inherited from A-1, but only a reduced number of marginal readings. 1 and 1582 are both independent witnesses to the text of Manuscript $\mathrm{C}$; they are also both very accurate copies of $\mathrm{C}$ and received little Majority Text correction.

- 118, 205abs, 205, 209 and 2713 descend from A-1 through a shared intermediate ancestor called Manuscript E. E was copied from a manuscript that was mutilated in certain sections and the mutilated text was supplemented with text from a predominately Majority Text manuscript. E also received some Majority Text correction in the sections where the family ancestor was not mutilated. Manuscript E shares an intermediate ancestor with Codex 1, called Manuscript D; and in turn, Manuscript D descends from A-1 through Manuscript C. 118, 205abs, 209 and 2713 are independent witnesses to the text of Manuscript E. Codex 205 is a copy of $205 \mathrm{abs}$.

- 22, 1192, 1210, 1278 and 2372 descend from a shared intermediate ancestor called Manuscript G. Manuscript G descends from A-1, either through Manuscript B or by another route; it does not descend from Manuscript C. Manuscript $G$ received quite significant amounts of Majority Text correction but retained some of the marginalia from A-1. 22 
and 1192 are the best representatives of the text of Manuscript G. 1278 and 2372 descend from G, but via a shared intermediate ancestor called Manuscript $\mathrm{H}$. Manuscript $\mathrm{H}$ did not retain all of the Non-Majority Text readings that existed in Manuscript $\mathrm{G}$; it is also likely that a number of Non-Majority Text readings originated in Manuscript $\mathrm{H}$ itself, or else Manuscript $\mathrm{H}$ was influenced by another, non-family manuscript. Codex 1210 is a copy of Codex 22.

- Codex 131 has very weak Family 1 affinity in John; it does, however, contain a number of notable agreements with corrections and marginal readings found in 2193 . This may suggest that 131 descends from a very heavily corrected family ancestor, and that the scribe of 131, while following the Majority Text corrections, also copied some of the NonMajority Text marginal readings. 131 has not been incorporated into the family stemma for John.

- Codex 872 shows no significant family affinity in John. It contains a very small number of notable agreements with the descendants of $B$, which may hint at a very distant link to B but not strong enough to be conclusive. 872 has not been incorporated into the family stemma for John. 
Figure 6: Family 1 Stemma for John

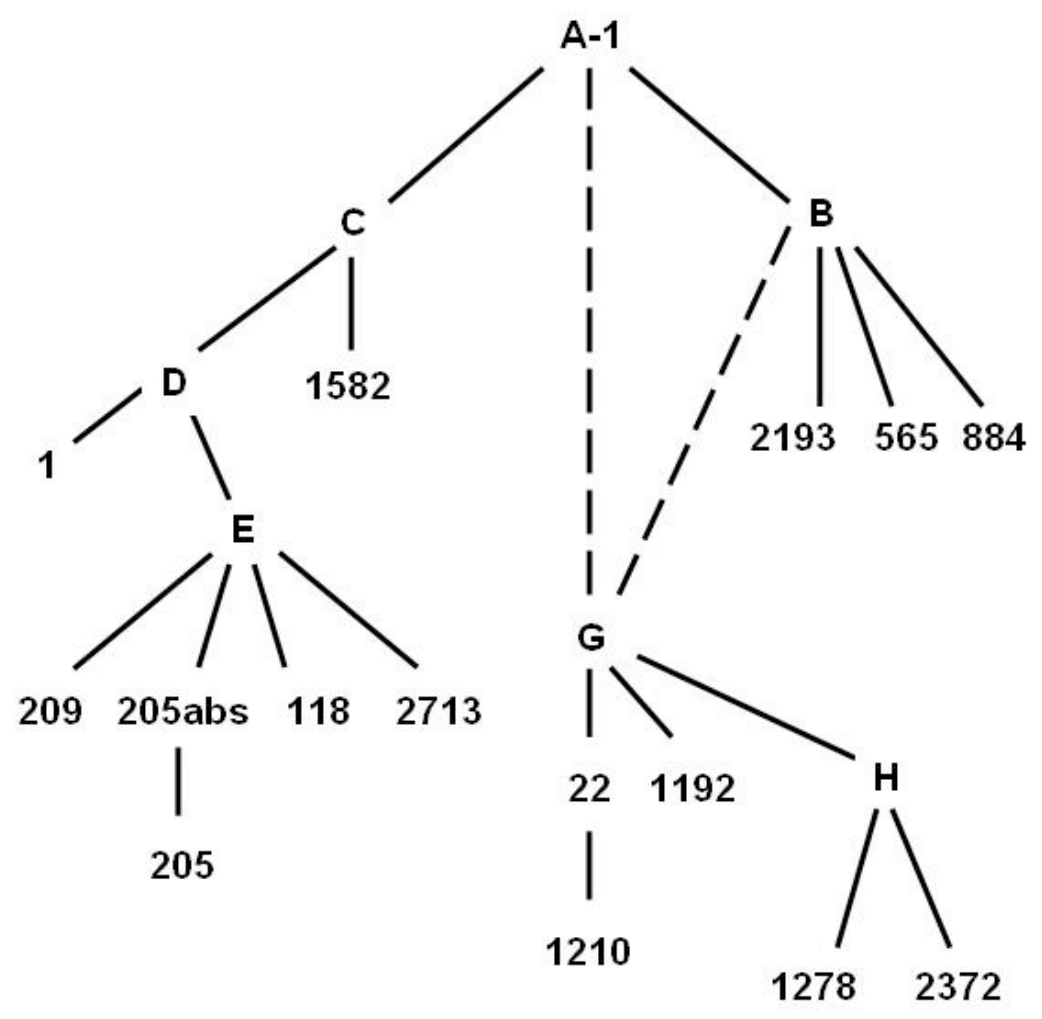




\section{Part Two: The Text of Family 1 in John}

\section{Reconstructing the Text}

\subsection{Introduction}

Part 2 of this thesis contains a reconstructed Family 1 text and apparatus for the Gospel of John. The text is a reconstruction of the text of A-1, the archetype of all known Family 1 manuscripts. The reconstruction is based on the evidence of readings found in A-1's extant descendants. Because of the broader pool of manuscript witnesses used to reconstruct the text, it differs significantly from that of Lake's 1902 text of John. The discovery of the intermediate manuscript, B, and the inclusion of its three extant descendants 565, 884 and 2193 in the family has been most significant in broadening the textual contours of the group, along with the confirmation of 1582 as a family manuscript in John. The witness of 2193 and 1582 has been particularly significant, making it possible to reconstruct at least part of the marginalia that existed in A-1. The reconstructed Family 1 text that follows, based on this wider textual group, is offered as an up-to-date replacement for Lake's 1902 Family 1 text of John.

\subsection{Majority Text Readings in the Reconstructed Text}

Because the universal tendency towards Majority Text correction has affected all branches of the Family 1 group, it cannot be known how many of A-1's Non- 
Majority Text readings have been lost. When a Majority Text reading occurs in the reconstructed text, therefore, its presence indicates that no reliable Family 1 manuscript or group of manuscripts contains an alternative Non-Majority Text reading that might be judged to have existed in A-1. It is not possible to ascertain whether that Majority Text reading originally existed in A-1, or whether A-1 had a Non-Majority Text reading at that point, which was lost through correction in A-1's descendants. It has only been possible to make editorial judgements, therefore, concerning the Non-Majority Text readings found among A-1's descendants; and only these readings have been examined to assess their likelihood of having existed in A-1. The text that follows is a reconstruction only as far as the Non-Majority Text readings of A-1 are concerned.

\subsection{Theory For the Reconstructed Text and Apparatus}

The Family 1 stemma was used as the basis for reconstructing the text of A-1 and creating the critical apparatus. Every Non-Majority Text reading found in the reconstructed text or the apparatus has been given a rating, indicating the likelihood of that reading having existed in A-1. The ratings are based on the level of support a reading has among A-1's extant descendants; and a reading's rating determines whether it is placed in the text or the apparatus.

Readings given the three highest ratings $(\mathrm{A}-\mathrm{C})$ usually appear as part of the reconstructed text. These readings are those judged to be either almost certain A-1 readings (A), likely A-1 readings (B), or possible A-1 readings (C). If an alternative Non-Majority Text reading exists, with an equal or close to equal 
rating, the reading in the text will appear within square brackets, indicating that there is uncertainty between two (or more) alternative Non-Majority Text readings. In cases of alternative readings of equal rating, an arbitrary numerical count of manuscript support determines which reading is placed in the text and which reading is placed in the apparatus. This ensures that the readings of 1582 , which was used as a base text, are not favoured over the readings of other manuscripts.

Readings rated D-E are only found in the apparatus. D rated readings are those considered 'notable' but may or may not have existed in A-1. When a D rated reading exists it is always cited in the apparatus. An E rated reading, on the other hand, is unlikely to have existed in A-1; it is a Non-Majority Text reading supported by only the weakest and least significant family manuscripts. E rated readings are only supplied at points where there is other, more significant, variation.

If an $\mathrm{A}$ rated reading exists and there are no alternative readings with $\mathrm{B}-\mathrm{D}$ ratings, the A rated reading will appear in the reconstructed text without note or comment in the apparatus. All other Non-Majority Text readings that appear in the reconstructed text are cited in the critical apparatus along with the alternative readings. For each reading that appears in the critical apparatus, a rating is given followed by a list of manuscript support for that reading. 


\subsection{The Rating of Readings}

\section{A Rated Readings}

An A rating indicates that a reading almost certainly existed in A-1. Readings which can be shown to have existed in both Manuscript $\mathrm{C}$ and Manuscript B are given this rating. Support from both 1 and 1582 indicates that a reading existed in Manuscript $\mathrm{C}$ and support from two or more of the descendants of $\mathrm{B}(565,884$ and 2193) indicates that a reading existed in Manuscript B. Agreement between Manuscript $\mathrm{C}$ and Manuscript $\mathrm{B}$ is the strongest possible evidence that a reading existed in A-1. Readings with support from only one descendant of $\mathrm{C}$ and one descendant of $\mathrm{B}$, when the other core group manuscripts have a Majority Text reading, are also given an A rating. In such cases, the cross branch agreement still provides compelling evidence that the reading is inherited from A-1, and it is judged that the manuscripts with the Majority readings must have been corrected. $^{314}$

Most readings with an A rating are given in the reconstructed text without note or comment in the apparatus. These readings are judged to be uncontested and so supportive evidence is not required for further judgements or assessments to be made. Only at points of Non-Majority Text division among the core group, or where a variant reading exists that is supported by three or more of the independent descendants of Manuscript G $(22,1192,1278,2372)$, will an A rated reading be cited in the apparatus along with the alternative readings.

\footnotetext{
${ }^{314}$ Note that first hand corrections in 1 and 1582 , and corrections in 2193, are considered as valid support for A rated readings.
} 


\section{$B$ Rated Readings}

All readings given in the reconstructed text that have a rating below $\mathrm{A}$ are cited in the critical apparatus along with a list of supporting evidence and all other variant readings that exist at that point. A rating of $\mathrm{B}$ indicates that a reading is likely to have existed in A-1. Readings that can be shown to have existed in either Manuscript $\mathrm{C}$ or Manuscript $\mathrm{B}$ are usually given this rating. In the case of such readings, it is judged to be most probable that the manuscript ( $\mathrm{C}$ or $\mathrm{B})$ not supporting the Non-Majority Text reading (or the manuscript's descendants), has been corrected towards the Majority Text and that the Non-Majority Text reading in the other manuscript (C or B) was inherited from $\mathrm{A}-1$; however, without evidence of both $\mathrm{B}$ and $\mathrm{C}$, the possibility that the Non-Majority Text reading arose in $\mathrm{C}$ or $\mathrm{B}$ must be considered, and, therefore, the reading is rated with a lower degree of certainty. B rated readings include those supported by:

- Both 1 and 1582.

- Two or more of the descendants of Manuscript B (565, 884 and 2193).

- 1582 and two or more of the Venice group manuscripts.

- 565 or 2193 and two or more independent descendants of Manuscript G. ${ }^{315}$

${ }^{315}$ That is to say, not including the copy 1210 when 22 is extant. 
A number of readings have been given an $\mathrm{A}-\mathrm{B}$ rating. These readings tend to be cases where descendants of both $\mathrm{C}$ and $\mathrm{B}$ agree on a Non-Majority Text reading but when these descendants are not all core group manuscripts. A-B rated readings include those supported by:

- 2193 and/or 565 with the Venice group.

- 1 and/or 1582 with a descendant/s of Manuscript G.

Although this kind of cross-branch support indicates possible agreement between Manuscript C and Manuscript B (and, therefore, inheritance from A-1), because one side of the core group does not support the reading, the possibility that it arose independently in the non-core group manuscripts is slightly higher than if both branches of the core group supported the reading.

\section{Rated Readings}

A rating of $\mathrm{C}$ indicates that a Non-Majority Text reading possibly existed in A-1. Readings that are likely to have existed in either Manuscript C or Manuscript B are usually given this rating. They are mostly readings supported by only one of the core group manuscripts $1,565,1582$, or 2193 . A reading supported by 884 alone is automatically excluded from this list as 884 has the lowest Family 1 affinity of the core group manuscripts and the highest number of singular readings; it has been judged, therefore, when standing alone, to be less reliable 
than the other four core group manuscripts. A reading supported by 884 and two or more descendants of Manuscript $\mathrm{G}$, however, is given a $\mathrm{C}$ rating, as the support of the descendants of Manuscript $G$ provides sufficient evidence that the reading did not originated in 884 . As both correctors of 2193 have been shown to have used 2193's original exemplar to make their corrections, the Non-Majority Text readings of $2193^{\mathrm{C} 1}$ and $2193^{\mathrm{C}}$ have also been considered for $\mathrm{C}$ ratings. $\mathrm{C}$ rated readings include those supported by:

- Any one of the core group manuscripts 1, 1582, 565 or 2193.

- $2193^{\mathrm{C} 1}$ and $2193^{\mathrm{C}}$.

- The Venice group and two or more of the descendants of G.

- 884 and two or more of the descendants of G.

\section{$D$ Rated Readings}

$\mathrm{D}$ rated readings are always noted in the apparatus. They are of interest because they occur in family manuscripts, but they are not strong candidates for A-1 readings, because they do not have support among the core group. D rated readings include readings supported by:

- 884 when the reading is not a long omission. ${ }^{316}$

- Three or more of the independent descendants of G: 22, 1192, 1278 and 2372.

\footnotetext{
316884 has a tendency to omit long strings of text; this tendency may be connected with it being a commentary manuscript. Long ommisions in 884 that are not supported by other family manuscripts are automatically given an E rating. See Appendix B for a list of 884's singular readings readings.
} 
- Three or more of the descendants of G: 1192, 12101278 and 2372, when 22 is missing text.

- Some singular long omissions in the core group manuscripts 1, 565 and $2193 .^{317}$

\section{E Rated Reading}

E rated readings are not considered to be A-1 readings. They are Non-Majority Text readings found in only the least significant family manuscripts. They tend to be singular readings in these manuscripts that probably originated in the manuscripts themselves. They are occasionally of interest because they constitute partial corrections of family readings and thus indicate that the manuscript's intermediate ancestor may have contained the family reading. E rated readings are cited in the apparatus only at points of other variation. They also include readings found among the Venice group in the sections where the group moves away from the family text.

\subsection{Note on Internal Reading Criteria}

Readings are usually rated on the basis of external manuscript support; however, on occasion internal evidence affects the rating of a reading. This is often the case when the core group is split between alternative Non-Majority Text readings, and one of these readings could have resulted from a partial correction towards the

\footnotetext{
${ }^{317}$ When it is possible, or likely, that the omission occurred in the manuscript itself.
} 
Majority Text. Such a reading may be judged less likely to be an A-1 reading, and is, therefore, given a lower rating. If such internal criteria have affected the rating of a reading, an exclamation mark (!) follows immediately after the rating.

\subsection{D! Rated readings in Core Group Manuscripts}

As already discussed, a number of Non-Majority Text readings supported by only one core group manuscript have been used to reconstruct the text of A-1; most of these readings have been given $\mathrm{C}$ ratings, indicating that they possibly existed in A-1, but that without the support of other core group manuscripts the readings cannot be considered certain or almost certain A-1 readings. ${ }^{318}$ Other NonMajority Text readings supported by only one core group manuscript, however, have not been used to reconstruct the text of A-1 because it is judged likely that these readings originated in the core group manuscripts themselves, through accidental scribal error. These readings have all been given D! ratings, indicating that although the reading may be of some interest (because of the manuscript that supports it), it is not likely to have been inherited from A-1. Below is a brief discussion of the $\mathrm{D}$ ! rated readings found among single core group manuscripts. ${ }^{319}$

\footnotetext{
${ }^{318}$ See section 7.4 'C Rated Readings'.

${ }^{319}$ Where physical or formatting evidence is relevant, the reader may find it useful to visit the website for the complete transcriptions of each manuscript. Physical features such as line breaks have been recorded in the transcriptions.

Note that singular readings in 884 are automatically given a $\mathrm{D}$ rating.
} 
Long omissions

There are a number of long omissions supported by only one core group manuscript. Most of these are likely to have been the result of simple scribal error, and probably arose in the core group manuscripts containing the omissions. For example, in 3:19-20 Codex 2193 omits the string of text $\eta \nu \gamma \alpha \rho \alpha v \tau \omega \nu \pi o v \eta \rho \alpha \tau \alpha$

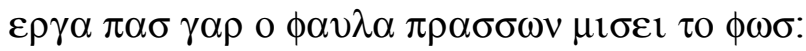

3:19 $\eta v \gamma \alpha \rho \alpha v \tau \omega \vee \pi 0 \vee \eta \rho \alpha \tau \alpha \varepsilon \rho \gamma \alpha 1205$ abs 20520956588415822713 W

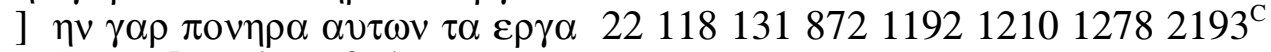
2372 M ] omit 2193* D

3:20 $\pi \alpha \sigma \gamma \alpha \rho$ о $\phi \alpha v \lambda \alpha \pi \rho \alpha \sigma \sigma \omega v \mu \iota \sigma \varepsilon \imath \tau o ~ \phi \omega \sigma \quad 122118131$ 205abs 205209 $56587288411921210127815822193^{\mathrm{C}} 23722713$ M ] omit 2193* $\mathrm{D}$

This omission was probably the result of homeoteleuton: the scribe of 2193 skipping the string of text because of the repetition in the ending of the previously copied text: $\tau \mathrm{o} \phi \omega \sigma$. Furthermore, in this string of text all the other core group manuscripts agree upon a Non-Majority Text reading (in 3:19). As such cross branch agreement on a Non-Majority Text reading indicates that the reading was likely to have been inherited from A-1, it supports the conclusion that 2193's omission originated in 2193 itself. The reading of 2193, therefore, has been ignored for the reconstruction of the text of A-1 and appears only in the apparatus with a D! rating. Other very similar omissions have likewise been given $\mathrm{D}$ ! 
ratings and appear only in the apparatus. They include omissions in: 3:19-20, $5: 26,6: 39,7: 27,8: 23,9: 21,13: 32,14: 2,14: 9$, and 19:21. ${ }^{320}$

It should be noted that one long omission in 19:38 supported by only Codex 1 of the core group has been given a C! rating rather than a D! rating. This is because there is some evidence that the omission may have originated in either Manuscript C or A-1.

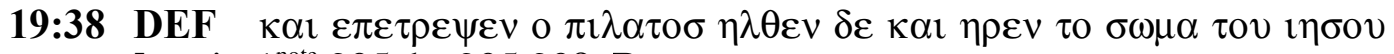
] omit $1^{\text {note }} 205$ abs 205209 R

Note 1: omission marked by a later hand.

$\left.\begin{array}{lll}\delta \varepsilon & 1582 & \mathrm{R}\end{array}\right]$ ovv $22118 \sup 13156588411921210127821932713$

In the string of text omitted by Codex 1, 1582 contains a singular and rare NonMajority Text reading while the descendants of Manuscript B follow the Majority Text. It is possible that the rare reading in 1582 was inherited from Manuscript $\mathrm{C}$ (and therefore possibly A-1); but without the support of any descendant of Manuscript B, the reading of 1582 cannot be considered to have certainly been inherited from A-1. The possibility, therefore, that the omission supported by Codex 1 was inherited from A-1, through Manuscript C, needs to be considered. It is possible that the omission existed in A-1 and was transmitted to Codex 1 through Manuscript C; that the scribe of Manuscript B spotted the omission and filled it in with the Majority Text reading; and that the scribe of 1582, finding the omission in Manuscript $\mathrm{C}$ also filled in the reading (perhaps from memory), but

\footnotetext{
${ }^{320}$ Note long omissions shared by Codex 1 and the Venice group have been treated similarly and usually carry a D! rating. Longer omissions in 884 are automatically ignored as long omission is a characteristic of 884 and is perhaps connected to it being a commentary text manuscript.
} 
used the less common reading of $\delta \varepsilon$ for ovv while completing the missing text. In the case of this reading there is not sufficient evidence to draw a firm conclusion and so both the reading of Codex 1582 and the reading of Codex 1 have been given C! ratings, reflecting this uncertainty. However, since elsewhere 1582 has a higher overall number of A-1 readings and because it has been shown that Codex 1's intermediate exemplar, Manuscript D, had a slight tendency towards long omission, ${ }^{321}$ the reading of 1582 has been preferred as the reading of the reconstructed text, though square brackets have been placed around the omitted text to highlight the uncertainty of the text at this point.

\section{Orthographic Variation}

Certain orthographic variants supported by only one core group manuscript have been discarded as accidental misspellings originating in the core group manuscripts concerned. For example, the spelling $\phi \imath \lambda \imath \pi \circ \sigma$ with only one $\pi$ by the scribe of Codex 1 in 12:22, or the same scribe's spelling $\phi 1 \lambda \pi \pi \varepsilon$ in 14:9. This first spelling has been judged to be a simple misspelling, as elsewhere the scribe consistently spells the name with the standard double $\pi$; and the second spelling is also judged to be a misspelling, probably the result of the repeated up and down strokes necessary for the double $\pi$ following the $\mathrm{l}$ - the scribe missed a stroke and so the $\mathrm{l}$ was lost. These two misspellings have therefore been ignored in the

\footnotetext{
${ }^{321}$ See section 3.2.8.
} 
reconstructed text and appear only as D! rated readings in the apparatus. ${ }^{322}$ Other minor spelling variants have been treated similarly: Codex 1's $\eta \mu \varepsilon \tau \varepsilon \rho o v$ for

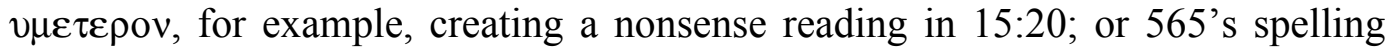
$\alpha v \theta \rho \omega \pi \circ v$ for $\alpha v \theta \rho \omega \pi \omega v$ in 5:41, which was probably affected by the following ov. Other D! rated readings that fall into this category can be found in: $2: 24,5: 41$, $8: 48,8: 52,11: 7,11: 53,12: 22,13: 38,14: 9,15: 11,15: 20,20: 12$, and 21:9.

\section{Small Omissions}

A number of variants that consist of small omissions have also been given D! ratings when it is judged that either the omission was caused by a physical or palaeographical factor in the manuscript, or if the omission has led to a nonsense, or at least very difficult reading. For example, the omission of $\alpha v \tau o \sigma \mu o v o \sigma$ in 565 at the end of 6:15 was probably caused by the line breaking after opo $\sigma$ and

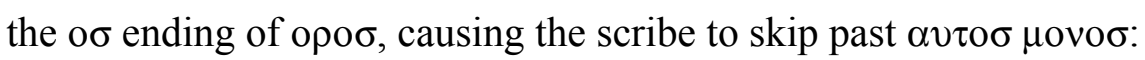

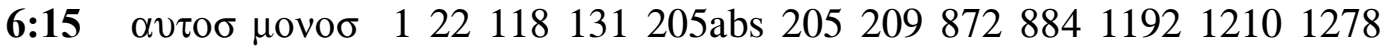 $1582219323722713 \mathfrak{M}]$ omit 565 D}

The scribe of 565 probably made a similar error in $15: 16$, omitting $\kappa \alpha \iota \varepsilon \theta \eta \kappa \alpha$ $v \mu \alpha \sigma$, again the result of homeoteleuton: the repetition of $v \mu \alpha \sigma$. A similar example in 2193 is the omission of a second $\alpha \mu \eta v$ on two occasions (in 13:21 and 13:38). On both occasions the $\alpha \mu \eta v$ is the last word before a line break, which

\footnotetext{
${ }^{322}$ Such a minor spelling difference on another word might have been regularised out of the collation at an earlier stage. This minor variant was not regularised out because it was decided early on to consistently retain all variants on the spelling of proper names.
} 
could explain the error; elsewhere the scribe consistently has the standard $\alpha \mu \eta v$ $\alpha \mu \eta v$. Other similar D! rated readings can be found in: 3:4, 3:27, 6:15, 6:33, 6:70, $9: 41,10: 17,10: 38,11: 12,11: 14,11: 16,12: 2,12: 39,13: 21,13: 28,13: 38,14: 2$ $14: 13,15: 16,16: 27$, and 19:12.

\section{Small Additions}

A number of minor additions supported by only one core group manuscript have been given $\mathrm{D}$ ! ratings because a nonsense or more difficult reading has been created, or because there is a possible physical reason for the creation of that reading. For example, the addition of what might be read as $\varepsilon v o \sigma$ in 565 at 18:25 was probably caused by a duplication of letters at the end of the word $\theta \varepsilon \rho \mu \alpha \imath{ }^{\prime} \mu \varepsilon v o \sigma$, which the scribe copied, breaking the word over a line ending. Similar D! rated readings can be found in: 3:4, 4:23, 9:21, 10:40, 12:13, 17:23, and 18:25.

Non-Majority Text Readings in Codex 565 in Chapter 1

Codex 565 contains a number of Non-Majority Text readings in chapter 1 but no family reading until 1:43 (and this reading is a widely attested reading and so may have arisen independently). In light of this, and the fact that 565 has only been shown to be Family 1 in the final gospel, it is probable that the scribe of 565 changed to his Family 1 type exemplar only after John chapter 1 . This conclusion is supported by the fact that a relatively high proportion of 565 's singular readings 
occur in chapter $1 .{ }^{323}$ Codex 565 's second Non-Majority Text reading shared with the rest of the family is a rare reading in $2: 5$. Chapter $2: 5$, therefore, has been considered as the point where 565 joins the family and so only from this point have readings in 565 been used to reconstruct the text of A-1. All singular NonMajority Text readings in 565 that occur in chapter $1(1: 18,1: 19,1: 21,1: 26,1: 27$, $1: 29,1: 33$, and 1:44) have been given D! ratings and are only cited in the apparatus.

\subsection{Note on the Treatment of Marginal Readings}

Marginal variants are uncommon in minuscule manuscripts. Among the seventeen manuscripts studied for this thesis, the tendency for scribes to either ignore marginal readings or to incorporate them into the text is more common than the tendency to retain them. Only five of the seventeen manuscripts examined have retained marginalia $(22,1192,1278,1582$, and 2193$)$, and each only a limited amount. As a result, there is less evidence among A-1's extant descendants for the marginal readings of A-1. Consequently, marginal readings in the reconstructed text of A-1 have been treated differently to text readings: smaller amounts of evidence have been considered acceptable, and marginal readings have not been rated in the same way as text readings. Additionally, text readings in manuscripts descended from intermediate exemplars that contained marginalia are occasionally cited as evidence in support of marginal readings.

${ }^{323}$ There are 8 singular readings in chapter 1 out of a total of 38 . 


\subsection{Note on Dealing with $\mathrm{M}^{\mathrm{pt}}$ Readings in the Main Gospel Text}

Occasionally the Majority Text is split between two or more different readings. In such cases, Majority Text readings are marked in the apparatus with the siglum $\mathrm{M}^{\mathrm{pt}} \cdot{ }^{324}$ If the core group manuscripts are split between different $\mathrm{M}^{\mathrm{pt}}$ readings and no core group manuscript supports an alternative Non-Majority Text reading, an arbitrary count of manuscript support is used to determine which $\mathrm{M}^{\mathrm{pt}}$ reading is placed in the text and which reading in the apparatus. This ensures that the readings of 1582, used as a base text, do not dominate the reconstructed text.

\subsection{The Text of the Pericope Adulterae in A-1}

\section{Evidence of the Core Group}

The evidence of the extant witnesses indicates that the Pericope Adulterae existed as an appendix in A-1, located after the Gospel of John and following a critical note regarding the story's authenticity. The pericope, therefore, is placed at the end of the gospel in the reconstructed text. Of the core group manuscripts, 1 and 1582 retain the note and the location of the pericope, though 1582 is missing text from $8: 7 \mathrm{~b}$, and the rest of the story is added by a supplementary hand; 565 contains a shorter version of the note at the end of the gospel, but the pericope is missing; 2193 contains it, located at the end of the gospel, but added by a supplementary hand; and 884 also contains it, without the note, located after John $7: 52$

${ }^{324}$ Following Hodges and Farstad, Majority Text, xxi. 
Before the lacuna in 1582, with the exception of one very minor spelling variation in Codex 1, 1 and 1582 have no disagreements in their pericope text, and display a genetic link through 2 distinctive Non-Majority Text exclusive agreements, and 1 rare agreement shared also with 884 and $2193^{\text {sup }}$. This textual closeness along with the location and format of the pericope clearly indicates that 1 and 1582 copied it from the same source, and this source must have been Manuscript C.

The text of 884 and $2193^{\text {sup }}$ is also close in the pericope: the manuscripts have only 6 disagreements, one of which is very minor; a similar profile of Majority Text subgroup readings; and 3 Non-Majority Text agreements, 2 of which are rare. It is very probable, therefore, that 884 and $2193^{\text {sup }}$ are also genetically related in the pericope, despite the story being relocated in 884 and added by a supplementor in 2193. This shared source for the pericope text is almost certainly Manuscript B, and if this is so, the supplementor of 2193 must have copied the story from original pages in 2193 that had become mutilated or detached in some way and so needed re-copying. The rare Non-Majority Text agreement in 7:53 between $1,884,1582$ and $2193^{\text {sup }}$ supports this argument and the cross branch agreements provide solid evidence of the existence of a link from both Manuscript $\mathrm{C}$ and Manuscript B back to A-1. This rare agreement is given below:

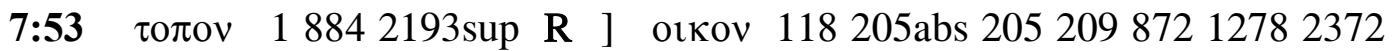
$2713 \mathfrak{M}$ 
In Codices 22, 1192, and 1210, which are the nearest descendants of Manuscript $\mathrm{G}$, the text of the pericope and the note are not present. The text (and possibly the note) must have been located as an appendix in an intermediate manuscript of the group, possibly G, but must have been later lost, with neither the scribe of the ancestor, nor the scribes of the three descendants, adding the story from another manuscript source. The witness of these manuscripts, although it cannot help to reconstruct the text of the pericope, does support its location in A-1 at the end of the Gospel of John.

In the Venice group, Codices 118, 205abs, 205, 209, and 2713 and the Decorative Style manuscripts, the descendants of H, 1278 and 2372, the story is present, but located at John 7:52, and the text of both subgroups is very different to that found in the four core group manuscripts. It is likely, therefore, that in the ancestors of these two subgroups (likely, Manuscripts E and H), the story was added from another non-family source, and the text of the pericope, therefore, as found in these manuscripts, is not of value for reconstructing the pericope text of A-1.

\section{Reconstruction of the Text}

In light of the changes in witness support for the pericope, a different set of criteria has been used to reconstruct the pericope text. Most significantly, only the witnesses $1,884,1582$ and $2193^{\text {sup }}$ have been employed. Additionally, 
readings have not been rated in the same way as those found in the rest of the gospel. The readings of 1 and 1582, and 1 alone after the supplementor takes over in 1582 , have been given precedence because the link back to A-1 is firmer in 1 and 1582: A-1's formatting and location have been retained; there are more NonMajority Text readings which are likely to have been inherited from A-1; and the text was copied by the first hand scribe of each manuscript, rather than a supplementor, as in 2193. Furthermore, 1 and 1582 in the rest of the gospel have also tended reliably to retain more A-1 readings than 884,884 also being more prone to both Majority Text correction and singular readings.

The reconstructed text of the pericope, therefore, follows closely the text of 1 and 1582 up until 8:7a, and follows closely the text of Codex 1 alone after 8:7b. The reconstructed text only differs from the text of 1 and 1582 (or 1 alone) if both 884 and $2193^{\text {sup }}$, or just $2193^{\text {sup }}$, contain a Non-Majority Text reading while 1 and 1582 have a Majority reading. In such cases, the reading of 884 and $2193^{\text {sup }}$, or $2193^{\text {sup }}$ alone, is placed in the text, but inside square brackets to indicate a level of uncertainty with the reading. If 1 and 1582 support a Majority Text subgroup reading while 884 and $2193^{\text {sup }}$ support a different Majority Text subgroup reading, the reading of 1 and 1582 is given precedence, and is placed in the text, but within square brackets to indicate the presence of the rival reading. If 1 and 1582 and either 884 or $2193^{\text {sup }}$, but not both, support the same Majority Text subgroup reading, the reading of 1 and 1582 is given in the text without square brackets, as the cross-branch agreement indicates that the reading in 1 and 1582 was inherited from A-1. 
As the witness pool is small for the pericope, and the variant readings few, all differences between $1,884,1582,1582^{\text {sup }}$ and $2193^{\text {sup }}$ are given in the apparatus. Readings are not given a rating as they are in the rest of the gospel, but instead are labelled according to how well attested they are in the wider textual tradition of the pericope. Majority Text readings are labelled following Hodges and Farstad's more detailed divisions of the Majority Text that exist in the pericope, and NonMajority Text readings are labelled as either distinctive (d), rare (r), or widely attested $(\mathrm{w}){ }^{325}$

\subsection{Note on the Creation of the Text}

The final transcription of Codex 1582 was used as a base text for the reconstructed text. ${ }^{326}$ The text, therefore, follows the pattern of movable nus, nomina sacra abbreviations, and other very minor orthographic features, found in 1582. As no attempt was made to reconstruct such matter, the employment of 1582 as a base text is inconsequential. The text is laid out chapter by chapter with the apparatus for each chapter following immediately after the text. As punctuation marks and accents were not recorded in the transcriptions, no

\footnotetext{
${ }^{325}$ This is the same way readings were rated in the full collation. See section 1.2 for a discussion of the rating system.

${ }^{326} 1582$ contains the highest number of A-1 readings, so the least number of changes needed to be made to create the reconstructed text. 1582 also contains very few singular readings or readings previously regularised out of the collation.
} 
punctuation or accents are used in the reconstructed text: ${ }^{327}$ final sigma and iota subscript are also not employed.

\subsection{Note on Witness Citation}

When extant, all of the seventeen manuscripts examined are cited as witnesses for every unit in the critical apparatus, with the exception of 205 and 1210. 205 has been shown to be a copy of 205abs, and so its witness is not of value when 205abs is extant; likewise, 1210 has been shown to be a copy of 22 , and so its witness is not of value where 22 is extant. When 22 is missing text, however, the witness of 1210 is of value, and is therefore cited in these sections.

\subsection{Note on Apparatus Format}

For ease of use, a modified set of the familiar symbols employed in the twentyseventh edition of Novum Testamentum Graece has been used for the apparatus of the reconstructed text. ${ }^{328}$ The main difference is in the treatment of marginal readings, the rating system, and the use of a first apparatus to record lacunas and the presence of manuscript supplements. A list of the symbols and abbreviations used in the reconstructed text and apparatus follows.

\footnotetext{
${ }^{327}$ Except for the capitalisation of the first letter in each chapter and a full stop at the end of each chapter.

${ }^{328}$ Aland et al., ed., Novum Testamentum, 50*-57*.
} 


\subsection{List of Symbols and Abbreviations Used in the Reconstructed Text}

Text

ㄴ The words between these two symbols are omitted in the witnesses cited. In the apparatus ${ }^{\square}$ precedes the witnesses listed in support of the omission.

s2 The words between these two symbols are transposed in the witnesses cited. In the apparatus digits followed by full stops, e.g. 2.3.1., indicate the alternative word order.

T At this point in the text a word/s is added by the witnesses cited. ${ }^{\top}$ precedes the added word/s in the apparatus.

r) The word/s enclosed is replaced by another word in the witnesses cited. ' precedes the replacement word/s in the apparatus.

- The word following in the text is omitted by the witnesses cited. In the apparatus ${ }^{\circ}$ precedes the witnesses listed in support of the omission.

[ ] The enclosed text is uncertain or an alternative reading of equal or almost equal support is given in the apparatus.

An underlined reading in the reconstructed text indicates the presence of a marginal variation on that reading.

() It is uncertain whether the reading given in the reconstructed text was the reading of the text or the margin in A-1.

Margin

[] The marginal reading enclosed is uncertain.

() It is uncertain whether the reading given in the margin was the reading of the margin or the reading of the text in A-1.

[MG] A marginal reading may have existed at this point. There is usually some physical evidence for this, such as traces of a marginal reading in 2193.

[VID] A marginal reading did exist at this point, but cannot be reconstructed.

[MG?] Non-Majority Text division between the core group may indicate that a marginal reading existed in A-1 at this point. 
? Used after a marginal reading to indicate uncertainty.

\section{First Apparatus}

Lac. Lacunas. Precedes a list of manuscripts that are missing text for all or part of the chapter.

Suppl. Supplements. Precedes a list of manuscript supplements present for part or all of the chapter.

Wit. Witnesses. Precedes a list of manuscript witnesses used to reconstruct the text of a passage. Used only when the usual witness list is reduced.

a Indicates that a lacuna or the presence of a supplement manuscript ends at the beginning of a verse. The letter follows immediately after the chapter and verse reference.

b Indicates that a lacuna or the presence of a supplement manuscript begins part way through a verse. The letter follows immediately after the chapter and verse reference.

\section{Main Apparatus}

TXT Text. Indicates that what follows is a list of support for readings in the main text. Used only when there is also a marginal reading present (i.e. to distinguish text readings from marginal readings).

MG Marginal reading. Precedes the list of witnesses cited in support of a marginal reading.

rell. All the rest. All other extant manuscripts not otherwise cited for this unit.

om. The word/s are omitted by the manuscripts cited.

txt Precedes the witnesses cited in support of the reconstructed text.

mg The marginal reading of a manuscript.

txt The reading in the running text of a manuscript at a point where it also contains a marginal variation. 
sup The reading of a supplement manuscript.

* The first hand reading of a manuscript at a point where that manuscript has been corrected (when $*$ follows a manuscript number).

C The reading of a corrector in a manuscript. ${ }^{\mathrm{C}}$ may be followed by a number distinguishing a particular corrector or by $*$ to indicate a first hand corrector.

vid The reading of this manuscript is uncertain.

[vid] The letter/s enclosed in square brackets in the cited reading are uncertain in this manuscript.

DEF Deficient. Indicates that the manuscript/s cited does not contain the text of the variation unit. Usually the manuscript has an omission of a long string of text that incorporates the variation unit. (This is never used with core group manuscripts as any long omissions are always cited in the apparatus).

VID The reading of the manuscript/s that follows is unknown.

[1] A number inside square brackets in place of a reading or as part of a reading indicates the approximate number of letter spaces present in an illegible word or part of a word in a manuscript.

${ }^{5} 2.1^{2}$ The order of words for a variant reading marked as a transposition is shown by digits representing the alternative word order placed within the transposition symbols ${ }^{52}$. (Each word is represented by a digit and the consecutive order of digits represents the order of words in the reconstructed text.)

M The reading of the Majority Text. ${ }^{329}$

$\mathrm{M}^{\mathrm{pt}} \quad$ The reading of the Majority Text when the Majority Text is divided.

M The reading of the Majority Text with reduced support.

$\mathrm{M}^{1} \quad \mathrm{M}$ followed by a number indicates a subgroup of the Majority Text as detailed by Hodges and Farstad. Used only in the apparatus for the Pericope Adulterae.

I Marks the end of a variation unit in the apparatus.

; $\quad$ Marks the end of each reading within a variation unit in the apparatus.

${ }^{329}$ All Majority Text readings are labelled using Hodges and Farstad, Majority Text. 
Rating System

A Indicates an almost certain A-1 reading.

A! Indicates an almost certain A-1 reading but that may have existed alongside another Non-Majority Text reading in A-1 (i.e. a correction or marginal reading).

B Indicates a likely A-1 reading.

C Indicates a possible A-1 reading.

D Indicates a notable Non-Majority Text reading.

E Indicates a very minor Non-Majority Text reading.

! Indicates that internal considerations have affected the rating for a reading. ! follows immediately the rating letter.

[A!] Indicates that the reading almost certainly existed in A-1 but in the form of a marginal reading or correction, not as part of the running text.

\subsection{Miscellaneous Notes on the Apparatus}

\section{Uncertain Marginal Readings}

When the existence of a marginal reading is doubtful (usually cited because of the presence of a possible but uncertain erasure in 2193), manuscript support for the reading's existence is given within square brackets preceded by the letters MG. Occasionally, for such erased readings, potential readings are suggested, based on the existence of Non-Majority Text readings in the texts of certain manuscripts. Such suggested readings are also cited within square brackets. 
Minor Variation

Very occasionally, a manuscript is cited in support of a reading when the manuscript itself has a minor variation on that reading. In such cases, the minor reading is noted inside round brackets.

Influence of Other Readings

Very occasionally, it has been judged that the existence of a reading elsewhere, in another verse, supports the existence of a different reading, for example, because it is judged that a correction or marginal reading in an ancestor may have been incorporated at different points in descendants. This kind of support for a reading is cited in round brackets followed by $*$ and the verse number for the reading.

Corrections and Text Readings as Evidence for Marginal Readings

On occasion, text readings or the readings of correctors are cited in support of marginal readings. Such support is cited inside round brackets and follows the list of witnesses that actually contain the reading in the margin. ${ }^{330}$ ${ }^{330}$ Only manuscripts which have been shown to descend from an intermediate ancestor that
contained marginalia are cited in this way. 


\section{Transpositions}

When a variant reading is marked as a transposition, but it also involves an alternative word, the alternative word is recorded in round brackets in place of the usual transposition number. 


\section{The Reconstructed Text of Family 1 in John}

\section{Chapter 1}

' [To $\kappa \alpha \tau \alpha \iota \omega \alpha \nu v \eta v \varepsilon v \alpha \gamma \gamma \varepsilon \lambda \mathrm{lov}]$ '

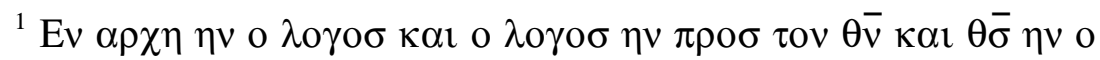

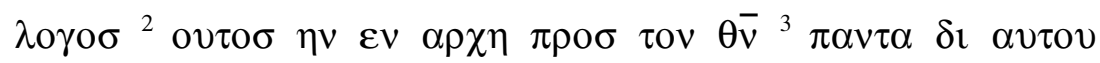

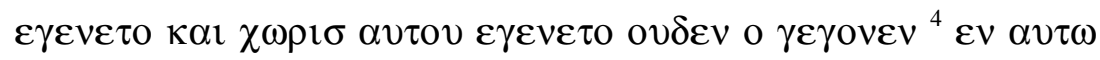
$\zeta \omega \eta \eta v \kappa \alpha l \eta \zeta \omega \eta \eta v \tau o \phi \omega \sigma \tau \omega v \alpha \bar{v} \omega v{ }^{5} \kappa \alpha l \tau o \phi \omega \sigma \varepsilon v \tau \eta$

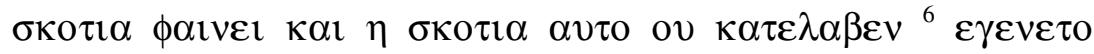

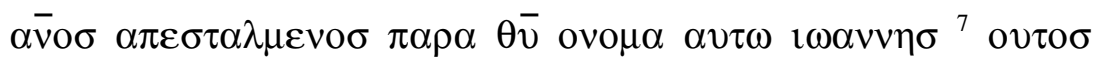

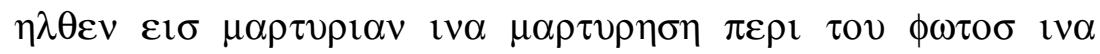

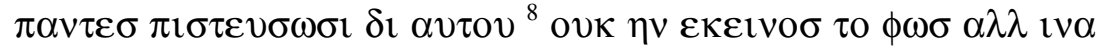

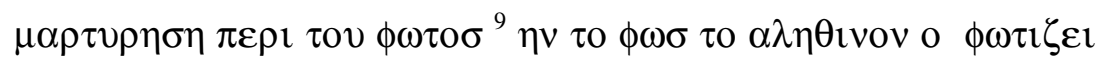

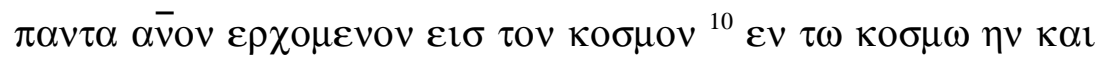

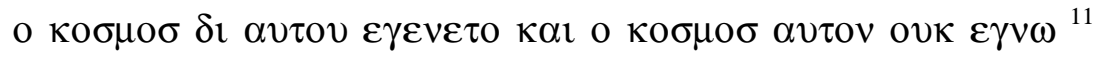

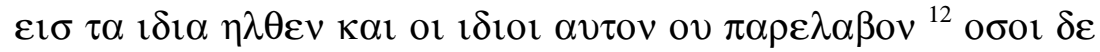

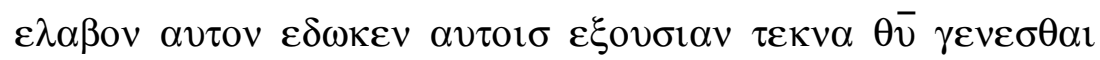

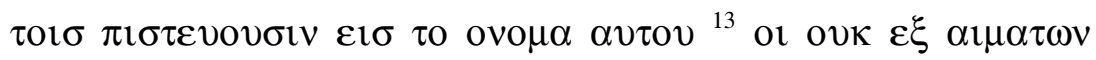

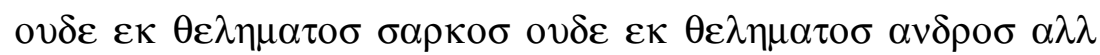

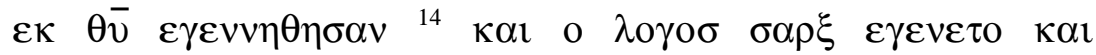

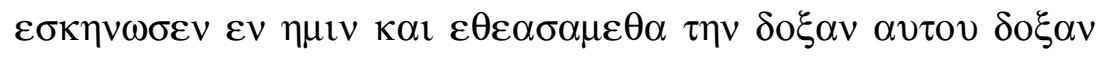

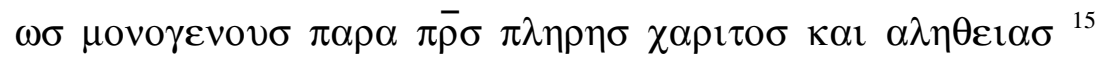

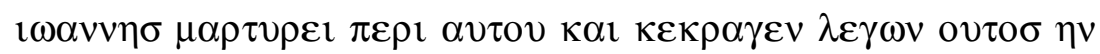

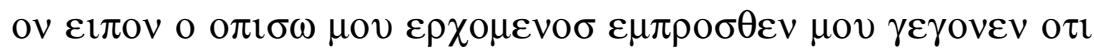

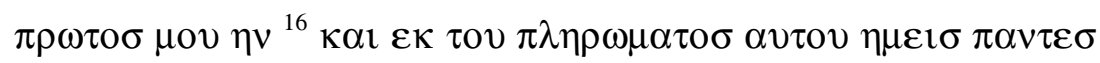

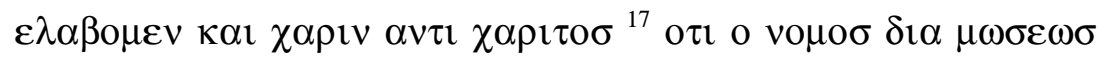

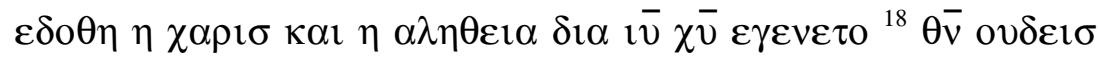

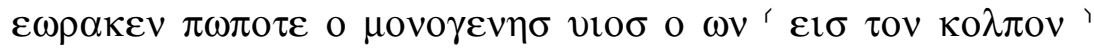

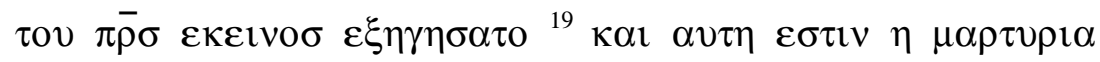

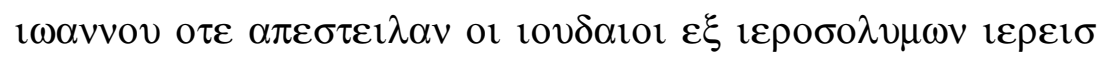
$\kappa \alpha \imath \lambda \varepsilon v i \tau \alpha \sigma{ }_{-}^{\top} \mathrm{lv} \alpha \varepsilon \rho \omega \tau \eta \sigma \omega \sigma \mathrm{lv} \alpha v \tau \mathrm{lov}$ ' $\sigma \mathrm{v} \tau \mathrm{ll} \sigma \varepsilon \mathrm{l}{ }^{1}{ }^{20} \kappa \alpha \mathrm{l}$

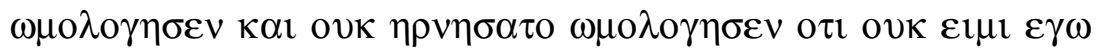




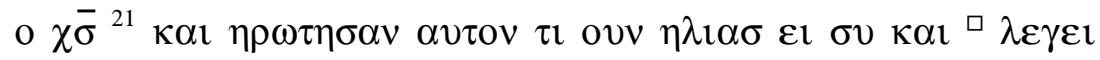

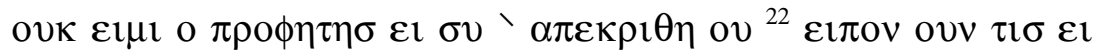
ıv $\alpha$ a $\sigma \varepsilon \alpha v \tau o v{ }^{23} \varepsilon \phi \eta \varepsilon \gamma \omega \phi \omega v \eta \beta O \omega v \tau o \sigma \varepsilon v \tau \eta \varepsilon \rho \eta \mu \omega \varepsilon v \theta v v \alpha \tau \varepsilon \tau \eta \nu$

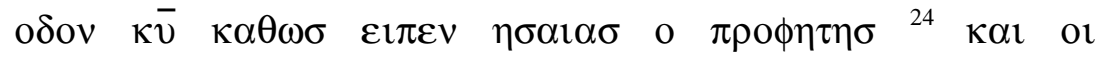

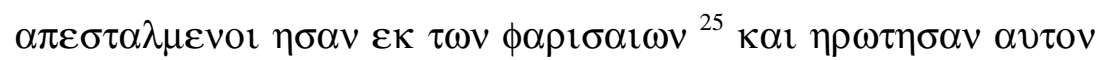

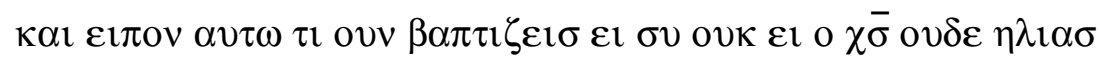

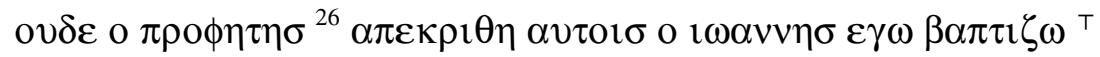

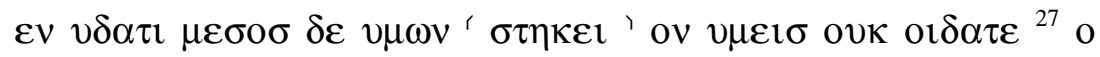

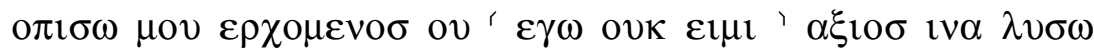

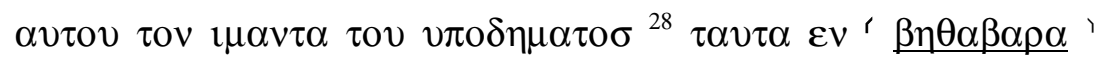

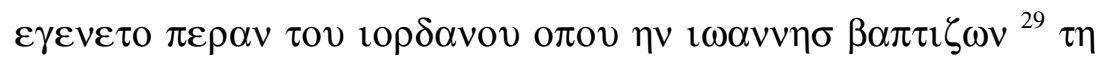

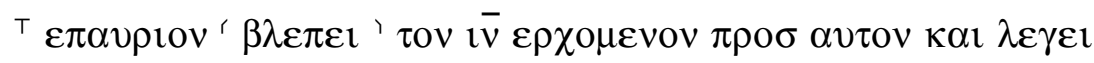

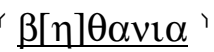

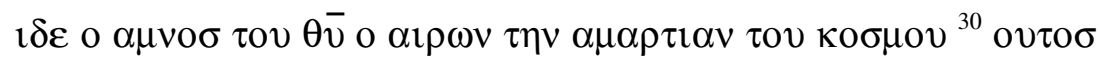

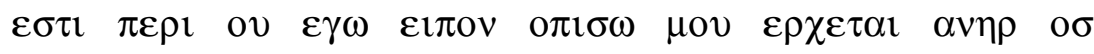

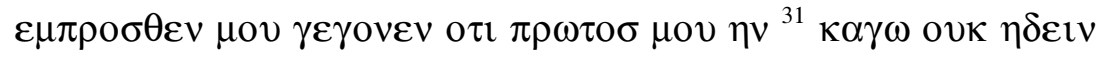

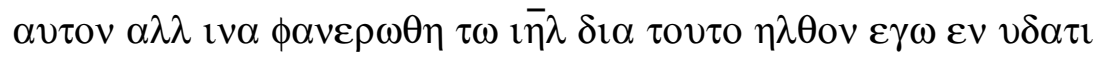
$\beta \alpha \pi \tau l \zeta \omega v{ }^{32} \kappa \alpha l \varepsilon \mu \alpha \rho \tau \nu \rho \eta \sigma \varepsilon v{ }^{\top} l \omega \alpha v v \eta \sigma \lambda \varepsilon \gamma \omega v$ o $\tau \imath ~ \tau \varepsilon \theta \varepsilon \alpha \mu \alpha \imath$

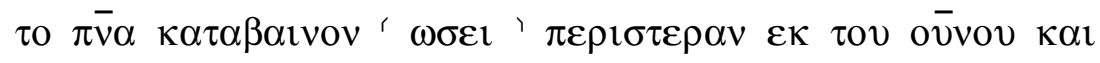

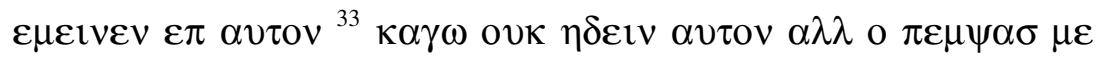

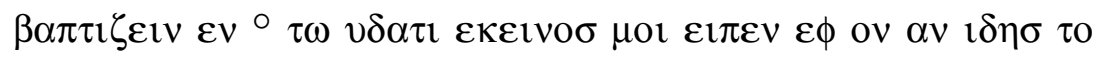

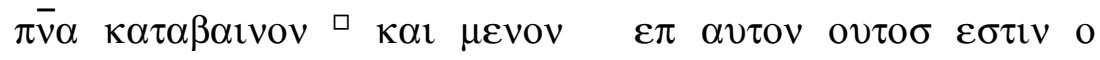

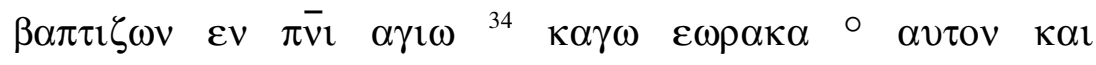

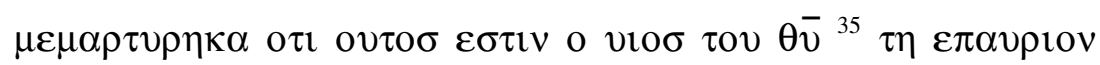

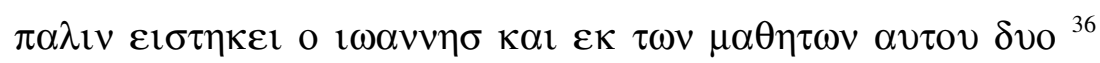

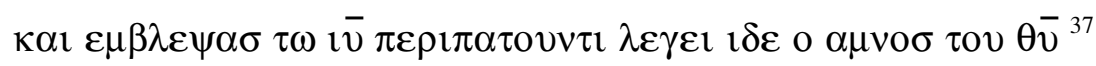

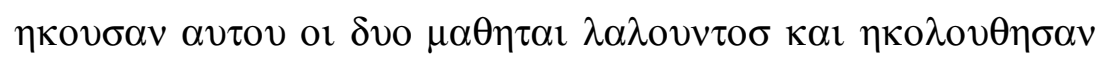
$\begin{array}{llllllllll}\tau \omega & \imath \bar{v} & 38 & \sigma \tau \rho \alpha \phi \varepsilon \imath \sigma & \delta \varepsilon & 0 & \imath \bar{\sigma} & \kappa \alpha l & \theta \varepsilon \alpha \sigma \alpha \mu \varepsilon v o \sigma & \alpha v \tau o v \sigma\end{array}$

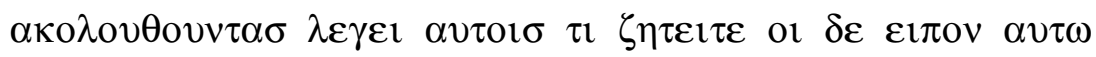

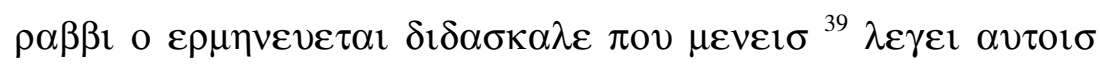

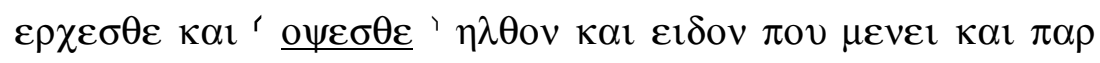
$\alpha v \tau \omega \varepsilon \mu \varepsilon \imath v \alpha \nu \tau \eta \nu \eta \mu \varepsilon \rho \alpha \nu \varepsilon \kappa \varepsilon i v \eta v \omega \rho \alpha \eta v \omega \sigma \delta \varepsilon \kappa \alpha \tau \eta{ }^{40} \eta v$

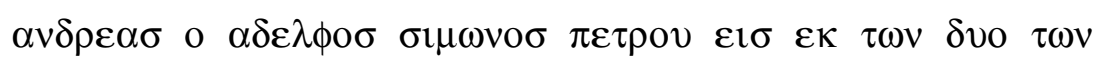
$\underline{1 \delta \varepsilon \tau \varepsilon}^{\prime}$

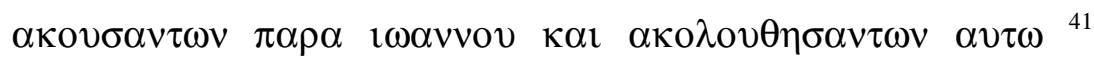




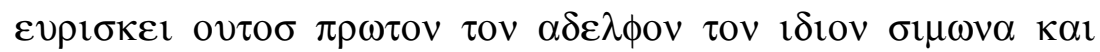

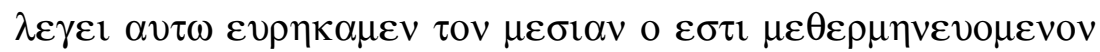

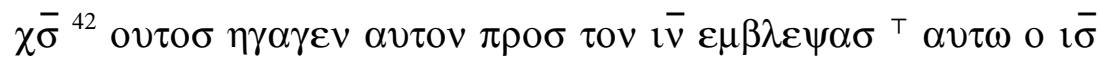

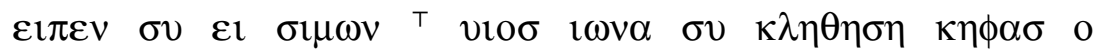

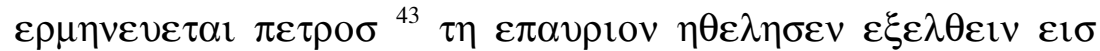

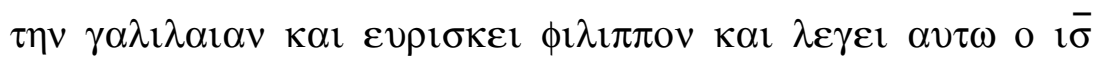

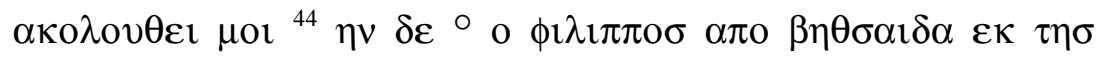

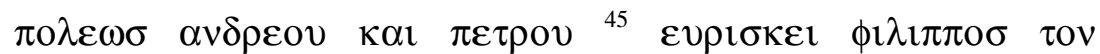

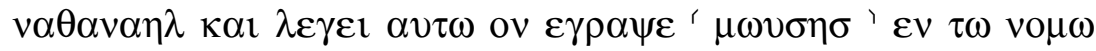

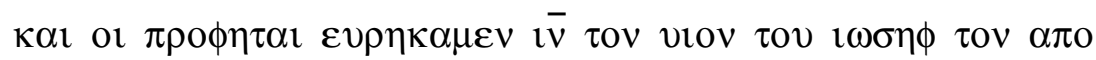
' $v \alpha \zeta \alpha \rho \varepsilon \tau$ ' ${ }^{46} \kappa \alpha \iota \varepsilon 1 \pi \varepsilon v \alpha v \tau \omega v \alpha \theta \alpha v \alpha \eta \lambda \varepsilon \kappa$ ' $v \alpha \zeta \alpha \rho \varepsilon \tau$ ' $\delta v v \alpha \tau \alpha \iota$

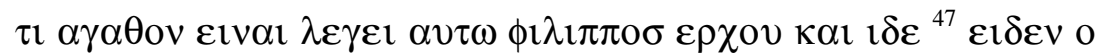

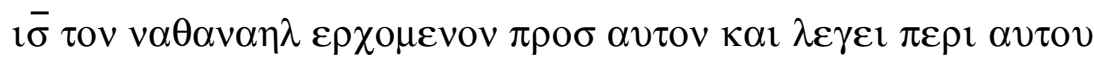

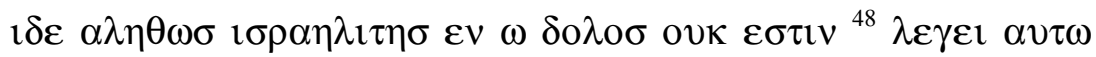

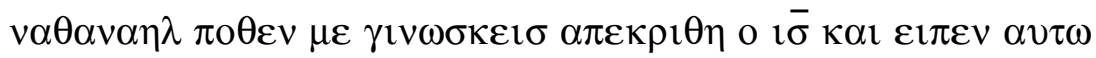

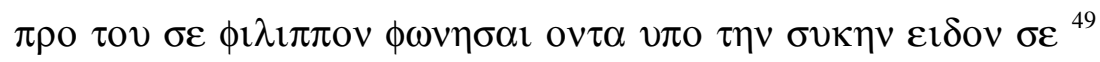

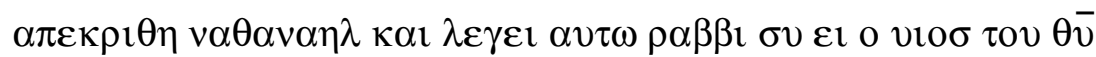
$\sigma v^{\prime} \beta \alpha \sigma \imath \lambda \varepsilon v \sigma \varepsilon \imath^{\prime} \tau o v i \bar{\eta} \lambda{ }^{50} \alpha \pi \varepsilon \kappa \rho \imath \theta \eta{ }^{\top} \imath \bar{\sigma} \kappa \alpha \iota \varepsilon \imath \pi \varepsilon v \alpha v \tau \omega$ o $\tau \imath$

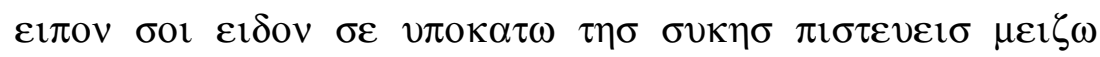

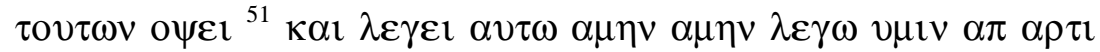

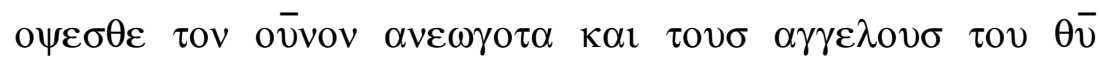

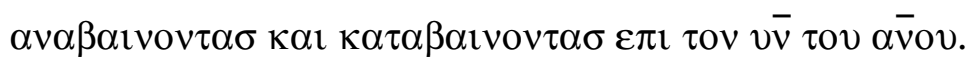

Lac. 884: 1: 24-1: 51.

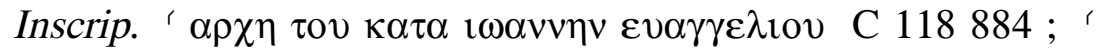

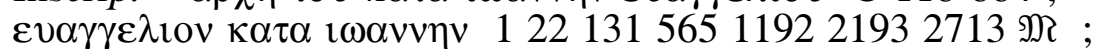

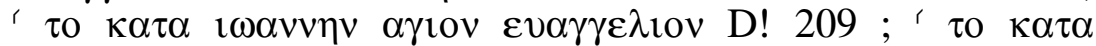

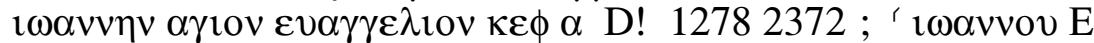

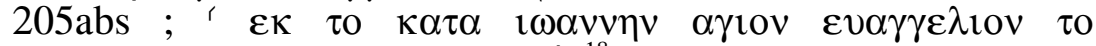

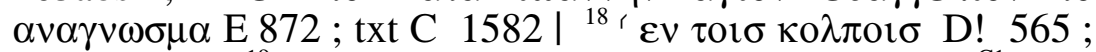

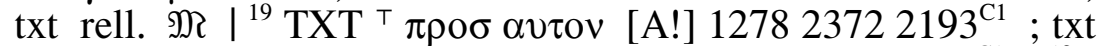

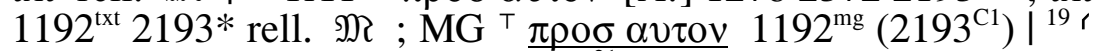

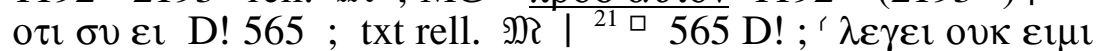

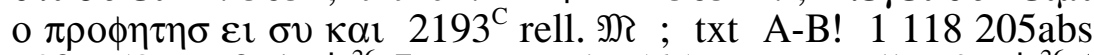
$\left.20915822193 *\right|^{26}$ T $v \mu \alpha \sigma$ D! 565 ; txt rell. MP| ${ }^{26}$,

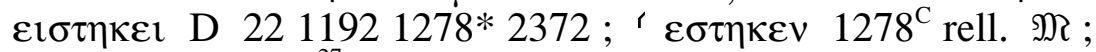

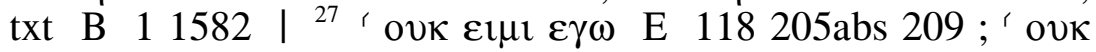


$\varepsilon 1 \mu \mathrm{L}$ ! 565 ; txt rell. $\mathfrak{N} \mid{ }^{28}$ TXT' $\beta \imath \theta \alpha v i \alpha 565$ [MN] ; $\beta \eta \theta \alpha v i \alpha 118131$ 205abs $2098721278^{\text {txt }} 2372$ M ; txt A $122^{\text {txt }}$ $1192^{\text {txt }} 15822193^{\text {txt }} 2713$; MG $\beta \eta \theta \alpha v i \alpha$ B $22^{\text {mg }} 2193^{\mathrm{mg}}$; MG

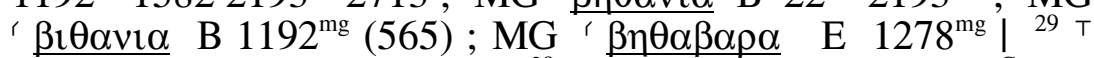

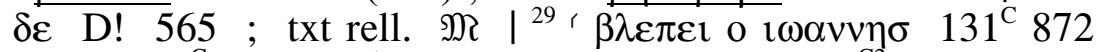
$12782193^{\mathrm{C}} 2372 \mathrm{M}^{\mathrm{pt}}$; o $1 \omega \alpha \nu v \eta \sigma \beta \lambda \varepsilon \pi \varepsilon \mathrm{E} 118^{\mathrm{C} 2}$; txt $118^{*}$ 131* 2193* rell. $\mathrm{M}^{\mathrm{pt}} \mid{ }^{32}{ }^{\mathrm{T}}$ o D 22119212782372 ; txt rell. M ${ }^{32}{ }^{3} \omega \sigma 2256511921278^{\mathrm{C}} \mathrm{M}^{\mathrm{pt}}$; txt $1278^{* \text { vid }}$ rell. $\left.\mathrm{M}^{\mathrm{pt}}\right|^{33} \mathrm{o}$ rell. $\mathfrak{N}$; txt B 1118 205abs 2091582 | ${ }^{33} \square$ D! 565 ; txt

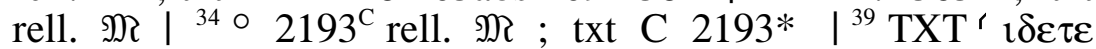
rell. M ; txt A $122^{\text {txt }} 118$ 205abs $2091192^{\text {txt }} 15822193^{\text {txt }}$; MG $\left.{ }^{\prime} \underline{\underline{l} \delta \varepsilon \varepsilon} 22^{\mathrm{mg}} 1192^{\mathrm{mg}} 2193^{\mathrm{mg}}\right|^{42} \mathrm{~T} \delta \varepsilon 87221932713 \mathrm{M}^{\mathrm{pt}} ; \mathrm{txt}$ rell. $\left.\mathrm{M}^{\mathrm{pt}}\right|^{42} \mathrm{~T}_{\mathrm{T}}$ o $209^{\mathrm{C} *} 1278^{\mathrm{C} *}$ rell. $\mathfrak{N}$; txt B-A $1209 * 1278^{*}$ $\left.1582\right|^{44} \circ \mathrm{D}$ ! 565 ; txt rell. $\mathfrak{M} \mid{ }^{45}(\mu \omega \sigma \eta \sigma$ rell. $\mathfrak{M}$; txt B! $\left.2193^{\mathrm{C}}\right|^{45}$ ' $v \alpha \zeta \alpha \rho \varepsilon \theta 122131205 a b s 20911922193^{\mathrm{C}} \mathrm{M}^{\mathrm{pt}}$; txt 2193* rell. $\mathrm{M}^{\mathrm{pt}}{ }^{46}{ }^{46}$ v $\alpha$ $\alpha \rho \varepsilon \theta 12213111922193^{\mathrm{C}} \mathrm{M}^{\mathrm{pt}} ; \mathrm{txt}$ 2193* rell. $\left.\mathrm{M}^{\mathrm{pt}}\right|^{49}$ ' $\varepsilon 1$ o $\beta \alpha \sigma \iota \lambda \varepsilon v \sigma$ rell. $\mathfrak{M}$; txt B $\left.11582\right|^{50} \mathrm{~T}$ o D $1182091278^{* \text { vid }}$; txt $1278^{\mathrm{C}}$ rell. $\mathfrak{N}$ । 


\section{Chapter 2}

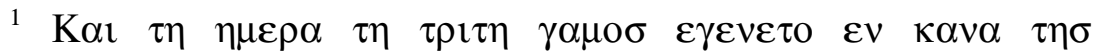
$\gamma \alpha \lambda \iota \lambda \alpha \iota \alpha \sigma \kappa \alpha \iota \eta \nu \eta \mu \bar{\eta} \rho$ ov $\imath \bar{v} \varepsilon \kappa \varepsilon \iota^{2} \varepsilon \kappa \lambda \eta \theta \eta \delta \varepsilon \kappa \alpha \iota$ o $\iota \bar{\sigma} \kappa \alpha \iota$

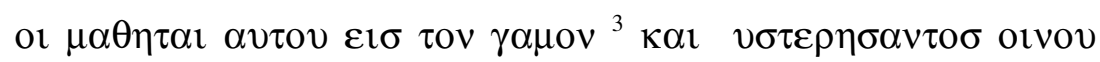

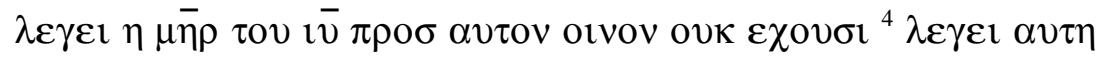

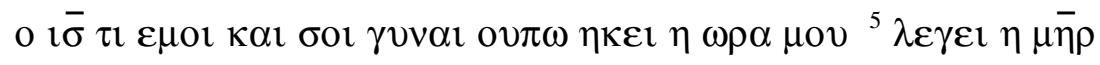

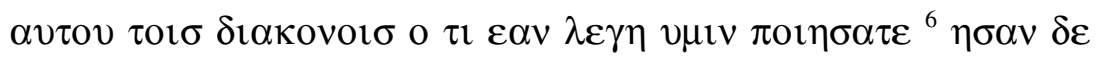

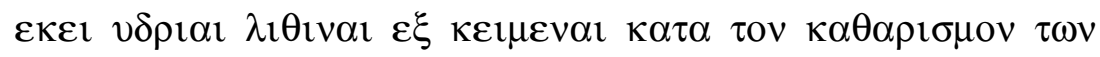

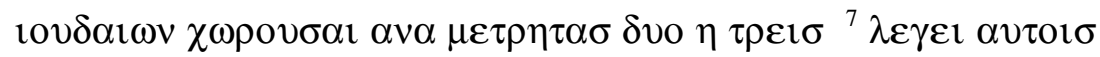

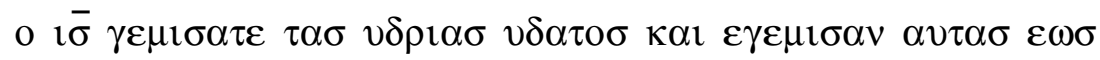

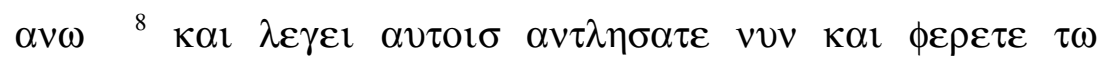

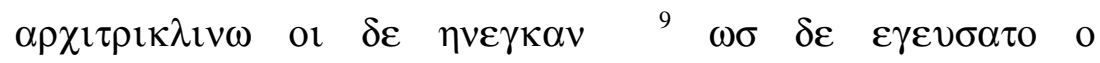

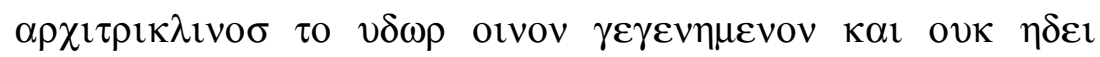

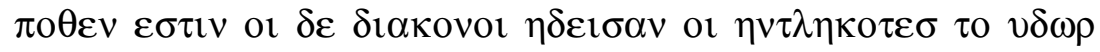

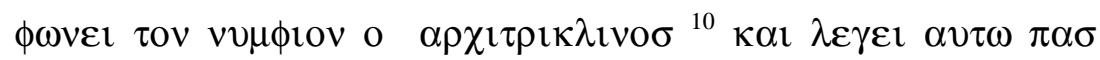

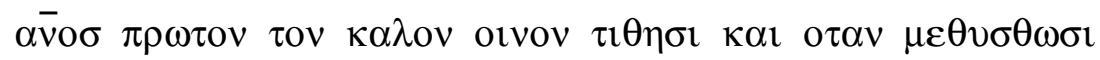

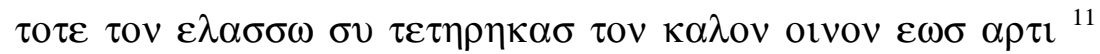

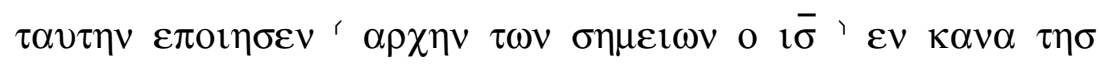

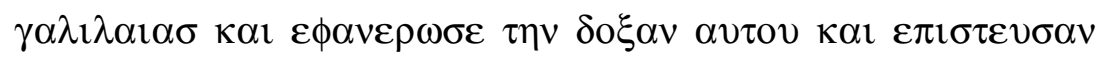

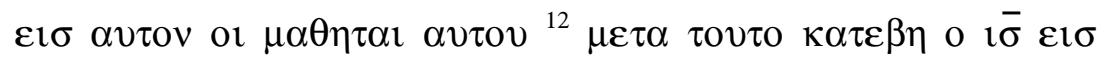

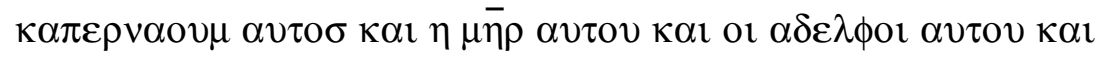

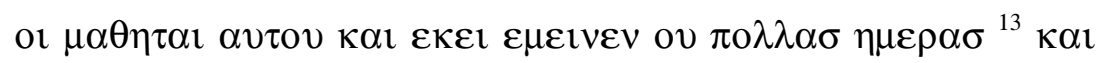

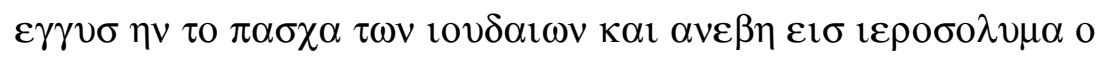

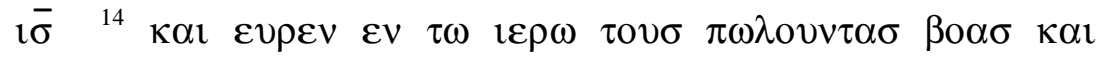

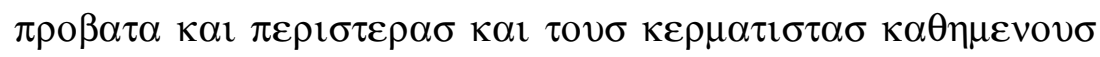

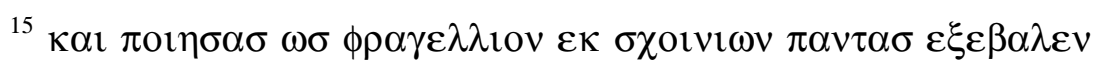

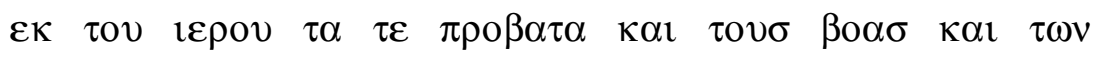

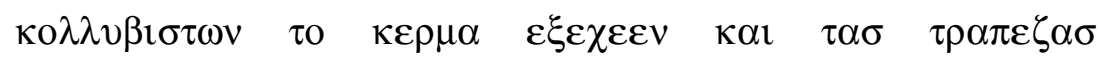

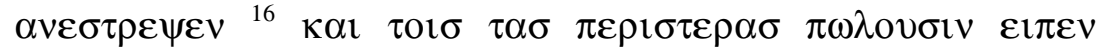

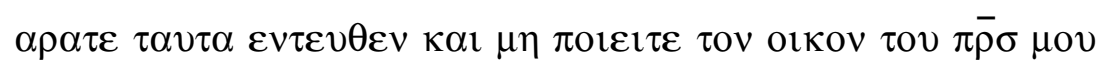

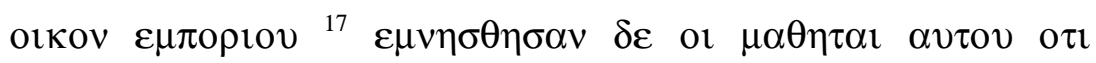

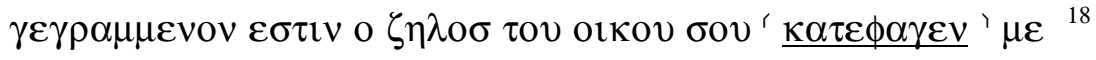
' $\underline{\kappa \alpha \alpha \phi \alpha \gamma \varepsilon \tau \alpha \imath}{ }^{\prime}$

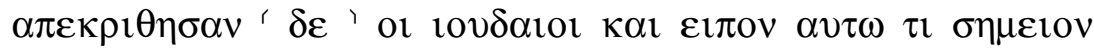




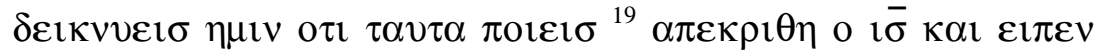

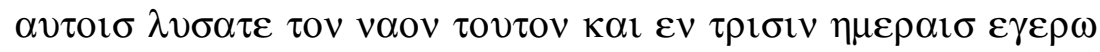

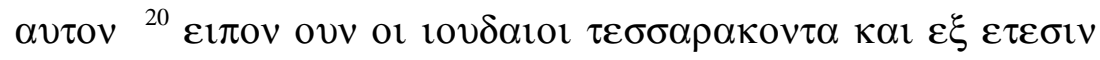

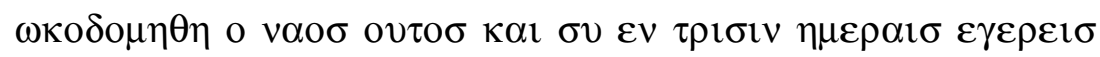

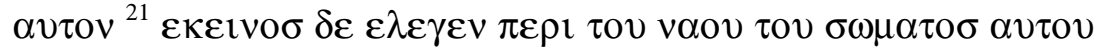

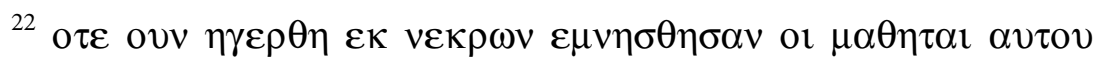

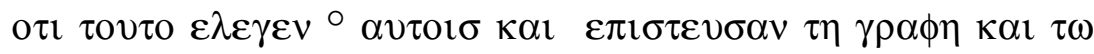

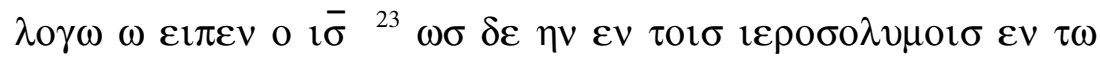

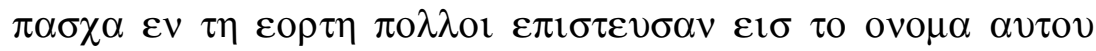

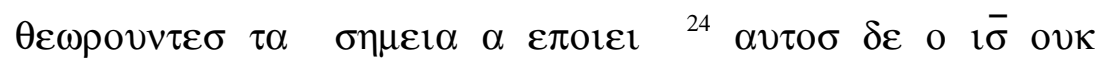

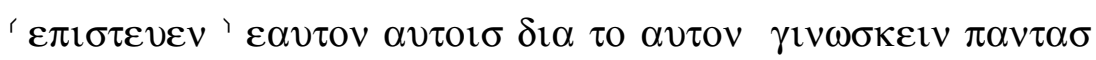

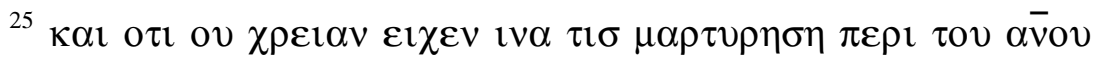
$\alpha v \tau \circ \sigma \gamma \alpha \rho \varepsilon \gamma \iota v \omega \sigma \kappa \varepsilon \tau \iota \eta v \varepsilon v \tau \omega \alpha \bar{v} \omega$.

Lac. 884: 2:1-2:19b.

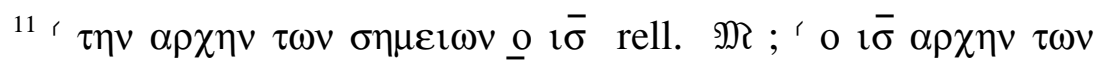

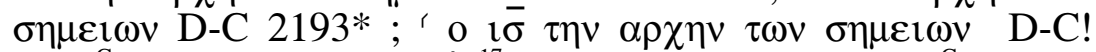
$2193^{\mathrm{C}}$; txt A! $\left.15651582\right|^{17} \mathrm{TXT}^{\prime} \kappa \alpha \tau \alpha \phi \alpha \gamma \varepsilon \tau \alpha \mathrm{l} 1192^{\mathrm{C}}$ rell. $\mathfrak{M}$

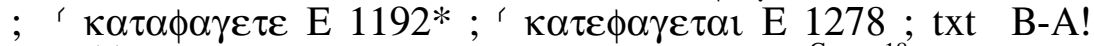

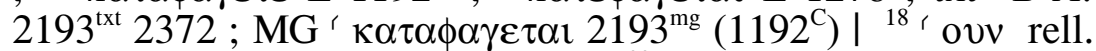
N ; ' om. E 2713 ; txt C $1582 \mid{ }^{22} \circ 2193 *$ rell. $\mathfrak{N}$; txt C $2193^{\mathrm{C} 1}{ }^{24}{ }^{\prime} \varepsilon \pi 1 \sigma \tau \varepsilon v \sigma \varepsilon v \mathrm{D} ! 565$; txt rell. $\mathfrak{N}$ । 


\section{Chapter 3}

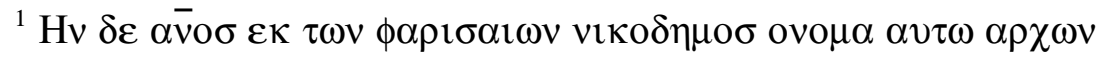

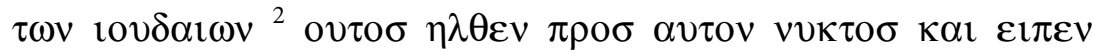

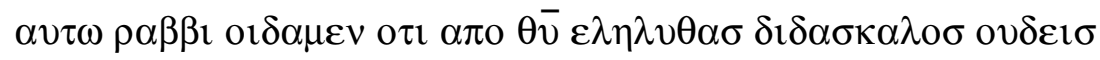

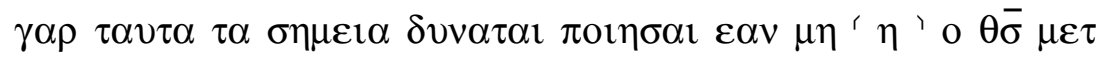

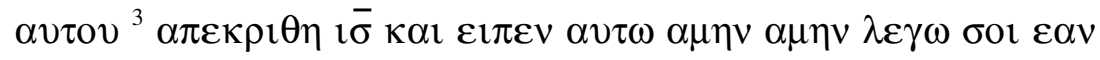
$\mu \eta \tau \imath \sigma \gamma \varepsilon v v \eta \theta \eta \alpha v \omega \theta \varepsilon v$ ov $\delta v v \alpha \tau \alpha \iota$ ı $\delta \varepsilon \imath v \tau \eta v \beta \alpha \sigma \imath \lambda \varepsilon \imath \alpha v \tau o v$

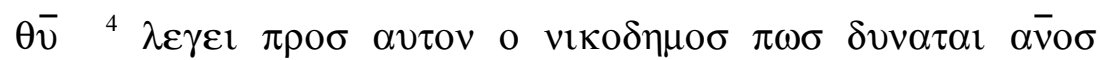

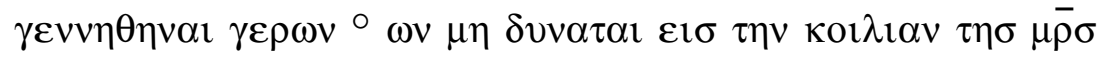

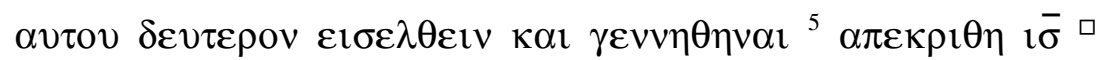

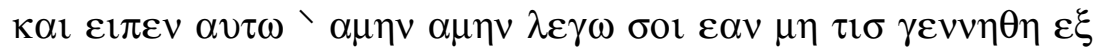

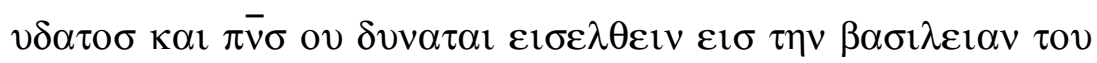

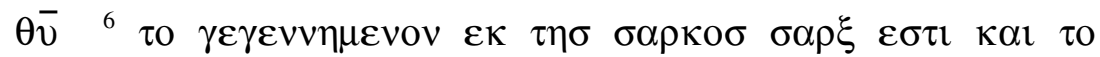

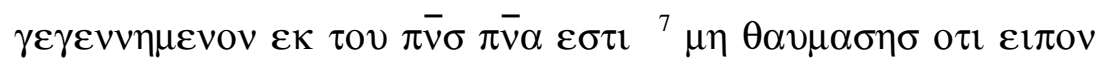
бol $\delta \varepsilon \iota^{\prime} \eta \mu \alpha \sigma^{\prime} \gamma \varepsilon v v \eta \theta \eta v \alpha \iota \alpha v \omega \theta \varepsilon v^{8} \tau \mathrm{o} \pi \bar{v} \alpha$ o $\pi \mathrm{ov} \theta \varepsilon \lambda \varepsilon \imath \pi v \varepsilon \iota$

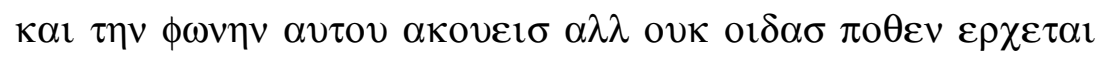

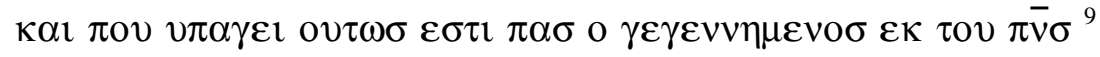

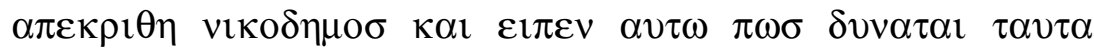

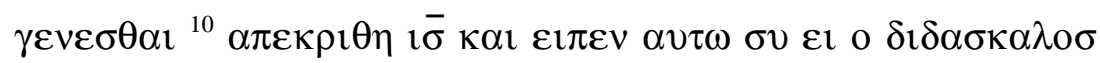

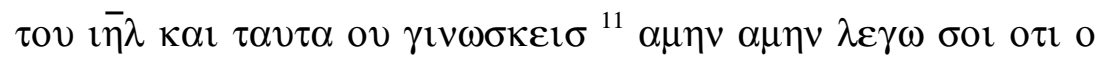

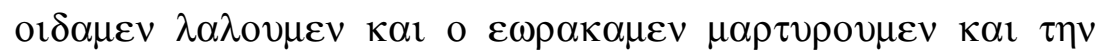

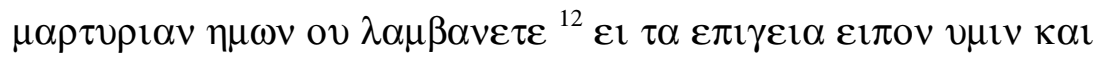

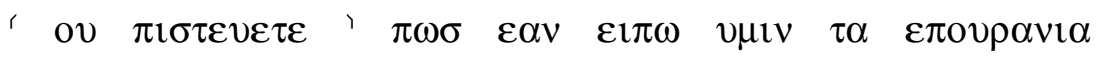

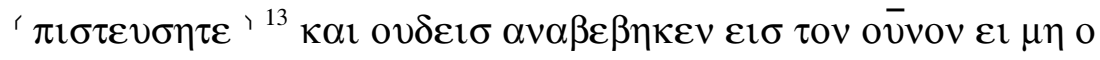

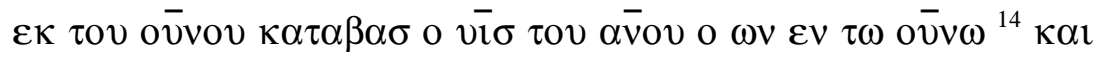

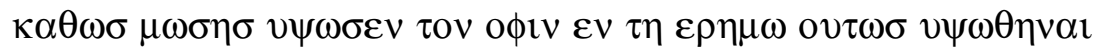

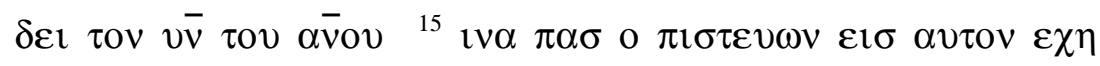

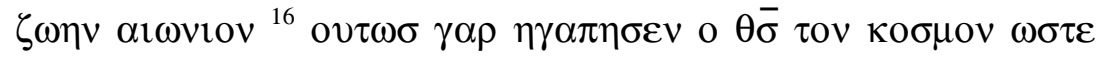

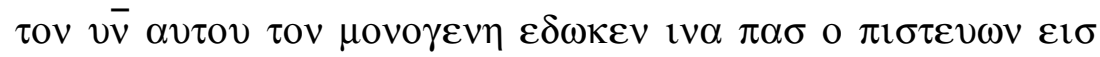

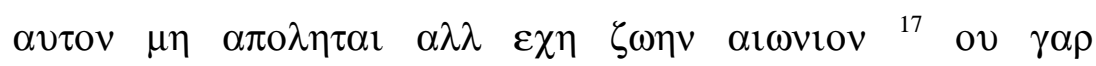

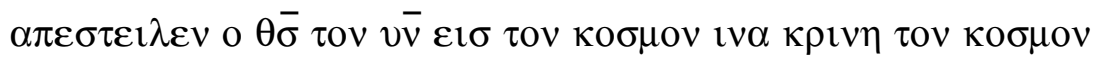

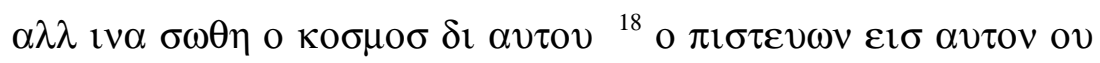

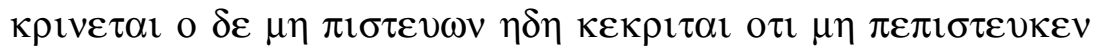




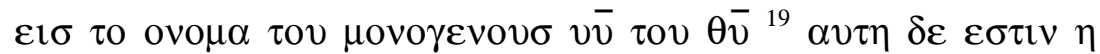

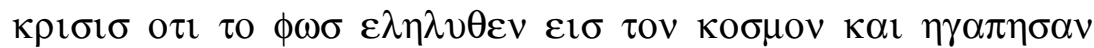

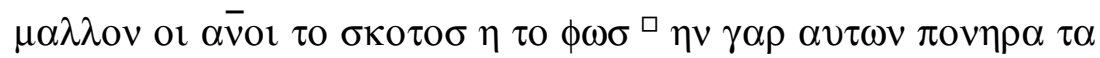

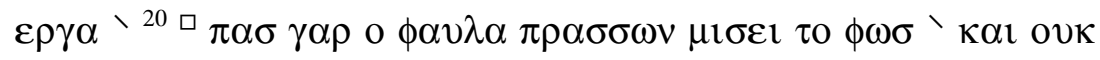

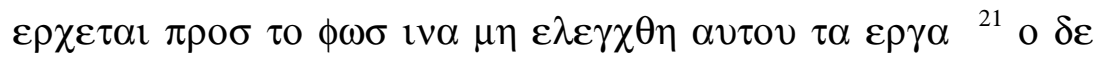

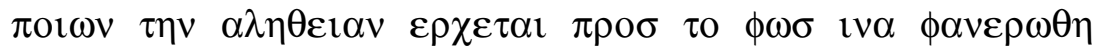

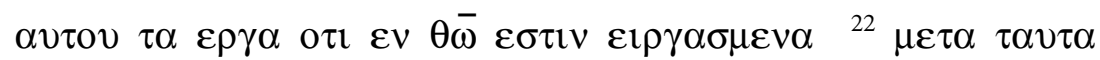

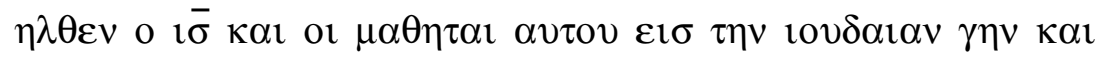

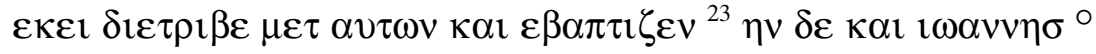

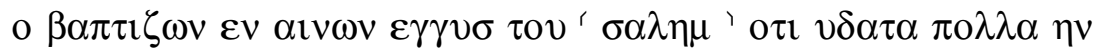

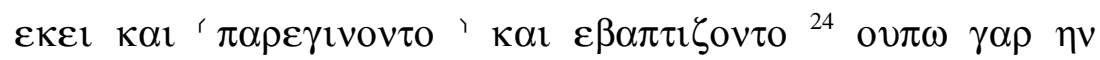
$\beta \varepsilon \beta \lambda \eta \mu \varepsilon v \sigma \sigma \varepsilon \iota \sigma \phi \nu \lambda \alpha \kappa \eta v$ o $1 \omega \alpha v v \eta \sigma{ }^{25} \varepsilon \gamma \varepsilon v \varepsilon \tau$ ovv $\zeta \eta \tau \eta \sigma \iota \sigma$

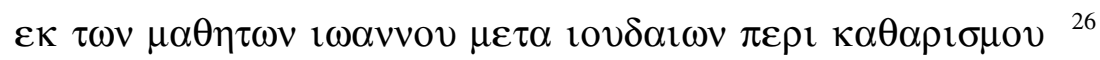

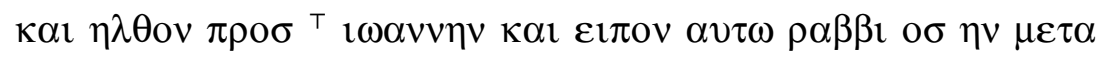

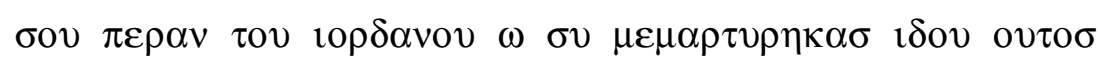
$\beta \alpha \pi \tau l \zeta \varepsilon \imath \quad \kappa \alpha \imath \quad \pi \alpha \nu \tau \varepsilon \sigma \quad \varepsilon \rho \chi 0 \nu \tau \alpha \imath \quad \pi \rho \circ \sigma \quad \alpha \nu \tau O \nu{ }^{27} \alpha \pi \varepsilon \kappa \rho \imath \theta \eta$

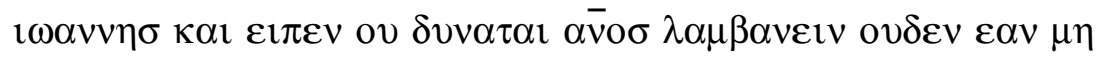

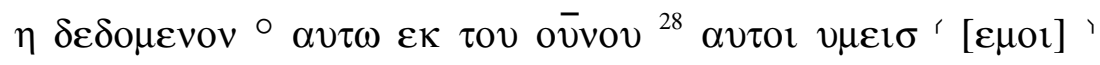

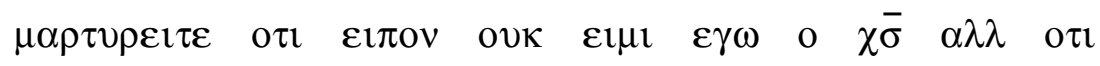

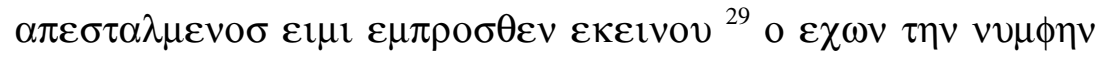

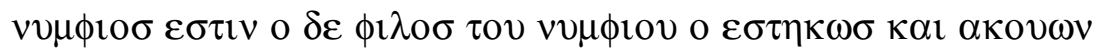

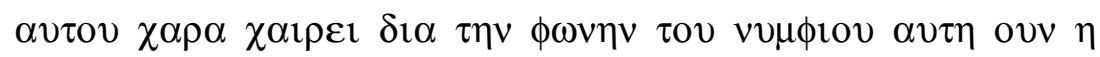
$\chi \alpha \rho \alpha \eta \varepsilon \mu \eta \pi \varepsilon \pi \lambda \eta \rho \omega \tau \alpha{ }^{30} \varepsilon \kappa \varepsilon \imath v O v{ }^{\top} \delta \varepsilon l \alpha v \xi \alpha v \varepsilon \imath v \varepsilon \mu \varepsilon \delta \varepsilon$ $\varepsilon \lambda \alpha \tau \tau o v \sigma \theta \alpha \imath{ }^{31}$ o $\alpha v \omega \theta \varepsilon v \varepsilon \rho \chi 0 \mu \varepsilon v o \sigma \varepsilon \pi \alpha v \omega \pi \alpha \nu \tau \omega \nu \varepsilon \sigma \tau \iota \nu$ o $\omega \nu \varepsilon \kappa \tau \eta \sigma \gamma \eta \sigma \varepsilon \kappa \tau \eta \sigma \gamma \eta \sigma \varepsilon \sigma \iota \kappa \alpha \iota \varepsilon \kappa \tau \eta \sigma \gamma \eta \sigma \lambda \alpha \lambda \varepsilon \iota$ o $\varepsilon \kappa \tau o v$

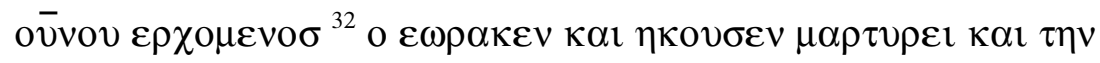

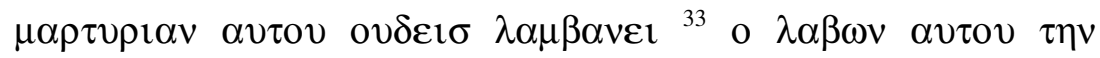

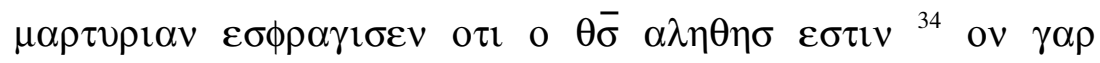

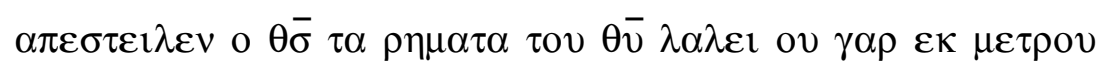

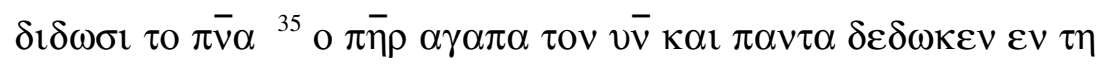

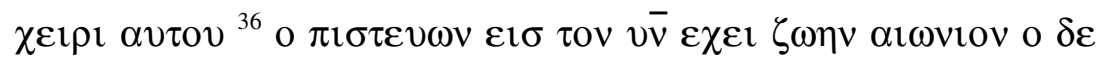

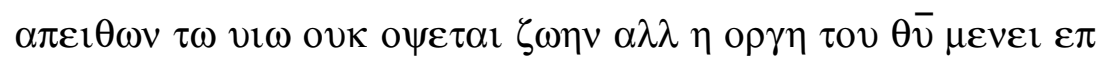

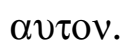


${ }^{2}$ ' $\varepsilon 1 \mathrm{D} 884$; txt rell. $\left.\mathfrak{M}\right|^{4} \circ \mathrm{D}$ ! 565 ; txt rell. $\left.\mathfrak{M}\right|^{5}$ 口 $2193 *$ rell. $\mathfrak{N}$; txt C $\left.2193^{\mathrm{C} 1}\right|^{7}$ । $v \mu \alpha \sigma$ rell. $\mathfrak{N}$; txt B 118 205abs 209

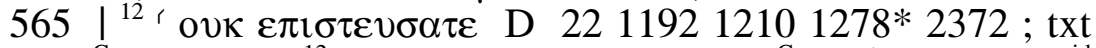
$1278^{\mathrm{C}}$ rell. $\left.\mathfrak{M}\right|^{12}\left(\pi \mathrm{l} \sigma \varepsilon v \sigma \varepsilon \tau \varepsilon \quad 8841278^{\mathrm{C}} \mathrm{M}^{\mathrm{pt}} ;\right.$ txt $872^{\mathrm{vid}}$ $1278 *$ rell. $\left.\mathrm{M}^{\mathrm{pt}}\right|^{19} \square \mathrm{D}$ ! 2193*; $\eta v \gamma \alpha \rho \pi \mathrm{ov \eta} \rho \alpha \alpha v \tau \omega \nu \tau \alpha$ $\varepsilon \rho \gamma \alpha$ ' $2193^{\mathrm{C}}$ rell. M ; txt A 1 205abs 20956588415822713

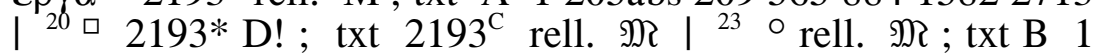
118 205abs $\left.20915822713\right|^{23}$ ' $\sigma \alpha \lambda \varepsilon 1 \mu 2213156511921210$ $1278^{*} 21932372 \mathrm{M}^{\mathrm{pt}}$; txt $1278^{\mathrm{C}}$ rell. $\mathrm{M}^{\mathrm{pt}}{ }^{23}$ ( $\pi \alpha \rho \varepsilon \gamma \varepsilon v o v \tau \mathrm{D}$

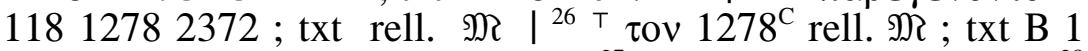
118 205abs $\left.2091278 * 23722713\right|^{27} \circ \mathrm{D}$ ! 565 ; txt rell. $\mathfrak{M} \mid{ }^{28}$ ' $\mu$ or B $1318842193^{\mathrm{C}}$;' om. 872 N ; txt B 2193*vid rell.| ${ }^{30}$ T $\delta \varepsilon \mathrm{D} 884$; txt rell. $\mathfrak{M}$ । 


\section{Chapter 4}

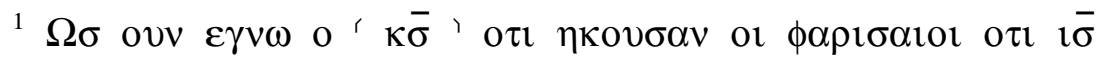

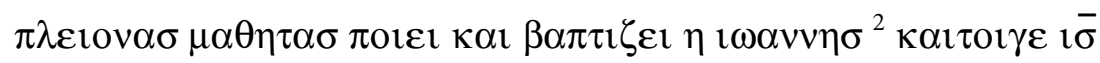
$\alpha v \tau \circ \sigma$ оvк $\varepsilon \beta \alpha \pi \tau \imath \zeta \varepsilon v \alpha \lambda \lambda$ or $\mu \alpha \theta \eta \tau \alpha \iota \alpha v \tau o v^{3} \alpha \phi \eta \kappa \varepsilon v{ }^{\circ} \delta \varepsilon \tau \eta \nu$

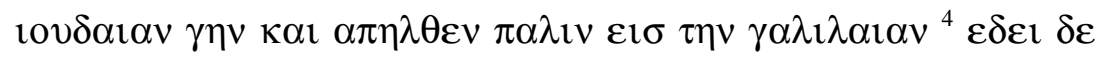

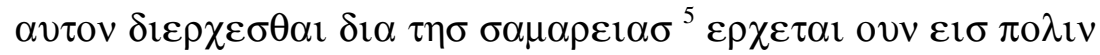

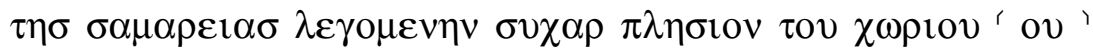

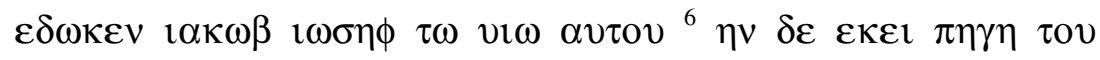

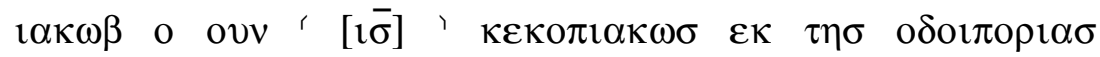

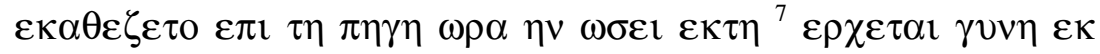

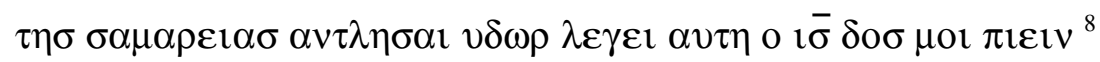

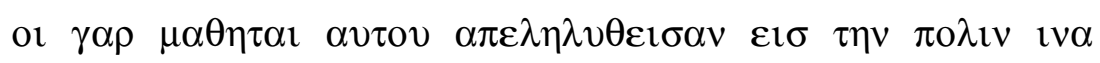
$\tau \rho о \phi \alpha \sigma \alpha \gamma о \rho \alpha \sigma \omega \sigma \iota v{ }^{9} \lambda \varepsilon \gamma \varepsilon \iota \alpha v \tau \omega \eta \eta \gamma v \vee \eta \eta \sigma \alpha \mu \alpha \rho \varepsilon \iota \tau \iota \sigma \pi \omega \sigma \sigma v$

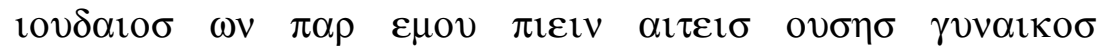

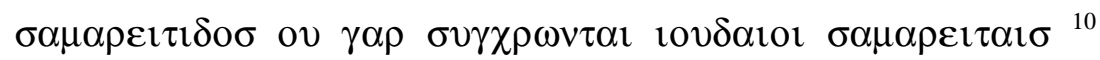

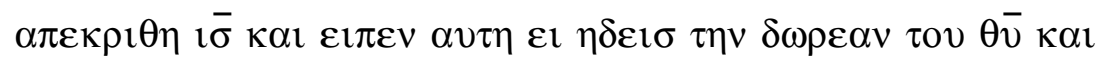

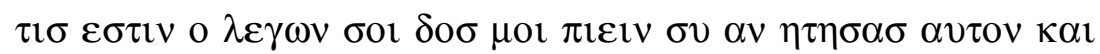

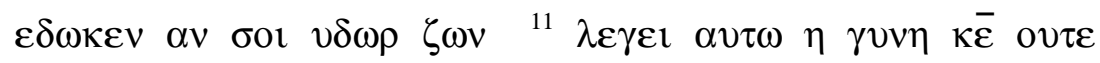

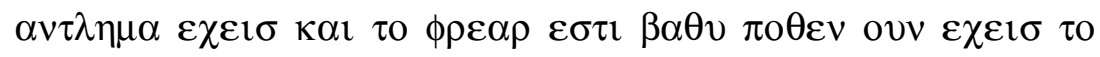

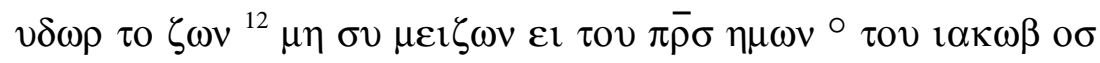

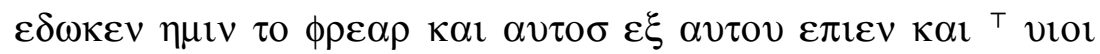
$\alpha v \tau \mathrm{ov} \kappa \alpha \imath \tau \alpha$ $\theta \rho \varepsilon \mu \mu \alpha \tau \alpha \alpha v \tau \mathrm{ov}{ }^{13} \alpha \pi \varepsilon \kappa \rho \imath \theta \eta \mathrm{\imath} \bar{\sigma} \kappa \alpha \imath \varepsilon \imath \pi \varepsilon v \alpha v \tau \eta$

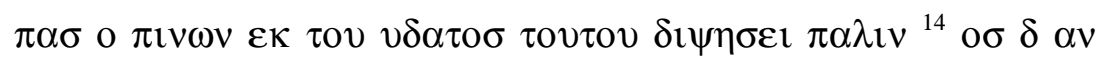

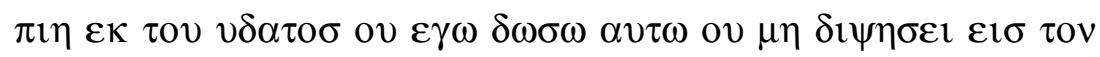
$\alpha \iota \omega v \alpha \alpha \lambda \lambda \alpha \tau$ o $v \delta \omega \rho$ o ${ }^{\top} \delta \omega \sigma \omega \alpha v \tau \omega \gamma \varepsilon v \eta \sigma \varepsilon \tau \alpha \iota \varepsilon v \alpha v \tau \omega \pi \eta \gamma \eta$

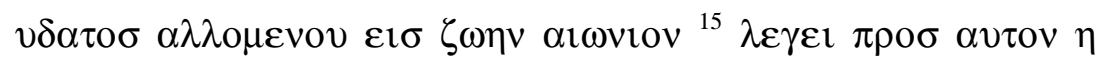

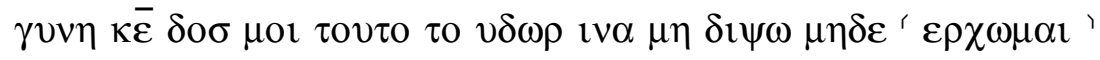

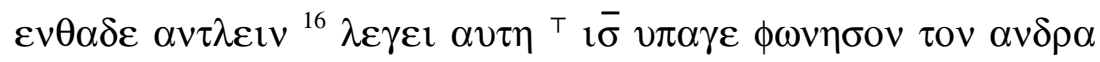

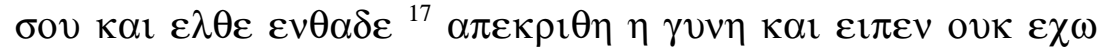

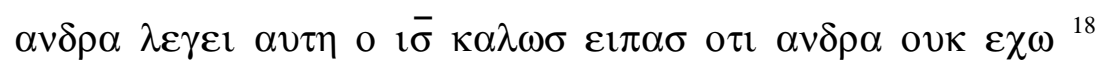

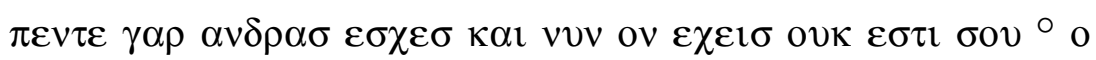

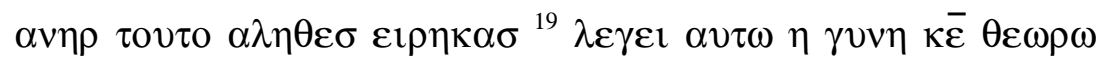

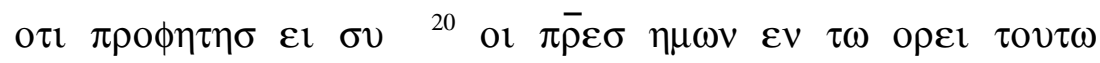




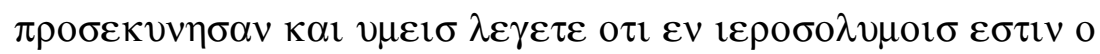

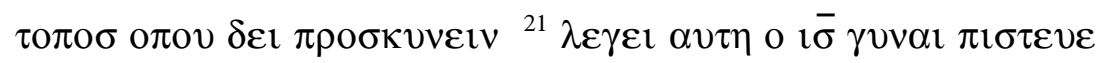

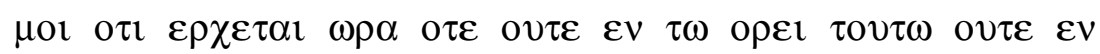

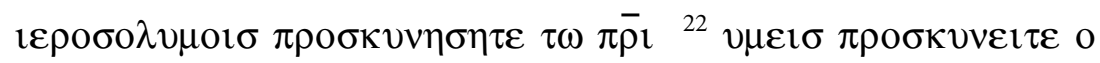

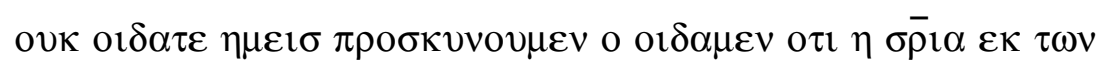

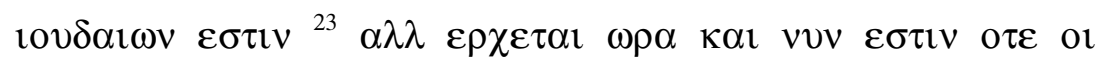

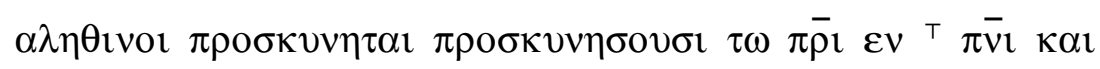

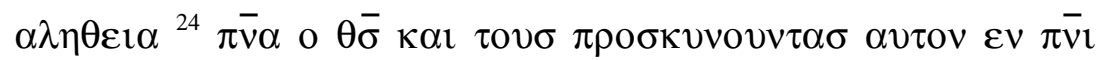
$\kappa \alpha \iota \alpha \lambda \eta \theta \varepsilon \imath \alpha \delta \varepsilon \imath \pi \rho \circ \sigma \kappa v v \varepsilon \imath{ }^{25} \lambda \varepsilon \gamma \varepsilon \imath \alpha v \tau \omega \eta \eta \gamma v \vee \eta$ oi $\delta \alpha$ o ${ }^{25}$

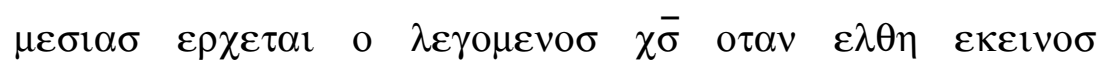

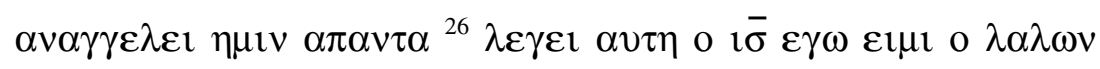

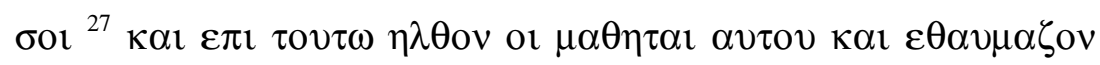

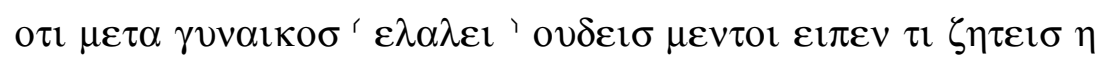

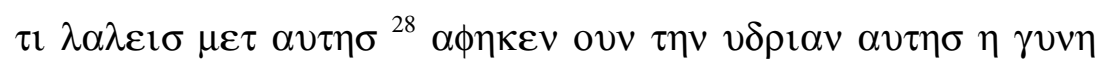

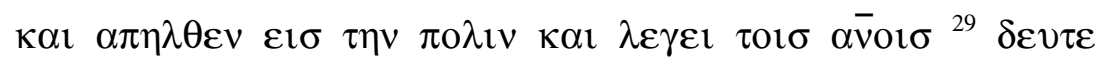

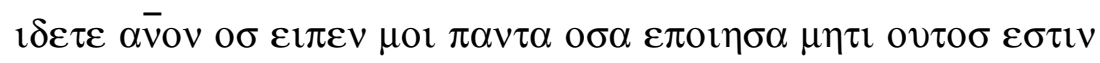

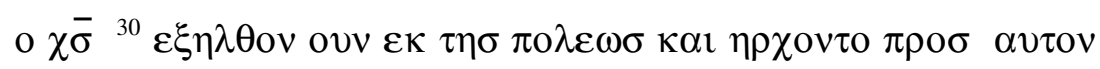

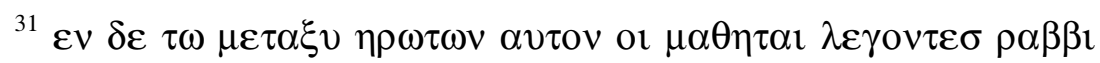

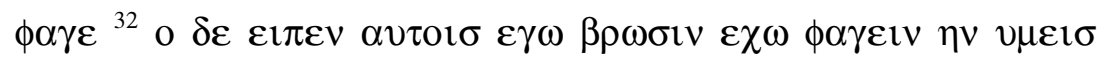

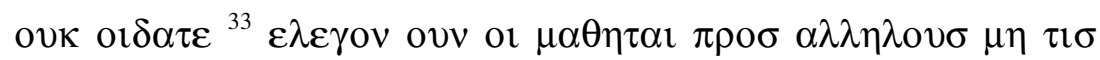

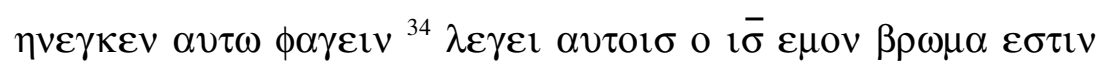

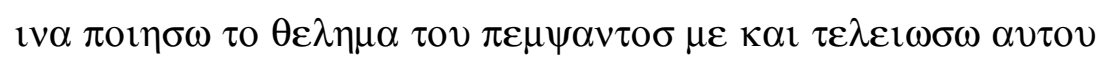

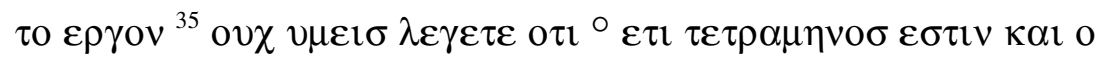

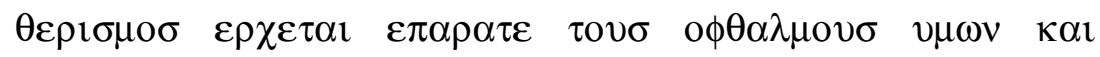

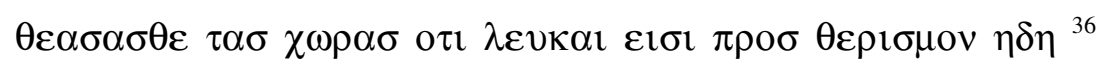

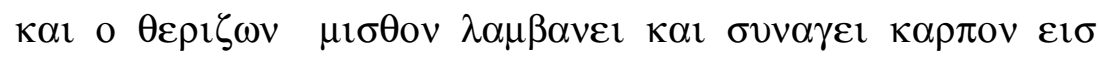

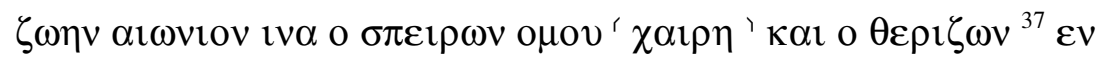

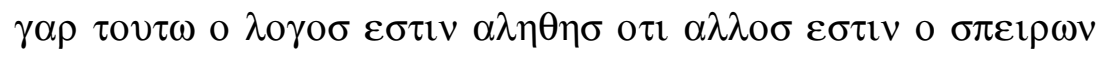

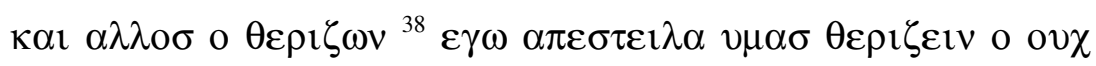

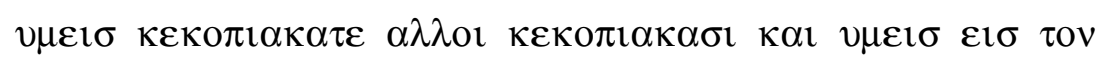

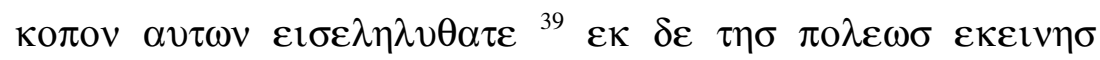

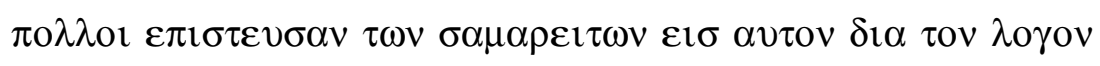

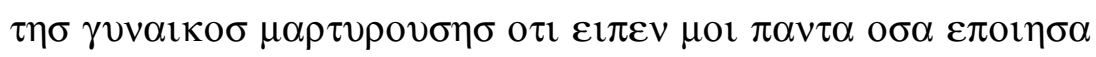

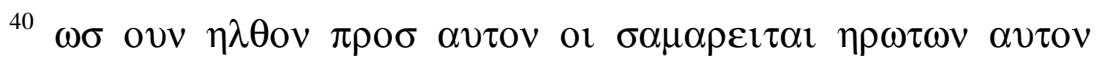




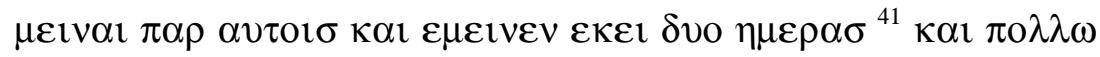

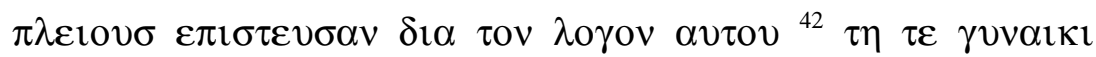

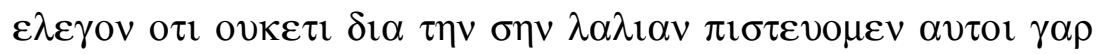

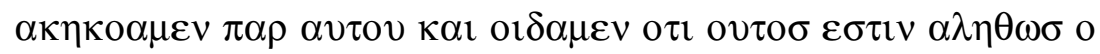

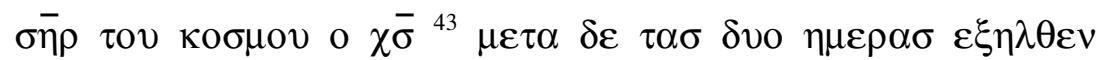

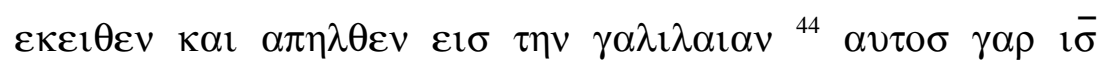

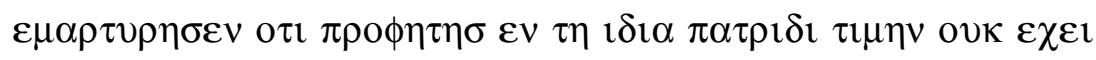

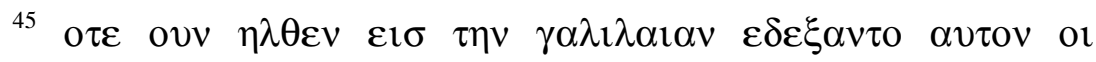

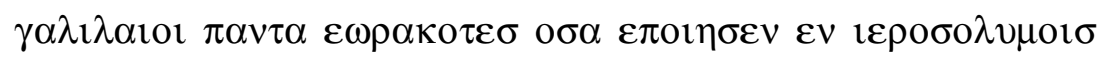

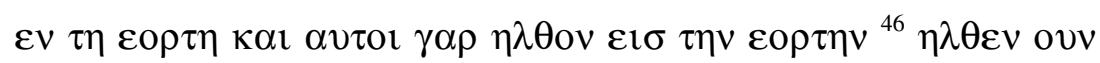

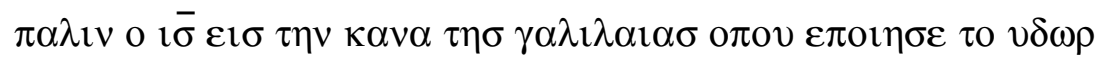

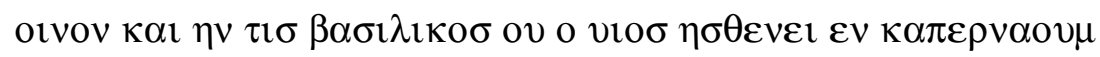

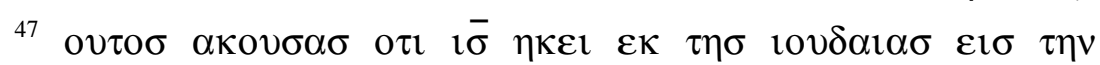

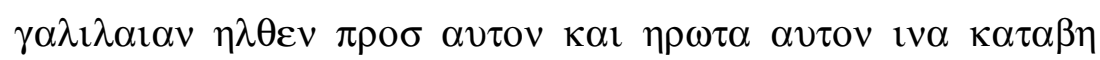

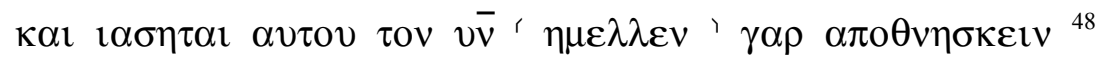

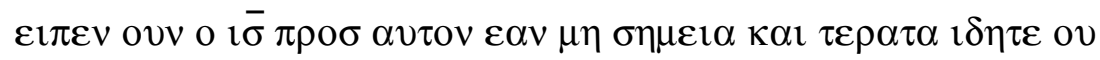

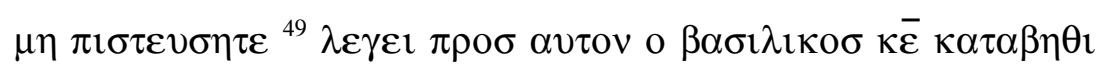

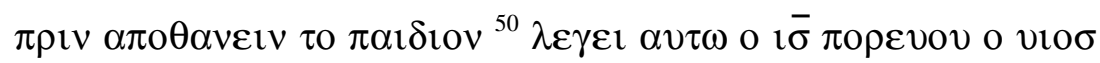

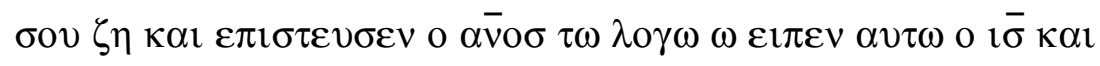

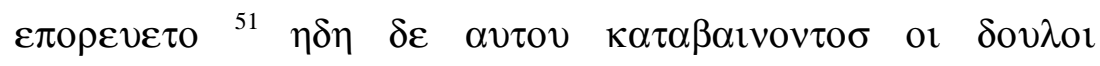

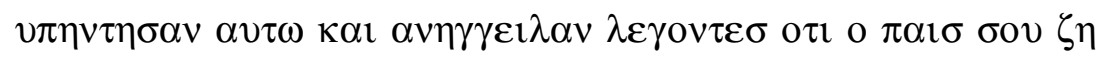

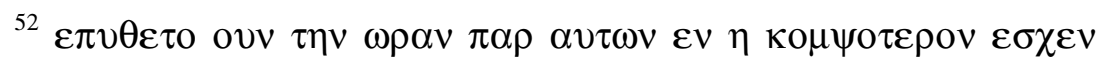

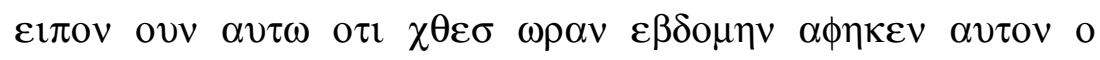
$\pi v \rho \varepsilon \tau o \sigma{ }^{53} \varepsilon \gamma \nu \omega$ ovv o $\pi \bar{\eta} \rho$ o $\tau \imath{ }^{\top} \varepsilon \kappa \varepsilon \imath v \eta \tau \eta \omega \rho \alpha \varepsilon \nu \eta \varepsilon \imath \tau \varepsilon v$

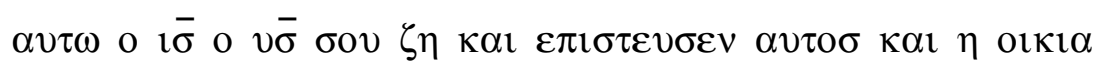

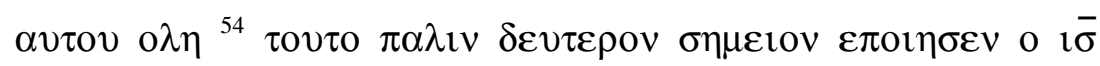
$\varepsilon \lambda \theta \omega \nu \varepsilon \kappa \tau \eta \sigma^{\prime} \operatorname{lov} \delta \alpha \iota \alpha \sigma \varepsilon \imath \sigma \tau \eta \nu \gamma \alpha \lambda \iota \lambda \alpha \iota \alpha v^{\prime}$.

${ }^{1}$ ‘ $\bar{\sigma}$ rell. M ; txt C-B! $\left.1318722193^{\mathrm{C}} 2713\left(*^{6}{ }^{6} \kappa \bar{\sigma}\right) 884\right)\left.\right|^{3} \circ$

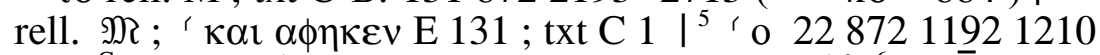
$2193^{\mathrm{C}} 2372 \_\mathrm{M}^{\mathrm{pt}}{ }^{\prime} \omega \mathrm{E} 131$; txt $2193 *$ rell. $\left.\mathrm{M}^{\mathrm{pt}}\right|^{6}+\kappa \bar{\sigma} \mathrm{D}-\mathrm{C}$ ! $884\left(*^{*}{ }^{\prime} \kappa \bar{\sigma}^{\prime} 2193^{\mathrm{C}}\right)$; txt rell. $\mathfrak{M} \mid{ }^{12} \circ$ rell. $\mathfrak{N}$; txt C $1205 \mathrm{abs}$ $\left.209\right|^{12}{ }^{\mathrm{T}}$ or $131^{\mathrm{C}} 2193^{\mathrm{C}}$ rell. $\mathfrak{N}$; txt B $118131^{*} 205 \mathrm{abs} 209$ $\left.8722193 * 2713\right|^{14} \mathrm{~T} \varepsilon \gamma \omega \mathrm{D} 2211921278^{*} 2372$; txt $884^{\mathrm{C}}$

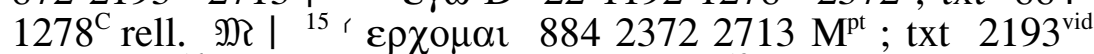
rell. $\left.\mathrm{M}^{\mathrm{pt}}\right|^{16}{ }^{\mathrm{T}}$ o rell. $\mathfrak{N}$; txt B $11582 \mid{ }^{18}{ }^{\circ}$ rell. $\mathfrak{N}$; txt B 1 
$\left.1582\right|^{23} \mathrm{~T} \tau \omega \mathrm{D}$ ! 1 ; txt rell. $\left.\mathfrak{M}\right|^{27}$; $\omega \mu \varepsilon \lambda \varepsilon \mathrm{D}$ ( $884 ;$ txt rell. $\mathfrak{M} \mid{ }^{35} \circ$ rell. $\mathrm{M}^{\mathrm{pt}}$; txt $1225651192127815822193 \mathrm{M}^{\mathrm{pt}}$ । ${ }^{36}$ ' $\chi$ atpel $131884^{*} \mathrm{M}^{\mathrm{pt}}$; txt $884^{\mathrm{C}} 2193^{\text {vid }} 2372^{\text {vid }}$ rell. $\left.\mathrm{M}^{\mathrm{pt}}\right|^{47}$, $\varepsilon \mu \varepsilon \lambda \lambda \varepsilon v 2193^{\text {vid }}$ rell. M $^{\text {pt }}$; txt 122565884119212781582 $\left.2372 \mathrm{M}^{\mathrm{pt}}\right|^{53} \mathrm{~T}^{\mathrm{T}} \varepsilon v$ rell. $\mathfrak{N}$; txt B 1 205abs $\left.2091582\right|^{54}$,

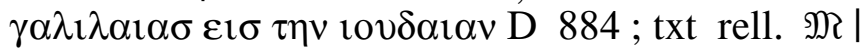




\section{Chapter 5}

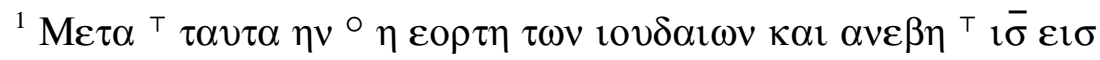

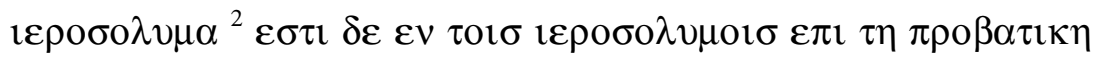
[MG?]

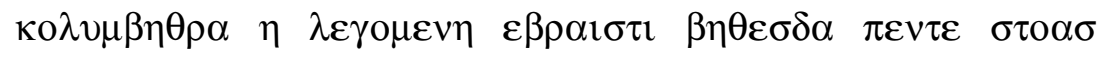

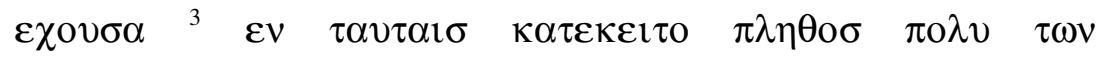

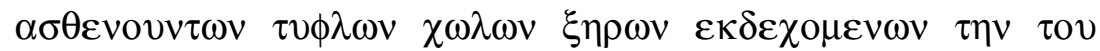

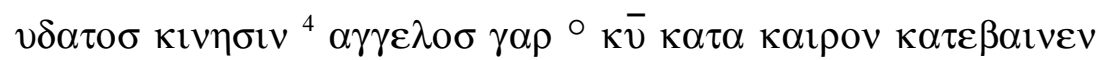
$\varepsilon v \tau \eta \kappa о \lambda v \mu \beta \eta \theta \rho \alpha \kappa \alpha l \varepsilon \tau \alpha \rho \alpha \sigma \sigma \varepsilon \tau$ o $v \delta \omega \rho$ о оvv $\pi \rho \omega \tau о \sigma \varepsilon \mu \beta \alpha \sigma$

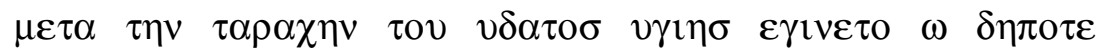

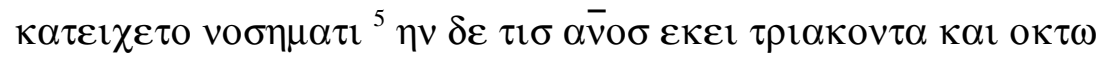

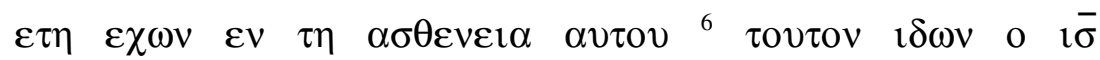

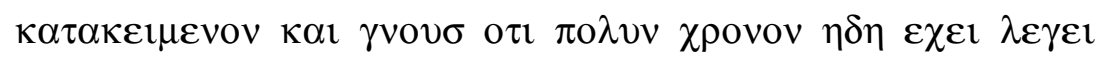

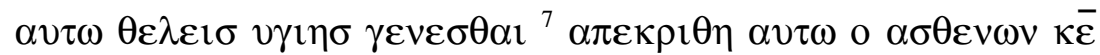

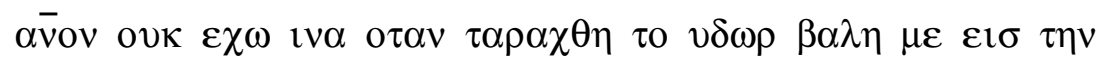

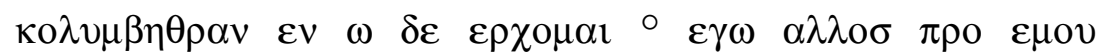

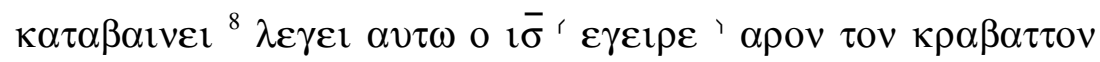

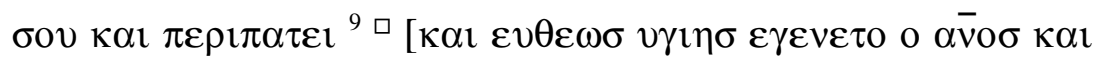

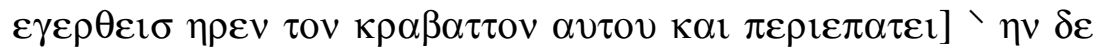

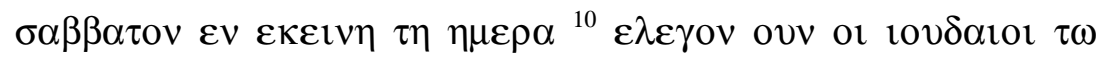

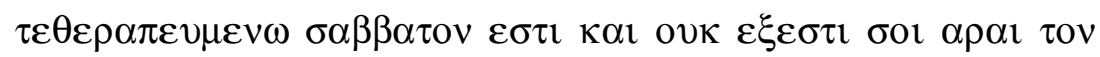

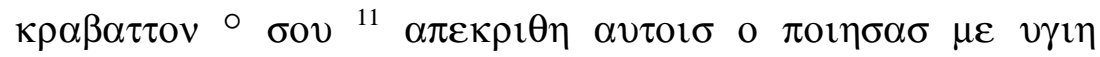

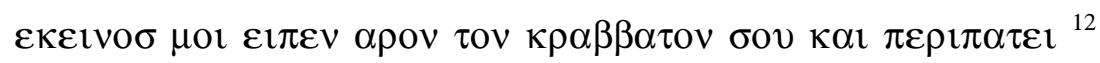

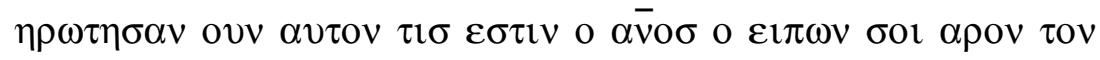

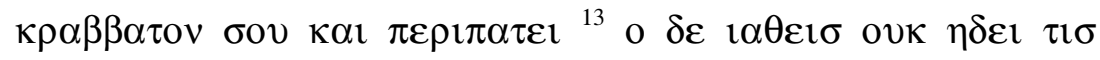

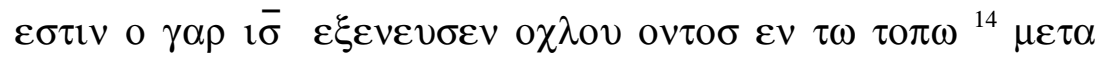

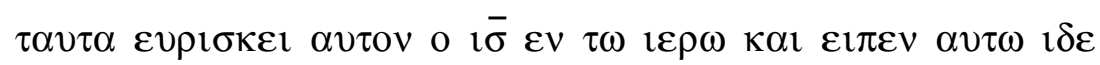

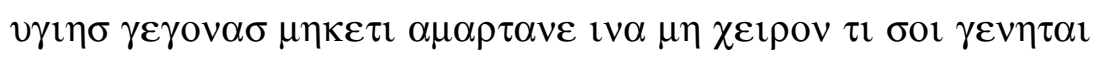

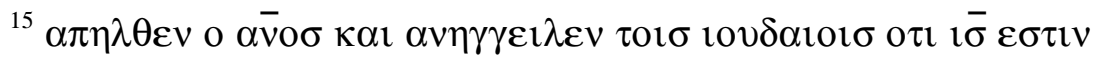

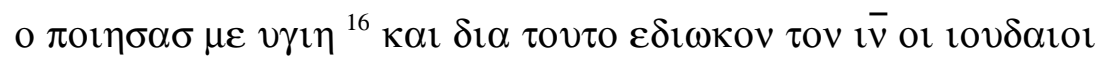

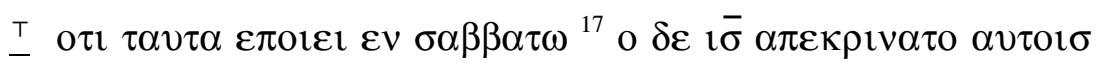

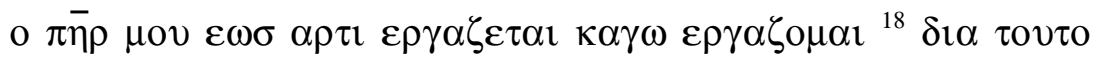

Т $\kappa \alpha \iota \varepsilon \zeta \eta \tau O v v$ $\alpha v \tau$ ov $\alpha \pi \mathrm{o \kappa} \tau \varepsilon \imath \alpha \iota$

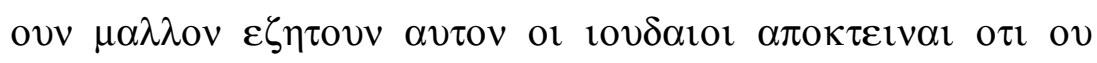

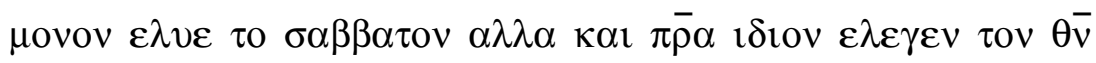




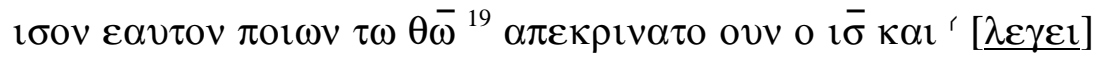

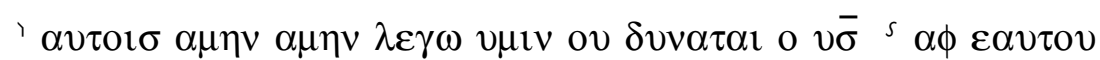

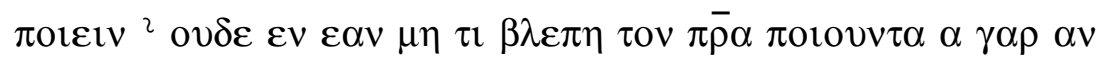

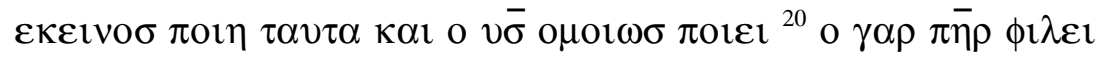

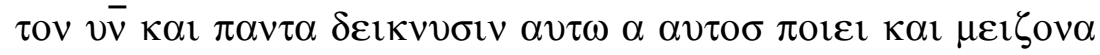

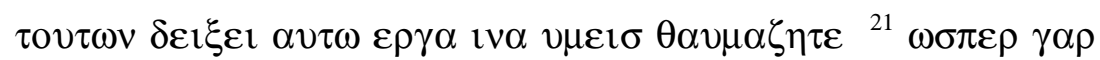

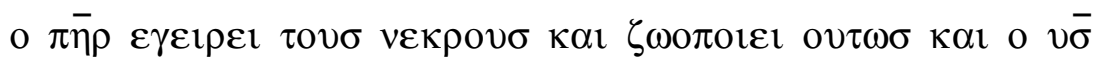

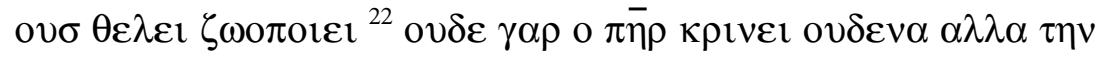

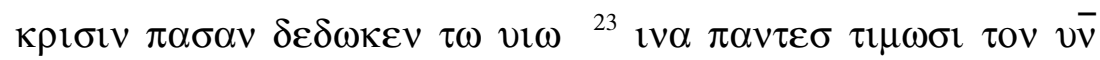

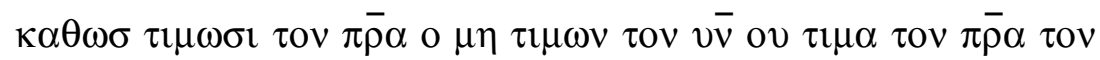

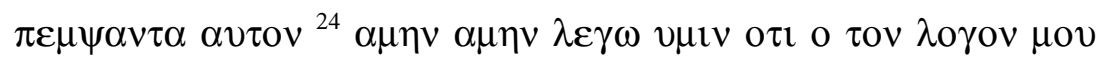

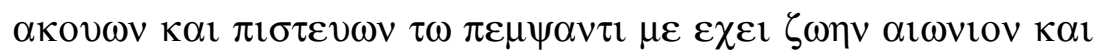

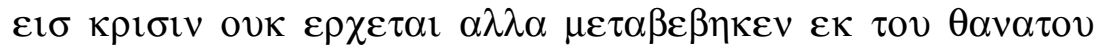

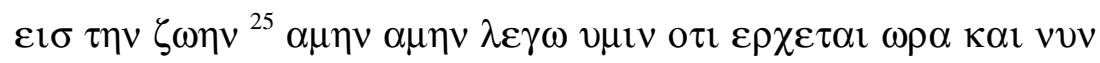

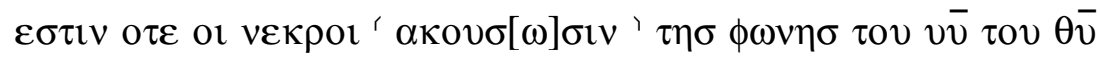

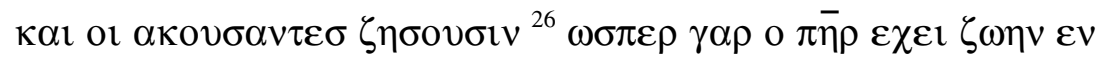

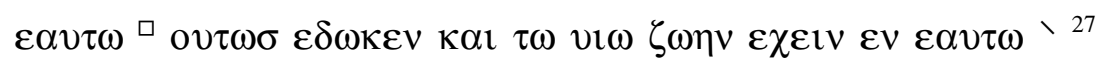

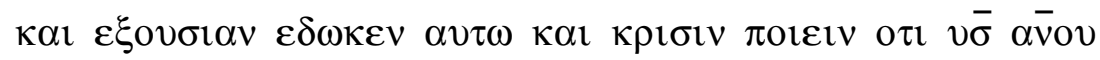

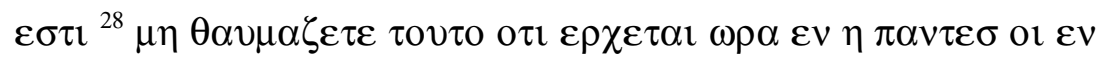

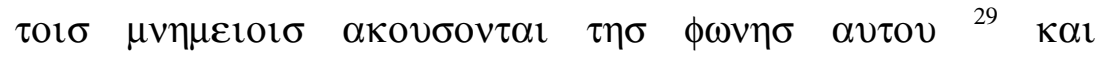

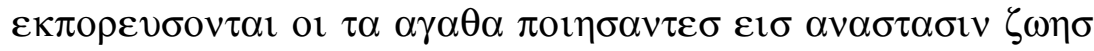
or $\delta \varepsilon \quad \tau \alpha \phi \alpha v \lambda \alpha \pi \rho \alpha \xi \alpha v \tau \varepsilon \sigma \quad \varepsilon 1 \sigma \quad \alpha v \alpha \sigma \tau \alpha \sigma l v \quad \kappa \rho l \sigma \varepsilon \omega \sigma{ }^{30}$ ov

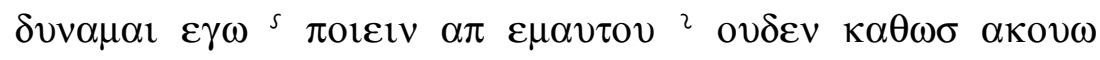

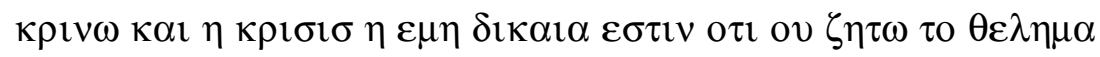

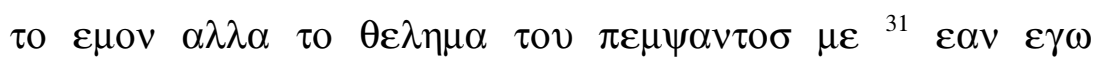

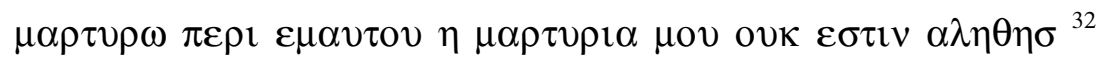

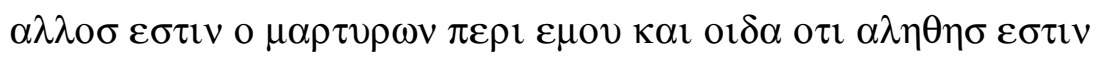

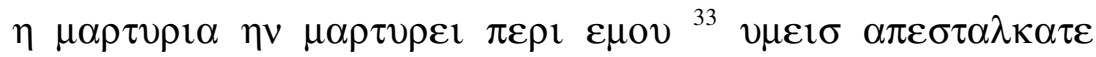

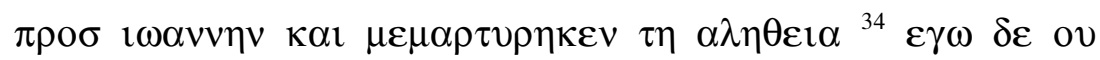

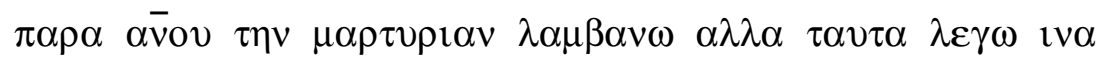

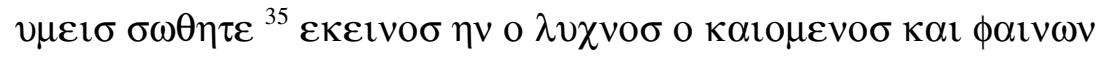

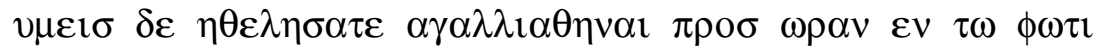

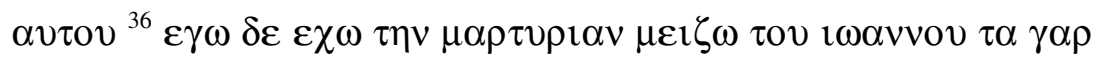

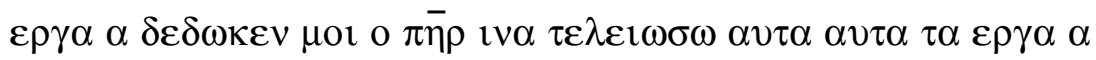




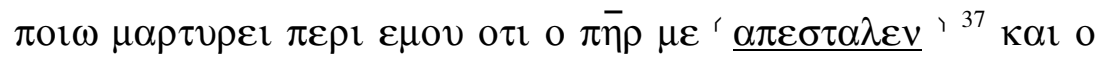
' $\alpha \pi \varepsilon \sigma \tau \alpha \lambda \kappa \varepsilon v '$

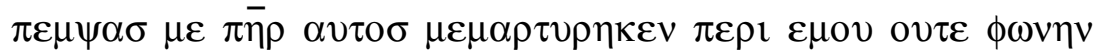

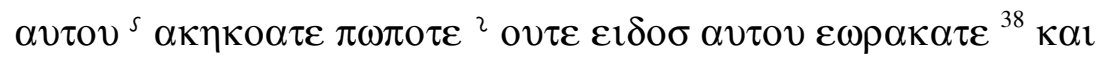

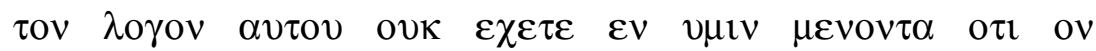

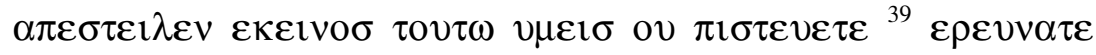

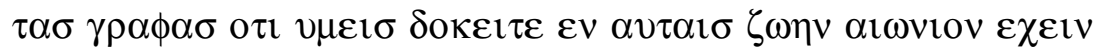

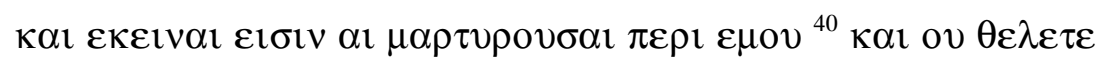

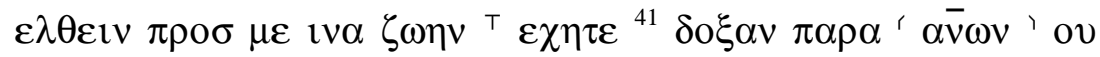

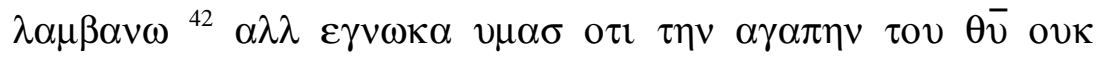

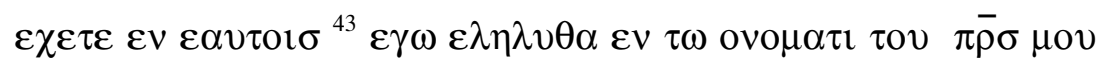

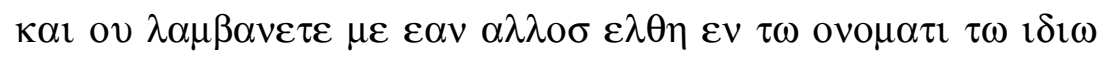

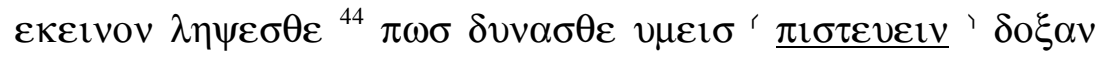
' $\pi \mathrm{\imath} \sigma \tau v \sigma \alpha \imath{ }^{\prime}$

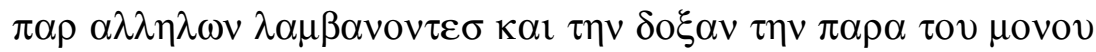

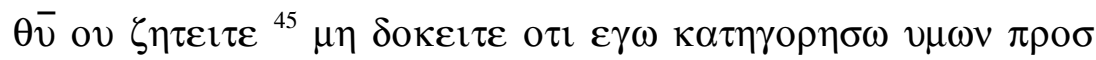

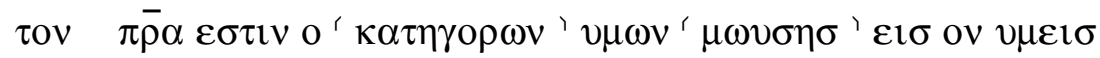

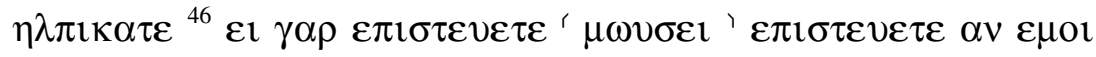

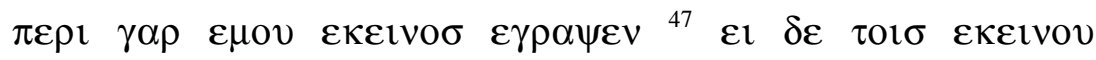
$\gamma \rho \alpha \mu \mu \alpha \sigma \imath v$ ov $\pi l \sigma \tau \varepsilon v \varepsilon \tau \varepsilon \pi \omega \sigma \tau o l \sigma \varepsilon \mu o เ \sigma \rho \eta \mu \alpha \sigma l \pi l \sigma \tau \varepsilon v \sigma \eta \tau \varepsilon$.

${ }^{1}$ T $\delta \varepsilon$ D $2213111921278^{* v i d} 2372$; txt $1278^{\mathrm{C}}$ rell. $\left.\mathfrak{M}\right|^{1} \circ$ $2213188411922713 \mathrm{M}^{\mathrm{pt}}$; ' VID 565; txt rell. $\left.\mathrm{M}^{\mathrm{pt}}\right|^{1}{ }^{\mathrm{T}} \mathrm{o}$ rell. $\mathfrak{N}$; txt C-B 2211922193 | $^{4} \circ 2193^{*}$ rell. $\mathfrak{N}$; txt C 131 $\left.2193^{\mathrm{C}}\right|^{7} \circ \mathrm{D} 2211922372$; txt rell. MN ${ }^{8}$ ' $1582^{\mathrm{C}} 2193^{\mathrm{C}}$ rell. $\mathrm{M}^{\mathrm{pt}}$; txt $\left.1565872 * 2193 * 1582 * \mathrm{M}^{\mathrm{pt}}\right|^{9}{ }^{8} \mathrm{~B}$

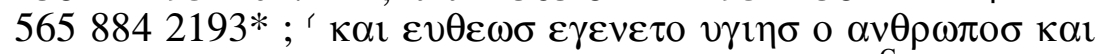

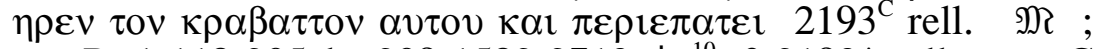
txt B 1118 205abs 20915822713 | ${ }^{10} \circ{ }^{\circ} 2193^{*}$ rell.; txt C

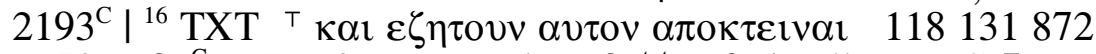
$12782193^{\mathrm{C}} 2372$ NR ; txt A! $1192^{\mathrm{txt}} 2193^{*}$ rell. ; $\mathrm{MG}^{\top} \kappa \alpha$

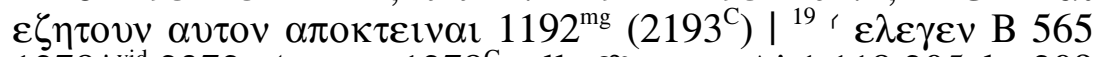
$1278 *$ vid 2372 ; ' $\varepsilon 1 \pi \varepsilon v 1278^{\mathrm{C}}$ rell. $\mathfrak{M}$; txt A! 1118 205abs 209 $\left.15822193\right|^{19}$ s3.1.2. ${ }^{2}$ rell. $\mathfrak{M}$; txt C 88412782372 | ${ }^{25}$,

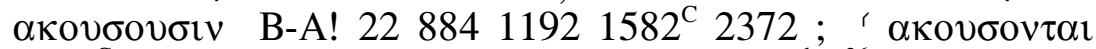
$2193^{\mathrm{C}}$ rell. $\mathfrak{M}$; txt B-A! $\left.1565158221933^{* \text { suppl }}\right|^{26} \square \mathrm{D}$ ! $1^{*}$; txt $1^{\mathrm{C}}$ rell. MP| ${ }^{30}{ }^{5} 2.3 .1 .^{2} \mathrm{D} 884 ;{ }^{s} 2.3 .^{2}$ E 2372 ; txt $884^{\mathrm{C}}$ rell. M | $^{36}$ TXT ' $\alpha \pi \varepsilon \sigma \tau \alpha \lambda \kappa \varepsilon v$ rell. $\mathfrak{N}$; txt A! $1315652193^{\text {txt }}$; MG

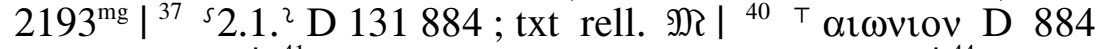
; txt rell. M | ${ }^{41}$ ' $\alpha v \theta \rho \omega \pi \mathrm{ov} \mathrm{D}$ ! 565 ; txt rell. $\left.\mathfrak{N}\right|^{44} \mathrm{TXT}$; $\pi \imath \sigma \tau \varepsilon v \sigma \alpha \mathrm{l} 2193^{\mathrm{C}}$ rell. $\mathfrak{N}$; txt A $122^{\mathrm{txt}} 118$ 205abs 209565 $8841192^{\mathrm{txt}} 15822193 *^{\text {vid }} 2713 ; \mathrm{MG}^{\mathrm{r}} \pi \mathrm{\tau} \sigma \tau \varepsilon v \sigma \alpha \mathrm{r} 22^{\mathrm{mg}} 1192^{\mathrm{mg}}$ 


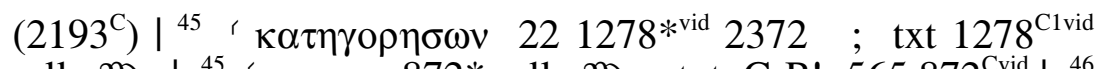
rell. $\mathfrak{M} \mid{ }^{45}{ }^{4} \mu \omega \sigma \eta \sigma \quad 872^{*}$ rell. $\mathfrak{N}$; txt C-B! $565872^{\text {Cvid }}{ }^{46}$ ' $\mu \omega v \sigma \eta$ D $872^{\text {vid }} 884$; $\mu \omega \sigma \eta$ E 2372 ; ' $\mu \omega \sigma \varepsilon \mathrm{r} 2193 *$ rell. M ; txt B $5652193^{\mathrm{C}}$ | 


\section{Chapter 6}

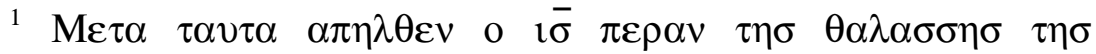

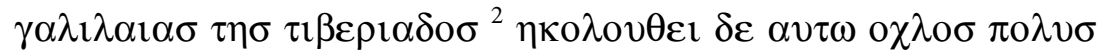

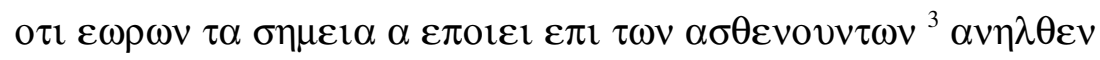

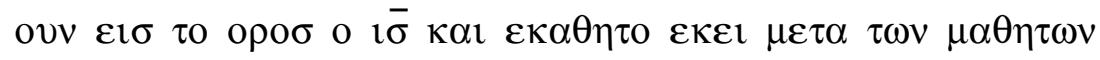

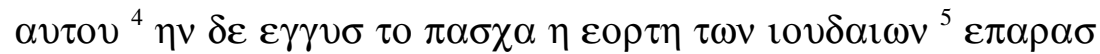

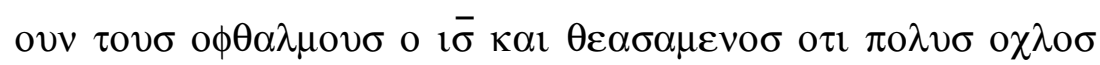

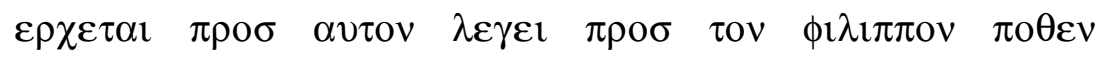

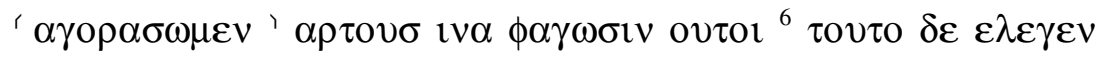

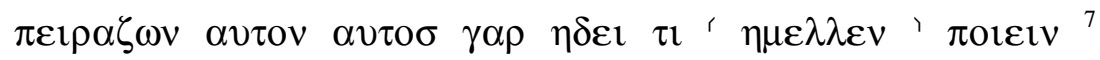

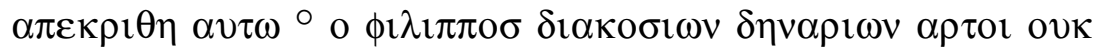

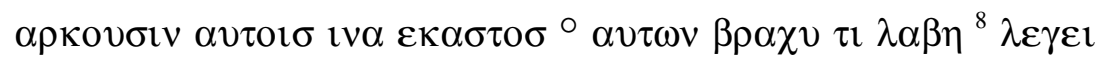

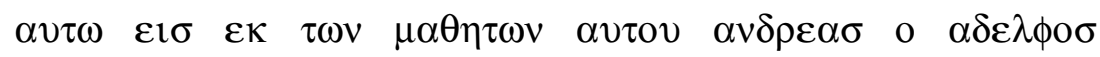

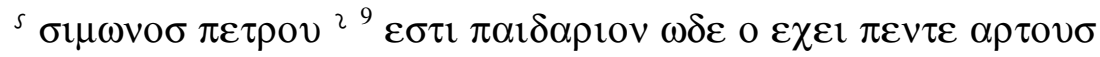

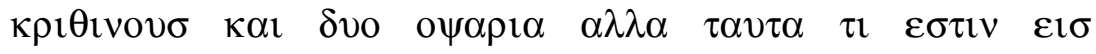

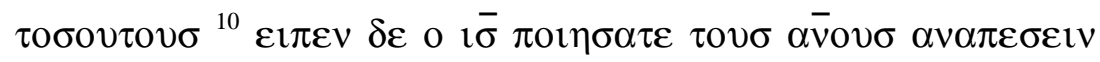

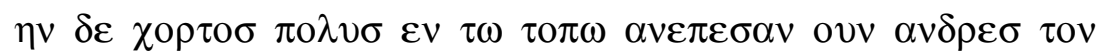

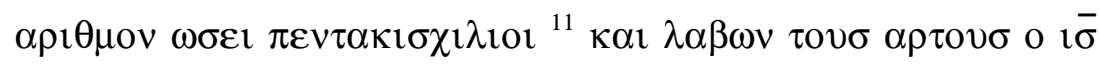

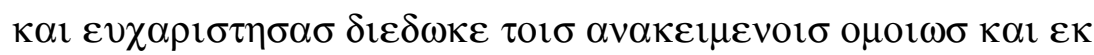

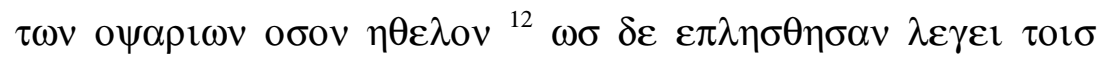

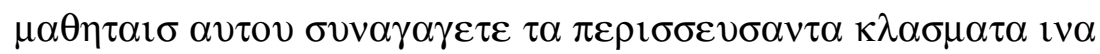

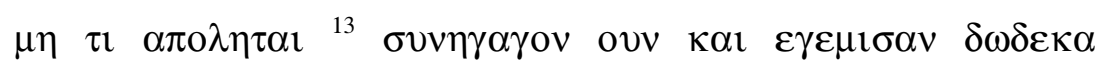

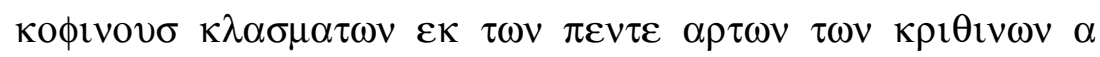

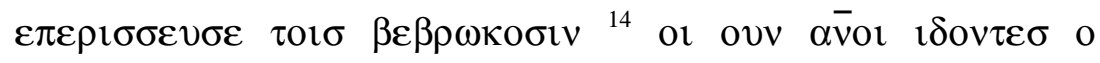

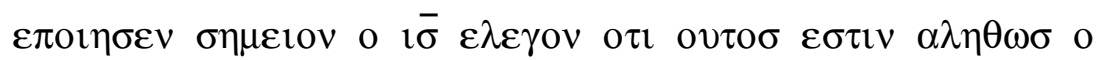

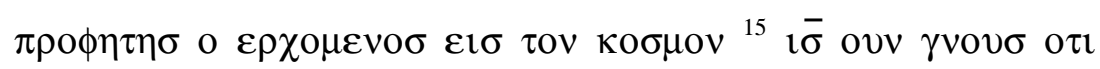

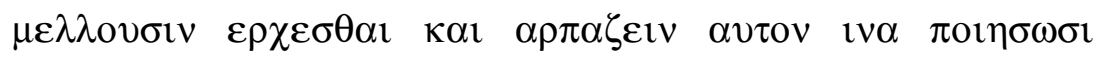

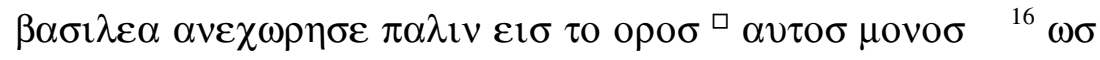

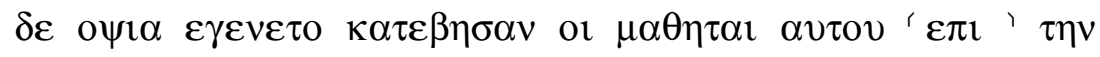

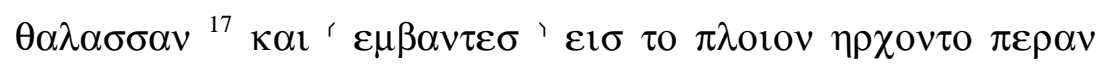

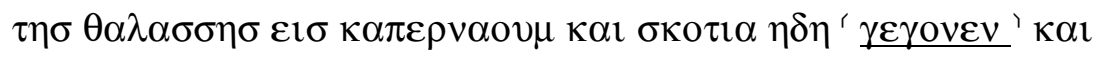
ovк $\varepsilon \lambda \eta \lambda v \theta \varepsilon i \pi \rho \circ \sigma \alpha v \tau o v \sigma$ o $1 \bar{\sigma} \quad \square \varepsilon 1 \sigma \tau$ o $\pi \lambda$ olov ${ }^{18} \eta \tau \varepsilon$

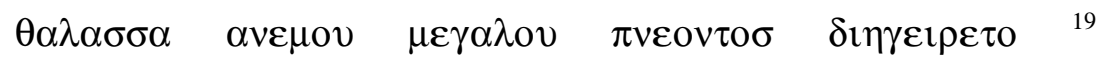




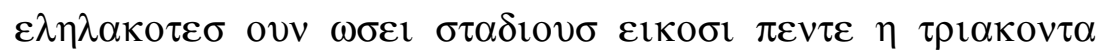

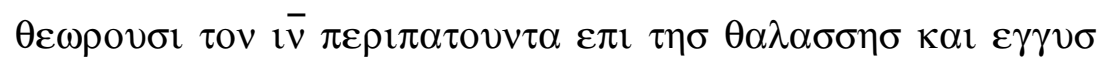

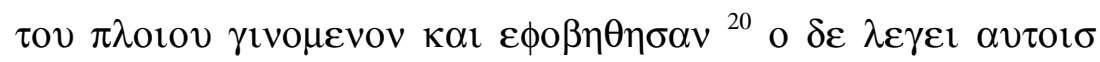

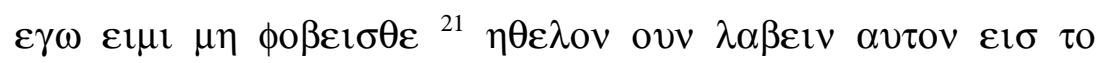

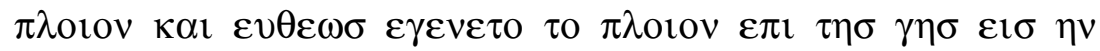

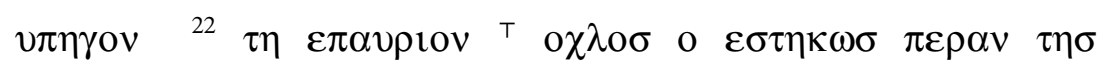

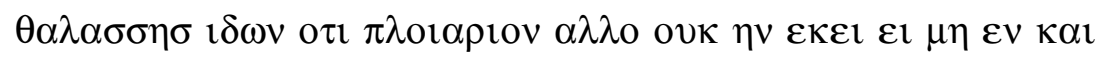

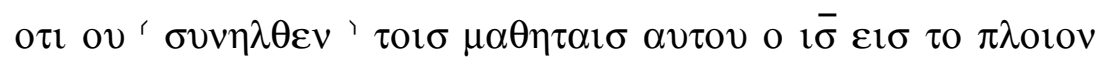

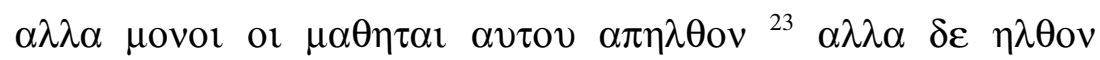

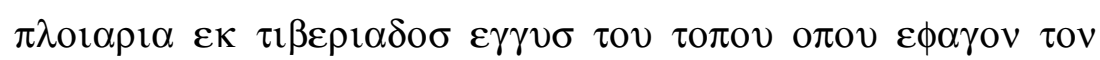

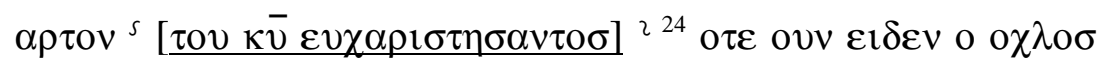

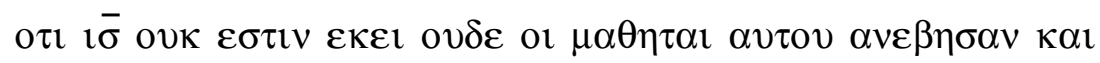

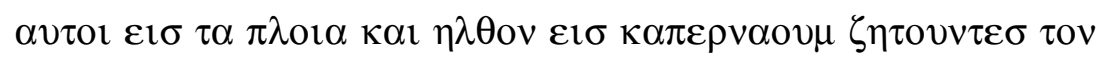

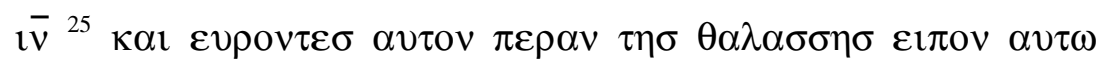

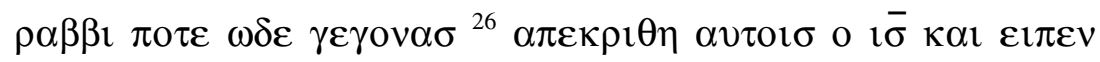

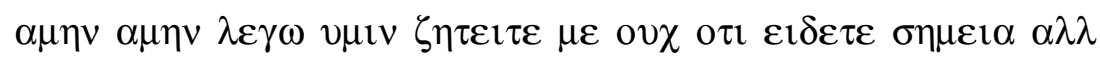

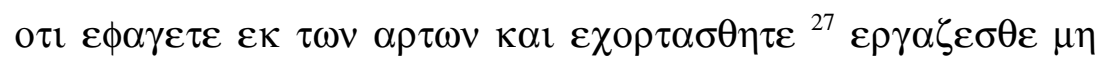
$\tau \eta \nu \beta \rho \omega \sigma \mathrm{l} v \tau \eta \nu \alpha \pi \mathrm{\alpha} \lambda \lambda v \mu \varepsilon v \eta \nu \alpha \lambda \lambda \alpha \tau \eta \nu \beta \rho \omega \sigma \mathrm{v} \tau \tau \eta \nu \mu \varepsilon v o v \sigma \alpha \nu$

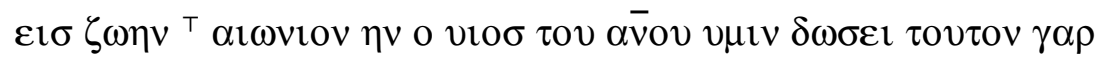

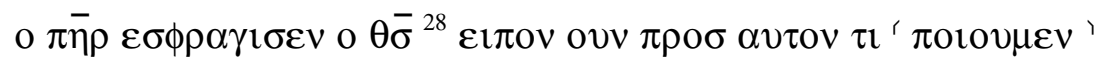

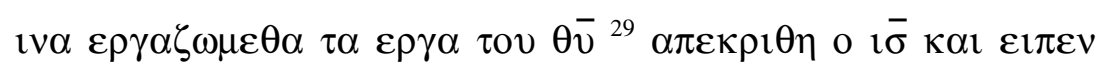

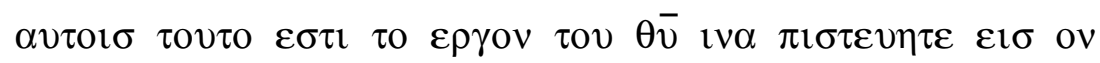

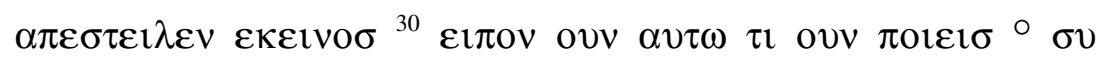

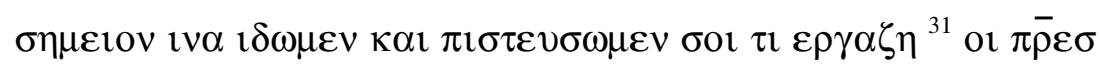

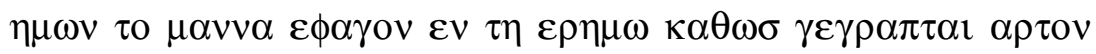

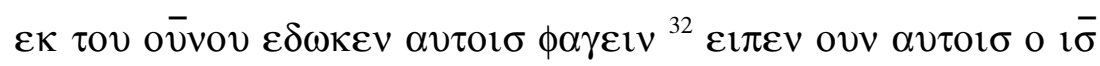

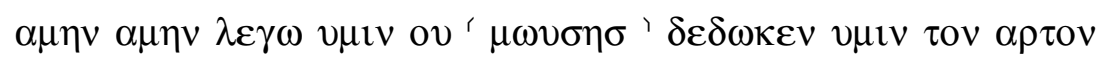

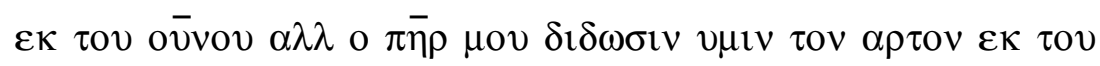

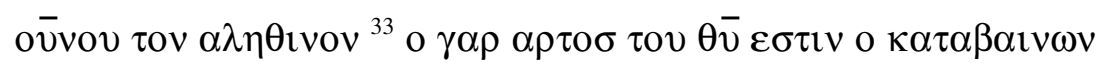

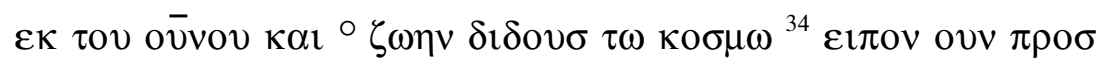

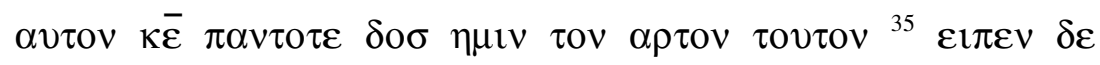

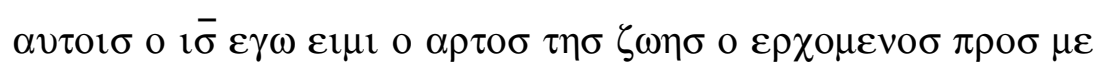

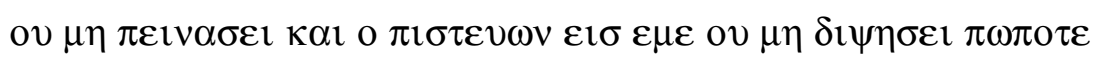

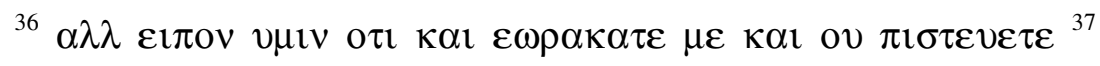




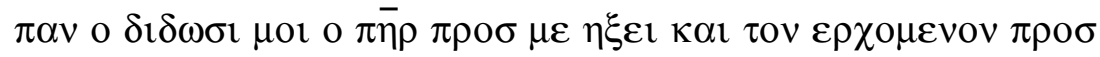

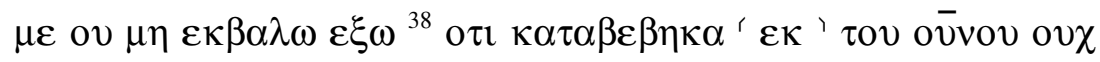

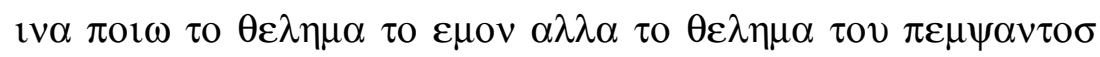

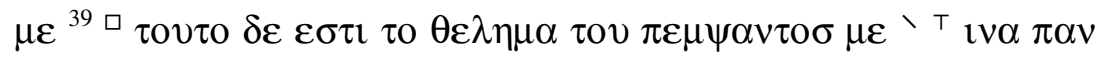
o $\delta \varepsilon \delta \omega \kappa \varepsilon \mu \mathrm{ol} \mu \eta \alpha \pi \mathrm{o} \lambda \varepsilon \sigma \omega \varepsilon \xi \alpha v \tau \mathrm{\varepsilon} \alpha \lambda \lambda \alpha v \alpha \sigma \tau \eta \sigma \omega \alpha v \tau \mathrm{o} \tau \eta$

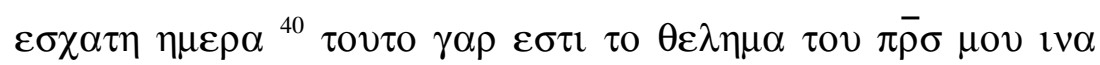

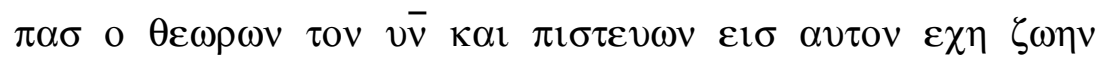

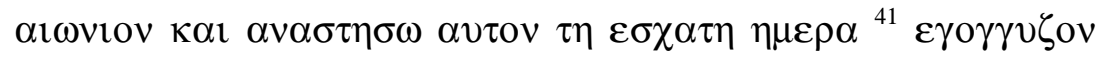

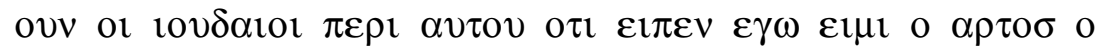

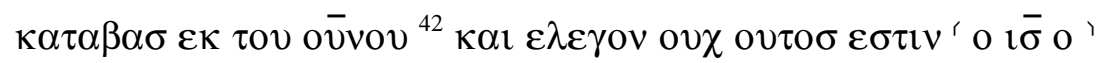

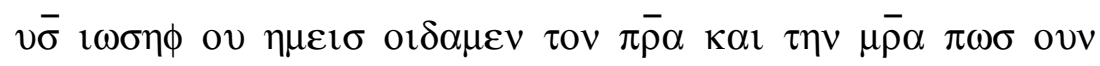

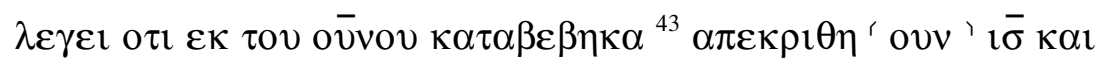

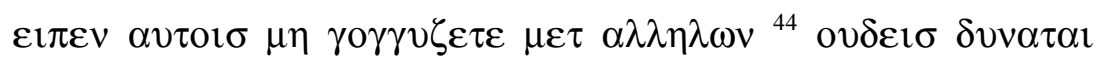
$\varepsilon \lambda \theta \varepsilon \imath \nu \pi \rho \circ \sigma \mu \varepsilon \quad \varepsilon \alpha \nu \mu \eta$ o $\pi \bar{\eta} \rho$ o $\pi \varepsilon \mu \psi \alpha \sigma \mu \varepsilon \varepsilon \lambda \kappa v \sigma \eta \alpha v \tau o v$

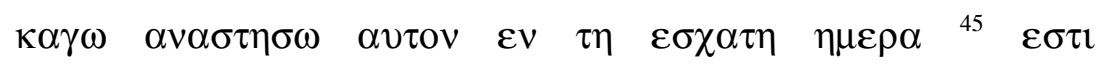

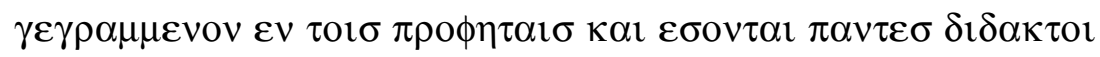

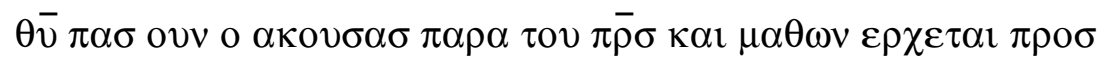

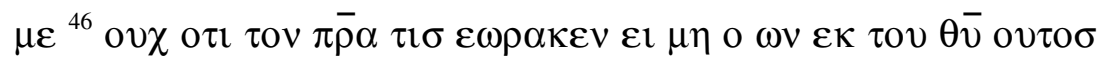

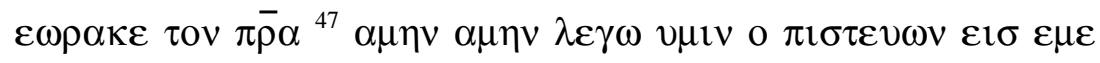

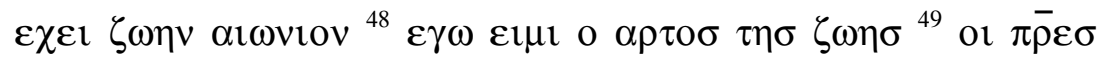

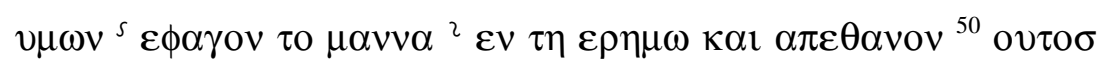

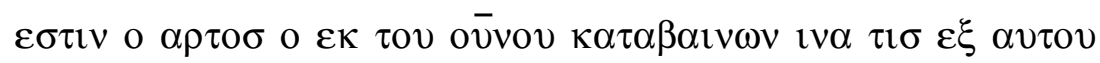

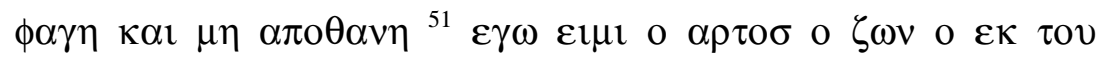

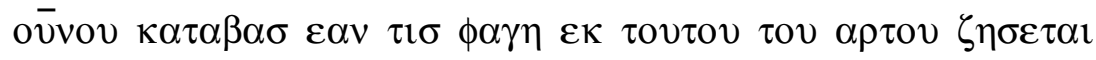

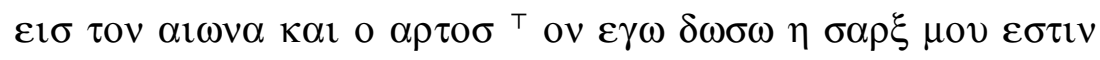

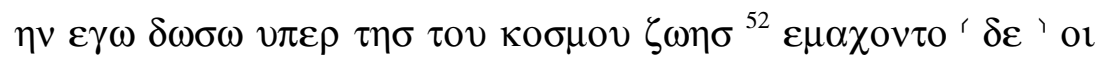

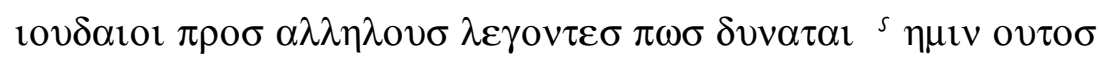

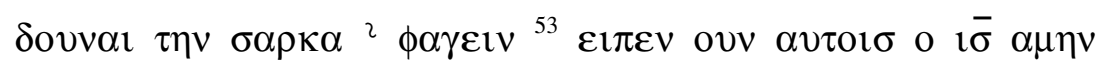

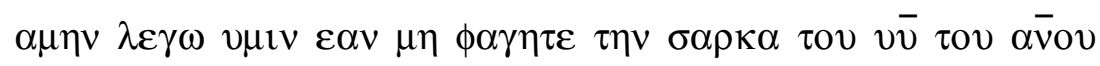

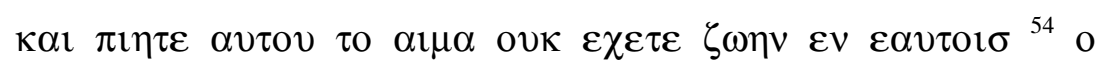

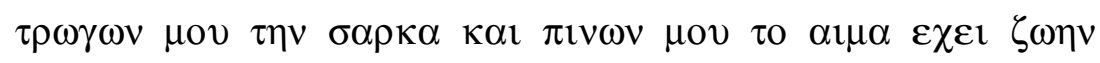

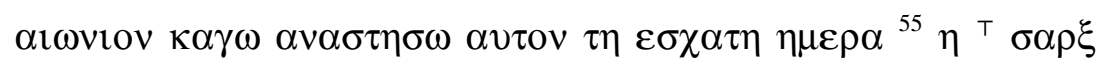

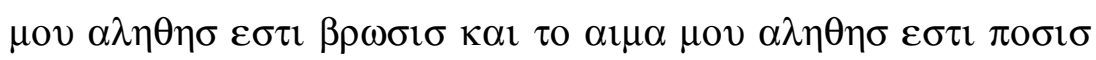

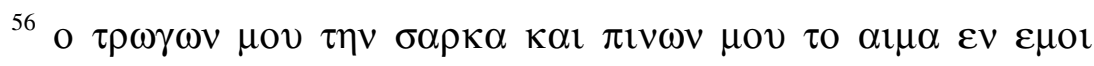




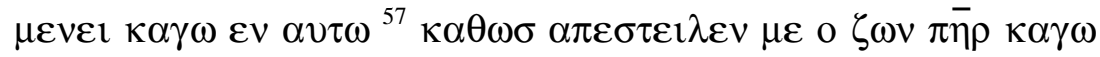

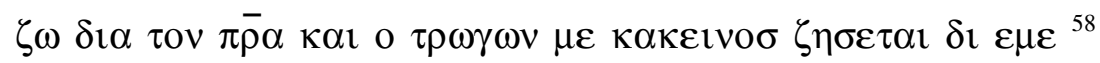

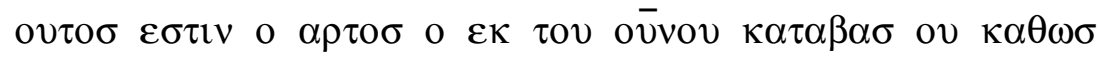

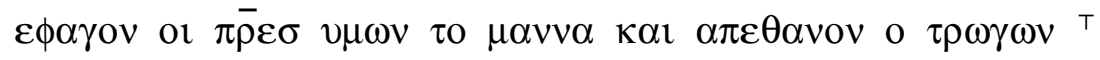

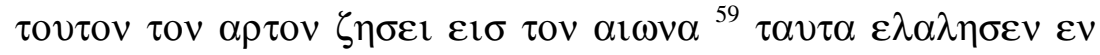

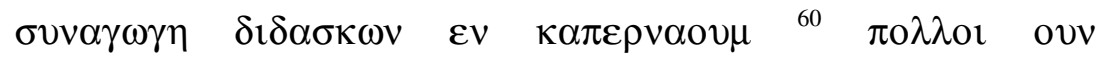

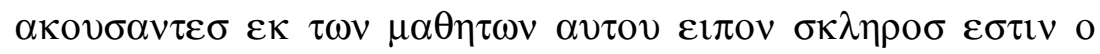

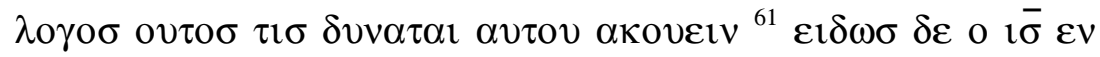

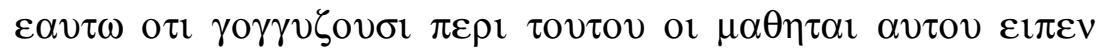

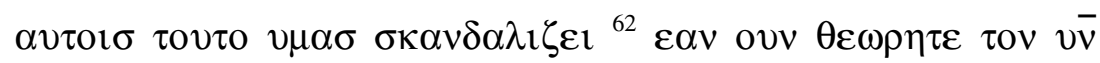

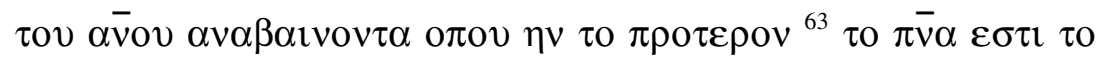

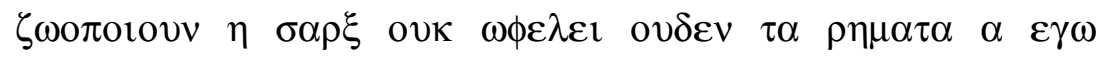

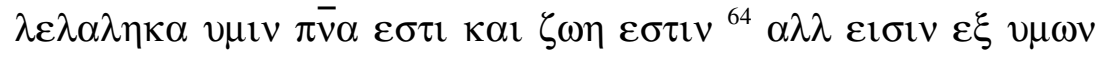

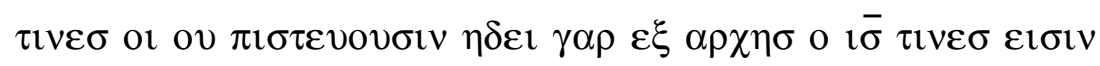

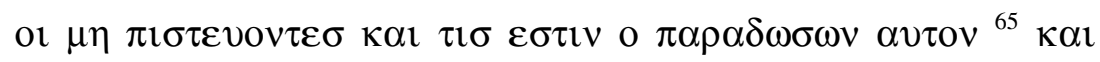

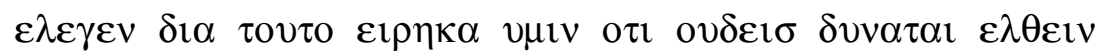
$\pi \rho \circ \sigma \mu \varepsilon \varepsilon \alpha \nu \mu \eta \eta \delta \varepsilon \delta$ o $\mu \varepsilon v o v \alpha v \tau \omega \varepsilon \kappa \tau \mathrm{\tau ov} \pi \bar{\rho} \sigma \mu \mathrm{\sigma ov}{ }^{66} \varepsilon \kappa \tau \mathrm{cov} \tau \mathrm{\sigma ov}$

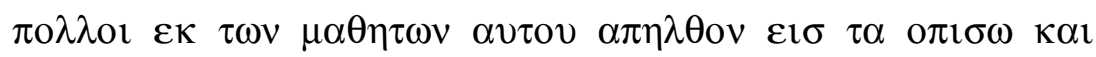

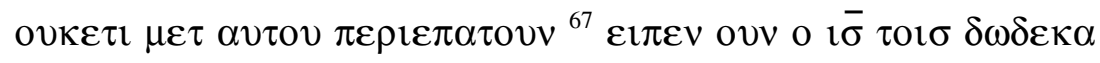

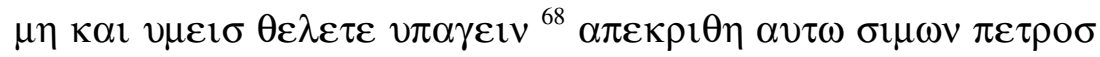

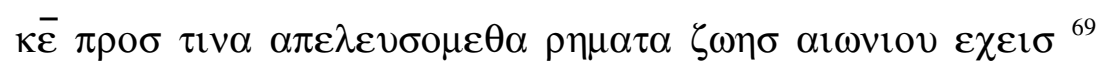

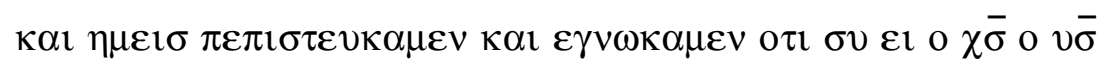

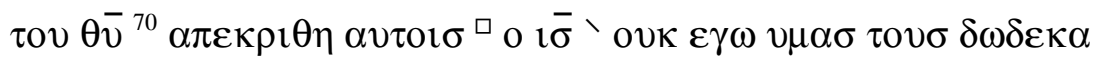

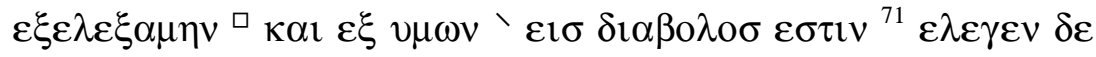

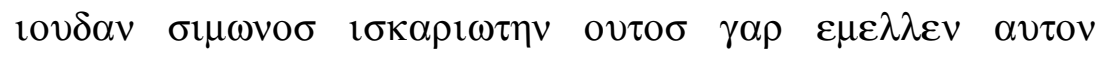
$\pi \alpha \rho \alpha \delta 1 \delta 0 v \alpha \iota \varepsilon 1 \sigma \omega \nu \varepsilon \kappa \tau \omega \nu \delta \omega \delta \varepsilon \kappa \alpha$.

${ }^{5}$ ( $\alpha \gamma о \rho \alpha \sigma o \mu \varepsilon v \quad 872^{\mathrm{C}} 1582^{\text {Cvid }} 2193^{\mathrm{C}}$ rell. $\mathrm{M}^{\mathrm{pt}}$; txt 1131565 872* $\left.15822193 * 2713^{\text {vid }} \mathrm{M}^{\mathrm{pt}} \quad\right|^{6}{ }^{6} \varepsilon \mu \varepsilon \lambda \lambda \varepsilon v \quad 221318721192$ $2193 \mathrm{M}^{\mathrm{pt}}$; txt rell. $\left.\mathrm{M}^{\mathrm{pt}}\right|^{7} \circ{ }^{\circ} 2193^{\mathrm{C}}$ rell. $\mathfrak{N}$; txt C $\left.2193^{*}\right|^{7}{ }^{\circ} \mathrm{D}$ 8842713 ; txt rell. M | ${ }^{8}$ s2.1. $^{2}$ D 884 ; txt rell. $\mathfrak{N} \mid{ }^{15}$ 口 D! 565 ; txt rell. $\mathfrak{M} \mid{ }^{16}{ }^{\prime} \varepsilon 1 \sigma$ D 131884 ; txt rell. $\mathfrak{M} \mid{ }^{17}$

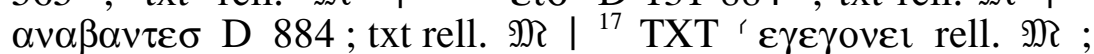

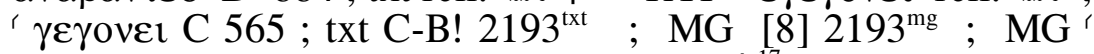

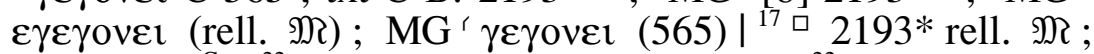
txt $\left.\mathrm{C} 2193^{\mathrm{C}}\right|^{22}{ }^{\mathrm{T}}$ o rell. $\mathfrak{M}$; txt B $\left.565884\right|^{22}$ ( $\sigma u v \varepsilon 1 \sigma \eta \lambda \theta \varepsilon v$ 
rell. $\mathfrak{M}$; txt B $\left.565884\right|^{23}$ s3.1.2. $^{2} 1582 * 2193 *$ rell. $\mathfrak{N}$; txt B-A! 1118 205abs $2091582^{\mathrm{C}^{*}} 2193^{\mathrm{C}} 2713$; [MG ${ }^{r}{ }^{s} 1.2 .3^{2}$ $\left.\left(1582^{\mathrm{C}^{*}} 2193^{\mathrm{C}}\right)\right]$ । ${ }^{27} \mathrm{~T} \tau \eta \mathrm{D} 884^{*}$; txt $884^{\mathrm{C}}$ rell. M I M $^{28}$,

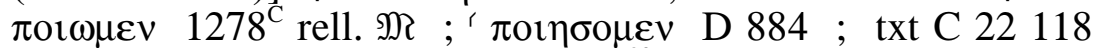

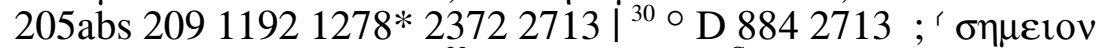
ov E 131; txt rell. $\left.\mathfrak{N}\right|^{32}$ ' $\mu \omega \sigma \eta \sigma 1278^{\mathrm{C}} 2193 *$ rell. $\mathfrak{N}$; txt

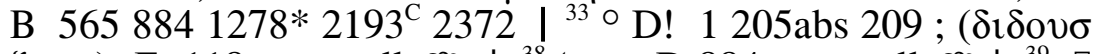
$\zeta \omega \eta v)$ E 118 ; txt rell. $\mathfrak{N}$ | ${ }^{38}$ r $\alpha \pi$ o D 884 ; txt rell. $\mathfrak{M} \mid{ }^{39}$ 口 C! 131565 ; txt rell. $\mathfrak{M} \mid{ }^{39}{ }^{\top} \pi \bar{\rho} \sigma$ rell. $\mathfrak{M}$; txt A-B! 1884 $\left.1582\right|^{42}$ ' $1 \bar{\sigma}$ o rell. $\mathfrak{M}$; ' o 1278 ; txt C 1118 205abs 209 $\left.2713\right|^{43}$ ' ovv o $2193^{*} 2372^{\mathrm{C}}$ rell. $\mathfrak{M}$; ' o C $2193^{\mathrm{C}}$; txt B 1

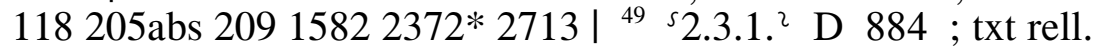
$\mathfrak{M} \mid{ }^{51}{ }^{\top} \delta \varepsilon 2193 *$ rell. $\mathfrak{N}$; txt C $2193^{\mathrm{C}} 2713$ | ${ }^{52}$ r ovv rell.

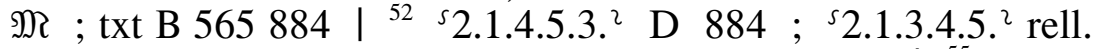
M ; txt A! 1118 205abs 209565158221932713 | 55 T $\gamma \alpha \rho$

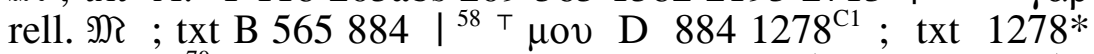

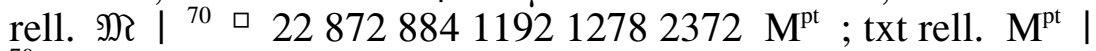
70 ㅁ $\mathrm{D}$ ! 565 ; txt rell. M | 


\section{Chapter 7}

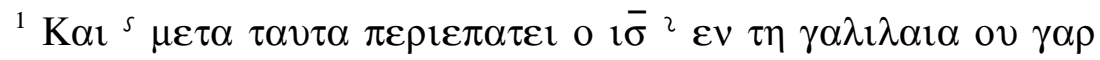

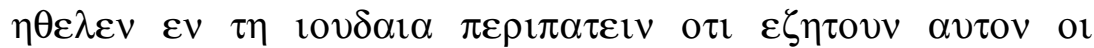

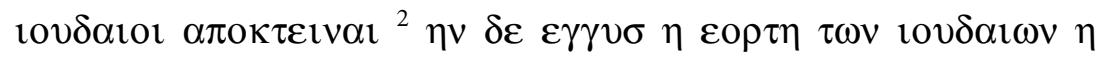

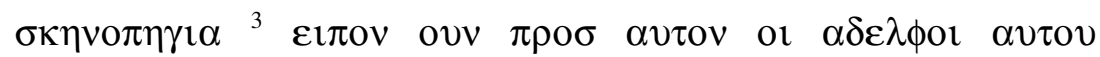

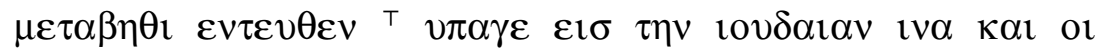

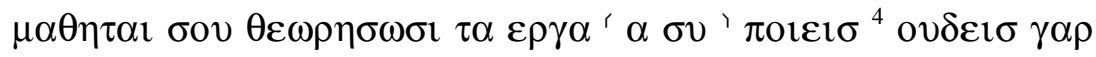

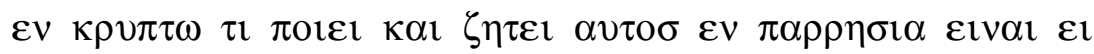

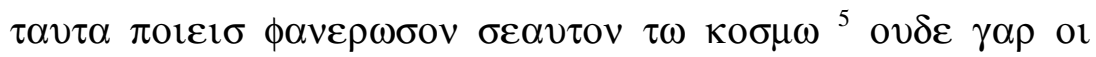

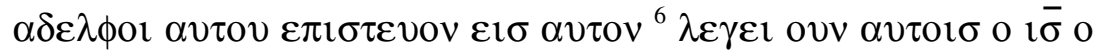

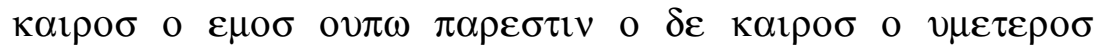

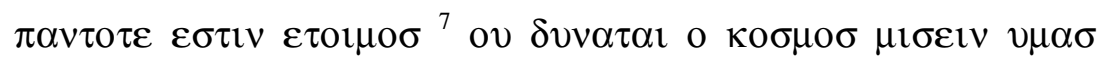

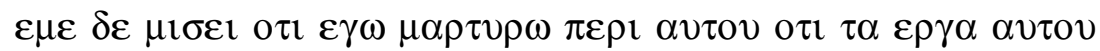

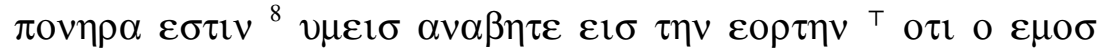

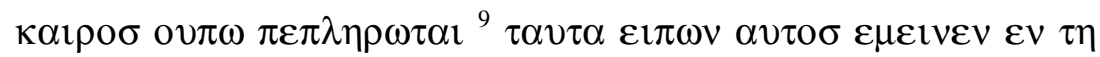

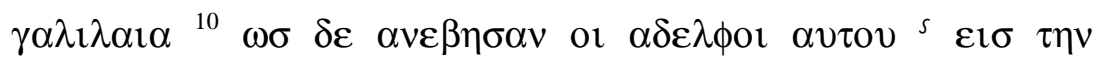

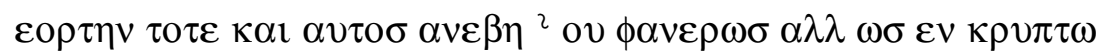

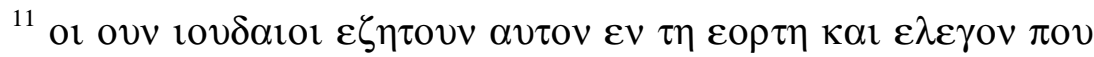

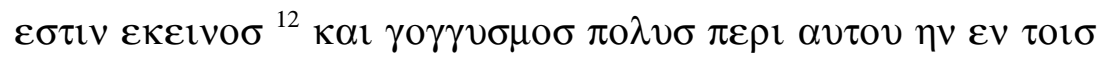

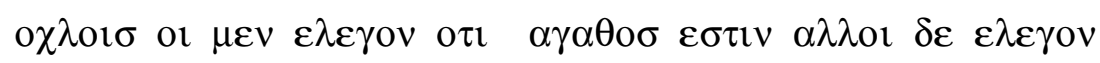

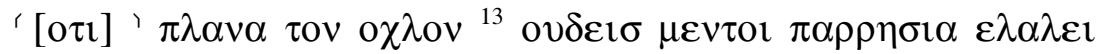

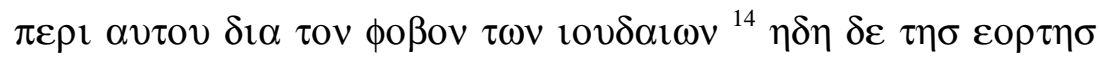

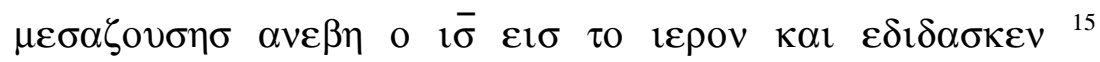

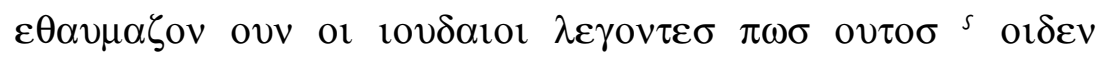

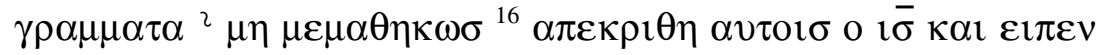

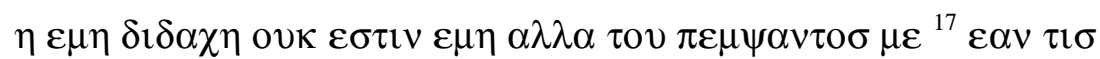

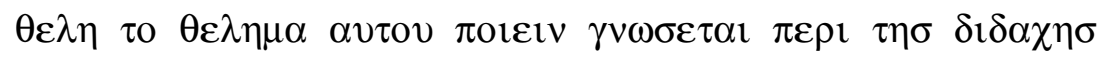

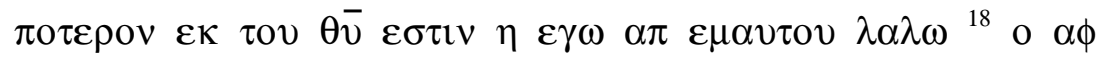

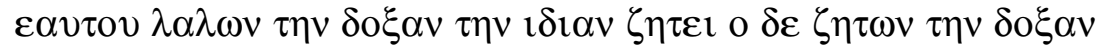

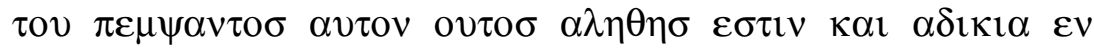

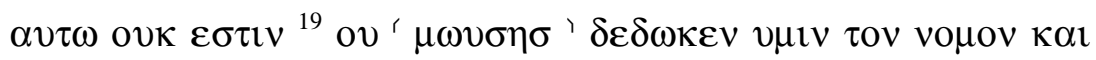

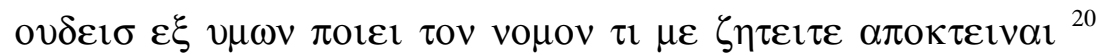

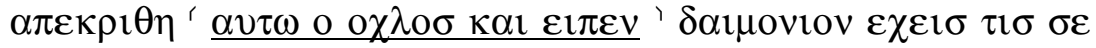




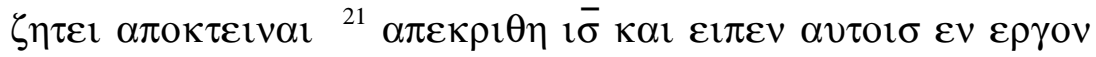

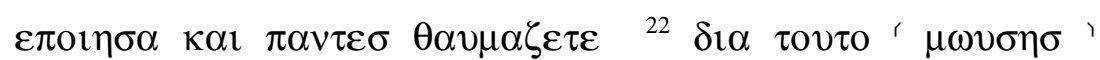

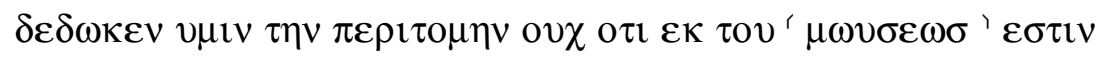

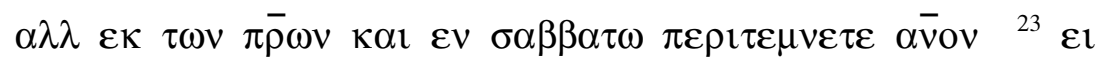

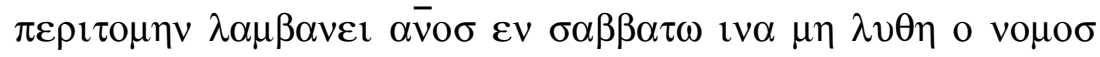

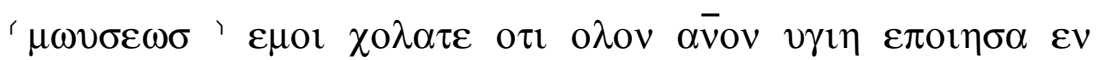

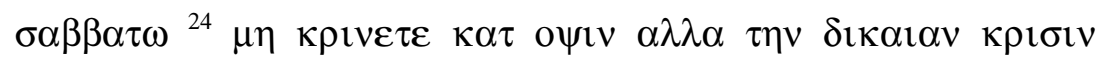

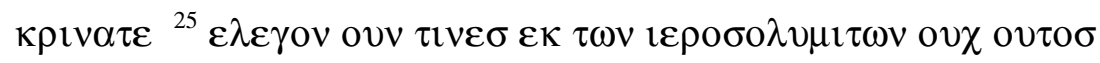

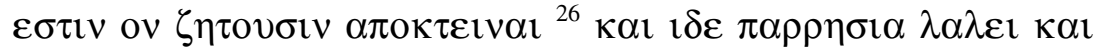

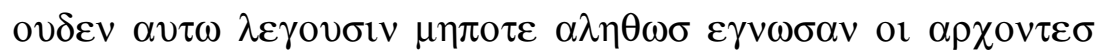

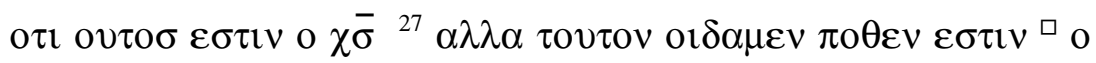

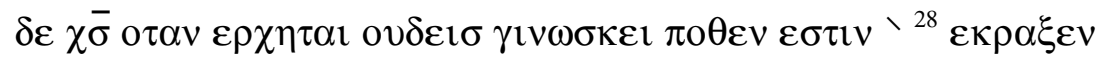

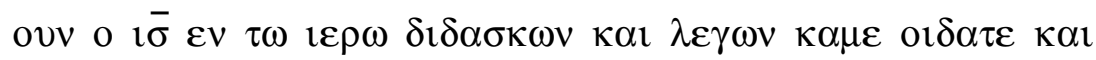

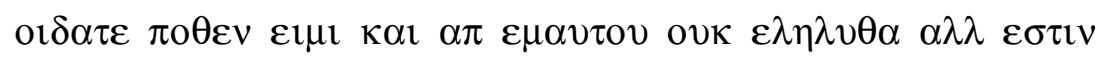

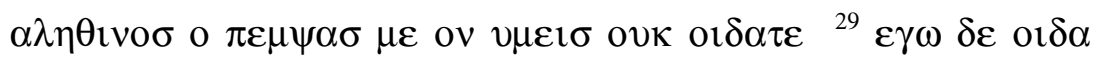

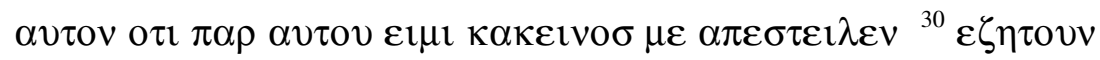

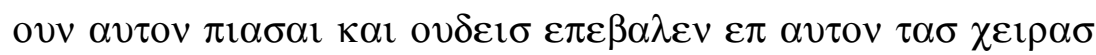

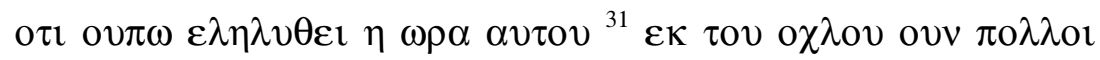

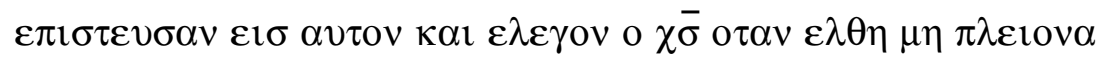

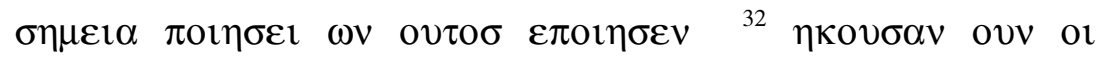

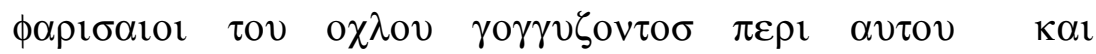

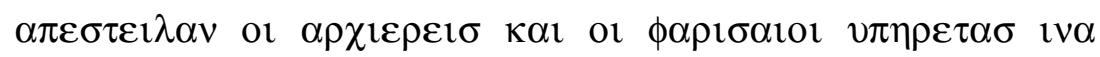

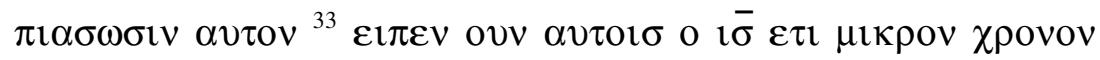

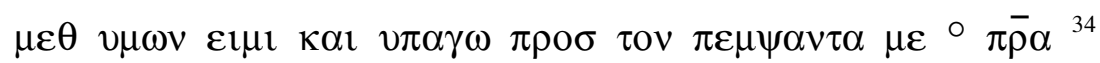

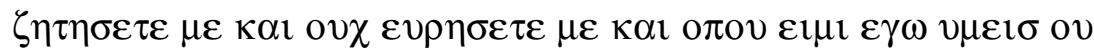

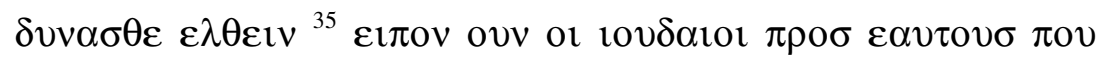

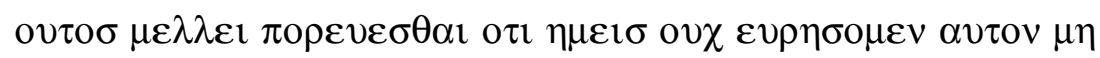

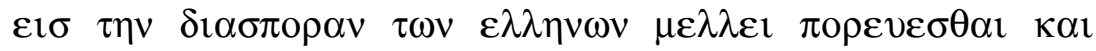

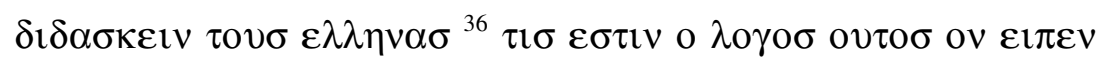

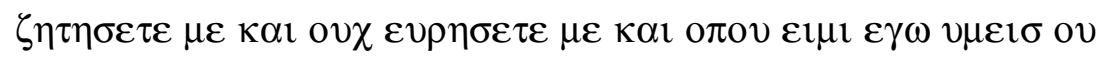
$\delta v v \alpha \sigma \theta \varepsilon \varepsilon \lambda \theta \varepsilon \iota{ }^{37} \varepsilon{ }^{\top}{ }^{\top} \tau \eta \varepsilon \sigma \chi \alpha \tau \eta \eta \mu \varepsilon \rho \alpha \tau \eta \mu \varepsilon \gamma \alpha \lambda \eta \tau \eta \sigma$

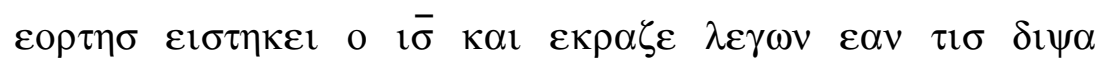
$\varepsilon \rho \chi \varepsilon \sigma \theta \omega \pi \rho \circ \sigma \mu \varepsilon \kappa \alpha \iota \pi \mathrm{lv \varepsilon \tau \omega}{ }^{38}$ о $\pi \mathrm{l} \sigma \tau \varepsilon v \omega \nu \varepsilon \iota \sigma \varepsilon \mu \varepsilon \kappa \alpha \theta \omega \sigma$

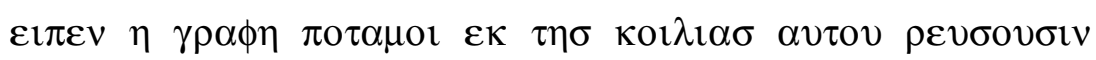




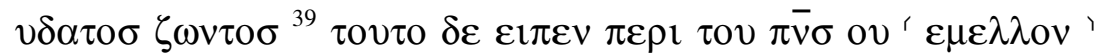

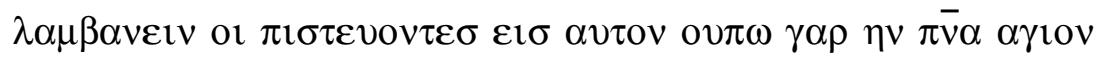

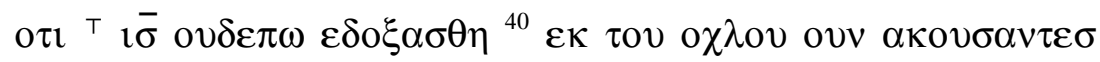

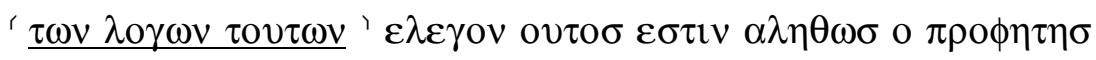
' [VID] '

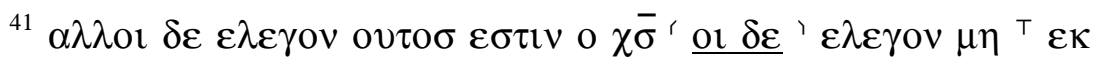
' $\alpha \lambda \lambda \mathrm{ol}$ '

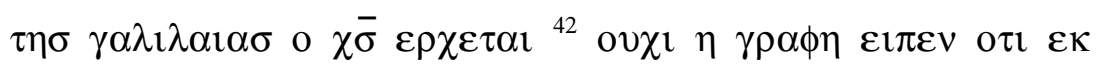
$\sigma \pi \varepsilon \rho \mu \alpha \tau \sigma \sigma \delta \bar{\alpha} \delta \kappa \alpha \iota^{\prime} \varepsilon \kappa$ ' ' $\beta \theta \lambda \varepsilon \varepsilon \varepsilon \mu{ }^{\prime} \tau \eta \sigma \kappa \omega \mu \eta \sigma{ }^{\top}$ o $\chi \bar{\sigma} \varepsilon \rho \chi \varepsilon \tau \alpha \iota$

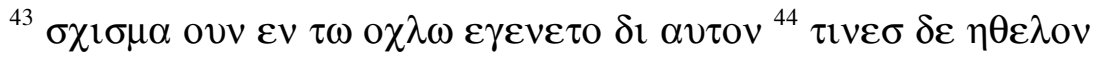

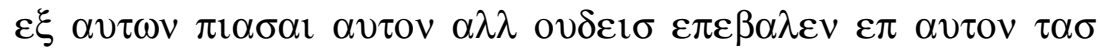

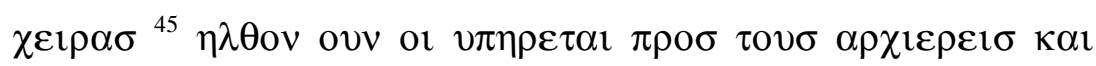

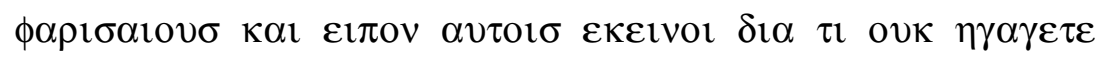

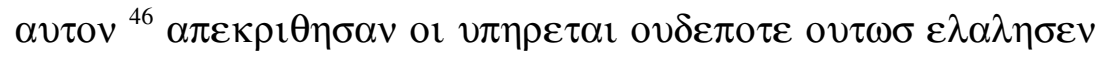

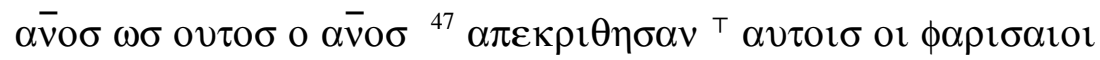
$\mu \eta \quad \kappa \alpha \imath \quad v \mu \varepsilon \imath \sigma \quad \pi \varepsilon \pi \lambda \alpha v \eta \sigma \theta \varepsilon{ }^{48} \mu \eta \quad \tau 1 \sigma \quad \varepsilon \kappa \quad \tau \omega v \quad \alpha \rho \chi 0 \nu \tau \omega v$

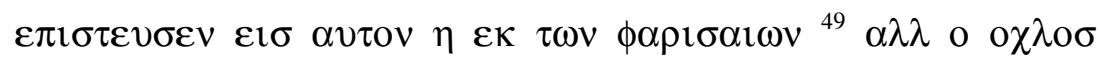

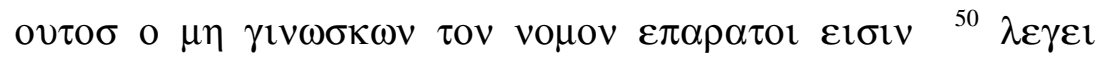

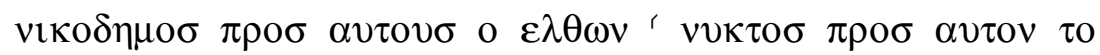

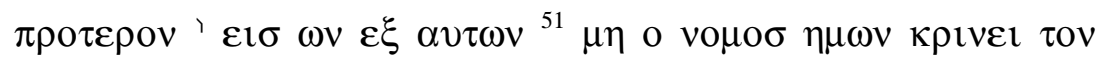

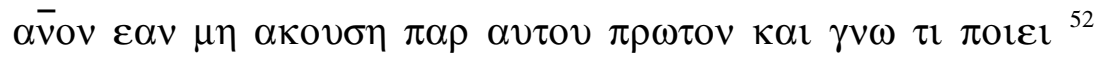

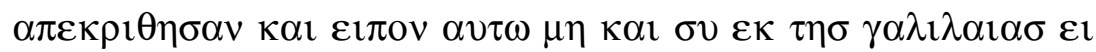

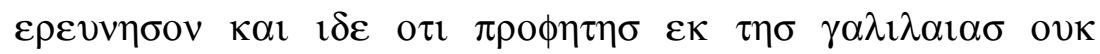

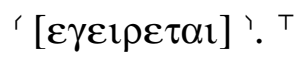

Suppl. 2193sup: 7:52.

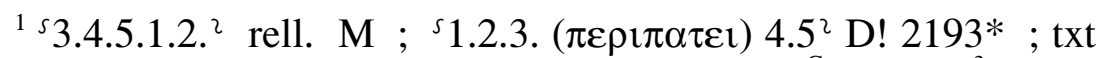
A! $\left.1118131205 \mathrm{abs} 20956588415822193^{\mathrm{C}} 2713\right|^{3} \mathrm{~T}^{\mathrm{T}} \mathrm{K \alpha l}$ rell. $\mathfrak{M}$; txt C $\left.565\right|^{3}{ }^{3}$ oov $\alpha$ rell. $2193^{\mathrm{C}} \mathrm{M} ;{ }^{\prime} \alpha \mathrm{D} 872884$; txt A 1118 205abs $20956515822193 * 2713 \quad{ }^{8}{ }^{8} \varepsilon \gamma \omega$ ov $\pi \omega$

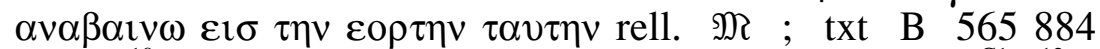
$\left.2193\right|^{10}{ }^{5} 4.5 \cdot 6.7 .1 .2 .3^{2} 2193 *$ rell. $\mathfrak{N}$; txt C $\left.1312193^{\mathrm{C} 1}\right|^{12}$; ov $\chi 1 \alpha \lambda \lambda \alpha$ B $8842193^{\text {Cvid }}$; ' ov $\alpha \lambda \lambda \alpha$ rell. $\mathfrak{N}$; txt A! 1565 $15822193^{* \text { vid }}$ l $^{15}{ }^{5} 2.1^{2} \quad 12213187211921582 \mathfrak{M}$; txt A-B rell. | ${ }^{19}$ ' $\mu \omega \sigma \eta \sigma 2193^{*}$ rell. $\mathfrak{N}$; txt B $\left.5658842193^{\mathrm{C}}\right|^{20}$ TXT

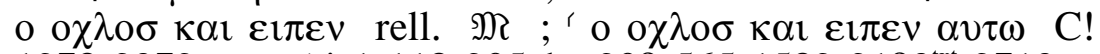
12782372 ; txt A! 1118 205abs $20956515822193^{\text {txt }} 2713$; $\mathrm{MG}^{\prime}$ VID $\left.2193^{\mathrm{mg}}\right|^{22}{ }^{2} \mu \omega \sigma \eta \sigma 1293 *$ rell. $\mathfrak{M}$; txt B $5652193^{\mathrm{C}}$; ${ }_{22}{ }^{\prime} \mu \omega \sigma \varepsilon \omega \sigma$ rell. $\mathfrak{M} ;$ txt B! 565| ${ }^{23}{ }^{2} \mu \omega \sigma \varepsilon \omega \sigma 2193 *$ rell. $\mathfrak{M}$; $\mu \omega v \sigma \varepsilon \sigma \sigma$ E $872^{\text {vid }}$; txt B $\left.5652193^{\mathrm{C}}\right|^{27} \mathrm{D} \mathrm{D}$ ! 565872 ; txt rell. 
$\mathfrak{M} \mid{ }^{33} \circ$ rell. $\mathfrak{N}$; txt B $\left.565884\right|^{37} \mathrm{~T} \delta \varepsilon$ rell. $\mathfrak{N}$; txt C 565 |

${ }^{39}$ ' $\eta \mu \varepsilon \lambda \lambda$ ov $565872884 \mathrm{M}^{\mathrm{pt}}$; txt rell. $\left.\mathrm{M}^{\mathrm{pt}}\right|^{39} \mathrm{~T}$ o $\mathrm{D} 205 \mathrm{abs}$

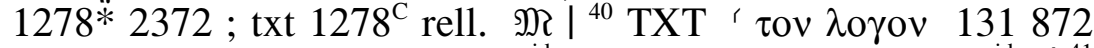
$8842713 \mathrm{M}$; txt A! 205abs ${ }^{\text {vid }}$ rell.; [MG ' VID $\left.2193^{\text {mgvid }}\right]^{41}$ TXT ' $\alpha \lambda \lambda$ or rell. NR; txt A! 1118 205abs 2052095651582

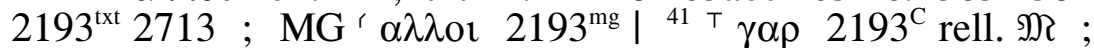
txt C 2193* $\left.\right|^{42}$ ' $\alpha \pi$ o rell. $\mathfrak{M}$; txt B 565 2193; (DEF 2713) $\mid{ }^{42}$ ' $\beta \eta \theta \lambda \varepsilon \varepsilon \varepsilon \mu$ rell. $\mathfrak{N}$; txt C $565 \mid{ }^{42}{ }^{\top}$ o o ${ }^{\top}$ o $\pi$ ov $\delta \bar{\alpha} \delta \mathrm{E} 205 \mathrm{abs}$; txt C $\left.2193\right|^{47}{ }^{\mathrm{T}}$ ovv rell. $\mathfrak{N}$; txt B 1 205abs $\left.2091582\right|^{50}$ ` ข

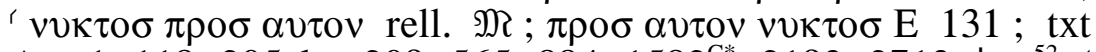
A 1118 205abs $209565 \quad 884 \quad 1582^{\mathrm{C}^{*}} 2193 \quad 2713 \quad$ । ع B $\left.15822193\right|^{52}$ T Jn. 7:53-8:11 D 118 205abs 2098841278 2713 ; $^{\top}$ om. C! 221311192 ; txt (pericope following 21:25) A $1565^{\text {vid }} 15821582^{\text {sup }} 2193^{\text {sup }}$ | 


\section{Chapter 8:12-59}

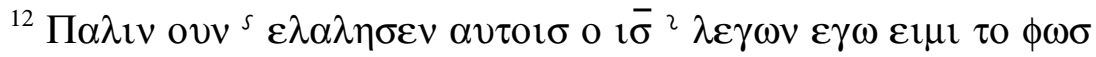

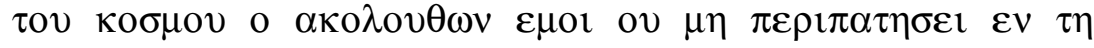

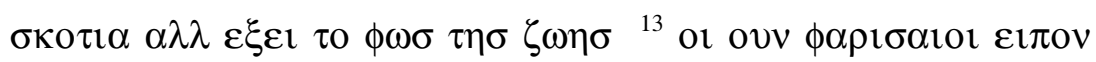

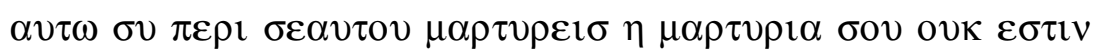

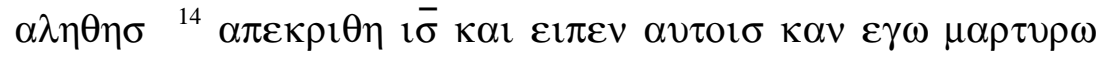

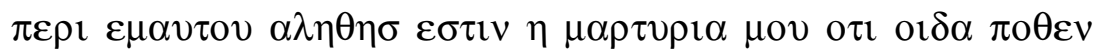

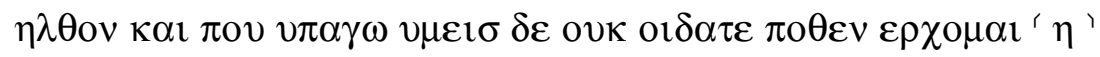

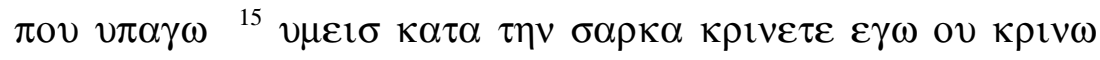

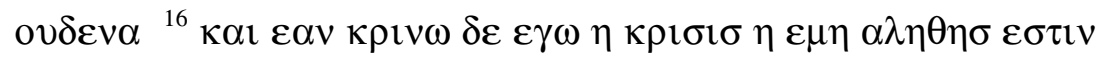

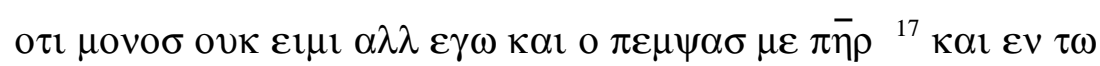

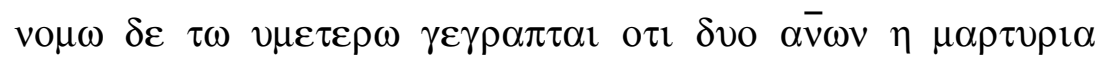

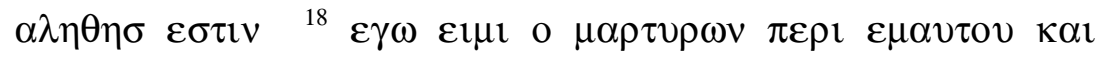
$\mu \alpha \rho \tau v \rho \varepsilon \imath ~ \pi \varepsilon \rho \imath ~ \varepsilon \mu o v ~ o ~ \pi \varepsilon \mu \psi \alpha \sigma \mu \varepsilon \pi \bar{\eta} \rho{ }^{19} \varepsilon \lambda \varepsilon \gamma o v$ ovv $\alpha v \tau \omega \pi \mathrm{ov}$

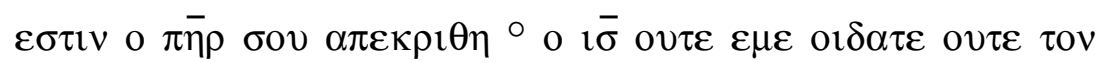

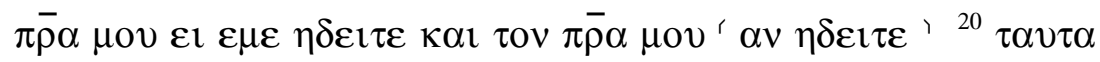

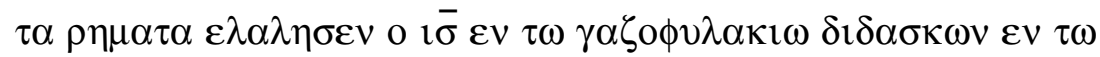

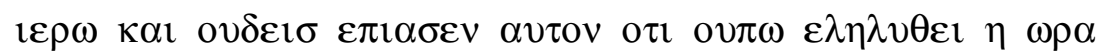

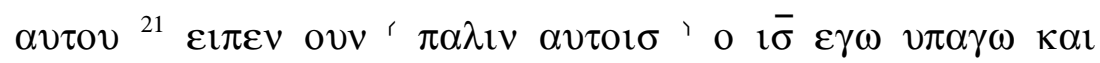

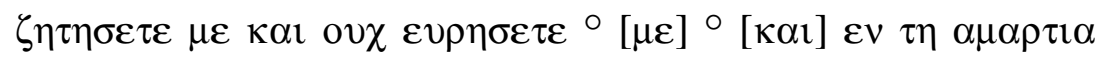

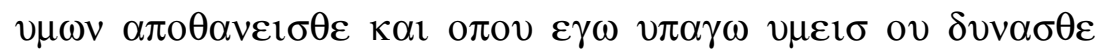

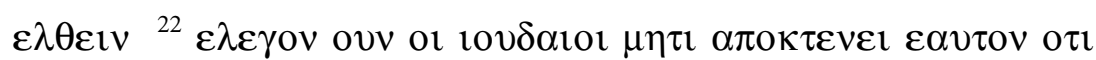

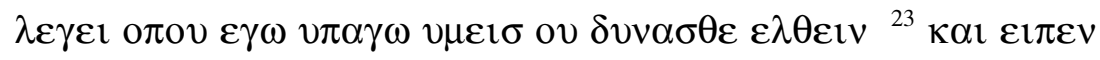

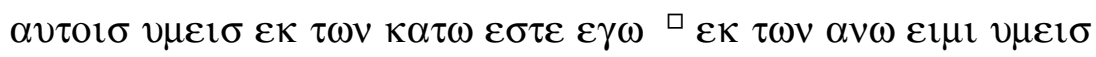

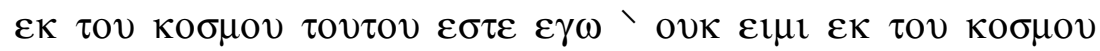

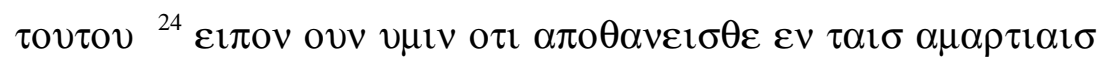

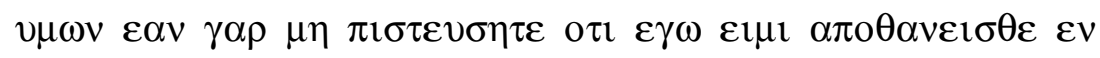

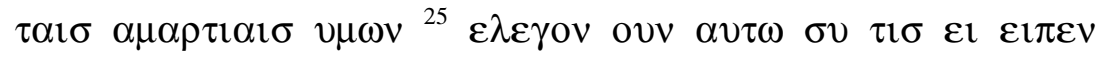

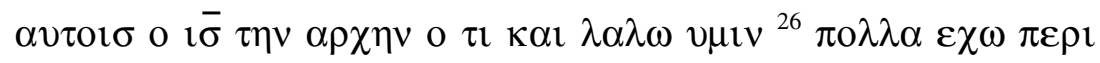

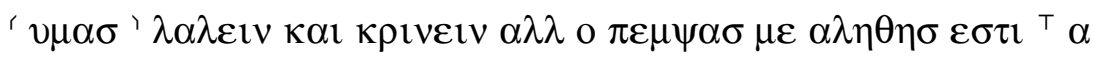

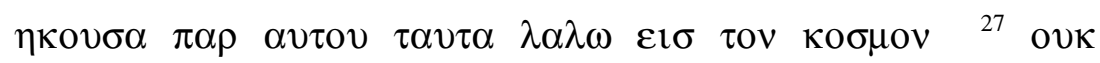

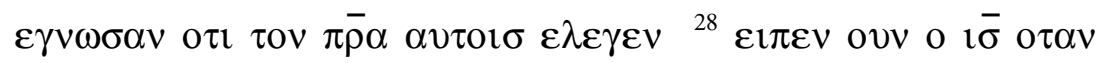

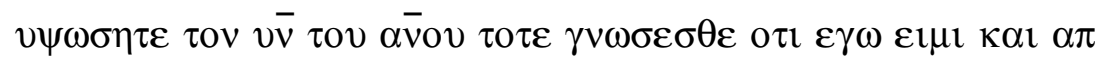




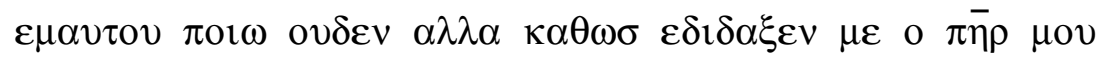

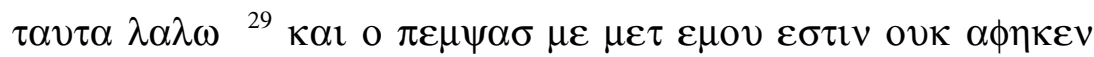

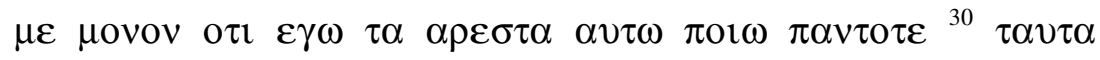

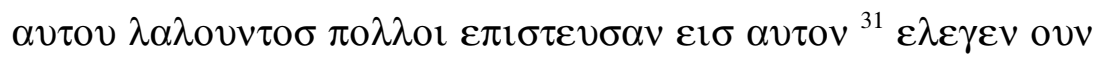

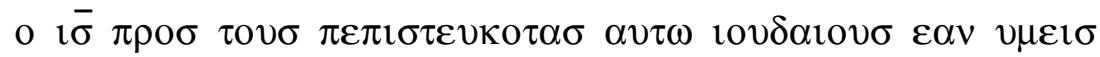
$\mu \varepsilon \imath v \eta \tau \varepsilon \varepsilon \nu \tau \omega \lambda \mathrm{o} \gamma \omega \tau \omega \varepsilon \mu \omega \alpha \lambda \eta \theta \omega \sigma \mu \alpha \theta \eta \tau \alpha \iota \mu \mathrm{ov} \varepsilon \sigma \tau \varepsilon{ }^{32} \kappa \alpha \imath$

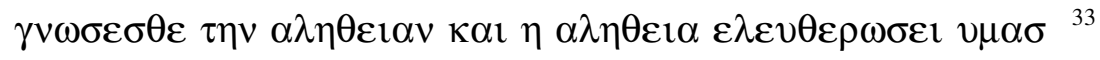

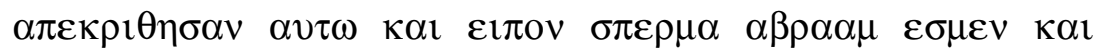

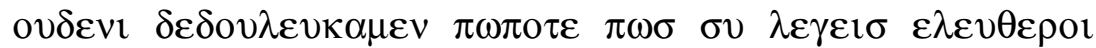

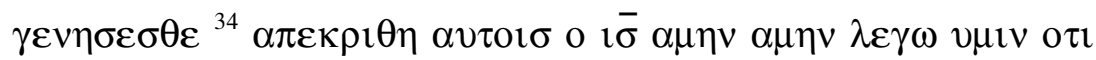

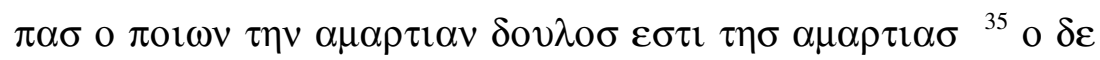

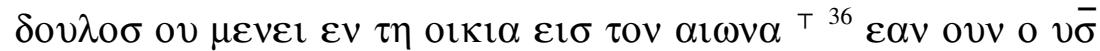

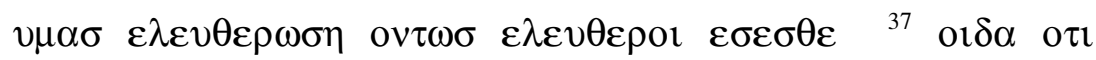

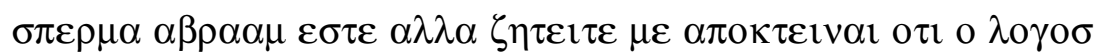

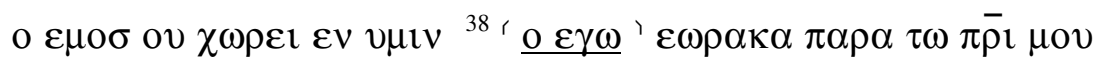

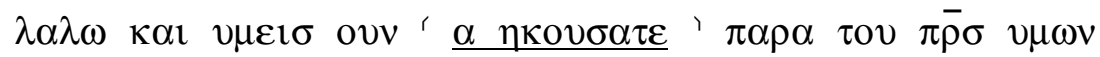

' $\alpha \varepsilon \gamma \omega$ ' ' о $\varepsilon \omega \rho \alpha \kappa \alpha \tau \varepsilon$ '

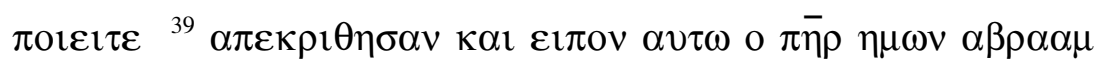

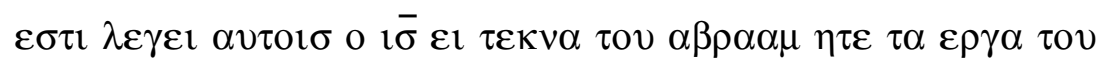

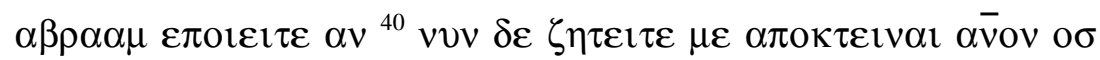

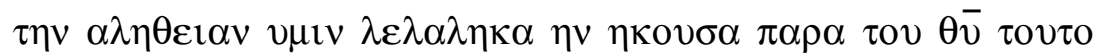

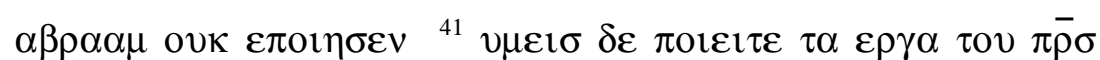

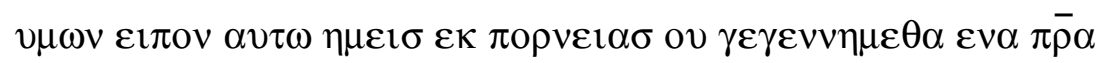

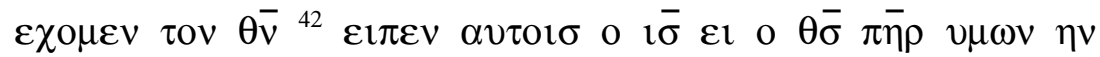

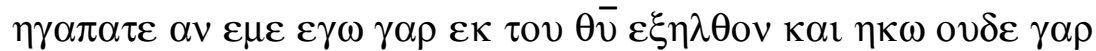

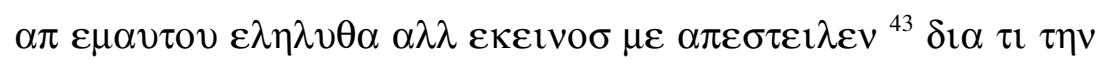

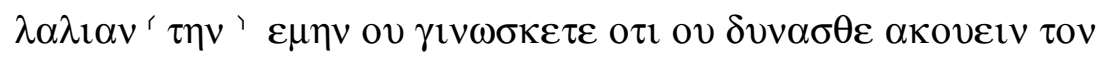

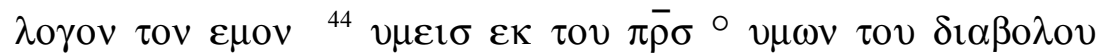

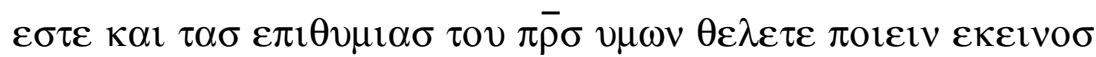

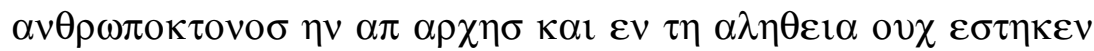

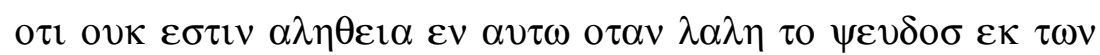

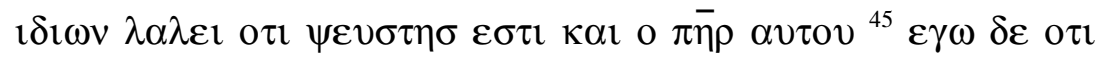

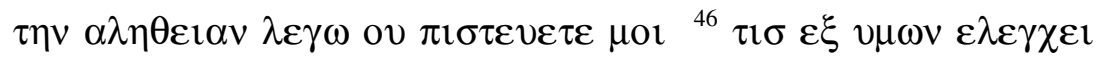

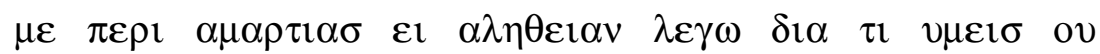

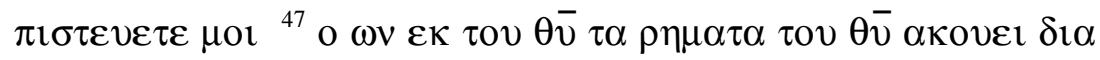




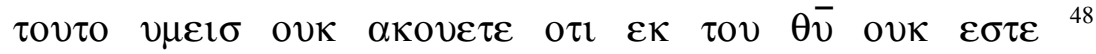

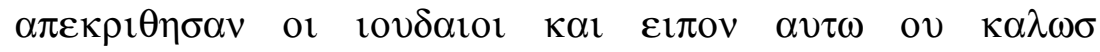

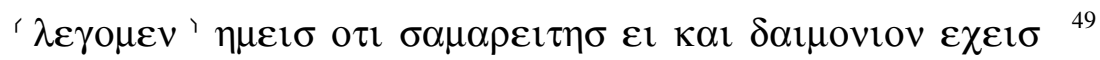

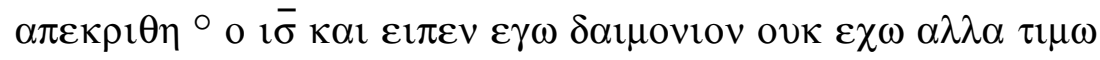

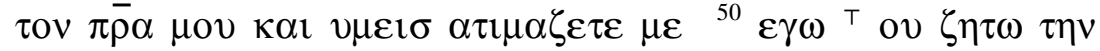

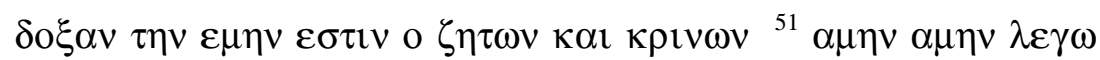

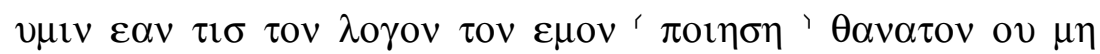

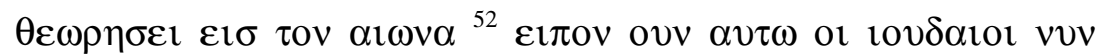

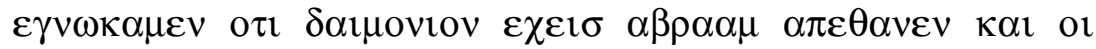

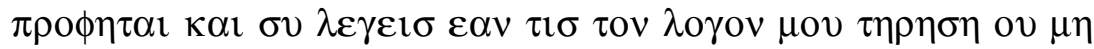

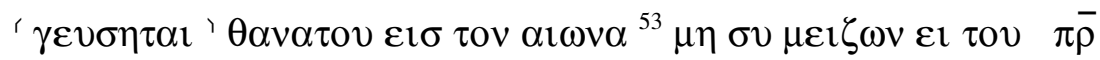

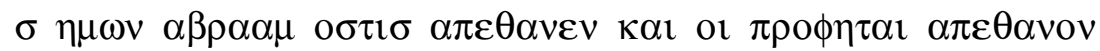

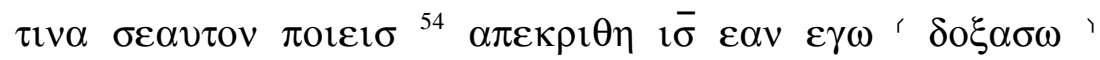

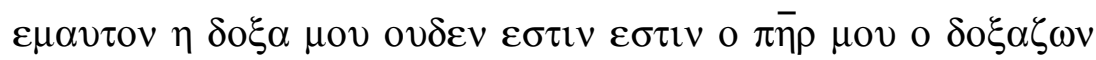

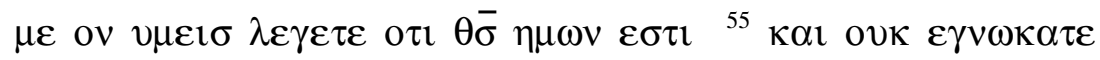

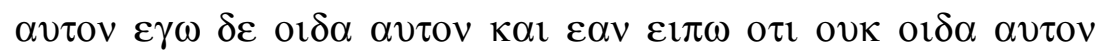

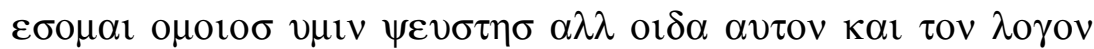

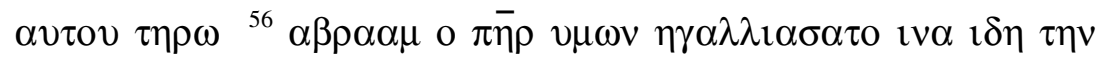

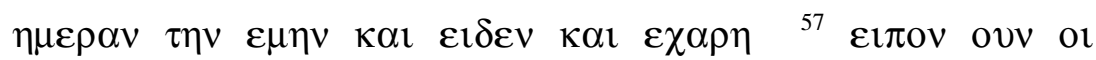

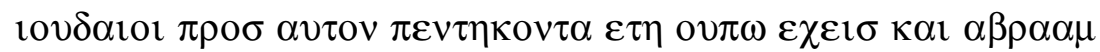

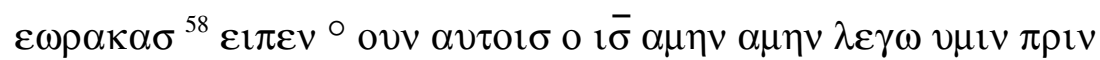

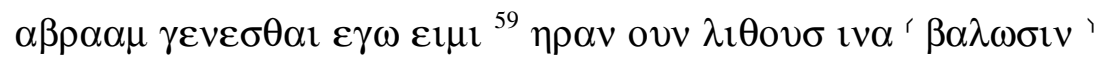

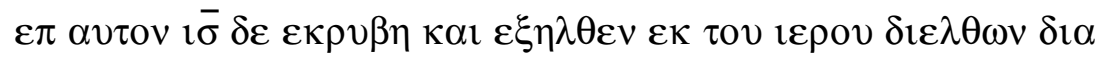
$\mu \varepsilon \sigma o v \alpha v \tau \omega v \kappa \alpha \imath \pi \alpha \rho \eta \gamma \varepsilon v$ ov $\tau \omega \sigma$.

Suppl. 2193 ${ }^{\text {sup }}:$ 8:12.

12 53.4.2.1. ${ }^{2} \mathrm{C} ! 884 ;{ }^{5} 3.4 .1 .2 .^{2} \mathrm{D} ! 118131$ 205abs 209 ; 52.1.3.4. ${ }^{2} \mathrm{C} ! 12782372 ;{ }^{5} 2.3 .4 .1^{2}$ rell. $\mathrm{M}$; txt A! 15651582 $\left.2193\right|^{14}$ ' kal 1315658728842193 M ; txt B-A rell. I ${ }^{19}$ rell M; txt C 88412782372 | ${ }^{19}$ ' $\eta \delta \varepsilon 1 \tau \varepsilon \alpha v$ rell. $\mathfrak{M}$; ' $\eta \delta \varepsilon \imath \tau \varepsilon$ D! 205abs 2092713 ; txt B 1 1582 | ${ }^{21}$ ' $\alpha v \tau 0 เ \sigma \pi \alpha \lambda \iota v$ D 884 ; $\pi \alpha \lambda$ tv E 131 ; txt rell. N | ${ }^{21} \circ$ B-A! 118 205abs $2092193^{\mathrm{C}} 2713$; txt A! 2193* rell. (DEF 1318721192 ) | ${ }^{21} \circ$ B 2288412782372 ; txt A! rell. (DEF 131872 1192) | ${ }^{23}$ D! 565872 ; txt rell. $\left.\mathfrak{M}\right|^{26}$ ( v $\mu \omega v$ rell. $\mathfrak{M}$; txt B $\left.565884\right|^{26}$

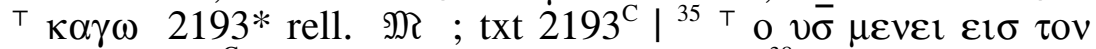
$\alpha \iota \omega v \alpha 2193^{\mathrm{C}}$ rell. $\mathfrak{N}$; txt B $8842193 * \mid{ }^{38}$ TXT ' $\alpha \varepsilon \gamma \omega \mathrm{C}$ ! 
5652193 ; ‘ $\varepsilon \gamma \omega$ o $1278^{\mathrm{C}}$ rell. $\mathfrak{N}$; ' $\varepsilon \gamma \omega \alpha \mathrm{C}$ ! $1318841278^{*}$ 2372 ; txt B-A! $11582^{\text {txt }}$; MG A ' $\alpha \varepsilon \gamma \omega$ B-A $1582^{\mathrm{mg}}(565$ 2193); MG ' $\varepsilon \gamma \omega \alpha$ C! (131 884 1278* 2372) $\left.\right|^{38} \mathrm{TXT}^{\prime} \alpha$

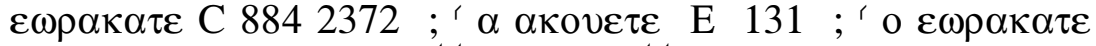
rell. $\mathfrak{N}$; txt A! $122^{\text {txt }} 5651192^{\text {txt }} 15822193 ;$ MG ' o $\varepsilon \omega \rho \alpha \kappa \alpha \tau \varepsilon$ A $22^{\mathrm{mg}} 1192^{\mathrm{mg}} ; \mathrm{MG}^{\prime} \alpha \varepsilon \omega \rho \alpha \kappa \alpha \tau \varepsilon \mathrm{D}$ ! (884 2372) | ${ }^{43}$ ( $\mu$ ov D 884 ; txt rell. N ${ }^{44} \circ$ rell. M ; txt B $118884^{\text {vid }}$ 2713 | ${ }^{48}$ < $\lambda \varepsilon \gamma \omega \mu \varepsilon v$ D! 565 ; txt rell. $\mathfrak{N} \mid{ }^{49} \circ$ rell. $\mathfrak{N}$; txt B 118 205abs $\left.209884127823722713\right|^{50}$ T $\delta \varepsilon$ rell. $\mathfrak{M}$; txt C-B 228841192 | ${ }^{51}$ ( $\tau \eta \rho \eta \sigma \eta ~ 118^{\mathrm{C}}$ rell. $\mathfrak{N}$; txt B $118^{*}$ 205abs 884| ${ }^{52}$ ' $\gamma \varepsilon v \sigma \varepsilon \tau \alpha l \mathrm{D} ! 2193^{\mathrm{C}}$; txt rell. $\mathfrak{M} \mid{ }^{54}$;

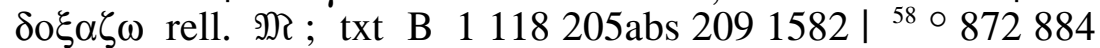
$12782372 \mathrm{M}^{\mathrm{pt}}$; txt rell. $\left.\mathrm{M}^{\mathrm{pt}}\right|^{59}{ }^{5} \beta \alpha \lambda \lambda \omega \sigma \mathrm{tv} \mathrm{D} 131884$; txt rell. MR | 


\section{Chapter 9}

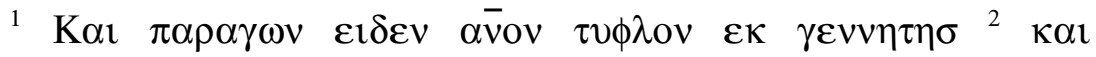

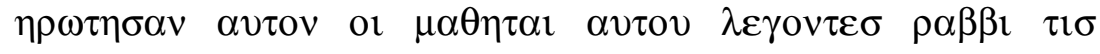

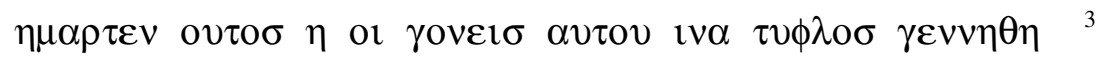
[MG]

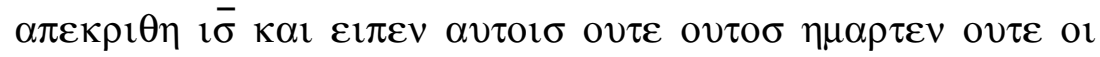

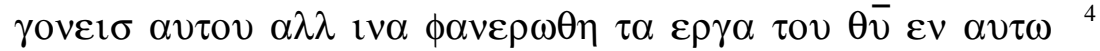
$\varepsilon \mu \varepsilon \delta \varepsilon \imath \varepsilon \rho \gamma \alpha \zeta \varepsilon \sigma \theta \alpha \iota \tau \alpha \varepsilon \rho \gamma \alpha \tau \circ \mathrm{\tau} \pi \varepsilon \mu \psi \alpha \nu \tau \sigma \sigma \mu \varepsilon{ }^{\top} \varepsilon \omega \sigma \eta \mu \varepsilon \rho \alpha$

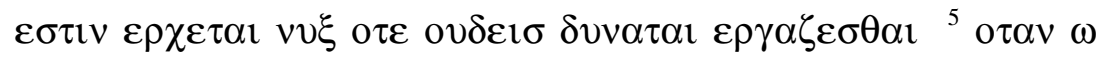

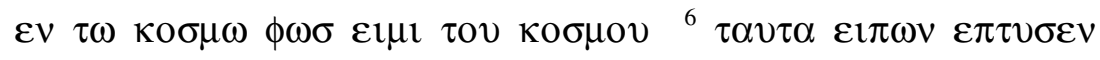

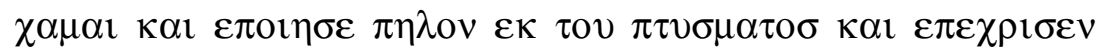

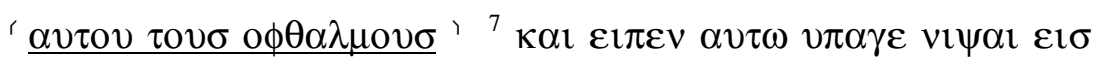

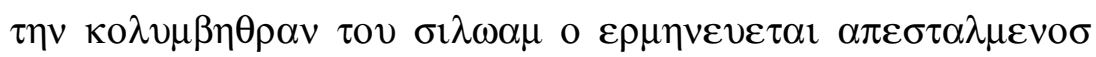

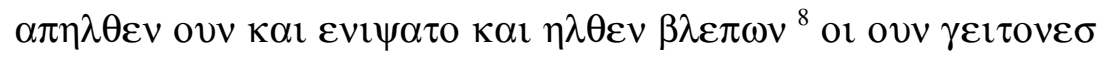

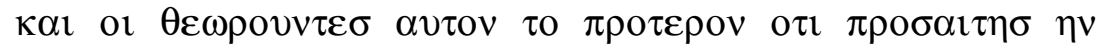

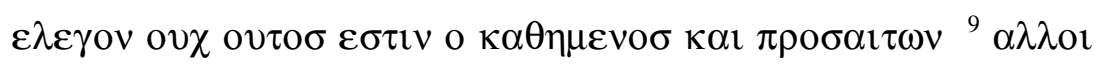

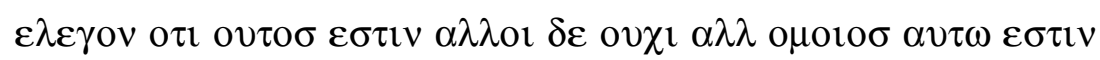

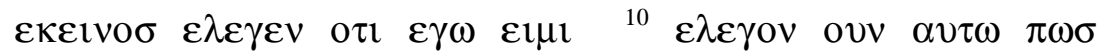

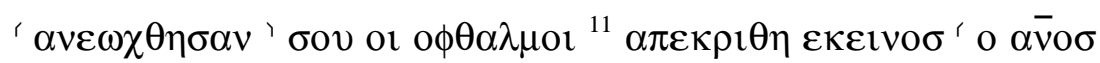

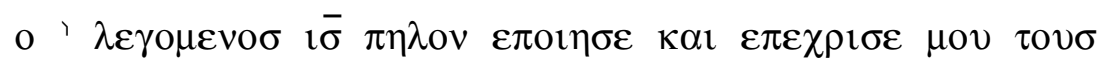

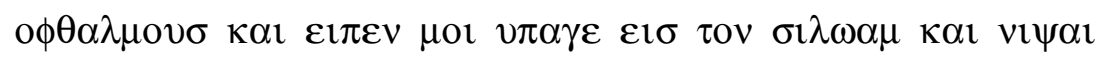

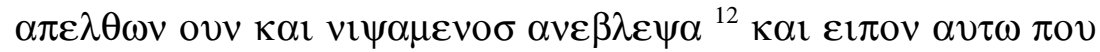

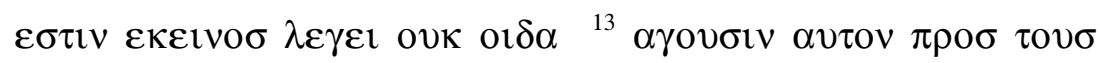

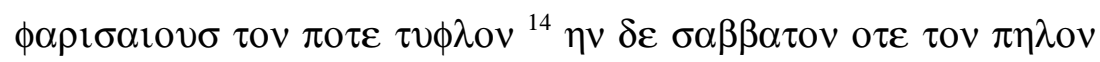

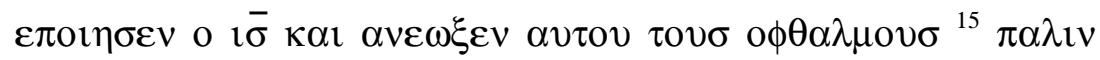

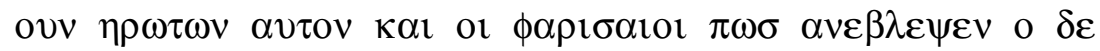

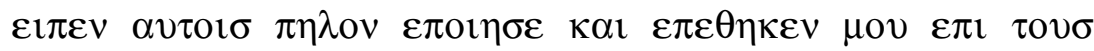

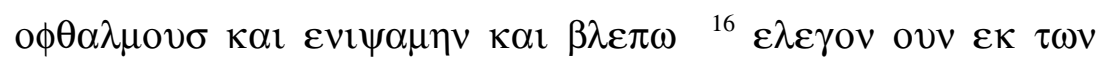

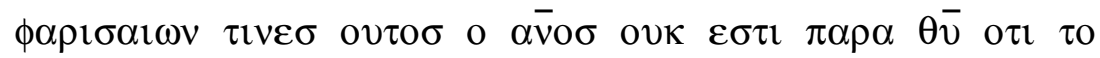

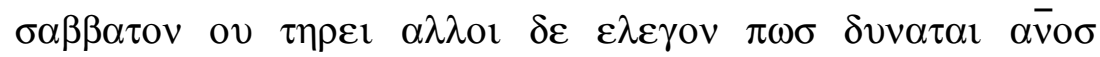

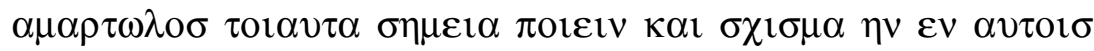

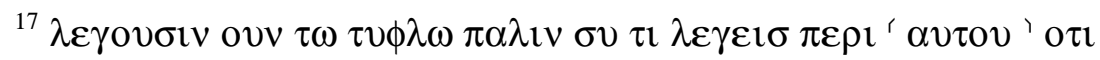

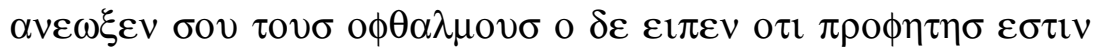

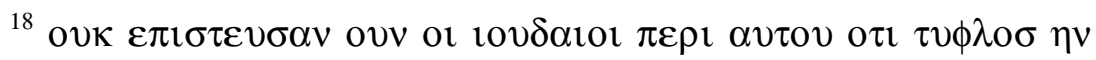




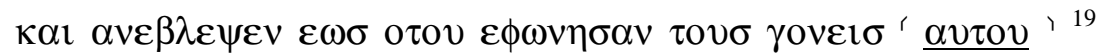

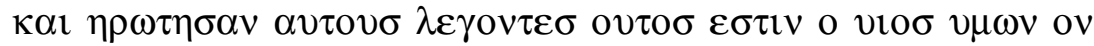

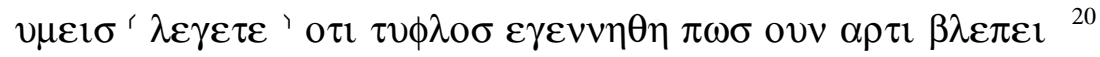

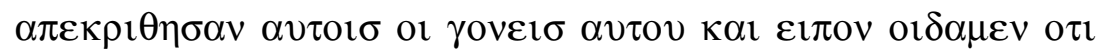

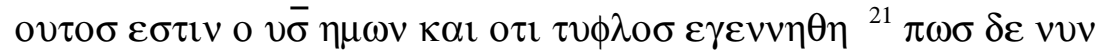

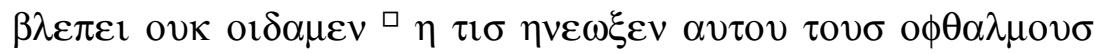

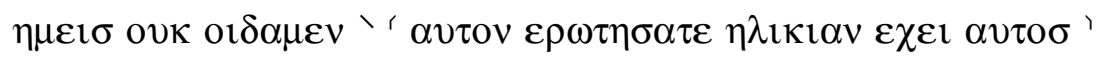

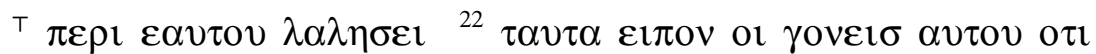

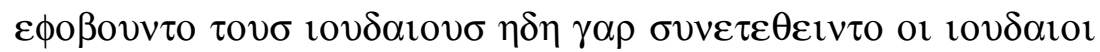

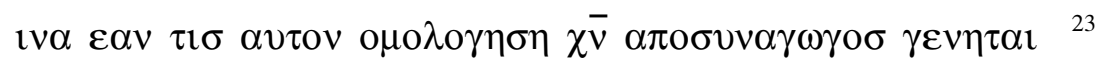

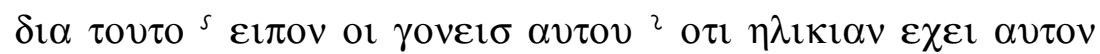

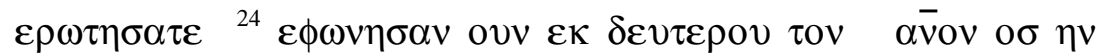

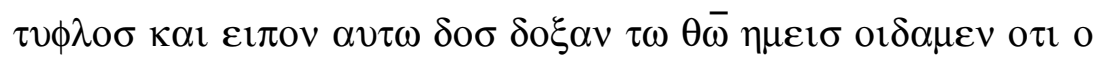

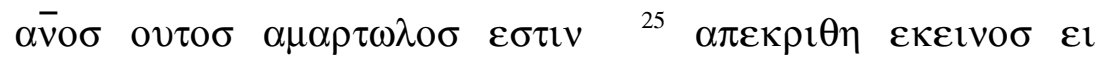

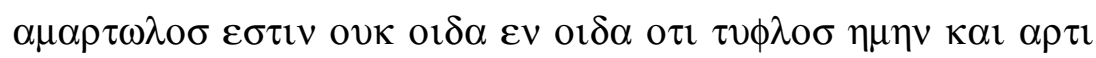

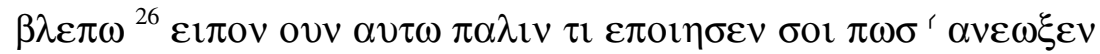

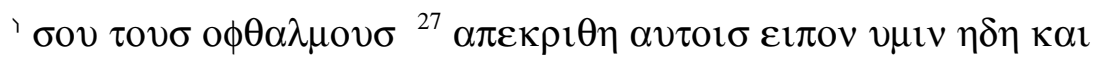

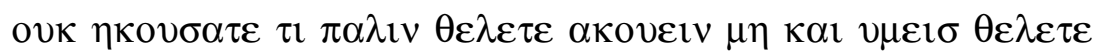

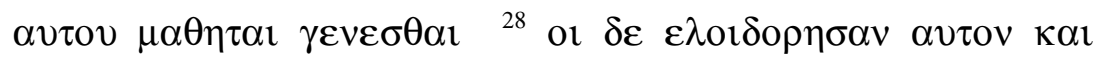

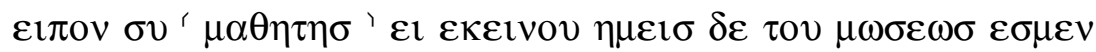

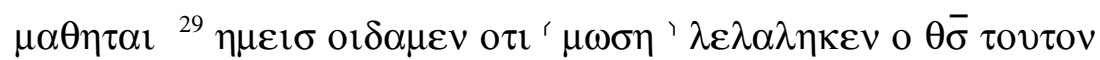

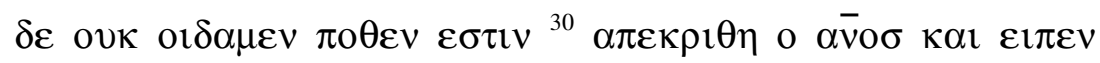

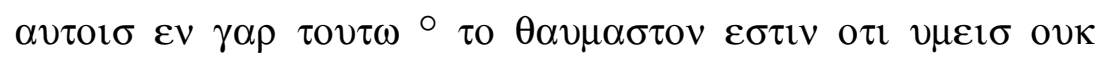

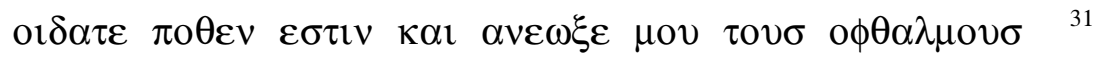

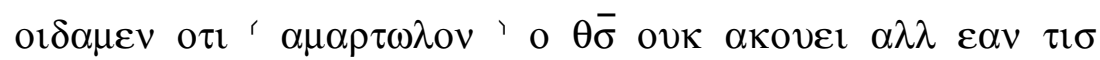

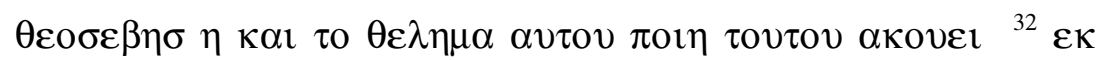

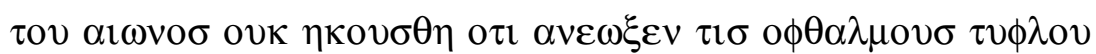

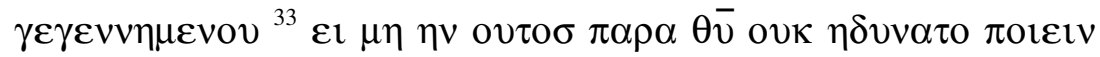

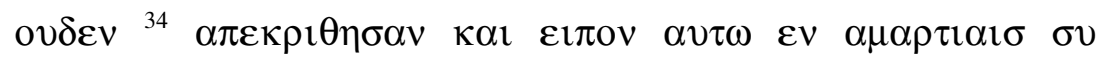

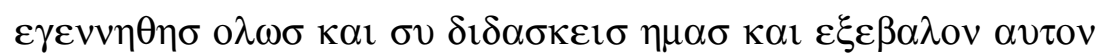

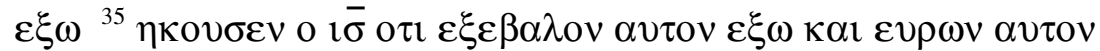

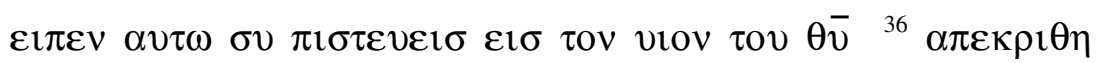

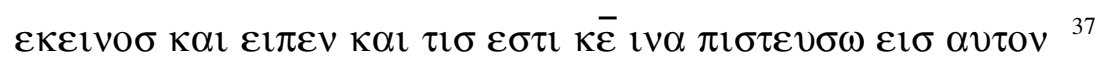

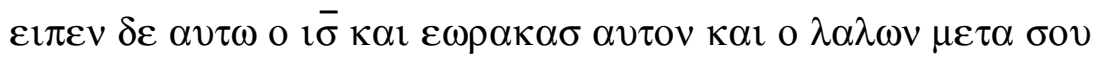




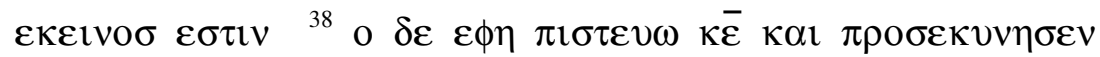

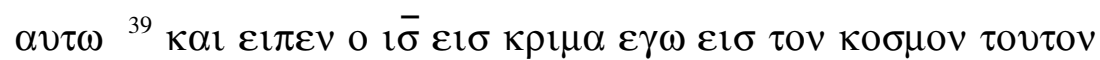

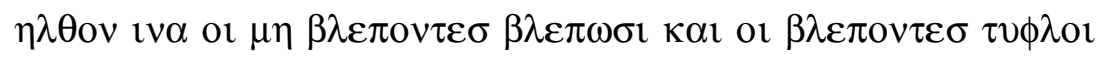

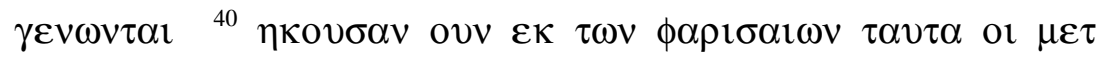

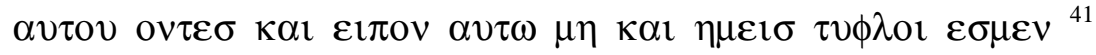

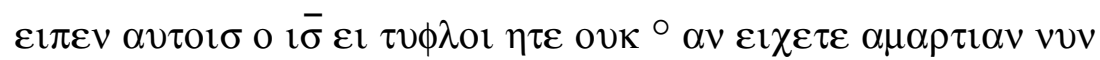

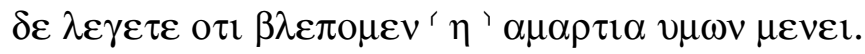

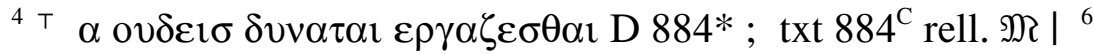

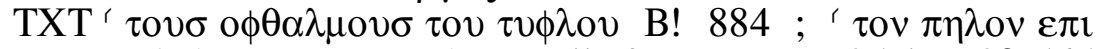
$\tau o v \sigma$ o $\phi \theta \alpha \lambda \mu \mathrm{ov \sigma} \tau \mathrm{ov} \tau \mathrm{\tau} \phi \lambda \mathrm{ov}$ rell. $\mathfrak{M}$; txt 1 205abs 209565

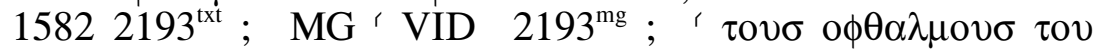

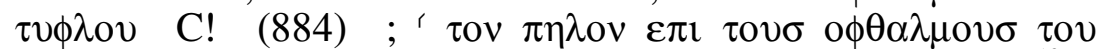
$\left.\begin{array}{llllllllll}\tau v \phi \lambda o v & (22 & 131 & 872 & 1192 & 1278 & 2372 & 2713 & \mathfrak{M}\end{array}\right)\left.\right|^{10}$ $\eta v \varepsilon \omega \chi \theta \eta \sigma \alpha \nu$ D $131884 \mathrm{M}^{\mathrm{pt}}$; txt rell. $\left.\mathrm{M}^{\mathrm{pt}}\right|^{11}$ ' $\alpha v \theta \rho \omega \pi \mathrm{\sigma} \sigma$ o B $5651278 * 2372 ;{ }^{\prime} \alpha v \theta \rho \omega \pi \mathrm{o} \sigma 1278^{\mathrm{C}}$ rell. $\mathfrak{M}$; txt B-A 122118

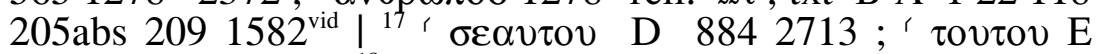

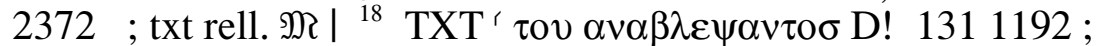

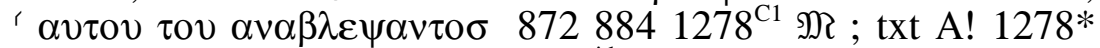
$2193^{\text {txt }}$ rell. ; [ MG ' VID $2193^{\text {mgvid }}$; MG ' $\tau$ ov $\alpha v \alpha \beta \lambda \varepsilon \psi \alpha v \tau o \sigma$

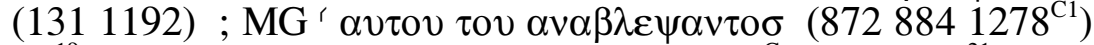
]| ${ }^{19} \varepsilon \lambda \varepsilon \gamma \varepsilon \tau \varepsilon$ D $221278 * 2372$; txt $1278^{\mathrm{C}}$ rell. MR | ${ }^{21} \square \mathrm{C}$ -

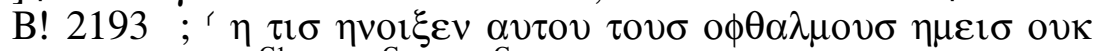

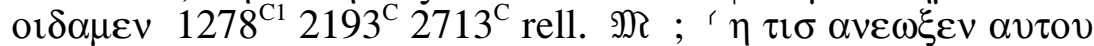

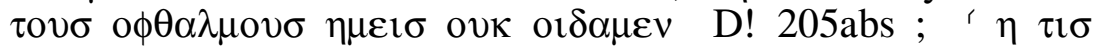

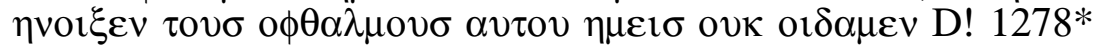

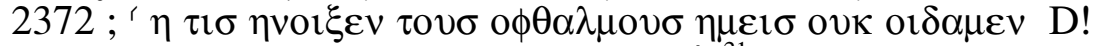
2713*; txt C-B! 111820927131582 | ${ }^{21}$ ' $\alpha v \tau \sigma \sigma \varepsilon \rho \omega \tau \eta \sigma \alpha \tau \varepsilon$

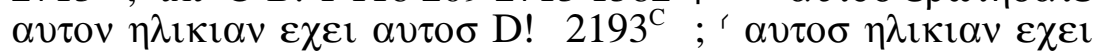

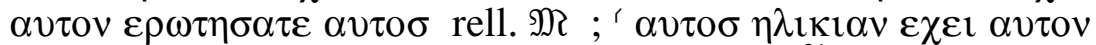
$\varepsilon \rho \omega \tau \eta \sigma \alpha \tau \varepsilon$ E 2713 ; txt A! $\left.115822193 *\right|^{21}{ }^{\top} \tau \alpha$ D! 565 ; txt rell. MR (DEF 2713) | ${ }^{23}$ 52.3.4.1. ${ }^{2}$ rell. M ; txt C 2193| ${ }^{26}$; $\eta v 01 \xi_{\varepsilon v} 1278^{*}$ rell. $\mathrm{M}^{\mathrm{pt}}$; txt 1118 205abs $2095651278^{\mathrm{C}}$ $\left.158221932713 \mathrm{M}^{\mathrm{pt}}\right|^{28}$ ' $\varepsilon 1 \mu \alpha \theta \eta \tau \eta \sigma$ rell. $\mathfrak{M}$; ‘ $\mu \alpha \theta \eta \tau \eta \sigma 205$ 2713 ; txt B 1118 205abs $\left.2091582\right|^{29}$ ' $\mu \omega \sigma \varepsilon$ 2 $2193 *$ rell. $\mathfrak{N}$ ; txt C $2193^{\mathrm{C}} 2372$ | ${ }^{30} \circ$ rell. $\mathfrak{N}$; txt A-B 1221582 | $^{31}$ r $\alpha \mu \alpha \rho \tau \omega \lambda \omega v \quad 2193^{\mathrm{C}} 2372^{*}$ rell. $\mathfrak{M}$; txt B $1315652193 *$ $\left.2372^{\mathrm{C}} 2713\right|^{41} \circ \mathrm{D}$ ! $2193^{\mathrm{C}}$; txt rell. $\left.\mathfrak{N}\right|^{41}{ }^{4} \kappa \alpha 1 \eta \mathrm{D} 884$; ' $\eta$ ovv $1582^{\mathrm{C}} 2193^{\mathrm{C}}$ rell. MR ; txt A! $156515822193^{*}$ । 


\section{Chapter 10}

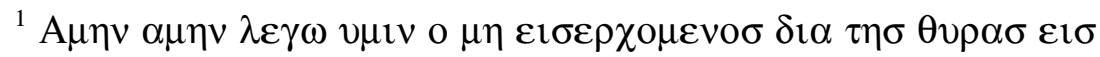
$\tau \eta v \alpha v \lambda \eta v \tau \omega v \pi \rho \circ \beta \alpha \tau \omega v \alpha \lambda \lambda \alpha \alpha v \alpha \beta \alpha \imath v \omega v \alpha \lambda \lambda \alpha \chi 0 \theta \varepsilon v \varepsilon \kappa \varepsilon \imath v o \sigma$

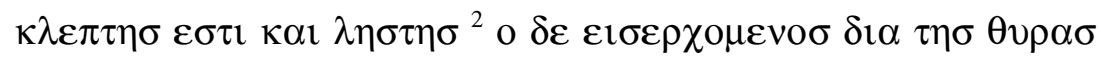

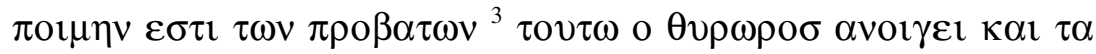

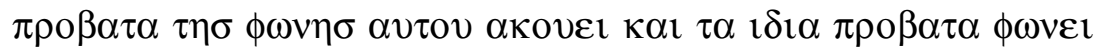

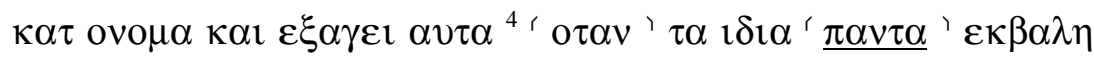

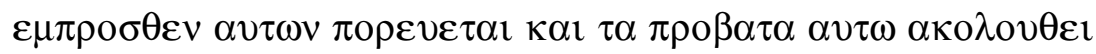

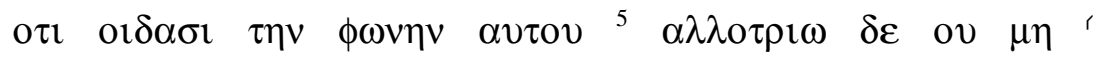

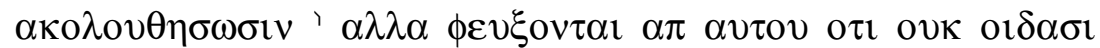

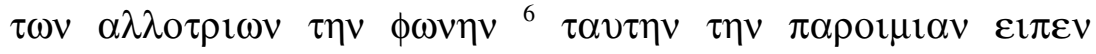

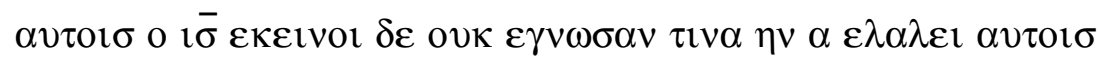

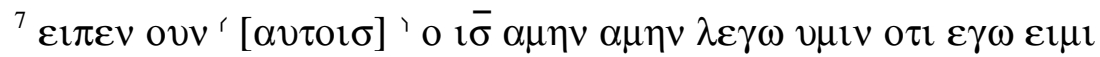

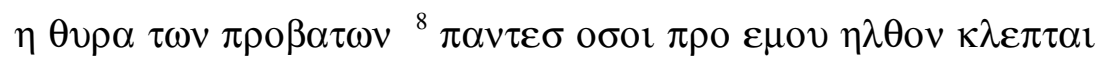

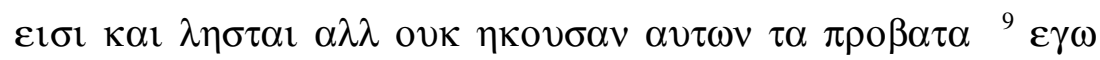

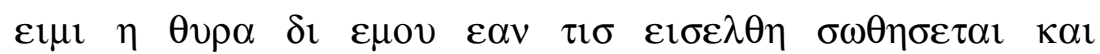

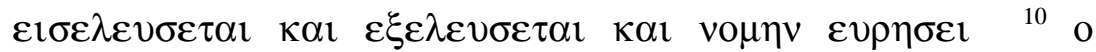

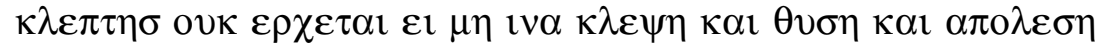

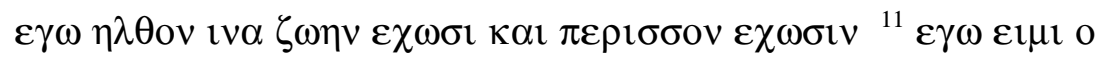

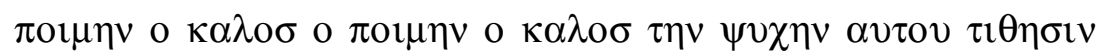

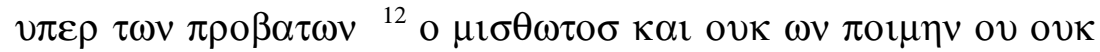

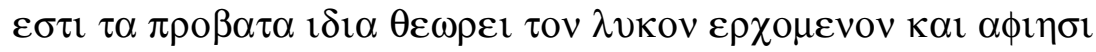

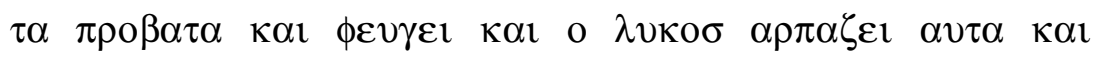

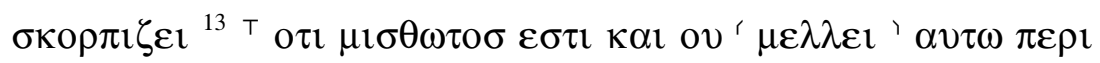

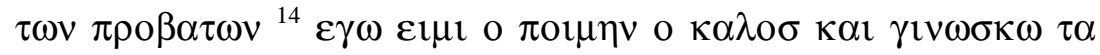

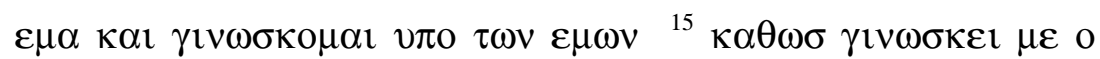

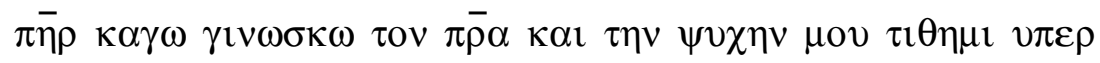

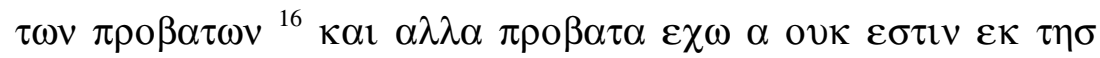

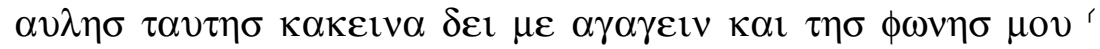

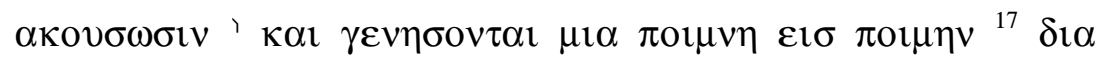

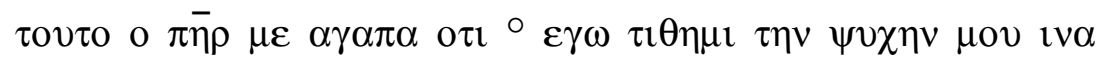

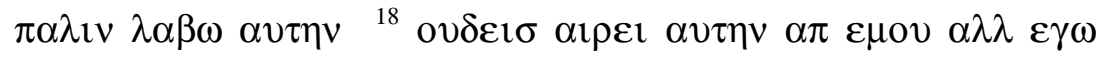

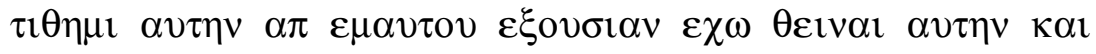


$\varepsilon \xi_{0} \sigma \sigma \alpha v \varepsilon \chi \omega \pi \alpha \lambda \iota v \lambda \alpha \beta \varepsilon \iota v \alpha v \tau \eta v \tau \alpha v \tau \eta v \tau \eta v \varepsilon v \tau 0 \lambda \eta v \varepsilon \lambda \alpha \beta o v$

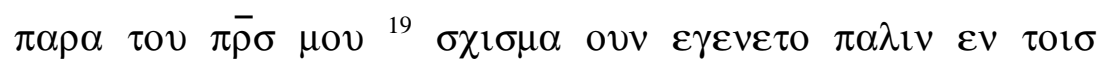

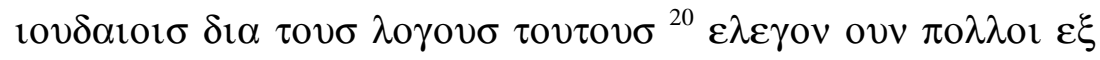

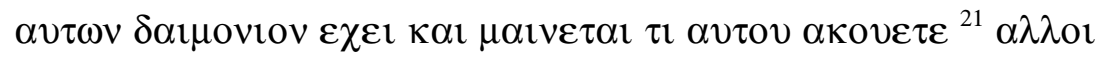

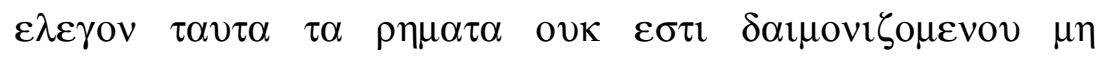

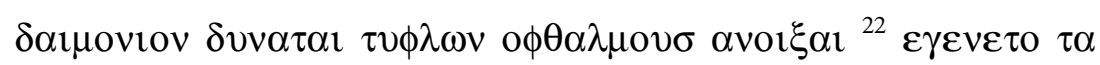

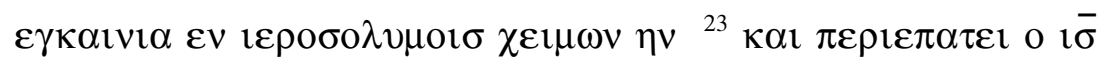

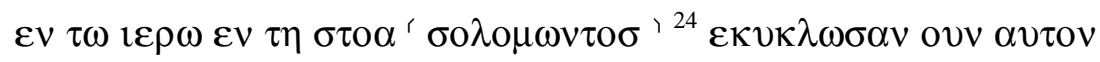

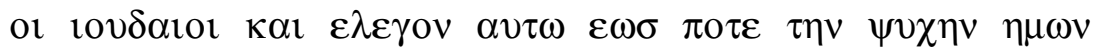

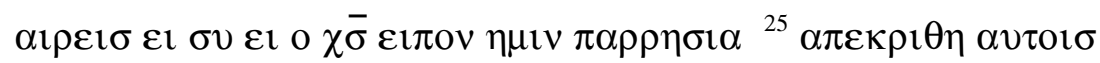

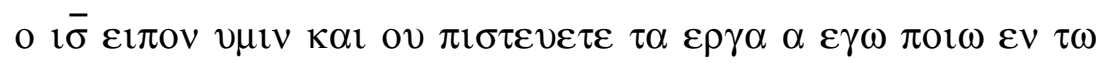

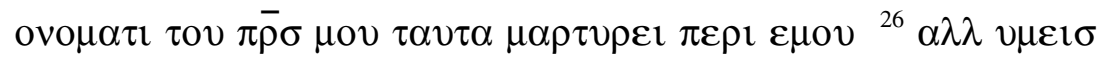

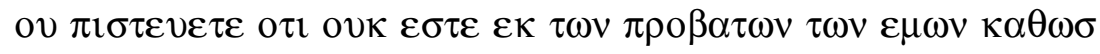

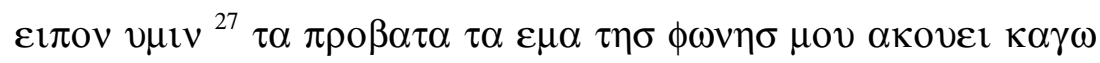

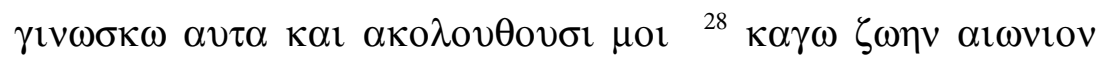

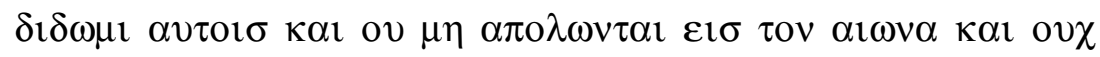

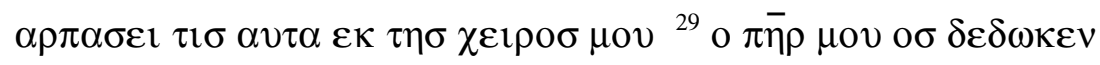

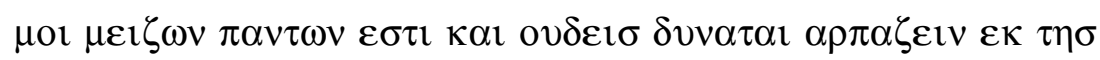

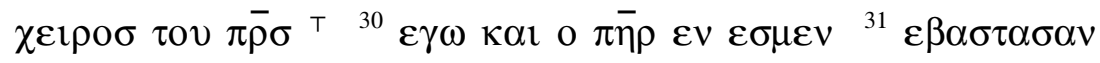

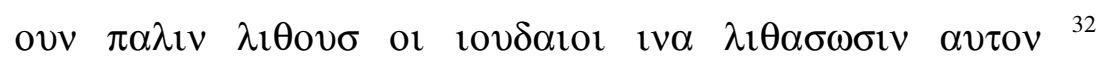

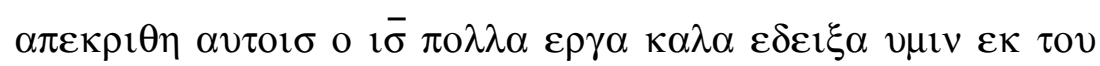
$\pi \bar{\rho} \sigma \mu \mathrm{ov} \delta 1 \alpha \pi$ olov $\alpha v \tau \omega v \varepsilon \rho \gamma o v \quad \lambda 1 \theta \alpha \zeta \varepsilon \tau \varepsilon \mu \varepsilon{ }^{33} \alpha \pi \varepsilon \kappa \rho \imath \theta \eta \sigma \alpha \nu$

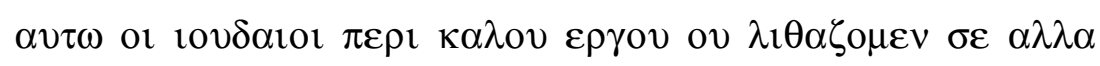

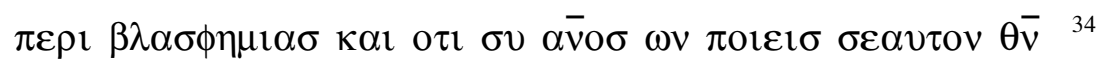
$\alpha \pi \varepsilon \kappa \rho \imath \theta \eta \alpha v \tau o \iota \sigma$ o

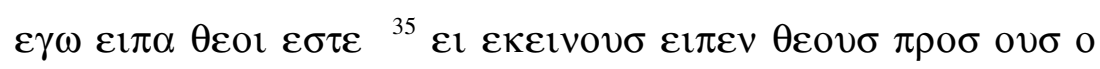

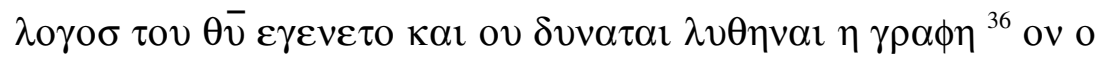

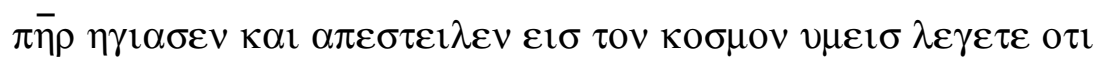

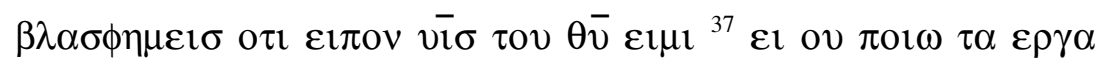
$\tau \mathrm{ov} \pi \bar{\rho} \sigma \mu \mathrm{ov} \mu \eta \pi \mathrm{l} \sigma \varepsilon v \varepsilon \tau \varepsilon \mu \mathrm{ol}{ }^{38} \varepsilon \mathrm{\varepsilon} \delta \varepsilon \pi \mathrm{ol \omega} \kappa \alpha \nu \varepsilon \mu \mathrm{or}{ }^{\circ} \mu \eta^{\prime}$

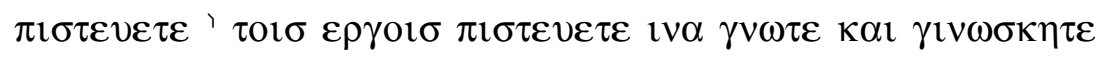

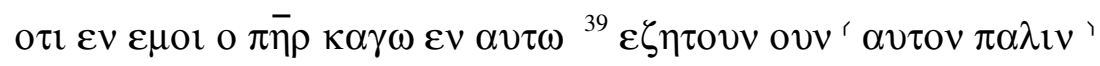

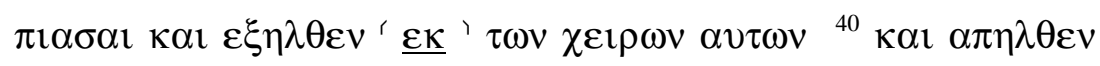

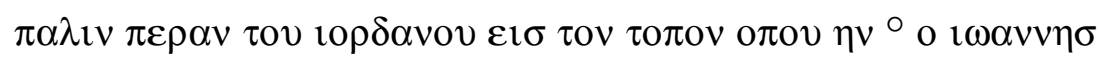




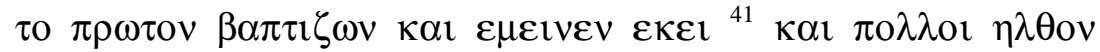

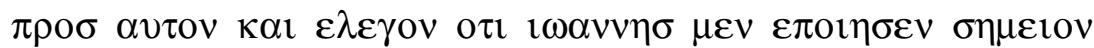

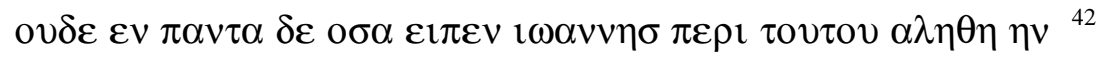

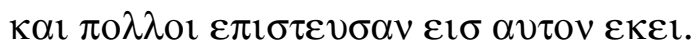

${ }^{4}$ ' o $\tau \alpha \nu \delta \varepsilon \quad D ! 2193^{\mathrm{C}}$; ' $\kappa \alpha$ o o $\alpha \nu$ rell. $\mathfrak{M}$; txt A! 1565884 $\left.15822193^{*}\right|^{4}{ }^{4} \mathrm{TXT}^{\prime} \pi \rho 0 \beta \alpha \tau \alpha 2193^{\mathrm{C}}$ rell. $\mathfrak{N}$; txt A! $122^{\mathrm{txt}}$ $5651192^{\mathrm{txt}} 15822193^{* \mathrm{vid}} ; \mathrm{MG}{ }^{\prime} \pi \rho \rho \beta \alpha \tau \alpha 22^{\mathrm{mg}} 1192^{\mathrm{mg}}\left(2193^{\mathrm{C}}\right)$

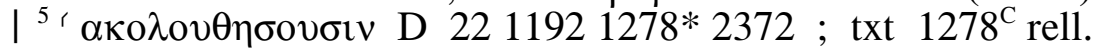
M | ${ }^{7}$ ' $\alpha v \tau o l \sigma \pi \alpha \lambda \iota v$ C-B! $88412782193^{\mathrm{C}} 2372$; ' $\pi \alpha \lambda \iota v$

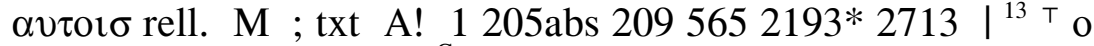

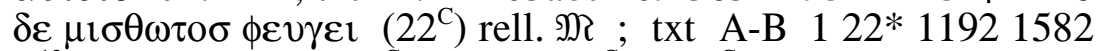

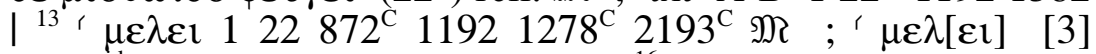

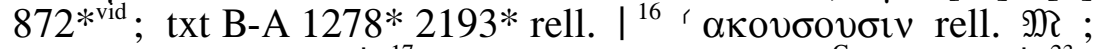
txt C 1315652713 | ${ }^{17} \circ \mathrm{D}$ ! 2193* ; txt $2193^{\mathrm{C}}$ rell. $\mathbb{N}$ | ${ }^{23}$; $\sigma o \lambda$ o $\mu \omega v 0 \sigma 115822193^{*} \mathrm{M}$; txt B-A $22^{\text {vid }} 2193^{\mathrm{C}}$ rell. $\left.\right|^{29} \mathrm{~T}$ nov 2193* rell. $\mathfrak{N}$; txt C $\left.2193^{\mathrm{C}}\right|^{38} \circ \mu \eta \mathrm{D}$ ! 1 ; txt $1^{\mathrm{C}}$ rell. $\left.\mathfrak{M}\right|^{38}\left(\pi 1 \sigma \tau \varepsilon v \eta \tau \varepsilon \quad 22^{\mathrm{C}} 1278^{\text {vid }}\right.$ rell. $\mathfrak{M}$; txt B $22^{*} 131565$ 1192 ; ' VID $2372 * 2372^{\mathrm{C}}$ | ${ }^{39}$ ' $\alpha v \tau$ ov D 884 ; ' $\pi \alpha \lambda$ tv $\alpha \nu \tau$ ov rell. 次 ; txt A 1118131 205abs 209565158221932713 | ${ }^{39}$ TXT ' $\alpha \pi \mathrm{o}[\mathrm{A} !] 565$; txt $2193^{\text {txt }}$ rell. $\mathfrak{M R}$; MG ' VID $2193^{\mathrm{mg}}$ ; $\left.{ }^{\prime} \alpha \pi \mathrm{o}(565)\right|^{40} \circ$ rell. $\mathfrak{N}$; txt C 1 । 


\section{Chapter 11}

${ }^{1} \mathrm{Hv} \delta \varepsilon \tau \imath \sigma \alpha \sigma \theta \varepsilon v \omega \nu \lambda \alpha \zeta \alpha \rho \circ \sigma \alpha \pi \mathrm{o} \beta \eta \theta \alpha v i \alpha \sigma \varepsilon \kappa \tau \eta \sigma \kappa \omega \mu \eta \sigma$ $\mu \alpha \rho \imath \alpha \sigma \quad \kappa \alpha \iota \mu \alpha \rho \theta \alpha \sigma \quad \tau \eta \sigma \quad \alpha \delta \varepsilon \lambda \phi \eta \sigma \quad \alpha v \tau \eta \sigma{ }^{2} \eta v \delta \varepsilon \mu \alpha \rho i \alpha \eta$

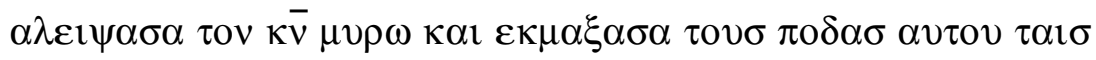

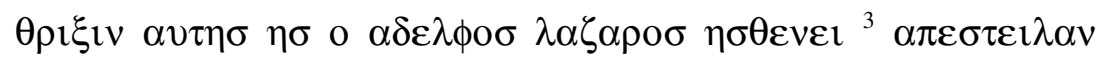

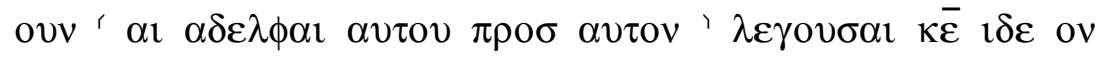
$\phi \imath \lambda \varepsilon \imath \sigma \alpha \sigma \theta \varepsilon v \varepsilon \imath{ }^{4} \alpha \kappa o v \sigma \alpha \sigma \delta \varepsilon$ o $\imath \bar{\sigma} \varepsilon \imath \pi \varepsilon v ' \alpha v \tau \eta \eta \alpha \sigma \theta \varepsilon v \varepsilon \imath \alpha$

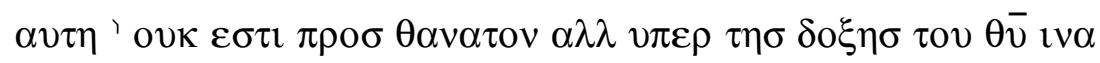

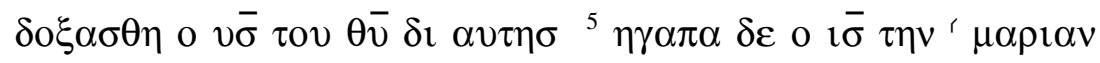

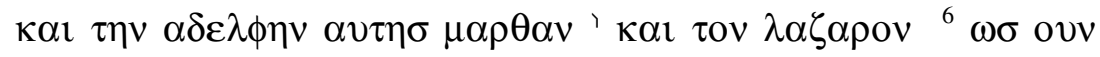

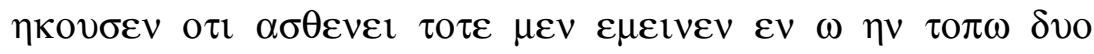

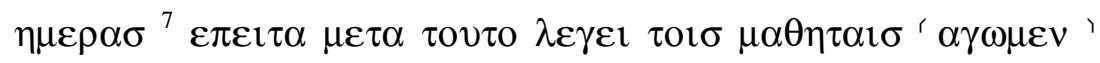
$\pi \alpha \lambda \iota v \varepsilon \imath \sigma \tau \eta v \operatorname{lov} \delta \alpha \iota \alpha v^{8} \lambda \varepsilon \gamma o v \sigma \iota v \alpha v \tau \omega$ ol $\mu \alpha \theta \eta \tau \alpha \iota \rho \alpha \beta \beta \imath v v v$

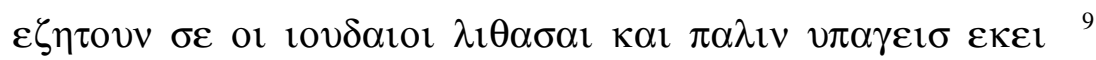

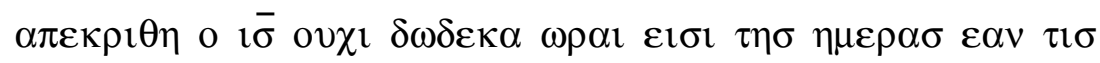

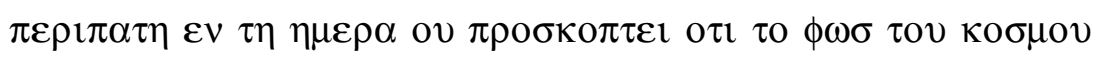

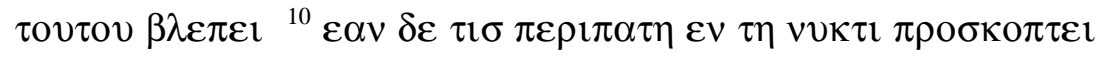

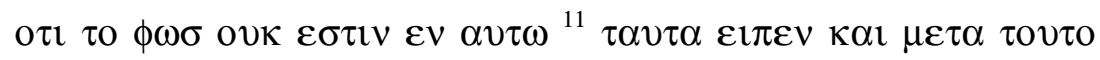

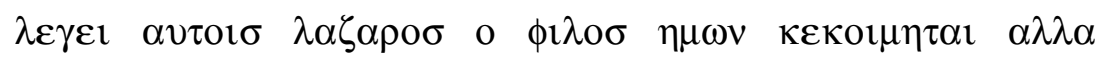

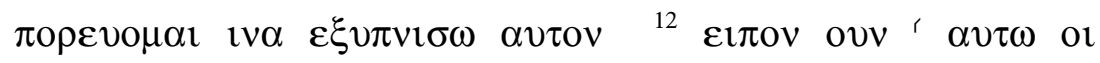

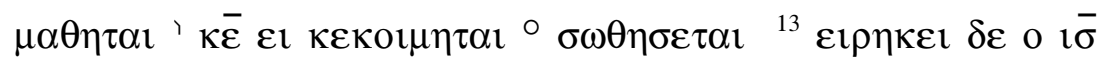

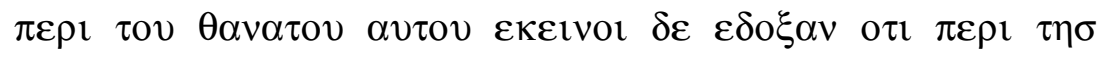
коц

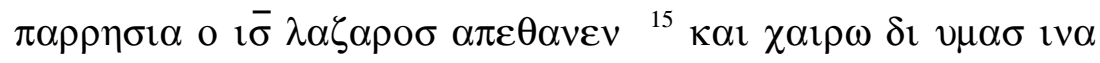
$\pi ı \tau \varepsilon v \sigma \eta \tau \varepsilon$ o $\tau$ о

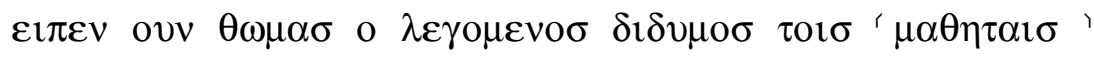

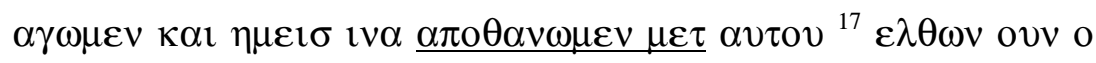
$\imath \bar{\sigma} \varepsilon v \rho \varepsilon v \alpha v \tau o v \tau \varepsilon \sigma \sigma \alpha \rho \alpha \sigma \eta \mu \varepsilon \rho \alpha \sigma \eta \delta \eta \varepsilon \chi 0 \nu \tau \alpha \varepsilon v \tau \omega \mu \nu \eta \mu \varepsilon i \omega$

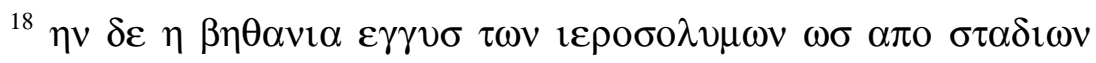

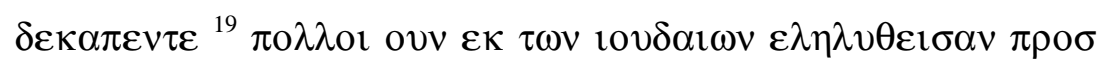

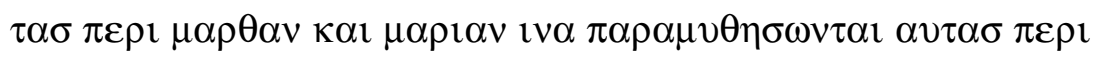

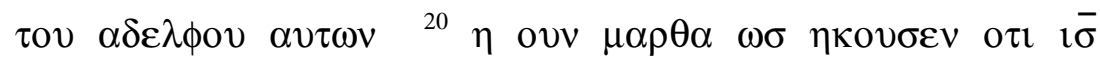

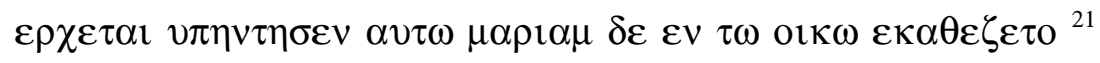




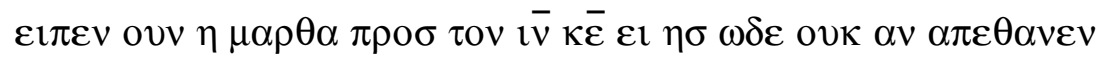

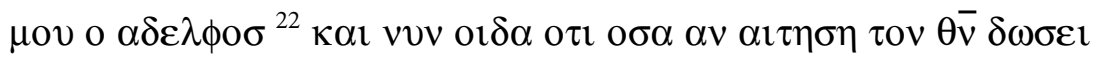

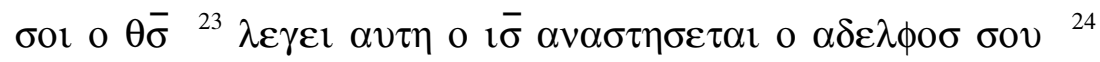

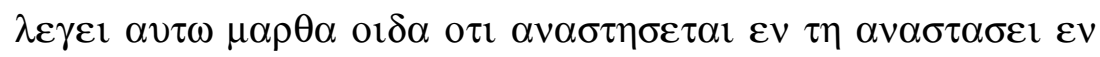
$\tau \eta \varepsilon \sigma \chi \alpha \tau \eta \eta \mu \varepsilon \rho \alpha^{25} \varepsilon \imath \pi \varepsilon \nu \delta \varepsilon \alpha v \tau \eta$ o $\imath \bar{\sigma} \varepsilon \gamma \omega \varepsilon \iota \mu \iota \eta \alpha v \alpha \sigma \tau \alpha \sigma \iota \sigma$

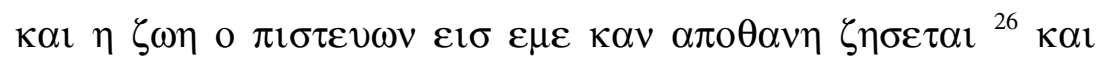

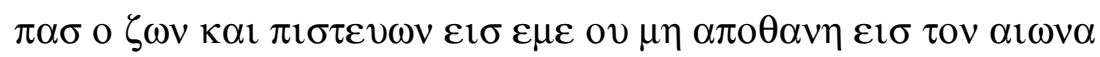

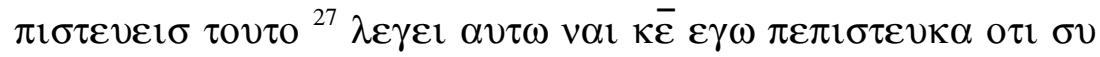

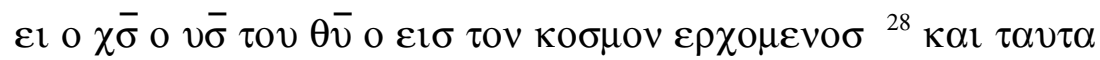

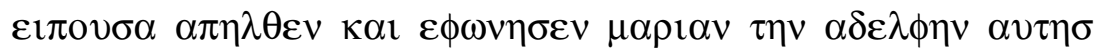

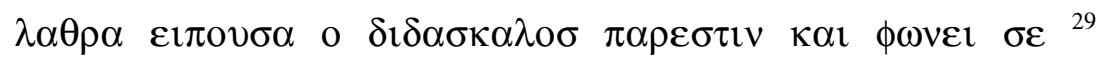

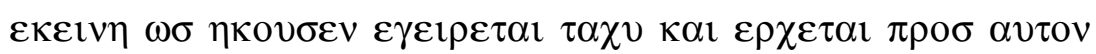
${ }^{30} \mathrm{ov \pi \omega} \delta \varepsilon \varepsilon \lambda \eta \lambda v \theta \varepsilon \imath$ o $\iota \bar{\sigma}^{\prime} \varepsilon 1 \sigma^{\prime} \tau \eta \nu \kappa \omega \mu \eta \nu \alpha \lambda \lambda \eta v \varepsilon \tau l \varepsilon v \tau \omega$

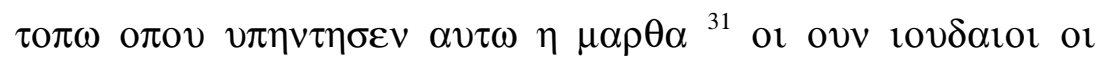

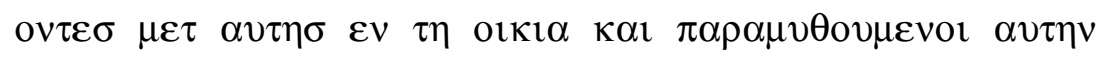

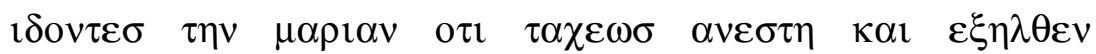

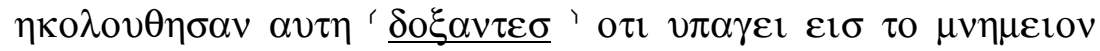

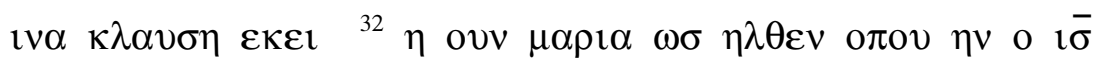
$'[\lambda \varepsilon \gamma \circ \nu \tau \varepsilon \sigma] '$

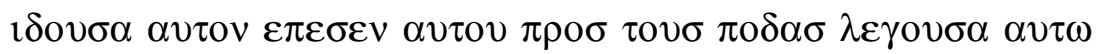

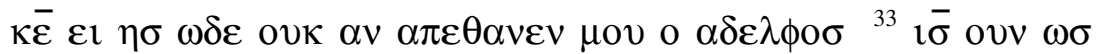

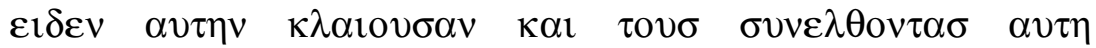

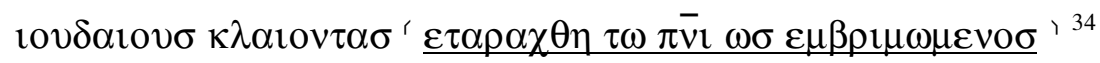

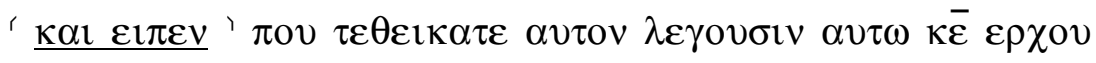

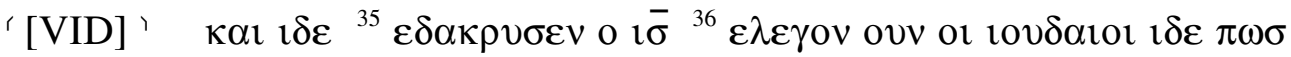

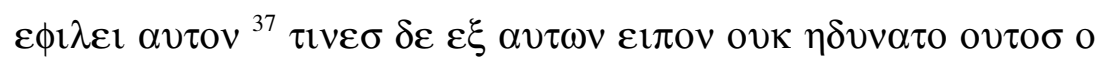

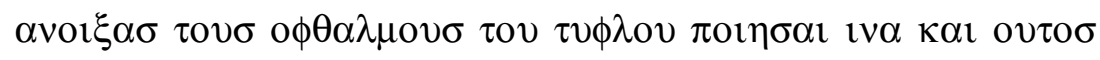
$\mu \eta \alpha \pi \mathrm{o} \theta \alpha v{ }^{38} \mathrm{l} \bar{\sigma}$ ovv $\pi \alpha \lambda \mathrm{\imath v} \varepsilon \mu \beta \rho \mu \omega \mu \varepsilon v o \sigma \varepsilon v \varepsilon \alpha v \tau \omega \varepsilon \rho \chi \varepsilon \tau \alpha \imath$

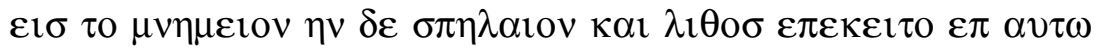

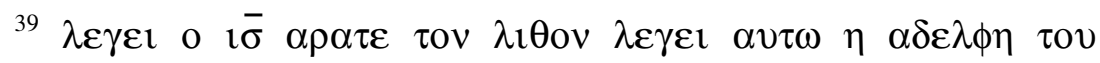

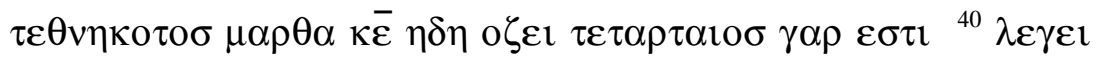

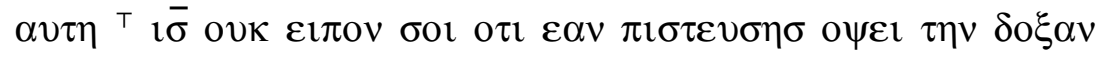

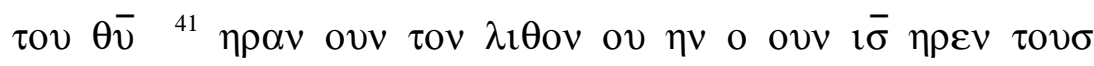

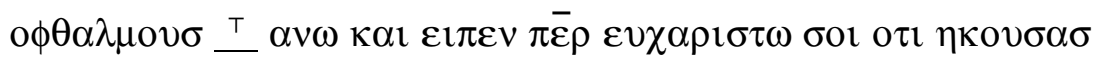

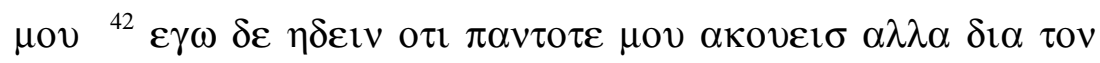




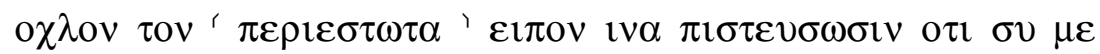
$\alpha \pi \varepsilon \sigma \tau \varepsilon 1 \lambda \alpha \sigma^{43} \kappa \alpha \imath \tau \alpha v \tau \alpha \varepsilon i \pi \omega v$ $\phi \omega v \eta \mu \varepsilon \gamma \alpha \lambda \eta \varepsilon \kappa \rho \alpha v \gamma \alpha \sigma \varepsilon v$

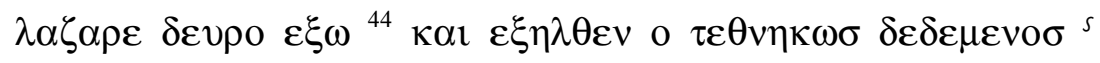

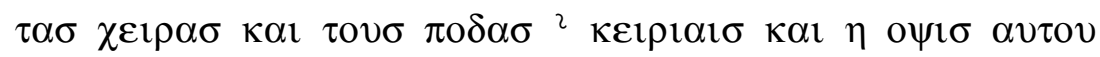

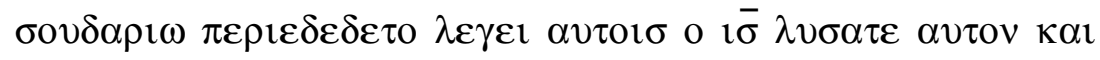

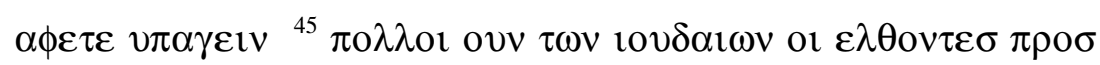

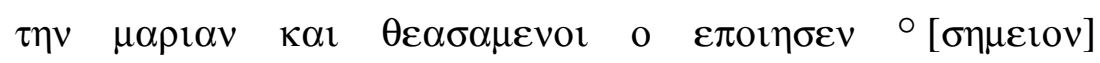

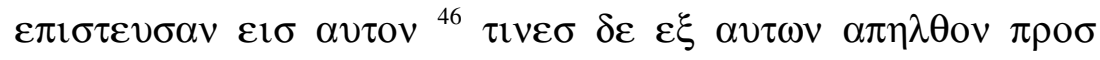

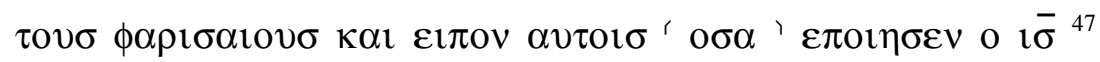

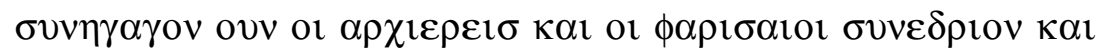

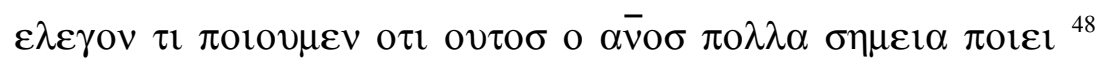

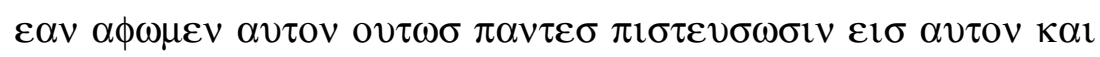

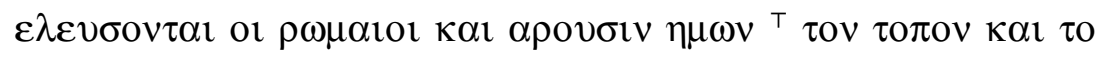

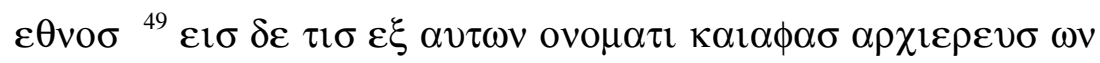

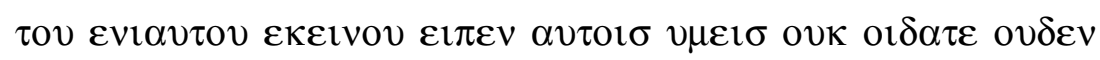

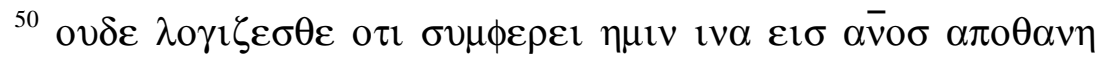

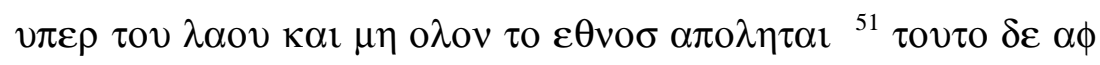

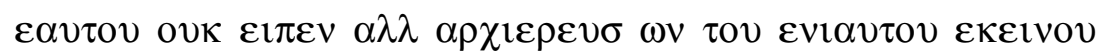

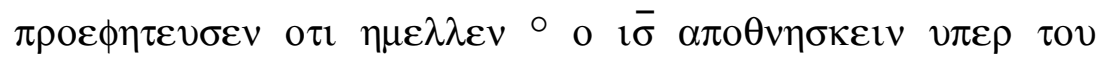

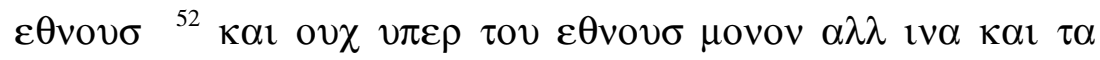

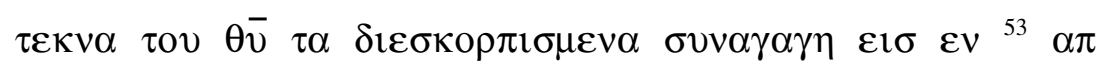

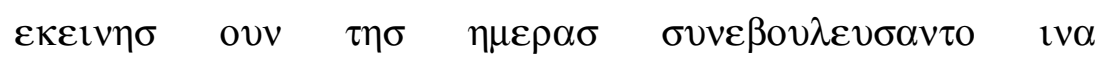

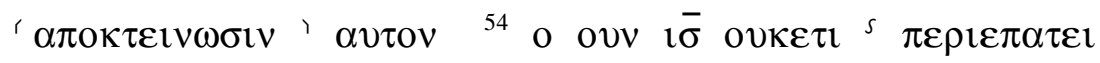

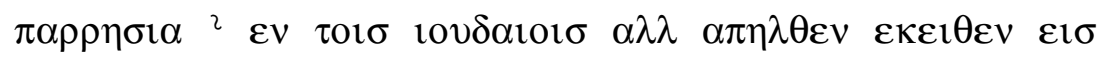

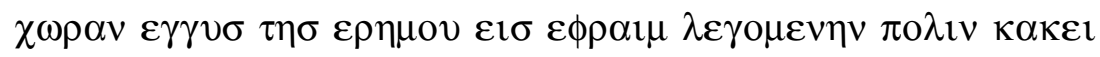
$\delta 1 \varepsilon \tau \rho \imath \beta \varepsilon \mu \varepsilon \tau \alpha \tau \omega \nu \mu \alpha \theta \eta \tau \omega v \quad{ }^{55} \eta v \quad \delta \varepsilon \varepsilon \gamma \gamma \nu \sigma \quad \tau o \pi \alpha \sigma \chi \alpha \tau \omega v$

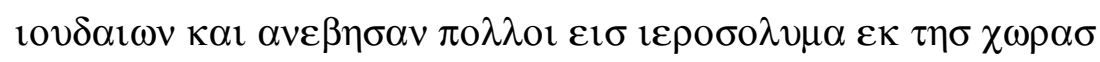

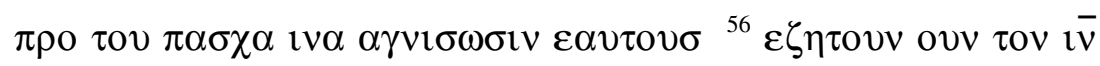

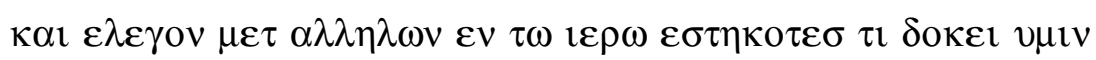

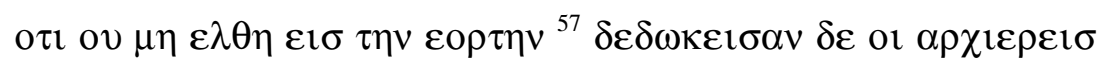

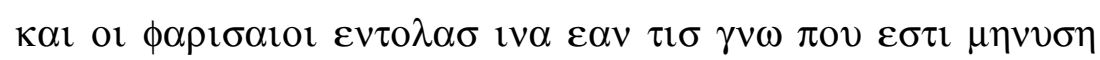
o $\pi \omega \sigma \pi \iota \alpha \sigma \omega \sigma \mathrm{lv} \alpha v \tau \mathrm{cov}$.

Lac. $\quad 565: 11: 26 b-11: 48$. 
${ }^{3}$ ' $\pi \rho \circ \sigma \alpha v \tau$ ov $\alpha \mathrm{l} \alpha \delta \varepsilon \lambda \phi \alpha \mathrm{l}$ D $22119212782372 \quad$; ' $\alpha \mathrm{l}$

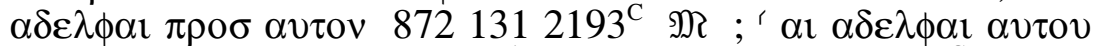
E 2713 ; txt A $2193^{*}$ rell. | ${ }^{4}$ ' $\alpha v \tau \eta \eta \alpha \sigma \theta \varepsilon v \varepsilon i \alpha ~ 2193^{\mathrm{C}}$ rell. $\mathfrak{N}$

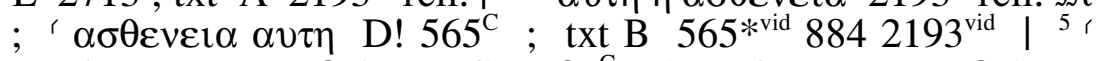

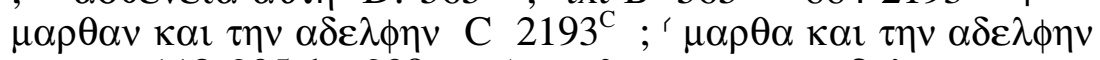

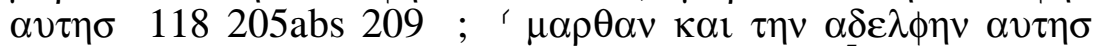

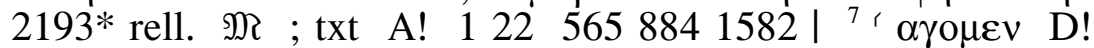
2193 ; txt rell. $\mathfrak{N} \mid{ }^{12}$ ' of $\mu \alpha \theta \eta \tau \alpha \mathrm{l} \alpha v \tau$ ov $2193^{*}$ rell. M ; txt C $\left.2193^{\mathrm{C}}\right|^{12} \circ \mathrm{D}$ ! 1 ; txt $1^{\mathrm{C}}$ rell. $\mathfrak{N} \mid{ }^{14} \circ \mathrm{D}$ ! 565 ; txt rell. M $\mid{ }^{16}, \sigma v \mu \mu \alpha \theta \eta \tau \alpha i \sigma$ rell. $\mathfrak{M} ;$ txt C 565| ${ }^{16}$ TXT txt rell. M ; [MG ' VID 2193 ${ }^{\text {mgvid }}$ ] | ${ }^{30}>\pi \rho 0 \sigma$ D 118 205abs 2092372 2713 ; txt rell. MR | ${ }^{31}$ TXT ' $\lambda \varepsilon \gamma o v \tau \varepsilon \sigma 1318721278^{\mathrm{C}} \mathfrak{M}$; txt

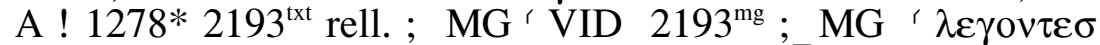

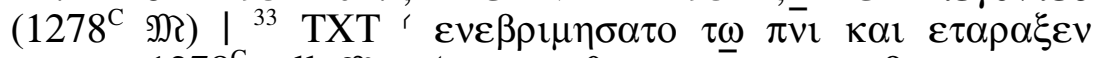

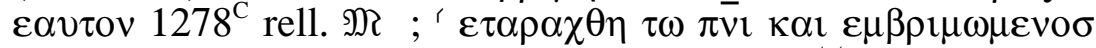
E 2372;' VID 1278*; txt A! $1221582^{\text {txt }} 2193$; MG'

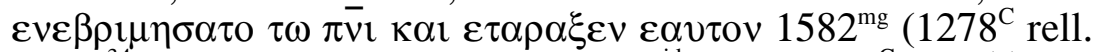
ग) | ${ }^{34}$ TXT ' $\varepsilon 1 \pi \varepsilon v$ D! $23721278^{* v i d}$; txt $1278^{\mathrm{C}} 2193^{\mathrm{txt}}$ rell. M ; MG $^{\prime}$ VID $2193^{\mathrm{mg}} ;\left.\mathrm{MG}^{\prime} \varepsilon \imath \pi \varepsilon V\left(23721278^{* \mathrm{vid}}\right)\right|^{40} \mathrm{~T}^{\mathrm{T}} \mathrm{o}$ rell. $\mathfrak{N}$; txt B $11582{ }^{41}$ TXT txt $2193^{\text {txt }}$ rell. $\mathfrak{N} ;$ MG $^{\top} \varepsilon 1 \sigma$

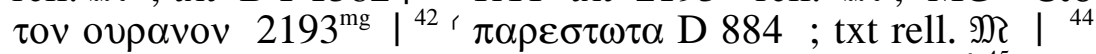
54.5.3.1.2. ${ }^{2}$ rell. $\mathfrak{N}$; txt B 118 205abs 2098842713 । $^{45} \circ \mathrm{C}$ ! $18841582 ;{ }^{\circ}\left({ }^{\top}\right.$ o $\left.t \bar{\sigma}\right) 2193^{\mathrm{C}}$ rell. $\mathfrak{N}$; txt C | ${ }^{46}$ ' $\alpha$ 2193* rell. $\mathfrak{M}$; txt $\left.\mathrm{C} 1312193^{\mathrm{C}}\right|^{48}{ }^{\mathrm{T}} \kappa \alpha \mathrm{t} 2193^{*}$ rell. $\mathfrak{N}$; txt 131 $\left.2193^{\mathrm{C}}\right|^{51} \circ 2193^{*}$ rell. M ; C-B txt $13187212782193^{\mathrm{C}} 2372$ | ${ }^{53}$ ' a txt C 2193 | 


\section{Chapter 12}

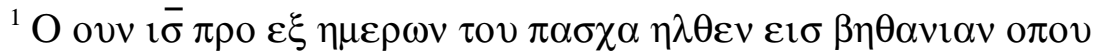

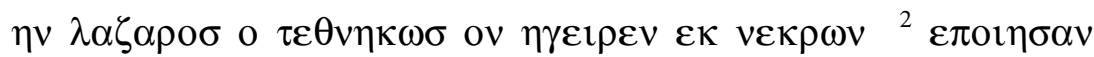

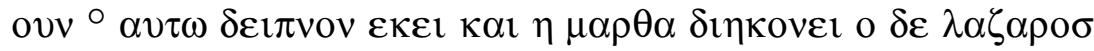
$\varepsilon 1 \sigma \eta v \tau \omega v \alpha v \alpha \kappa \varepsilon 1 \mu \varepsilon v \omega v \sigma v v \alpha v \tau \omega{ }^{3} \eta$ ovv $\mu \alpha \rho i \alpha \mu \lambda \alpha \beta o v \sigma \alpha$

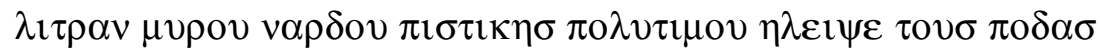

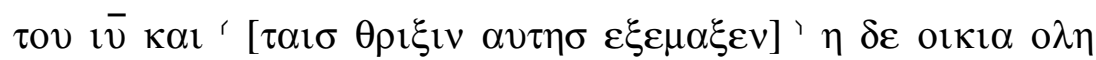

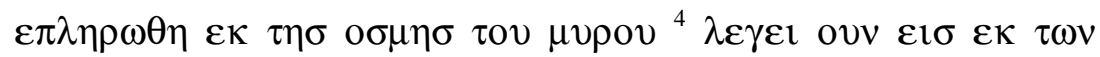

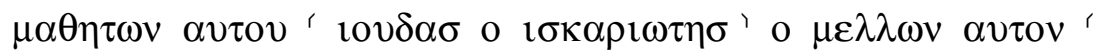

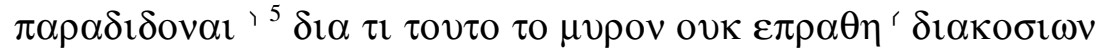

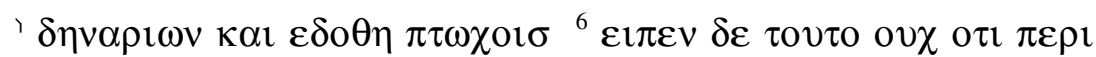

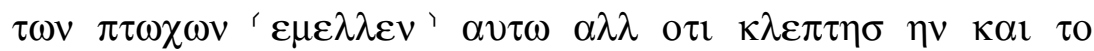

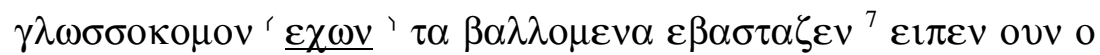

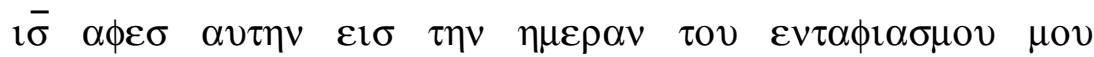

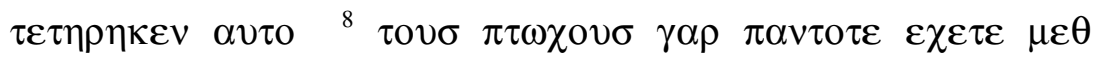
$\varepsilon \alpha \nu \tau \omega \nu \varepsilon \mu \varepsilon \delta \varepsilon$ ov $\pi \alpha \nu \tau \sigma \tau \varepsilon \varepsilon \chi \varepsilon \tau \varepsilon{ }^{9} \varepsilon \gamma \nu \omega$ ovv o $\chi \lambda \circ \sigma \pi \mathrm{o} \lambda \nu \sigma \varepsilon \kappa$

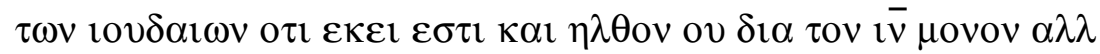

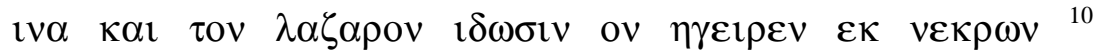

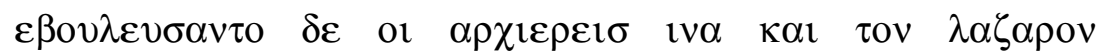

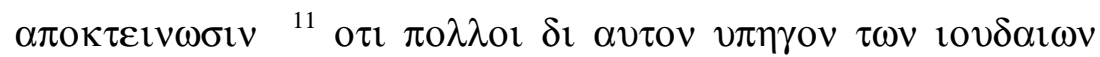

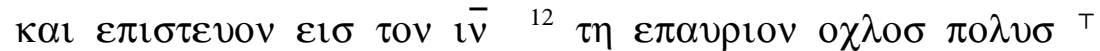

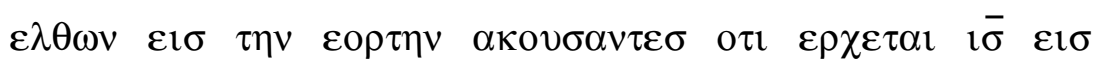

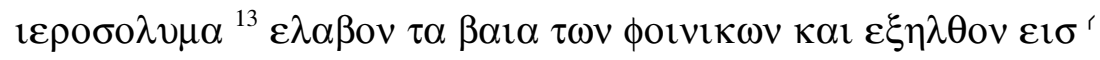

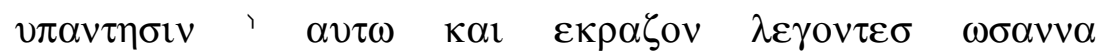

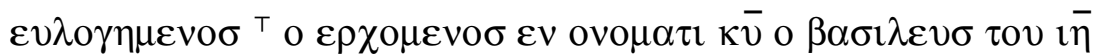

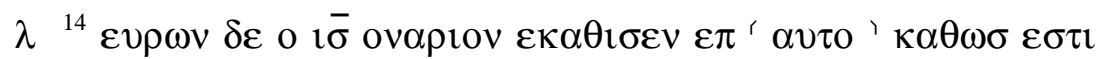

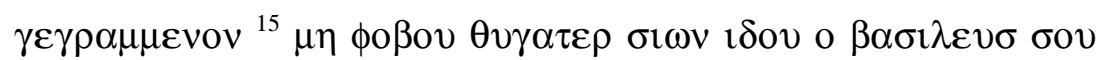

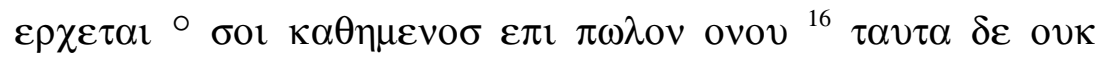

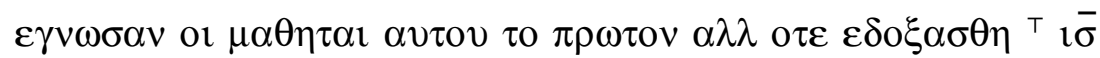

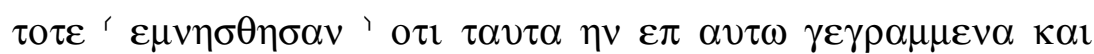

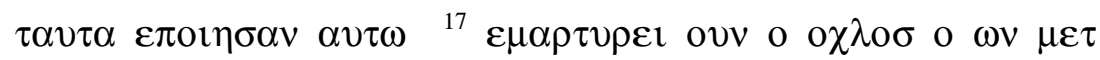

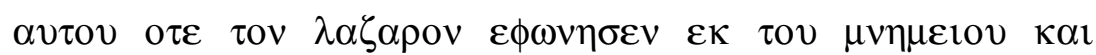

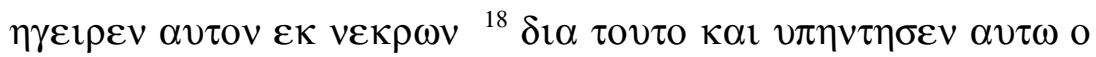




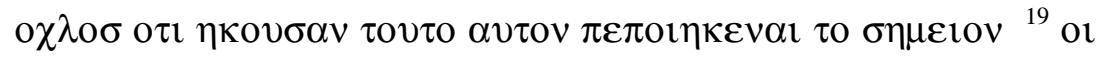

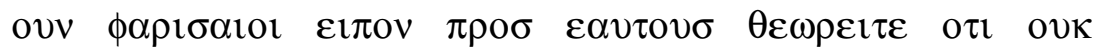

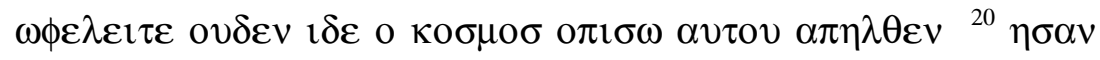

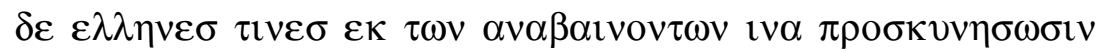

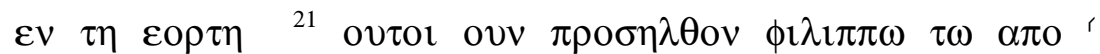

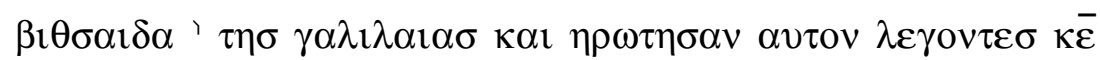

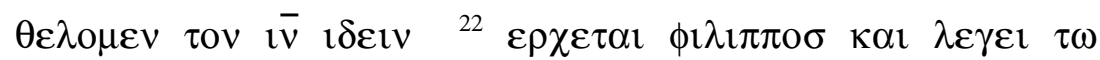
$\alpha v \delta \rho \varepsilon \alpha \kappa \alpha \iota \pi \alpha \lambda \iota v \alpha v \delta \rho \varepsilon \alpha \sigma \kappa \alpha \iota^{\prime} \phi \imath \lambda \iota \pi \pi \sigma \sigma^{\prime} \lambda \varepsilon \gamma \sigma v \sigma \iota \tau \omega \imath \bar{v}{ }^{23} \mathrm{o}$

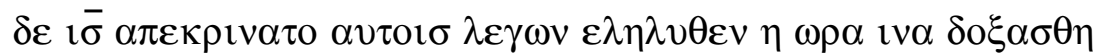

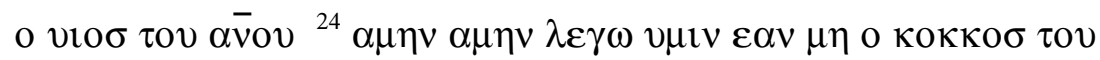

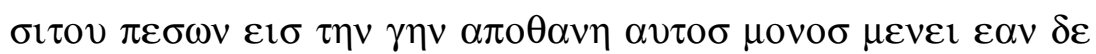

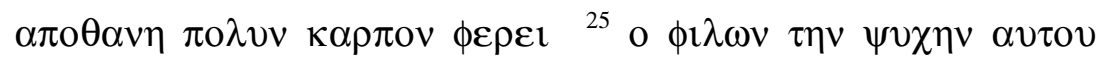

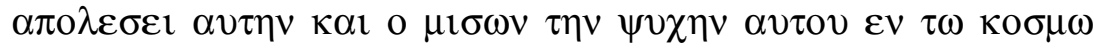

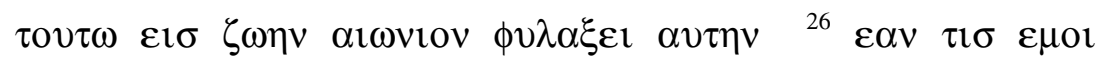

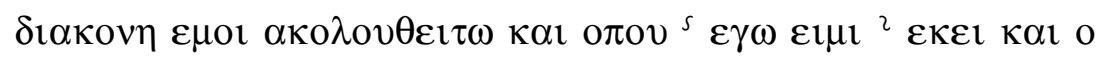

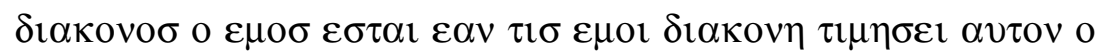

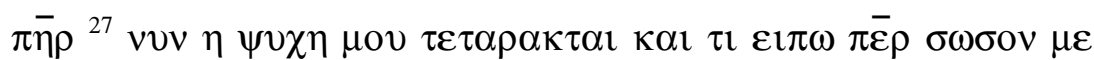

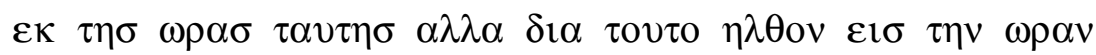

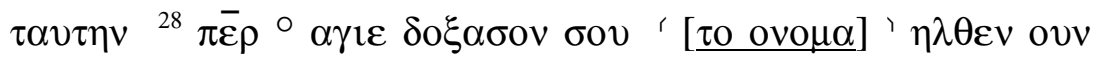

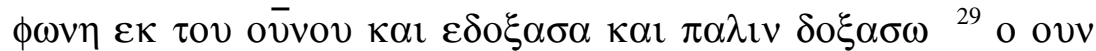

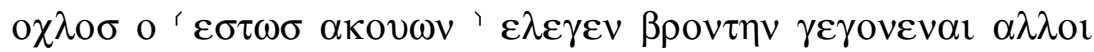

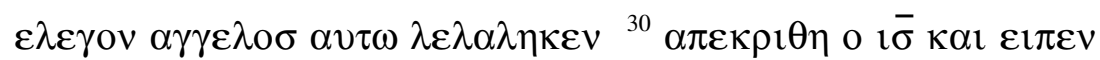

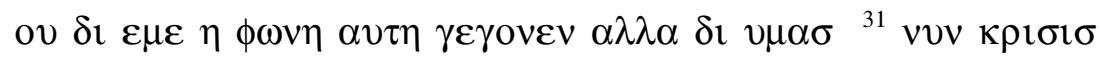

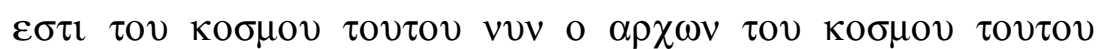

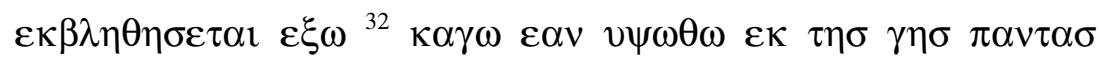

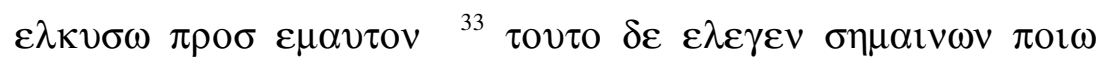
$\theta \alpha v \alpha \tau \omega \varepsilon \mu \varepsilon \lambda \lambda \varepsilon v \quad \alpha \pi \circ \theta v \eta \sigma \kappa \varepsilon \imath{ }^{34} \alpha \pi \varepsilon \kappa \rho i \theta \eta \quad \alpha v \tau \omega$ о о о $\chi \lambda \circ \sigma$

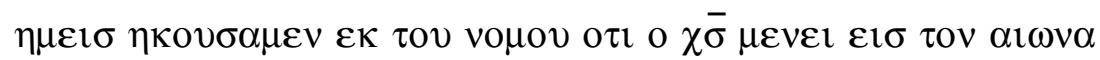

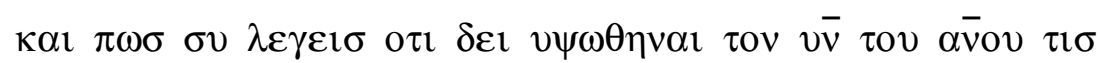

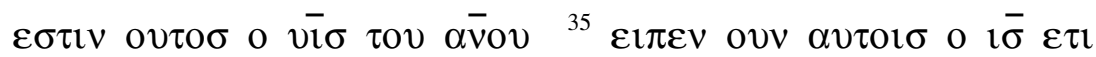

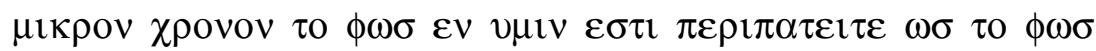

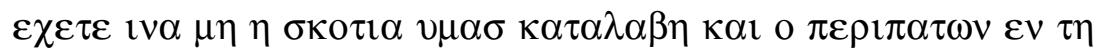

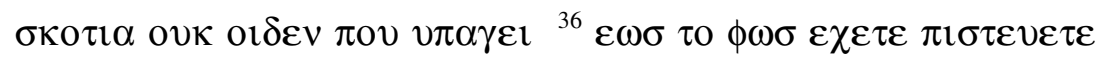

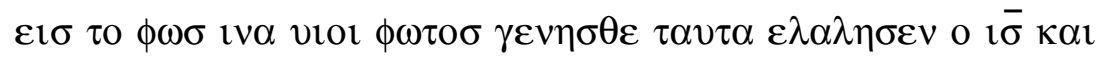




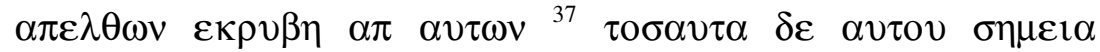

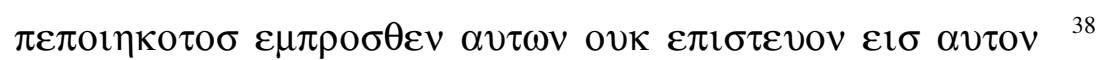

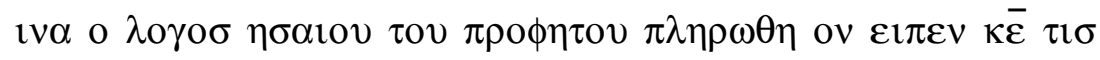

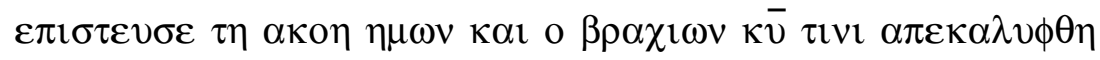

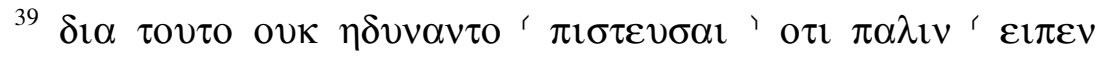

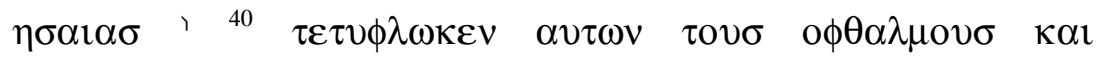

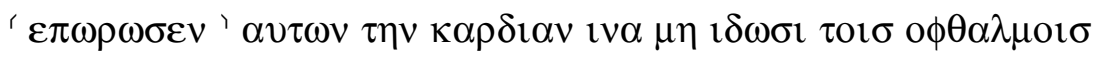

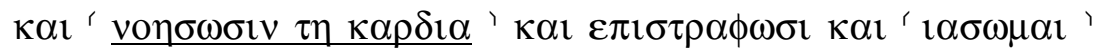

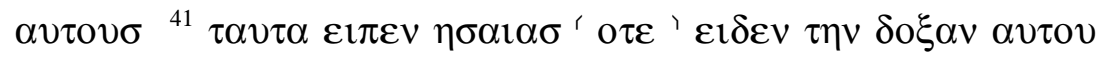

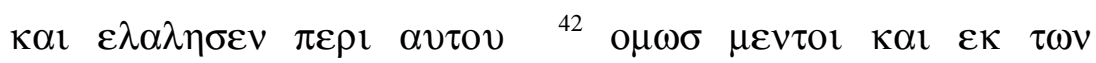

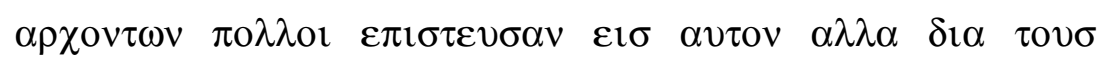

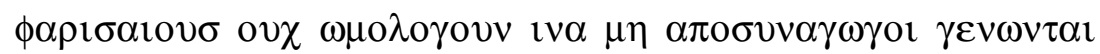

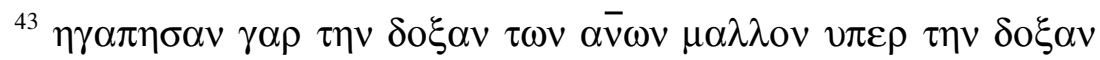

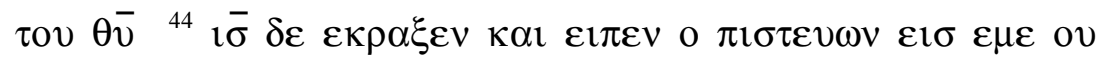
$\pi \imath \sigma \tau \varepsilon v \varepsilon \imath \varepsilon 1 \sigma \varepsilon \mu \varepsilon \alpha \lambda \lambda \varepsilon 1 \sigma \tau$ ov $\pi \varepsilon \mu \psi \alpha \nu \tau \alpha \mu \varepsilon{ }^{45} \kappa \alpha$ о $\theta \varepsilon \omega \rho \omega \nu$

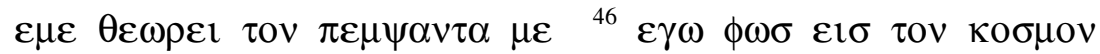
$\varepsilon \lambda \eta \lambda v \theta \alpha \iota v \alpha \pi \alpha \sigma$ o $\pi \iota \sigma \tau \varepsilon v \omega v \varepsilon \iota \sigma \varepsilon \mu \varepsilon \varepsilon v \tau \eta \sigma \kappa o \tau \iota \alpha \mu \eta \mu \varepsilon \iota v \eta{ }^{47}$ $\kappa \alpha l \varepsilon \alpha v \tau \imath \sigma \mu \mathrm{ov} \alpha \kappa o v \sigma \eta \tau \omega v \rho \eta \mu \alpha \tau \omega v \kappa \alpha \iota \mu \eta^{\prime} \phi v \lambda \alpha \xi \eta$ ' $\varepsilon \gamma \omega$ ov

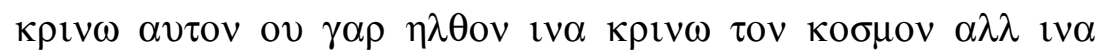

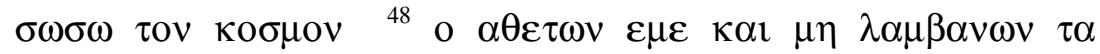

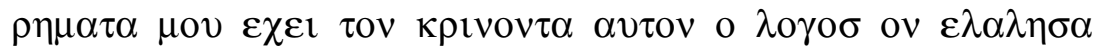

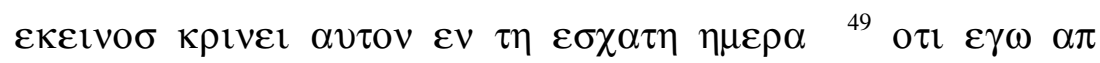

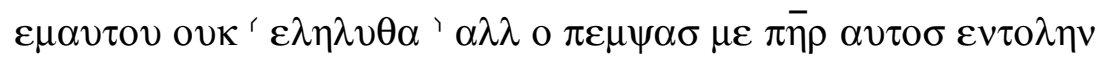
$\mu \mathrm{ol} \delta \varepsilon \delta \omega \kappa \varepsilon v \tau \mathrm{l} \varepsilon \mathrm{l} \pi \omega \kappa \alpha \mathrm{l}{ }^{\circ} \tau \mathrm{l} \lambda \alpha \lambda \eta \sigma \omega{ }^{50} \kappa \alpha \mathrm{l}$ ol $\delta \alpha$ o $\tau \mathrm{l} \eta \varepsilon v \tau \mathrm{\nu} \lambda \eta$

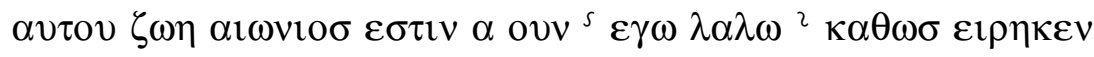
$\mu$ o о $\pi \bar{\eta} \rho$ ov $\tau \omega \sigma \lambda \alpha \lambda \omega$.

${ }^{2} \circ \mathrm{D}$ ! 565 ; txt rell. $\left.\mathfrak{M}\right|^{3}{ }^{\prime} \tau \alpha \iota \sigma \theta \rho 1 \xi i v \alpha v \tau \eta \sigma \alpha \pi \varepsilon \mu \alpha \xi \varepsilon v \quad \mathrm{~B}$

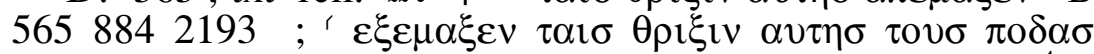

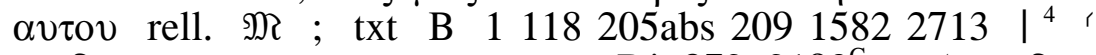

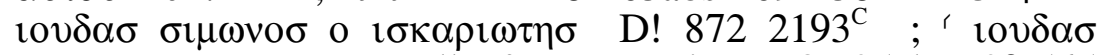

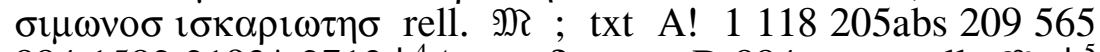
$\left.88415822193 * 2713\right|^{4}{ }^{4} \pi \alpha \rho \alpha \delta o v v \alpha 1$ D 884 ; txt rell. $\left.\mathfrak{N}\right|^{5}$

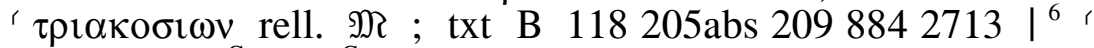
$\varepsilon \mu \varepsilon \lambda \varepsilon v \quad 872^{\mathrm{C}} 2193^{\mathrm{C}}$ rell. ; txt B-A 118131 205abs 209565

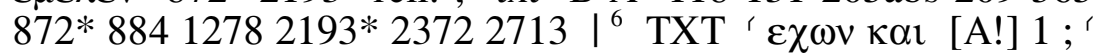

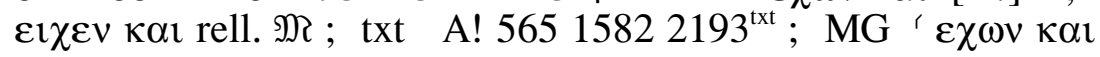


$2193^{\mathrm{mgvid}}$ (1) $\left.\right|^{12}{ }^{\mathrm{T}}$ o $2193^{\mathrm{C}}$ rell. $\mathfrak{N}$; txt B $\left.5658842193^{*}\right|^{13}$, $\alpha \pi \alpha \nu \tau \eta \sigma l v 2193^{\mathrm{C}} \mathrm{M}^{\mathrm{pt}}$; txt 2193* rell. $\left.\mathrm{M}^{\mathrm{pt}}\right|^{13} \mathrm{~T}$ El 2193*; txt $2193^{\mathrm{C}}$ rell. $\mathfrak{M}^{14^{14}}$ ' $\alpha v \tau \omega 2^{\text {vid }}$ rell. $\mathrm{M}^{\mathrm{pt}}$; txt 1118131 205abs $20956587215822713 \mathrm{M}^{\mathrm{pt}} \mid{ }^{15} \circ$ rell. $\mathfrak{M}$; txt B 565 $\left.884\right|^{16}{ }^{\mathrm{T}}$ o rell. $\mathrm{M}^{\mathrm{pt}}$; txt 122118 205abs 2095658721192 $\left.1582 \mathrm{M}^{\mathrm{pt}}\right|^{16}$ ' $\alpha v \varepsilon \mu v \eta \sigma \theta \eta \sigma \alpha \nu \mathrm{D} 884$; txt rell. $\mathfrak{N}$ | ${ }^{21}$, $\beta \eta \theta \sigma \alpha \iota \delta \alpha 2193 *$ rell. $\mathfrak{N}$; txt C $\left.2193^{\mathrm{C}}\right|^{22}$ ' $\phi \imath \lambda \iota \pi \circ \sigma \mathrm{D} ! 1$; txt rell. M ${ }^{26}{ }^{26} 2.1 .^{2}$ rell. $\mathfrak{M}$; txt C $\left.2193\right|^{28} \circ 1^{*} 1278^{\mathrm{C}}$ 2193* rell. $\mathfrak{N}$; txt B-A $\left.1^{\mathrm{C}} 1312193^{\mathrm{C}} 1278^{\text {vid }} 2372\right|^{28}$ TXT ' $\tau$ ov vv B-A! 1118 205abs $2092193^{\text {txt }}$; B-A! txt 1582

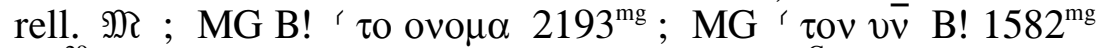
| ${ }^{29}$ ' $\varepsilon \sigma \tau \eta \kappa \omega \sigma \kappa \alpha \iota \alpha \kappa o v \sigma \alpha \sigma \quad \mathrm{C} 1312193^{\mathrm{C}}$; ' $\varepsilon \sigma \tau \omega \sigma \kappa \alpha \iota$

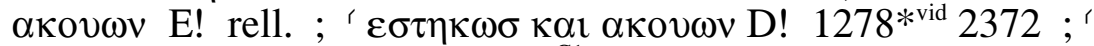
$\varepsilon \sigma \tau \omega \sigma \kappa \alpha \iota \alpha \kappa o v \sigma \alpha \sigma 8721278^{\mathrm{Cl}}$ 礼 ; txt A! 1 205abs 205 $20956588415822193 *$ vid ${ }^{39}$ ( $\pi \mathrm{i \sigma \tau \varepsilon v \varepsilon iv} \mathrm{rell.} \mathfrak{N}$; txt B

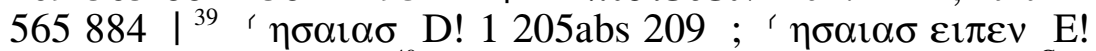
2713 ; txt rell. $\mathfrak{M} \mid{ }^{40}{ }^{4} \pi \varepsilon \pi \omega \rho \omega \kappa \varepsilon v$ rell. $\mathfrak{N}$; ' VID $2193^{\mathrm{C}}$;

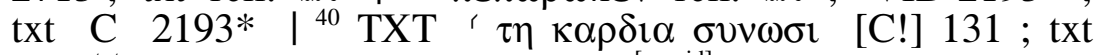
$2193^{\text {txt }}$ rell. $\mathfrak{M} ;$ [MG $^{\prime}$ VID $2193^{\text {[mgvid] }} ;$ MG ' $\tau \eta \kappa \alpha \rho \delta 1 \alpha$

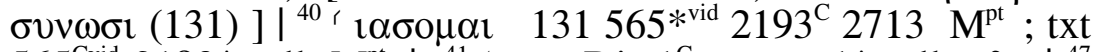

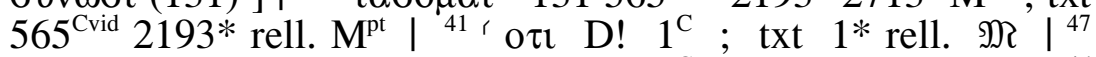
TXT ' $\pi$ เ $\tau \varepsilon v \sigma \eta 13187211931278^{\mathrm{C}} \mathfrak{M}$; txt A! $1278^{* v i d}$ $2193^{\mathrm{txt}}$ rell. ; MG ' VID 2193 ${ }^{\mathrm{mg}} ; \mathrm{MG}^{\prime} \pi \mathrm{i} \sigma \tau \varepsilon v \sigma \eta$ (131 872 $11921278^{\mathrm{C}}$ ) | ${ }^{49}$ ( $\varepsilon \lambda \alpha \lambda \eta \sigma \alpha$ rell. $\mathfrak{M}$; txt B $\left.565884\right|^{49} \circ \mathrm{D}$ ! $2193^{\mathrm{C}}$; txt $2193^{* \text { vid }}$ rell. N | ${ }^{50}{ }^{5} 2.1^{2} \mathrm{D}$ ! 221318721192 1278 2372; txt A! rell. I 


\section{Chapter 13}

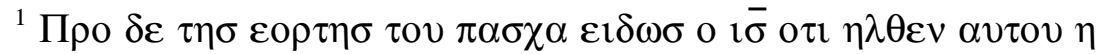

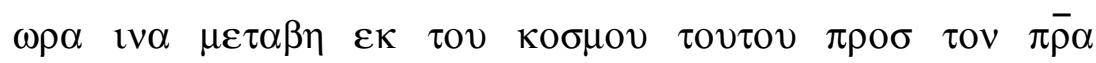

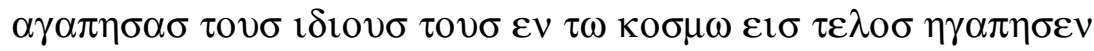

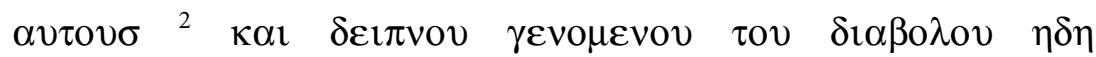

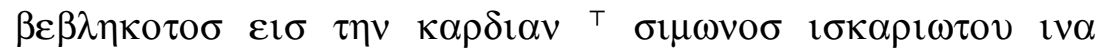
${ }^{s} \pi \alpha \rho \alpha \delta \omega \alpha v \tau o \nu^{2}{ }^{3} \varepsilon i \delta \omega \sigma$ o $\imath \bar{\sigma}$ o $\tau \imath \pi \alpha \nu \tau \alpha \varepsilon \delta \omega \kappa \varepsilon v \alpha v \tau \omega$ o $\pi \bar{\eta} \rho$

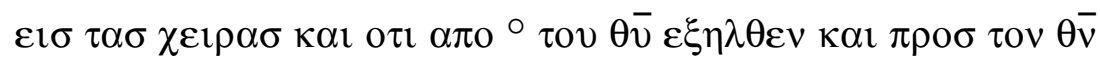

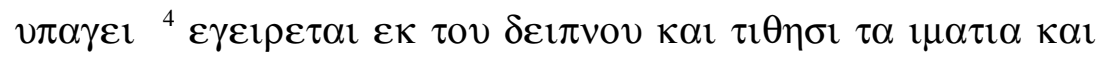

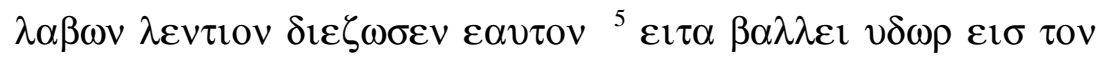

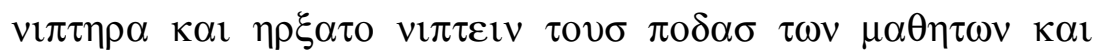
$\varepsilon \kappa \mu \alpha \sigma \sigma \varepsilon \imath \tau \tau \omega \lambda \varepsilon v \tau \imath \omega \omega \eta \nu \delta i \varepsilon \zeta \omega \sigma \mu \varepsilon v o \sigma{ }^{6} \varepsilon \rho \chi \varepsilon \tau \alpha \iota$ ovv $\pi \rho \circ \sigma$

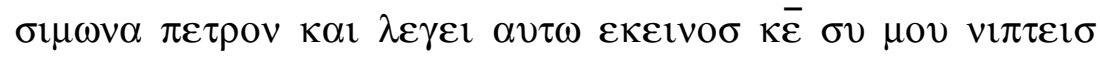

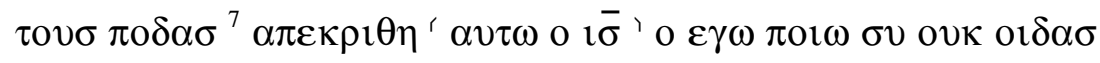
$\alpha \rho \tau \imath \gamma \nu \omega \sigma \eta \delta \varepsilon \mu \varepsilon \tau \alpha \tau \alpha v \tau \alpha{ }^{8} \lambda \varepsilon \gamma \varepsilon \imath \alpha v \tau \omega^{\prime}$ o $\pi \varepsilon \tau \rho \circ \sigma$ ' ov $\mu \eta$

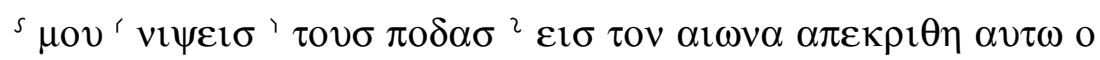

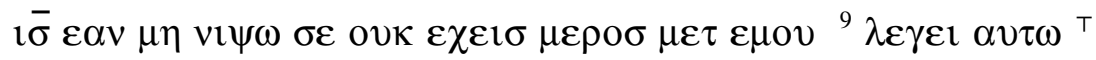

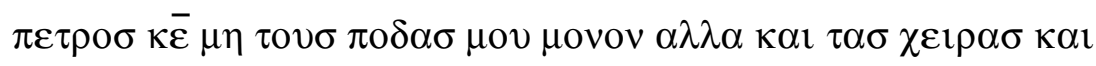

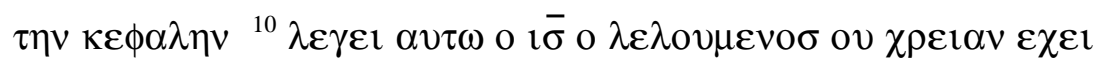

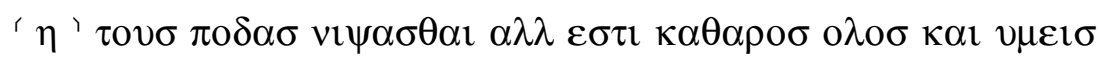

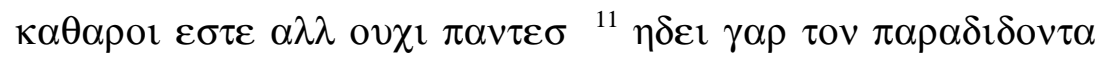

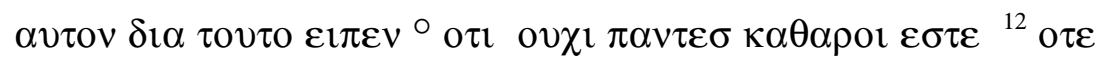

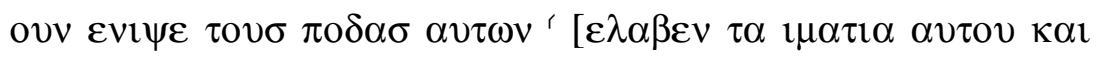

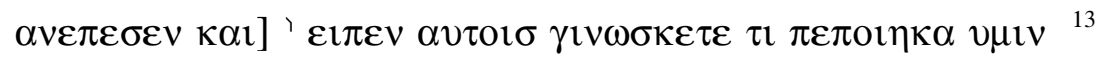

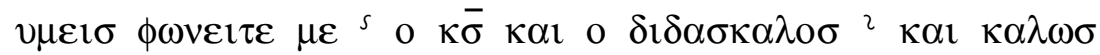

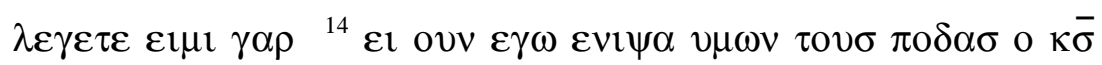

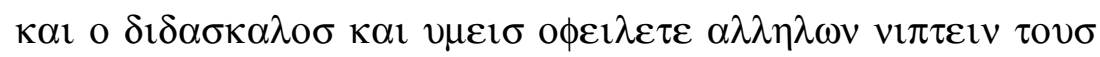

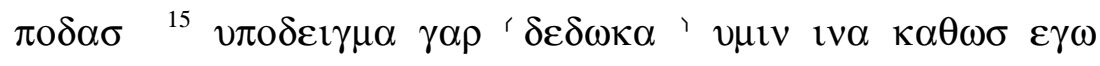

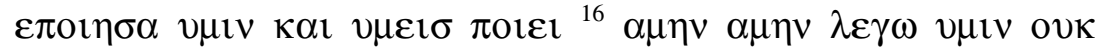

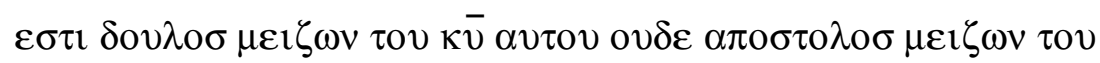

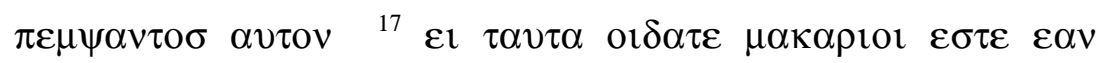

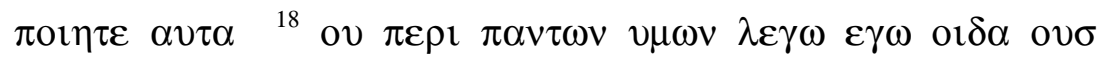
$\varepsilon \xi \varepsilon \lambda \varepsilon \xi \alpha \mu \eta \nu \alpha \lambda \lambda$ iv $\eta \gamma \gamma \rho \phi \eta \pi \lambda \eta \rho \omega \theta \eta$ o $\tau \rho \omega \gamma \omega v$ ' $\mu \varepsilon \tau \varepsilon \mu \mathrm{ov}$ ' 


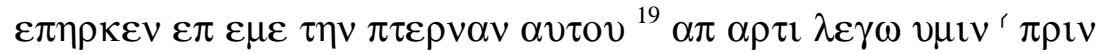

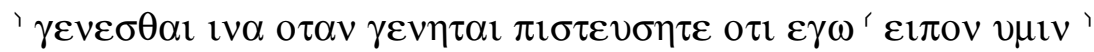

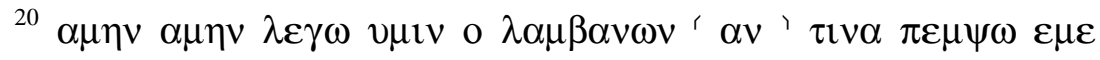

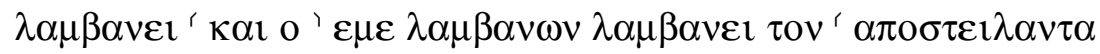

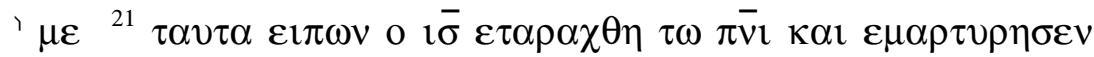

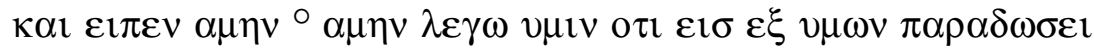

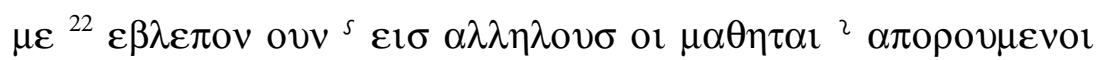

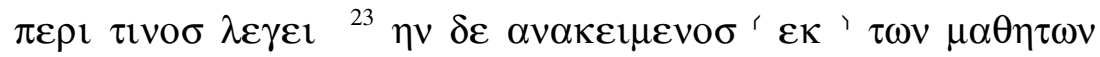

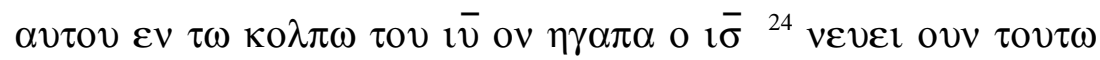
$\sigma \iota \mu \omega v \pi \varepsilon \tau \rho \circ \sigma \pi v \theta \varepsilon \sigma \theta \alpha \imath \tau \imath \sigma \alpha v \varepsilon ı \eta \pi \varepsilon \rho \imath$ ov $\lambda \varepsilon \gamma \varepsilon{ }^{25} \varepsilon \pi \imath \pi \varepsilon \sigma \omega v$

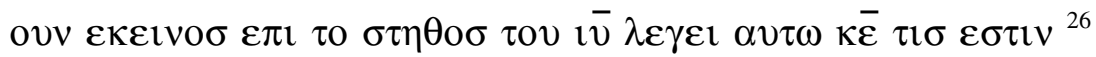

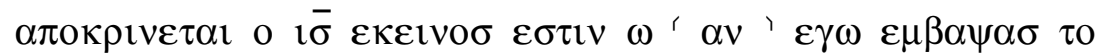

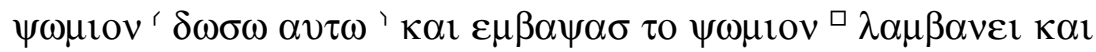

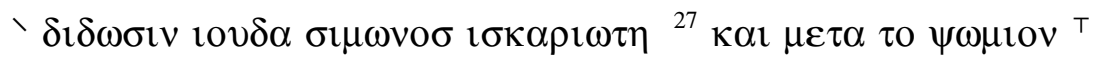

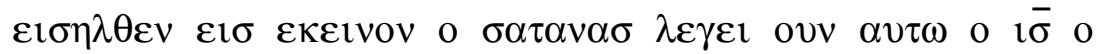

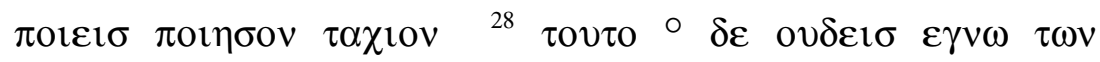

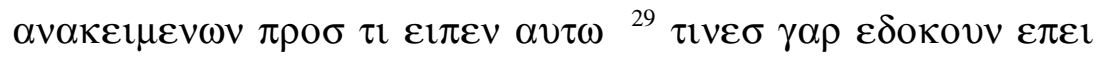

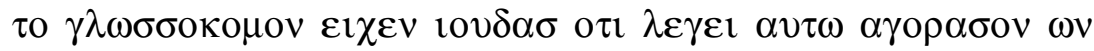

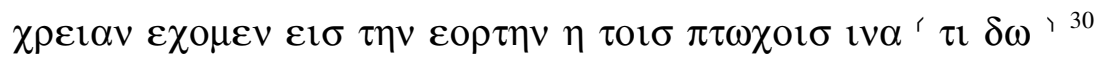

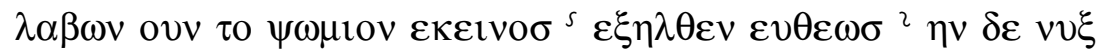

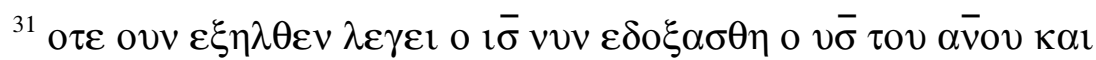

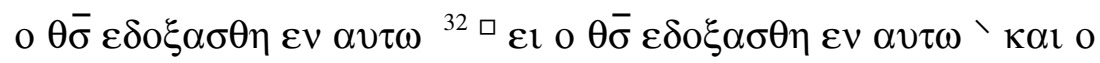

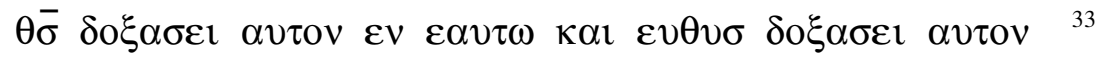

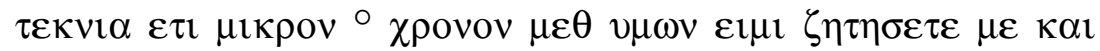

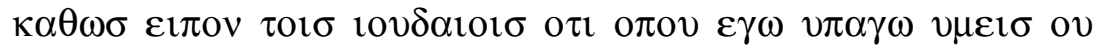

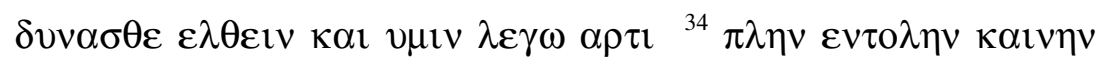

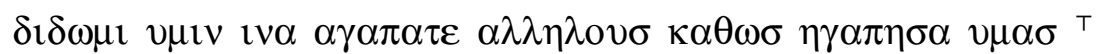

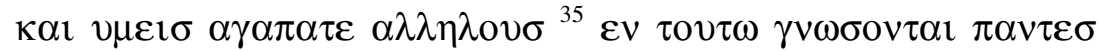

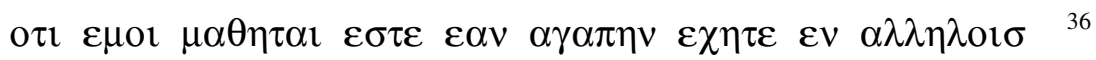

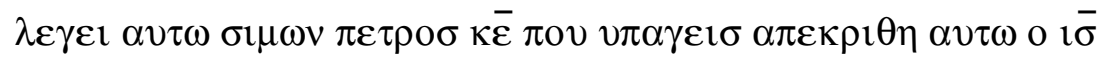
' o

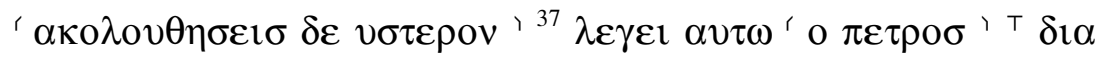

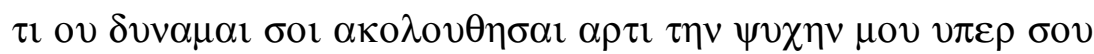

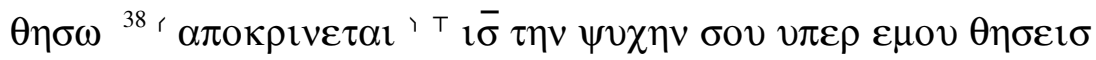




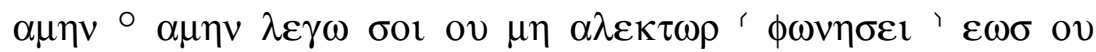
$\alpha \rho \vee \eta \sigma \eta \mu \varepsilon \tau \rho \imath \sigma$.

Lac. $\quad 872: 13: 16 \mathrm{~b}-$ end ; 565: 13:2b-13:23a.

${ }^{2}{ }^{\top}$ $\left.2193\right|^{3} \circ$ rell. $\mathfrak{M}$; txt B $\left.11182091582\right|^{7}{ }^{\prime}$ o $\iota \bar{\sigma} \kappa \alpha \iota \varepsilon \imath \pi \varepsilon \nu$ $\alpha v \tau \omega$ D 884 ; ' ${ }^{8}{ }^{1} \sigma \mu \omega \omega v \pi \varepsilon \tau \rho \circ \sigma \mathrm{D}$ ! $1278^{* \text { vid }} 2372$; ' $\pi \varepsilon \tau \rho \circ \sigma$ \% $1278^{\mathrm{C}}$ rell. $\mathfrak{M}$; txt C $\left.21932713\right|^{8}{ }^{5} 2.1 .3 .4 .^{2}$ C 2193 ; $2.3 .4 .1^{2}$ rell. $\mathfrak{M}$;

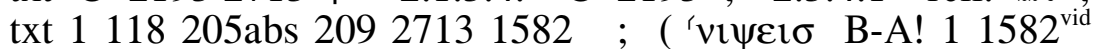
$2193^{\text {vid }}$; vi $\psi \eta \sigma$ rell. $\left.\mathfrak{N}\right)\left.\right|^{9}{ }^{\mathrm{T}} \sigma u \mu \omega \mathrm{v}$ rell. $\mathfrak{N}$; txt C $\left.2193\right|^{10}$ '[4] D! 2193*; ' om. E 131 ; txt $2193^{\mathrm{C}}$ rell. M| ${ }^{11}{ }^{\circ}$ rell.

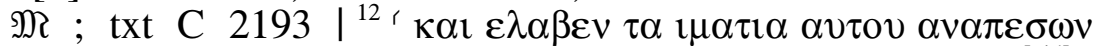

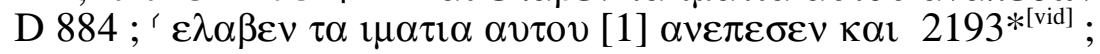

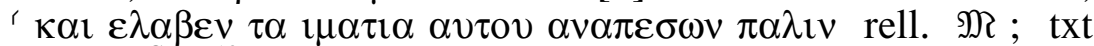
C! $\left.2193^{\mathrm{C}}\right|^{13}{ }^{5} 4.5 .3 .1 .2^{2}$ rell. $\mathfrak{M}$; txt C-B 127821932372 ।

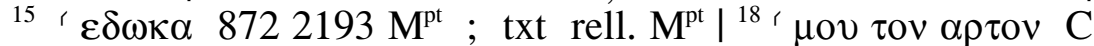
2193 ; ' $\mu \varepsilon \tau \varepsilon \mu$ ov $\tau$ ov $\alpha \rho \tau$ ov rell. $\mathfrak{M}$; txt A! 1118 205abs

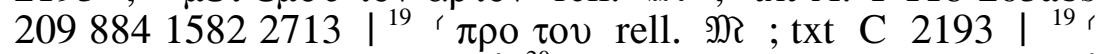
$\varepsilon 1 \mu$ rell. $\mathfrak{N}$; txt C $2193 \mid{ }^{20}$ ' $\varepsilon \alpha v$ rell. $\mathfrak{M}$; txt C 2193 | ${ }^{20}$ ' o $\delta \varepsilon$ rell. $\mathfrak{M}$; txt C $\left.2193\right|^{20}{ }^{20} \pi \varepsilon \mu \psi \alpha \nu \tau \alpha$ rell. $\mathfrak{N}$; txt $\mathrm{B}$ 1118 205abs $\left.20915822713\right|^{21} \circ \mathrm{D}$ ! 2193; txt rell. $\mathfrak{M} \mid{ }^{22}$ 33.4.1.2. ${ }^{2} \mathrm{D} 884$; txt rell. $\mathfrak{N} \mid{ }^{23}$ ' $\varepsilon 1 \sigma$ rell. $\mathfrak{N}$; txt C 131 $\left.2193\right|^{26}$ ' $\varepsilon \alpha \nu$ D 884 ; ' om. rell. N ; txt A 1118 205abs $\left.20956515822713\right|^{26}$ < $\varepsilon \pi 1 \delta \omega \sigma \omega 2193^{\mathrm{C}}$ rell. $\mathfrak{M}$; txt C $\left.2193 *\right|^{26} \square 2193^{\mathrm{C}}$ rell. $\mathfrak{N}$; txt C $\left.2193^{*}\right|^{27}$ T $\tau$ o $\tau \varepsilon$ rell. $\mathfrak{N}$; txt B $884565 \mid{ }^{28} \circ \mathrm{D} ! 2193^{*}$; txt $2193^{\mathrm{C}}$ rell. $\mathfrak{N} \mid{ }^{29}<\delta \omega$ D $884 ; ' \delta \omega \tau \mathrm{l}$ E 131 ; txt rell. $\mathfrak{N} \mid{ }^{30}{ }^{5} 2.1^{2}$ rell. $\mathfrak{N}$; txt C $\left.2193\right|^{32} \square$ D! 1 ; txt rell. $\left.\mathfrak{N}\right|^{33} \circ$ rell. $2193^{\mathrm{C}} 2713^{\mathrm{C}} \mathfrak{M}$; txt B-A 118 205abs 209 2193*2713* | ${ }^{34}$ T $t v \alpha 2193 *$ rell. $\mathfrak{N}$; txt C 2193' ; (DEF 884)| ${ }^{36}$ TXT' o

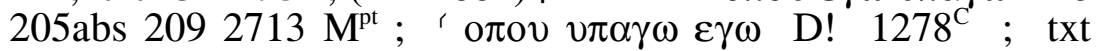

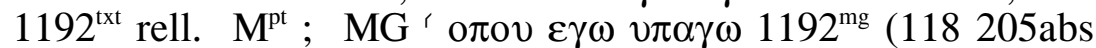
$2092713)\left.\right|^{36}$ ' $\delta \varepsilon \alpha \kappa о \lambda о \nu \theta \eta \sigma \varepsilon 1 \sigma \mu$ or $2193^{\mathrm{C}}$ rell. $\mathfrak{N}$; txt A 15658841582 | ${ }^{37}$ ' om. D $221192 * 1278 * 2372 ; \pi \varepsilon \tau \rho o \sigma \quad 1192^{\mathrm{C}} 1278^{\mathrm{C} 1}$ $2193^{\mathrm{C}}$ rell. $\mathfrak{M}$; txt A! $12193 * 1582{ }^{37} \mathrm{~T} \kappa \bar{\varepsilon}$ rell. $\mathfrak{M}$; txt $\mathrm{C}$ $\left.565\right|^{38}{ }^{\prime} \alpha \pi \varepsilon \kappa \rho \imath v \varepsilon \tau \alpha \iota \mathrm{D} ! 1 ;{ }^{\prime} \alpha \pi \varepsilon \kappa \rho \imath \theta \eta$ rell. $\mathfrak{N}$; txt A 118 205abs $\left.20956588415822713\right|^{38}{ }^{\top} \alpha v \tau \omega$ o rell. $\mathfrak{N}$; ${ }^{\top}$ o D! 118 205abs 2092713 ; txt C 2193| ${ }^{38} \circ$ o D! 2193; txt rell. M | ${ }^{38}$ ' $\phi \omega v \eta \sigma \eta ~ 118^{* \text { vid }}$ rell. $\mathrm{M}^{\mathrm{pt}}$; ' VID 1582 ; txt $1118^{\mathrm{C}}$ $2193 \mathrm{M}^{\mathrm{pt}} \mid$ 


\section{Chapter 14}

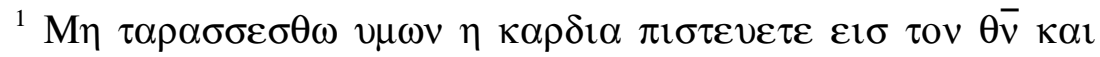

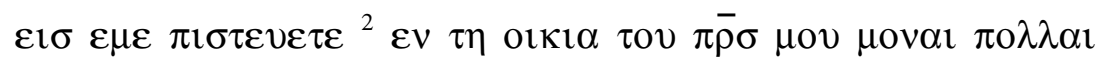

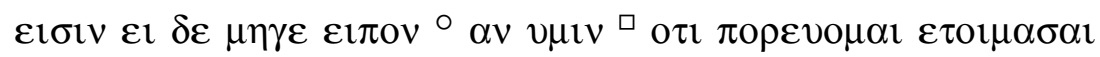

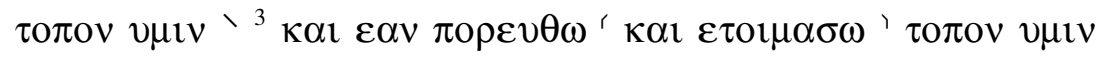

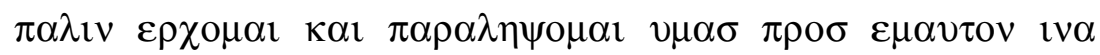

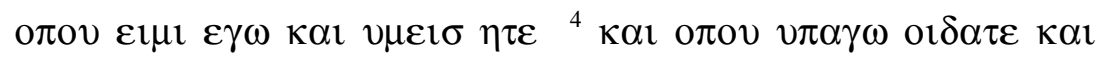

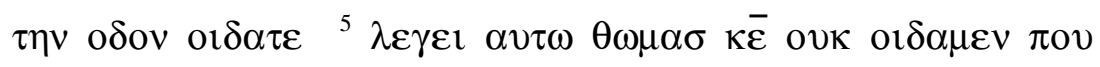

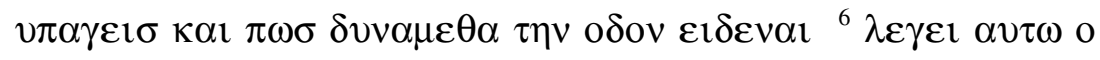

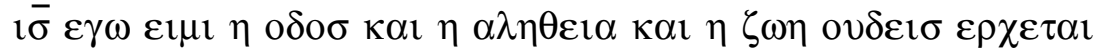

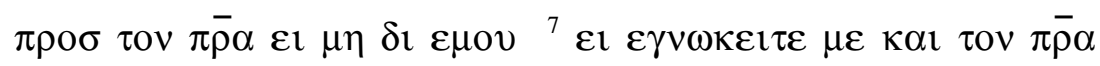

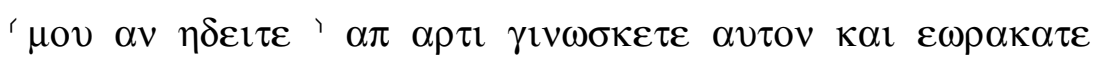

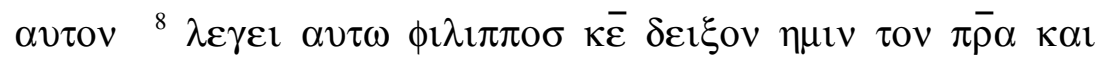

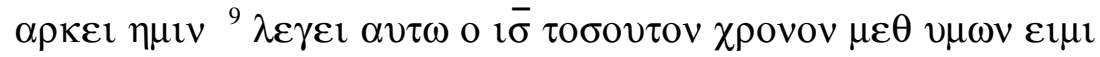

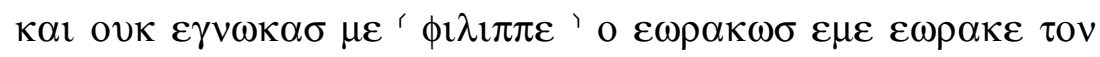

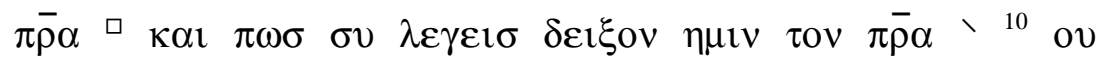

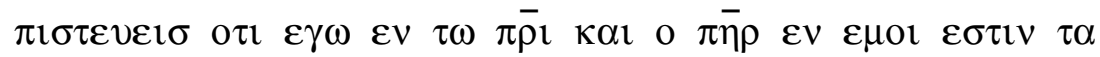

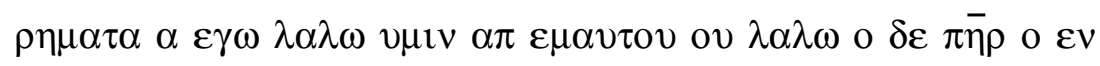

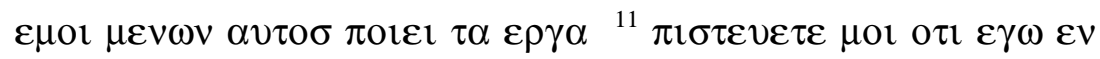

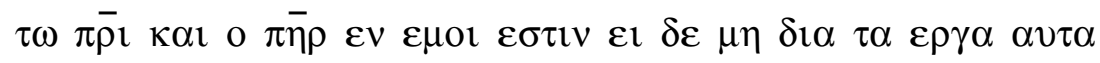

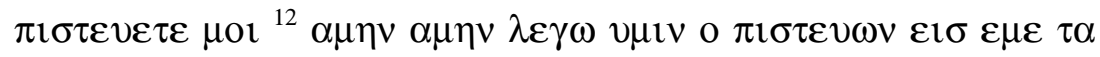

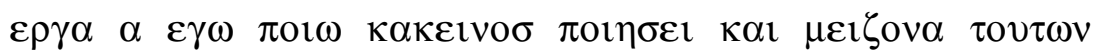

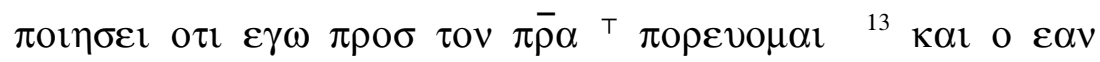

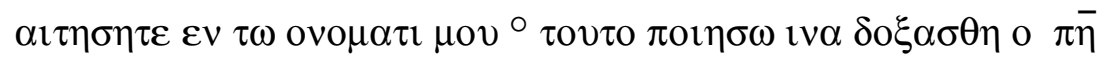
$\rho \varepsilon v \tau \omega v i \omega{ }^{14}$ om. ${ }^{15} \varepsilon \alpha \nu \alpha \gamma \alpha \pi \alpha \tau \varepsilon^{\prime} \mu o v{ }^{\prime} \varepsilon v \tau o \lambda \alpha \sigma \tau \alpha \sigma \varepsilon \mu \alpha \sigma$

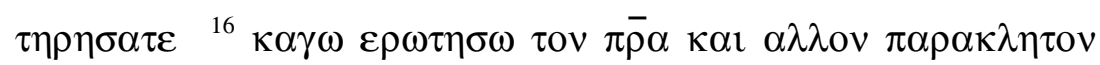

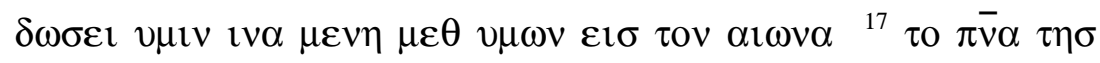

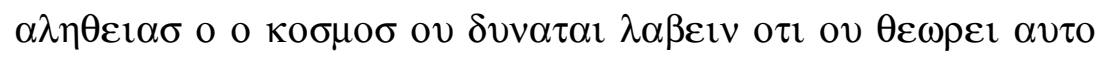

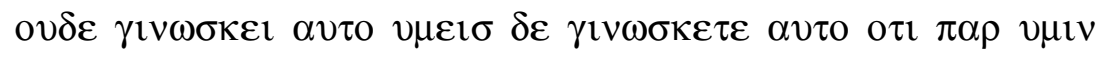

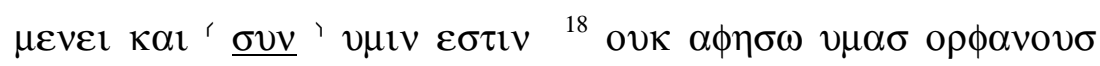

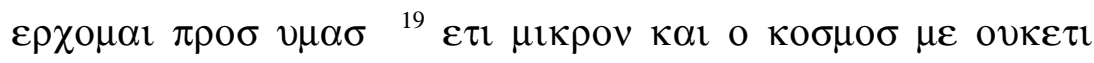

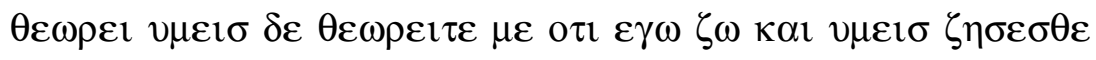

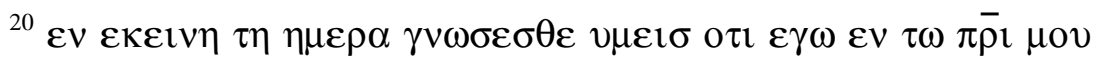




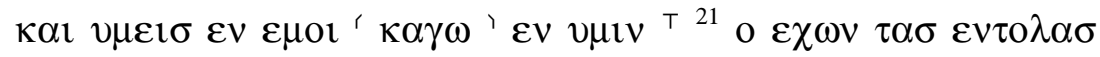

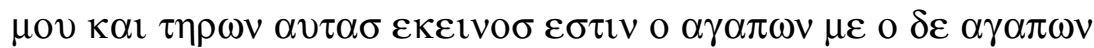

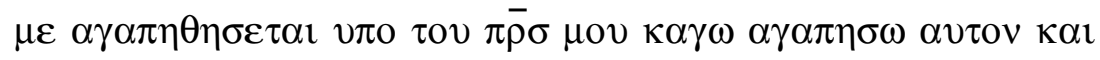

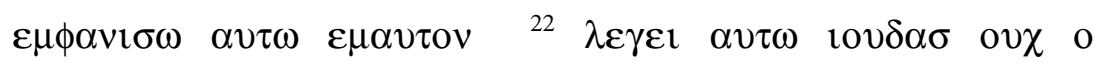

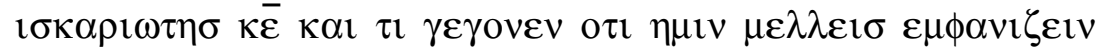

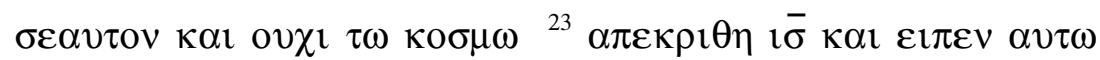

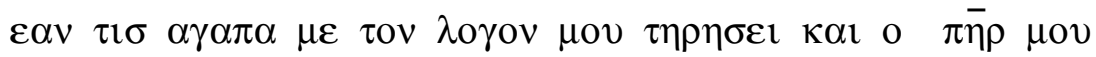

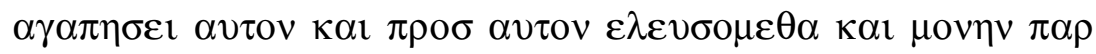

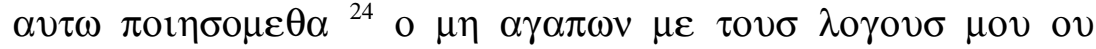

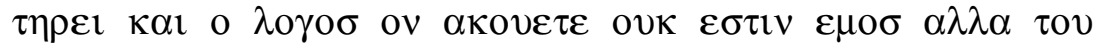

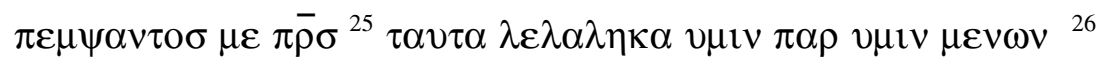

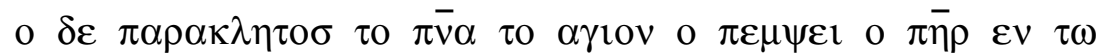

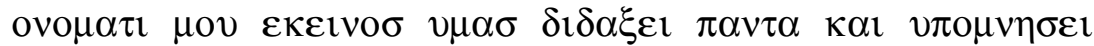

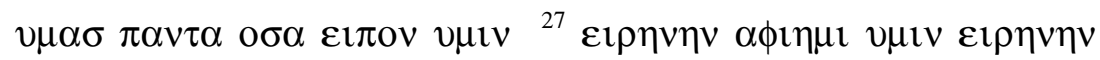

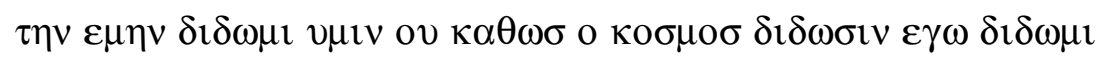

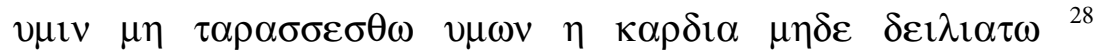

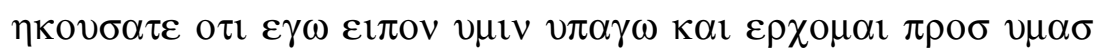

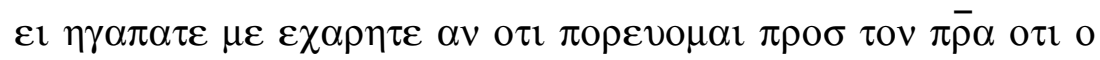

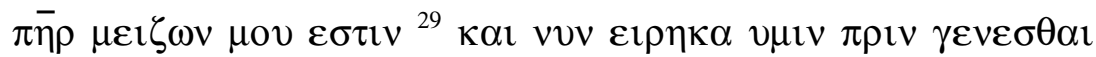

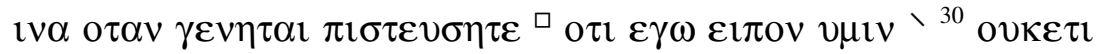

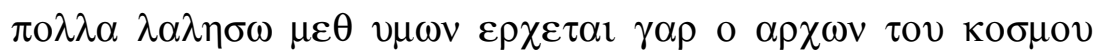

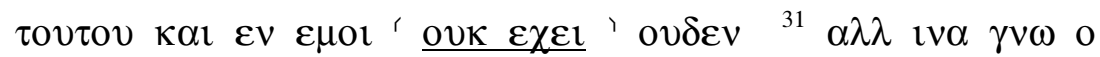

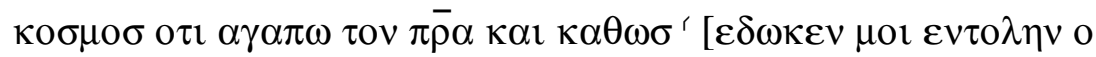

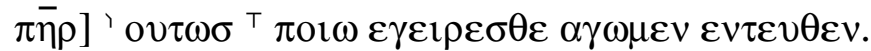

Lac. $\quad 22: 14: 22 b-16: 27 b ; 872:$ all.

${ }^{2 \circ} \mathrm{D}$ ! $2193^{*} ;$ txt $2193^{\mathrm{C}}$ rell. $\left.\mathfrak{M}\right|^{2} \square \mathrm{D}$ ! 1 ; txt rell. $\left.\mathfrak{M}\right|^{3}$, $\varepsilon \tau 01 \mu \alpha \sigma \omega \quad 1315658841278 * \mathrm{M}^{\mathrm{pt}} ;{ }^{\prime} \varepsilon \tau \mathrm{O} \mu \mu \alpha \sigma \alpha \mathrm{l} \quad 2372 \mathrm{M}^{\mathrm{pt}}$; txt $1278^{\mathrm{C}}$ rell. $\left.\mathrm{M}^{\mathrm{pt}}\right|^{7}{ }^{\prime} \mu \mathrm{ov} \alpha \nu \eta \delta \eta \tau \varepsilon$ C 565 ; ' $\mu$ ov $\varepsilon \gamma \nu \omega \kappa \eta \tau \varepsilon$ $\alpha \nu$ E 118 205abs 2092713 ; ' $\mu$ ov $\eta \delta \varepsilon \imath \tau \varepsilon \alpha \nu$ D 2211921210 2372 ; ' $\mu$ ov $\varepsilon \gamma \nu \omega \kappa \varepsilon 1 \tau \varepsilon$ ov $1278^{\mathrm{C} 1}$ rell. $\mathfrak{N}$; txt B $\left.11582\right|^{9}$ ' $\phi 1 \lambda \pi \pi \varepsilon$ D! 1 ; txt rell. $\left.\mathfrak{N}\right|^{9} \square \mathrm{D}$ ! 565 ; txt rell. NR $\left.\right|^{12}{ }^{13}$

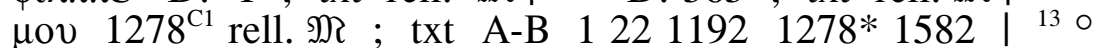
D! 2193 ; txt rell. $\mathfrak{N} \mid{ }^{15}$ ( $\tau \alpha \sigma \varepsilon \mu \alpha \sigma$ rell. $\mathfrak{N}$; txt B-A 118 205abs $\left.2092193\right|^{17}$ TXT ' $^{\prime} \varepsilon v$ rell. $\mathfrak{M}$; txt A! $18841582^{\mathrm{txt}}$; $\left.\mathrm{MG}^{\prime} \varepsilon v 1582^{\mathrm{mg}}\right|^{20}{ }^{2} \kappa \alpha \mathrm{l} \varepsilon \gamma \omega \mathrm{D} 22131119212782372$; txt 
rell. $\mathfrak{M R ~ | ~}{ }^{20}{ }^{\top} \kappa \alpha \theta \omega \sigma \alpha \pi \varepsilon \sigma \tau \alpha \lambda \kappa \varepsilon v \mu \varepsilon$ o $\pi \alpha \tau \eta \rho ~ \kappa \alpha \gamma \omega \alpha \pi \sigma \sigma \tau \varepsilon \lambda \lambda \omega$

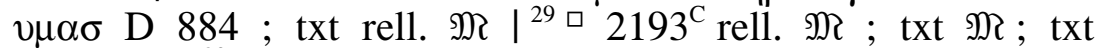
C 2193* ${ }^{30}$ TXT ' $\varepsilon v \rho \eta \sigma \varepsilon 1 ~[A !] ~ 131 ; ~ t x t ~ 21933_{-}^{\text {txt }}$ rell. MR ;

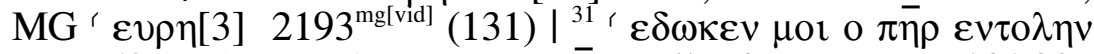
B 11582 ; ' $\varepsilon v \varepsilon \tau \varepsilon 1 \lambda \alpha \tau$ o

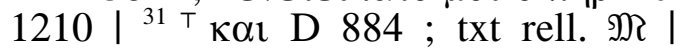




\section{Chapter 15}

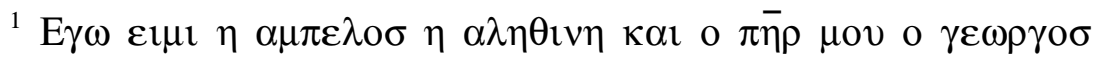

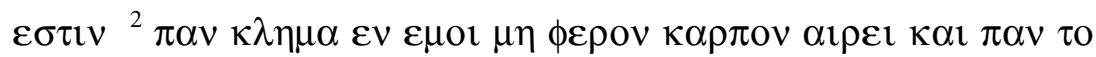

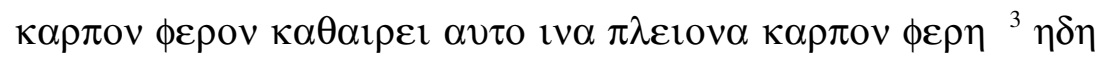

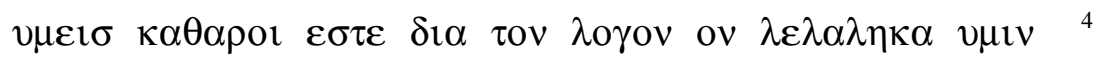

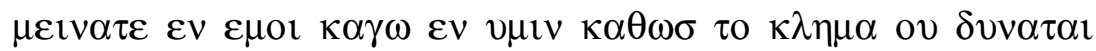

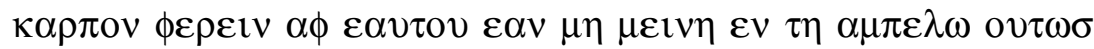

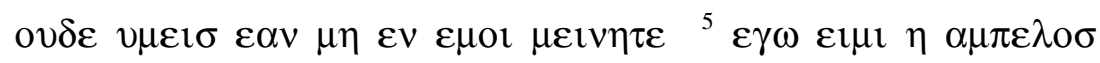

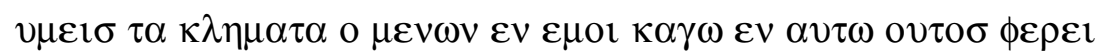

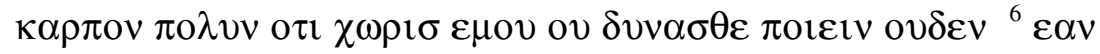

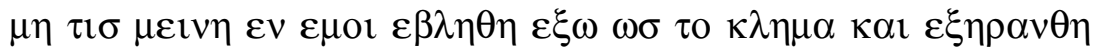

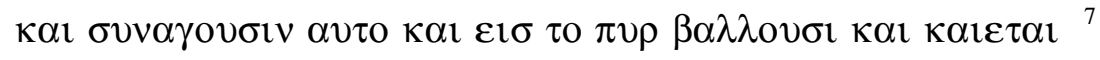

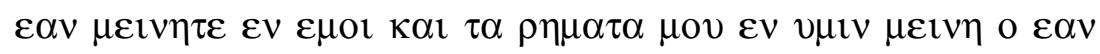

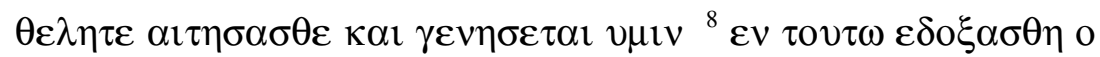

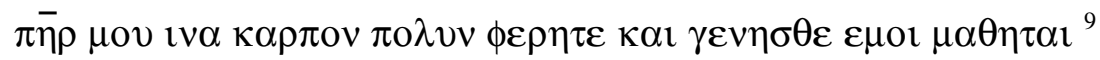

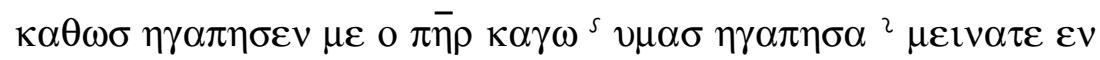
$\tau \eta \alpha \gamma \alpha \pi \eta \tau \eta \varepsilon \mu \eta{ }^{10} \varepsilon \alpha \nu \tau \alpha \sigma \varepsilon v \tau \sigma \lambda \alpha \sigma \mu \rho v \tau \eta \rho \eta \sigma \eta \tau \varepsilon \mu \varepsilon v \varepsilon \imath \tau \varepsilon \varepsilon v$

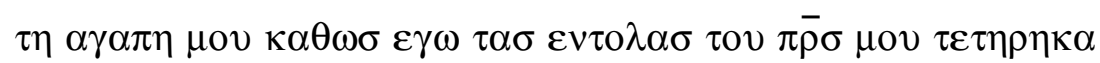

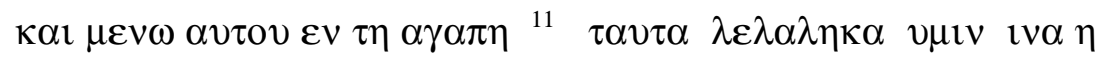
$\chi \alpha \rho \alpha \eta \varepsilon \mu \eta \varepsilon v^{\prime} v \mu \mathrm{tv}$ ' ' $\eta$ ' $\kappa \alpha \iota \eta \chi \alpha \rho \alpha v \mu \omega v \pi \lambda \eta \rho \omega \theta \eta{ }^{12} \alpha v \tau \eta$ $\varepsilon \sigma \tau \iota \nu \eta \varepsilon v \tau o \lambda \eta \eta \varepsilon \mu \eta \mathrm{\imath v} \alpha \alpha \gamma \alpha \pi \alpha \tau \varepsilon \alpha \lambda \lambda \eta \lambda \mathrm{ov \sigma} \kappa \alpha \theta \omega \sigma \eta \gamma \alpha \pi \eta \sigma \alpha$

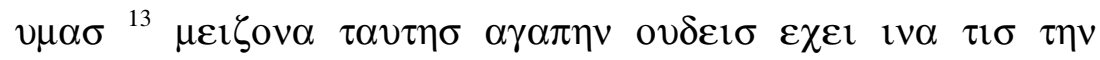

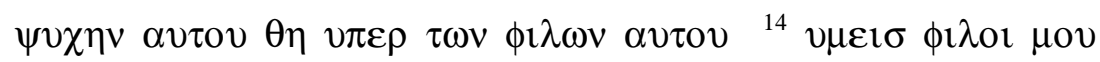

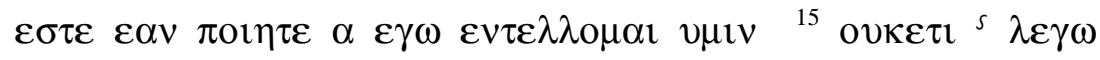

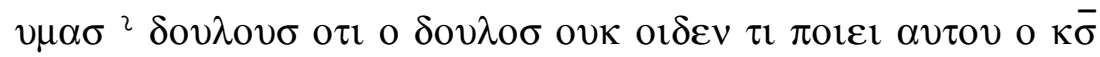

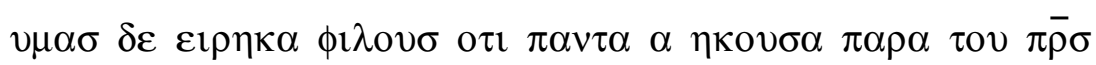

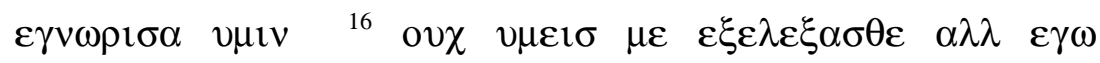

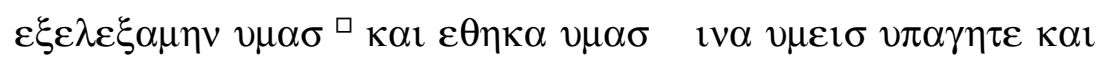

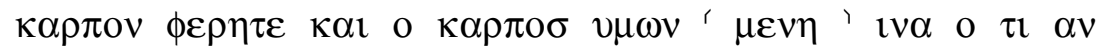

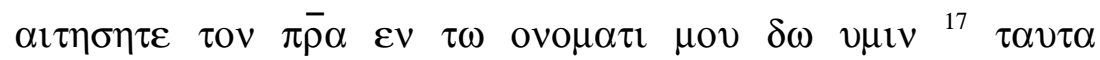

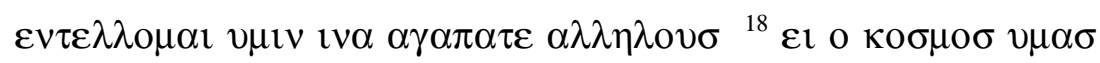

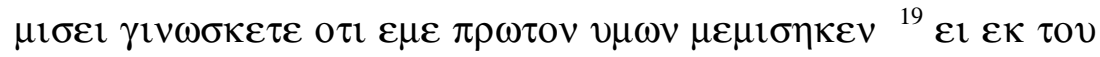

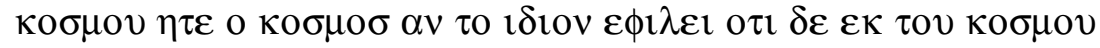




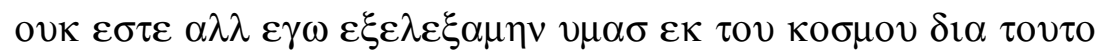

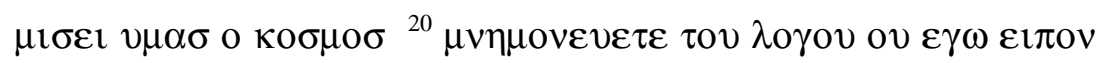

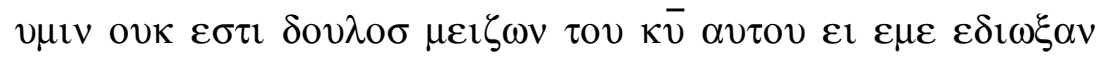

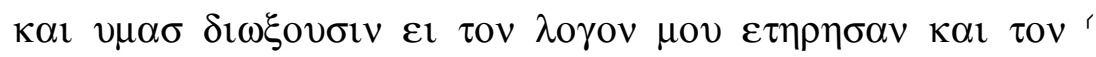

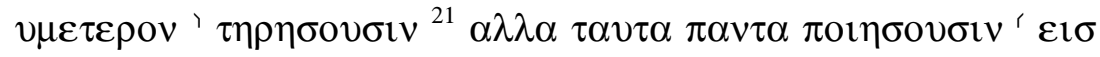

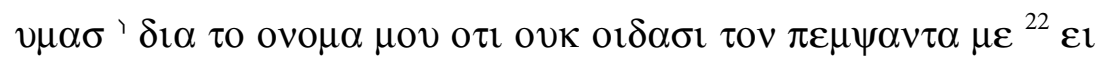

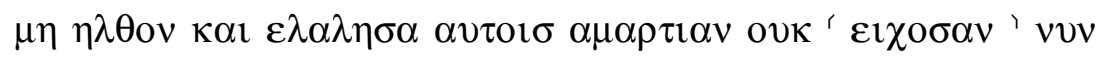

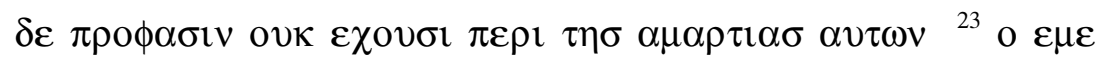

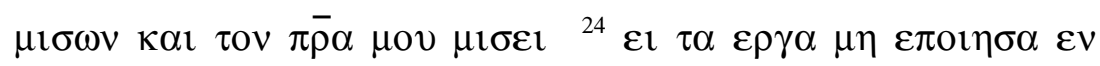

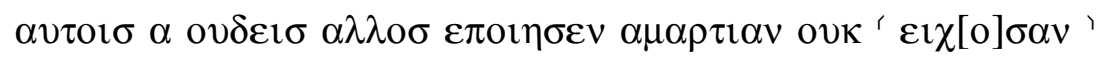

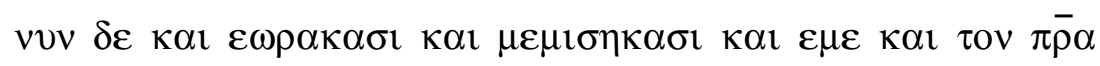

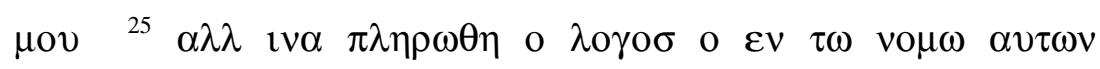
$\gamma \varepsilon \gamma \rho \alpha \mu \mu \varepsilon v о \sigma$ o $\tau \imath \varepsilon \mu 1 \sigma \eta \sigma \alpha \nu \mu \varepsilon \delta \omega \rho \varepsilon \alpha \nu{ }^{26}$ o $\tau \alpha \nu \delta \varepsilon \varepsilon \lambda \theta \eta \mathrm{o}$

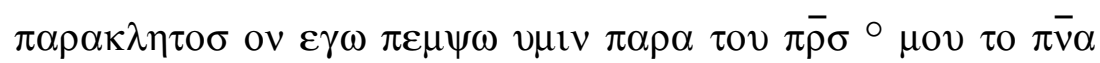

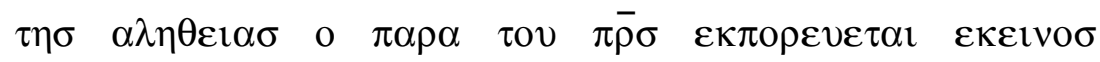

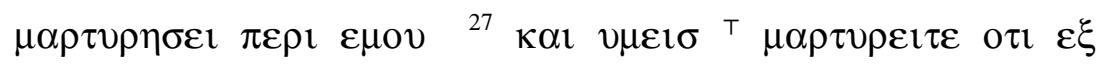
$\alpha \rho \chi \eta \sigma \mu \varepsilon \tau \varepsilon \mu о v \varepsilon \sigma \tau \varepsilon$.

Lac. $\quad 22:$ all ; 872 all.

${ }^{9}{ }^{5} 2.1^{2}$ rell. $\mathfrak{N}$; txt B $\left.11582\right|^{11}$ ‘ $\eta \mu \mathrm{tv}$ D! 1 ; txt rell. $\mathfrak{N}$ । ${ }^{11}$ TXT ' $\mu \varepsilon \imath v \eta$ rell. $\mathfrak{N}$; txt A! $156588415822193^{\text {txt }}$; MG ${ }^{\prime}$ $\left.\mu \varepsilon \downarrow v \eta 2193^{\mathrm{mg}}\right|^{15}{ }^{5} 2.1 .^{2}$ rell. NR ; txt C 2193| ${ }^{16 \square} \mathrm{D}$ ! 565 ; txt rell. $\mathfrak{N} \mid{ }^{16}{ }^{1} \mu \varepsilon v \eta 1192^{\mathrm{C}}$ rell. $\mathfrak{N}$; ' $\mu \varepsilon v \varepsilon \mathrm{E} 1192 *$; txt

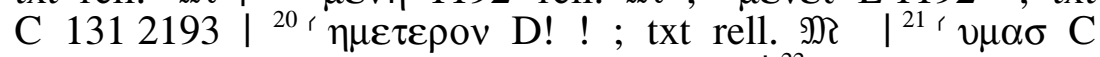

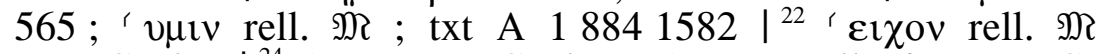
; txt C-B! $\left.1\right|^{24}$ ' $\varepsilon \imath \chi \omega \sigma \alpha \nu \mathrm{C}-\mathrm{B} ! 1$; ' $\varepsilon \imath \chi \sigma \nu$ rell. $\mathfrak{N}$; txt CB! $\left.565\right|^{26} \circ$ rell. $\mathfrak{N}$; txt $\left.\mathrm{C} 2193\right|^{27}{ }^{27} \delta \varepsilon$ rell. $\mathfrak{M}$; txt $\mathrm{B}$ 565884 । 


\section{Chapter 16}

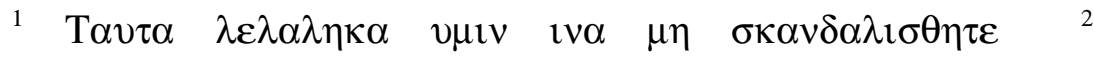

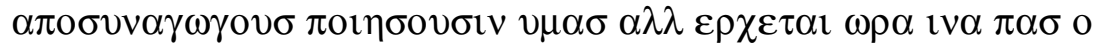

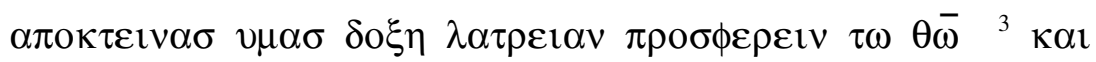

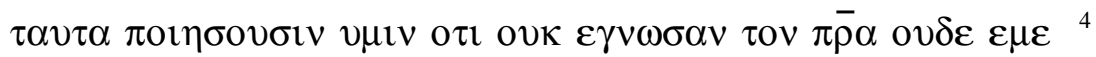

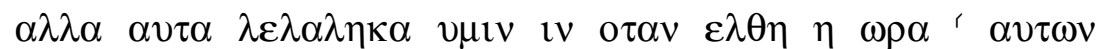

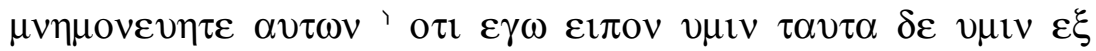

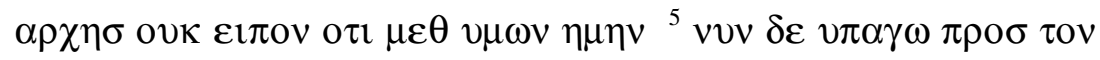

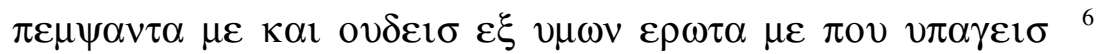

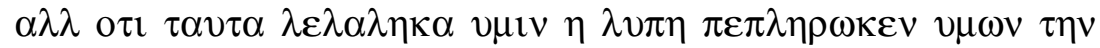

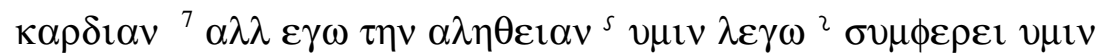

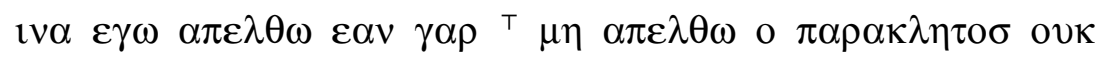

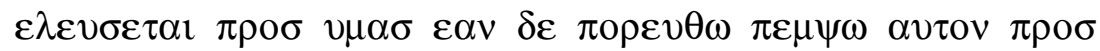

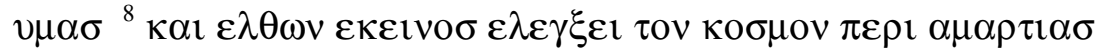

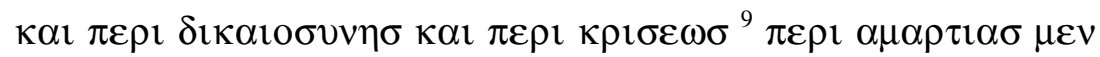

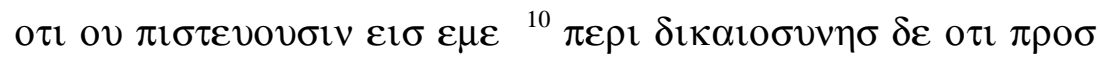
$\tau$ ov $\pi \bar{\rho} \alpha{ }^{\top} v \pi \alpha \gamma \omega \kappa \alpha l^{\prime}$ ov ' $\theta \varepsilon \omega \rho \varepsilon \imath \tau \varepsilon \mu \varepsilon{ }^{11} \pi \varepsilon \rho \imath \delta \varepsilon \kappa \rho \imath \sigma \varepsilon \omega \sigma$

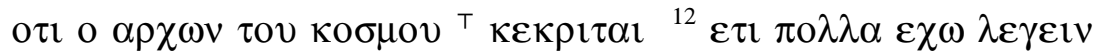

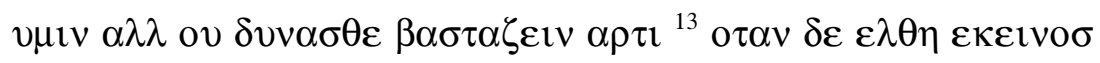

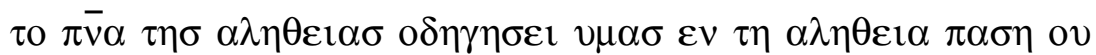

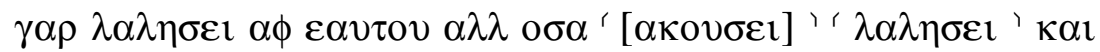

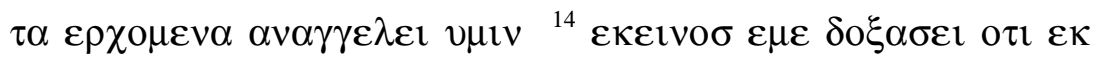

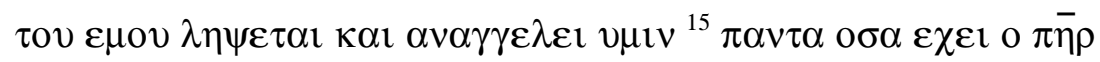

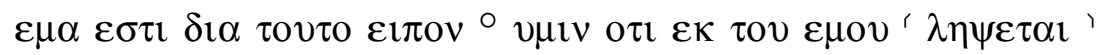

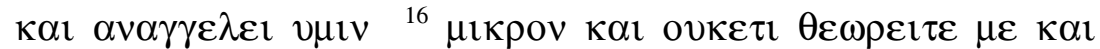

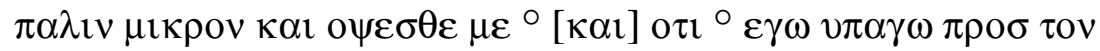

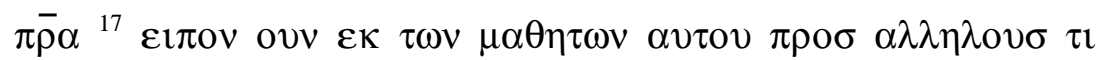

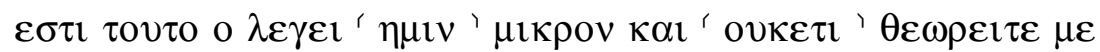

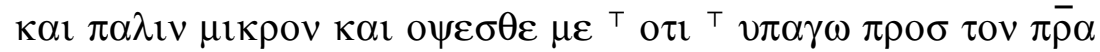

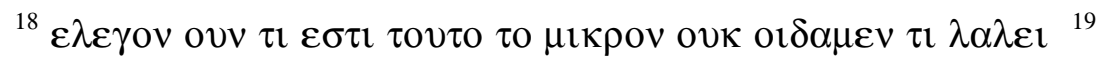

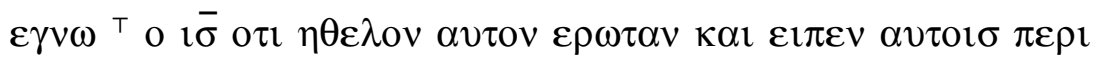

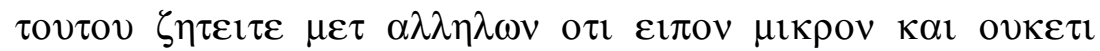

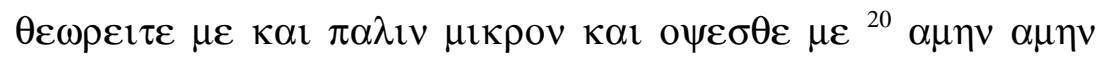




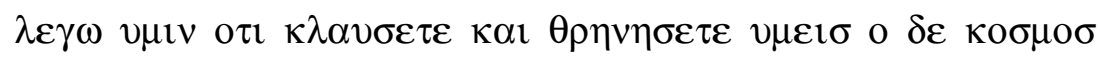

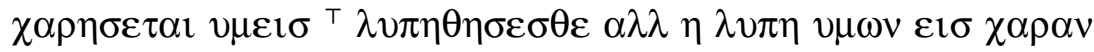
$\gamma \varepsilon v \eta \sigma \varepsilon \tau \alpha{ }^{21} \eta \gamma v v \eta$ o $\tau \alpha \nu \tau \iota \kappa \tau \eta \lambda \nu \pi \eta v \varepsilon \chi \varepsilon l$ o $\tau \imath \eta \lambda \theta \varepsilon v \eta \omega \rho \alpha$

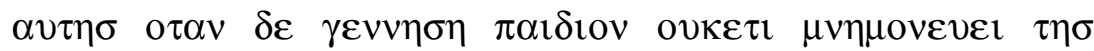

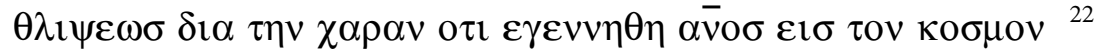

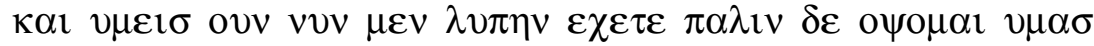

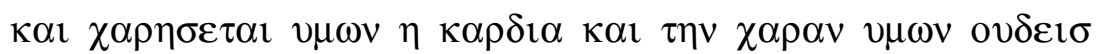
$\alpha \iota \rho \varepsilon \imath \alpha \phi v \mu \omega \nu{ }^{23} \kappa \alpha \iota \varepsilon v \varepsilon \kappa \varepsilon \imath \nu \eta \tau \eta \eta \mu \varepsilon \rho \alpha \varepsilon \mu \varepsilon$ о ${ }^{23} \varepsilon \rho \omega \tau \eta \sigma \varepsilon \tau \varepsilon$

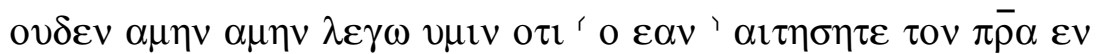

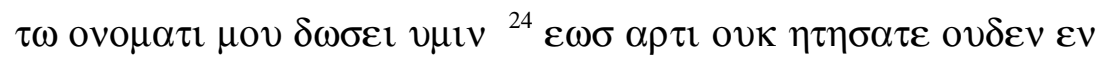

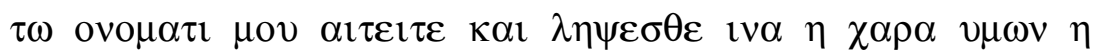

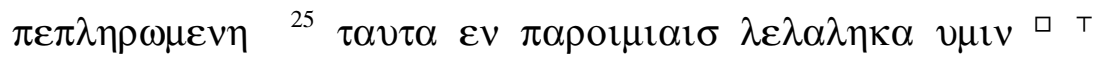

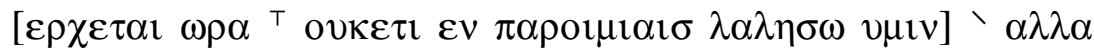

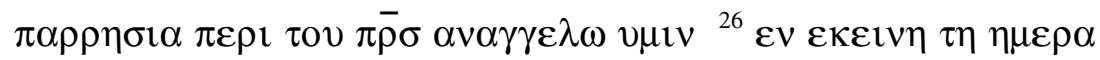

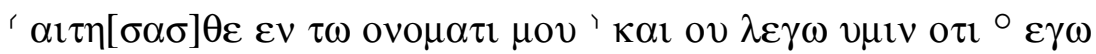

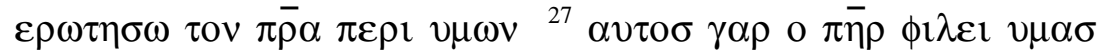

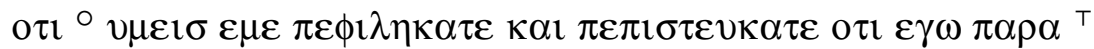

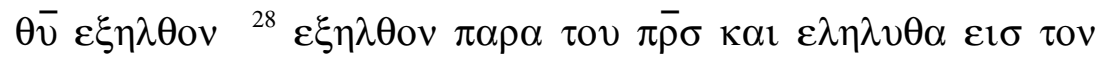

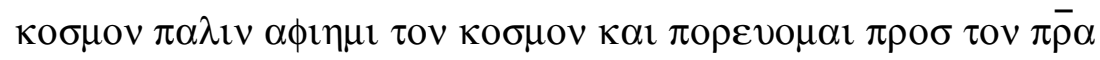

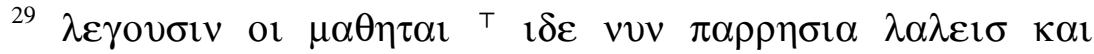

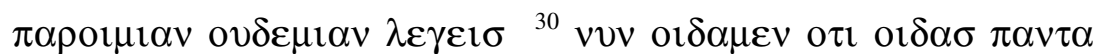

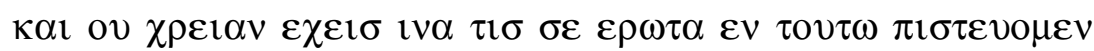

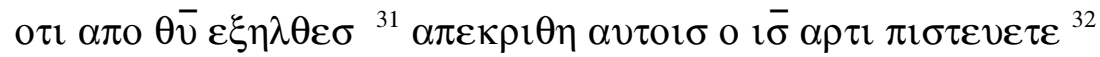

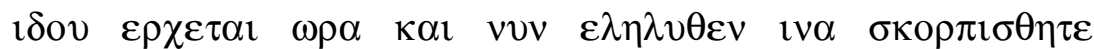

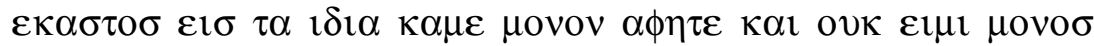

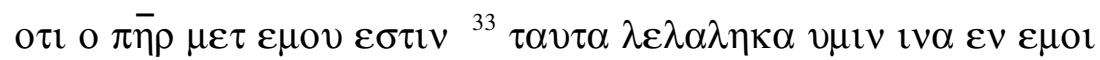

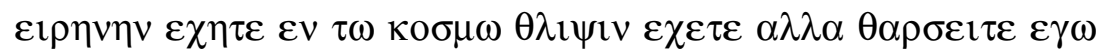

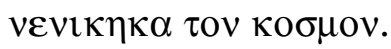

Lac. $\quad$ 872: all ; 22: 16:1-27b ; 118: 16:25b-end.

Suppl. $118^{\text {sup }}: 16: 25 \mathrm{~b}-$ end.

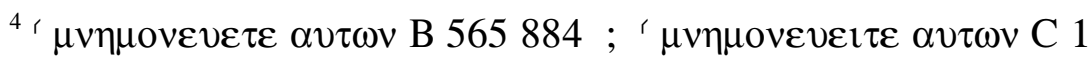

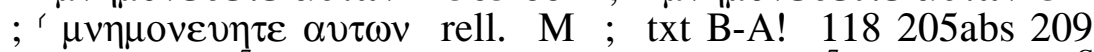
$\left.21932713\right|^{7}{ }^{5} 2.1^{2}$ rell. $\mathfrak{N}$; txt C $\left.2193\right|^{7 \mathrm{~T}} \varepsilon \gamma \omega 1582^{\mathrm{C}}$ 
rell. N ; txt B $\left.11582^{*}\right|^{10}{ }^{\top} \mu$ ov $1582^{\mathrm{C}}$ rell. N ; txt B 1

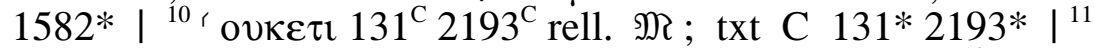

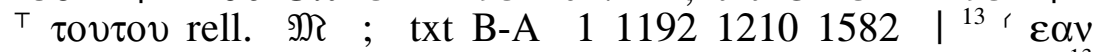

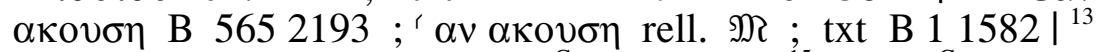
' $\lambda \alpha \lambda \eta \sigma \eta \mathrm{D}$ ! $2193^{*}$; txt $2193^{\mathrm{C}}$ rell. $\left.\mathfrak{M}\right|^{15} \circ 2193^{\mathrm{C}}$ rell. $\mathfrak{N}$ ; txt B-A 118 205abs $\left.2092193^{*} 2713\right|^{15}$ ' $\lambda \alpha \mu \beta \alpha v \varepsilon r$ rell. N ; txt C $\left.1312193\right|^{16} \circ$ rell. $\mathfrak{M}$; txt D-C $\left.8841210\right|^{16}$ 。 rell. $\mathfrak{N}$; txt C $\left.88411921210\right|^{17}$ r om. D $12101278 * 2372$; ' vutv E 205abs ; txt $1278^{\mathrm{Cl}}$ rell. $\left.\mathfrak{M}\right|^{17}$ ' ov rell. $\mathfrak{N}$; txt C$\left.\mathrm{B} ! 1582\right|^{17} \mathrm{~T}^{\mathrm{T}}$ kat $1278^{\mathrm{C} 1}$ rell. $\mathfrak{N}$; txt C-B 118 205abs 209 $\left.1278 * 23722713\right|^{17} \mathrm{~T} \varepsilon \gamma \omega$ rell. $\mathfrak{M} ;$ txt B-A $118205 \mathrm{abs}$ 20956521932713 | ${ }^{19}{ }^{\top} \delta \varepsilon$ C 1312193 ; ${ }^{\top}$ ovv rell. $\mathfrak{N}$; txt A! $\left.15658841582\right|^{20}{ }^{\mathrm{T}} \delta \varepsilon$ rell. $\mathfrak{M}$; txt B $\left.11582\right|^{23}$ r o $\sigma \alpha$ av rell. N ; txt C $\left.1312193\right|^{25 \square} \mathrm{D}$ ! 884*; txt C-B! 1 1582 ( ${ }^{\top} \alpha \lambda \lambda{ }^{2} 884^{\mathrm{C}}$ rell. $\mathfrak{N}$ ) ; ( ${ }^{\top}$ o $\tau \varepsilon 884^{\mathrm{C}}$ rell. $\mathfrak{N}$ ) | ${ }^{26}$;

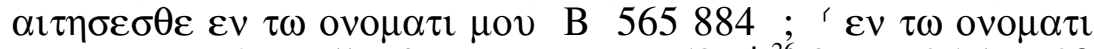
$\mu \mathrm{ov} \alpha \iota \tau \eta \sigma \varepsilon \sigma \theta \varepsilon$ rell. $\mathfrak{M}$; txt B $11582 \mid{ }^{26} \circ \mathrm{D}$ 205abs 209

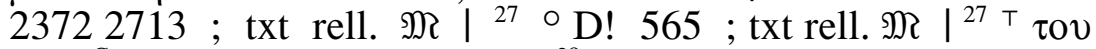

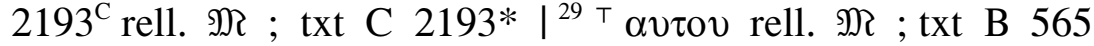
884 | 


\section{Chapter 17}

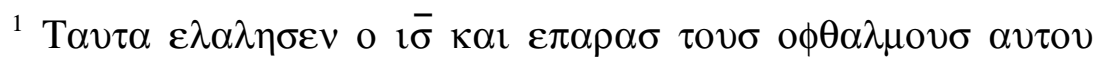

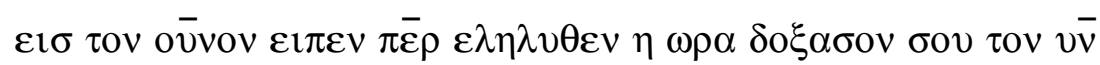

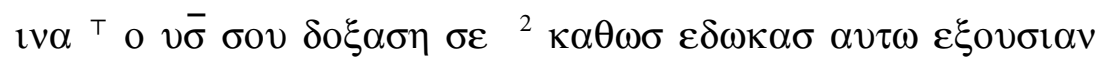
$\pi \alpha \sigma \eta \sigma \sigma \alpha \rho \kappa о \sigma \mathrm{lv} \alpha \pi \alpha \nu \mathrm{o}^{\prime} \varepsilon \delta \omega \kappa \alpha \sigma^{\prime} \alpha v \tau \omega^{\prime} \delta \omega \sigma \varepsilon \mathrm{l} \alpha v \tau \omega^{\prime} \zeta \omega \eta v$

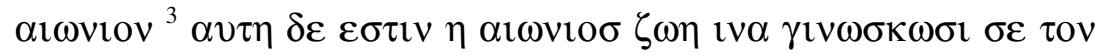

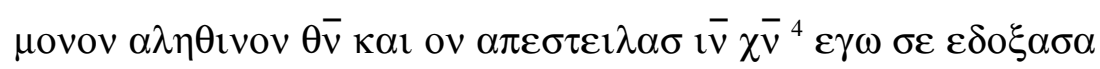

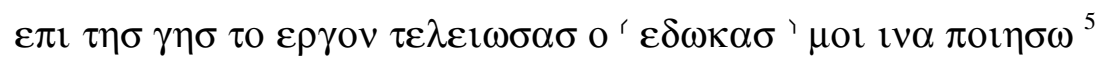

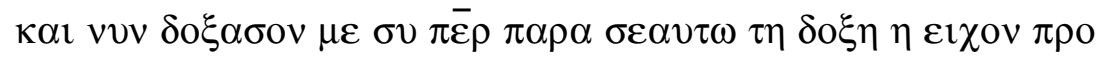

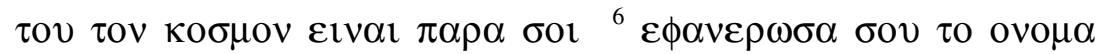

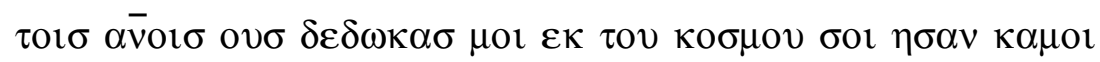

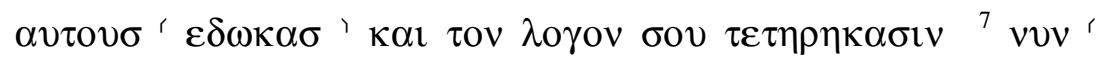

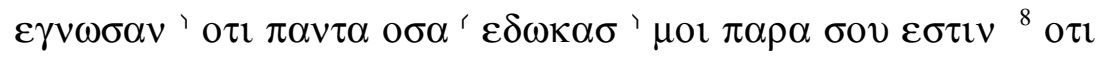

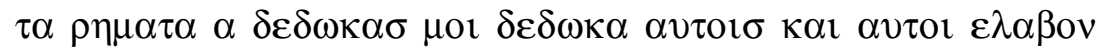

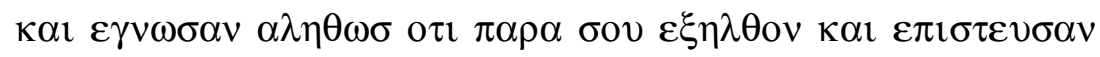

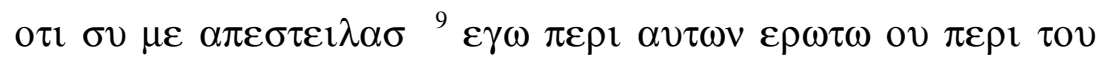

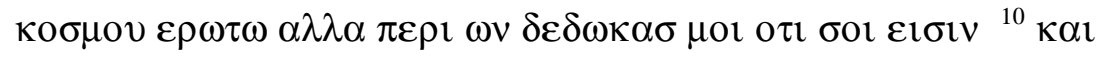

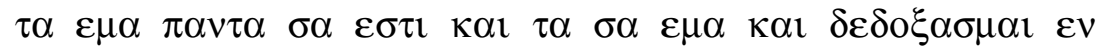

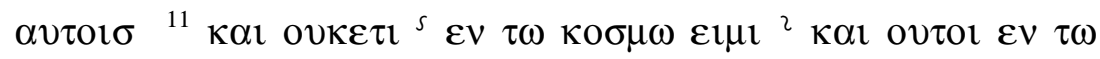

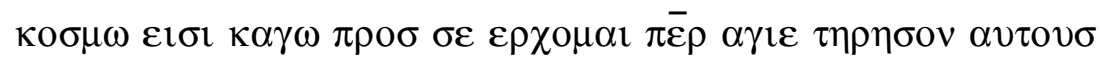

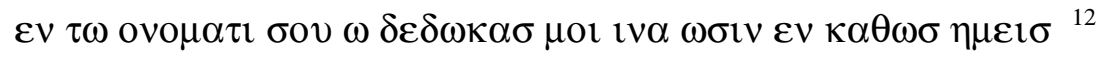

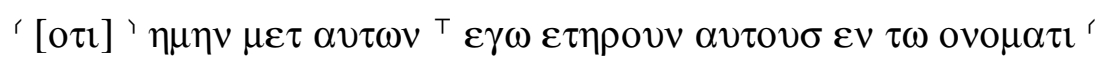

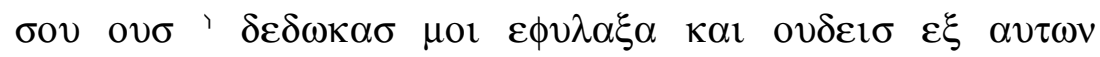

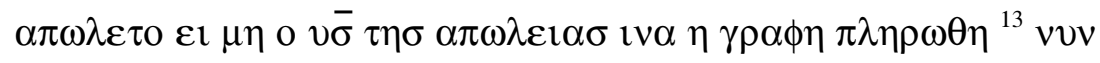

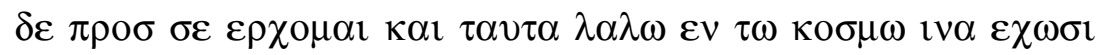
$\tau \eta \nu ~ \chi \alpha \rho \alpha \nu \tau \eta \nu \varepsilon \mu \eta \nu \pi \varepsilon \pi \lambda \eta \rho \omega \mu \varepsilon v \eta \nu \varepsilon v$ ' $\varepsilon \alpha v \tau O 1 \sigma$ ' ${ }^{14} \varepsilon \gamma \omega$

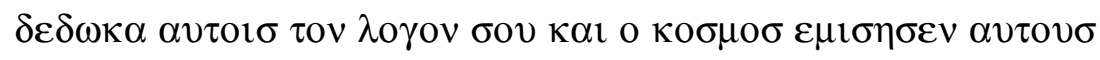

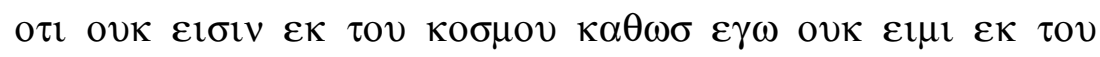

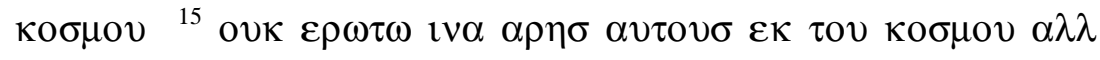

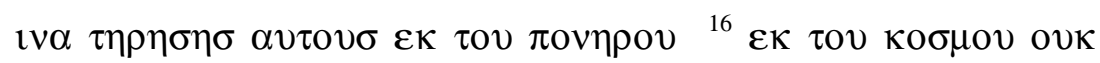

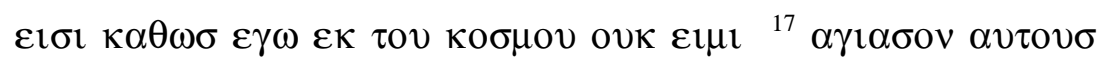

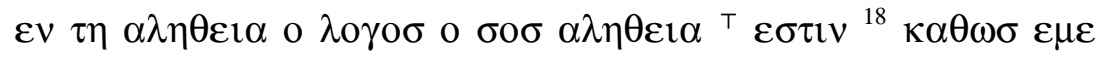

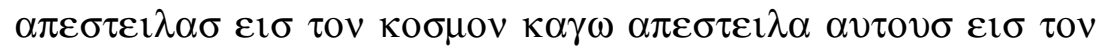




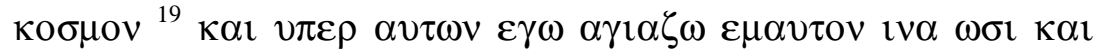
$\alpha v \tau$ or $\eta \gamma 1 \alpha \sigma \mu \varepsilon v o r \quad \varepsilon v \alpha \lambda \eta \theta \varepsilon 1 \alpha{ }^{20}$ ov $\pi \varepsilon \rho \imath \tau o v \tau \omega \nu \delta \varepsilon \varepsilon \rho \omega \tau \omega$

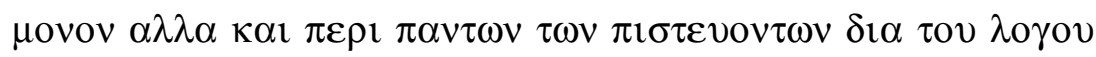
$\alpha v \tau \omega \nu \varepsilon 1 \sigma \varepsilon \mu \varepsilon{ }^{21} \mathrm{l} v \alpha \pi \alpha \nu \tau \varepsilon \sigma \varepsilon v \omega \sigma \mathrm{lv} \kappa \alpha \theta \omega \sigma \sigma v \pi \bar{\varepsilon} \rho \varepsilon v \varepsilon \mu \mathrm{\rho}$

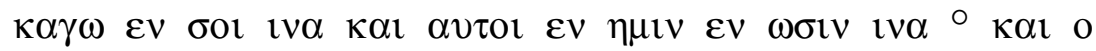

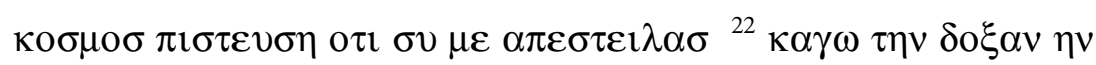

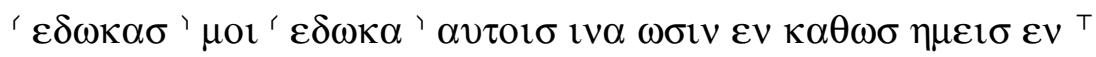

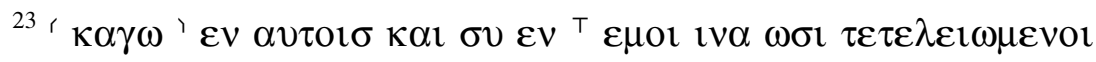

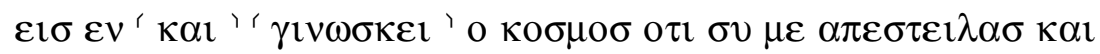
$\eta \gamma \alpha \pi \eta \sigma \alpha \sigma \alpha v \tau o v \sigma \kappa \alpha \theta \omega \sigma \varepsilon \mu \varepsilon \eta \gamma \alpha \pi \eta \sigma \alpha \sigma^{24} \pi \bar{\varepsilon} \rho$ оv $\delta \varepsilon \delta \omega \kappa \alpha \sigma$

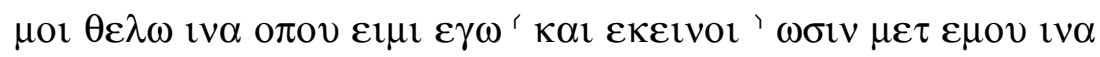
$\theta \varepsilon \omega \rho \omega \sigma \imath \tau \eta \nu \delta o \xi \alpha \nu \tau \eta \nu \varepsilon \mu \eta \nu \eta \nu \delta \varepsilon \delta \omega \kappa \alpha \sigma \mu о \imath ~ o \tau \imath ~ \eta \gamma \alpha \pi \eta \sigma \alpha \sigma \mu \varepsilon$

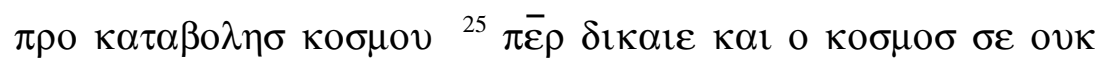

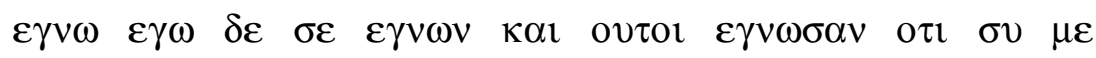

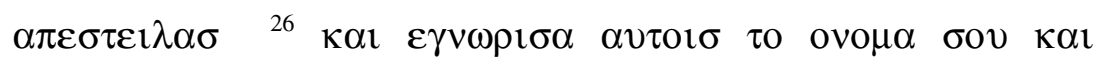

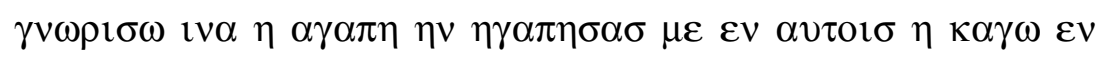

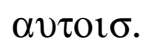

Lac. $\quad$ 118: all ; 872: all ; 565: 17:1b-17:12.

Suppl. $118^{\text {sup }}$ : all $; 565^{\text {sup }}: 17: 1 \mathrm{~b}-17: 12 \mathrm{~b}$.

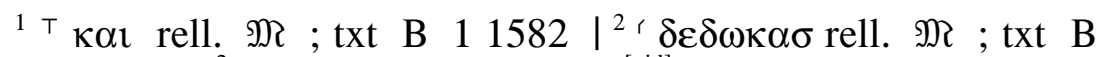
$\left.8842193\right|^{2} ; \delta \omega \sigma[\eta] \alpha v \tau \omega 1582 *[v i d] \quad D ! ; ~ ' \delta \omega \sigma \eta \alpha v \tau o 1 \sigma \mathrm{E}$

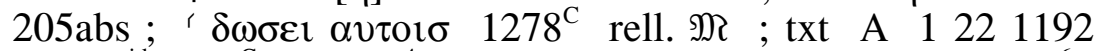
$\left.1278^{* \text { vid }} 1582^{\mathrm{C}} 2372\right|^{4}{ }^{4} \delta \varepsilon \delta \omega \kappa \alpha \sigma$ rell. $\mathfrak{M}$; txt C $\left.2193\right|^{6}$, $\delta \varepsilon \delta \omega \kappa \alpha \sigma$ rell. $\mathfrak{M}$; txt $\mathrm{B} 1118$ sup $\left.1582\right|^{7}$ ' $\varepsilon \gamma \nu \omega \kappa \alpha \nu$ $2193^{* \text { vid }}$ rell. $\mathfrak{N R}$; ' $\varepsilon \gamma v \omega \kappa \alpha$ E 118 sup ; txt C $\left.2193^{\mathrm{C}}\right|^{7}$; $\delta \varepsilon \delta \omega \kappa \alpha \sigma$ rell. $\mathfrak{M}$; txt B $\left.11311582\right|^{11}{ }^{5} 4.1 .2 .3 .^{2}$ rell. $\mathfrak{M}$; txt C 2193 | ${ }^{12}$ o o ${ }^{2} 1^{\mathrm{C}}$ rell. $\mathfrak{M}$; txt D-C! $1^{*} 118$ sup 205abs

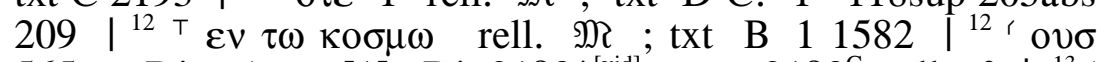
565sup D! ; ' oov [1] D! 2193*[vid]'; txt $2193^{\mathrm{C}}$ rell. $\mathfrak{M} \mid{ }^{13}$,

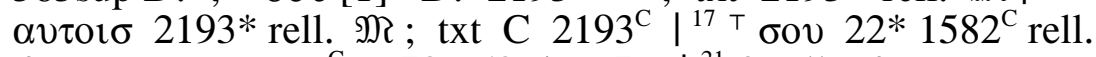
$\mathfrak{N}$; txt B-A $\left.122^{\mathrm{C}} 12781582 * 2372\right|^{21} \circ$ rell. $\mathfrak{N}$; txt B 1 131 205abs $\left.2091582\right|^{22}$ ' $\delta \varepsilon \delta \omega \kappa \alpha \sigma$ rell. $\mathfrak{N}$; txt C-B 2193 $\left.2713\right|^{22}$ ' $\delta \varepsilon \delta \omega \kappa \alpha$ rell. $\mathfrak{M}$; txt C $\left.2193\right|^{22}{ }^{\mathrm{T}} \varepsilon \sigma \mu \varepsilon v{ }^{2} 1582^{\mathrm{C}}$ rell. M ; txt B $\left.11582\right|^{23}, \varepsilon \gamma \omega$ rell. $\mathfrak{N}$; txt B $\left.565884\right|^{23}{ }^{2} \varepsilon v$

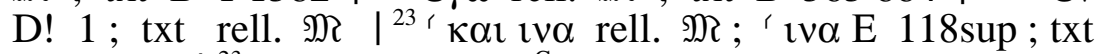
B $\left.11582\right|^{23}{ }^{23} \gamma \mathrm{iv \omega \sigma \kappa \eta} 1278^{\mathrm{C}}$ rell. $\mathfrak{N}$; txt B 118sup 565 $\left.8841278^{* \text { vid }}\right|^{24}$ ' $\kappa \alpha \kappa \varepsilon t v o r$ rell. $\mathfrak{M}$; txt B-A 205abs 209 21932713 | 


\section{Chapter 18}

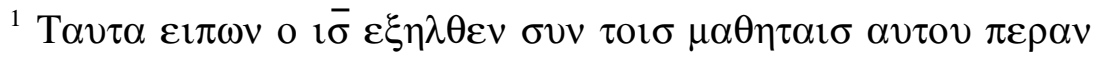

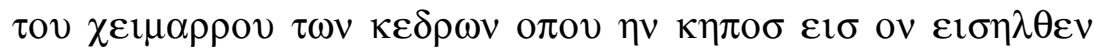

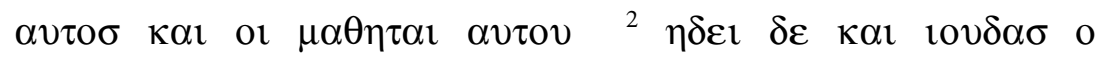

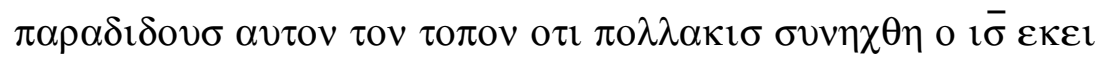
$\mu \varepsilon \tau \alpha \tau \omega v \mu \alpha \theta \eta \tau \omega v \alpha v \tau o v^{3} \mathrm{o}^{\prime}$ ovv $10 v \delta \alpha \sigma^{\prime} \pi \alpha \rho \alpha \lambda \alpha \beta \omega v \tau \eta v$

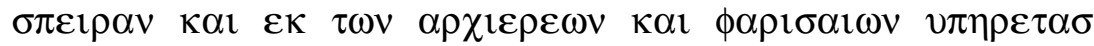
$\varepsilon \rho \chi \varepsilon \tau \alpha \imath \varepsilon \kappa \varepsilon l \mu \varepsilon \tau \alpha \phi \alpha \nu \omega v \kappa \alpha l \lambda \alpha \mu \pi \alpha \delta \omega v \kappa \alpha l$ o $\pi \lambda \omega v{ }^{4}{ }_{\imath} \bar{\sigma} \delta \varepsilon$

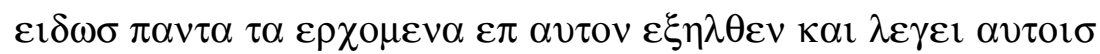

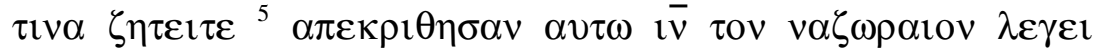

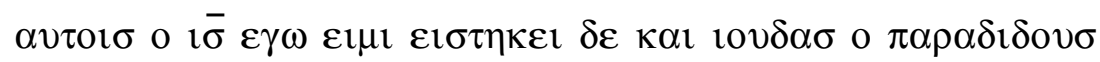

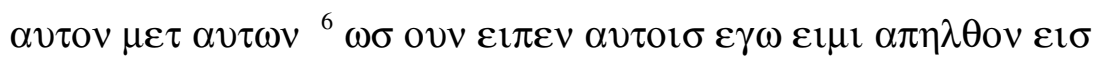

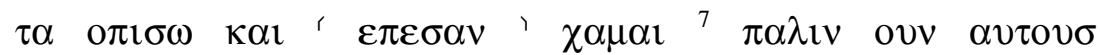

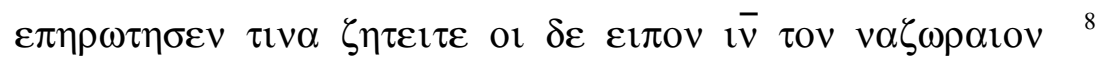

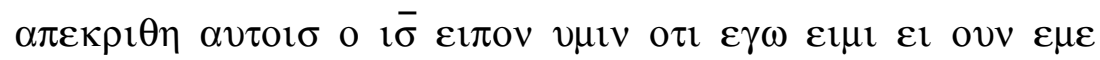

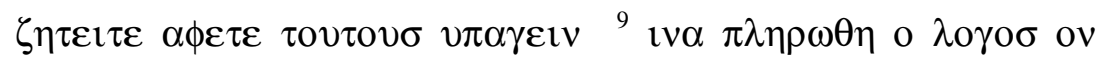

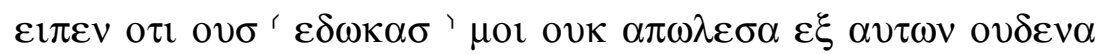

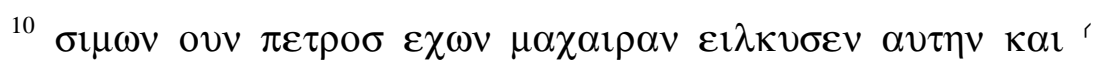

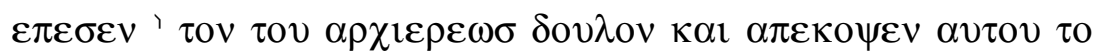
$\omega \tau$ Iov $\tau$ o $\delta \varepsilon \xi$ lov $\eta \vee \delta \varepsilon$ ovo $\mu \alpha \tau \omega \delta$ ov $\lambda \omega \mu \alpha \lambda \chi 0 \sigma{ }^{11} \varepsilon i \pi \varepsilon v$ ovv o

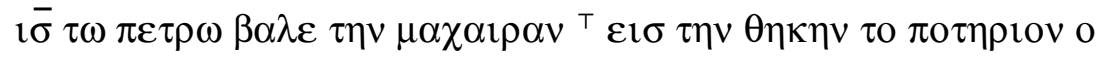

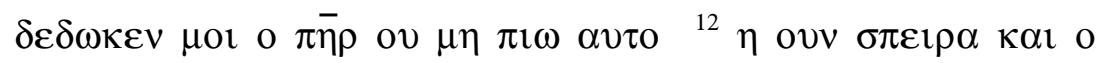

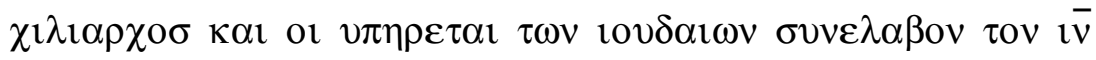

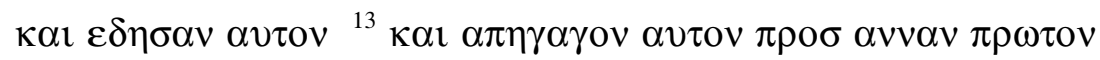

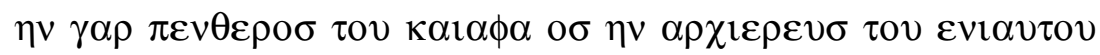

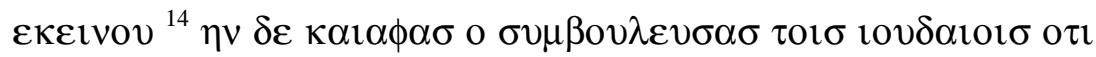

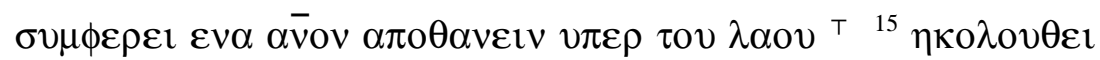

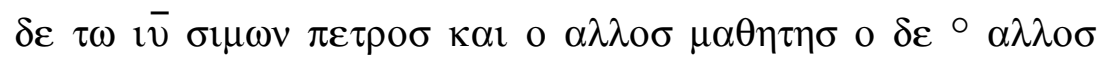

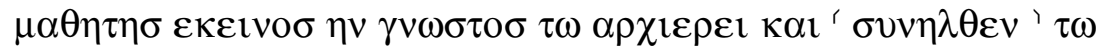

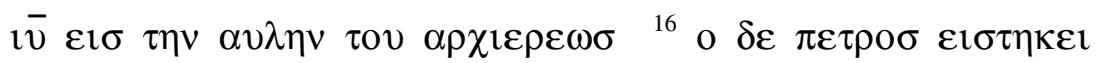

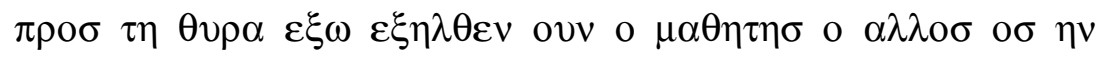

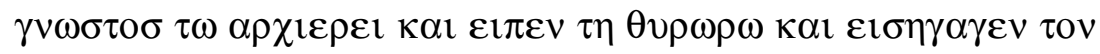
$\pi \varepsilon \tau \rho \circ{ }^{17} \lambda \varepsilon \gamma \varepsilon$ ovv $\eta \pi \alpha 1 \delta 1 \sigma \kappa \eta \eta \theta v \rho \omega \rho о \sigma \tau \omega \pi \varepsilon \tau \rho \omega \mu \eta \kappa \alpha \iota$ 


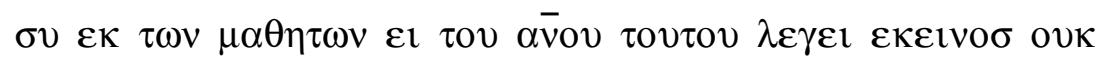

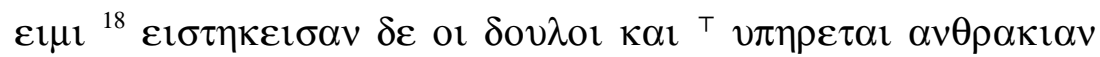

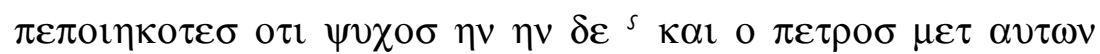

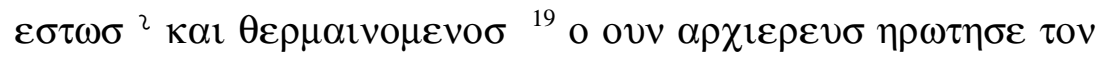

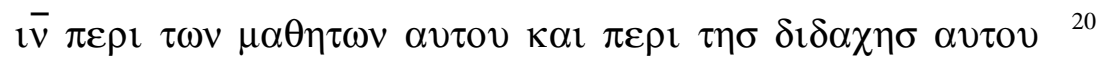

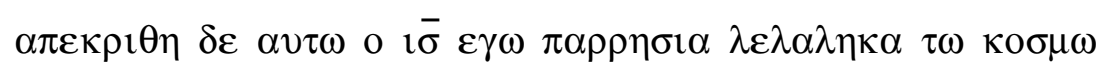

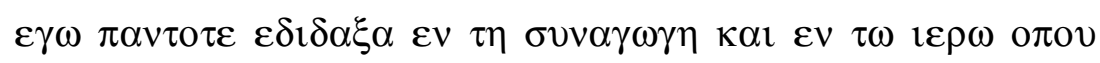

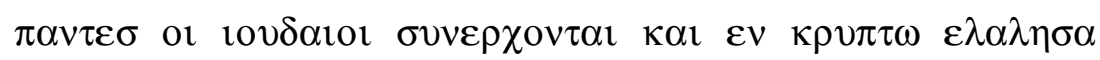

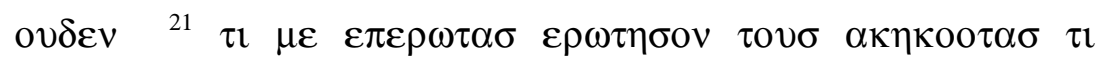

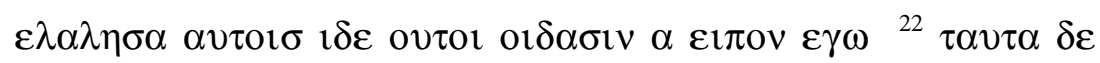

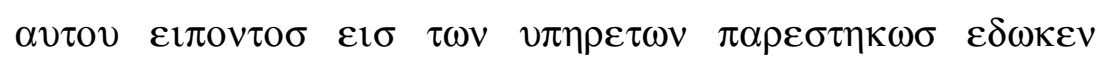

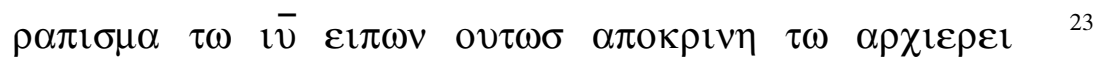
$\alpha \pi \varepsilon \kappa \rho \imath \theta \eta \alpha v \tau \omega$ о $\imath \bar{\sigma} \varepsilon \imath \kappa \alpha \kappa \omega \sigma \varepsilon \lambda \alpha \lambda \eta \sigma \alpha \mu \alpha \rho \tau v \rho \eta \sigma o v ~ \pi \varepsilon \rho \imath \tau o v$

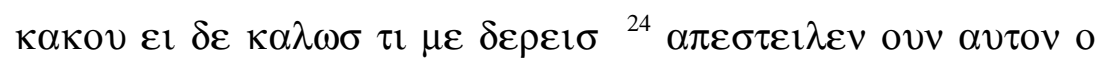

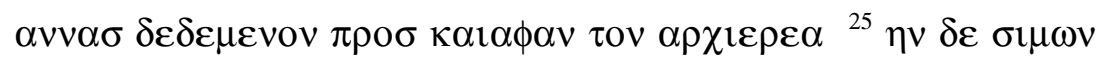

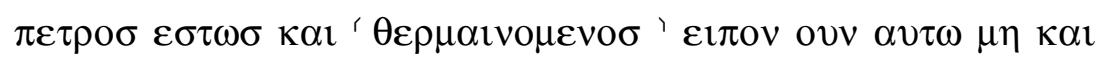

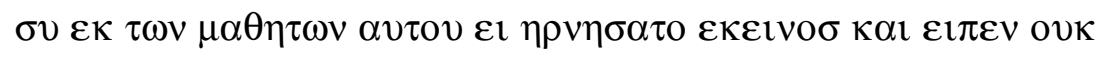

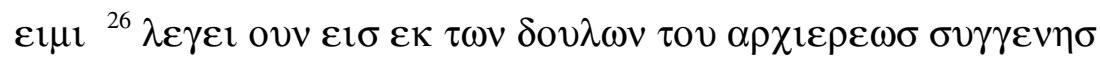

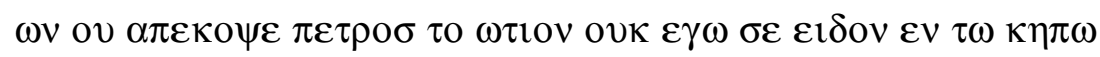

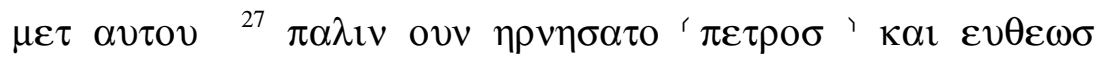

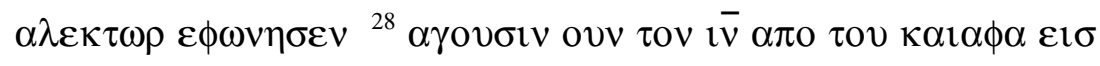

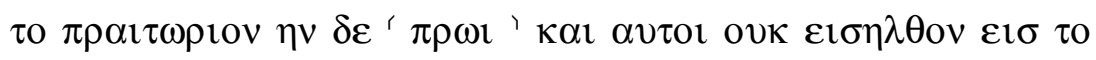

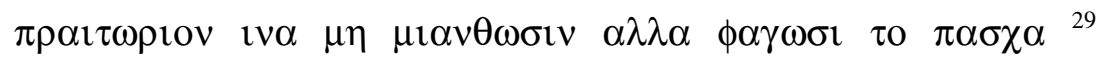

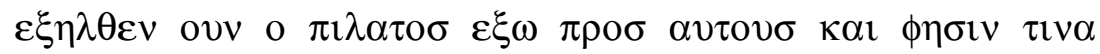

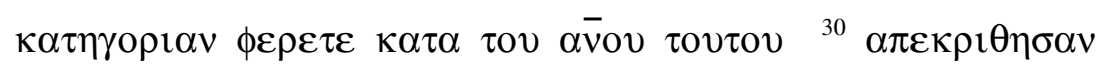

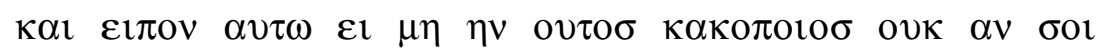

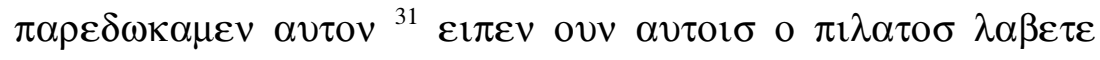

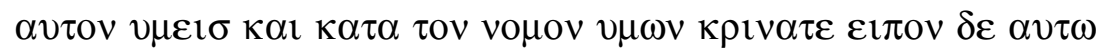

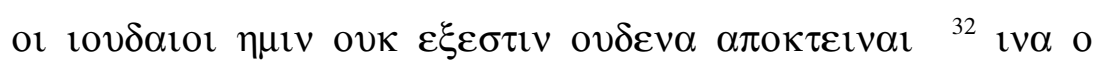

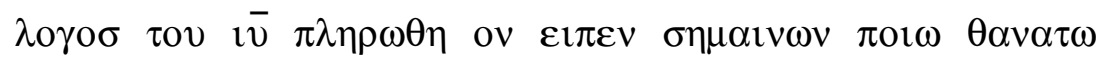

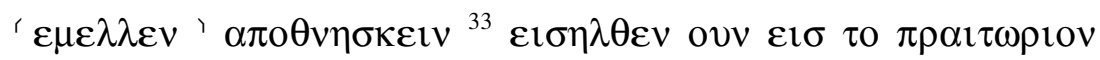

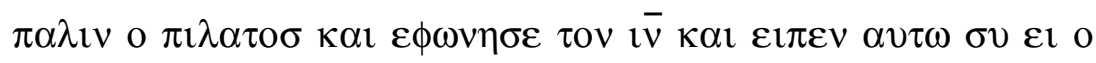

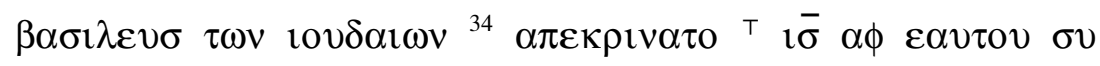

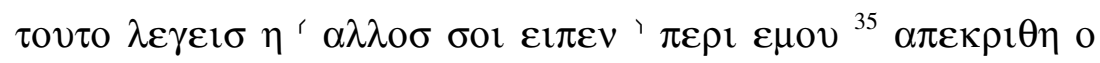




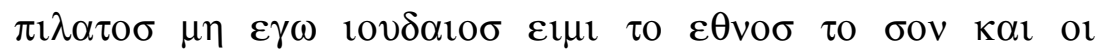
$\alpha \rho \chi \imath \varepsilon \rho \varepsilon \imath \sigma \pi \alpha \rho \varepsilon \delta \omega \kappa \alpha \nu \sigma \varepsilon \varepsilon \mu \mathrm{ol} \tau \imath \varepsilon \pi \mathrm{ol \eta} \sigma \alpha \sigma{ }^{36} \alpha \pi \varepsilon \kappa \rho \imath \theta \eta{ }^{\top} \imath \bar{\sigma} \eta$

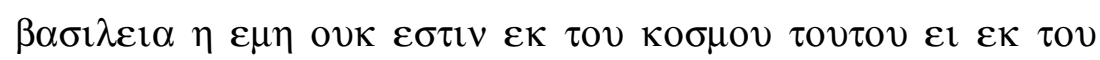

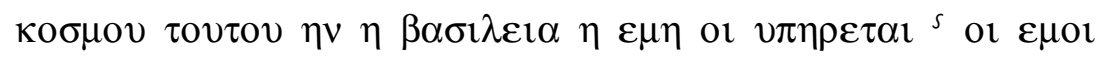

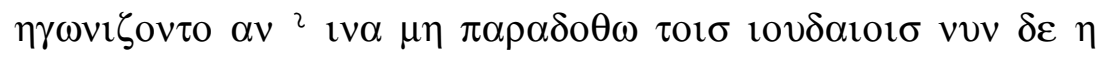

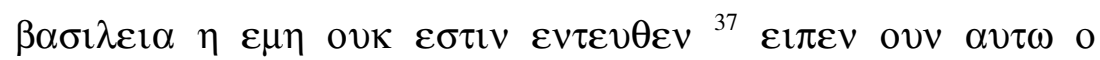

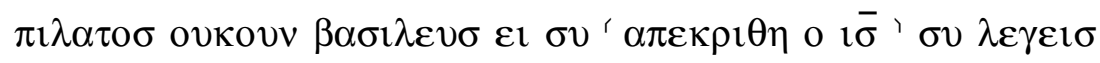

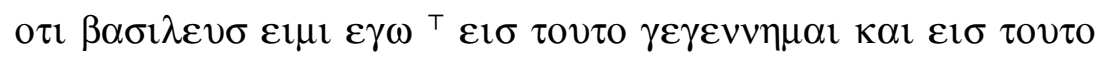

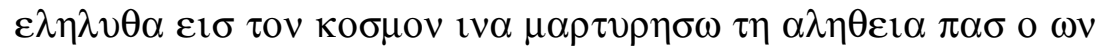

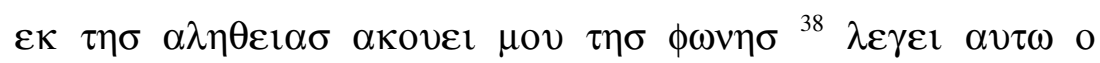

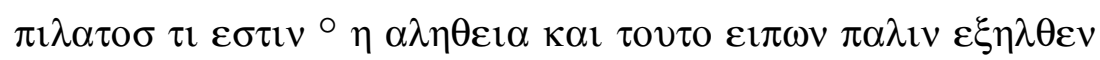

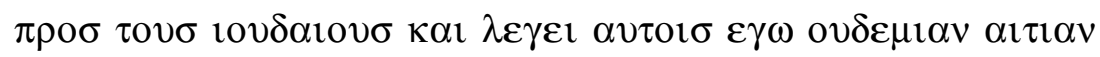

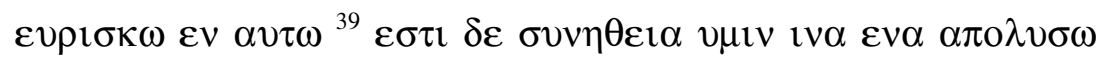

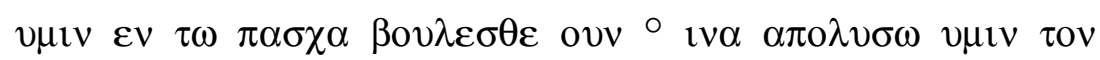

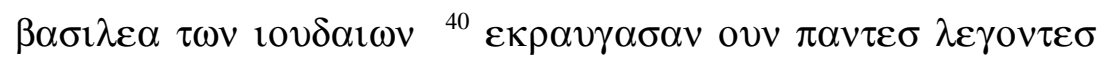

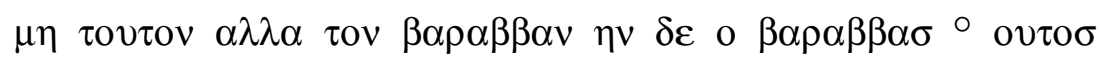
$\lambda \eta \sigma \tau \eta \sigma$.

Lac. $\quad$ 872: all ; 118: all ; 2372: 18:31b-end.

Suppl. $118^{\text {sup }}$ all.

\footnotetext{
${ }^{3}$ ' ${ }^{6}$ ' $\varepsilon \pi \varepsilon \sigma o v$ 1582 ${ }^{\text {Cvid }}$ rell. $\mathfrak{M}$; txt C-B $11582 *$ vid $\mid{ }^{9}$ ' $\delta \varepsilon \delta \omega \kappa \alpha \sigma$ rell. $\mathfrak{N}$; txt C $\left.2193\right|^{10}$ ' $\varepsilon \pi \alpha \iota \sigma \varepsilon v 209^{\mathrm{C} *} 1278^{\mathrm{C}}$ rell. $\mathfrak{N}$; txt B $\left.209 * 8841278 * 2372\right|^{11} \mathrm{~T}$ oov 122121 205abs $2092193^{\mathrm{C}}$

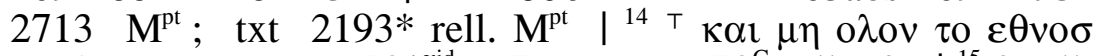
$\alpha \pi \mathrm{o} \lambda \eta \tau \alpha \mathrm{r}$ D $221278^{* \mathrm{vid}} 2372$; txt $1278^{\mathrm{C}}$ rell. $\left.\mathfrak{N}\right|^{15}{ }^{\circ}$ rell. N ; txt C 565 | ${ }^{15}$; $\sigma u v \varepsilon 1 \sigma \eta \lambda \theta \varepsilon v 1^{\mathrm{C}}$ rell. $\mathfrak{N} ;$

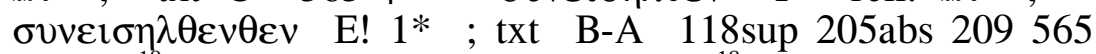
$\left.2713\right|^{18}{ }^{\top}$ or rell. $\mathfrak{M}$; txt B $\left.565884\right|^{18}{ }^{s} 1.2 .3 .6 .4 .5^{2} \mathrm{C} 565$ ; ${ }^{5} 4.5 .2 .3 .6{ }^{2}\left({ }^{\circ} 1.\right)$ rell. $\mathfrak{M}$; txt A! 1 205abs 2098841582

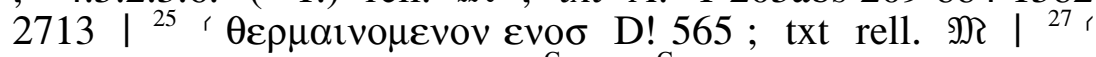
om. C 565 ; ${ }^{\prime}$ o $\pi \varepsilon \tau \rho o \sigma \quad 1582^{\mathrm{C}} 2372^{\mathrm{C}}$ rell. $\mathfrak{N}$; txt A! 122 $\left.88411921582 * 2372 *\right|^{28}$; $\pi \omega \omega 1 \alpha 1312193 \mathrm{M}^{\mathrm{pt}}$; txt rell. $\mathbf{M}^{\mathrm{pt}}$ | ${ }^{32}$ ' $\eta \mu \varepsilon \lambda \lambda \varepsilon v 122$ 118sup $11921278 \mathrm{M}^{\mathrm{pt}}$; txt rell. $\left.\mathrm{M}^{\mathrm{pt}}\right|^{34} \mathrm{~T} \mathrm{o}$

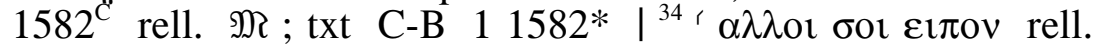




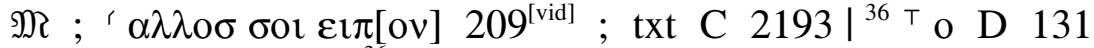
884 ; txt rell. $\left.\mathfrak{M}\right|^{36}{ }^{5} 4.1 .2 .3{ }^{2}$ rell. $\mathfrak{N} ;{ }^{s} 4.1 .(\eta) .2 .3 .^{2} \mathrm{E} 131$ ; txt B $\left.11582\right|^{37}$ ' $\alpha \pi \varepsilon \kappa \rho i \theta \eta 1 \bar{\sigma}$ 118sup 131 5658841192 $1278 \mathrm{M}^{\mathrm{pt}}$; ' om. E 131 ; txt rell. $\left.\mathrm{M}^{\mathrm{pt}}\right|^{37}{ }^{\mathrm{T}} \varepsilon \gamma \omega$ rell. $\mathfrak{N}$; txt B 1 205abs $\left.20915822713\right|^{38} \circ$ rell. $\mathfrak{N}$; txt B $\left.11582\right|^{39} \circ$ rell. $\mathfrak{N}$; txt A-B 205abs $\left.20921932713\right|^{40} \circ$ rell. $\mathfrak{N}$; txt B 11582 | 


\section{Chapter 19}

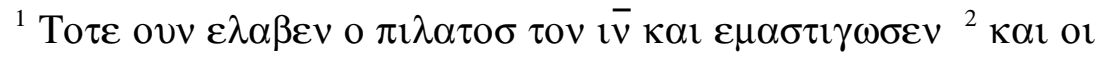
$\sigma \tau \rho \alpha \tau \iota \omega \tau \alpha \iota \pi \lambda \varepsilon \xi \alpha \nu \tau \varepsilon \sigma \sigma \tau \varepsilon \phi \alpha \nu \circ \nu \varepsilon \xi \alpha \kappa \alpha v \theta \omega \nu \varepsilon \pi \varepsilon \theta \eta \kappa \alpha \nu \alpha v \tau \circ v$

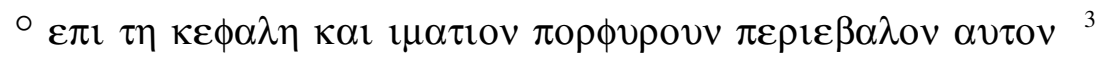

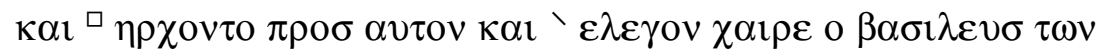

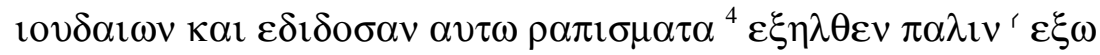

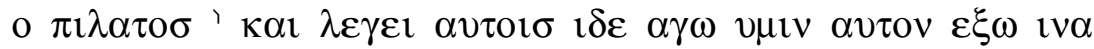

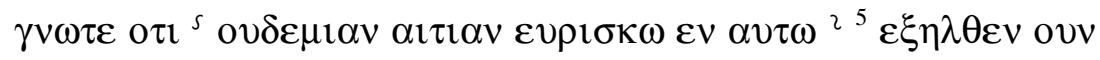

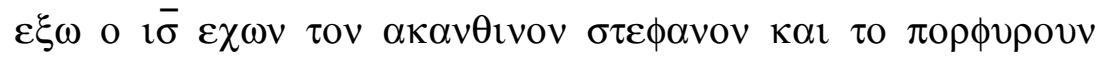

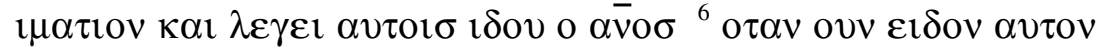

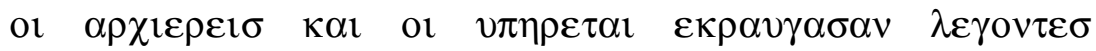

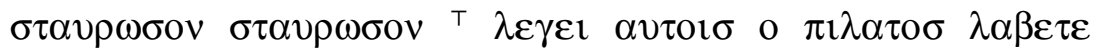

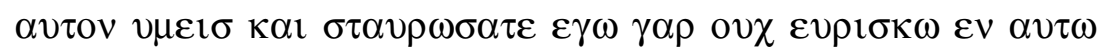

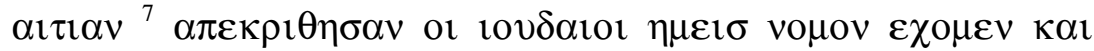

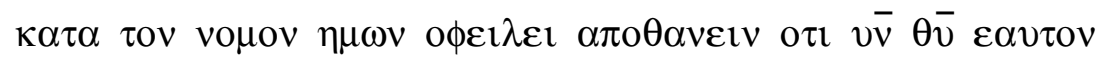

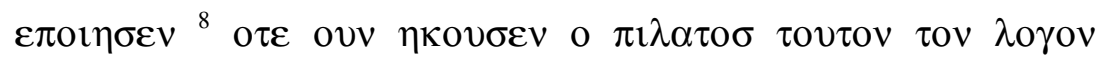

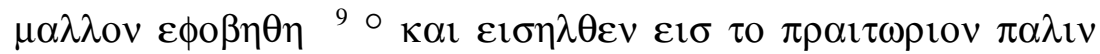

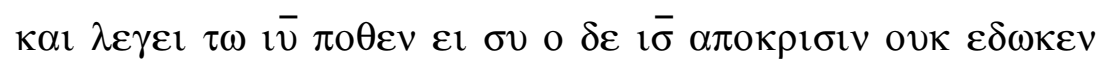

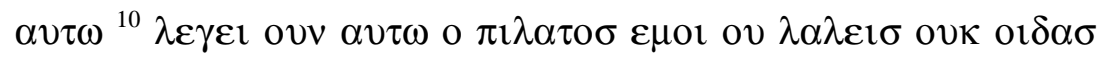

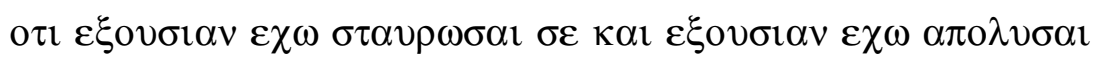

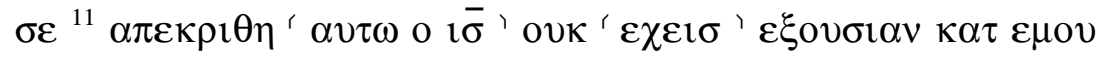

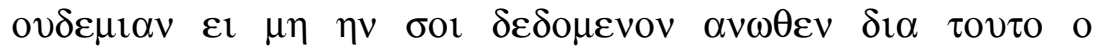

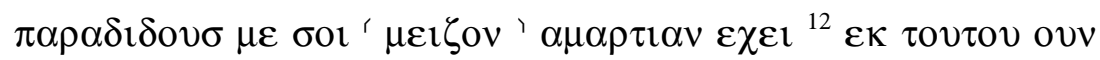

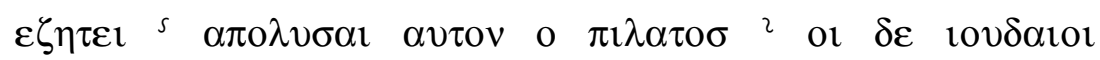

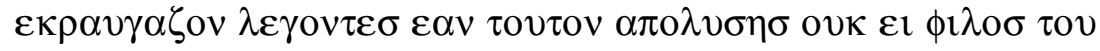

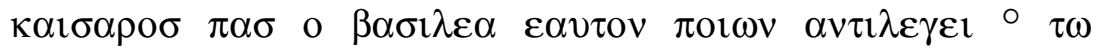

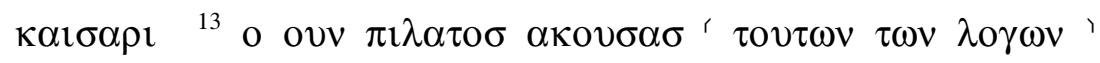

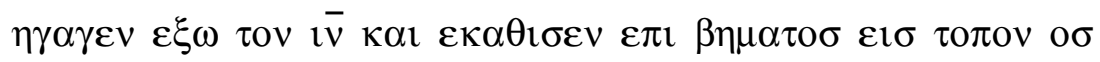

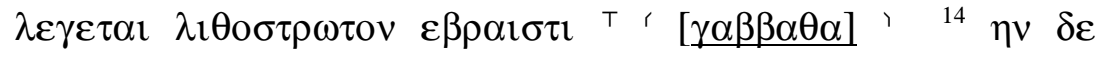

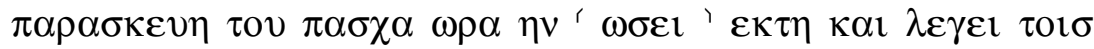
$10 v \delta \alpha 101 \sigma 1 \delta \varepsilon$ o $\beta \alpha \sigma 1 \lambda \varepsilon v \sigma v \mu \omega v{ }^{15}$ ol $\delta \varepsilon$ ' $\varepsilon \kappa \rho \alpha v \gamma \alpha \sigma \alpha v^{\prime}$ ' $\alpha \rho o v$ ' $(\kappa \alpha \pi \pi \alpha \theta \alpha)$ '

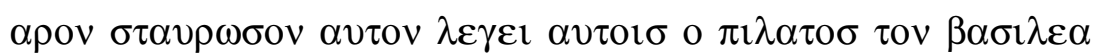

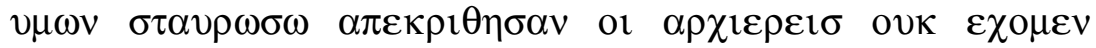




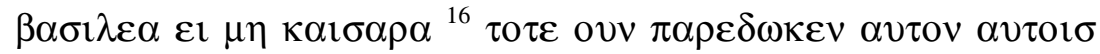

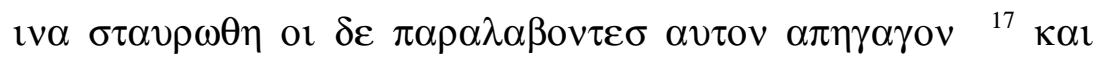

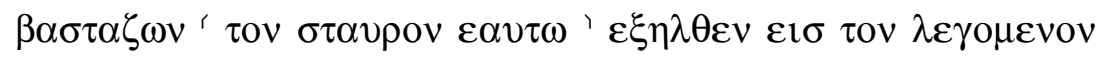

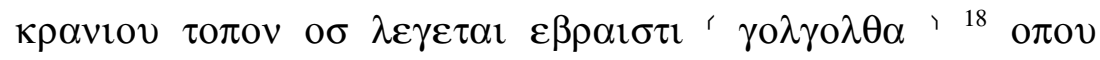

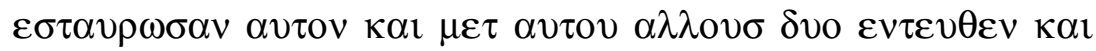

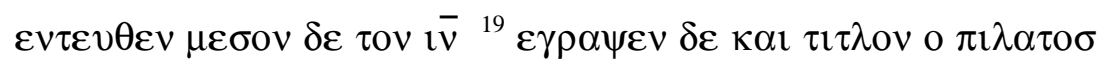

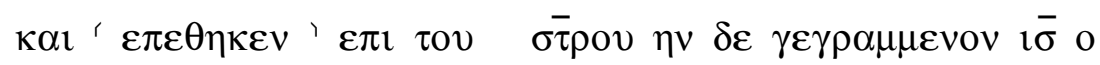

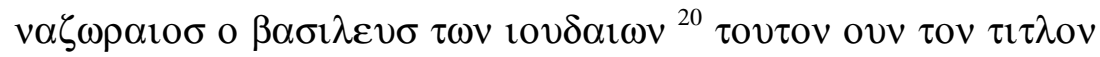

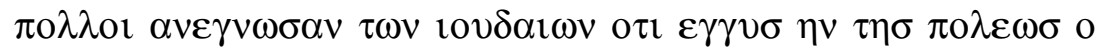

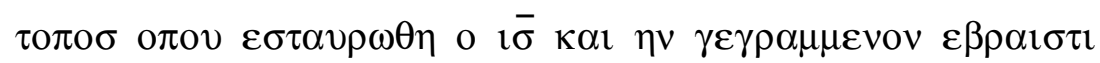
$\varepsilon \lambda \lambda \eta v \imath \sigma \tau \imath \rho \omega \mu \alpha \imath \sigma \tau l ~{ }^{21} \varepsilon \lambda \varepsilon \gamma o v$ ovv $\tau \omega \pi \imath \lambda \alpha \tau \omega$ or $\alpha \rho \chi \imath \varepsilon \rho \varepsilon \imath \sigma$

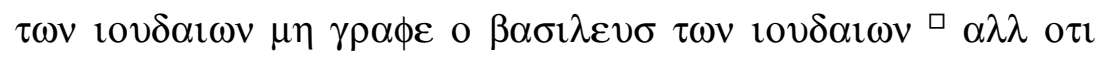

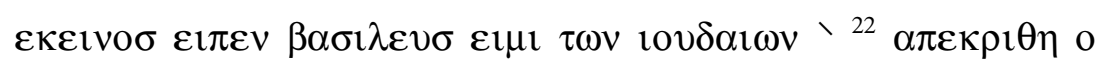

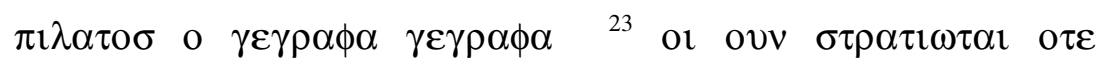

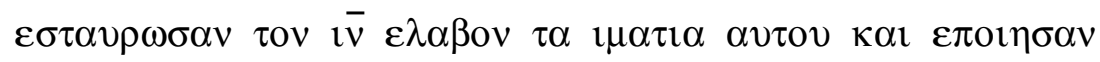
$\tau \varepsilon \sigma \sigma \alpha \rho \alpha \mu \varepsilon \rho \eta \varepsilon \kappa \alpha \sigma \tau \omega \sigma \tau \rho \alpha \tau \iota \omega \tau \eta \mu \varepsilon \rho о \sigma \kappa \alpha \iota ~ \tau o v ~ \chi \imath \tau \omega v \alpha \eta \nu ~ \delta \varepsilon$

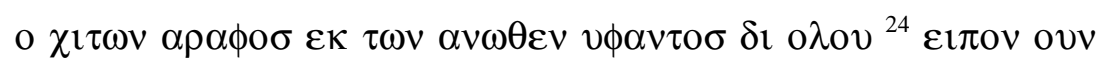

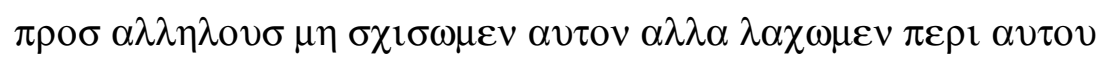

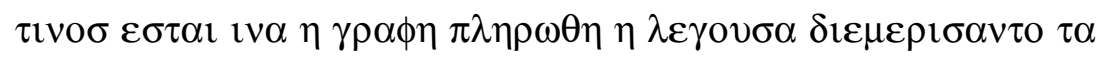

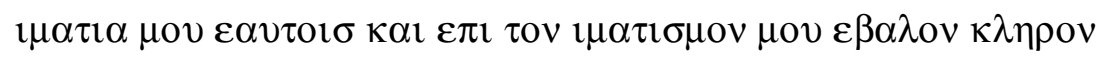

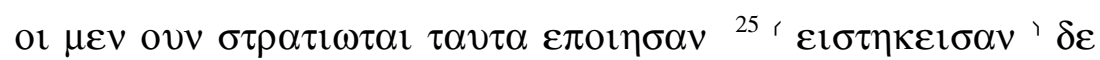

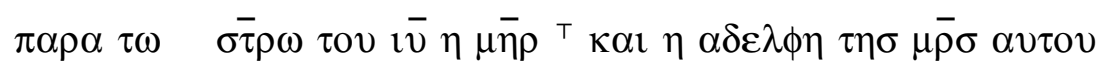

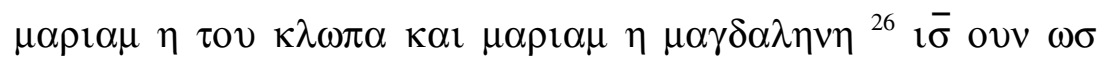

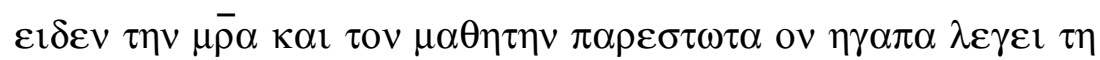

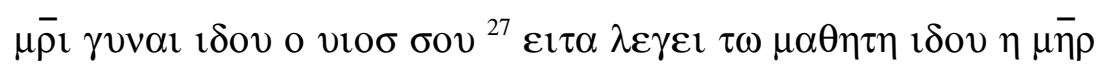
бov $\alpha \pi \varepsilon \kappa \varepsilon i v \eta \sigma$ ovv $\tau \eta \sigma \omega \rho \alpha \sigma \varepsilon \lambda \alpha \beta \varepsilon v^{\prime} \alpha v \tau \eta v$ o $\mu \alpha \theta \eta \tau \eta \sigma \sigma^{\prime} \varepsilon 1 \sigma$

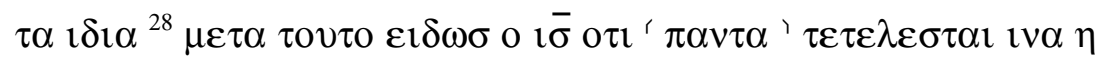

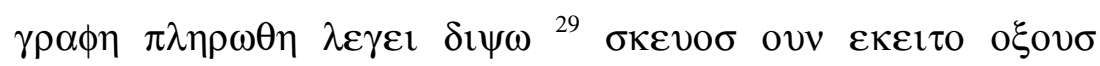

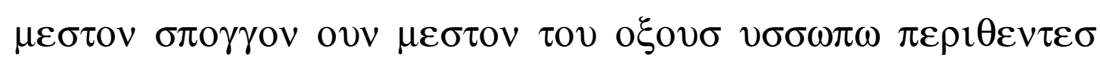

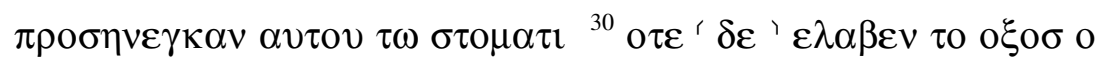

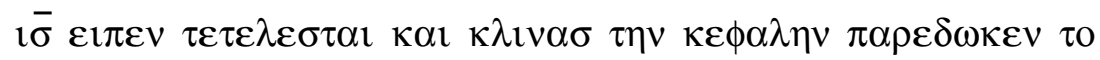

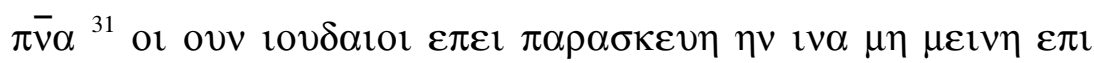
$\tau o v \sigma \bar{\tau} \rho o v \tau \alpha \sigma \omega \mu \alpha \tau \alpha \varepsilon v \tau \omega \sigma \alpha \beta \beta \alpha \tau \omega \eta \nu \gamma \alpha \rho \mu \varepsilon \gamma \alpha \lambda \eta \eta \eta \mu \varepsilon \rho \alpha$

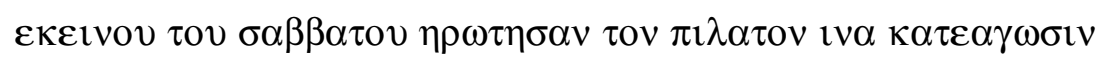




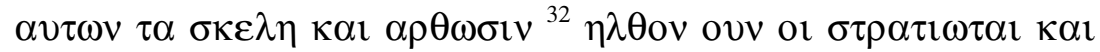

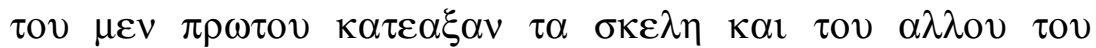

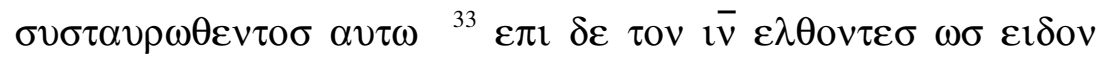

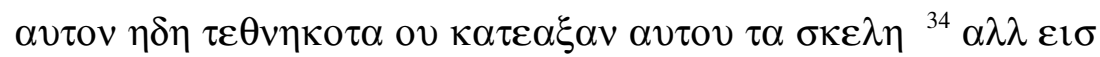

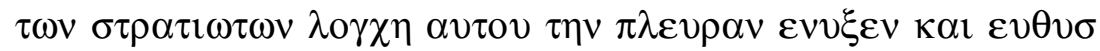

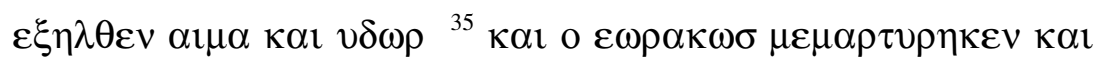

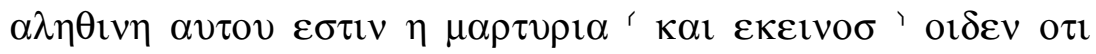

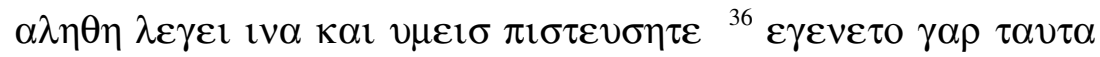

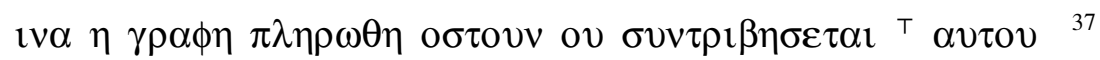

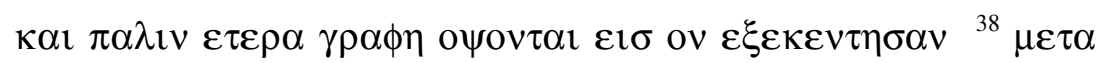

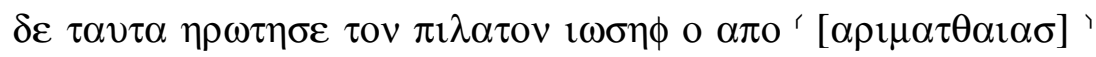

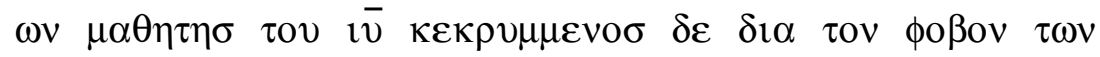

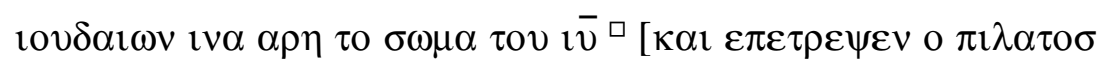

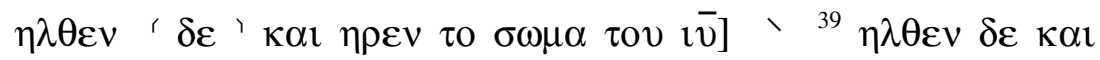

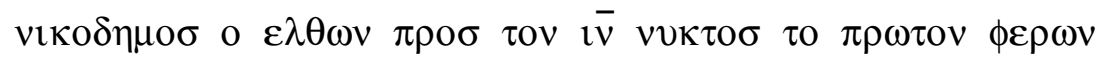

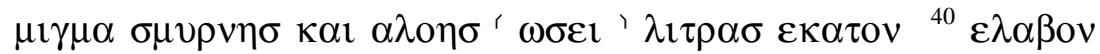

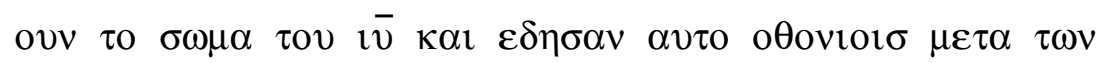

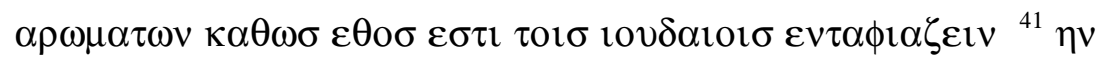

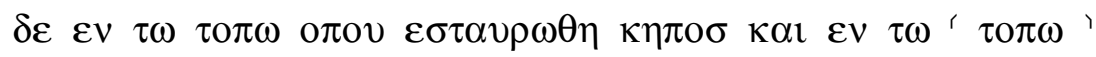

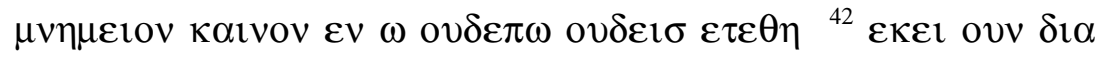

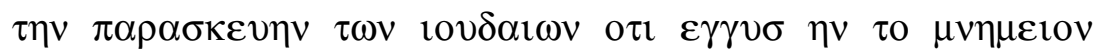

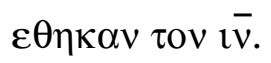

Lac. $\quad 118$ : all ; 872: all ; 2372: all.

Suppl. $118^{\text {sup }}$ : all.

${ }^{2} \circ 2193^{\mathrm{C}}$ rell. $\mathfrak{M}$; txt C $\left.2193 *\right|^{3}{ }^{\square}$ rell. M ; txt B 565884 $\left.11922193\right|^{4}{ }^{\prime}$ o $\pi \iota \lambda \alpha \tau 0 \sigma$ D $131884 ;$ ' o $\pi \iota \lambda \alpha \tau o \sigma \varepsilon \xi \omega$ E 118sup ; txt rell. $\mathfrak{M} \mid{ }^{4}$ s $1.4 .5 .2 .3 .^{2}$ C $2193 ;{ }^{5} 4.5 .1 .2 .3 .^{2}$ $131^{\mathrm{C}}$ rell. $\mathfrak{N} ;{ }^{s} 1.2 .3 .^{2}\left({ }^{\circ} 4.5\right.$.) E $131^{*}$; txt A! 1 118sup 205abs $\left.20956588415822713\right|^{6}{ }^{\top}$ avtov rell. $\mathfrak{M}$; txt B 1

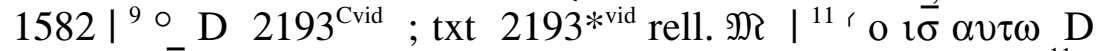
$884 ;{ }^{\prime} i \bar{\sigma}$ rell. $\mathfrak{N}$; txt A 1 205abs $\left.20956515822713\right|^{11}$ r

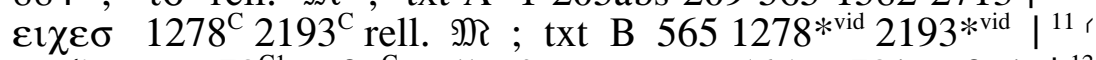
$\mu \varepsilon i$ Cova $1278^{\mathrm{C} 1} 2193^{\mathrm{C}}$ rell. $\mathfrak{M}$; txt B $\left.5651278^{*} 2193^{*}\right|^{12}$ 33.4.1.2. ${ }^{2}$ rell. $\mathfrak{M}$; txt C $\left.2193\right|^{12} \circ \mathrm{D}$ ! 1 ; txt rell. $\left.\mathfrak{M}\right|^{13}$,

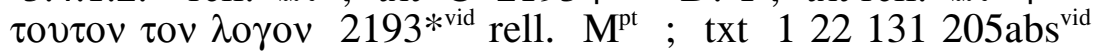


$\left.2091192127815822193^{\text {Cvid }} \mathrm{M}^{\mathrm{pt}}\right|^{13} \mathrm{~T} \delta \varepsilon$ rell. $\mathfrak{N}$; txt B 565

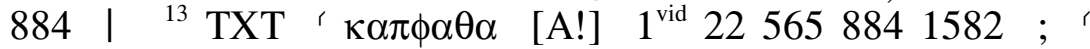
$\gamma \alpha \beta \alpha \theta \alpha 12782713 \quad \mathrm{M}^{\mathrm{pt}}$; txt 118sup 131 205abs $2091192^{\mathrm{txt}}$ $2193 \mathrm{M}^{\mathrm{pt}}$; MG1 ' $\kappa \alpha[\pi] \phi \alpha \theta \alpha 1192^{\mathrm{mg}[\text { [vid] }}\left(1^{\text {vid }} 225658841582\right)$ ; MG2 ' $\left.\kappa \alpha \pi \pi \alpha \theta \alpha 1192^{\mathrm{mg} 2}\right|^{14}{ }^{14} \omega \sigma 2193^{*} \mathrm{M}^{\mathrm{pt}}$; txt $2193^{\mathrm{C}}$ rell.

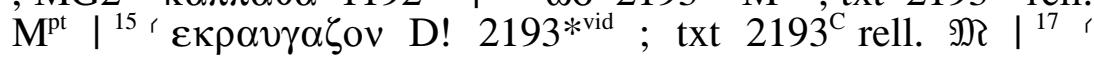

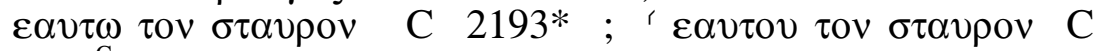

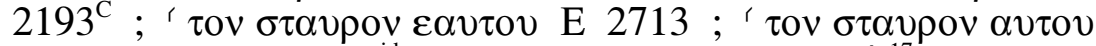

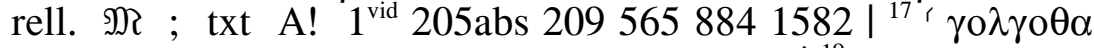
rell. $\mathfrak{N}$; ' $\gamma_{0} \lambda \gamma_{0} \theta \alpha \sigma$ E 131 ; txt C 1582 | ${ }^{19}$; $\varepsilon \theta \eta \kappa \varepsilon v$ rell. $\mathfrak{N}$; txt B-A 131 205abs $\left.2092193\right|^{21} \square \mathrm{D}$ ! 565 ; txt rell. $\mathfrak{N}$ ।

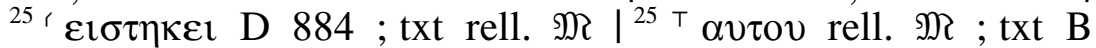
11582 | ${ }^{27}$; о $\mu \alpha \theta \eta \tau \eta \sigma \alpha v \tau \eta v ~ 22$ 118sup $11922193 \mathrm{M}^{\mathrm{pt}}$; $\alpha v \tau \eta \nu$ o $\mu \alpha \theta \eta \tau \eta \sigma \varepsilon \kappa \varepsilon ı v o \sigma$ E rell. ; txt 11315658841278 $\left.1582 \mathrm{M}^{\mathrm{pt}}\right|^{28}{ }^{2} \eta \delta \eta \pi \alpha v \tau \alpha \mathrm{D} ! 2193 ;{ }^{3} \pi \alpha \nu \tau \alpha \eta \delta \eta$ rell. M ; txt A! $\left.156588415822713\right|^{30}$ ' ovv rell. MR ; txt C 1312193 ।

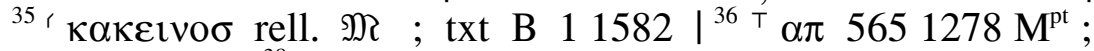
txt rell. $\left.\mathrm{M}^{\mathrm{pt}}\right|^{38}{ }^{3} \alpha \rho \mu \alpha \theta i \alpha \sigma$ C $2193 ;{ }^{\prime} \alpha \rho \mu \alpha \theta \alpha i \alpha \sigma$ rell. $\mathfrak{N}$ ; txt C $\left.1209\right|^{38}$ 口 C! 1 205abs 209; txt C! 1582 (' ovv rell. $\mathfrak{N})\left.\right|^{39}\left(\omega \sigma\right.$ 118sup $1312193 \mathrm{M}^{\mathrm{pt}} ;$ txt rell. $\left.\mathrm{M}^{\mathrm{pt}}\right|^{41}$ r $\kappa \eta \pi \omega$ rell. $\mathfrak{N}$; txt B 1 205abs 2091582 | 


\section{Chapter 20}

${ }^{1} \mathrm{~T} \eta \delta \varepsilon \mu 1 \alpha \tau \omega \nu \sigma \alpha \beta \beta \alpha \tau \omega \nu \mu \alpha \rho \iota \alpha \mu \eta \mu \alpha \gamma \delta \alpha \lambda \eta \nu \eta \varepsilon \rho \chi \varepsilon \tau \alpha \imath \pi \rho \omega \imath$

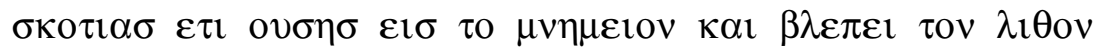

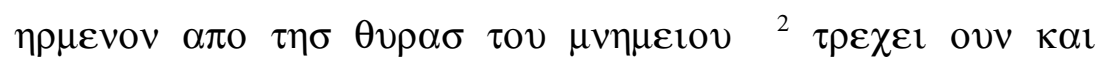

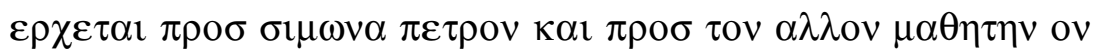

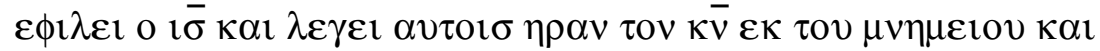

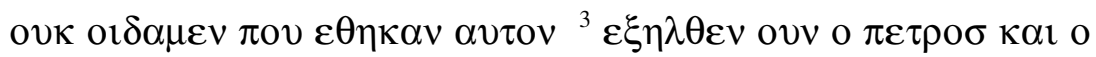

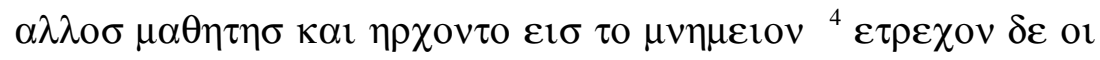

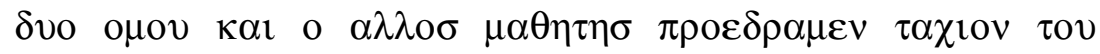

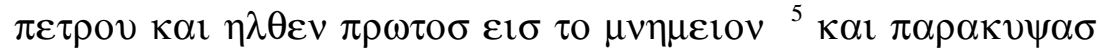

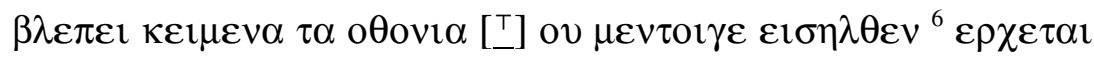

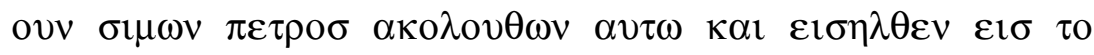

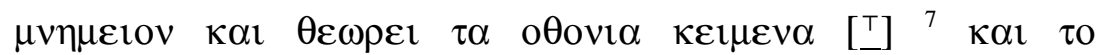

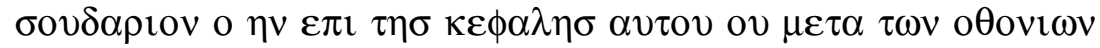

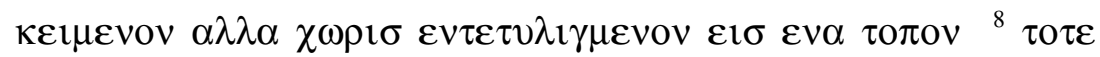

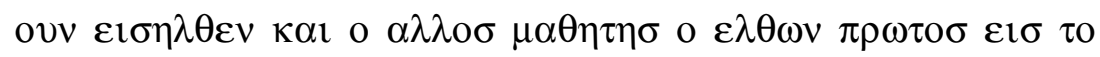

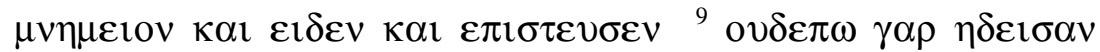

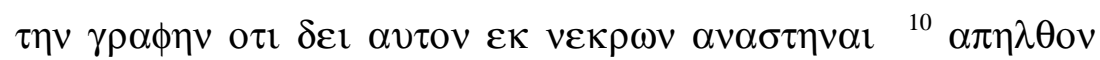

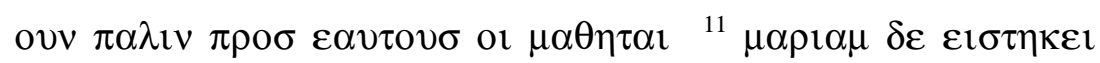
$\pi \rho \circ \sigma \tau \omega \mu \nu \eta \mu \varepsilon \imath \omega \varepsilon \xi \omega \kappa \lambda \alpha 10 v \sigma \alpha \omega \sigma$ ovv $\varepsilon \kappa \lambda \alpha 1 \varepsilon v \pi \alpha \rho \varepsilon \kappa v \psi \varepsilon v$

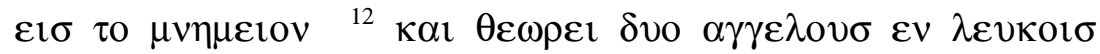
$\kappa \alpha \theta \varepsilon \zeta o \mu \varepsilon v o v \sigma \varepsilon v \alpha \pi \rho \sigma^{\prime} \tau \eta \kappa \varepsilon \phi \alpha \lambda \eta{ }^{\prime} \kappa \alpha l \varepsilon v \alpha \pi \rho \circ \sigma \tau o l \sigma$

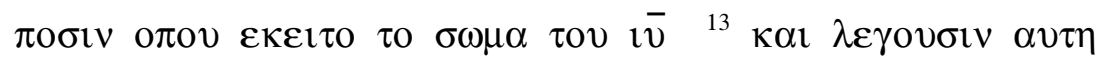

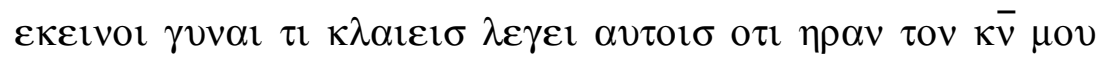

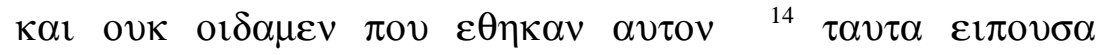

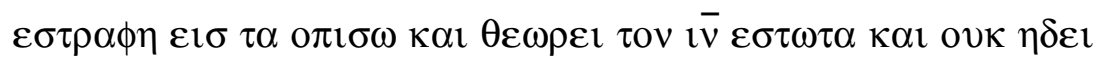

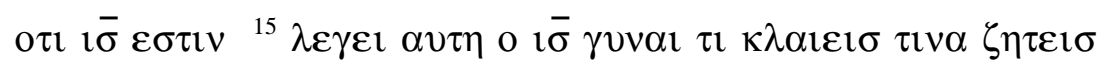

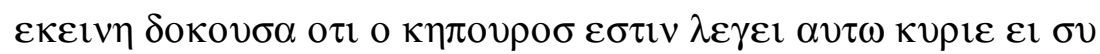

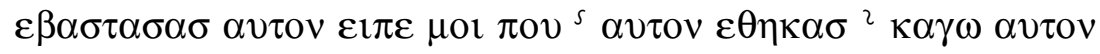

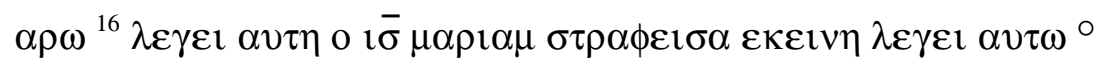

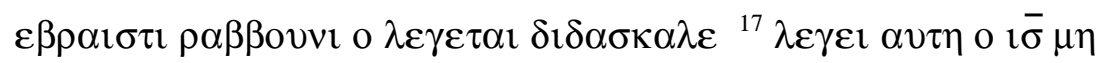

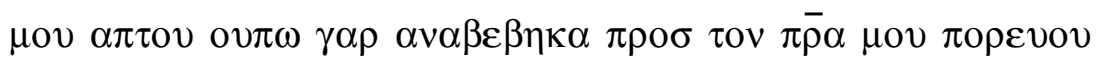

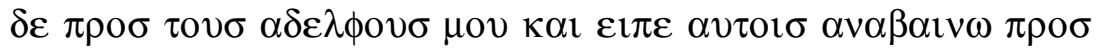




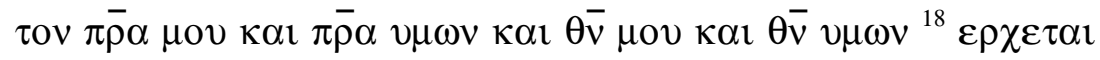

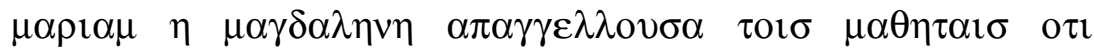

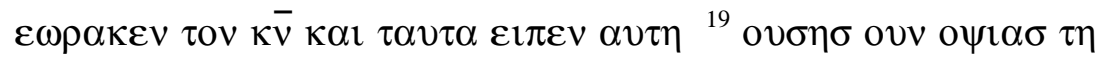
$\eta \mu \varepsilon \rho \alpha \quad \varepsilon \kappa \varepsilon \imath \nu \eta \quad \tau \eta \quad \mu l \alpha \quad \tau \omega v \quad \sigma \alpha \beta \beta \alpha \tau \omega v \quad \kappa \alpha \imath \quad \tau \omega v \quad \theta v \rho \omega v$

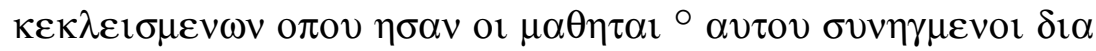

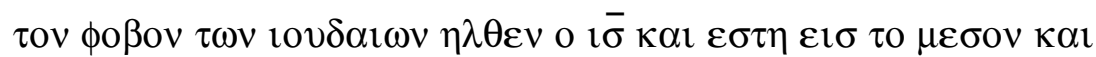

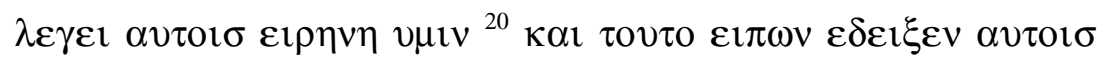

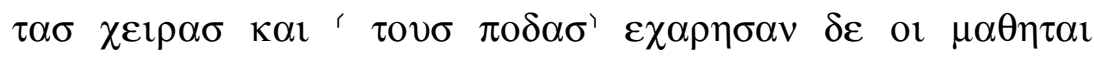

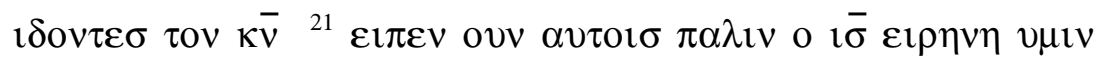

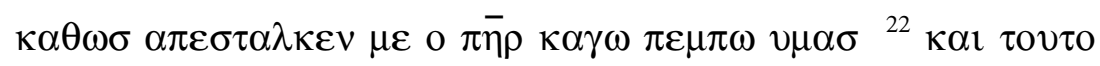

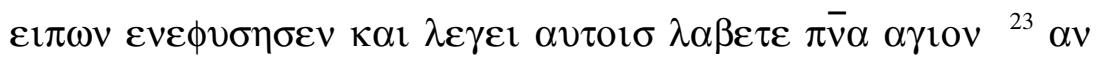

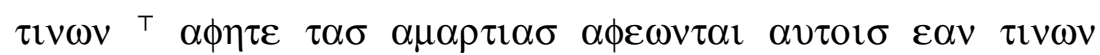
$\kappa \rho \alpha \tau \eta \tau \varepsilon \kappa \varepsilon \kappa \rho \alpha \tau \eta \nu \tau \alpha l{ }^{24} \theta \omega \mu \alpha \sigma^{\prime}$ ovv ' $\varepsilon l \sigma \varepsilon \kappa \tau \omega \nu \delta \omega \delta \varepsilon \kappa \alpha$ o

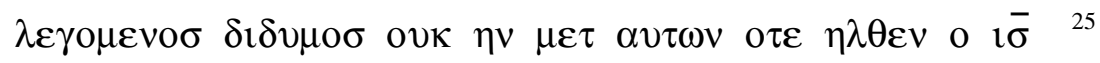
$\varepsilon \lambda \varepsilon \gamma o v$ ovv $\alpha v \tau \omega$ or $\alpha \lambda \lambda$ or $\mu \alpha \theta \eta \tau \alpha$ r $\varepsilon \omega \rho \alpha \kappa \alpha \mu \varepsilon v$ tov $\kappa \bar{v}$ o $\delta \varepsilon$

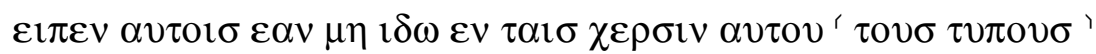

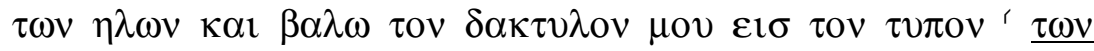

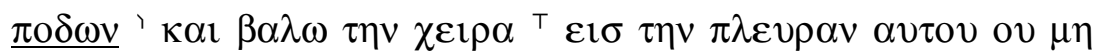

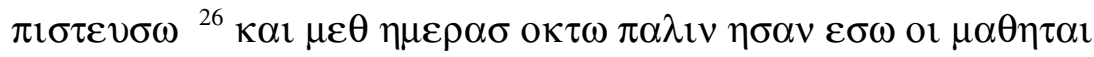

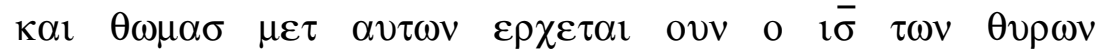

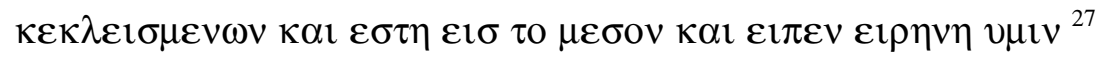

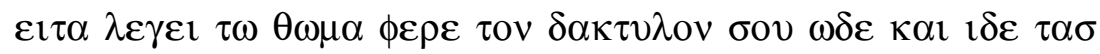

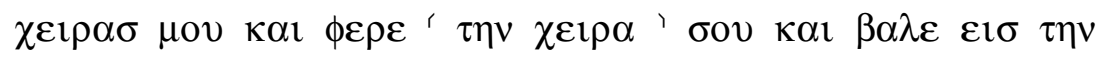

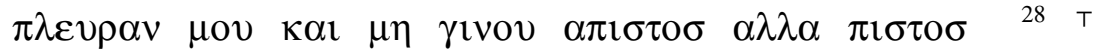

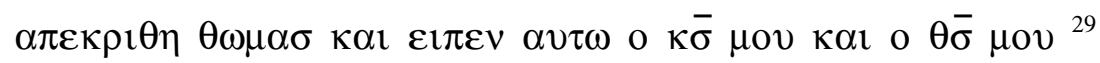

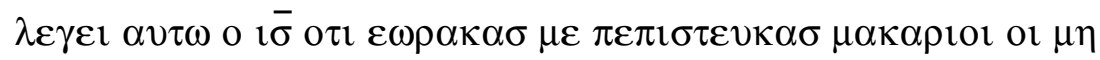

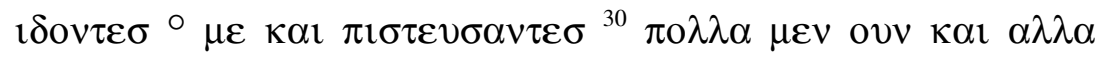

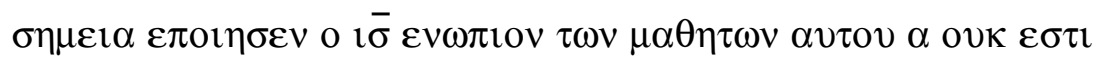

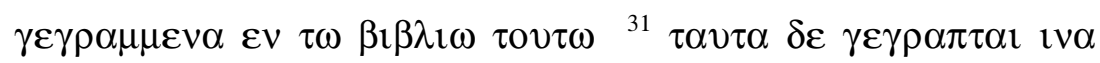

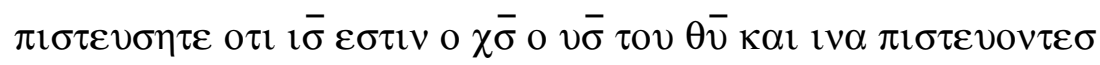

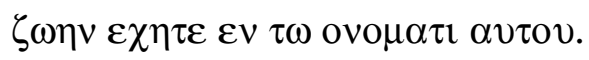

Lac. $\quad 118$ : all ; 872: all ; 2372: all ; 2713 several lines affected by parchment damage. 
Suppl. $118^{\text {sup }}$ all $; 2713^{\text {sup }}$.

${ }^{5} \mathrm{TXT}^{\top} \mu \mathrm{o}[v \alpha] \mathrm{D} ! 2193^{\mathrm{C}[\mathrm{vid}]} ;$ txt $2193 *$ rell. $\mathfrak{N} ;$; [MG] $\left.\mu \mathrm{o}[v \alpha] 2193^{\mathrm{C}[\mathrm{vid}]}\left(*^{6} 1582^{\mathrm{C}}{ }^{\mathrm{T}} \mu \mathrm{ov} \alpha\right)\right|^{6} \mathrm{TXT}^{\mathrm{T}} \mu \mathrm{ov \alpha} \mathrm{D} ! ;$ txt 1582* rell. $\mathfrak{N} ;$; [MG] ${ }^{\top} \mu \mathrm{ov} \alpha 1582^{\mathrm{C}}\left(*^{4} 2193^{\mathrm{C}[\mathrm{vid}]}{ }^{\mathrm{T}} \mu \mathrm{o}[v \alpha]\right)$

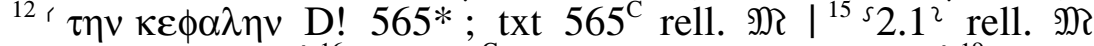
; txt B $\left.222193\right|^{16} \circ 2193^{\mathrm{C}}$ rell. N ; txt C $\left.2193^{*}\right|^{19} \circ$ rell. M ; txt C 2193 | ${ }^{20}$ < $\tau \eta v \pi \lambda \varepsilon v \rho \alpha \nu$ rell. $\mathfrak{N}$; txt B 565884 । ${ }^{23}$ T $\alpha \phi \eta \tau \varepsilon \tau \alpha \sigma \alpha \mu \alpha \rho \tau \imath \alpha \sigma \alpha \phi \imath \varepsilon v \tau \alpha \iota \alpha v \tau 01 \sigma \alpha \nu \tau \imath v \omega \nu$ E! 884 ;

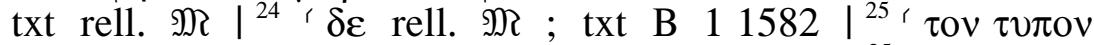
rell. MR ; ' $\tau u \pi$ ov E 118sup ; txt B 22565 | ${ }^{25}$ TXT ' $\tau \omega v$ $\eta \lambda \omega \mathrm{V}$ rell. $\mathfrak{N}$; txt A! $221582^{\text {txt }}$; MG $1582^{\mathrm{mg}}$ (22) | $\left.\right|^{25} \mathrm{~T} \mu \mathrm{ov}$ $209^{\mathrm{C}}$ rell. $\mathfrak{N}$; txt B $\left.1209 * 1582\right|^{27}$ ( $\tau \alpha \sigma \chi \varepsilon \varepsilon 1 \rho \alpha \sigma$ D 884 ; txt rell. $\left.\mathfrak{M}\right|^{28} \mathrm{~T} \kappa \alpha \mathrm{l} 22^{\text {vid }} 1278^{\mathrm{C} 1}$ rell. $\mathfrak{M}$; txt B-A 1 205abs 209 $\left.1278 * 1582\right|^{20} \circ$ rell. $\mathfrak{N}$; txt B-A 122 205abs 2091582 | 


\section{Chapter 21}

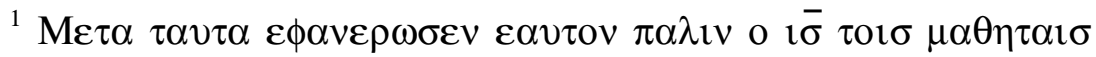

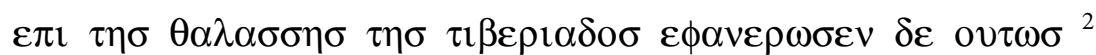

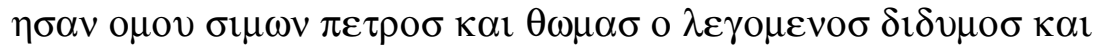

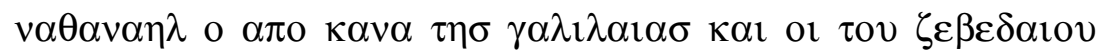

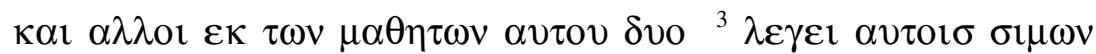

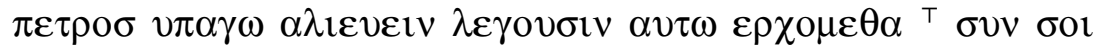

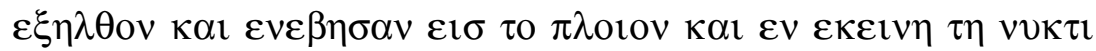

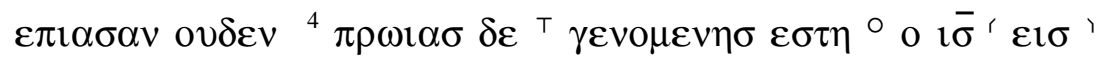

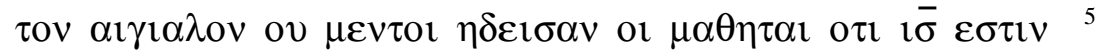

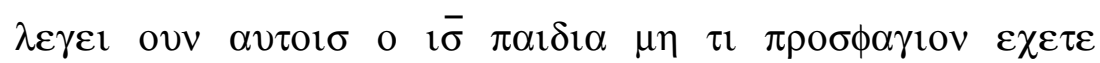

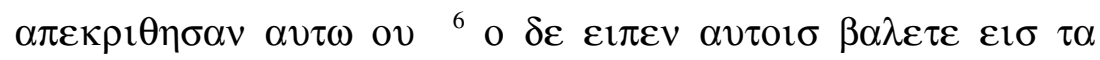

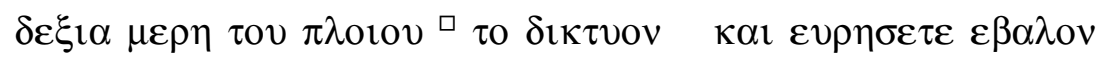

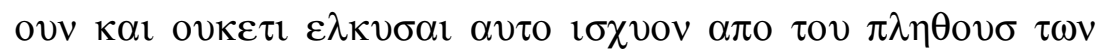

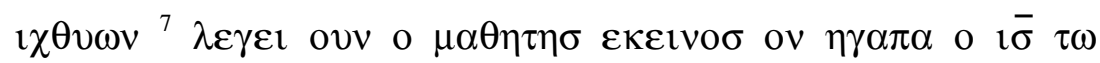
$\pi \varepsilon \tau \rho \omega$ o $\kappa \bar{\sigma} \varepsilon \sigma \tau \imath \mathrm{v} \sigma \mu \omega \mathrm{v}$ ovv $\pi \varepsilon \tau \rho \circ \sigma \alpha \kappa o v \sigma \alpha \sigma$ o $\tau$ о $\kappa \bar{\sigma} \varepsilon \sigma \tau \imath$

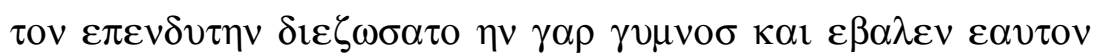
$\varepsilon \iota \sigma \tau \eta v \theta \alpha \lambda \alpha \sigma \sigma \alpha \nu{ }^{8}$ or $\delta \varepsilon \alpha \lambda \lambda$ ol $\mu \alpha \theta \eta \tau \alpha \iota \tau \omega \pi \lambda$ ol $\alpha \rho \iota \omega \eta \lambda \theta$ ov

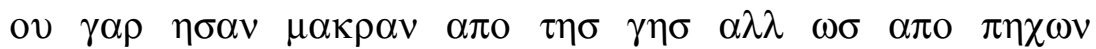

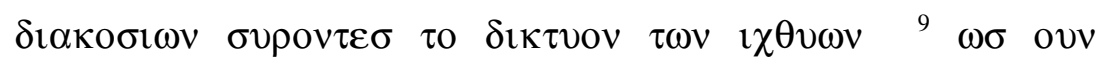

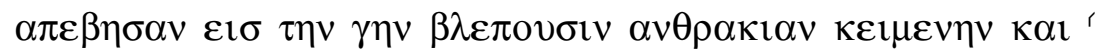

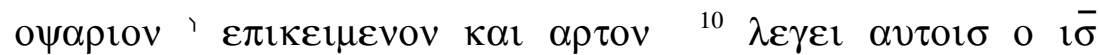

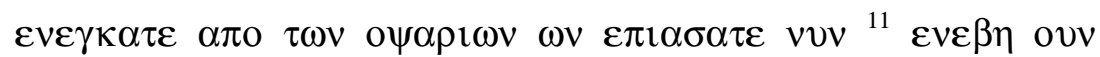

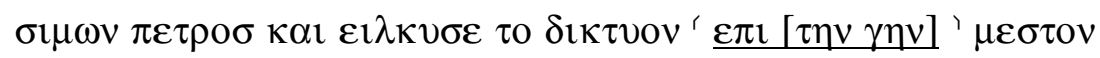

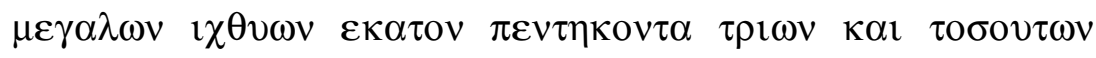

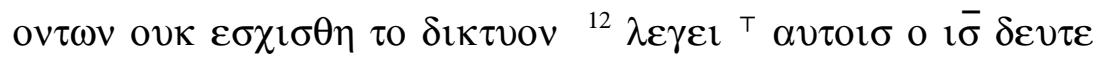

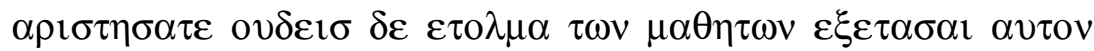

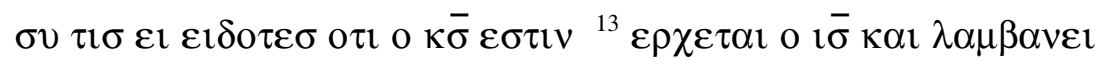

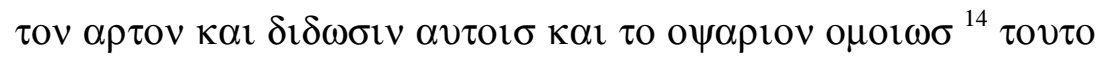

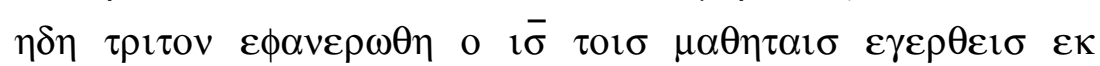

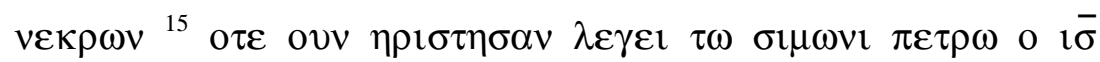

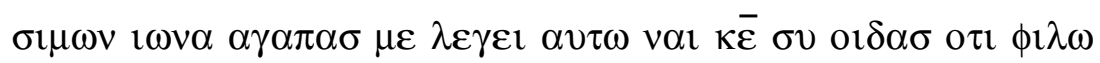




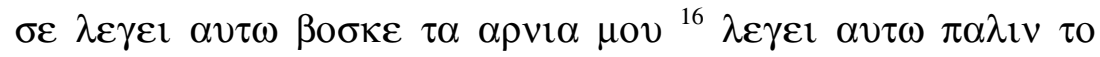

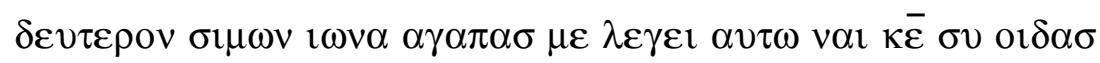

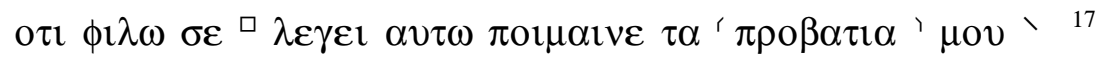

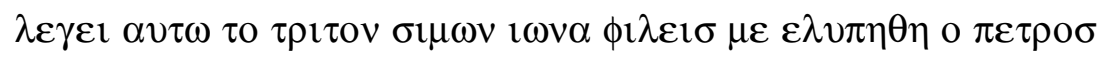

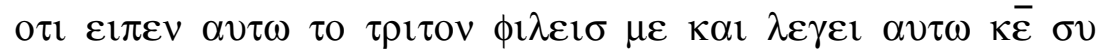

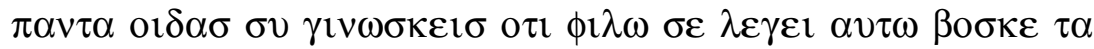

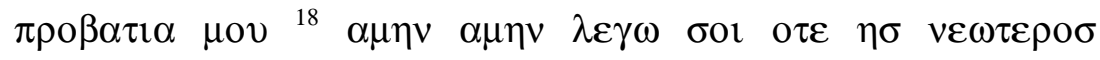

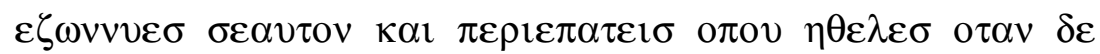

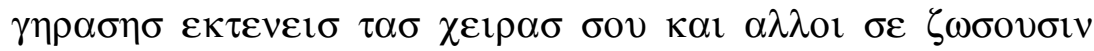
$\kappa \alpha \imath$ a

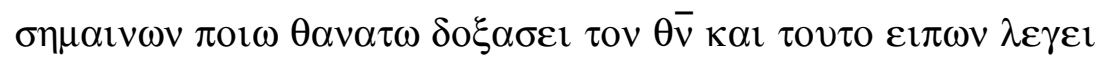

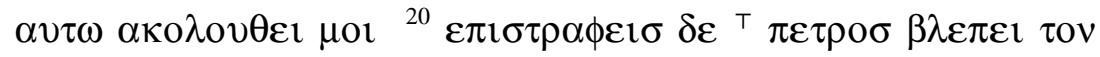

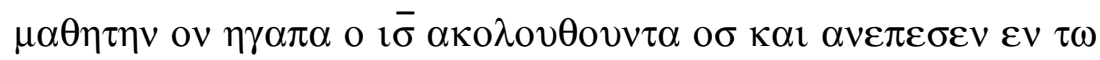

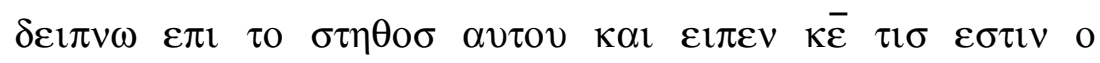

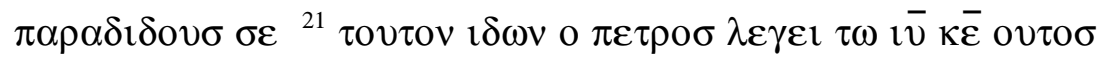

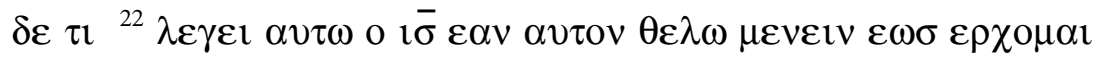

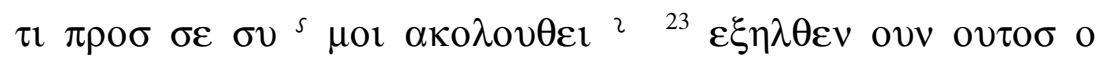

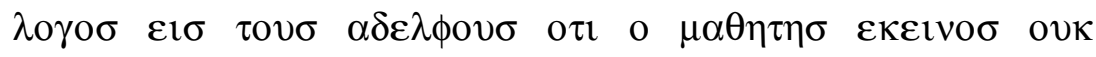

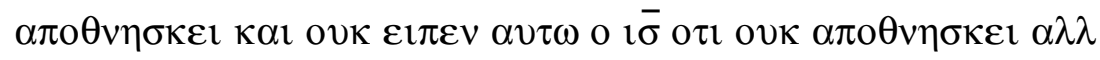

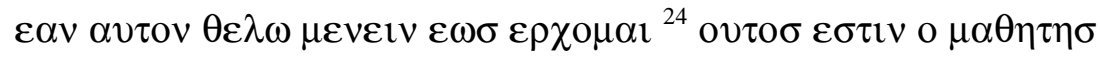

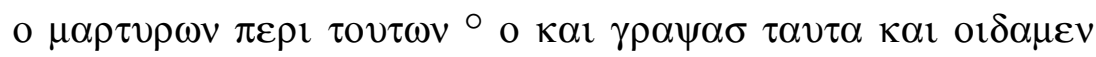

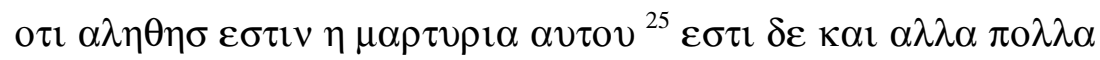

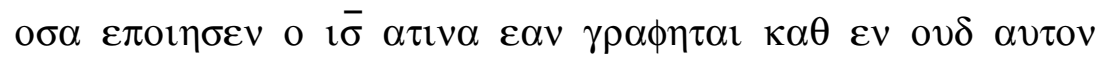

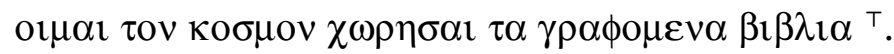

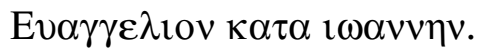

Lac. 118: all ; 872: all; 2372: all ; 2713: parts.

Suppl. $118^{\text {sup }}$ : all ; 2713: several lines affected by parchment damage.

${ }^{3}$ T $\kappa \alpha \iota ~ \eta \mu \varepsilon \iota \sigma$ rell. $\mathfrak{M}$; txt B $\left.11582\right|^{4}{ }^{\mathrm{T}} \eta \delta \eta$ rell. $\mathfrak{M} ;$ txt B-A 205abs 209565 । $^{4} \circ$ D 22 205abs 209 ; txt rell. $\mathbb{M}^{4}{ }^{4}$;

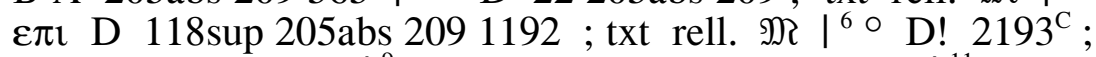

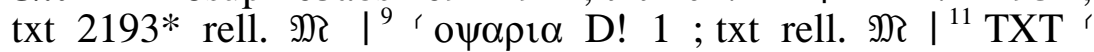
$\varepsilon \pi \imath \tau \eta \sigma \gamma \eta \sigma 2193^{\text {txt }}$ rell. $\mathfrak{M}$; txt B-A! 1 205abs 209565884 
1582 ; $\left.\mathrm{MG}^{\prime} \varepsilon 1 \sigma \tau \eta \nu \gamma \eta \nu 2193^{\mathrm{mg}}\right|^{12} \mathrm{~T}$ ovv D 884 ; txt rell. $\mathfrak{M} 1^{16} \square \mathrm{E}$ ! 1 205abs 209 ; txt A 225651582 (' $\pi \rho \circ \beta \alpha \tau \alpha$ rell. $\mathfrak{N})\left.\right|^{20} \mathrm{~T}$ o rell. $\mathfrak{N}$; txt B $\left.11582\right|^{22}{ }^{5} 2.1^{2}$ rell. $\mathfrak{M}$; txt B $\left.11582\right|^{24} \circ 2193^{*}$ rell. MR ; txt C $\left.2193^{\mathrm{C}}\right|^{25}$ T $\alpha \mu \eta v 22^{\text {vid }}$ rell. $\mathfrak{N}$; txt B 11582 | 


\section{Appendix to the Gospel of John}

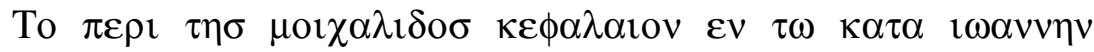

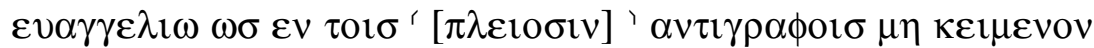

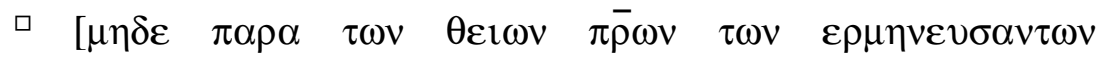

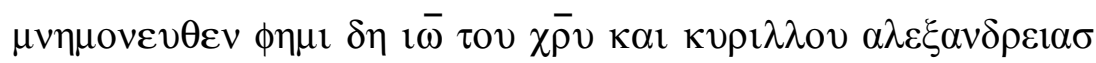

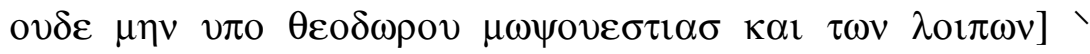

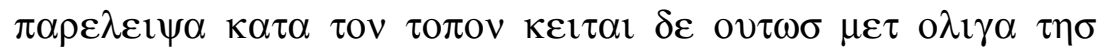

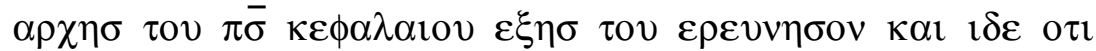

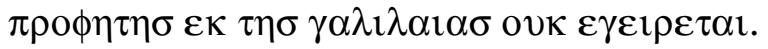

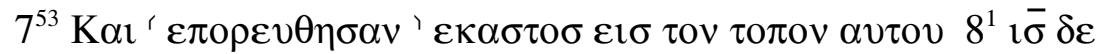

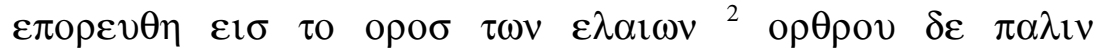

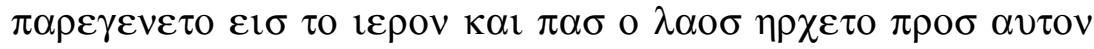
$\kappa \alpha \iota \kappa \alpha \theta \imath \sigma \alpha \sigma \varepsilon \delta 1 \delta \alpha \sigma \kappa \varepsilon v \alpha v \tau o v \sigma{ }^{3} \alpha \gamma o v \sigma \imath v \delta \varepsilon$ ol ' $\alpha \rho \chi \imath \varepsilon \rho \varepsilon \imath \sigma^{\prime}$

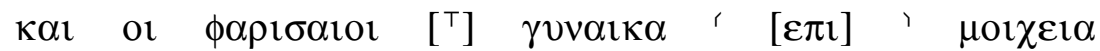

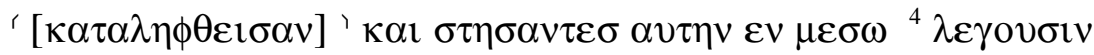
$\begin{array}{lllllll}\alpha v \tau \omega & \circ & {[\pi \varepsilon 1 \rho \alpha \zeta o v \tau \varepsilon \sigma]} & \delta 1 \delta \alpha \sigma \kappa \alpha \lambda \varepsilon & \alpha \nu \tau \eta & \eta & \gamma \nu v \eta\end{array}$ ' $[\kappa \alpha \tau \varepsilon 1 \lambda \eta \pi \tau \alpha 1]^{\prime} \varepsilon \pi \alpha v \tau o \phi \omega \rho \omega \mu \mathrm{ol} \chi \varepsilon v o \mu \varepsilon v \eta{ }^{5} \varepsilon v \delta \varepsilon \tau \omega$ vo $\mu \omega$

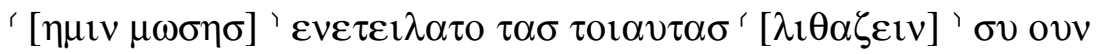

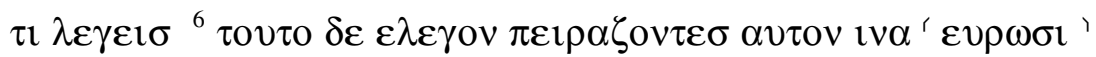

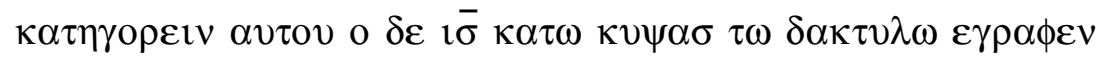
$\varepsilon 1 \sigma \tau \eta \nu ~ \gamma \eta \nu\left[{ }^{\top}\right]^{7} \omega \sigma \delta \varepsilon \varepsilon \pi \varepsilon \mu \varepsilon v o v$ ' $\varepsilon \pi \varepsilon \rho \omega \tau \omega \nu \tau \varepsilon \sigma$ ' $\alpha v \tau o v$ '

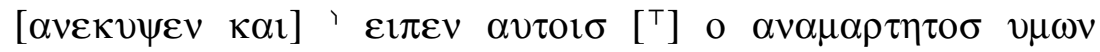
$\pi \rho \omega \tau \sigma \sigma^{\prime} \beta \alpha \lambda \lambda \varepsilon \tau \omega \lambda_{l} \theta 0 \nu \varepsilon \pi \alpha v \tau \eta v^{\prime 8} \kappa \alpha \iota \pi \alpha \lambda \iota v^{\prime} \kappa \alpha \tau \alpha \kappa v \psi \alpha \sigma^{\prime}$ $\varepsilon \gamma \rho \alpha \phi \varepsilon v \varepsilon 1 \sigma \tau \eta \nu \gamma \eta \nu{ }^{9}$ ' $\alpha \kappa o v \sigma \alpha \nu \tau \varepsilon \sigma \delta \varepsilon$ ' [ ['] $\varepsilon \xi \eta \rho \chi 0 \nu \tau \sigma \varepsilon \varepsilon \sigma^{\prime}$

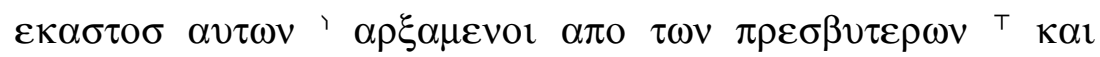

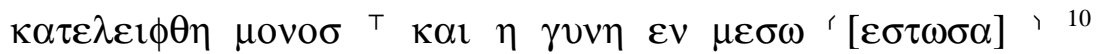
$\alpha v \alpha \kappa v \psi \alpha \sigma \delta \varepsilon$ o $1 \bar{\sigma}\left[{ }^{\top}\right] \varepsilon \imath \pi \varepsilon v \alpha v \tau \eta{ }^{\circ}[\gamma v v \alpha \imath] \pi \mathrm{ov} \varepsilon \mathrm{\varepsilon l \sigma lv}\left[{ }^{\top}\right]$

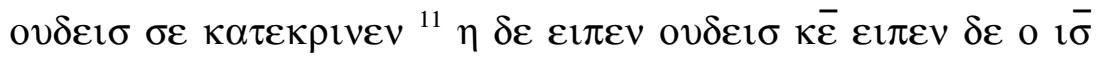

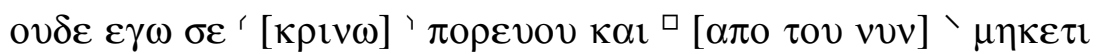
$\alpha \mu \alpha \rho \tau \alpha v \varepsilon$. 
Wit. $156588415821582^{\text {sup }} 2193^{\text {sup }}$

Lac. 884 : note (text located after 7:52); 565: 7:53$8: 11 ; 1582: 8: 7 b-11$.

Note: ' vvv 565 ; txt 11582 | $\square 565$; txt 11582 |

$7^{53}$ । $\varepsilon \pi о \rho \varepsilon v \theta \eta$ 2193sup $\mathrm{M}^{35}$; txt $18841582 \mathrm{M}^{12} \mid 8^{3}$;

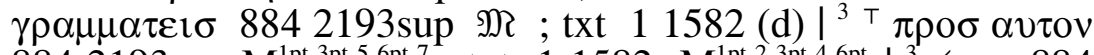
884 2193sup $\mathrm{M}^{1 \mathrm{pt} 3 \mathrm{pt} 56 \mathrm{pt} 7}$; txt $\left.11582 \mathrm{M}^{\mathrm{lpt} 23 \mathrm{pt} 46 \mathrm{pt}}\right|^{3}{ }^{3} \varepsilon v 884$

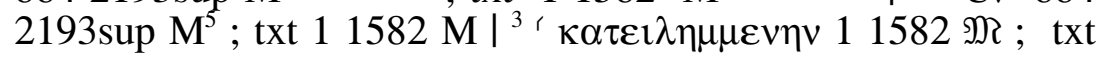
884 2193sup (r) $\left.\right|^{4} \circ 11582$ 次 ; txt 8842193 (w) $\left.\right|^{4}$; $\kappa \alpha \tau \varepsilon \lambda \eta \phi \theta \eta 884$ 2193sup $\mathrm{M}^{5}$; txt $11582 \mathrm{M}^{1} \mathrm{I}^{5}{ }^{\prime} \mu \omega \nu \sigma \eta \sigma \eta \mu \mathrm{tv}$ 884 2193sup $\mathrm{M}^{1 \mathrm{pt} 5}$; txt $\left.11582 \mathrm{M}^{3 \mathrm{pt} 4}\right|^{5}{ }^{\mathrm{r}} \lambda_{\mathrm{l}} \theta \mathrm{o} \beta \mathrm{o} \lambda \varepsilon \imath \sigma \theta \alpha \mathrm{l} 884$ 2193sup $\mathrm{M}^{\mathrm{pt} 57}$; txt $\left.11582 \mathrm{M}^{\mathrm{pt} \mathrm{2346}}\left(\lambda_{\mathrm{r}}[\zeta] \alpha \zeta \varepsilon \mathrm{ctv}\right) 1^{[\mathrm{dub}]}\right|^{6}$, $\varepsilon \chi \omega \sigma \mathrm{v} \quad 884$ 2193sup $\mathfrak{M}$; txt 11582 (d) | ${ }^{6}{ }^{\top} \mu \eta$

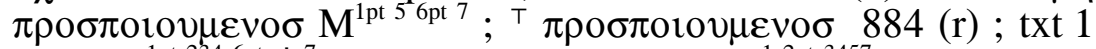
$\left.1582 \mathrm{M}^{\mathrm{lpt} 2346 \mathrm{pt}}\right|^{7}{ }^{7} \varepsilon \rho \omega \tau \omega v \tau \varepsilon \sigma 2193$ sup $\mathrm{M}^{12 \mathrm{pt} 3457}$; txt 1884 $\left.1582 \mathrm{M}^{2 \mathrm{pt} 6}\right|^{7}\left(\alpha v \alpha \kappa v \psi \alpha \sigma 8842193\right.$ sup $\mathrm{M}^{1 \mathrm{pt} 57}$; txt $11582 \mathrm{M}^{2} \mid$ ${ }_{7} r_{\pi \rho o \sigma} \alpha v \tau o v \sigma 8842193$ sup $\mathrm{M}^{57}$; txt $\left.11582 \mathrm{M}^{12346}\right|^{7}$ ' $\varepsilon \pi$

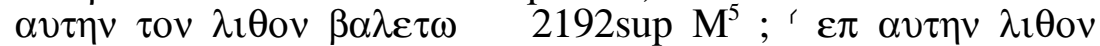

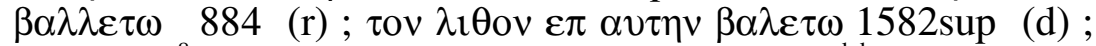
txt 1 (d) $\left.\right|^{8}{ }^{8} \kappa \alpha \tau \omega \kappa v \psi \alpha \sigma \quad 884$ 1582sup 2193sup sub $^{\text {du }}$; txt 1 (r) | ${ }^{9}$ or $\delta \varepsilon \alpha \kappa o v \sigma \alpha \nu \tau \varepsilon \sigma 884$ 1582sup 2193sup $\mathfrak{N}$; txt 1 (r) | ${ }^{9}$ T

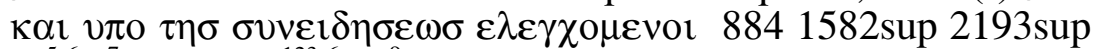
$\mathrm{M}^{5}{ }^{6 \mathrm{pt}} 7$; txt $\left.1 \mathrm{M}^{1236 \mathrm{pt}}\right|^{9}{ }^{\mathrm{r}} \kappa \alpha \theta \varepsilon \mathrm{\varepsilon} \sigma \quad 884$ 1582sup 2193sup $\mathfrak{N}$; txt 1 (d) $\left.\right|^{9}{ }^{\top} \varepsilon \omega \sigma \tau \omega v \_\varepsilon \sigma \chi \alpha \tau \omega v \quad 1582$ sup $\mathrm{M}^{\text {lpt } 23467}$; txt 1884 2193sup $\left.\mathrm{M}^{1 \mathrm{pt} 5}\right|^{9}{ }^{\mathrm{T}}$ o $\mathbf{l}_{\bar{\sigma}} 884$ 1582sup 2193sup $\mathrm{M}^{25}$ 6pt 7 ; txt 1 (r) $\mid{ }^{9}$ ' ov $\sigma \alpha \quad 884$ 1582sup 2193sup $\mathrm{M}^{1 \mathrm{pt} 234567}$; txt $\left.1 \mathrm{M}^{\mathrm{lpt}}\right|^{10} \mathrm{~T}$

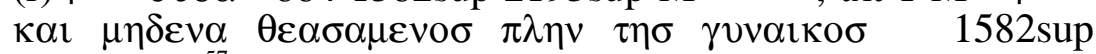

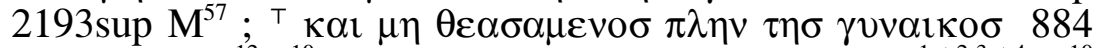
(r); txt $\left.1 \mathrm{M}^{12}\right|^{10} \circ 8842193$ sup ; txt 1 1582sup $\left.\mathrm{M}^{\text {1pt } 23 \mathrm{pt} 4}\right|^{10}$

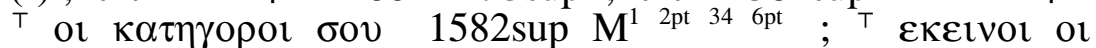

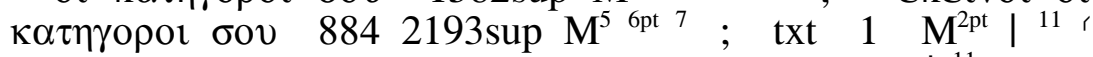

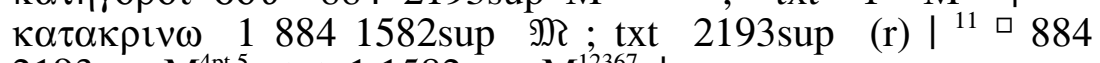
2193sup $\mathrm{M}^{4 \mathrm{pt} 5}$; txt 1 1582sup $\mathrm{M}^{12367}$ । 


\section{Appendix A: Full Family 1 Collation}

\section{Format and Layout of the Collation}

Appendix A contains the full collation of the Gospel of John in the seventeen manuscripts investigated. The collation is included in PDF files on a CD Rom (for PC). For ease of navigation, the collation has been divided into chapters. Each chapter in the collation opens with a list of manuscript supplements that are present for all or parts of that chapter (followed by the verse references for the relevant sections). This list is followed by a list of manuscripts that are missing text for all or parts of the chapter (followed by the verse references indicating the relevant sections). The collation of each chapter begins beneath these lists and is divided into separate meaningful units of variation. Each unit is separated by a space. Chapter and verse references for each unit are given in bold in the left hand margin. Each variation unit begins with the reading of 1582, which was used as a base text for the collation. Immediately following the reading is a list of manuscript support for that reading. Manuscripts are cited in numerical order by their Gregory-Aland numbers. Following the list of witness support, a letter is given indicating how well that reading is attested in the wider textual tradition of John. ${ }^{331}$ Variant readings within a unit are separated by a closing square bracket ( ] ). Following the closing bracket, the first variant from the base text is cited, followed by a list of manuscript support and a letter, indicating how well

\footnotetext{
${ }^{331}$ See section 1.2 for further details of this labelling. See also List of Symbols and Abbreviations Used in the Collation below. Uncertain readings are not rated nor are certain orthographic variants.
} 
attested that reading is in the wider textual tradition. The same pattern is repeated if there are further variant readings in that unit.

\section{Replacements, Transpositions, Additions and Omissions}

When a variant reading constitutes a replacement or a transposition, the alternative text (or order of words) is given; no symbols or abbreviations are used to indicate replacements and transpositions. For additions and omissions 'add' and 'omit', respectively, follows the word or words cited for the variant reading. Unless otherwise indicated, additions of text always come after the text cited as the reading of the base text. ${ }^{332}$

\section{Repeated Text in Verses}

If a word or word combination occurs in a verse more than once, a number inside round brackets follows immediately after the reading of the base text to indicate the point in the verse where the actual variation occurs.

\section{Lacunas and Supplements}

The existence of lacunas and the presence of supplement manuscripts is also noted at the relevant section in the collation, noted in bold inside square brackets before the first unit where the lacuna or supplement is present and following the final unit where the lacuna or supplement is present.

\footnotetext{
332 [ante] before a unit indicates that additions should be added before the text cited as the reading of the base text.
} 


\section{Deficient Manuscripts (DEF)}

Occasionally a manuscript or number of manuscripts omit a long string of text where there are variations among the remaining manuscripts on that same string of text. On such occasions a deficiency apparatus (DEF) is employed, as for example in 5:9:

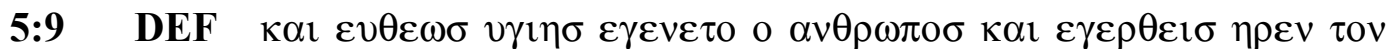

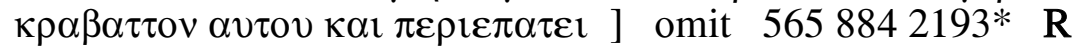

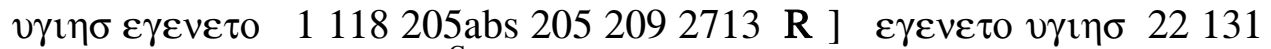
$8721192121012782193^{\mathrm{C}} 2372 \mathfrak{M}$

$\varepsilon \gamma \varepsilon \rho \theta \varepsilon 1 \sigma \quad 1118$ 205abs 2052092713 R ] omit 2213187211921210 $12782193^{\mathrm{C}} 2372 \mathfrak{M}$

In such cases, the manuscripts containing the long omission are cited first in the deficiency apparatus, indicated by the preceding DEF. DEF is followed by the string of omitted text as it occurs in the base text, a closing square bracket followed by 'omit' precedes the list of manuscripts that contain the omission. The deficiency apparatus is followed by the variant readings found in the remaining manuscripts, as usual beginning with the reading of the base text; however, only the text where there is disagreement among the remaining manuscript is cited. ${ }^{333}$ The rest of the unit follows the usual pattern.

The deficiency apparatus is never counted as a variation unit on its own but is part of a wider unit, or number of units, that follow. If one unit follows, the

${ }^{333}$ Deficiency apparatuses in the full collation are always taken into account when calculating figures of agreements and disagreements. 
deficiency counts as one unit, if two units follow the deficiency counts as two units and so on. In 5:9, therefore, the reading of 565, 884 and $2193 *$ is counted as two units (or readings) because there are two different points of variation on the omitted string of text among the remaining manuscripts. ${ }^{334}$

\section{Regularisation}

As discussed in section 1.2, a number of regularisations were made before the final collation was produced, discarding minor variations that were considered insignificant for determining the genetic relationships between manuscripts. On occasion, however, certain readings that would have been regularised out of the collation have been retained at points where there is other genetically significant variation. For the sake of consistency all variations on the spelling of place names and character names have been retained.

\section{List of Symbols and Abbreviations used in the Collation}

a Indicates that a lacuna or the presence of a supplement manuscript ends at the beginning of a verse. The letter follows immediately after the chapter and verse reference.

b Indicates that a lacuna or the presence of a supplement manuscript begins part way through a verse. The letter follows immediately after the chapter and verse reference.

\footnotetext{
${ }^{334}$ Note that the deficiency apparatus has always been taken into account when calculating figures of agreements and disagreements among manuscripts.
} 
D A distinctive Non-Majority Text reading not attested by any other Greek manuscript outside of Family $1 .^{335}$

R A rare Non-Majority Text reading, attested by no more than nine Greek manuscripts outside of Family 1.

W A widely attested Non-Majority Text reading found in ten or more Greek manuscripts outside of Family 1.

$\mathfrak{M} \quad$ The reading of the Majority Text. ${ }^{336}$

M The reading of the Majority Text with reduced support.

$\mathrm{M}^{\mathrm{pt}} \quad$ The reading of the Majority Text when the Majority Text is divided.

$\mathbf{M}^{1} \quad \mathbf{M}$ followed by a number indicates a subgroup of the Majority Text as detailed by Hodges and Farstad. ${ }^{337}$ Used only in readings found in the Pericope Adulterae.

omit Omission. The manuscripts following omit the word/s of the base text.

add Addition. The manuscripts cited add the given word to the base text. The addition always comes after the word in the base text unless otherwise indicated.

[ante] Before. Any 'additions' in the unit occur before the given word/s in the base text. [ante] always precedes the reading of the base text.

DEF Deficient. Opens a deficiency apparatus.

DEF! ! Indicates that the deficiency lasts for a complete verse.

mg Margin. The marginal reading of a manuscript.

txt Text. The reading in the running text of a manuscript at a point where it also contains a marginal variation.

suppl Supplied. The reading of the manuscript is supplied.

sup Supplement manuscript. The reading of a supplement manuscript.

\footnotetext{
${ }^{335}$ See section 1.2 for further details of this labelling system and the use of the IGNTP editions of John.

${ }^{336}$ All Majority Text readings are labelled using Hodges and Farstad, Majority Text.

${ }^{337}$ Hodges and Farstad, Majority Text, xxiii-xxxii.
} 
* The first hand reading of a manuscript at a point where that manuscript has been corrected.

C Corrector. The reading of a corrector in a manuscript. ${ }^{\mathrm{C}}$ may be followed by a number distinguishing a particular corrector or by $*$ to indicate a first hand corrector.

Dubious. The reading of this manuscript is uncertain.

[dub] Dubious. The letter/s enclosed in square brackets in the cited reading are uncertain in this manuscript.

[] The letters enclosed are uncertain for the manuscript cited.

[1] A number inside square brackets in place of a reading or as part of a reading indicates the approximate number of letter spaces present in an illegible word or part of a word in a manuscript.

[dub] The reading of the manuscript is illegible and the number of letters also uncertain.

pcorr Possible Correction. Indicates that the reading cited for the manuscript may be the reading of a corrector in that manuscript, rather than the reading of the first hand.

[lac] The text cited inside square brackets is missing in the manuscript cited.

(1st) The number inside the brackets distinguishes the point in a verse where a variation exists when the text of the reading occurs more than once in a verse. 


\section{Appendix B: Lists of Selected Readings}

Introduction to Appendix B

Appendix B contains selected lists of readings from the full collation of the Gospel of John. These lists are intended to give the reader access to as much of the original data used for this thesis as possible; and to allow readers to check for accuracy many of the figures given in the thesis. The lists may also be of use to readers who wish to use the data for their own purposes. The lists are included as separate PDF files on a CD Rom insert. The title of each list is preceded by a numerical reference indicating which section of the thesis the list is most relevant to. The contents of the appendix are given below.

Contents of Appendix B

Lists for Chapter 2

2.1.5. List of Non-Majority Text Corrections in 2193

2.2.1. List of Disagreements Between 1 and 1582

2.2.2. List of Non-Majority Text Readings in 156588415822193

2.2.2. List of Non-Majority Text Readings in 1

2.2.2. List of Non-Majority Text Readings in 565

2.2.2. List of Non-Majority Text Readings in 884

2.2.2. List of Non-Majority Text Readings in 1582

2.2.2. List of Non-Majority Text Readings in 2193

2.2.3. List of Marginal Readings in 1582 
2.2.3. List of Marginal Readings in 2193

2.2.5. List of Disagreements Between 156588415822193 (not counting Majority Text Corrections)

2.2.5. List of Disagreements Between 156588415822193 (where there is NonMajority Text Division)

2.2.5. List of Disagreements Between 156588415822193

2.2.5. List of Disagreements Between 11582565 (not counting Majority Text Corrections)

2.2.5. List of Disagreements Between 11582884

2.2.5. List of Disagreements Between 115822193 (not counting Majority Text Corrections)

2.2.5. List of Disagreements Between 565 and 884 (not counting Majority Text Corrections)

2.2.5. List of Disagreements Between 565 and 2193 (not counting Majority Text Corrections)

2.2.5. List of First Hand Disagreements Between 884 and 2193

2.2.7. List of Disagreements Between 5658842193 (not counting Majority Text Corrections)

2.2.7. List of Non-Majority Text Readings in 5658842193

2.2.12. List of Non-Majority Text Readings in 565884 and 2193 not supported by 1 or 1582

2.2.13. List of Non-Majority Text text Readings supported by 2 or more Descendants of B not supported by 1 or 1582

Lists for Chapter 3

3.2.2. List of Non-Majority Text Readings in 118 205abs 2052092713

3.2.2. List of Non-Majority Text Readings in 118

3.2.2. List of Non-Majority Text Readings in 205

3.2.2. List of Non-Majority Text Readings in 205abs 
3.2.2. List of Non-Majority Text Readings in 209

3.2.2. List of Non-Majority Text Readings in 2713

3.2.4. List of Disagreements Between 118 205abs 2052092713

3.2.5. List of Exclusive Non-Majority Text Readings shared by all extant Venice Group Manuscripts

3.2.8. List of Exclusive Readings shared by 1 and the Venice Group

3.2.15. List of Disagreements Between 205abs and 205

3.2.17. List of Disagreements Between 205abs and 209

Lists for Chapter 4

4.2.2. List of Marginalia in 2211921278

4.2.2. List of Non-Majority Text Readings in 221192121012782372

4.2.2. List of Non-Majority Text Readings in 2211921210

4.2.2. List of Non-Majority Text Readings in 22

4.2.2. List of Non-Majority Text Readings in 1192

4.2.2. List of Non-Majority Text Readings in 1210

4.2.2. List of Non-Majority Text Readings in 1278

4.2.2. List of Non-Majority Text Readings in 2372

4.2.4. List of Disagreements Between 221192121012782372

4.2.11. List of Disagreements Between 22 and 1210

4.2.12. List of First Hand Disagreements Between 1278 and 2372

4.2.12. List of Non-Majority Text Readings in 1278 and 2372 
Lists for Chapter 5

5.2.2. List of A-1 Readings in 131

5.2.2. List of Non-Majority Text Readings in 131 with limited support from Family 1 Manuscripts

5.2.5. List of Singular Readings in 131

5.4.2. List of A-1 Readings in 872

5.4.2. List of Non-Majority Text Readings in 872 with limited support from Family 1 Manuscripts

5.4.2. List of Non-Majority Text Readings in 872

List for Chapter 7

7.4. List of Singular Readings in 884 


\section{Bibliography}

Agati, Maria Luisa. La Minuscola "Bouletée". Vatican City: Scuola Vaticana di Paleografia, Diplomatica e Archivistica, 1992.

Aland, B., K. Aland, J. Karavidopoulos, C. M. Martini and B. M. Metzger, ed. The Greek New Testament. $4^{\text {th }}$ revised edition. Stuttgart: Deutsche Bibelgesellschaft, 1998.

Aland, B., K. Aland, Eberhard Nestle and Erwin Nestle, ed. Novum Testamentum Graece. 27th edition. Stuttgart: Deutsche Bibelgesellschaft, 2002.

Aland, K. with M. Welte, B. Köster and K. Junack. Kurzgefasste Liste der griechischen Handschriften des Neuen Testaments (ANTF 1), Berlin: Walter de Gruyter, 1963; $2^{\text {nd }}$ edition, 1994.

Aland, K. and B. Aland. The Text of the New Testament. An Introduction to the Critical Editions and to the Theory and Practice of Modern Textual Criticism. Grand Rapids: William B. Eerdmans Publishing Company, 1995.

Aland, K, B. Aland and K. Wachtel, ed. Text und Textwert der griechischen Handschriften des Neuen Testaments. IV, die synoptischen Evangelien. Das Matthäusevangelium. Band 2,1 und 2,2. Berlin: Walter de Gruyter, 1999.

Aland, K, B. Aland and K. Wachtel, ed. Text und Textwert der griechischen handschriften des Neuen Testaments. IV, die synoptischen Evangelien. Das Lukasevangelium. Band 3,1 und 3,2. Berlin: Walter de Gruyter, 1999.

Aland, K, B. Aland and K. Wachtel, ed. Text und Textwert der griechischen Handschriften des Neuen Testaments. IV, die synoptischen Evangelien. Das Markusevangelium. Band 4,1 und 4,2. Berlin: Walter de Gruyter, 1999.

Aland, K, B. Aland and K. Wachtel, ed. Text und Textwert der griechischen Handschriften des Neuen Testaments $V$, das Johannesevangelium. Bands 1,1 und 1,2. Berlin: Walter de Gruyter, 2005.

Allen, T. W. "The Origin of the Greek Minuscule Hand." Journal of Hellenic Studies 40 (1920): 1-12.

Anderson, Amy S. "Codex 1582 and Family 1 of the Gospels: The Gospel of Matthew." PhD diss., University of Birmingham, 1999.

Anderson, Amy S. The Textual Tradition of the Gospels: Family 1 in Matthew. Leiden: E. J. Brill, 2004.

Anderson, Jeffrey C. "The Illustration of Cod. Sinai. Gr. 339." The Art Bulletin, vol. 61 , no. 2 (1979): 167-185. 
Anderson, Jeffrey C. "Manuscripts" In The Glory of Byzantium: Art and Culture of the Middle Byzantine Era A.D. 843-1261, edited by Helen C. Evans and William D. Wixom. New York: The Metropolitan Museum of Art, 1997: 82-92.

Axinia, Dzurova. Byzantinische Miniaturen Schätze der Buchmalerei vom 4. bis zum 19. Jahrhundert. Regensburg: Schnell and Steiner, 2002.

Barbour, Ruth. Greek Literary Hands-AD. 400-1600. Oxford: Clarendon, 1981.

Brown, J. "Latin Palaeography since Traube." Transactions of the Cambridge Bibliographical Society 3 (1963): 361-381.

Brown, S. "Concerning the Origin of the Nomina Sacra." Studia Papyrologica 9 (1970): 7-19.

Buchthal, Hugo. "A Byzantine Miniature of the Fourth Evangelist and Its Relatives.” Dumbarton Oaks Papers 15 (1961): 127-139.

Buchthal, Hugo. "Studies in Byzantine Illumination of the Thirteenth Century." Jahrbuch der Berliner Museen 25 (1983): 27-102.

Burkitt, F. C. "Review of The Four Gospels, a Study of Orgins, by B. H. Streeter. Macmillan, 1924.” Journal of Theological Studies 26 (1925): 278-294.

Burkitt, F. C. "The Caesarean Text." Journal of Theological Studies 30 (192829): $347-358$.

Burkitt, F. C. "The Chester Beatty Papyri." Journal of Theological Studies 34 (1933): 363-368.

Burkitt, F. C. "Some Notes on the Chester Beatty Gospels and Acts." In Quantulacumque, edited by Robert P. Casey, Silva Lake, and Agnes K. Lake. London: Christophers, 1937. 145-148.

Canart, Paul, and Peri, Vittorio. Sussidi Bibliografici per i Manoscritti Greci della Biblioteca Vaticana, Studi e Testi 261. Rome: Biblioteca Apostolica Vaticana, 1970.

Cavallo, G. and Maehler, H. Greek Bookhands of the Early Byzantine PeriodA.D. 300-800. Bulletin Supplement 47. London: University of London Institute of Classical Studies, 1987.

Childers, J.W. and D.C. Parker, ed., Transmission and Reception: New Testament Text-Critical and Exegetical Studies. Texts and Studies 3rd series, no. 4. Piscataway: Gorgias Press, 2006.

Clark, K. W. A Descriptive Catalogue of Greek New Testament Manuscripts in America. Chicago: University of Chicago Press, 1937. 
Colwell, Ernest Cadman. "The Complex Character of the Late Byzantine Text of the Gospels." Journal of Biblical Literature 54, 4 (1935): 211-221.

Colwell, Ernest Cadman. Studies in Methodology in Textual Criticism of the New Testament. Leiden: E. J. Brill, 1969.

Colwell, Ernest Cadman. "Slandered, Ignored: the Armenian Gospels." Journal of Religion 17 (1937): 48-61.

Colwell, Ernest Cadman, Irvin Alan Sparks, Frederik Wisse and Paul R. McReynolds. "The International Greek New Testament Project: A Status Report." Journal of Biblical Literature 87, 2 (1968): 187-197.

Coxe, Henry O. Catalogi codicum manuscriptorum Bibliothecae Bodleianae pars prima recensionem codicum Graecorum continens. Oxford: EP Publishing Company, 1853; reprinted with corrections, 1969.

Dearing, Vinton, A. "Some Notes on Genealogical Methods in Textual Criticism." Novum Testamentum 9 (1967): 278-97.

Devreesse, Robert. Codices Vaticani Graeci, Tomus II, Codices 330-603. Città del Vaticano: Biblioteca Apostolica Vaticana, 1937.

Devreesse, Robert. "Manuscrits Grecs de l'Italie Méridionale (Histoire, Classement, Paléographie)." Studi e testi 183. Città del Vaticano: Biblioteca Apostolica Vaticana, 1955.

Diller, Aubrey. "Notes on Greek Codices of the Tenth Century." Transactions and Proceedings of the American Philological Association 78 (1947): 184-188.

Diller, Aubrey. "Codex T of Plato.” Classical Philology 75, 4 (1980): 322-324.

Diller, Aubrey. Studies in Greek Manuscript Tradition. Amsterdam: Adolf M. Hakkert, 1983.

Ebersolt, J. La Miniature Byzantine. Paris: Librairie Nationale d'Art et d'Histoire, 1926.

Ehrman, Bart D. "The Use of Group Profiles for the Classification of New Testament Documentary Evidence." Journal of Biblical Literature, 106, 3 (1987): 465-486.

Ehrman, Bart D. "Methodological Developments in the Analysis and Classification of New Testament Documentary Evidence." Novum Testamentum 29, Fasc. 1 (1987): 22-45.

Ehrman, Bart D. "Heracleon, Origen, and the Text of the Fourth Gospel." Vigiliae Christianae, 74 (1993): 105-118. 
Ehrman, Bart D. "Heracleon and the 'Western' Textual Tradition." New Testament Studies 40 (1994): 161-179.

Ehrman, Bart D., Gordon D. Fee and Michael W. Holmes, The Text of the Fourth Gospel in the Writings of Origen, vol. 1. Atlanta: Scholars Press, 1992.

Ehrman, Bart D. and Michael W. Holmes, ed., The Text of the New Testament in Contemporary Research. Grand Rapids: Eerdmans, 1995.

Elliott, J. K. "The Biblical Manuscripts of the John Rylands University Library of Manchester." Bulletin of The John Rylands University Library of Manchester 81, 2 (1999) reprint.

Elliott, J. K.. A Bibliography of Greek New Testament Manuscripts. Society for New Testament Studies Monograph Series 109. $2^{\text {nd }}$ edition. Cambridge: Cambridge University Press, 2000.

Elliott, W. J., and D. C. Parker, ed., The New Testament in Greek IV. The Gospel According to John, vol. 1, The Papyri. Leiden: E. J. Brill, 1995.

Epp, E. J. "The Claremont Profile Method for Grouping New Testament Minuscule Manuscripts." In Studies in the History and Text of the New Testament in Honor of Kenneth Willis Clark, edited by Boyd L. Daniels and M. Jack Suggs. Salt Lake City, UT: University of Utah, 1967, 27-38.

Epp, Eldon J. "The Twentieth Century Interlude in New Testament Textual Criticism." Journal of Biblical Literature 93, 3 (1974): 386-414.

Epp, Eldon J. "A Continuing Interlude in New Testament Textual Criticism." Harvard Theological Review 73, 1/2 (1980): 131-151.

Escher, K.. Die Miniaturen in den Basler Bibliotheken, Museen und Archiven. Basel: Bibliotheken Basel, 1917.

Eustratiades, Sophronios and Arkadios Batopedinos. Catalogue of the Greek Manuscripts in the Library of the Monastery of Vatopedi on Mt. Athos, Harvard Theological Studies XI. Cambridge: Harvard University Press, 1924.

Farthing, G. P. "Numerical Methods of Demonstrating the Relationships of Greek New Testament Manuscripts." PhD diss., University of Birmingham, 1990.

Fee, G. D. Papyrus Bodmer II (P66): Its Textual Relationships and Scribal Characteristics, SD, 34. Salt Lake City: University of Utah Press, 1968.

Fee, G. D. "Codex Sinaiticus in the Gospel of John." New Testament Studies 15 (1968-69): 22-44. 
Fee, G. D. "The Text of John in Origen and Cyril of Alexandria: A Contribution to Methodology in the Recovery and Analysis of Patristic Citations." Biblica 52, 3 (1971): 357-394.

Fee, G. D. "The Lemma of Origen's Commentary on John, Book X-An Independent Witness to the Egyptian Textual Tradition." New Testament Studies 20 (1973): 78-81.

Fee, G. D. " $\mathrm{P}^{75} \mathrm{P}^{66}$ and Origen: The Myth of Textual Recension in Alexandria." In New Dimensions in New Testament Study, edited by Richard N. Longenecker and Merrill C. Tenney. Grand Rapids, MI: Zondervan, 1974, 19-45.

Friend, A. M. "The Portraits of the Evangelists in Greek and Latin Manuscripts." Art Studies 5 (1927): 115-47.

Friend, A. M. "The Portraits of the Evangelists in Greek and Latin Manuscripts: Part 2." Art Studies 7 (1929): 3-29.

Galavaris, George. The Illustrations of the Prefaces in Byzantine Gospels. Vienna: österreichische Akademie der Wissenschaften, 1979.

Gamillscheg, E et al. Repertorium der griechischen Kopisten 800-1600. Vienna: österreichische Akademie der Wissenschaften, 1981.

Geanakoplos, Deno J. "The Council of Florence (1438-1439) and the Problem of Union Between the Greek and the Latin Churches." Church History 24, 4 (1955): 324-346.

Geanakoplos, Deno J. Greek Scholars in Venice: Studies in the Dissemination of Greek Learning from Byzantium to Western Europe. Cambridge: Harvard University Press, 1962.

Geer, Thomas C. "Analyzing and Categorizing New Testament Greek Manuscripts: Colwell Revisited." In The Text of the New Testament in Contemporary Research, Essays on the Status Quaestionis, edited by Bart D. Ehrman and Michael W. Holmes. Grand Rapids, Michigan: Eerdmans , 1995, 253-267.

Gill, Joseph. The Council of Florence. Cambridge: Cambridge University Press, 1959.

Goodspeed, Edgar. The Newberry Gospels. Chicago: Chicago University Press, 1902.

Gregory, Caspar René. Textkritik des Neuen Testamentes, Erster Band; Zweiter Band; Dritter Band. Leipzig: J.C. Hinrichs, 1900-1909. 
Hatch, W. H. P. The Greek Manuscripts of the New Testament at Mount Sinai: Facsimiles and Descriptions. Paris: Librairie orientaliste Paul Geuthner, 1932.

Hatch, W. H. P. Facsimiles and Descriptions of Minuscule Manuscripts of the New Testament. Cambridge: Harvard University Press, 1951.

Hills, Edward F. "Harmonization in the Caesarean Text of Mark." Journal of Biblical Literature 66, 2 (1947): 135-152.

Hills, Edward F. "The Inter-Relationship of the Caesarean Manuscripts." Journal of Biblical Literature 68, 2 (1949): 141-159.

Hills, Edward F. "A New Approach to the Old Egyptian Text." Journal of Biblical Literature 69, 4 (1950): 345-362.

Hodges, Zane C. and Arthur L. Farstad. The Greek New Testament According to the Majority Text. New York: Thomas Nelson Publishers, 1982.

Horowitz, Deborah. A Catalogue of Greek Manuscripts at the Walters Art Museum and Essays in Honour of Gary Vikan, vol. 62. Houten: HES \& DE GRAAF Publishers, 2004.

Hoskier, H. C. A Full Account and Collation of the Greek Cursive Codex Evangelium 604. London: D. Nutt, 1890.

Hoskier, H. C. "Von Soden's Text of the New Testament." Journal of Theological Studies 15 (1913): 307-326.

Hoskier, H. C. "Von Soden's Text of the Greek New Testament Examined in Selected Passages." The Expositor 8, 10 (1915): 429-44.

Houghton, H. A. G. and D. C. Parker, ed., Textual Variation: Theological and Social Tendencies? Papers from the Fifth Birmingham Colloquium on the Textual Criticism of the New Testament. Text and Studies Third Series, Vol. 6. Piscataway: Gorgias Press, 2008.

Huffman, Norman. "Suggestions from the Gospel of Mark for a New Textual Theory." Journal of Biblical Literature 56, 4 (1937): 347-359.

Hunger, H. and C. Hannick. Katalog der griechischen Handschriften der österreichische Nationalbibliothek. 4 Supplementum Graecum. Vienna: österreichische Akademie der Wissenschaften, 1994.

Hunger, H, ed., Repertorium der Griechischen Kopisten 800-1600, 3. Teil, Band C. Vienna: österreichische Akademie der Wissenschaften, 1997. 
Hurtado, L. W. "Beyond the Interlude? Developments and Directions in New Testament Textual Criticism." In Studies in the Early Text of the Gospels and Acts, edited by D. G. K. Taylor. Atlanta: Society of Biblical Literature, 1999, 2648.

Hurtado, L. W. Text-Critical Methodology and the Pre-Caesarean Text: Codex W in the Gospel of Mark. Grand Rapids, Michigan: Eerdmans, 1981.

Hurtado, L.W. "The Origin of the Nomina Sacra: A Proposal." Journal of Biblical Literature 117 (1998): 655-73.

Hurtado, L.W. The Earliest Christian Artefacts: Manuscripts and Christian Origins. Grand Rapids: Eerdmans, 2006.

Hutter, Irmgard. Corpus der byzantinischen Miniaturenhandschriften, I: Oxford, Bodleian Library. Stuttgart: Hiersemann, 1977.

Hutton, E. A. Atlas of Textual Criticism. Cambridge: Cambridge University Press, 1911.

Irigoin, Jean. "Pour une étude des centres de copie Byzantins." Scriptorium 12 (1958): 177-209.

Kenyon, F. G. Handbook to the Textual Criticism of the New Testament. 2nd edition. London: MacMillan, 1912.

Kilpatrick, G. D. The Principles and Practice of New Testament Textual Criticism, edited by J. K. Elliott. Leuven: Leuven University Press, 1990.

Kim, K. W. "The Matthean Text of Origen in His Commentary on Matthew." Journal of Biblical Literature 68, 2 (1949): 125-139.

Kim, K. W. “Codices 1582, 1739, and Origen.” Journal of Biblical Literature 69 (1950): 167-175.

Kim, K. W. "Origen's Text of John in his On Prayer, Commentary on Matthew, and Against Celsus." Journal of Theological Studies n.s. 1 (1950): 74-84.

Klijn, Albertus Frederik Johannes. A Survey of the Researches into the Western Text of the Gospels and Acts. Leiden: Brill, 1969.

Labowsky, Lotte. Bessarion's Library and the Biblioteca Marciana, Six Early Inventories. Rome: Edizioni di Storia e Letteratura, 1979.

Lake, K.. Codex 1 of the Gospels and Its Allies. Cambridge: Cambridge University Press, 1902. 
Lake, K. "Professor von Soden's Treatment of the Text of the Gospels." The Review of Theology and Philosophy 4 (1908-09): 204-17.

Lake, K., and R. P. Blake. "The Text of the Gospels in the Koridethi Codex." Harvard Theological Review 16 (1923): 267-286.

Lake, K., R. P. Blake and Silva New. "The Caesarean Text of the Gospel of Mark." Harvard Theological Review 21 (1928): 207-404.

Lake, K. and Silva Lake. Monumenta Palaeographica Vetera. Dated Greek Minuscule Manuscripts to the Year 1200, vol. II. Manuscripts in Venice, Oxford and London. Boston: The American Academy of Arts and Sciences, 1934.

Lake, K. and Silva Lake. Monumenta Palaeographica Vetera. Dated Greek minuscule manuscripts to the year 1200, vol. V. Manuscripts in Paris, part II, Oxford, Berlin, Vienna and Jerusalem. Boston: The American Academy of Arts and Sciences, 1936.

Lake, K. and Silva Lake. Monumenta Palaeographica Vetera. Dated Greek Minuscule Manuscripts to the Year 1200, vol. VI. Manuscripts in Moscow and Leningrad Boston: The American Academy of Arts and Sciences, 1936.

Lake, K and Silva Lake "The Byzantine Text of the Gospels." In Mémorial Lagrange, edited by L.-H. Vincent. Paris: J. Gabalda, 1940, 251-258.

Lake, K. and Silva Lake "The Scribe Ephraim." Journal of Biblical Literature 62, 4 (1943): 263-268.

Lake, K., J. de Zwaan and Morton S. Enslin. Six Collations of New Testament Manuscripts. Harvard Theological Studies 17. Cambridge: Harvard University Press, 1932.

Lake, S. Family $\Pi$ and the Codex Alexandrinus. The Text According to Mark. Studies and Documents V. London: Christophers, 1936.

Lampros, S. Catalogue of the Greek Manuscripts on Mount Athos I-II Cambridge: Cambridge University Press, 1895, 1900.

Lowry, Martin. "Two Great Venetian Libraries in the Age of Aldus Manutius." Bulletin of the John Rylands University Library 57 (1974-1975):128-166.

Madigan, S. P. "Three manuscripts by the 'Chrysostom Initialer': The Scribe as Artist in Tenth-Century Constantinople." Script 41 (1987): 214-215.

Mango, C. "The Date of Cod. Regin. Gr. 1 and the 'Macedonian Renaissance'." Acta ad Archaeologiam et Artium Historiam Pertinentia 4 (1969): 121-126. 
McReynolds, P. R. "Two New Members of Family One of the New Testament Text: 884 and 2542." In Texte und Textkritik: eine Aufsatzsammlung, edited by J. Dummer. Berlin: Wiley-VCH Verlag, 1987, 397-403.

Meredith, C. "The Illustration of Codex Ebnerianus." Journal of the Warburg and Courtauld Institutes 29 (1966): 419-424.

Metzger, Bruce. "The Caesarean Text of the Gospels." Journal of Biblical Literature 64, 4 (1945): 457-489.

Metzger, Bruce. Manuscripts of the Greek Bible. An Introduction to Palaeography. Oxford: Oxford University Press, 1981.

Metzger, Bruce. The Text of the New Testament: Its Transmission, Corruption, and Restoration. $3^{\text {rd }}$ enlarged edition. Oxford: Oxford University Press, 1992.

Metzger, Bruce. The Canon of the New Testament: Its Origin, Development and Significance. Oxford: Clarendon Press, 1997.

Mioni, Elpidius. Bibliothecae Divi Marci Venetiarum: Codices Graeci Manuscripti. Vol. I. Rome: Istituto poligrafico dello Stato, 1967.

Monfasani, John. Byzantine Scholars in Renaissance Italy: Cardinal Bessarion and Other Émigrés. London: Variorum, 1995.

Moore, J. The Manuscript Tradition of Polybius. Cambridge: Cambridge University Press, 1965.

Mullen, R. L., Simon Crisp and D. C. Parker, ed. The Gospel According to John in the Byzantine Tradition. Stuttgart: Deutsche Bibelgesellschaft, 2007.

Muralt, E. Catalogue des manuscrits grecs de la Bibliothèque Impériale publique. St. Petersburg: Imprimerie de l'Académie Impériale des Sciences, 1864.

Murphy, Harold. 'Eusebius' New Testament Text in the Demonstratio Evangelica." Journal of Biblical Literature 73, 3 (1954): 162-168.

Nelson, Robert S. The Iconography of Prefaces and Miniatures in the Byzantine Gospel Book. New York: University Press, 1980.

Nelson, Robert S. Theodore Hagiopetrites: A Late Byzantine Scribe and Illuminator; Text and Plates. Vienna: Verlag der österreichische Akademie der Wissenschaften, 1991.

Nelson, Robert S. "The Italian Appreciation of Illuminated Byzantine Manuscripts, ca. 1200-1450." Dumbarton Oaks Papers 49, Symposium on Byzantium and the Italians, $13^{\text {th }}-15^{\text {th }}$ Centuries (1995): 209-235. 
Nelson, Robert S. Later Byzantine Painting. Art, Agency, and Appreciation. Aldershot: Ashgate, 2007.

Nestle, E. Introduction to the Textual Criticism of the Greek New Testament. London: Williams and Norgate, 1901. Reprint, Eugene: Wipf and Stock Publishers, 2001.

Omont, H. Catalogue des manuscrits grecs des bibliothèques de Suisse. Paris: E. Leroux, 1903.

Omont, H. "Inventaire de manuscrits grecs et latins donnés à Saint-Marc de Venise par le Cardinal Bessarion, (1468)" Revue des bibliothèques, 4 (1894): 129-87.

Osburn, Carroll. "The Text of the Pauline Epistles in Hippolytus of Rome." The Second Century 2 (1982): 97-124

Parker, D. C. Codex Bezae: an Early Christian Manuscript and its Text. Cambridge: Cambridge University Press, 1992.

Parker, D.C. "The Magdalen Papyrus of Matthew. Was Matthew Written Before 50 CE?" The Expository Times 107 (1995): 40-43.

Parker, D. C. The Living Text of the Gospels. Cambridge: Cambridge University Press, 1997.

Parker, D. C. "A Comparison Between the Text und Textwert and the Claremont Profile Method Analyses of Manuscripts in the Gospel of Luke." New Testament Studies 49 (2003): 108-138.

Parker, D. C. An Introduction to the New Testament Manuscripts and their Texts. Cambridge: Cambridge University Press, 2008.

Pelekanides, S. M. et al. The Treasures of Mount Athos, vol. 1-3. Athens: Ekdotike Athenon S. A., 1973-1979.

Perria, L. "Osservazioni su Alcuni Manoscritti in Minuscola 'Tippo Efrem'." Studi Bizantini e Neogreci (1983): 137-145.

Perria, L. "Un Nuovo Codice di Efrem: L’Urb. Gr. 130." Rivista di Studia Bizantini e Neoellenici n.s. 14-16 (1977-1979): 44-82.

Petersen, W. L. "The Text of the Gospels in Origen's Commentaries on John and Matthew." In Origen of Alexandria: His World and his Legacy, edited by Charles Kannengiesser and William L. Petersen. Indiana: University of Notre Dame Press, 1988: $34-47$. 
Reynolds L. D. and N. G. Wilson. Scribes and Scholars-A Guide to the Transmission of Greek and Latin Literature. $2^{\text {rd }}$ revised edition. Oxford: Clarendon, 1991.

De Ricci, S. and W.J. Wilson. Census of Medieval and Renaissance Manuscripts in the United States and Canada. vol. 1. New York: American Council of Learned Societies, 1935.

Richard Olivier, J. Répertoire des bibliothèques et des catalogues de manuscrits grecs de Marcel Richard. Turnhout: Brepols, 1995.

Richards, W. L. The Classification of the Greek Manuscripts of the Johannine Epistles. Missoula MT: Scholars Press, 1977.

Richards, W. L. "Manuscript Grouping in Luke 10 by Quantitative Analysis." Journal of Biblical Literature 98 (1979): 379-91.

Richards, W. L. "An Examination of the Claremont Profile Method in the Gospel of Luke: A Study in Text Critical Methodology." New Testament Studies 27 (1980-81): 52-63.

Richards, W. L. "Test Passages or Profiles: A Comparison of Two Text-Critical Methods." Journal of Biblical Literature 115, 2 (1996): 251-269.

Robinson, Peter. Collate 2: A User Guide. Oxford: The Computers and Variant Texts Project, Oxford University Computing Services, 1994.

Sanders, Henry A. “A New Collation of Codex 22." Journal of Biblical Literature 33 (1914): 91-117.

Sanders, Henry A. "The Egyptian Text of the Four Gospels and Acts." Harvard Theological Review 26 (1933): 77-98.

Schmid, Josef. Studien zur Geschichte des griechischen Apokalypse-textes, 1. Teil. Der Apokalypse-Kommentar des Andreas von Kaisareia: Einleitung. München: Karl Zink, 1956.

Schmid, Ulrich. "Scribes and Variants-Sociology and Typology." In Textual Variation: Theological and Social Tendencies? Papers from the Fifth Birmingham Colloquium on the Textual Criticism of the New Testament. Text and Studies Third Series, Vol. 6, edited by Houghton, H. A. G. and D. C. Parker. Piscataway, NJ: Gorgias Press, 2008.

Scrivener, F. H. A. A Plain Introduction to the Criticism of the New Testament for the Use of Biblical Students. Cambridge: Deighton, Bell and Co., 1883. 
Soden, Hermann von, Die Schriften des neuen Testaments, in ihrer ältesten erreichbaren Textgestalt / hergestellt auf Grund ihrer Textgeschichte: 4 vols. Berlin: Glaue, 1902-1910.

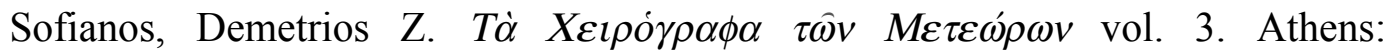
Akademia Athenon, 1986.

Spatharakis, I. Corpus of Dated Illuminated Greek Manuscripts. Vols.1-2. Leiden: E. J. Brill, 1981.

Speake, G. Mount Athos. Renewal in Paradise. New Haven: Yale University Press, 2002.

Streeter, Burnett Hillman. "The Caesarean Text of the Gospels." Journal of Theological Studies 26 (1924-1925): 373-378.

Streeter, Burnett Hillman,. "The Washington MS. and the Caesarean Text of the Gospels." Journal of Theological Studies 27 (1925-26): 144-147.

Streeter, Burnett Hillman. "The Washington MS. of the Gospels." Harvard Theological Review 19, 2 (1926): 165-172.

Streeter, Burnett Hillman. The Four Gospels: A Study of Origens. $4^{\text {th }}$ revised edition. London: MacMillan \& Co., 1930.

Streeter, Burnett Hillman. "The Caesarean Text of Matthew and Luke." Harvard Theological Review 28, 3 (1935): 231-235.

Streeter, Burnett Hillman. "Codices 157, 1071 and the Caesarean Text" In Quantulacumque, edited by Robert P. Casey, Silva Lake, and Agnes K. Lake. London: Christophers, 1937: 149-150.

Swanson, Reuben J. New Testament Greek Manuscripts: Variant Readings Arranged in Horizontal Lines Against Codex Vaticanus: John. Sheffield: Sheffield Academic Press, 1995.

Tarelli, C. C. "The Chester Beatty Papyrus and the Caesarean Text." Journal of Theological Studies 40 (1939): 46-55.

Tasker, R. V. G. "The Readings of the Chester Beatty Papyrus in the Gospel of John.” Journal of Theological Studies 36 (1935): 387-391.

Tasker, R. V. G. "The Quotations from the Synoptic Gospels in Origen's Exhortation to Martyrdom." Journal of Theological Studies 36 (1935): 60-65.

Tasker, R. V. G. "The Text Used by Eusebius in Demonstratio Evangelica in quoting from Matthew and Luke." Harvard Theological Review 28, 1 (1935): 6169. 
Tasker, R. V. G. "The Chester Beatty Papyrus and the Caesarean Text of Luke." Harvard Theological Review 29 (1936): 345-352.

Tasker, R. V. G. "The Chester Beatty Papyrus and the Caesarean Text of John." Harvard Theological Review 30 (1937): 177-164.

Tasker, R. V. G. "The Text of St. Matthew Used by Origen in his Commentary on St. Matthew." Journal of Theological Studies 38 (1937): 60-64.

Turyn, A. Dated Greek Manuscripts of the Thirteenth and Fourteenth Centuries in the Libraries of Italy, vol. 1 and 2. Chicago: University of Illinois Press, 1972.

Vaganay, L. and C-B. Amphoux. An Introduction to New Testament Textual Criticism. Cambridge: Cambridge University Press, 1991.

Vogel, M. and Victor Gardthausen. Die Griechischen Schreiber des Mittelalters und der Renaissance XXXIII: Beiheft zum Zentralblatt fuer Bibliothekswesen. Leipzig: Otto Harrassowitz, 1909.

Vogels, J. Handbuch der Textkritik des Neuen Testaments. Bonn: Hanstein, 1955.

Wallace, Daniel B. “The Majority Text: A New Collating Base?” New Testament Studies 35 (1989): 609-618.

Weitzmann, Kurt. Die byzantinische Buchmalerei des 9. und 10. Jahrhunderts, Berlin, 1935. Vienna: österreichische Akademie der Wissenschaften, 1996.

Weitzmann, Kurt and George Galavaris. The Monastery of Saint Catherine at Mount Sinai: the Illuminated Greek Manuscripts. Vol. 1: from the Ninth to the Twelfth Century. Princeton: Princeton University Press, 1990.

Westcott, B. F., and F. J. Hort. The New Testament in the Original Greek. Introduction and Appendix. London: MacMillan and Co., 1896.

Weyl Carr, Annemarie. "Two Manuscripts of Joasaph in the United States." The Art Bulletin 63, 2 (1981): 182-190.

Weyl Carr, Annemarie. Byzantine Illumination 1150-1250: The Study of a Provincial Tradition. Chicago: University of Chicago Press, 1987.

Willard, Louis Charles. A Critical Study of the Euthalian Apparatus. Berlin: Walter de Gruyter, 2009.

Wilson, N. Mediaeval Greek Bookhands. Cambridge, MA: The Mediaeval Academy of America, 1973.

Wilson, N. "Books and Readers in Byzantium." In Byzantine Books and Bookmen, edited by Nigel Wilson, Jean Irigoin, Cyril Mango, Hans-George Beck 
and Kurt Weitzmann. Dumbarton Oaks Center for Byzantine Studies. New York: J. J. Austen, 1975, 1-15.

Wilson, N. Scholars of Byzantium. Revised edition. London: Gerald Duckworth, 1996.

Wisse, Frederick. The Profile Methods for the Classification and Evaluation of Manuscript Evidence, as Applied to the Continuous Greek Text of the Gospel of Luke. Grand Rapids: Eerdmans, 1982.

Zanetti, A. M. and Bongiovanni. Graeca D. Marci Bibliotheca Codicum Manu Scriptorum. Venice, Apud Simonem Occhi Bibliopolam, 1740.

Zuntz, G. "The Byzantine Text in New Testament Criticism." Journal of Theological Studies 43 (1942): 25-30.

Zuntz, G. The Text of the Epistles: A Disquisition upon the Corpus Paulinum: The Schweich Lectures of 1946. London: The British Academy, 1953.

\section{Websites and Software}

Mullen, R. L. with Simon Crisp and D. C. Parker and in association with W. J. Elliott, U. B. Schmid, R. Kevern, M. B. Morrill and C. J. Smith, ed., An Electronic Edition of the Gospel According to John in the Byzantine Tradition. Birmingham: Institute for Textual Scholarship and Electronic Editing, 2007.

(http://arts-itsee.bham.ac.uk/itseeweb/iohannes/byzantine/index.html)

Robinson, Peter. Collate 2.1. Scholarly Digital Editions, March 1992-September 2003.

(www.sd-editions.com)

Schmid, Ulrich with W. J. Elliott and D. C. Parker, ed., An Electronic Version of the New Testament in Greek IV. The Gospel According to St. John. Vol. 2. The Majuscules. Birmingham: Institute for Textual Scholarship and Electronic Editing, 2007.

(http://itsee.bham.ac.uk/iohannes/majuscule/index.html) 